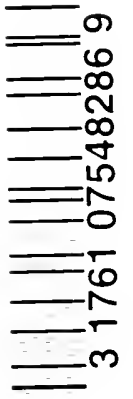







FOOD AND FEEDING IN HEALTH AND DISEASE 



\section{FOOD AND FEEDING}

IN

\section{HEALTH AND DISEASE}

A MIANUAL OF

PRACTICAL DIETETICS

BY

CHALMERS WATSON, M.D., F.R.C.P.E.

Assistant Physician, Royal Infirmary, Edinburgh

Editor of the "Encyclopadia Medica"

SECOND EDITION-REVISED

TORONTO

$\mathrm{M}^{\mathrm{C}} \mathrm{AINSH} \&$ CO., LIMITED

4-I 2 COLLEGE STREET

I 9 I 5 


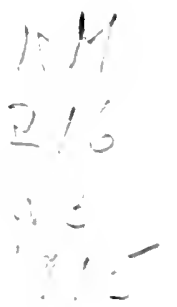




\section{PREFACE}

THE aim of this work is purely practical. It aims at providing a complete and practical epitome for the dietetic student. It is now many years since the late Sir Henry Thompson, a distinguished authority on dietetics, pointed out that no one can be a really accomplished practitioner who has not made dietetic principles and practice an important part of their professional education, yet the subject of dietetics has still no recognised place in medical teaching, and the facilitics for the student acquiring a practical knowledge of it can hardly be described as adequate.

The first thing necessary for food and feeding in health and discase is to be well instructed in the elements of physiology, the nature of foods, the normal laws of feeding, as well as in the deviation by which the action of these laws is modified. To this must be added some practical acquaintance with kitchen usage and processes. A certain familiarity with the resources of the cook is essential to provide a suitable daily menu which will be agreeable to the invalid, and as much as possible varied within the narrow limits induced by the circumstances of each case. In the following pages an attempt is made to present this information conciscly, and applied, so far as possible, to the everyday requirements of the medical practitioner.

In the preparation of the work I have derived much help (more especially with the data of the chemical composition of foods) from many sources, special mention being made of the writings of Atwater, Langworthy, and of the analytical reports published from the Lancet laboratory. The reader will observe that in the section on disease, less attention than is usual in 
works on diet is devoted to the details of the chemical composition and heat values of the food, and more to its influence on the digestive and bacterial processes in the gastro-intestinal tract. This plan has been deliberately adopted as being in strict accordance with the general trend of recent advances in our knowledge of the physiology and pathology of digestion, and also more in harmony with the teaching of everyday clinical experience.

It is both a duty and a pleasure to me to express my very great indebtedness to my wife for invaluable assistance in this work. In my capacity as editor of The Encyclopadia Medica, I received many requests from its readers for the republication of the article on invalid feeding, arranged for that work and written by her. This experience confirmed me in thinking that there is room for a work on dietetics which deals more fully with the practical aspects of the subject than other works with which I am familiar, and it is impossible for me to overestimate the assistance gained from her in $m y$ endeavour to supply this deficiency.

I have also to acknowledge my indebtedness to $\mathrm{Dr}$ Dingwall Fordyce for the section on infant feeding in health and discase. Keeping in view the practical nature of the work, I felt I could not do better than entrust this section to one of his recognised abilitics, both in the scientific and practical aspects of this subject.

I have taken the opportunity of republishing in the form of an appendix the results of the experimental researches carricd out by myself and others in collaboration, in the Physiological Laboratory of Edinburgh University since 1900.

It is hoped that the practical value of the book as a work of reference may be enhanced by the inclusion of an exhaustive index. 


\section{PREFACE TO THE SECOND EDITION}

As a medical text-book the present work is an acknowledged departure from long-established routine. In the section on Disease less attention than is usual in works on diet is devoted to the chemical composition of the heat values of food, and more to its influence on the digestive and bacterial processes in the digestive tract. This plan has been deliberately adopted as being in strict accordance with the general trend of recent advances in our knowledge of the physiology of digestion, and also more in harmony with the teaching of clinical experience. The very gratifying reception which the book has received may be taken as a proof of the soundness of this plan.

In the last year or two special attention has been directed to the important subject of the adulteration of some common foodstuffs, for example-bread. An account is here given of the present-day methods of the bleaching of flour, and of other methods, which, there is good reason to believe, impair the nutritive properties of some every-day foods. 



\section{O N T E N T S}

\section{CHAPTER I}

FoOd AND ITS Functions-

Classification of Foods

Methods of Determining the Nutritive Value

Physiological Properties $\quad$. $\quad . \quad$. $\quad . \quad 5$

\section{CHAPTER II}

Digestion, Absorption, and Metarolism of Foods-Rôle OF BACIERIA-

Digestion

Absorption

Metabolism

Rôle of Bacteria in Digestion.

\section{CHAPTER III}

DAILy Amount of Food Required, AND FACTORS MOdifyING IT-

The usually Accepted Standard . . . 20

The Chittenden Standard . $\quad$. $\quad$. $\quad$. 22

The Influence of Various Conditions . $\quad$ • $\quad ~ 24$

\section{CHAPTER IV}

MILK AND ITS PRODUCTS-EgGS-

Composition of Milk • $\quad$ • $\quad$ • $\quad$ • $\quad$ • $\quad 28$

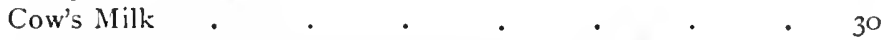

Digestion, Absorption, and Nutritive Value of Milk $\quad 33$

Milk Adulteration and Impurities . $\quad . \quad$. $\quad 37$

Milk Derivatives . $\quad . \quad$. $\quad . \quad .38$

Eggs • 
ANIMII. Fonns-

Composition of Meats. $\quad . \quad$. $\quad . \quad$. 50

Fish . . . . . . . . . . . 58

1)igestibility of Meats. . . . . . . . . 65

Cooking of Flesh and Fish . $\quad$. $\quad . \quad 0 \quad 65$

Soups. . . . . . . . . 72

Home-made Heef-Teas, Extracts, and Essences • • 75

CHAPTER VI

VEGETAMLE FOODS-

Cereals
Breadmaking.

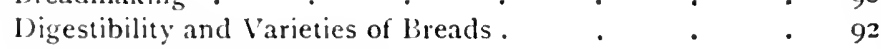

Other Preparations of W'heat $\quad$. $\quad$ • $\quad .95$

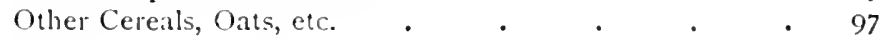

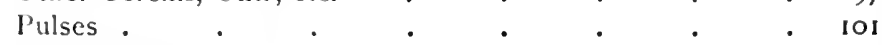

Fruits, Nuts, and Fungi $\quad . \quad$. $\quad . \quad . \quad . \quad 105$

Roots and Tubers . $\quad$. $\quad$. $\quad$. $\quad$. $\quad$. II4

Green Vegetables . . . . . . . . $\quad$. 117

Methods of Preparing Vegretables . . . . $\quad$ I22

\section{CHAPTER VII}

Minerat, Constituents of Food-Food Accessories-

Mineral Salts.

Acidity and Alkalinity of Foods $\cdot+125$

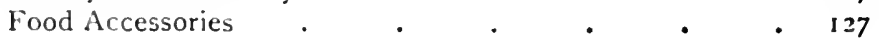

CHAPTER VIII

BeVeragfs-Water, AERAtfin Waters, TEA, etc.-Alcohol-

Nater.

. $\quad . \quad 132$

Aerated and Mineral WVaters . . . . . . I $\quad$ I 34

Tea, etc.

Alcrihol. 


\section{CHAPTER IX}

Patent, Proprietary, and Predigesten Foons-

PArit:

I. Nitrogenous lioods .

2. Carbohydrate foods

3. Cow's Milk with Cereal Additions.

4. Combined loods

Predigested Preparations

(a) Ferments

(b) Predigested Milk Products

(c) Predigested Meats

(d) Malt Extracts.

Invalid Foods .

\section{CHAPTER X}

Food Preservatives, Food Adulteration, and Diseases Causen by Food-

Methods of Preservation Food Adulteration .

Diseases Caused by Food

\section{CHAPTER XI}

Diet at Different Perions of Life-

Childhood

At School

Diet in Old Age

During Pregnancy

\section{CHAPTER XII}

UNDER-FEEDING AND OVER-FEEDING-

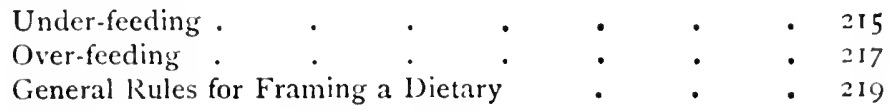

\section{CHAPTER XIII}

Generai, Serving, of Food for Invalids-Rectal Feening-

General Serving of Food for Invalids $\quad \cdot \quad \cdot \quad \cdot 220$ Rectal Feeding 


\section{CHAPTERS XIV ANI XV}

INFANT FEFUING IN IIEALTH AND DISEASE

(By D) Dingwall fordyce)

I'hysiolngical Characteristics of Early Infancy

IBreast-feeding .

Artificial Feeding

Dietetic Treatment in Cases of Mlinor Ailment

235

Improper Feedin

251

In Serious lllness

b) ietary of Second Year

\section{CHAPTER XVI}

DIETARV IN FEVERS ANI ACUTE INFECTIVE Diseases-

Principles of Feeding .

Milk and its Derivatives

Eggrs, and Meat Preparations.

Farinaceous Foods

Thirst-quenchers

Stimulants

Typhoid Fever.

I'neumonia

Acuie Rheumatism

Scarlet Fever

Whooping-cough

Measles

Influenza

Diphtheria

Smallpox

Typhus Fever.

CHAPTER XVII

Dift DURING; CONVALESCENCE-

I'rinciples of Feeding .

Daily I)ietaries

Farinaceous l'uddings

Soups.

Fish

Meats

Vegretables 


\section{CHAPTER XVIII}

Diseases of THE STOMACH-

Indigestion

Chronic Indigestion in Children . . . . $\quad$. 320

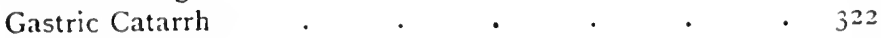

Hyperchlorhydria $\quad . \quad$. $\quad . \quad$. $\quad . \quad 326$

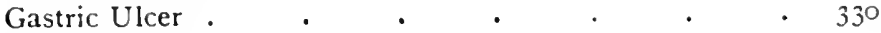

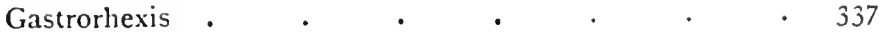

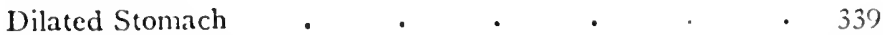

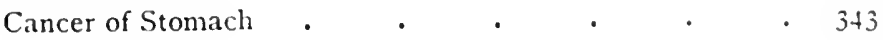

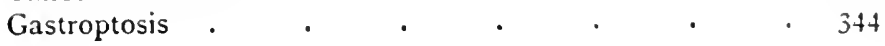

\section{CHAPTER XIX}

Diseases OF THE INTESTINE-

Auto-intoxication

Acidosis

Constipation

Diarrhœa

Enteritis

Colitis .

Intestinal Colic

Intestinal Ulceration

intestinal Obstruction

Meteorism

Appendicitis

Hæmorrhoids .

Sprue .

\begin{tabular}{|c|c|c|c|c|}
\hline • & • & . & - & - $\quad 346$ \\
\hline 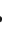 & - & - & • & - $\quad 349$ \\
\hline • & • & - & - & 352 \\
\hline • & • & • & • & 354 \\
\hline • & • & - & - & 355 \\
\hline • & • & - & - & 357 \\
\hline , & • & - & • & $3^{6} 3$ \\
\hline$\cdot$ & • & - & • & 364 \\
\hline • & · & - & • & · \\
\hline • & $\cdot$ & - & • & $3^{64}$ \\
\hline • & • & - & • & • \\
\hline • & • & - & & • \\
\hline • & • & - & • & $\cdot$ \\
\hline
\end{tabular}

CHAPTER XX

Diseases of the Liver and PANCreas-

\begin{tabular}{|c|c|c|c|c|c|c|}
\hline Biliousness & - & - & - & - & - & - \\
\hline Jaundice & - & - & - & • & - & - \\
\hline Gall-stones & - & • & - & • & - & - \\
\hline Cirrhosis of the Liver & . & • & - & • & - & • \\
\hline Pancreatitis & . & . & . & . & . & - \\
\hline
\end{tabular}

CHAPTER XXI

ANFMIA AND Diseases OF THE BLOOD-

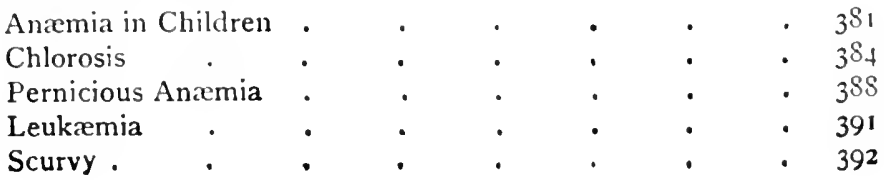


ARTERTO-SCLEROSIS-

Dietetic Errors as a Cause of .

Illustrative Dietaries.

Hyperpeiesis

\section{CHAPTER NXIII}

DISEASES OF THE HEART-

Functional Heart Disease . . . . . 399

Acute Pericarditis and Endocarditis. . . . . 401

Chronic Heart Disease . . . . . 402

The Senile Heart . $\quad$. $\quad$. $\quad$. $\quad$. 407

Diet in Aneurism . . . . . . . 408

CHAPTER XXIV

Diseases of THE KIDNEY-

Acute Nephritis . . . . . . 4II

Sulbacute and Chronic Nephritis . . . 412

Treatment of Chronic Nephritis by a Chloride-free Diet . 416

Other Renal Disorders . . . . . 417

Albuminuria $. \quad . \quad$. $\quad . \quad$. $\quad . \quad$. 417

Lithrmia $. \quad . \quad . \quad . \quad . \quad . \quad . \quad 418$

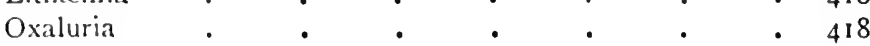

Phosphaturia . $\quad . \quad$. $\quad . \quad$. . . 419

\section{CHAPTER XXV}

TUBERCUI.OSIS-

P'rinciples of Feeding . $\quad$. $\quad$. $\quad$ - $\quad$. $42 \mathrm{I}$

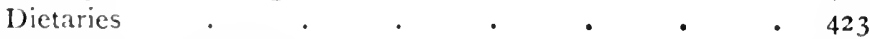

Diet for the Poorer Classes . . . . . . 425

Tulerculosis in Cases with Impaired Digestion . . 428

Tuberculosis of Intestine $\quad . \quad$. $\quad . \quad$ • • 433

Hamoptysis . . . . . . . . 435

Laryngeal Tuberculosis and Dysphagia • . . 436

Tuberculosis in Children . . . . . . 440 


\section{CHAPTER XXVI}

Gout, Rheumatism, and Rheumatold Arthritis-

Gout

Rheumatism

Rheumatoid Arthritis.

\section{CHAPTER XXVII}

Glycosuria AND Diabetes

470

OBESITY -

\section{CHAPTER XXVIII}

Principles of Treatment

Banting Method

Oertel System .

Ebstein Regime

Salisbury Diet, etc.

Fluids in Obesity

\section{CHAPTER XXIX}

Diet in Nervous Diseases-

In Organic Disease . $\quad$. $\quad$. . 501

In Nervous Children . . . . . . . 504

Headache, Insomnia, etc. . . . . . 505

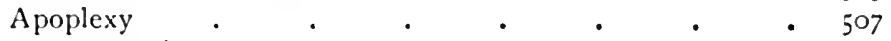

Neurasthenia . . . . . . . $\quad . \quad 508$

\section{CHAPTER XXX}

Diet in Diseases of the Lungs, Thyroid Gland, and SKIN-

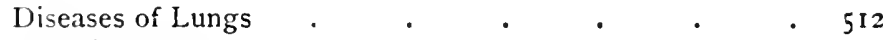

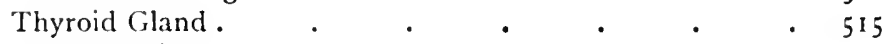

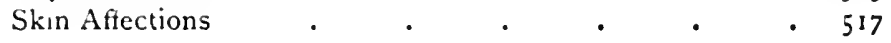

CHAPTER XXXI

Special, Diet Cures-

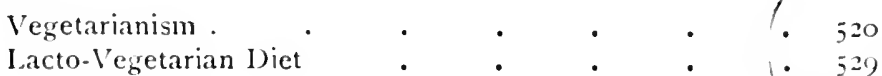

Purin-free I)iet . . . . . . 531

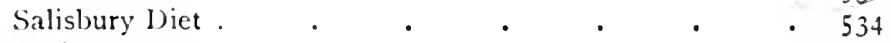

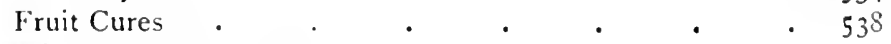

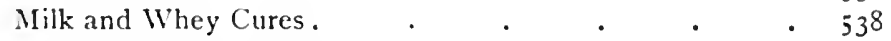

Buttermilk and Lactic Preparations . $\quad . \quad$. 540 


\section{CHAPTER XXXII}

Hospital, Dietarife-

PAOR

Clas-ification

Comparison of Official and Actual Dictaries.

- 545

- 547

\section{APPENDIX}

RECORI OF EXPERIMENTII, OHSERVATIONS ON THE EFFECT OF

DIET ON THE STRUCTURE OF THE TISSUES • $551-615$

INDEX . $\quad . \quad+\quad . \quad+\quad . \quad+617$ 


\section{FOOD AND FEEDING}

\section{CHAPTER I}

FOOD AND ITS FUNCTIONS

Classification of fools-

1. As tissue-builders .

2. As sources of heat and energy 2 Method of determining the nutritive value-

(a) Chemical composition
PAGE

Method of determining the nutritive value-contmued.

(b) Heat value . . . . 3

(c) Physiological properties -digestitility and rate of absorption . . 4

Foon is required for wwo purposes-to build up the body and repair tissuc waste, and to supply potential energy, which can be converted into heat and worh. Foods are classified as follows :-

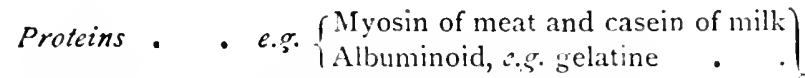

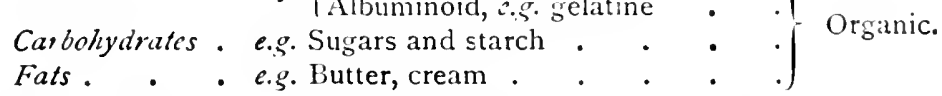
Mineral matter. $\cdot\left\{\begin{array}{r}\text { Sodium, potassium, calcium, mag- } \\ \text { nesium, iron, phosphorus, chlo- }\end{array}\right.$

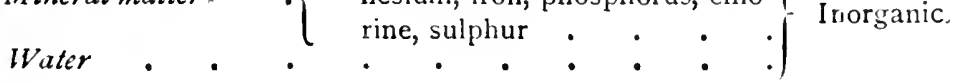

The proteins contain carbon, hydrogen, nitrogen, oxygen, and a small amount of sulphur. Carbohydrates and fats contain carbon, hydrogen, and oxygen only.

Almost all articles of food are complex substances containing both nitrogenous and non-nitrogenous ingredients, and the element which predominates in the food gives it its distinctive class. The various foods perform the functions of supplying building material, muscular energy, and heat in different degree. 
The building material for forming and repairing tossue is commonly supposed to be supplied only by the

$$
\begin{array}{llll}
\text { l'roteins } & \cdot & . & . \\
\text { Mineral salts } & \cdot & . & \text {. Tissue-builders, } \\
\text { lliner } & . & . & . j
\end{array}
$$

the carhohyleates and bats not ranking as tissue-builders. ln recent years, however, it has been shown that a carbohyeluate radicle enters into the composition of the protein molecule, and this sugrests that carbohydrates may play a much more important part in the rowth and repair of tissue than lias formerly been supposed. The second great function of food-source of heat and enersy-is shared by ail the organic foodstuffs--

$$
\begin{array}{llll}
\text { lyoteins } & \cdot & \cdot & \cdot \\
\text { Fats. } & \cdot & \cdot & \cdot \\
\text { Carbohydrates } & \cdot & .
\end{array}
$$

These presess potemial energy. The force which holds the food clements tosether in combination is called potential (nergy. In the body the proteins, fats, and carbohydrates undergo oxidation, the oxysen necessary for their combustion being taken in with the inspired air. The oxidation processes are attended by the liberation of energy, which may take the form of heat or work. Fats require the greatest amount of oxidition, and are thus the most important fuel food. It is owing to fat's rreat value as a heat producer that it forms such a prominent article of food in the dietaries of the inhabitants of the Arctic regions.

The animal body has been aptly compared to a steam engine. The fuel, the suurce of energy, is represented by the food. The inlet for the draught of air and the outlet for the waste gases, the products of combustion, are combined in one organ, the lungs, which we use to take in Oxygen, and rive out $\mathrm{CO}_{2}$, and $\mathrm{I}_{2} \mathrm{O}$; and just as the coal used in engines has some incombustible constituents which remain as ash and have to be raked out, so there are parts of our food which the body cannot make use of, and which leaves the body as cxcrementitious matter or faces, having passed through the direstive tract without at any time having formed part of the tissucs. 
There are still two constituents of foodstuffs which have to be got rid of after the elimination of $\mathrm{CO}_{2}$ and $\mathrm{H}_{2} \mathrm{O}$ by the lungs, viz., the nitrogen and sulphur present in proteins. This function is served by the kidneys. The nitrogen is combined in the body with carbon and oxygen and forms urea, and in this form is excreted by the kidneys, together with salts and water as urine. The sulphur is oxidised to a sulphate, and in this form appears in the urine. The income and output of the body may be arranged in the form of an equation-

Food + Oxygen taken up $=$ Freces $+\mathrm{CO}_{2}+\mathrm{H}_{2} \mathrm{O}+$ Urea

and in the same way we may make an equation of the income and output of energy-

$\left.\begin{array}{c}\text { Energy set free by the } \\ \text { combustion of food }\end{array}\right\}=\left\{\begin{array}{c}\text { Work done by the body, } \\ \text { and heat given off. }\end{array}\right.$

Methods of Determining the Nutritive Value of Foods. - A knowledge of the nutritive value of food may be gained in the following ways:-

I. By a study of its chemical composition.

2. By ascertaining its heat value.

3. By reference to its physiological properties-the ease with which it is digested and absorbed.

Chemical composition of food. - Chemical anaiysis of a food tells us the proportion of protein, fat, carbohydrates, salts, and water present in its composition. The results of chemical analysis, therefore, give us some information as to the value of food, both as a tissue-builder and as a source of energy or heat production.

The heat value of a food-Physical and physiological heat values. - The heat value of different foods may be determined experimentally by the use of an instrument known as the Bomb calorimeter, the result being expressed in calories. The standard of heat production is the calorie, which means the amount of heat required to raise the temperature of I kilogram of water I centigrade. The amount of heat evolved by the combustion in a calorimeter of I gramme of the different foodstuffs is as follows :-

I gramme of Carbohydrate produces 4 calories.

I " Protein produces 4 calories.

$1 \quad$ "Fat produces 8.9 calories. 
These figures represent the amount of energy set free by I gramme of the foodstuff combining with oxygen to form the end-products of its combustion. This constitutes the physical heat value of the food-that is, the amount of heat produced by complete combustion of the food in a special calorimeter chamber. The physiological heat value of the food is the amount of heat produced by the complete combustion of the food in the living tissues. Carbohydrates and fats are completely oxiclised in the tissues; their physiological and physical heat values are therefore the same. Proteins, on the other hand, are not completely burnt up, urea, the end-product of nitrogenous metabolism in the tissue, being an incompletely oxidised product. The physiological heat value of protein is, therefore, less than the physical heat value by the extent to which urea is capable of further oxidation outside the body.

The physiological propertics of food. - The digestibility of food and the ease with which it can be absorbed in the intestine are the most important facts to be considered in connection with any food. The time required for food to be digested in the stomach can be gauged by the time which elapses before it passes into the intestine. During this time the food is being converted into a fluid condition, and the more rapidly this is done the greater the digestibility of the food. The following table gives the results of some standard observations on the rate of digestion of some common foods :-

(a) One to two hours.

7 oz. boiled milk.

7 oz. beef-tea.

Whites of 3 eggrs.

$7 \mathrm{oz}$. water, tea, coffee, and cocoa.

(b) Two to three hotrs.

5 raw or poached egys.

$3 \frac{1}{2}$ oz. raw meat.

9) oz. sweetbread.
50 . white fish.

7 oz. cauliflower or asparagus. $2 \frac{1}{2}$ oz. toast, rusk, biscuits.

$2 !$ oz. oysters.

5: 0z. bread or biscuits.

$5 \frac{1}{2} \mathrm{Oz}$. rice, spinach, apples, or carrots.

(c) Three to four hours.

8 oz. stewed or roast chicken.

$3 \frac{1}{2}$ oz. beefsteak.

(d) Four to five hours.

Ruast beef, hoose, or duck.

Mashed lentils, peas, French beans. 
The most easily digested fonds are not necessarily the most easily absorbed. Information as to the ease and completeness of absorption of different foods is obtained by a comparison of the results of a joint analysis of the food and faeces. The figures gained by analysis of the frecal matters are, strictly speaking, not entirely reliable, sinec some of the nitrogen in the fxecs is an excretion from the epithelial lining of the bowel. Proteins are less completely absorbed than fats and carbohydrates. Carbohydrates are the most completely absorbed. Experiments on the absorption of fats have shown that as much as $\frac{1}{4} \mathrm{lb}$. of butter can be absorbed daily by individuals in health, but when taken in excess of that amount the balance appears in the freces. The perecntage of protein absorbed is greater when taken in a mixed liet. On a diet of beef, bread and butter, milk, oatmeal, potatoes, and fruit the percentage absorbed has been found as follows:-

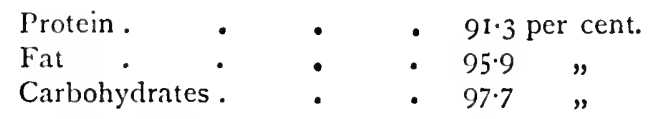

The proteins of vegetable food are less casily absorbed than the proteins of animal foods. This is well brought out in the following table:-

Table showing percentage of Proteins, Fats, and Carbohydrates absorbed for different Foods.

\begin{tabular}{|c|c|c|c|c|}
\hline & & Proteins. & Fats. & Carbohydrates. \\
\hline $\begin{array}{l}\text { Animal Foods } \\
\text { Cereals and Sugars } \\
\text { Vegetables and Fruits }\end{array}$ & $\dot{:}$ & $\begin{array}{l}98 \\
85 \\
80\end{array}$ & $\begin{array}{l}97 \\
90 \\
90\end{array}$ & $\begin{array}{r}100 \\
98 \\
95\end{array}$ \\
\hline
\end{tabular}

The bowcls require a certain amount of residuc (ballast) to act as a stimulus to peristalsis. In "invalid" feeding it is sometimes imperative to take advantage of the different absorptive powers of the intestine for various foodstuffs. For example, in cases of diarrhcea where peristalsis is excessive, foods like rice, milk, white of egg, pounded meat, which leave little residue, are indicated. 
On the ofleer hand, constipated subjects require a certain proportion of food to act as ballast for the intestine-these being taken from wholemeal bread, coarse oatmeal porridge, green vegetables, and the like. These points are further considered in the sections dealing with the treatment of disease.

In health, diet is usually prescribed in one of two ways, cither by using tables of percentages by weight of proteins, fats, and carbohydrates - known as the weight per cent. method; or by using tables with the number of calories in form of proteins, fats, and carbohydrates per ounce of food-known as the culories per ounce method. These methods are necessary for the formation of dictaries for healthy people in large institutions, such as the army, navy, prisons, and workhouses; they are also of some value in the framing of hospital dietaries. Their value in clinical work is, however, much less than is commonly supposed. In diseased conditions the diet has to be adjusted in each instance from a knowledge of the digestive and assimilative power of the patient, special reference being paid to the influence of the food on fermentative and putrefactive processes in the intestine, little clinical importance attaching to the caloric value of the food.

Before passing to the more detailed consideration of the nutritive constituents of food, it is advisable to give a résumé of our present knowledge of the processes of digestion, absorption, and assimilation of lood. This is given in the follow ing chapter. 


\section{CHAPTER II}

DIGESTION, ABSORPTION, ANI METABOLISM-ROLE OF BACTERIA

\begin{tabular}{|c|c|c|c|c|c|c|}
\hline \multicolumn{7}{|c|}{ FAGE } \\
\hline Digestion . & & & & 7 & Metabolism . . . & I 3 \\
\hline \multirow{2}{*}{\multicolumn{4}{|c|}{$\begin{array}{l}\text { The changes undergone by the } \\
\text { food in the aliment ry canal }\end{array}$}} & & \multirow{2}{*}{\multicolumn{2}{|c|}{$\begin{array}{l}\text { Rôle of bacteria in digestion of- } \\
\text { Carbohydrates . . . . I6 }\end{array}$}} \\
\hline & & & & 8 & & \\
\hline The freces & . & . & . $\quad$. & 10 & Proteins-putrefactive bacteria & . I6 \\
\hline Absorption of- & & & & & Influence of various factors or & \\
\hline Proteins . & - & . & - & I I & digestion $\quad . \quad$. & 8 \\
\hline Fals. & - & - & - & II & Influence of diet on resis'ance t & \\
\hline Carbohydra'es & . & - & - & I 2 & disease,$\quad \circ \quad \cdot$ & \\
\hline Water and salts & & . & . & I 3 & & \\
\hline
\end{tabular}

\section{Digestion.}

UNDER the vague term disestion all these processes may be included to which the foorl substances are subjected and the resultant changes which the various food constituents unrlergo in order to prepare them for assimilation by the tissues. It therefore comprises a series of changes all tending towards the same point, namely, the transformation of substances which in their original state could not be made use of by the cell into pabulum which can be easily talien up, assimilated, and used for the nutrition of the tissues. The changes which the food undergoes are brought about by secretions, which special glands elaborate, and are carried out mainly by the action of enzymes (ferments). The decomposition of the food principles into smaller molecules takes place gradually, the final products of metabolism being found in the tissue cells. The final transformation aliuals results in the production of work and heat, and prodlicts which cannot be used further by the organism are excreted. The food 
principles are the following:-l'roteins, fats, carbolydrates, mineral matter, water.

In order to prepare the food for absorption it is nccessary to break it down and transform it into material which can pass into the blood or lymph. This is effected in the alimentary canal, where the food is subjected to processes of two great types -mechanical and chemical. A short summary of the changes which the food undergoes in the alimentary canal is here given; this is followed by an account of the manner in which the food is absorbed, and of its fate after absorption, those points only being considered which are of practical importance in dictetics.

The changes undergone by the Food in the Alimentary Canal. - In the month the food is broken up into small particles by mastication, and moistened with alkaline saliva, in order to fit it for deglutition. A small part of the starch is converted into dextrin or maltose under the infuence of the ferment ptyalin in the salivary secretion. Thorough mastication of the food is of the first importance, not only for enabling this oral digestion to be normally carried out, but as an aid to healthy sastric and intestinal digestion. Defective mastication with impaired oral digrestion from a septic condition of the teeth or gums, is frequently referred to in later chapters as an important contributory factor in the etiology of disease.

In the stomach the action of the saliva may go on for an hour. At the end of this time the secretion of gastric juice excited by the prcsence of food and of alkaline saliva in the stomach is sufficiently abundant to neutralise and render acid all the gastric contents, and so stop the action of the ptyalin. Under the action of the gastric juice the greater part of the protein is dissolved and converted into syntonin, albumoses, or peptones. The connective tissues are also dissolvecl, setting free the fat, which floats about in a free state. At the same time some of the salts and sugar which have been swallowed, and the peptones formed from the food, are being absorbed by the gastric mucous membrane. For the first half-hour after ingestion of a meal of solid food the pylorus is firmly closed. At the end of this time it relaxes at intervals to allow the passage of the fluid parts of the gastric contents, which are spotien of at this period as chyme 
The passage of food through the pylorus goes on for seven or eight hours after the ingestion of food, and towards the end of this time larger lumps of undigested material are allowed to pass on into the duodenum.

As the acid chyme is squirted through the pylorus into the duodenum, it comes into contact with the cells of the mucous membrane, and in them causes a conversion of pro-secretin into secretin (Starling). The latter is absorbed by the blood-stream and carricd to the pancreas ancl liver, causing a flow of pancreatic juice and an increased sccrction of bile. The strongly alkaline pancrcatic juice neutralises the acid chyme. So long as the duodenal contents are acid the pylorus remains closed, but opens as soon as sufficient pancreatic juice has been secreted to neutralise the chyme that has already passed through. When this happens the pylorus relaxes, a fresl quantity of acid gastric contents is forced through, more secretin is formed, and the pancreatic secretion is again excited until the second amount of chyme is neutralised; and this self-regulating mechanism of the activities of the stomach, pancreas, and intestines goes on until all the food has passed through the pylurus. At the same time the pancreatic juice poured into the gut evokes a secretion of intestinal juice (Succus entericus), which supplies the enterokinase necessary for the formation of the proteolytic ferment of the pancreatic juice.

In the duodenum the chyme comes into contact with the bile, the flow of which is also quickened under the influence of the secretin which is being poured into the circulation. This causes a precipitate in the chyme consisting of bilc acids, syntonin, and albumoses. This precipitate is dissolved later on by the further operation of the pancreatic juice. Here the remaining digestive processes take place; the undigested proteins are dissolved, and the acid albumin and albumoses resulting from gastric digestion are converted into peptone and partially into leucine, tyrosine, and similar nitrogenous bodies (amino-acids). Starches are changed into dextrin and maltose, and under the further agency of the intestinal juice into dextrose. The fats are partially split up and emulsificd.

Throughout the whole of the small intestines active sccre- 
tion and absorption are taking place, so that the amount of water in the intestmal contents in the lower part of the small intestine is about the same as in the upper part. The contents of the lower part acquire a distinct faccal odour from the indol and skatol produced by the action of putrefactive bacteria on the proteins of the food. In this part of the intestine carbohydrates are also acted on by bacteria, which produce from them organic acids, which excrcise a restraining influence on the putrefaction of the proteins. In the large intistine the processes of absorption predominate over those of secretion; hence that part of the intestinal contents which has not been absorbed becomes less and less watery, and acquires the character of feeces, in which form it is periodically cxpelled from the body.

The feces consist mainly of the indigestible residue of the food, or of substances which have been talien in too large quantities to be digested, and contain-

(a) Cellulose, wondy fibre, elastic tissue, keratin, and remains of muscle fibre, starch grains, and fat.

(l) The unabsorbable part of the digestive juices, such as mucin, bile pigments, cholesterin.

(c) Disintegrated epithelial cells from the intestinal mucous membrane, and indol and skatol, decomposition products derived from the proteins of the food.

(d) Various folms of bacteria, and especially members of the Bacillus coli group. The influence of bacteria on the digestive process is further considered on p. 15; their importance becomes much more pronounced in variuus pathological conditions.

Valuable information as to the motor power of the stomach and bowels is given by the use of bismuth test meals. Precise information as to the existence of gastric stasis, and stasis in the small or large intestine, is afforded by this means.

\section{Absorption.}

There are two main paths by which the food constitucnts are absorbed into the circulation-the blood-vessels and lymphatics. The blood-vessels pour their contents into the rarlicles of the portal vein, which carry them to the liver. The lymphatics in the submucous coat of the intestine join to form larger trunlis, which run between the two layers of the mesentery to a collection of lymphatic glands at the back of the peritoneal cavity. The lymph, after flowing through these glands, is collected into a large vessel, the receptaculum 
chyli, from which it is carried in the thoracic duct to be rlischarged into the blood-stream at the junction of the left jugular and subclavian veins.

Absorption of proteins. - The most recent investigations render it probable that proteins are not absorbed in the form of peptones, as was formcrly supposed, but in the form of amino-acids and bases, products which represent an even more complete disintegration of the proteins. These amino-acids are absorbed as such into the blood, and built up again into proteins in the living cells of the tissucs, the extent to which any individual protein is b:oken down during digestion being determined by the degree in which its composition approximates to that of the normal proteins of the digesting animal.

Absorption of fats.--It has been shown that the greater part of the fat is absorbed by the chyle, and 60 per cent. of the absorbed fat can be obtained from the chyle through a canula placed in the thoracic duct. It has not been found possible to trace the mechanism of absorption of that portion of the fat which does not enter the blood by way of the lacteals. It is believed that it may be utilised or built up into more complex compounds in the tissues of the intestinal mucous membrane. In what form is the fat taken up by the cpithelial cells covering the intestinal cells? It was formerly thought that the digestion of fat essentially consisted in a splitting up into particles fine enough to be taken up by the epithelial cells, but this is now disproved, and it is now believed that fats, like proteins and carbohydrates, are absorbed in a state of solution. In the digestion and absorption of fat there is a concerted action of the pancreatic juice and the bile. The pancreatic juice splits about 6 per cent. of the neutral fat-which forms the great proportion of the fat of food-into fatty acids and glycerine. In the presence of excess of alkalis the fatty acid forms a soluble soap, which, together with the glycerine, is absorbed by the epithelial cells, and reconverted in the body of the ccll into neutral fat. If, as is often the case with a highly fatty dict, the reaction of the small intestine be acid, the formation of soaps can no longer go on. The fat-splitting action of the pancreatic juice, however, continues, and the fatty acids set free are dissolved by the bile acid and taken up by the 
epithelial cells. Here the synthesis of the neutral fat once more occurs, and the bile acid is carricd by the portal blood to the liver, to be resecreted with the bile into the intestine, where it may aid the absorption of a further amount of fat. As the free fatty acids and soaps are absorbed, the pancreatic juice is able to split up a further portion of the neutral fat until the whole of the neutral fat of the food has been absorbed by the cpithelial cells of the intestine in a state of solution as soaps or fatty acids. It is partly on this account that, after extirpation of the pancreas, fats are not absorbed, even if administered to the animal in the form of a fine cmulsion containing neutral fat suspended in a solution of soap. If, however, to this cmulsion chopped-up pancreas is added, a large proportion of the fat is absorbed.

Absorption of carbohydrates. - It is generally belicved that the blood in the capillaries of the intestinal wall takes up sugar in the form of dextrose, and carries it to the liver, where the excess of sugar is taken up by the hepatic cells, and converted by them into the colioid carbohydrate glycogen which is deposited in the substance of the cell. In this way the liver acts as a storchouse of carbohydrate material, and prevents the sugar in a rich carbohydrate meal from cscaping into the general circulation. According to Pavy, this view of the manner of absorption of carbohydrates is an erroncous one. This author believes that the main channel of absorption of carbohydrates is the lacteal system, the sugar being absorbed in a combined state, a synthesis between the carbobyclrate and protein radicle taking place in the intestinal villi through the agency of the lcucocytes. Our knowledge of the exact incchanism of absorption of carbohydrate foods is as yet uncertain. Viewed from the clinical stand point, there is much to be said in favour of the general correctness of Pavy's view. Alosorption of water and salts.-Water and salts are absorbed almost entirely by means of the blood-vesscls. The rate of absorption of water by the alimentary canal increases from above downwards. No water or dilute saline solution appears to be absorbed by the stomach. In the small intestine the process of absorption is much more rapid in the ileum than in the jejunum. In consequence, however, of the continual secretion of the Succus entericus the intestinal 
contents reach the ileo-creal valve in a fluid condition, and the excess of water is only absorbed in the large intestinc. The absorption depends on two factors, a physical and physiological one. When the salts are of small or of nu physiological importance the cells appear to have little power of physiological absorption, and the salts exert their full physical influence, absorbing water or retaining that by which they are dissolved, so that they act as saline purges, $\epsilon . s$. sodium or magnesium sulphate.

\section{Metabolism.}

Proteins. - The combustible parts of the food are built up together with oxygen into the living protoplasm of the cell to form a highly unstable molecule with large potential energy. In the breaking down of this molecule there is a rearrangement of atoms to form more stable compounds, the carbon and oxygen combining into carbon dioxide with the evolution of energy, which may be displayed either as heat or work. The earliest scientific observations concerning nutrition were founded upon the commonly noted fact that in spite of large quantities of food eaten, a normal man did not vary greatly in size from year to year. The weight added by the ingestion of food and drink is lost in the urine and freces and in the excretions of the lungs and skin. The expenditure of the body must balance its income; it must lose as much nitrogen as it takes in, otherwise it would put on flesh; it must lose as much carbon as it takes in, otherwise it would put on fat. Again, the body may be losing or gaining fat, giving off more or less carbon than it takes in, while its "flesh"-its protein constituents-remain constant in amount, the expenditure of nitrogen being exactly equal to the income. In both cases we say that the bocly is in nitrogenous equilibrium. A starving animal or a fever patient, on the other hand, is living upon capital-the former entirely, the latter in part; the expenditure of nitrogen is greater than the income. A growing child is living below its income, and is incrcasing its capital of flesh. In neither case is nitrogenous equilibrium present. IWhere fats or carbohydrates are given in addition to proteins, nitrogenous equilibrium is attained with a smaller quantity of the latter. Fats and carbohydrates 
therefore economise proteins 1, a certain extent, and are spoken of as protein-sparers.

The greater part of the living structure of the body is composed of proteins, or of more complex nitrogenous bodies in the building-up of which the proteins play a preponderating part. In the young and growing animal these tissues are constantly being added, and the raw material for growth can be supplicd by proteins, and by proteins only. Moreover, in the period of adult life when the body is neither gaining nor bosing weight, every vital act is associated with a certain degree of what we may term "wear and tear" of the living structure. Most of the cells are continually dying and bcing replaced by fresh ones. For this nutritional metabolism a supply of proteins in the food is an absolute necessity. Every diet therefore must contain a certain minimum amount of protein to supply the nutritional needs of the organism, while the encrev requirements can be supplied at the expense of either protcins, fats, or carbohydrates. Feeding an animal with excess of protein only leads to increased excretion of urea. If, for ustance, a man were taking Io grammes of nitrogen in the form of protein in the day, with a sufficiency of fats and carbobydrates to maintain his weight constant, he would probably excretc also Io grammes (9 grammes in the urine, I gramme in the freces), and would therefore be in a state of nitrosenous equilibrium. On doubling the protein intake, the nitrogenous excretions would rise in proportion, and the man would remain in a state of nitregenous equilibrium, however much his protein intake were increased. The increased protein dict would, however, raise his encrgy income above his daily requirements. A certain amount of the fat and carbohydratcs would therefore escape oxidation, and would be stored up in the form of fat, and the man would therefore increase in weight. In these circumstances there has also to be considered the extent of the wear and tear of the tissues involved in eliminating the excess of proteins.

Gelatine is a special type of protein, with interesting and valuable properties. When used alone it has little nutritive powcr, but in proper combination with other foods it is a most useful aliment. It has been shown that by the addition of gelatine very large quantities of albumin can be spared in 
the body or devoted to increase of bulk, just as by the supply of fats and carbohydrates.

Fats. - The fats absorbed as food may subserve several purposes. Through its oxidation it is a source of heat earergy; it may be stored in the tissues as part of the borly fat; it may be synthetised with other substanees to form more complex constituents of the body, such as lecithin; and in view of the fact that fats economise proteins to a certain extent, they play an important part as protein-sparers. The final fate of fat in the economy is its transformation through oxidation into carbon dioxide and water. The exclusion of fat from the dietary leads to the development of cold extremities, notably the fingers, feet, and ears; also a liability to chilblains.

Carbohydrates. - The carbohydrates of the food may be stored up as glycogen or be converted into fat. As in the case of fat, the final end-products resulting from its oxidation are carbon dioxide and water. In the metabolism of carbohydrates the internal secretion of the pancreas plays an important part. The sunction of carbohydrates in the economy are-

(a) A source of en. rgy for muscular work.

(b) Source of heat production; each gramme of sugar yields 4 calories of heat.

(c) Oxidation of the sugar protects the proteins of the body; like fats, they are protein-sparers.

It has long becin taught that carbohydrates, like fats, are of no value as tissue-builders. Some doubt has of late been thrown on the correctness of this view by recent rescarches, which go to show that there is a carbolydrate radicle in the protein molecule. These researches seem to point to the necessity of additional importance being attached to the carbchydrates of the food as tissue-builkers, as well as sources of energy and heat production. When carbohydrates are giren in excess, actual or relative, the:r mctabulism is incomplete, ard sugar appears in the urine.

\section{Rôle of Bacteria in Digestion.}

It is becoming increasingly recognised that the role of bacteria in digestion is, from the clinical standpoint, a much 
more important one than formerly supposed. Active bacteria are: numerous in the alimentary canal. These include:bacteria, spores of fungi, yeasts, sarcine.

Since many bacteria can break up carbonydrates, and also proteins, in a manner similar to that of the intestinal ferments, it is admittedly difficult to say where pancreatic digestion cnds and bacterial activity begins. The chief points of importance in regard to bacteria and their action in digestion are as follows.

Bacteria acting on Carbohydrates.-Lactic acid bacilli of many kinds are introciuced with the food. These make lactic acid from cane sugar and milk sugar as follows :-

$$
\begin{aligned}
& \text { Cane Sugar. Lactic Acil. } \\
& \mathrm{C}_{6} \mathrm{H}_{12} \mathrm{O}_{6}=2 \mathrm{C}_{3} \mathrm{H}_{6} \mathrm{O}_{3} \\
& \text { Mllk Suga:- } \\
& \mathrm{C}_{12} \mathrm{H}_{22} \mathrm{O}_{11}+\mathrm{H}_{22} \mathrm{O}={ }_{4} \mathrm{C}_{3} \mathrm{H}_{6} \mathrm{O}_{3}
\end{aligned}
$$

Trere arc aiso scveral varicties of butyric acid forming bacteria in the alimentary tract. These change lactic acid and cane sugar into butyric acid, hydrogen, and carbouic acid. Yousts change dextrose (grape sugar) into alcohol, succinic acid, and glycerine; and the Mycetoma aceti and other bacteria convert carbohydrates and alcohol into acetic acicl, carbonic acid, and water, and also change acetates into carbonic acid and carbonates. It has to be noted that the organic aciels produced by decomposition of carbohydrates inhibit or reduce the activity of the putrefactive bacteria.

Putrefactive bacteria.-Putrefactive bacteria are numerous. These split up proteins into the following :-

I. Fatty acids and amino-acids, e.g., leucine, tyrosine, indol, skatol.

2. Other aromatic bodies, e.g. phenol and cresol.

3. Various ptomaines, c.g. , neurine, choline, cadaverine, and other ammoniacal compounds.

4. Various gases, e.s. sulphuretted hydrogen.

Putrefactive bacteria also split up fats into fatty acids, which are later changed into volatile acids.

In health the decomposition products arising from the infuence of bacteria on carbohydrates and proteins are either removed or neutralised by the liver or other gland, or are 
changed into harmless compounds, as in the ethereal sulphate's in the urine. As already mentioned, the organic acids produced from the decomposition of the carbohydrates exercise an inhibiting influence on the putrefactive bacteria.

In various diseased states these decomposition products are produced in excess, with the result that they are absorbed into the system and induce various manifestations of discase (see Auto-intoxication). The products of bacterial activity may be roughly grouped as follows :-

I. Gases and acids which are produced chiefly from carbohydrates.

2. Alkaloids produced from decomposition of protcins.

The recently published results of Herter and Kendlall on the influence of dictary alternations on the types of intestinal flora are of great interest. Experimenting with monkcys and cats, these observers showed that on a protein diet the bacterial flora was of a strongly proteolytic character, but that on a change to a carbohydrate diet these organisms were rapidly replaced by others of a non-protcolysing type. Associated with this change there was a change in the putrefactive products of the urine and fieces, and a reduction in the indol, skatol, phenol, and sulphuretted hydrogen, and diminution in the indican in the urine. These observations are of great valuc, as from analogy there is every likelihood that similar results hold good for man.

It will be obvious from the foregoing that diet may profoundly modify the bacterial activity in the intestinal tract. Speaking generally, a restriction in the amount of protein reduces the formation of putrefactive decomposition products, and a reduction in the carbohydrates lessens the development of gases and acids which are injurious to the system. Some authors consider that the administration of any protein above 70 grammes is bad, as inevitably tending to auto-intoxication. Further, the kind of food has to be considered. In some patients a milk diet may be unsuitable because of the large amount of lactose leading to the formation of lactic acid, and later, butyric acid, carbonic acid, and water. Again, certain carbohyclates such as potatoes are by many digested with difficulty, being carried well down into the 
ileum before digestion, thus forming a suitable niclus for abnormal bacterial activity. On the other hand, in certain cases the administration of stewed fruits may be advisable, on account of the organic acids present. These points are further referred to in discussing different diseases.

\section{Influence of various Factors on Digestion.}

Reference must be made to varjous conditions which interfere with normal digestion. One of the commonest is unduly hurrid meals. The bolting of imperfectly masticated food is a fruitful cause of indigestion. Iminularity in meals is another factor which may derange digestion. This irregularity may take the form of unequal and irregular hours between meals, as, for instance, allowing six hours to elapse between the first and second meal of the day, and three hours between the second and last, or it may take the form of want of regularity in the size and nature of the meals, as the partaking of a heavy middle-day meal by a person who has accustomed himself to a light luncheon in the middle of the day. Constipation interferes with healthy digestion, more especially if it be associated with auto-intoxication such as frequently arises from altered bacterial activity in the digestive tract, the result of a septic condition of the teeth (oral sepsis). Lack of appetite may lead to a weakening of the digestive powers, but in this connection we have to note that in some people the introduction of food into the stomach seems to induce an appetite. A sudden change in dict may adversely affect digestion. The researches of Pawlow have shown that the digestive juices adapt themselves in a remarkable mamer to the kind of food-a protein diet leading to the development of juices specially adapted for the digestion of protcins, a carbohydrate diet similarly inducing secretions specially adapted to digest carbohydrates. It is therefore easy to understand that any sudden and complete change of diet may for the time being interfere with nor:nal digestion. The digcetive pewers may also be modified by the nature of the fomel. For example, a fatty eliet interferes with the actirn of the sastric juice; excess of flud may lead to an impaiment of its action, through orer-dilution; or new bread, new potatoes, and the like may throw a strain on the 
gastric secretion which it is unable adcquately to deal with. The temperature of the food is of some importance, hot ford stimulating the flow of the salivary and gastric secretions, iced foods sometimes arresting the digestive process, especially when taken immediately after hot foods. Lastly, active physical or mental work should be avoided during the carlice stages of digestion, as the blond is then primarily required for the digestive processes.

Sleep in relation to marls. - Sleep is affected by tr:c quantity and kind of food taken. A heavy meal taken shortly before going to bed may be followed by a disturbed and restless night, and sleep of an unrefreshing character. As it ordinarily takes three hours to complcte gastric digestion, that time at least should elapse between the last regular meal of the day and bedtime. Niany patients find that their sleep is disturbed after taking certain articles of food or drink in the preceding afternoon or evening, c. $g$., strong tea or coffee, new scones, and the like. On the other hand, slecplessness is often observed in elderly subjects who have taken only a light evening meal, and may be promoted by taking a little fluid food at bedtime, c.g., cup of hot Leef-tea, malted milk, or thin gruel.

\section{The effect of Diet on the Resistance of Animals to certain Poisons.}

Dr Reid Hunt ${ }^{1}$ has recently made a valuable contribution to our knowledge of the specific action of various foods upon the resistance of animals to certain poisons. Dr IJunt's earlier experiments showed some very striking alterations in the resistance of animals to certain poisons produced entirely by changes in diet, animals on certain diets being able to resist as much as forty times the amount of certain poisons fatal to animals fed upon other diets. The results obtained by Dr Hunt were attributed by lim liargely to at specific action of the diet upon the thyroid gland, and they confirm in a striking manner the results of the author's experimental observations in illustrating how an internal secretion maly be modified in a definite manner by diet (sie Appendix). Dr Ilunt's experiments are of mucl value in suggesting new lines of rescarch by the experinental nuethod

1 bulletin No. 69, Hygienic Laboratory, U.S. l'ublic llealth Insutute, Washington, IDIO. 


\section{CHAP'TER III}

\section{DAILY AMOUNT OF FOOD REQUIRLD, AND FACTORS MODIFYING IT}

\begin{tabular}{|c|c|c|c|c|}
\hline \multicolumn{5}{|c|}{ PAOE } \\
\hline The usually accepted stan & rd d:et & Rest and exercise & & \\
\hline The Chittenden standard & . $\quad$. & Climate and season & . & - \\
\hline Influence of age and sex & & Idiosyncrasy. & . & - \\
\hline
\end{tabular}

Amount of Food required.-The amount of food required varies under different conditions. Thus, the growing child requires relatively more than the adult, old people need less than the middle-aged, and the food requirements of a stout muscular subject engaged in active physical work are greater than those of a thin weakly subject leading a sedentary life. Ve will here consider the minimum diet required for a man of average build and weight, doing a moderate amount of muscular work-in other words, the standard amount of the different nutritive constituents required daily. At the outset it must be clearly indicated that no final statement can yet be made on this important point, since the results of recent researches have thrown considerable doubt on the correctness of the teaching that has long been regarded as definitely established.

A healthy man of average weignt and doing a moderate amount of muscular work, excretes from 16 to 20 grammes of nitrogen and about 320 grammes of carbon daily. The investigations of Atwater, Rubner, Voit, and others, until lately regarded as classical, established the standard amounts of the nutritive constituents required to make good this loss daily, as follows :-

\begin{tabular}{|c|c|c|c|c|c|}
\hline I'rolein & • & - 125 & $\mathrm{~mm}$ & or $4 \frac{1}{2}$ & tunces. \\
\hline Carboliydiate & 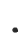 & $j(x)$ & , & or 18 & ", \\
\hline Fat & $\bullet$ & 50 & $"$ & or $1:$ & $"$ \\
\hline
\end{tabular}


These yield the following amount of heat in calories:-

\begin{tabular}{|c|c|c|c|c|c|c|}
\hline Protein . & - & - & - & $\mathrm{I} 25 \times 4 \cdot \mathrm{I}$ & & 512.5 \\
\hline Carbohydrate & . & - & - & $500 \times 4.1$ & $=$ & 2050 \\
\hline Fat & - & - & - & $50 \times 9 \cdot 3$ & $=$ & 465 \\
\hline
\end{tabular}

If expressed in terms of nitrogen and carbon :-

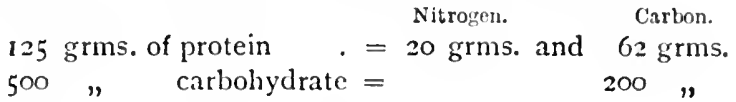

$$
\begin{aligned}
& \text { 5o " fat . . = __ } 38 \text { _ } \\
& 20 \text { grms. and } 300 \text { grms. }
\end{aligned}
$$

or, in the proportion of I gramme $\mathrm{N}$ to $\mathrm{I} 5$ grammes of carbon. No single article of food contains these elements in a proper proportion, and for this reason a mixed diet is necessary, as by that means only can we avoid taking too largely of one or other ingredients.

Expressed in terms of ordinary foods, the above dietary is approximately as follows :-

\begin{tabular}{|c|c|c|c|c|}
\hline I lb. Bread, & ntaining & . & $\begin{array}{l}\text { grms. } \\
\text { II }\end{array}$ & grms. \\
\hline$\frac{1}{2}$ lb. Meat & " & . & $\begin{array}{r}17 \\
\text {. } \quad 34\end{array}$ & $\begin{array}{l}3.5 \\
7.5\end{array}$ \\
\hline${ }_{4}^{1} \mathrm{lb}$. Fat & $"$ & . & - $\quad 8_{4}$ & $\ldots$ \\
\hline I lb. Potatoes & $"$ & - & 45 & $\mathrm{I} \cdot 3$ \\
\hline$\frac{1}{2}$ pint Milk & $"$ & - & 20 & $I \cdot 7$ \\
\hline$\frac{1}{4} \mathrm{lb}$. Eggs (2 eggs) & s) ", & - & 15 & $2 \cdot 0$ \\
\hline$\frac{1}{8} \mathrm{lb}$. Cheese & " & - & 20 & 30 \\
\hline & & & 355 & 21 \\
\hline
\end{tabular}

or, if expressed in meals :-

Breakfast-

2 slices of thick bread and butter.

2 eggs.

Dinner-

I plateful of potato soup.

Large helping of meat with fat (about 6 ounces of cooked meat).

4 moderate-sized potatoes $\left(\begin{array}{l}3 \\ 3\end{array}\right.$ lb.).

I thick slice of bread and butter.

Tea-Glass of milk and 2 thick slices of bread and butter.

Supper-2 thick slices of bread and butter and 2 ounces of cheese.

In the case of subjects engaged in severe muscular work, it has long been taught that the amount of food required is 
sreater than the above, the increase being shared by all three food constituents so as to furnish an energy value of 4500 to $5(x)$ calorics.

In recent years the researches of Chittenden have thrown considerable doubt on the correctness of these views. Chittenden's observations were made on three classes of subjects:

(1) Men engaged in mental work,

(2) Soldiers engaged in moderate excrcises, and

(3) Highly skilled athletes,

his experiments being conducted with great care and over long periods. Chittenden's work has rightly attracted a very large amount of attention, because of the very large number of persons simultaneously experimented upon, and the completeness of the experiment from the point of view of chemical analysis. Chittenden found that a state of nitrogrenous equilibrium and good bodily health was maintained on a diet which contained from $\frac{l}{2}$ to $\frac{1}{3}$ of the protein in the standard diet.

It will be seen that Chittenden's results throw much doubt on the correctness of the teaching hitherto regarded as well established. There is no question that the ideal diet consists in the smallest amount of protein food, together with non-nitrogenous food, that will kcep the body in a state of vigour. The question is whether it is right to accept as correct, for protein consumption,

(I) The minimum of 100 to 120 grammes of the commonly accepted stanclard dictary; or

(2) The minimum of 50 to 70 grammes of the Chittenden stanclard.

These figures refer to men of average size and weight. Strictly speaking, the amount of proteins should be indicated in terms of so many grammes per kilogram of body-weight, since we must recognise the necrl for varying the amount of food taken with the size of the budy to be nourished.

Chittenden's explanation of the advantages of a low protein is that the protein ford when motabolised yields a number of crystalline nitrogenous products which are excreted through the kidneys. If proteins are taken in 
excess, the kidneys are overworked, and the end-products of protein metabolism either surcharge the blood or are deposited in the tissues, giving rise to various diseased states (see Auto-intoxication, p. 346). Reviewing the position as a whole, it may be said that further observations are required before we can finally accept Chittenden's results as giving a standard for universal application. There is, in the author's opinion, however, no doubt whatever as to the correctness of Chittenden's main contention that the amount of protein required daily to maintain the bocly in a satisfactory state of health is considerably less than the amount hitherto regarced as essential; and secondly, that some at lcast of the excess is injurious to health. This view is now very largely held by clinicians. Some of the directions in which excess of protein may injuriously effect the tissues are indicated in the results of the author's investigations (see Appendix).

With regard to the amount of carbohydrates and fats, it has to be borne in mind that the more fat and carbohydrates in the diet, the less is the protein of the food used up for the production of energy. Carbohydrates and fats are both protein-sparcrs; and one cannot replace the other in a mixcd diet as a source of energy. Any excess of protein-sparers in the diet may produce similar results to an excess of protein itself, by protecting the latter from complete oxidation.

Mineral Constituents of Food.-Death ensues if salts are withheld from the food. They are essential for the growth and repair of the tissue. There are no exact data available for indicating how much is required, but we know from experience that there is enough in an ordinary mixed diet, the mineral matter being present, as a rule, in organic combination. Calcium is specially required for the growth of bone-it occurs abundantly in milk, eggs, and rice; meat foods are deficient in calcium. Oxalate of lime is present in certain foods, notably tea, coffee, spinach, rhubarb, and pepper. It is absent in animal foods. About 10 milligrams of iron are required daily, and are taken in organic combination. It is relatively abunclant in meat and yolk of eggs; it is deficient in milk and its derivatives. For this reason, persons who are kept for a long time on a purely milk diet are apt to become anamic. It might be assumed that the paucity of iron in milk is a 
disadvantage in the feeling of infants and young children, but this is not so, as the yound child has a large reserve store of iron in the liver which it has obtained from the blood of the mother.

Vegetable foods, c.s., green vegetables and fruits, are rich in potassium; animal foods are rich in sodium. It is probable that the potassium in vegetables and fruits acts beneficially, largely because of the vegetable acids with which it is combined, and which by oxidation assists in maintaining the normal alkalinity of the blood. Sodium is taken abundantly in the form of common salt, of which about 20 grammes are taken daily in a mixed diet, this amount being considerably above the actual body requirements. Phosphorus is one of the most important mineral ingredients in the food, more especially for growing subjects. It is present in organic form, and also in an inorganic form as phosphates of the alkalis or earthy metals, and there is reason to believe that the former are the more valuable. Animal foods are much richer in phosphorus than vegetable foods. The foods richest in phosphorus in combined organic form, are fish roe, thymus, calves' brains, and the germ of wheat.

\section{The Influences of various Conditions upon the Amount of Food required.}

Influence of Age and Sex.-The age of the individual not only modifies the absolute amount of food required, but also the relative quantity in proportion to body-weight. The rapid growth of children in early life necessitates a relatively larger consumption of food than at any other period of life ; more especially it calls for a large supply of building material, i.e. proteins.

The standard of increase usually adopted is as follows :-

A child under 2 requires 0.3 the food of a man doing moderate work.

$A$ child of 3 to 5 requires 4

A child of 6 to 9 requires 5

A child of 10 to 13 requires 6

A girl of 14 to 16 requires 7

A boy of 14 to 16 requires 8

$\begin{array}{lll}" & " & " \\ " & " & " \\ " & " & \end{array}$

In old age the processes of assimilation are less active and the bodily activities are restricted, hence less food is required. 
Over-fecling is a fruitful cause of serious trouble in elderly subjects.

Under similar conditions women require less food than men, for the reason that they are usually smaller, and do less muscular work. Given precisely similar conditions as to weight of subject and amount of physical work performed, there is probably no difference in the amount of food consumed. The dict in pregnancy should be liberal but not excessive. During lactation the amount of food must be increased, more especially in protein and fat, in order to make good the nutritive elements lost in the milk.

Rest and Exercise.-Much less food is required during rest than during cxercise. The following is the generally accepted statement of the number of calories which must be supplicd for work of different degrees of scverity (Rubner).

\begin{tabular}{|c|c|c|c|}
\hline & & & Calories \\
\hline Rest, e.g. a child at a desk & & & - 2500 \\
\hline Moderate muscular work, $e . g$ & house-painter & & - $3 \mathrm{III}$ \\
\hline Severe muscular work, e.g. sh & hoemaker & $\dot{\theta}^{\circ}$ & 365 \\
\hline Hard labour, e.g. blacksmith & . & - & 5213 \\
\hline
\end{tabular}

The researches of Chittenden, however, already alluded to, throw great doubt on the correctness of this teaching. Chittenden found that the average daily nitrogen excretion of eight athletes on a reduced protein diet was 8.8 grammes, this being obtained from a protein intake of 55 grammes, the caloric value of the total food being from 2500 to 2300 calories. Similar results were obtained in the case of the soldiers on the prescribed diet. The meals were selected from the following:-

Breakfast-

Coffee, rolls and butter, bananas, fruit, hominy with sugar and cream, farina, Indian meal, baked potato, boiled rice or oatmeal.

Lunch-

Coffee, bread and butter, sphagetti, potato, stewed tomato, boiled onions, string beans, fruit, hominy and syrup, oysters, cold tongue, baked apple.

Dinner-

Soup, pea, cream of celery, bean, tomato ; fish, bacon, sausage, chicken, lamb chop, steak, fried or boiled potatoes, spinach, lettuce, celery, apple salad, Lima beans, cream puffs.

In the present state of our knowledge it is not possible to be 
ton fingmatic on the subject, but there is in the writer's view little duble that, just as the hitherto accepted standard of soocalories for a man engaved in light worl has been proved by (hittenden to be excessine, so the abore increase of over 2000 calories is materially sreater than is necessary or advisable for subjects engaged in hard physical labour. It is probable that an increase of food by onc-fourth or one-third of the normal is all that is necessary for subjects engaged in severe muscular work.

The question arises as to whether the increase of food undoubtedly necessary for subjects engaged in hard physical work should affect mainly the proteins, fats, or carbohyclrates. There are no data by which this can be precisely determined. By those engaged in training for athletics, proteins are largely relicel on to supply the extra encrgy; lut for ordinary purposes it is certainly advisable that the increase should be equally distributed among the proteins, fats, and carbohydrates of a mixed dictary, sugar being specially advantageous.

Climate and Seasons. - Climate and temperature influence the fuantity and quality of food required. In tropical countries the natives live larely on vegetable foods and fruits, and consume less animal foor and fat; in the Arctic regions the inhabitants consume enormous quantities of flesh and fat. The explanation of this is to some extent to be found in the fact that the natives of any country eat what they can most casily obtain. At the same time, the necessity for supplying the body with a large proportion of combustible food, such as carbohydrates and fats, when the external temperature is very low is obvious; and it is also clear that less food of this kind is required when the external temperature is high. In this country common experience has shown the advisability of modifying the diet in the heat of summer, less animal food being taken, vegctable substances and fruits entering more larely into the rlictary.

Personal Idiosyncrasy.-It is a mattcr of common obscrvation that some people habitually eat much less than others, although living under the same general conditions. This is, in all probability, to some extent a result of habit and grencral training. At the same time there is no reason to 
doubt that some tissties work inore conomically than sthers, with corresponding atvantage to the individual. Many special idiosyncrasies with regarel to dict have to be consielered. Some persons cannot talic egges in any form; others camot take milk; some are made ill by certain kinds of fruit or meat. These may be the result of inh"rited tendencie's, or may be the growth of nabit. 


\section{CIIAPTER IV}

\section{MIL AND ITS PRODUCTS-EGGS}

\begin{tabular}{|c|c|c|c|}
\hline & PAOE & & PAOE \\
\hline Introduction. & . $2 S$ & Methods of increasing the digesti & \\
\hline Composition of milk of differen & & bility $\cdot \quad \cdot \quad \cdot \quad \cdot$ & 33 \\
\hline animals . & 29 & Adaptations of milk for the sick & 34 \\
\hline Cow's milk z. II uman milk & 29 & Methods of altering the taste. & 34 \\
\hline Milk, composition of- & & Uses of milk. & 36 \\
\hline Proteins, fats, etc. . . & $3 \mathrm{I}$ & Milk adulteration and impurities & 37 \\
\hline Other milks-Mure's, goat's . & 32 & Milk derivatives - Cream, whey & \\
\hline Clotting and curdling of milk & 33 & butter, cheese, koumiss, etc. & 38 \\
\hline Digestion and absorption of milk & 33 & Eggs • • • • . & \\
\hline
\end{tabular}

Milk is the type of a complete food provided by nature. In carly life it forms the exclusive food of all young mammals. It can also be employed as the chief food for adults under certain pathological conditions, which will be referred to in later chapters; but on account of the large amount that is required for daily consumption, it is not a very practicable food for healthy adults.

It is in the highest degree important for the well-being of young children to have milk which is of excellent quality at its source; and, sccondly, it is equally necessary that it should not be adulterated or infected in the process of transit and distribution. Since the sources of contamination are numerous, the task of obtaining an absolutely pure supply is a difficult one, and in recent years the question of the milk-supply of our large towns has engaged more and more the attention of the profession and of civic authoritics.

The mille of all animals contains the elementary substances-proteins, fats, carbohydrates, salts, and water-com- 
bined in such proportions as are best aclapted for the period during which growth is most active. The proportions of these elements vary in different milks, as shown in the following table:-

Composition of milk of different animals.--

\begin{tabular}{|c|c|c|c|c|c|c|c|c|c|}
\hline & & & & & Protein. & Fat. & Sugar. & Ash. & $\begin{array}{c}\text { Other Nitrogenous } \\
\text { and Unknown } \\
\text { Bodies. }\end{array}$ \\
\hline Human & & . & . & . & 0.9 & 3.52 & $6 \cdot 75$ & 0.19 & 0.6 \\
\hline Cow & & . & . & . & 3.0 & $3 \cdot 55$ & $4 \cdot 51$ & 0.70 & 0.3 \\
\hline Goat & . & • & • & . & $2 \cdot 8$ & 3.10 & 3.530 & 0.95 & $\ldots$ \\
\hline Mare & . & • & . & . & 1.9 & $1 \cdot 00$ & $6 \cdot 33$ & $0 .+5$ & 0.49 \\
\hline Ass & ، & . & . & . & 1.6 & 0.93 & 5.60 & 0.36 & $\ldots$ \\
\hline
\end{tabular}

Milk is an emulsion consisting of fine oil globules suspended in a colourless liquid or plasma-

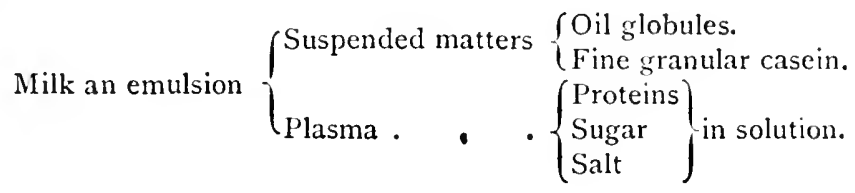

When freshly drawn, the reaction of milk varies in difierent animals. Human milk is alkaline; cow's milk is neutral; and the mills of carnivora is acid in reaction. On standing, all milk becomes acid, owing to the formation of lactic acid, through the action of bacteria normally present in milk. The average proportion of the chief ingredients in cow's milk and human milk are here given for comparison :-

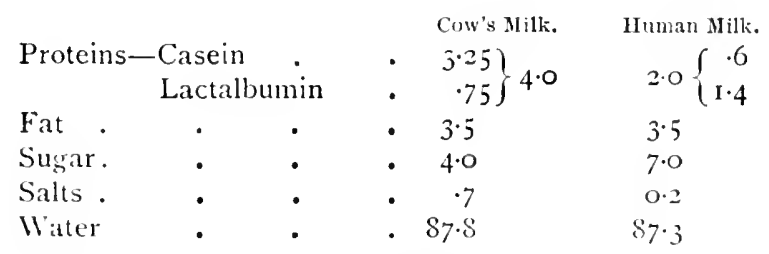

It will be seen that the chief differences in composition are the much larger amount of protein and the smaller proportion of sugar present in cow's mills. There is further an 
impo:tant difference in the nature of the proteins, for while in cow's milk they consist chiefly of cascin, the proportion of cascin to lactalbumin being $4: \mathbf{I}$, in human milk lactalbumin is the chicl protein, the proportion of cascin to lactalbumin beiner approximately $1: 2$. The practical importance of this is readily appreciated if samples of the two millis are treated by the addition of weak hydrochloric acid. Large masses of curcl are at once formed in the cow's milk, while the human milk shons a fine flocculent precipitate. Similar changes occur 12 the stomach. Another important difference is the sterility of human milk in contrast with the large number of bacteria normally present in cow's milk as it reaches the consumer. Human milk is further considered on p. 23I. We w:ll now consider cow's milli and its derivatives.

Cow's Milk. - The composition of milk varies within wide limits, so that it is impossible to gauge within 20 per cent. the amount of nutritice materials contained in a given quatity. The main variations are in the amount of fat and protein present. The composition, quality, and quantity of m!lk are influcneed by a variety of circumstances:-

(1) The infuence of brecl. Alderneys give a milk rich in fat; Longhurns a milk proportionately rich in casein.

(2) The mills with a first calf contains less water, and is richer, but the quantity yielded is less than in subsejuent presnancies.

(3) The oftener the mamme are empticl the richer the wilk becomes in casein, and the mills withdrawn at tee cond of milling is always richer in butter than at tue besinning. The erening milk contains a larger proportion of butter than the morning.

(4) The nature and guality of the food cxercise considerable influence over the amount and quality of the mill: liresh sreen pastures produce the sweetest flaveured and best milli. lisectroot and carrots increase the amount of sugar. Turnips, brewers' srains, and rilcake impart a peculiar flavour and lecepen the crilour. The colour, the odour, and cren poisonum properties may pass from the vegetables or plants cumsumed into the mills secreted. 
(5) The degree to which the milli has been adulterated by the addition of water, sugar, or of preservatives such as formalin, salicylic acid, and the like.

The specific gravity of mill: is from 1026 to 1035 . This is, however, of no value as a test of its quality, because skimming milk raises the specific gravity, since fat is lighter than water. I Ience, milk can be skimmed and water added to keep the specific gravity the same. An estimation of the fat is essential for determining the nutritive value of milk. Good milk should contain 4 per cent. of fat.

The proteins of milk consist of casein and a small amount of lactalbumin.

Casein is the principal protein, and is liept in a state of solution by the phosphate of lime present in mill. This protein is distinctive in containing no nuclein, and secms to yield no uric acid when split up. Casein further differs from other proteins in not being coagulated by heat; it is readily coagulated by acids and also by rennet, a ferment secreted by the stomach. From casein a substance resembling flour has been prepared, and is in the market under the name protenc. Another substance-Nutrose-is casein in combination with a soda salt. Plasmon is a similar preparation. These preparations of casein are used to increase the nutritive value of gruels, soups, teas, and pucldings. They are further referrecl to on p. I 58 .

Lactalbumin is present only in very small quantity in milk; it coagulates slowly when boiled, and forms the "skin" on boiled milk.

The carbohyclrate of milk is in the form of lactose or milk sugar. This is less soluble than ordinary sugar, from which it also differs in having no sweet taste. Unlike glucose, it is not readily fermented by yeasts, but it is readily split up by certain micro-organisms, with the production of lactic acid, a process which occurs in the souring of milk. Many cases of cliarrhoea in infancy are clue to the irritation of lactic acid produced in this manner. The absence of cartbohydrate in mills malies it a specially uscful food in cases of severe diabetes.

The fat of milk is in the form of an exceedingly fine 
cmulsion, being suspended in the plasma of milli in the form of slobules, which impart to milk its white, opaque appearance. The proportion of fat should not be less than 3 per cent. On standing, the fat globules run together and foat on the surface in the form of cream. This fincly divided form of fat is one of the most easily digestible fats. When the cream is removed skimmed milk is left; this, however, may still contain ! to 1 per cent. of fat. If the cream be removed by a separator, the fat is much more completely abstracted, and the milk so prepared is known as separated milk.

The mineral mattivs are of great importance, the most important salts being the phosphate of lime and phosphate of potassium. The one important mincral constituent that milk lacks is iron, and this has to be borne in mind when giving a prolonged course of strict milk diet to adults. The deficiency of iron in milk is of less importance in the feeding of infants because of the large reserve amount of iron normally stored in the fuetal liver.

Citric acid is present in milk, chiefly combined with line as calcium citrate. This is only sparingly soluble. It is stated that a good cow yiclds as much citric acid in a day as would be found in two or three lemons. It has been susgrested that the citric acid is the antiscorbutic element of milk.

The remaining ingredient is atatcr. This keeps the solid constituents in solution, but makes milk a dilute and bulky foocl.

As was shown by table on p. 29, the relative proportions of the different constituents of milk vary considerably in different animals.

Goat's milk is rich in fat and protein. It is poor in sugar, and is not much liked on account of its peculiar smell, due to the characteristic acid. Still rccords the case of an infant who was fed on soat's milk for several months; the goat cost fourteen pence it weck to keep, and yielded at least two to three pints of milk twice a day. Goat's milk requires dilution in the same way as cow's mill:

Mare's milk resembles human milk very closely, but is rather pereser in fat and protedns. Like himan milk, it is richer in sugar than the other varieties. The richness in 
sugar is taken advantage of to prepare koumiss by alcoholic fermentation.

Ass's milk is the poorest in solids, but it is a swect milk. The deficiency of fat and casein makes it easily digestible for infants and invalids who are unable to digest cow's milk. The small amount of fat present makes it unsuitable for continued use.

Cow's milk is remarkable for its large proportion of protein and fat, and the comparatively small amount of sugar.

Clotting of milk, and its effect on the digestibility.Milk is not truly a fluid food, for whencver milk enters the stomach the ferment rennin and the acid of the gastric juice change the milk into a solid curd. This is brought about under the influence of the salts of lime. The clotting of milk is well illustrated in the making of curds or junket. This coagulation or clotting of milk must be distinguished from the curdling of milk. Curdling is due to the casein separating out of the milk in the form of a fine precipitate of unaltered casein, this taking place under the influence of lactic acid fermentation, which removes the casein from its combination with lime salts. In the process of clotting, on the other hand, the casein is profoundly changed, and acquires new and distinctive characters. The clot consists of the soliclified casein with fat entangled in its meshes. The clot gradually shrinks and becomes more tough and less easily digested. Under normal conditions this clot redissolves in the alimentary tract; but in pathological conditions, such as enfeebled states of the digestive ferments, a hard, firm, indigestible mass forms in the stomach, which proves an irritant to the whole intestinal tract, inducing pain, flaiulence, diarrhoea, or constipation, and sometimes is recognisable unchanged in the faces.

Various methods are adopted to control the density of the curd, and so improve the digestibility of mills.

(a) By reducing the proportion of casein; this is done by diluting the milk. The diluent may be simply plain water; a mixture of half and half will materially lessen the clotting. The addition of an acrated mineral water acts in two ways; firstly, by dilution, and, secondly, the aeration makes the clot 
more friable; potash, seltzer, sorla, or Salutaris may be used. The admixture of barley-water, toast, rice, or oatmeal water is also useful; the thickened fluid hinclers the formation of larece curds and makes the clot more friable. Gelatine jelly, using it in the proportion of I tcaspoonful to 2 ounces mills and 2 ounces of water, is also uscful.

(b) by reducing the toughness of the clot, the addition of lime-iviter in the proportion of $I$ in 3 acts in three ways on the milli. It dilutes it; the addition of lime renders some of the soluble lime salts insoluble, and so neutralises the acidity of the mill; ; this effects the desired result of lessening the toughness of the clot. I.ime-water causes constipation, and if the paticnt is suffering from diarrheea, this may be an advantage, but in other cases it is prejudicial. Sodium bicarbonate in solution (f drams to I ounce) can be used in the same proportion ats lime-water ( 1 in 3), and does not produce constipation.

The method of preparation of the diluents is as fullows:--

\section{Thick Barley-IVater.}

(Barley can be used twice.)

? ounces pearl barley.
z pints cold water.
Rind and juice of half lemon.

Sugrar to taste.

Mcthod. Wash the barley well, put it into a saucepan with cold water to cover it. liring the water to the boil, and then pour it away. Wash again with cold water, and rinse out the saucepan. (This is to blanch the barley, and if it were not done, the colour of the water would be dark.) leturn the barley to the saucepan with 2 pints of cold water and the thinly peeled rind of half a lemon. Simmer slowly for two hours, strain, sweeten, and strain in lemon juice. 'This is served hot or cold. Time, wo hours.

Note.- This is a refreshing drink, and a favourite with most invalids. The lomon juice must be omitted if it is to be used as a diluent for milk.

\section{Clear Barley-IVater.}

2 ounces pearl barley (Robinson's).

1 pint boilingr water.
Rind of half a lemon.

Sugrar to taste.

Methot.-Wash lsarley well, and put into a jusr with thinly peeled rind of a temon and a little sugrar. I'our freshly boiled boiling water on barley. Cover jugr: and stand till cold. Strain, and it is ready for use. 


\section{Toast Water.}

I slice crust of bread.

I pint cold water.

Method.-The crust of bread is better than the crumb; as it does not sour so soon.

Toast well on both sides until dry and nicely browned-not burnt. Have the fresh cold water in a jugr, and break the toast into pieces and put into it. (If the water is poured on to the toast it makes a thick muddy mixture.) Cover the jug, and let the toast remain soaking until the water is the colour of sherry wine.

\section{Rice Water.}

I tablespoonful rice.

I quart water.

Wash the rice, then allow it to soak in a quart of water at the side of the fire for two hours, then boil for one hour, and strain.

\section{Oatmeal Water. \\ I tablespoonful oatmeal. \\ I pint water.}

Mix the meal and boiling water, and then boil for one hour. Keep adding water to keep the quantity up to a pint. Strain.

\section{Gelatine Jelly.}

Soak a teaspoonful of chopped leaf gelatine in half a pint of cold water for three hours, then stand it over boiling water until the gelatine is dissolved.

The boiling of milk does not apparently render it more easily digested. It has been found that a pint of buttermilk remains three hours, raw milk about three and a half hours, and boiled milk four hours in the stomach of a healthy man.

Nutritive value. - With regard to its nutritive value as a food for adults, milk cannot be recommended as the sole article of food, for the following reasons:-In order to get sufficient carbohydrates a very large quantity of mill; is required ( $S$ pints). This means that the body is supplied with more fat, protein, and fluid than is necessary, or than can readily be digested. Further, although milk is bulky it does not supply sufficient residue to set up peristalsis, and it is therefore constipating. If combined with a carbohydrate, that element in which it is defective, milk is an excellent food, and if taken with bread a smaller quantity of milk would suffice. A combination of 10 ounces of bread ( $I_{2}^{1} \mathrm{~d}$.) and I pint of slimmed mills ( $\frac{1}{2} \mathrm{~d}$.) may be cited as a practical illustration of a cheap meal, with a fuel value of over 900 caluries. In states of illness or during convalescence these objcctions 
to a milk dictary largely disappcar, and milk at once takes its place as the most useful food.

The chicf clinical uses of milk may be summarised as follows :-

(1) In fever, milk acts as a quencher of thirst as well as a foorl.

(2) Milk, from the large amount of fluid present, acts as a dituretic; it is the main article of food in inflammatory conditions of the kidney.

(3) In paticnts requiring extra nourishment, milk may be taken with meals in the place of other non-nutritive fluids.

(4) The digestibility of milk is increased by the addition of substances which tend to make a finer clot, such as barley-water; also the administration of some solid food, such as bread.

(5) Milk is of special value in cases of hyperacidity of the stomach and other gastric disorders, since the casein is an efficient neutraliser of the acid. Skimmed milk is here of very special value.

(6) Owing to the lack of residue from this food, milk is of great value in states of catarrh and ulceration of the gastro-intestinal tract.

(7) In patients at rest in bed the bulkiness of milk is no drawback, as not more than 3 or 4 pints are required.

To vary the monotony of a milk diet the following recipes will be found helpful :-

\section{Milk Borril.}

Make a meat-extract preparation as directed upon the bottles, but use bollng milk instead of water. This quite disguises the taste of the milk.

\section{Milk Tea and Milk Coffee.}

Two teaspoonfuls of tea in a warmed teapot, and pour over it a small quantity of boiling water, about 3 tablespoonfuls. Allow to stand for three minutes, then add a pint of boiling milk. Stand another minute, pour off, and strain. Hot milk flavoured with coffee may also be used.

\section{Milk Fortificd with Starch.}

Milk, I pint. Cornflour, arrowroot, or farina, 2 ounces.

Benger's liquor pancreaticus, 1 teaspoonful.

Mix the coruflour into a thin paste, with a little milk; boil the rest of 
the milk and pour it upon the mixed cornflour, stirring continually until the whole mass thickens. Adrl the liquor pancreaticus, stirrins continu. ously until the preparation is the consistence of cream, when it is ayain boiled for five minutes.

\section{Milk and Cinnamon Drink.}

Boil I pint of new milk with sufficient cinnamon stick to flavour it pleasantly; slightly sweeten with sugar. Taken cold, with a teaspoonful of brandy, this is specially valuable as a nutritive drink in diarrhoa.

\section{Milk Adulteration and Impurities.}

It is advisable to refer very brieny to some of the more common defects in milk as an article of food. The most commonly encountered adulteration is dilution with water. When the dilution is made with pure water it is a fraud, and when, as sometimes happens, the water is from an impure source, it is a crime. Milk is sometimes artificially coloured by the addition of minute quantitics of colouring matter, a little special pigment being added to impart the yellow colour characteristic of good cream. A pinkish or reddish coloration of the milk may arise from the ingestion by the animals of food rich in pigment. Various preservatives are frequently added to the milk, notably borax, boric acid, salicylic acid, and formaldehyde, and these may be very prejudicial to the digestion of milk in the case of infants and delicate children. The milk, after a preliminary dilution, is frequently fortificd by the addition of flour, farina, whiting, tragacanth, or magnesium carbonate; the addition of one or other of these substances gets rid of the thin colour of diluted mills. Sugar may also be added to the diluted milk to raise its specific gravity to a satisfactory standard.

Milk contamination.-Milk may be contaminated by the cow's disease germs, e.g., tuberculosis and diphtheria. Extrancous discase germs may find their way into milk through contact with unclean hands, or from polluted water used for dilution or for washing cans and pans. Examples of discases so induced are typhoid fever, scarlet fever, gastro-enteritis, diarrhoa, etc. The milk is often tainted with exerementitious matter from the cowshed. Professor Silvanus Thompson describes the ideal system of cleanliness which provides a "guaranteed mills" :-

"Each milkman, before milking, is required to cleanse his 
hands in hot water with soap and a nail-brush; he then dons a clean white linen suit from the sterilising chamber, and takes a clean towel and milking stool; he is not allowed to moisten his hands with the milk in milking, and he must wash his hands each time before milking another cow. All cows must have given a negative tubcrculin test, and all are groomed twice a day before milking. The milk is drawn into pails with small openings, and exclude droppings from the animal's belly. The milk is strained through sterilised absorbent cotton, and placed in a cooler, which reduces the temperature to $40^{\circ} \mathrm{F}$. within twenty minutes after leaving the udder. It is then bottled and stored in icc water ready for shipment."

Good, clean, uncontaminated milk should keep fresh, cxposed in a clean room at ordinary tempcrature of $68^{\circ} \mathrm{F}$, for forty-cight hours, without sonmg and coxgulating. But if the air is warmer, or if the milk be in any way contaminated, it will sour in a few hours. Boiled milk will keep fresh about half as long again as fresh milk. A large number of bacteria are capable of inducing lactic acid fermentation of the milk sugar, and some of them carry the decomposition further, to the development of carbonic acid and alcohol. This latter interferes with the normal digestion of milk. Lastly, it is important to bear in mind the absorbent power of milk: it may acquire a flavour or odour from substances in its vicinity. It should not, therefore, be kept in a pantry beside such foodstuffs as stale checse or onions, and it should not be left exposed in a sick-room or anywhere near a waste-pipe.

\section{Milk Derivatives.}

\begin{tabular}{|c|c|c|c|c|c|c|c|c|c|c|c|}
\hline & & & & & PAGE & & & & & & PAOK \\
\hline Cream. & - & - & - & - & - 38 & Cheese & - & - & - & - & \\
\hline Whey. & • & . & . & . & . 40 & Buttermilk & . & . & . & . & \\
\hline Butter. & . & . & . & . & . $4 \mathrm{I}$ & Koumiss & . & . & . & . & \\
\hline Margauine & . & . & . & . & . $4 \mathrm{I}$ & Kephir & . & . & . & . & \\
\hline
\end{tabular}

Cream.-Cream consists mainly of the fat of milk. It, however, also contains protein and sugar in the same proportion as milk. The real difference between cream and milk is that cream contains less water.

When milk is allowed to stancl for some time the fat globules in the milk rise to the top, forming cream. The 
thickness of this layer of cream varics. The nomal arerage quantity of cream is over $S$ to 9 per cent. of the volume of the milk, but there may be over 20 per cent. If the cream falls below 5 per cent. of the volume of milk, the milli has becn watered. The proportion of cream in milk is dependent on various factors, such as the brecd, age, and food of the cows. Alelerneys and Guernsey cows give a millk very rich in cream. The milk which comes towards the end of milking contains more fat than that which is first drawn. Afternoon milk is richer than morning milk, both in protein and fat. The rise of the cream is favoured by a cool temperature; the acldition of a little warm water added to the milk hastens the rising of the cream by altcring the specific gravity of the mills.

The percentage of fat in cream may be 10 to 20 per cent., as in crcam obtained by skimming milk; cream producect by centrifuge may contain from 40 to 60 per cent.; and the clotted Devonshire cream may contain as much as $7 \mathrm{C}$ per cent. or more. A legal standard for cream would bc advantageous.

Varieties of Cream.-Tea cream as sold in the clairy is generally a thin cream produced by skimming milk in the ordinary way.

Double cream, or separator cream, is obtained from the milk: by centrifugal force. A small and large drum are placed onc within the other, leaving a space of a few inches betwecn. The inner drum is made of porous material. It is filled with milk and set in rapid revolution. The lighter portion, the cream, remains in the inner drum, while the other ingredients are forced through it into the outer drum.

This method of obtaining cream is far more rapid than when it is allowed to rise by standing, and also it obtains almost all the fat from the mills. Cream procured in this manner does not remain fresh so long as ordinary crcam, for it is separated at a temperature favourable to the growth of bacteria.

Condensed or evaporated cream consists of one-fourth cream and three-fourths other ingredients of milk, the whole milk having becn evaporated. It is, therefore, a natural product and is not artificially sweetcned.

Clotted or Dewonshire cream is a special varicty prepared 
hy heating the milk :n cleep pans over a slow fire not above I $50^{\circ} \mathrm{F}$. This causes a rapid and complete separation of fat. The proportion of fat in such cream is about 60 to 70 per ccnt. Devonshire cream contains only about half as much sugar as ordinary cream, and it is peculiarly suited to be a source of fat in the dictary of diabetics. Fothergill wrote: "Devonshire cream is delicious with preserved ginger, while cream and maraschino form a nutritive drink for the affluent consumptive."

Cream is one of the most wholesome and agreeable forms of fat. It is often eaten too rich and may disagree on that account, whereas diluted with an equal bulk of water or of lime-water it can be easily digested.

Where there is difficulty in digesting milk, 3 or 4 tablespoonfuls of cream in a tumblerful of Vichy makes a nourishing and digestible beverage. The mutritive value may be increased, if desired, by the addition of half an ounce of sugar of milk. It may be used along with or to replace cod-liver oil in pulmonary tuberculosis, and it is an admirable food in any case of long-continued suppurative disease, $c . g$., hip joint, empyema. It must be avoided in cases of flatulent indigestion, in most forms of gastric disorder, in obesity, and in gall-stones

In the feeding of infants who cannot readily take diluted milk, and in infants suffering from diarrhoea, marasmus, and the like, cream given in well-diluted form is of great value.

The addition of strong liquors to cream lessens its digestibility: the alcohol coagulates and toughens the envelopes of the fat globules.

Ice cream is a frozen mixture of cream, sugar, and flavouring agent. When very simply made it is nutritious, and may be allowed to many patients. It is soothing to inflamed throats, and is enjoyed by convalescents from fevers. It should be eaten very slowly, so that it may get warmer in its passage to the stomach, and not retard digestion by a cold mass being suddenly introduced. The nutritional value of ice cream can be increased by the arddition of egg or plasmon.

Whey.-When milk has been standing for some time a spontaneous coasrulation occurs, and whey is squeezed out of the contracting clot. Whey so prepared has a sourish taste, and is less palatable than the artificially prepared varieties. Whey is also artificially prepared by the addition of rennet. 
To the pint of fresh milk warmed to bluod heat (98 to $100^{\circ} \mathrm{F}$.) add 2 teaspoonfuls of rennet, set it aside in a warm place for a quarter of an hour, when clotting will have occurred. The clot is then very thoroughly broken up by stirring, and the whole strained through muslin. The whey has percentage composition of water 93 , lactose 5 , albumin $\cdot 8$, ash .6 , fat 3 . It is practically an aqueous solution of milk sugar. It is apt to turn sour.

Whey can also be prepared from milk by boiling with lemon juice, $\epsilon_{g}$. ., boil a pint of milk with 2 teaspoonfuls of lemon juice. Strain in muslin; squeeze out all fluid from the curd. The whey can be added to beef-tea, or yolk of egg beaten up in hot water.

Whey may be simiiarly prepared by boiling two parts of milk with one part of white wine, c.g., sherry.

Whey makes a palatable drink, with slightly diuretic and laxative properties. Whey cures, where up to 5 pints of the whey are taken in twenty-four hours, have been established for the treatment of renal and dropsical affections (see p. 538).

Butter.-Butter is made from the cream of milk by churning. It consists of about 80 per cent. of fat, I 5 per cent. of water, with a little casein and sugar. A certain amount of common salt is added to increase its keeping qualities and to improve its taste. Pure cultures of certain organisms are made use of to ripen butter, and so impart a constant flavour. The rancidity which develops when butter is kept too long is due to the casein, the protein decomposing and liberating a ferment which separates fatty acids and glycerine. Butter is easily digested and absorbed. Most persons eat about an ounce a day of butter, but two or three times that amount may be taken by some people.

Margarine and Butterine.-These are purified animal fats so made up as to closely resemble butter. They are made by melting down and clarifying various animal fats. The melted fat is allowed slowly to cool, and in the process the various fats solidify at different temperatures. After the stearin and palmitin have solidified, the olein is removed by pressure, churned up with a little milk, and tinted with a vegetable dye, and is then ready for use. These butter substitutes, in comparison with butter, contain fewer soluble and 
rolatile fatty acids. The absence of butyric acid and cascin is a distinct advantage, as these two ingredients are the main cause of butter becoming rancid, and therefore the substitutes "keep" much better. They have been declared to be perfectly innocuous, and are an admirable and cheap substitute for a necessary but expensive food. They could with advantage be made more use of, especially in cooking. The legal control of their sale is mainly intended to prevent them from being fraudulently offered as butter.

Cheese is another milk derivative, consisting of casein of the milk, separated by rennet, with some of the fats or oils. Cheese, as a foodstuff, presents a large amount of nutrinuent in small bulk, one pound of checse containing as much nitrogenous food as two pounds of meat. In countries where meat is scarce and dear, the country people consume large quantitics of the heavier, less highly flavoured cheeses. The wealthy classes eat cheese more as an extra taken after meals, and employ the higher flavoured varieties.

Method of preparation. - In all cheese the method is to take the milk, either whole, skimmed, or fortified with cream, heat it to about $S \mathrm{O}^{\circ} \mathrm{F}$., and then curdle with rennet. The curd is then minced, strained, coloured, salted, and finally pressed into shape, the whey being thus expelled. The varieties of cheese depend upon-

(a) The quantity of water they contain; this chiefly determines the hardness or softness.

(b) The quantity of fat present, this being small in amount in cheese made from skimmed milk, and large in amount in cheese made from milk fortified with cream.

(c) The kind and degree of the fermentation processes, upon which the flavour largely depends.

The nutritive value of cheese depends largely on the proportion of fat present in its composition. There are three leading varicties-soft, hard, and skimmed milk. A fair average for the fat and nitrogen present in these three types, when fresh, is as follows (Fleischman):-

$\begin{array}{llccc} & & \text { Soft. } & \text { Hard. } & \text { Skimmed Milk. } \\ \text { Fat } & * & \text { 3i to } 44 & 29 & 2 \text { to } 3 \\ \text { Nitrogen } & \text { - } & \text { I3 to } 24 & 28 & 19 \text { to } 33\end{array}$

Such cheeses as Stiltun, Gloucester, Gorgonzola, Edam, 
Cheshire, and Requefort, are examples of rich cheese made from milk fortified with cream; while skimmed milk is chiefly used in the manufacture of Single Gloucester, American, Dutch, Suffolk, and Parmesan. The fat present in the "rich cheeses" makes the cheese soft and friable, and they decompose more rapidly. This process is called "ripening."

The fatty acids present in cheese have been considered detrimental, but, on the other hand, it is possible that in some cheeses, especially the richer varieties, the acids formed by bacteria in them may be inimical to other putrefactive processes going on in the alimentary canal. If so, this would explain the absence of injurious effects from the taking of these cheeses, noted in some cases of otherwise weak digestion.

Cheese cannot be regarded as an article of diet suitable for patients with a weak digestion. This is specially true of the richer cheeses, in which the large amount of fat interferes with the ready digestion of the casein. It is well to recommend patients who are very fond of cheese to partake of one of the softer varieties, as, although less digestible, they are much less likely to be taken to excess. The addition of an alkali (e.g. bicarbonate of potash) makes it more easily digested, the alkali forming a soluble compound with the casein. This is best done by adding a pinch of the salt to $\frac{1}{4} \mathrm{lb}$. of grated cheese, which may then be mixed with another foodstuff, such as milk or eggs. The large number of bacteria in ripe cheese is another factor which makes cheese an unsuitable article of diet for invalids. The recently introduced lactic St Ivel cheese is a very palatable cheese, rich in lacto-bacilli. It has undoubted advantages over other cheeses for patients not endowed with a robust digestion (sce p. 544).

Buttermilk.-Buttermilk is the milk left after churning, and removing the fat. Its sourness is due to the presence of lactic acid, derived from the conversion of sugar. Chemical analysis gives the following average composition:-

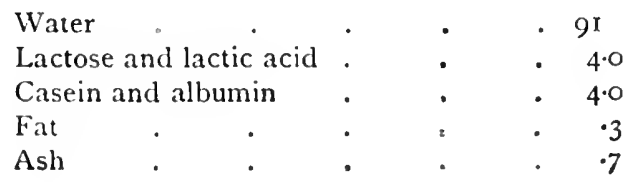


The cascin is present in a focculent form, and on this account buttermilk is a readily digested fook. It is a cheap food, since it is a grood source of protein. A pint of it contains as much nourishment as 2 ounces of bread. It is a wholesome drink, with diuretic and special medicinal properties. These are specially. considered on p. 540.

Koumiss.-Koumiss is a fermented milk, mepared by both lactic acid and alcoholic fermentation. It is made from the mille of a certain breed of mares in South-eastern Russia; it is also made from cow's milk, to which an artificial ferment has been added. The milk is mixed with a koumiss ferment, the hactic acid ferment changing some of the sugar into lactic acid, while another part of the sugar is converted into alcohol and carbonic acicl. Koumiss is an acid cffervescing drink, with an agreeable bitter taste, and contains from 1 to 2 per cent. of alcohol. The strength of koumiss varics with the duration of fermentation, as shown in the following table. It is very sensitive to temperature changes, and its composition is always changing, unless the fermentation is controlled by extreme cold. It is very easily digested, being much more digestible than milk (see also p. 540).

Koumiss-Duration of Fermentation.

\begin{tabular}{|c|c|c|c|c|c|}
\hline & & 6 hours. & 18 hours. & 30 hours. & 4 days. \\
\hline Carbonic acid. & & 3.8 & 6.0 & 70 & II $\cdot 0$ \\
\hline Alcohol. & • & $18 \cdot 5$ & 19.5 & $30 \cdot 0$ & $30 \cdot 0$ \\
\hline 1.actic acid & . & 3.9 & $5 \cdot 6$ & $6 \cdot 4$ & $6 \cdot 4$ \\
\hline Milk sugar & • & 18.8 & $16 \cdot 3$ & $\ldots$ & \\
\hline Albumin & • & 22.5 & 22.6 & 20.0 & $16 \cdot 1$ \\
\hline Fat . & - & 18.9 & $20 \cdot 0$ & $19 \cdot 0$ & $19 \cdot 0$ \\
\hline Salts & . & $4 \cdot 5$ & $4 \cdot 0$ & $4 \cdot 0$ & $4 \cdot 0$ \\
\hline
\end{tabular}

Kephir. - Kephir is another form of fermented milk, resembling koumiss. It is made from cow's milk-alcohol, lactic acid, and albumin being formed as a result of the fermentative process. The casein is partly digested. Tablets of the kephir ferment are sold for the home manufacture of the milk; it may also be made as follows :-

Boil fresh milk, and when nearly cold put into quart bottles, leaving room to shake. Add half an ounce of crushed lump sugar and a piece of Vienna yeast the size of a hazel 
nut (i.e. Lo srammes), cork with new corks, tic down, keep cool; lay the bottles hori\%ontal, but shake twice daily. It will be ready to drink about the sixth day, or earlier in hot weather and later in cold weather. It can be made with skimmed milk (see also p. 540.

\section{Eggs.} Composition of . . . . 4j Suhstitutes for egg ; ovo, elc. • 47 Nutritive value and digestibility . 47 Recipes . . . 47

Eggs contain all the ingredients necessary to support life and develop the organism.

From their chemical composition it is readily understond how they are such valuable articles of food in the dietetic treatment of diseasc, especially in some ailments occurring in childhood and youth.

Comparing the composition of the elible part of the whole egrs with that of moderately lean meat, we find as follows :-

\begin{tabular}{|c|c|c|c|c|}
\hline Water & . & . & $\begin{array}{l}\mathrm{Egg} . \\
73 \cdot 7\end{array}$ & $\begin{array}{c}\text { Lean Meat. } \\
73^{\circ} 0\end{array}$ \\
\hline Protein & . & - & 14.8 & 21.0 \\
\hline Fat & - & - & 10.5 & $5 \cdot 5$ \\
\hline Ash & . & . & $1 \cdot 0$ & $1 \cdot 0$ \\
\hline
\end{tabular}

The nutritive matter is thus seen to be almost the same as meat, eggs being poorer in protein but much richer in fat. The nutriment found in the yolk and white of the eggr is as follows :-

\begin{tabular}{|c|c|c|c|c|c|}
\hline Water & • & • & & $\begin{array}{l}\text { White. } \\
85.7\end{array}$ & $\begin{array}{l}\text { Yolk. } \\
50.9\end{array}$ \\
\hline Protein & . & • & 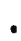 & $12 \cdot 6$ & $16 \cdot 2$ \\
\hline Fat & - & • & ${ }^{\circ}$ & $6 \cdot 25$ & $31 \cdot 75$ \\
\hline Ash & . & . & . & 0.59 & 1.09 \\
\hline
\end{tabular}

The white of $i g g$ contains its protein in a solution enclosed in numberless little cells. When white of egg is beaten up, the walls of the cells are ruptured and the protein is set free. The result of beating is to increase the digestibility of egs-white, the protein being more easily broken up when released from the cell.

From this table it is evident that the yolk of the egrg is 
much the most nourishing portion. In its ash there are some very important mineral constituents, vize, phosphoric acid, lime, and iron. The phosphorus and iron are almost entirely present as organic compounds. As mineral matters are most easily absorbed when combined with an organic substance, it follow's that yolk of egg is a useful adjunct in the treatment of several forms of nutritional and blood diseases. In chlorosis and some other forms of anemia, and also in rickets, the great richness of the yolk in lime, phosphorus, and iron make it most valuable.

The fats present are the same as those present in butter. They appear in emulsion form, and are thus very easily digested. Eggs, from their chemical composition, should be used with a carbohydrate dict. The usual custom of preparing rice and starchy preparations, such as arrowroot, tapioca, cornflour, with eggs in the making of milk puddings is a perfectly right one, the result being a perfect food. The nutrient value of an egg corresponds approximately to a full half-tumblerful of milk, or to $I_{2}^{\frac{1}{2}}$ ounces of fairly fat meat.

The discstibility of $\mathrm{cgs}_{\mathrm{s} s}$ varies, depending on the form in which they are taken. From results of experiments by l'enzoldt, it is surprising to find that a raw egg takes longer to leave the stomach than a lightly boiled one; a raw egg is hardly digested by the stomach, being passed into the duodenum almost unchanged. A raw egg, therefore, is probably the better article of diet for a stomach requiring rest. Hard-boiled egrgs are much more indigestible than those lightly boiled.

Esys are very constipating for some people. This is partly due to the large amount of lime present, and partly to the fact that absorption in the intestine groes on to such an extent that only a very small residue remains.

Some patients show a remarkable idiosyncrasy to eggs, being unable to take any without acute symptoms of gastrointestinal derangement supervening. Others are unable to take coggs in a plain form, but can take them in the form of a pudding or calic. If the absorption of eggs from the intestine is delayed, decomposition ensues, with production of sulphuretted hydrogren and ammonia with accompanying intestinal derangement. 
Ovo, a powder made up in packets, is solet as a substitute for eggs; each paclict containing the equivalent of one esgs. It is the egg dried, and on the application of water is redissolved. Its only use is for cooking purposes if fresh egors are not obtainable.

Esger and custurd pozeders are also sold as substitutes for eggs. These have no nutritive value, and are in no way equal to genuine custard. They consist chielly of starch, a little baking soda, tartaric acid, and some vegetable dye to give the yellow colour.

Raw Eggs are of special value in the treatment of tubercuilosis. They are given in the following ways:-

$$
\text { Ilater of Egs-allite, or Albumin IVater. }
$$

Take the white of an egg, and to this add twice its own volume of water and striin it through muslin. This grives about 3 ounces of a clear solution, containing as much protein as is found in an aterage sample of commercial beef juice.

This fuid added to a beef extract-either home-made beef-tea or to one of the many beef extracts in the market (lemco, etc.), just dissolved in hot water-makes a very nutritive solution alinost indistinguishable from beef juice, and at a fraction of the cost. Egsg-white water added to any of the beverages (see p. 275) makes them at once possess a decided nutritive value, and is useful especially in pyrexial conditions.

\section{Prairic Ojster.}

\section{I fresh egre. I tablespoonful of vinegar.}

lut the vinegar into a small cup and break the egg into it. Serve at once 'This is a very digestible way of serving an egg, and it is very cool and refreshing.

The next three recipes give the way of making up raw eggs into notrishing stimulant drinlis. By adding nutmeg, cinnamon, or lemon juice, the flavour can be altered.

$$
\begin{array}{ll} 
& \text { Esgr Drink. } \\
\text { I egg } & \text { I teaspoonful sugar. } \\
\text { I teacup of milk. } & \text { I tablespoonful sherry wine. }
\end{array}
$$

Beat up the egrs. add to it the wine and sugar, beat together with a fork slightly, and strain through a fme wire strainer. Heat the milk in a small saucepan, and when almost boiling pour it on to the egs, stirring all the time. Serve hot.

This can be made without wine, flavouring with cimnamon or lemon juice. The yolk of the esg only may be used, and soda-water instead of milk. 


\author{
Plain Egrs Flip. \\ I teacup of milk. \\ I teaspoonful sugar.
}

I white of egrg.

Boil the milk or make it thoroughly hot; beat up the white of egg to a stiff frotl. l'our the boiling milk over the white of egg, stirring all the time. Add sugar to taste, and serve.

$$
\begin{aligned}
& \text { Kich Egsr litip. } \\
& \text { I white of egg. I tablespoonful brandy. } \\
& \text { I tablespoonful cream. Sugar to taste. }
\end{aligned}
$$

leat up the white of egg stiftly. Add to it the brandy and cream. with a little sugar if wished. Mix very thoroughly, and serve.

$$
\begin{aligned}
& \text { Egst with brandy and Cream. } \\
& \text { t white of egss. I tablespoonful cream. } \\
& \text { I tablespoonful brandy. }
\end{aligned}
$$

Beat up the white of egrg stiffly. Add to it the brandy, cream, and a little sugar Mix very thoroughly, and serve.

\title{
Caudle.
}

Feat up an egg; add a glass of sherry and halt a pint oi gruel; flavour with lemon peel, nutmeg, or sugar.

Cooked Eggs appear as the main basis in custards, souffecs, and omelets. They are also used with carbohydrates in the making of puddings, and for the thickening of somps and sauces. Eirgs cooked by themselves can be used in the following ways:-

\section{Boiled Egg.}

Put enough water into a small saucepan to entirely cover the egg. Allow the water to boil ; lower the egg gently into it. Draw the pan to the side of the fire, and allow the water to simmer slowly. Cook the egg for three and a half to four minutes, then lift out and serve at once. If it is allowed to stand it becomes hard.

\section{Poached Egg.}

$\begin{array}{ll}1 \mathrm{egg} . & \text { Lemon juice. } \\ \text { boiling water. } & \text { Pinch of sali. }\end{array}$

Round of toasi.

lircak the egg into a cup, keeping the yolk whole. Into a small saucepan of boiling watcr add a pinch of salt and a squeeze of lemon juice. Uraw the water to the side, and when just off the boil slip the egg carefully into it. Cook slowly for three minutes, when the white should 
be quite set. Lift it out with a small fislı-slice or perforated spoon, and trim off any ragged edges of white. Place on a square of newly-made toast, and serve at once.

If required, this egrr can be made richer by being served on buttered toast, or a little hot cream poured over it. A poached eyg served on z tablespoonfuls of carefully prepared spinach is also a very nice dish.

\title{
Rumbled Egg.
}

\author{
I egg. \\ I tablespoonful milk. \\ Pepper and salt. \\ $\frac{1}{4}$ ounce butter.
}

A piece of toast.

Heat in a small saucepan the milk. Pour into the hot milk the egg beaten up in a cup with pepper and salt. Stir quickly over the fire until it begins to thicken, remove it then from the fire and continue stirring until it forms a creamy mixture. Put on a piece of newly-made toast, and serve at once. If cooked too long, or allowed to stand, it becomes leathery and indigestible.

\section{Baked Egro.}

Grease a china or paper ramekin case thoroughly; into this care. fully break an egg. Add pepper and salt and a teaspoonful of cream. Place in a moderate oven and bake three or four minutes until lightly set, and serve at once.

\section{Savoury Custard.}

Add the yolk of two eggs and a cupful of beef-tea, with pepper and salt to taste; butter a cup or jam-pot, pour the mixture into it, let it stand in a pan of boiling water till the custard is set. 


\section{CIIAPTER V}

\section{ANIMAL, lOOUS}

\begin{tabular}{|c|c|c|c|c|c|}
\hline & & & PAOE & & PAOK \\
\hline Composition of Alesh & . & . & 50 & Comparative digestibility of meat & \\
\hline liaricties of meats - & & & & foods. . . . . & 65 \\
\hline Bsef, muton, etc. & - & - & 54 & Cooking of flesh and fish- & \\
\hline Poultry, sume, etc. & . & . & 58 & (a) When juices retained. & 67 \\
\hline lish- & & & & (b) When juices extracted & 70 \\
\hline Varicties of & - & & 60 & Soup and soupmaking , . & 71 \\
\hline Crustacea and mollusc & $\mathrm{ca}$ & . & 63 & Home-made beef-teas and extracts & 75 \\
\hline
\end{tabular}

\section{Animal Foods.}

Tile term animal food is popularly used to denote the flesh of animals, birds, and fish only, though it ought also to include soups (made from meat or bones), beef extracts, beef-teas, beef juices, jellies, i.c. food prepared from gelatine; milk, with its derivatives of cream, butter, skimmed milk, cheese; and eggs.

Composition of Flesh. - The flesh of animals comprises muscle with the connective tissue, fat, nerves, and bloodressels supplying the muscle. Microscopic examination shows the muscle to be made up of fibres. The length of the fibre varies in different varieties of animal flesh; e.g., very short fibres are present in the breast of a chicken, and very long fibres in the limbs. For this reason the former are more casily digested.

The fibres are held together by connective tissue; this connective tissue yields gelatine on boiling. The amount of connective tissue is proportionate to the age of the animal, being large in amount in old animals. Everyone is familiar with the difference between a chicken and an old hen; the latter, however, malics better soup.

The composition of meat is affected by various factors, such as the arre of the animal, breed, condition, and fecding; 
and whether the blood has been drained off, as in veal, or retained, as in beef.

In young animals the muscles are not fully formed, and are more watery, so that young meat (lamb and veal) loses half to three-quarters of its weight in cooking; the muscle albumin is replaced by gelatine-forming substances, and the fats and salts are also smaller in amount. Veal is known to be very indigestible to some people, but it is useful for making soup, as the protein-forming gelatine, on boiling, produces good jelly stock.

The best beef is obtained from a two-year-old ox, and the best mutton from a two-year-old sheep. In addition to being more digestible, the flesh of full-grown animals is richer in extractives and has more flavour than the flesh of an immature animal; this explains why lamb is eaten with mint sauce and veal with mixed herbs.

The influence of feeding, on the flavour of the flesh, is illustrated in the difference between the flavour of mutton from hill-fed sheep and from sheep fed on turnips. IVild rabbits are much more palatable than tame ones, probably on account of the aromatic herbs, such as thyme, in their dict. Seabirds have a fishy flavour, and are not easily digested.

The chemical composition of the meat is greatly influenced by the breed, the condition, and general health of the animal, i.e., the degree to which the animal has been fattened, and also by the particular part from which the cut is made. The flank contains 43 per cent. of water, and the round of beef 60 per cent. (see fig., p. 52).

The average composition of meat is given in the following table :-

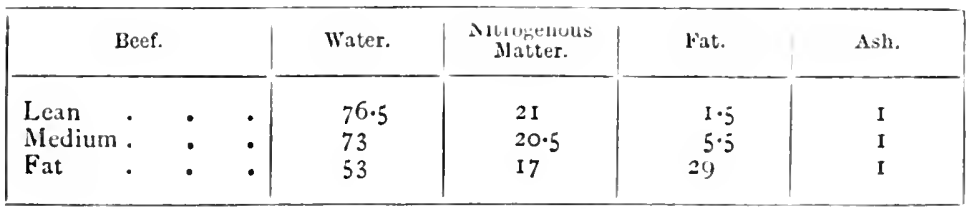

Note the relationship between water and fat-the less water the more fat. Fattening, therefore, represents an absolute gain of nutritive value, and not a replacensent of nitrogenous matter by fat. 
THE USUAL SCotch MODE of CutTing-up AN Ox. (More economical than the English mode.)

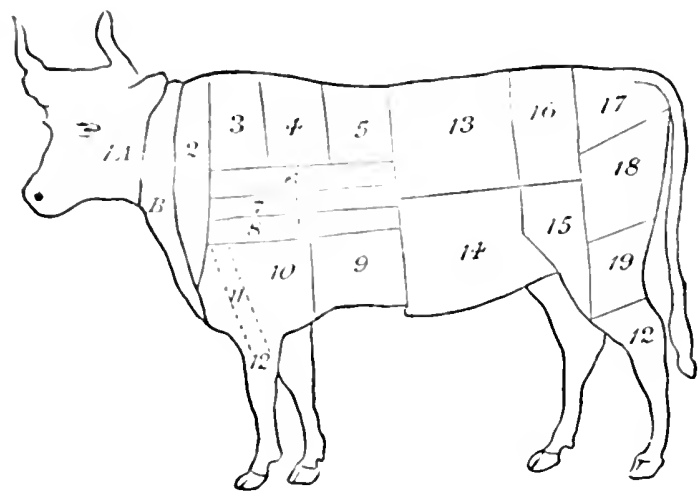

Explanation of diagram of the usual Scotch mode of cutting-up an ox :-

IA. Cheek.

IB. Chip, genera!ly used for hare-soup.

2. Neck, used for soups, stews.

3 and 4. Spare riis, generally roasted; sometimes stewed.

5. The ris, roasted; sometimes boned, rolled, and salted.

6. Finst runner. This is cut close by the shoulder-bone, and is used for boiling or stewing.

7 and 8. Also runters. These two are sometimes divided across by the dotted line, and the fleshy end (next the head) used for stewing, boiling, or beefsteak pie, and the thin end salted. Sometimes only two runners are cut, sometimes only one.

9. Nine holes, used chiefly for pickling, sometimes for plain boiling or stewing; not so fat as the brisket.

10. Eriskel, stewed or corned.

11. . Harrow lione.

12. Hough or shin, used for soup; the fleshy end is good for stewing.

13. Sirlom, cut generally into three parts, called the double side, middle cut (or Scotch and English), and the thin end.

1. Thin fink, used for boiling; often salted.

15. Thick flunk or fleshy end of heuck-bone, used for stewing steak, or salted and rolled, also for pies; no bone in it.

If. Heuck-bone, best for gridiron steak.

17. Riump, generally boned and salted; sometimes stewed with the bone in, or boiled. It is used in France for pot-au-feu.

18. The rount. This weighs about 30 to to lbs.; the upper part is sometimes cut into steiks. Sontimes the whole is cut into two rounds; a thick fl.tp of fat, called the slatugh, is feft to roll round the bare side of the bone.

19. U'sed for mince, stew, or beef-tea. 
The chicf mineral sulstances present in meat are salts of phosphoric acirl and potassium. Iron is present in the red colouring matter. These mineral substances are of great importance in nutrition.

The nitrogenous part of flesh consists chicfly of the following proteins: Myosin, muscle albumin, and hremoglobin. Myosin coagulates after death, this condition being known as rigor mortis. Meat in this state is tough and indigestible; on this account meat should either be eaten immediately after killing, before rigor mortis has had time to supervene, or it should hang until the stiffening has passed off. In hot climates, where decomposition sets in rapidly, flesh is cooked immediately on being killed. The disappearance of rigor is due to sarcolactic acid being formed, and the transformation of the myosin into an acid albumin. Whenever the rigor mortis is over, the flesh begins to decompose slowly, and this incipient decomposition makes it more tender and better flavoured for a time.

The serum albumin of muscle is one of the most soluble of the muscle protcins, and this albumin can be extracted by water; and this extract, amounting to 5 or 6 per cent., represents the maximum strength of an aqueous extract of beef-tea. The remaining $I_{4}$ or $I_{5}$ per cent. of proteins are insoluble in water, though dissolved by the digestive juices.

The extractives in meat are substances which can be extracted by boiling water. They have no direct nutritive value, but are important since they impart the characteristic flavour to meat. These are more fully considered in the section on beef-teas and extracts on p. 75 .

Fat is embedded in the connective tissue between the fibres in mutton and beef. Fat is almost entirely absent in game, and in the breast of chicken, and in most varieties of white fish. In pork, duck, goosc, herring, mackerel, and salmon the fat is abundant. The fat seems to lessen the digestibility of the meat, possibly by forming a coating round the fibres.

Meat should be cut or carved at right angles to the long axis of the fibre. It is then more easily chewed, the flavour is better, and the digestive juices reach the fibres more casily.

The acids which develop in meat while hanging improve 
the favour, and also help to increase the digestibility. This effect can be brought about by various devices, such as the Mhlition of vinesar to boiling meat, the rubbing over veal with lemon juice before frying or stewing, and by eating vinegar with crab and lobster.

\section{Varieties of Meats.}

Parkes gives the following characteristics of good meat:The flesh should be firm, elastic, of a bright, uniform colour; in fresh meat the outside is lighter than the inside, owing to oxidation of the hrmoglobin of the blood; lean meat is paler than blood, so that a dark purple colour shows that the blood has not been properly drained away; when fresh meat is placed on a plate it should always part with a slight amount of reddish juice; the flesh of young subjects is always paler than that of the mature animal. The muscle should be finesrained, have a slight, pleasant odour, becoming savoury when heated; the flesh should present a marbled appearance, owing to the admixture of fat with the muscular fibres. On cutting, the interior should show no softening of the connective tissue, as this indicates the commencement of decomposition. The "knife-blade" test is casily applied: push a clean knife-blade down to the bone, and any internal softening will be detected by lessened resistance, and by an unpleasant smell of the blade on withdrawal. The fat should be healthylooking, free from blecding, and firm, not jelly-like in texture; its colour varies from straw-white to pale yellow, being whiter in young animals. The state of the marrow is often a good test of the condition of the meat. It should be light rosy red in colour, and in the hind legs solid and firm twenty-four hours after hilling, while in the forc lers it is rather softer, like honcy.

Beef is at its best when got from an ox of two ycars of agc. Besides being affected by the factors already mentioned, it varics in quality according to the part of the animal used, and also to the style of cooking employed. The best parts are the rump, sirloin, and ribs (see fig., p. 52). Ox fat is softer than mutton fat, on account of the larger proportion of olein in it.

Mutton is grenerally considered to be more casy of digestion 
than beef; this may be due to the fincr fibres and looser connective tissue. Experiments, however, do not seem to prove this conclusively. The flesh of the sheep is usually much fatter than beef, and the fat is hard and solirl, owing to the greater proportion of stearin. There is no cloubt that hot mutton fat is irritating to some digestions. Mutton differs very greatly in quality and flavour; when of the best quality; it is a most excellent form of animal food.

The ueval Scotch Mlode of Cutting-up a Sheep.

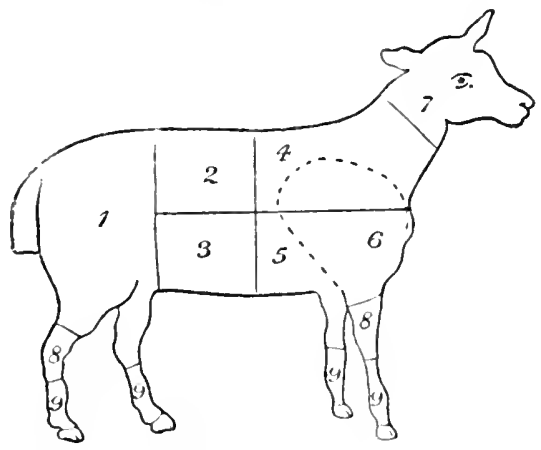

Explanation of Scotch mede of cutting-up a sheep :--

I. Gigot, leg, or haunch; roasted or boiled.

2. Loin. This is the finest piece for chops; sometimes roasted.

3. Flank or flap, used for soup or cheap stews.

4. The back-ribs and neck, used for chops, stews, and scup.

5. The brisket or breast, generally stewed.

6. The shoulder. When 4 and 5 are not cut through at the black line which separates them, the shoulder may be removed at the dots, and it is generally baked, sometimes roasted. If a large shoulder is wanted, cut it off close to the bone; if, on the other hand, it is desired to leave the meat beneath for chops, the shoulder should be taken off by the seam.

7. The head, boiled; used for broth.

8. The shank, used for soup; sometimes stewed.

9. The trotter's, made into broth with the head; sometimes stewed.

Of the brecds of shecp, the black-faced stand first in swectness of flavour; then come South Downs. The best parts of mutton are the leg or gigot, and thick rib chops.

A leg of mutton improves by hanging. It should rot be in contact with other food. Before cooking, the meat can be made more tender by being smacked (beaten with a wooden 
roller). The probable explanation is that some of the fibres are broken.

Lamb greatly excecls mutton in its proportion of fat, and is correspondingly less digestible. The flesh is more watery than that of the mature animal. Lamb needs to be freshly killed, as it does not keep well.

Veal is much less nutritious than beef, containing more gelatinous and fewer albuminous substances. In spite of its fibres being softer, experience and experiment show that it is not so easily digested as becf. When the same quantity of beef and veal are taken, it is found that the former takes two hours, while the latter takes two and a half hours to digest.

Hare, when young, is very tender, and possesses an excellent flavour. The fibres are short, and the flesh is very digestible.

Rabbits, when young and cooked with plenty of gravy, are very digestible; they are the better of the addition of a little fat in the form of streaky bacon.

Tongue.-The tongue of the ox, sheep, and pig is eaten both fresh and pickled. It is very tender, and is quite suitable for invalids and children if the tender central part is used; the base contains much fat, and the fibre is indigestible.

Tripe.-This is the name applied to the stomach and intestines of the ox or sheep; the mucous lining is scraped off, leaving connective tissue, fat, and muscle. The latter is very easy of digestion, and the large proportion of fat in it malies tripe one of the most nutritive diets, and most suitable for those with a weak digestion. It is rather deficient in flavour, owing to the want of extractives. The average composition of tripe is as follows :-

$\begin{array}{cccc}\text { Water. } & \text { Proteing. } & \text { Fat. } & \text { Salts. } \\ 68 & 13.2 & 16.4 & 2.4\end{array}$

The special points to be noted in the preparation of tripe will be found on page 309 .

Sweetbreads.- Under this term two distinct organs are referred to-the thymus or "throat sweetbread," and the pancreas or "stomach sweetbread." Both glands are cellular organs, held together by a loose connective tissue. They are very rapidly digested by the stomach-nine ounces being 
digested completely in two and three-quarter hours, while a similar quantity of beefsteak demands four and a half hours. Sweetbreads require great care in the preparation for cooking, so as to rid them of the masses of fat mixed in the connective tissue.

Liver and Kidneys.-These are compact solid organs containing little connective tissue. Tiney are not very digestible. The livers of the calf and lamb are the most tender; these parts should be used very shortly after killing. The protein contained in these organs is nucleo-protein, which yields nuclein on digestion. The glycogen in liver makes it an unsuitable article of food for diabetics.

Bones.-All the connective tissues, including bones and cartilages, yield gelatine on boiling. Gelatine itself can take no part in the repair and growth of tissue, but it is valuable as a protein-sparcr. By adding gelatine to the dict the protein in the food can be spared in the body, or devoted to the increase of bulk, just as by the supply of fats and carbohydrates. It is specially useful in soupmaking and for making jellies. Well-prepared jellies are very useful foods for invalids, and may be administered with advantage in feverish states.

In order to get the maximum amount of gelatine, the bones are brokien up into small pieces, and cooked in the oven with a high-pressure pot (see p. 76 ).

Bones arc a really cheap source of gelatinc, as they contain gelatine to the extent of 15 to 50 per cent.; the ordinary jelly, such as calf's-foot jelly, is an expensive food, because, as already indicated, it has little or no nutritive value, and as a source of energy it ranks very low.

The marrow of bone has much nutritive valuc. It is an easily digested fat. It can be used in the form of marrow bones or marrow toast, and has the advantage of being a very cheap food (see p. 197).

Heart.- The heart of an ox or shecp is denser in structure than ordinary beef, but forms an admirable diet for the healthy individual. It has the merit of cheapness.

Blood.-Blood is sometimes used in the form of black puddings. It is not an easily digested food, nor is it at all palatable. 
Poultry. - These are characterised by short muscular fibres and a small amount of fat. Birds like the common fowl and turker, which have a white flesh, are the most easy of disestion, beins tender and of a delicate flawour. A young, well-fed chicten is the most digestible of all animal foods. Short-legered fowls are more delicate in flavour, and as for age a one-year-old cock will be found too tough for roasting or brazing, and only cdible when stewed for soups. The flavour and tenderness of the flesh is greatly increased by removal of the sexual organs-the capon is the term for this. Ducks and geese have more fat, are senerally richer, and have a stronger flavour than fowls. Their flesh is darker in colour, and is more difficult of digestion.

Game.-Partridges and pheasants, when young, are very deicate in flavour; pigeons less so. Grouse, woodcock, snipe, quail, ptarmigan, and wild cluck have muscles with a very firm, close fibre, and on this account are generally "hung," to impart tenderness and develop flavour. The best portion for people with clelicate digestion is the breast.

Pork is indigestible on account of the large amount of tat present. The amount of fat may be greater than the amount of protein in the pork.

Bacon is much more digestible than pork, and ham occupies an intermediate position. The fat in bacon is friable, and much more easily acted on by the digestive juices, and for this reason bacon is an admirable food for delicate children, and invalids in general, who require abundance of fat in the dietary.

Sausages.-In this country these are made of uncooked meat, and various carbohydrate substances such as bread are frequently added; the vegetable matter is not infrequently disguised by the addition of colouring material. Scasonings of various sorts also enter into their composition. As sources of protein they are not more economical than ordinary meat, and their uncertain composition makes them unsuitable for invalids.

Fish, including Crustacea and Mollusca.

A rlintinguished authority on dietetics long ago pointed out that a large proportion of our town population would 
profit by exchanging some of their meat as an article of diet daily for fish. There is no dloubt that without exercise in the. open air the digestive system is apt to become overloaled and oppresserl by meals consisting chichly of meat, and even if, as often happens, the primary digestion of the meat is, in the circumstances, fairly accomplished, many constitutions suffer from an over-sup!ly of nutritive material which cannot be disposed of easily without considerable habitual muscular energy. In comparison with meat, fish is characterised by an alteration in the relative proportion of nitrogenous constituents, fish containing more gelatine and a smaller amount of extractives than meat. The proportion of water in the heavier varicties of fish is, moreover, much greater than in lean meat.

The special value of fish as an article of diet thus lies in the fact that it contains, in smaller proportion than meat, those materials which, taken abundantly, demand much physical labour for their complete combustion. The moderate amount of flesh-forming material present in fish, and in a form which entails little labour on the digestive organs-for most persons certainly less than meat-render fish a particularly valuable article of diet. The smaller amount of extractives present in fish is in one respect no disadvantage, since this diminishes the tendency to indulge in excess. Its greater richness in gelatine-yielding substances causes fish to lose more in boiling than meat docs, and on this account boiled fish is an insipid and unattractive article of diet. The cheapest fish are cod, ling, herring, mackerel, and sprats, the cost of course varying with the supply.

Fish as a foodstuff contains a large proportion of water, a varying amount of fat and protein. The latter belongs chiefly to the gelatine-forming order. Isinglass, the finest form of gelatine, is obtained from fish bones, but more especially from cartilaginous fish, like the skate and sturgeon. According to the proportion of protein and fat in fish, they may be divided into two groups of "fat" and "lean."

Fish with more than 5 per cent. of fat-eel, salmon, turbot, herring.

Fish with from 2 to 5 per cent. of fat-halibut, maclierel, mullet. 
Fish with less than 2 per cent. of fat-cod, whiting, harkluck.

Fish are at their best just before spanming, when they are said to be in scason (sec table); later they become poor and flabby:

Fish in Season.

\begin{tabular}{|c|c|c|c|c|c|c|c|c|c|c|c|c|}
\hline & Jan. & Fint. & Mar. & Alr. & May. & June. & July & Aug. & Sopll. & Oct. & Nov. & Dre. \\
\hline Bloater & + & + & + & $\ldots$ & $\ldots$ & $\ldots$ & $\ldots$ & $\ldots$ & + & + & + & + \\
\hline corl. & + & + & + & $\ldots$ & $\ldots$ & $\ldots$ & $\ldots$ & $\ldots$ & ... & + & + & + \\
\hline Crab & $\ldots$ & $\ldots$ & $\ldots$ & + & + & + & + & + & + & $\ldots$ & $\ldots$ & $\ldots$ \\
\hline $\mathrm{Fl}$ lounder. & $\ldots$ & 4 & + & + & $\ldots$ & $\ldots$ & + & + & + & + & $\ldots$ & $\ldots$ \\
\hline Ifaldork. & + & $\ldots$ & $\ldots$ & $\ldots$ & $\ldots$ & $\ldots$ & $\ldots$ & + & + & + & + & + \\
\hline Halibut. & + & + & + & $\ldots$ & $\ldots$ & $\ldots$ & $\ldots$ & $\ldots$ & $\ldots$ & + & + & + \\
\hline llerring. & $\ldots$ & $\ldots$ & $\ldots$ & $\ldots$ & + & + & + & + & + & + & + & + \\
\hline Ling . & + & + & + & + & $\ldots$ & $\ldots$ & $\ldots$ & $\ldots$ & 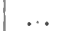 & $\ldots$ & + & + \\
\hline 1.obster. & + & 4 & + & + & + & + & + & + & + & + & $\ldots$ & $\ldots$ \\
\hline Mackerel. & + & + & + & + & + & + & $\ldots$ & $\ldots$ & $\ldots$ & + & + & + \\
\hline Oysters. & + & + & + & + & $\ldots$ & $\ldots$ & $\ldots$ & $\ldots$ & + & + & + & + \\
\hline Plince & + & + & + & + & $\ldots$ & $\ldots$ & $\ldots$ & $\ldots$ & + & + & + & + \\
\hline Salmon & $\ldots$ & + & + & + & + & + & + & + & + & $\ldots$ & $\ldots$ & $\ldots$ \\
\hline Sk:t & + & + & + & + & $\ldots$ & $\ldots$ & $\ldots$ & $\ldots$ & $\ldots$ & $\ldots$ & + & t \\
\hline Smelts & + & + & + & + & $\ldots$ & $\ldots$ & $\ldots$ & $\ldots$ & $\ldots$ & + & + & + \\
\hline Sole. & + & + & $\ldots$ & $\ldots$ & + & + & + & + & + & + & + & + \\
\hline Troul & $\ldots$ & + & + & + & + & + & + & + & $\ldots$ & $\ldots$ & & $\ldots$ \\
\hline Turbot. & + & + & + & + & $\ldots$ & $\cdots$ & $\ldots$ & $\ldots$ & 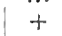 & $\ddot{+}$ & $\ddot{+}$ & $\ldots$ \\
\hline Whitetrit & + & + & + & + & + & + & + & $\ldots$ & $\ldots$ & $\ldots$ & $\ldots$ & \\
\hline Whiting & + & + & + & + & $\ldots$ & $\ldots$ & $\ldots$ & + & t & + & + & $\ldots$ \\
\hline
\end{tabular}

Fish decompose readily, and cannot be conked too fresh. The perfection of fish-cooking is obtained when the fish is transferred immediately from the water to the pot. Keeping in ice deteriorates the flavour. Skate and sturgeon are exceptions; they improve by being "hung," the muscular fibre becoming softer. Smoked, salted, and pickled fish are much less digestible than when fresh, and in this form they are better avoided by dyspeptics. The fish best suited for smoking are firm, oily fish, like the salmon and herring.

In selecting fish, the following are the main indications of freshness:- The flesh is stiff and firm, the animal being in a state of rigor mortis; the skin should be well covered with scales, and there should be no disagrecable smell. A most important point is that the eyes and gills are bright, while the tail is firm and not drooping. Cod, haddock, and whiting keep best, then flat fish; mackerel and herrings very rapidly get soft.

Varieties. - The edible fishes fall into two groups- 
"white" and "oily" - the difference being whether they have the fat stored in the liver or distributed throughout the body.

The white fishes are the most digestible; they comprise the whiting, haddock, cod, brill, sole, plaice, flounder.

The following analysis of the flesh of cooked fish may be taken to represent approximately their average composition :-

Analy'sis of Flesh of Cooked Fish.

\begin{tabular}{|c|c|c|c|c|c|c|c|}
\hline & \multirow{2}{*}{$\begin{array}{l}\text { Water } \\
\text { ill F'leslı. }\end{array}$} & \multirow{2}{*}{ 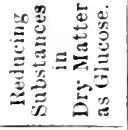 } & \multirow{2}{*}{$\begin{array}{l}\text { Ash in Dry } \\
\text { Substance. }\end{array}$} & \multicolumn{3}{|c|}{ Solids in Dry Substance. } \\
\hline & & & & & Nitrogen. & Fat. & Protein. \\
\hline Brill & . & $62 \cdot 74$ & & $4 \cdot 42$ & $15 \div 49$ & 1.62 & $93 \cdot 9$ \\
\hline Cod ; & • & $76 \cdot 32$ & $6 \cdot 67$ & $3 \cdot 31$ & $15 \cdot 30$ & $1 \cdot 15$ & $91 \cdot 5$ \\
\hline,$\quad($ salt $)$ & - & $72 \cdot 35$ & $7 \cdot 14$ & 14.26 & $12 \cdot 4 \mathrm{I}$ & 0.94 & $76 \cdot 0$ \\
\hline Eels . & - & $61 \cdot 05$ & $8 \cdot 91$ & $2 \cdot 11$ & $7 \cdot 36$ & $44 \cdot 68$ & $42 \cdot 8$ \\
\hline Gurnet & - & $73 \cdot 77$ & 14.77 & $3 \cdot 53$ & $1+24$ & 1.81 & $89 \cdot 1$ \\
\hline Haddock & & $72 \cdot 37$ & I $3 \cdot 15$ & 3.28 & $13 \cdot 11$ & 1.29 & $79 \cdot 5$ \\
\hline Hake . & - & 84.85 & 13.64 & $3 \cdot 90$ & $12 \cdot 86$ & $5 \cdot 67$ & $81 \cdot 3$ \\
\hline Halibut. & . & $7 \cdot 4 \cdot 46$ & $\ldots$ & $4 \cdot$ II & I $3 \cdot 32$ & 15.81 & $79 \cdot 6$ \\
\hline Herrings & & 60.54 & $\ldots$ & $5 \cdot 56$ & I I. I I & $25 \cdot 25$ & $67 \cdot 0$ \\
\hline , (salt & & $46 \cdot 03$ & $17 \cdot 59$ & $19 \cdot 69$ & $7 \cdot 12$ & $21 \cdot 90$ & 38.8 \\
\hline John Dory & & $77 \cdot 89$ & $14 \cdot 29$ & $2 \cdot 06$ & I $3 \cdot 32$ & $S \cdot 52$ & $79 \cdot 5$ \\
\hline Lemon Soles & & 78.11 & $1+.80$ & $4 \cdot 42$ & 11.04 & 12.96 & 69.8 \\
\hline Mackerel & - & $73 \cdot 13$ & 13.93 & $4 \cdot 07$ & $10 \cdot 46$ & 25.73 & $62 \cdot 3$ \\
\hline Oysters. & - & $77 \cdot 7 \mathrm{I}$ & $18 \cdot 32$ & I $2 \cdot 16$ & I 1.85 & $7 \cdot 77$ & $65 \cdot 4$ \\
\hline Plaice & - & 76.86 & I I 56 & $4 \cdot 06$ & 13.02 & $9 \cdot 84$ & $75 \cdot 1$ \\
\hline Red Mullet & • & $68 \cdot 26$ & $9 \cdot 79$ & $5 \cdot 43$ & II 59 & $24 \cdot 52$ & $66 \cdot 2$ \\
\hline Roach . & - & $75 \cdot 37$ & $6 \cdot 28$ & 1.08 & 13.03 & 15.03 & $79 \cdot 1$ \\
\hline Salmon. & & $65 \cdot 32$ & 14.59 & 4.94 & 10.70 & $29 \cdot 43$ & $56 \cdot 6$ \\
\hline Sardines & - & $4+35$ & $\ldots$ & $12 \cdot 03$ & $8 \cdot 34$ & 33.49 & 55.4 \\
\hline Smelts. & - & So.73 & $2 \cdot 17$ & $4 \cdot 73$ & $1 \mathrm{I} \cdot 6 \mathrm{I}$ & $9 \cdot 76$ & $82 \cdot 0$ \\
\hline Soles . & - & $79 \cdot 20$ & I I 87 & $3 \cdot 47$ & $14 \cdot 00$ & $I \cdot 7 I$ & $86 \cdot 0$ \\
\hline Sprats. & - & $75 \cdot 77$ & $9 \cdot 83$ & $6 \cdot 42$ & $9 \cdot 26$ & $27 \cdot 37$ & $57 \cdot 9$ \\
\hline Trout . & - & 73.58 & $4 \cdot 68$ & $6 \cdot 60$ & I I.96 & $8 \cdot 8+4$ & $80 \cdot 0$ \\
\hline Tunny . & - & $63 \cdot 49$ & $\ldots$ & $5 \cdot 52$ & $10 \cdot 55$ & $30 \cdot 68$ & $66 \cdot 0$ \\
\hline Turbot . & - & $77 \cdot 84$ & II $8 \mathrm{I}$ & $2 \cdot 41$ & 13.76 & 4.75 & $84 \cdot 7$ \\
\hline Whiting & - & 78.78 & I $7 \cdot 54$ & $I \cdot 92$ & 13.28 & 1.86 & $79 \cdot 5$ \\
\hline
\end{tabular}

The Whiting has been termed "the chicken of the sea." It is very light, easily digested, and when fresh possesses a very delicate flavour.

Haddock, when fresh, possesses a very delicate flavour; the flesh is firmer ancl harder than whiting. It is best to select one of merlium size; when large, their flesh is coarse. Smoked hadrlueks are very well known, and vary greatly in rigestibility. The small sort, known as the "Aberdecn findon," are quite tender; they are smoked with peat smoke. The 
Arbroath smokies are also easily digested. The largyer forms, smoked with petroleum, are tough, and lave not nearly so tine a flavour.

Cod is the toughest of the white fish. Its quality varies at the different seasons; sometimes the flesh is hard and full of fibre. In selecting cod a plump one of medium size, the head and tail small in proportion, and the sides looking as if the ribs were in the flesh, should be selected. The tail portion is the most tender, but has least flavour.

I.ing.-A cheap fish, not unlike cod; rather tasteless; requires a good sauce.

Trout.-A fresh-water fish. The body has a silver and solden appearance when fresh. Those weighing about one pound are best. When in condition have excellent flavour, and rery digestible.

Smelts. - A very small fish, but much esteemed. When fresh, have a silvery hue.

Whitcbait. - A very small fish, of silvery appearance. Highly esteemed. Must be used quite fresh. Best in May, June, and July.

Joln Jory.-The flesh is rather tough, and it is the better of bcing kept a day or two before being coolied. It is an unsightly fish, but of good flavour. It is best baked.

The flat fishes form another section of the white fishes, and comprise-

Sole-Very delicate, and easily digested. It is a fish of excellent quality. Meclium size is best.

Plaice and Flounders. - Flat fish of rather poor quality and flavour, easily digested. Moderate price. Choose one with a thick, firm body. They are best boiled, fried, or bakcd an gratin.

Skate-Tough. A very decided flavour; improves with kecping for a day or two. The flesh should be firm and creamy in appearance. It requires to be skinned; unwholesume when out of season.

Brill.-Like turbot in appearance, and much cheaper. When fresh, the hesh should be of a yellowish tint; if blue, it is not somel. It is senerally boiled.

Mcilibut.- A fiat fish, like turbot in appearance. Its flesh is rery wholesome, and of excellent flavour. A middle cut of this fish is the best. 
The oily fishes comprise-

Turbot.-The best of all flat fish. The flesh is firm, rich, and white. The thick part of the fins is especially favoured by the epicure. A middle-sized fish is the best. This fish improves by keeping for a day.

Salmon.-A red fish; this is very rich in fat, which is found most abundantly on the under side. Its flesh is so rich that most people require a corrective in the way of vinegar or other acid sauce. In selecting salmon, one with a small head and tail and broad shoulders is best. The scales should be bright and silvery. The more freshly a salmon is cooked the better.

$E_{e l}$ is exceptionally rich in fat, the proportion being about double that of proteins. Although oily, it is readily digestible and possesses a delicate flavour. There are salt- and freshwater eels. The conger cel is a favourite with many pcople. The flesh is firm and hard, and requires long and careful cooking.

Herring is the cheapest and most abundant of the oily fishes. West coast fishes are the richest and largest; those caught off the East coast are smaller, seem less fat, and are not so indigestible. This fish should be cooked fresh; when newly caught they have a bright and silvery appearance. If red about the eyes they have been dead some time. It should be well covered with scales, and plump. Herring are much used in the salted and smoked forms. When smoked for an hour or two they are called "bloaters." As the smoking continues, they become "kippers," "red herring," or "black herring."

Wackerel readily taints, and gives rise to symptoms of ptomaine poisoning if eaten in this condition. The nackerel seasons are spring and autumn; the latter fish are the finer. Sardines, sprats, and pilchards belong also to this group of fish.

The Crustacea require a few words; the edible forms are lobster, crab, crayfish, shrimps, and prawns.

The lobster and crab consist of two distinct parts. The flesh, which is contained in the claws, legs, and tail, is very indigestible, mainly on account of the density and coarseness of the fibres. The habit of eating vinegar with lobster and 
crab is perfectly sound, the acid helping to soften the fibre. The body of these animals is also eaten. This is composed mainly of liver; it contains a considerable quantity of fat, and is very rich.

Lolister.-The lobster is more digestible than the crab; the flesh of the claws is better than that of the tail. It decomposes rapidly, and therefore is best bought alive. The bright red part within the body is the ovary; their spawn is very nutritious, and is often used in sauces for the sake of its havour and colour.,

Crat is inferior to lobster; the flesh is tougher and more indigestible. The medium-sized ones are best. Choose a heary one, for if light it is watery. The male crab is best for table, and may be distinguished by the large claws.

Crayfish.-Used principally as a garnish, or for making soup. Like lobsters in appearance, but smaller and of more delicate flavour.

Shrimps and Prawns can scarcely be classed as a food. They are best cooked in salt water, and have a distinctly appetising effect.

Mollusca are represented by the oyster, mussel, whelk, periwinkle, and cockle. The oyster is the most typical and popular, and is the only one described. Oysters are in season from September to April. There are several kinds; the "Natires" are considered the best.

The composition of oy'ster is mainly water, over 88 per cent.; proteid, 6 per cent.; and carbohydrates, 3 per cent. The proportion of solid nutriment is not large, three dozen moderate-sized oysters only containing $5 \frac{1}{3}$ ounces of solids. The carbohydrate is present in oysters in the form of glycogen; this makes oysters unsuitable in diabetic cases where a rigid dietary is being enforced. When eaten raw, oysters are an exceedingly easily digested food, three medium-sized oysters being completely digested in threequarters of an hour. Cooking tends to make them tough and leathery:

In recent years oysters have fallen into some disrepute, as they are known in some cases to have been the cause of typhoid fever. If oysters are grown in the mouths of rivers, they can easily be contaminated by typhoid germs in the sewage. 
This risk can be avoided by keeping the oysters alive for a day or two in salt water which is frequently changed. This washes out and destroys the bacilli. Cooking renders them innocuous, but they are rendered less digestible by the process.

The roe of the sturgeon is known as caviare, when highly salted. It should be of a greyish colour when in good condition. Fresh roe of herring, haddock, and cod, prepared in different way's, are a very pleasant addition to an invalid's dietary, being both nutritious and easily digested.

Digestibility of Meats. - The digestibility of meat foods varies so much according to the quality of the meat, the manner of cooking, and the state of the digestive organs, that no very precise statements can be made on this subject. At the same time, the following table may be taken as an average of the ease of digestibility of the different animal foods referred to :-

Table of Comparative Digestibility, commencing with the Most Digestible and ending with the Least Digestible of Meats and other common Animal Foods.

Oysters, raw.

Soft-cooked eggs.

Sweetbread.

White fish, boiled or broiled.

Chicken, boiled or broiled.

Lean roast beef or beefsteak.

Eggs, scrambled, omelet.

Mutton, roasted or boiled.

Partridge.

Bacon, crisp.

Roast fowl, chicken, capon, turkey.

Tripe, brains, liver.

Roast lamb.
Chops, mutton or lamb.

Corned beef.

Veal.

Ham.

Duck, snipe, venison, rabbit, and other game.

Salmon, herring, mackerel.

Roast goose.

Lobsters and crabs.

Pork.

Smoked, dried, or pickled fish and meats in general.

\section{Cooking of Flesh and Fish.}

The chemical composition of meat is modified by cooking, the results varying according to the method of cooking employed. Cooking abstracts a large amount of water, about 20 per cent., also part of the extractives, salts, and fat. A large amount of the extractives are removed by boiling; hence boiled beef is deficient in flavour. The cooking of animal food develops in it new flavours and a greatly im- 
proved appearance-two factors of importance in promoting the digestibility of meat, the attractiveness of well-cooked food producing an increascd secretion of gastric juice. The functions of digesíion and assimilation are best carried on at a blood heat, therefore another object of cooking is to raise the food to a suitable temperature. The application of heat exercises a mechanical and also a chemical action on all foodstuffs. The mechanical action is more important when the question of cooking vegetable substances is considered. The prolonged heat acts by softening hard tissues and preparing tough tissues for mastication. Cooking of food is also of value in destroying parasites and pathogenic bacteria. With regard to the influence of cooking on the digestibility of meat foods, it is probable that most forms of cooking tend to lessen the digestibility of meat, the reverse holding good for vegetable foods.

The effect of heat on the proteins is to coagulate themthe connective tissues being transformed into gelatine, and the protein of the meat at the same time developing odorous substances (cxtractives) which impart flavour and stimulate the appetite.

The fats of food do not appear to be much affected by heat. Fat which has been heated and allowed to cool again is often found to become more granular than before. This is probably due to the driving off of water, which tends to make the fat more brittle and therefore more digestible. This change is well seen in fried bacon.

The effect of different degrees of heat on albumin is the keynote of all the various culinary methods, which are variations of one another, depending on whether the meat juices are to be retained or extracted.

(a) When the meat juices are to be retained there is first a preliminary case-hardening of the albumin by intense heat; after which, cooking proceeds at a lower temperature, rising in the interior of the meat just to the coagulating point of albumin. This object may be carried out by any of the following methods :-

(1) Roasting, grilling, baking.-The heat being radiant heat and hot gases.

(2) Stcaming and boiling.- In this the heat is hot water. 
(3) Frying, wet or dry.-This process is carried on by hot oil or hot oil and conduction.

By following these methods we retain all the nutritive sapid qualities within the portion, leaving none of them, or very little, in the medium used.

(b) When the juices are to be extracted from the meat, the result is a stew or a soup. Stewing first extracts the juice and then cooks the meat in it, and is thus conducted slowly and over a long time. Soupmaking aims at extracting as much as possible, and therefore begins in the cold, never rising above $160^{\circ} \mathrm{F}$. The processes will now be referred to in detail.

When the Meat Juices are Retained.-When this is the main object there is first a preliminary case-hardening of the albumin by intense heat; after which cooking proceeds at a lower temperature, rising in the interior of the meat just to the coagulating point of albumin. This object may be carried out by :-

I. Roasting.-In this method of cookery the meat is cooked by the radiant heat of a fire from a large giowing surface free from smoke. The meat is exposed to this heat, a few inches from the fire, for five to ten minutes, and is basted with melted dripping, the surface albumin being coagulated to the thickness of a sixpence. After this has taken place the meat is removed one-half to one foot farther from the fire, and the cooking process is continued slowly at a greatly reduced temperature, the meat being slowly cooked in its own juices.

If the heat is too great the hardened case is apt to crack, allowing the juices to escape. To prevent this the meat is basted with hot dripping, which prevents charring and cracking of the surface. If properly done, this fat does not soak into the meat. Although the surface heat is very great, the heat in the interior of the joint should not be much above the coagulating point of albumin, and any rise above this renders the meat less digestible, the albuminous matters becoming hard and horny. The inside parts of a properly roasted joint are the best for a weak digestion.

This process requires a quarter of an hour per pound for beef and mutton, but longer for veal and poultry. The meat loses weight from expulsion of water-from about 20 to 25 per cent. 
2. Fuking-Joints of meat can be well cooked in the oven of an ordinary kitchen range or in a gas-cooker, and the results are very similar to roasting.

If the heat of the oven is not properly regulated the results are different, the meat being richer, more flavoured, but more indigestible. This is owing to the process being conducted at too high a temperature after the preliminary case-hardening.

3. Broiling, grilling, or brandering.-This is a similar process to roasting, and is admirably adapted for quickly cooking a chop, steak, kidney, fish, fowl, or mushroom. The object is the same as in roasting-the formation of a surface shin of coagulated albumin, and the retention within this of all the juices of the meat. The effect of the heat on a thin piece of meat seals the surface, but also coagulates the protein throughout, so that the meat is practically cooked at once. This happens when a clop is cooked on a grill; the completeness of the sealing is shown by the fact that the water-vapour produccd from the fluids is unable to escape, and causes the chop to assume the puffy form characteristic of good cooking.

A clear smokcless fire is required, and the process of cooking is carricd on by holding the article to be cooked over the fire. To avoid breaking the coagulated layer of protein, steak-tongs should be used instead of a fork for turning the meat. This form of cookery is so rapidly carried out that there is not much time allowed for softening the food, so that, unless the meat is very tender, this process is not to be recommended.

4. Boiling and steaming, as described here, consists in cooking meat or fish, either with hot water or steam, with a view to retain in the meat all the flavours, and is the opposite of soupmaking, which aims at withdrawing the meat juices. Here, again, the first step is to coagulate a surface layer of albumin by plunging the joint into a large pot of boiling water to which has been addeci a handful of salt. Salt is added on account of the boiling-point of salt water being higher than that of fresh water. The formation of this hardened case takes about seven minutes; the pot should then be withdrawn and kept at the side of the fire, the temperature not higher that $180^{\circ}$. This method is not only 
much more economical, but the meat is very much more tender if the cooking is slowly conducted over a period of five or six hours. The best method of slow cooking is by steaming the article of food in its own juice; this can be done most satisfactory in a Warren cooking-pot or Bain-Maric. This is a pot consisting of three compartments connected by a steam chimney. Watcr is put into the lowest pot, in the sccond the meat and its flavourings, and in the top the vegetables. The food is thus cooked by steam; less fuel is required, and therefore it is more economical; all the juices of the meat are retaincd; and the meat will be found to be much more succulent, tender, and digestible than if simply boiled in water. If the boiling is carried to excess and the water really boils, the meat is boiled to shreds. In these circumstances the connective tissue has become gelatinised, and the muscle fibre has become tough like leather, and may often be recognised in the fæces.

Steaming is an excellent way of cooking fish. It retains the flavour and also preserves the shape.

5. Frying is boiling in oil, but as practised in this country is a dirty and wasteful method, being usually a combination of broiling and scorching. There are two forms. In dry frying-which is our national form of frying-a shallow fryingpan is used, and the food is either cooked in its own fat or with the aid of sufficient fat to prevent burning. It is only suitable for fatty food like herrings and sausages, but the products of this form of frying are often greasy, and for many persons exceedingly indigestible.

IVet frying or sautéing is, essentially, boiling in oil. For this there is required a deep pan of clarified dripping, or of olive oil. If the process is properly carried out, the food is deliciously cooked and absolutely free from grease. The temperature of the fat is important. When fat is placed on the fire and reaches $212^{\circ} \mathrm{F}$. (the boiling-point of water), it bubbles and makes a hissing sound, due to a small portion of the water in the fat becoming steam and being got rid of. Fat, however, docs not boil until it has reached a much higher temperature. At a temperature of $340^{\circ} \mathrm{F}$. a slight bluish vapour is given off, and this is the time when, if a piece of bread be dropped in, it becomes brown in a second 
or two; on being taken out of the fat, it almost instantly loses its greasy appearance. If the fat gets hotter and begins to boil-a state of affairs to be avoided-it begins to smoke and decompose.

The principle on which the success of frying depends is that at the moment of contact with the almost boiling fat a thin film is formed over part of the surface of the fish or other object to be fried, and all the juices and flavours are retained. The food is kept in until it has a golden brown colour, when it is removed from the oil bath. It may look greasy for a moment, but this drains off very quickly if put on a piece of paper near the fire, and it is absolutely free from grease when it appears at table. If the object to be fried is coated with egg and breadcrumbs, the crumbs should be very fine, and firmly pressed down, to prevent the grease adhering to the surface and being absorbed by it.

The best substance to use is second quality of olive oil, or roast-beef dripping; clarified lard should never be used, as the other media for frying are as easily obtained, and are much better.

When the Juices are Extracted.-Stewing and braising are processes by which meat and poultry can be prepared and served in the most tender condition possible.

I. Stewing aims at making an extract of nutritive juices of the food, which are then used for cooking. A low, steady heat is wanted, and since nothing is lost in this process, it is one of the most economical ways of preparing food. The meat is chopped into convenient-sized portions, seasoned (if there are bones, they are also broken up and put into the pot); the whole is covered with cold water and a tight-fitting lid put on to the pot, which is placed near the fire but never allowed to boil. The old saying, "A stew boiled is a stew spoiled," is a true one. If vegetables are to be added, they are best put into the pot after the meat is half-done, as the flavours of the vegetables are lost with too continuous cooking. The more slowly the stew is cooked the better it is done. Tough meats are rendered more digestible by the addition of a little vinegar to loosen their fibres and to convert them into acid albumoses.

2. Braising is very much the same as stewing. The meat 
is again slowly cooked in a closed vesecl, the meat being just covered with an extract of animal and vegetable juices (stock) instead of water, and by this means the flavour of the meat is improved, the meat becoming impregnated with the flavours. This method is best adapted for foods somewhat insipid in themselves, like veal, poultry, and sweetbreads. At the end of the process the meat should be browned; this is carried out by having a concave lid in which hot cinders can be placed, or it may be done by radiation before the fire.

3. Boiling.- This brings us to the consideration of Soup and Soupmaking.

\section{Soups.}

Nutritional value.-The amount of nutriment to be got from a simple soup is very small. Soupmaking proceeds upon the principle of taking as much as possible from the materials, the extraction being effected by the use of a considerable quantity of water at a very moderate heat, extending over a long time. A clear soup contains the flavouring constituents and some of the salts of the meat of which it is prepared, also a very small proportion of soluble protein, all the coagulated protein having floated to the top and been removed as a brownish scum during the making; there is also present a small quantity of fat. Most clear soups contain only from I to 2 per cent. of solids; thick soups contain a little more, as may be seen from the following analysis by König :-

\begin{tabular}{|l|c|c|c|c|c|c|}
\hline & Water. & $\begin{array}{c}\text { Nitrogenous } \\
\text { Matter. }\end{array}$ & Fat. & $\begin{array}{c}\text { Other Nitrogen. } \\
\text { free Substances. }\end{array}$ & $\begin{array}{c}\text { Cellu. } \\
\text { lose. }\end{array}$ & $\begin{array}{c}\text { Mixed } \\
\text { Substances }\end{array}$ \\
\hline Pea Soup . & 88.26 & 3.38 & 0.93 & 5.60 & 0.70 & 1.13 \\
Potato Soup & 50.95 & 1.37 & 1.53 & 4.87 & 0.26 & 0.99 \\
\hline
\end{tabular}

If soup is to be made even moderately nutritious, the soup must simply be used as a vehicle by means of which other food materials can be made use of. The following ingredients are frequently used to thicken soup:-Starchy materials, such as cornflour, barley, rice, and potatoes; macaroni and vermicelli, both containing a good deal of gluten. The pulses, $\epsilon_{g} g$., lentils, peas, beans, added to weak stock, produce the most 
nutritious soups to be found on the table. Eggs, srated cheese, and cream have all their places in the preparation of nutritious soups. Purées of meat, chicken, game, and fish can also be added to soup.

In spite of its low nutritional value, ciear soup has its own place in dietetics. To begin dinner with, a small quantity ( $S$ to IO Oz.) of soup is a good method; it promotes the gastric secretion, and consequently aids the digestion of the meal that follows. A larger quantity may be a drawback to digestion, on account of diluting the gastric juice. For some invalids a strong soup is useful as a stimulant for rousing the appetite and increasing the digestive powers, but it does not count for much as nutriment.

Soupmaking.-In order to expose as large a surface to the water as possible, the meat is cut up into picces; the solvent power of the water is increased by the addition of a little vinegar to the water. The temperature is lept at a little below $160^{\circ} \mathrm{F}$. for several hours. As vegetables require a rery much greater heat than this to soften them, they should either be first boiled, and then the meat should be added, or the vegetables can be cooked separately, and only adcled to the soup when it is almost ready; this preserves the colour best. Flavouring herbs should be put in at the last moment. In all soups made from meat, great care should be cxercised in the removal of the fat. This is done by the soup being made the day before it is required, put aside in a basin to cool, and, when quite cold, the fat carefully skimmed from the top.

Varieties of Soup.-The term "stock" is usually given to the liquid part, to which the nutritious thickening and other ingredicnts are added.

Stock is the foundation of soups, and to be successful in soupmaking the manufacture of stock is necessary. There are varicties of stock, i.e., white, brown, and fish stock. Of white and brown a first and second stock is made.

White stock is made principally from beef, with sometimes a little mutton or veal added.

Brown stock is made in the same way as white, but more vegetables are added to colour it.

Fish stock is made from fish and fish trimmings. 
"Meat boilings" is the name griven to the water in which a joint of meat, fowl, or rabbit has been boiled.

Consommé is a clear soup made from first stock, and served with different garnishes.

Purée is a thick sou made from first or second stock. The thickening may be either meat, game, or verretables, the substance with which it has been thickened being first rubbed through a sieve.

Stock may be made in a proper stock pot, or in a large goblet. The stock pot should receive all scraps of meat and vegetables that are over from the preparation of other dishes; also any meat boilings. A sufficient quantity of fresh cold water must always be added, and a iittle salt to throw up the scum.

A stock pot should be kept slowly boiling, gradually concentrating its contents, and should not stand by the side of the fire in a lukewarm condition. Skim the stock thoroughly once or twice. A few washed egg-shells put into the stock will help to clear it. One whole day is sufficient to boil stock; then strain thoroughly, wash the pan, and set it outside to air. These precautions are necessary to prevent the stock becoming sour from fermentation.

The bones and any pieces of the meat may be put on next day with any fresh scraps. The vegetables are useless once the flavour has all been extracted.

Stock and soup should never be allowed to cool in the saucepan, but should be poured into basins and left uncovered. The grease that rises to the top should not be removed before the soup is used, as the covering of fat helps to preserve it.

If the stock has to be liept some time, it is best preserved by putting into a saucepan and bringing it to the boil each day.

The next variety of soup is that which is made on the lines of a good Scotch broth, of meat and vegetables, either boiled in stock or in water. This is known in France as pot-au-fen, and here the boiled meat is intended to be eaten with or immediately after the soup.

Grand bouillon is a stronger extract than pot-au-feu. In this, to the meat and vegetables are added bones and connective tissue for the sake of the gelatine. This, when cold and 
strained, forms a slightly firm jelly, which can be cleared and fawoured in many ways. (This variety is usually "clear soup.") If an extract sufficiently strong to be termed grand bouillon be taken, and to this is added extract or purée of roast meat, fowl, or vegetable, the result is known as a consommé. This form of soup is the most nutritious, because it contains most albumin.

In framing a diet, due weight must always be given to the composition of the particular soup to be taken.

\section{METHOD OF MAKING STOCK. First Stock for Clear Brown Soup.}

3 lbs. shin of beef, or

2 lbs. " , and

I lb. knuckle of veal.

3 quarts cold water.

I carrot.

I turnip.

I teaspoonful mixed herbs.

2 small onions.
2 or 3 stalks of celery, or teaspoonful celery seed.

2 doz. peppercorns.

8 cloves.

I blade of mace.

A few parsley stalks.

I dessertspoonful of salt.

Method.-Wipe the meat with a damp cloth, and remove all marrow from the bone. Take a very sharp knife and cut the meat into small pieces, keeping back any fat, but using the skin. Put the bones and meat into a stock pot with the cold water and salt, and let them soak for half an hour; then put the pot on the fire, and bring the contents slowly to the boil. Simmer for half an hour, and then remove any scum that may be on the top. Add the vegetables, prepared and cut rather small, and the herbs, celery, seed, and peppercorns, etc., tied in a small piece of muslin. Simmer slowly from four and a half to five hours, never letting it go off the boil. Then strain through a hair sieve or cloth stretched over a colander into a basin, and stand until cold.

A darker coloured stock may be obtained by frying the meat in a little dripping or butter before pouring on the water.

Do not throw away the meat or vegetables left after straining, but put them on again with the same quantity of water as before, and boil again for second stock.

\section{First Stock for White Soup.}

3 lbs. knuckle of veal, or 2 lbs. knuckle of veal and $1 \mathrm{lb}$. neck of mutton.

3 quarts cold water.

Make in the same way as first stock for brown soup, but use fewer vegretables. Rabbit or chicken may be used along with the veal. A plece of lean ham or a small ham bone will improve the flavour. 
Second Stock for Purés, Gravies, and General Use.

After the first stock is made, the meat and vegetables should be put on again with the same quantity of water, and boiled as before. This has not the fresh flavour of first stock, but is useful for making sauces, gravies, and many soups for which a good stock is not required. Sometimes the meat and vegetables are fried in a little dripping first. This gives the stock a darker colour and a richer flavour.

\section{Home-made Beef-teas, Extracts, and Essences. ${ }^{1}$}

Meat Infusions or Teas.-Home-made infusions of beef, mutton, veal, and chicken are always in demand for the sickroom. They are to be regarded more in the nature of pleasant, palatable, and stimulating beverages than as foods. Their nutritive value depends entirely on how they are made. If the cooking is carried out so that the infusion contains some of the protein of the meat, then there is some nutritive value; but, on the other hand, if made as ordinarily done, only the extractives and salts of the meat are dissolved out, and it cannot rank as a food. There is evidence that the meat extractives are capable of removing the effects of muscular fatigue, and enabling an exhausted muscle to become active again. On this account they can claim to be stimulating.

Preparation of meat infusion or tea.-When it is possible to select the portion of meat to be used, it is best to order for beef-tea, meat freshly killed, from the buttock, rump, or thick flank in preference to the shin of beef. In the same way fillet of veal is preferable to the knuckle or neck. For chicken-tea a full-grown fowl should be selected; the legs and dark part of the fowl can be used for soup, while the white portion can be served in some other way. In mutton and veal tea equal parts of the meats are used: this gives a very delicate flavour, and is often a plcasant change. In the process of cooking, the tea must not be allowed to boil, otherwise the juices are not extracted, owing to the insolublc albuminous coating formed on the surface of the meat. In every case care must be taken to insure that all the fat is removed from the surface before serving.

1 The patent and proprietary meat extracts are described on p. IGI. 


\section{beef-tea}

Methot 1.- The following recipe gives method of extracting the greatest possible quantity of nutriment :-

I lb. lean juicy beef.

1 pint cold water.

I small teaspoonful salt.

Wipe the meat with a damp cloth, and then place on a board, and with a sharp knife shred down as finely as possible. Keep back any pieces of connective tissue and fat. In this way all the fibres of the meat are remo:ed from the connective tissue which holds them together. Place the shredded meat in a basin with salt and water, stir it well up, cover the basin with a plate, and let it stand for half an hour. While the mixture is standing most of the soluble proteins of the meat will be dissolved out along with the extractives and salt. By the end of the half-hour the solution is practically a raw-beef juice. Then pour the contents of the basin into a clean, lined saucepan, place the pan over a slow fire, and whisk it well until it almost reaches boiling-point-on no account let it boil. Draw the pan to the side of the fire, put on the lid, and allow the beef-tea to simmer as slowly as possible for about fifteen minutes. Strain through a coarse strainer, pressing the meat as dry as possible with a wooden spoon. Skim all the fat off carefully before serving. After cooling, the tea will be found to have settled into two layers, a lower layer composed of flocculent particles and an upper layer of brown fluid. The lower flocculent layer consists of the protein which has been slightly coagulated by the heat. If the tea has passed through a muslin or fine strainer these particles would have been kept back and the value of the infusion lessened. The upper or fluid layer consists of a solution of the extractives and salts of the meat only.

Mcthod 2.- The same proportion of meat and water are used. The meat is prepared in the same way, but is placed, after standing in water for half an hour, in a beef-tea jar, and cooked in a very cool oven for two hours. The jars are strong stone jars, with a strong screw lid, and can be obtained from Dale \& Co., Edinburgh. This method of making beef-tea gives the best flavour. It may be too savoury for a delicate palate.

(Caution.-After making beef-tea in this way the jar must not be opened until the contents are cold. If opened too soon the steam rushes up, and it is very apt to scald the cook's face and arms.)

Tharictics of teas. - There are various ways in which beef-tea may be thickened, e.g., with tapioca, breadcrumbs, or baked flour, thus adding considerably to the nutritive value. When permissible, the flavouring can be improved by the addition of vegretables and celery seed; or a muslin bag containing a variety of vegetables can be cooked with the beef-tea and afterwards removed. 


\section{(1) Thick Becf-tea.}

$\$$ pint of made beef-tea.

1 teaspoonful tapioca grotit.

Warm the beef-tea and sprinkle in the tapioca, stirring all the time. I.et it simmer slowly by the side of the fire until the tapioca turns quite clear. This will probably take about fifteen minutes. Beat up the yolk of an egg in a cup, pour the beef-tea gradually over it, stirring all the time, and it is ready for serving.

(2) $\frac{1}{2}$ pint of made beef-tea.

I teaspoonful of arrowroot.

I teaspoonful cold water.

Mix the arrowroot and the water in a small basin until quite smooth. Then add it to beef-tea that is being warmed in a pan; stir well for a few minutes to prevent it becoming lumpy. Then simmer slowly for fifteen minutes.

\section{(3) Beef-tea Gruel.}

I tablespoonful fine oatmeal.

1 gill cold water or milk.
1 gill beef-tea.

Salt.

Make the gruel (see p. 296). When cooked, add it to the beef-tea ; stir them together until quite hot, but do not boil. It is then ready for use.

\section{(4) Becf Purée.}

$\frac{1}{2}$ pint good beef-tea.

$\frac{1}{4}$ lb. lean juicy meat.

Warm in a pan the beef-tea. Wipe and shred very finely $\frac{1}{4} 16$. of meat, pound it well, and rub it through a fine wire sieve. Take a cup, make it thoroughly hot, put in the pounded meat, and pour on the hot beef-tea. Stir it up well, and serve at once.

Bsef Essence.-One pound of meat will malie I gill of essence. Chicken can be prepared in a similar manner.

Prepare meat as in last recipe, shredding it down very finely. The chicken is jointed and meat chopped down finely. Place in a jar with a pinch of salt, cover with a strong piece of greased kitchen paper. Place the jar in a saucepan containing sufficient cold water to reach fully halfway up the jar, and let it steam slowly from four to five hours. When ready, strain through a coarse strainer, and press the meat well with the back of a wooden spoon to extract all the juice. This liquid is thus pure extract. When cold, this is in the form of a jelly.

Meat Juices. - This variety of food differs greatly in nutritive value from the beef-teas and essences previously mentioned. The meat juice is extracted without any heat and under strong pressure, and thus a large portion of the albumin is present. The preparation and value of the pro- 
prictary meat juices, such as Brand's and Wyeth's meat juices, will be later referred to (p. I6I).

\section{Home-made Mcat Juice}

is cheaper than the proprietary preparations, and is more valuable on account of its freshness and the absence of preservatives. It contains a relatively small quantity of extractives, and can be given in considerable amounts without causing diarrhœa or thirst. The great drawback to the home-made product is its red colour, which is decidedly objectionable. This can be partially overcome by serving in a red glass or a cup.

\section{Method of Preparation-}

$\frac{1}{4} \mathrm{lb}$. best rump steak. Pinch of salt or sugar to taste.

I gill cold water.

Wipe and shred very finely $\frac{1}{2} \mathrm{lb}$. of meat, pound it well, and rub it through a fine wire sieve. Place the meat in a basin with water and salt, let it stand, stirring occasionally, for a couple of hours. The liquid will then be a bright red colour. Strain through a fine strainer, pressing the meat with the back of a spoon. The fluid obtained will contain 4 to 5 per cent. of protein.

Meat juice should be made in very small quantities as it very soon becomes rancid. Another method, such as squeezing the meat in a lemon squeezer, may be tried, but this is wasteful, as the pressure is not sufficiently powerful to extract all the juice. 


\title{
CHAPTER VI
}

\author{
VEGETABLE FOODS
}

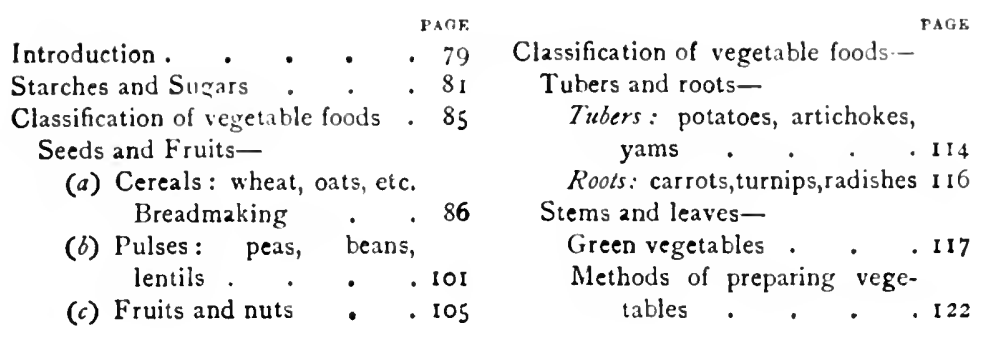

THE large and varied class of foodstuffs derived from plants have a strikingly common feature as far as their chemical composition goes. They are all very rich in carbohydrates, and as a rule are poor in fats. They contain vegetable proteins in different proportions.

Richness in protein and fat is the characteristic of animal foods, while the vegetable kingdom yields carbohydrates in abundance in the form of starch and sugar.

Vegetable proteins exist as vegetable albumin and vegetable casein. Vegetable albumin is not unlike egg albumin, and is coagulated by heat. Legumin or vegetable casein is coagulated by rennet and by acids, and is not coagulated by heat. There is a striking difference in the protein from animal and vegetable sources, the former yielding I I per cent. glutaminic acid on decomposition, the latter 37 per cent. Little is known as to the significance of this. Vegetable proteins do not contain many of the substances known as "nucleo-proteins," and are therefore considered by some authorities as a more suitable source of protein in gout. Extractives are present in vegetables in abundance, and belons to the group of 
chemical substances called amines. Asparagin, found in the potato, is one of the best known; these are of no value as foods.

Though there is no true gelatine substance in carbohydrates, there is a peculiar group of bodies known as "pectoses." These substances grive to fruits their power of forming jellies when boiled. Little is known of their exact chemical nature.

The salts of plants exist largely as salts of potash and phosphorus; in many of the cereals ( $\varepsilon . g$. wheat) iron is also present in combination with phosphoric acid. This differs from animal food, where the salts are mainly chlorides; thus in the eating of vegetables it is important to add sodium chloride (common salt).

Vegetable proteins are not so easily digested and assimilated as animal proteins. The proteins in peas and beans are rich in sulphur, and are therefore prone to induce Alatulence.

On the whole, plant life is not rich in fats. The fat resembles in chemical composition the animal fats, but contains as a rule more of the oily constituent (olein) and less of the solid components. The solid vegetable fats are cocoa-nut oil, palm oil, and cocoa butter, none of which are in great use as foods. The fluid oils are classed as drying and non-drying oils, owing to the fact that on exposure to air some absorb oxygen and become dry and solid, e.g., linseed, hemp, walnut, and poppy; others are non-drying oils, e.g., olive oil, cotton-seed oil, and almond oil.

Vegetable butters are now made from mixtures of these fats, and closely resemble cooking and table butter. In addition to the oils obtained by pressure, most plants contain volatile or essential oils, to which they owe their fragrance. These oils are diffused through every part of a plant, but are more concentrated in certain parts. Thus in the orange and lemon they are found in the rind, in the rose tribe they are found in the petals, in the umbellifera chiefly in the seeds. They are mainly used in perfumery, but they enter also largely into flavouring agents, and act as condiments to excite the appetite and stimulate the digestive juices.

The carbohydrates form the great bulk of vegetable food, 
and are represented by starch, sugar, and cellulose. There is a framework of cells and binding tissue known as cellulose; starch is the substance stored in the cells; and sugrar is the partially digested starch which circulates through the plant. These will be shortly considered.

Cellulose belongs to the carbohydrate group, but is characterised by its extraordinary insolubility: neither cold or hot water has any effect upon it, and in order seriously to influence it, prolonged boiling with a dilute acid is necessary. Cotton wool may be taken as almost pure cellulose, and paper is just felted vegetable fibre. When a plant is young its cellulose can be digested readily by man, but as the plant grows older the cellulose becomes more woody in structure and gets enveloped in resinous material, so that it is indigestible like paper or sawdust. It is this peculiarly insoluble envelope that makes the whole vegetable group difficult to digest unless very thoroughly cooked.

The nutritive parts of the plant are the starch, which is stored up in the cells, and the sugar, which circulates through the framework. The starches and sugars are convertible: the sugar is the digested nutriment of the plant, while the starch is the form in which the nourishment of the plant is stored for further use. It is also interesting to note that all starch eaten by animals has first to be converted into sugar before it can be used for the needs of the body.

Starch is really made up of a number of minute cells; microscopically they are of various shapes, depending on the plant from which they are taken, $\epsilon . g$., round, oval, polyhedral. The starch granules show concentric markings, showing that the cells have been built up layer by layer. Starch grains are insoluble in cold water; when boiled, the starch grains swell up and burst the cellulose envelopes, and forms with water the sticky substance used in laundry work. Cooking is essential for vegetable foods in order to rupture the starch granules so that the broken-up grains may be brought more readily into contact with the digestive juices. Dry heat applied to starch, as in baking of bread, pastry, tartmaking, partially converts the carbohydrate into another form known as clextrin (British gum). A temperature of about $300^{\circ} \mathrm{F}$. is necessary to produce this. Dextrin differs 
from starch in being very soluble in water, and gives a reddishbrown instead of blue reaction with iodine.

\section{Sugars.}

Sugars are crystallisable carbohydrates with oxygen and hydrogen existing in proportion to form water. There are several varieties of sugars, e.g., cane sugar, grape sugar, milk sugar, fruit sugar, and malt sugar. They present slight differences in their physical properties, such as specific gravity, solubility, and effect upon polarising light. They also differ in taste and digestibility.

Sugars have essentially the same use as starches, for all starch must be converted into glucose or dextrose before it can be made use of in the body.

Sugars are of value as energy and heat producers, and they also can be transferred into fat; they are, however, not essential for this purpose, as they can be replaced either by starches or fat. They are largely used for preserving purposes. Thus, sugars and syrups are used to preserve fruits in solution, or in the dried form as preserved cherries and crystallised ginger.

Cane sugar requires to be converted into grape sugar before it is absorbed, and therefore grape sugar may be considered a predigested carbohydrate.

There has been a very striking increase in the consumption of sugar in recent years; the immoderate use of sugar gives rise to flatulent dyspepsia and disorders of nutrition (see Glycosuria).

There are three groups of sugars:-

1. Sucroses, or di-saccharids, examples of which are cane sugar, beet sugar, maple sugar, and malt sugar.

2. Glucoses, or mono-saccharids, grape sugar (dextrose), fruit sugar (levulose).

3. Invert sugar, best known as honey.

I. Sucroses.-(a) Cane sugar is the clarified and crystallised juice of the sugar cane, but may be made also from beetroot. To the ordinary consumer the source of the sugar, whether from cane or beet, is indistinguishable, but for the manufacture of fruit syrups and British wines sugar from 
cane is said to be less liable to fermentation. Commercial sugar is extracted from sugar cane and the juice of the compressed beetroot by a process of refining which produces commercial white sugar of various grades. The principal steps in this process are as follows:-(I) Melting of the sugar; (2) straining through filters; (3) filtering through charcoal; (4) boiling or evaporating the decolorised liquid in vacuum pans; (5) separation of crystallised sugar by centrifuge.

Coarse brown sugar is somewhat impure and has a slightly laxative action; it is not cheaper than the more refined varieties.

Maple sugar is derived from the sap of the sugar maple of North America. The bark is tapped in early spring, and allows the sap to escape as it flows upwards. The sap is evaporated, the sugar crystallises out, and the residue is used as maple syrup.

There is no chemical difference between maple sugar and the other two described above, but it contains certain ethereal substances which give it its peculiar flavcur. Maple sugar is chiefly used as a confection.

Molasses, treacle, and syrup are by-products formed during the process of refining the above sugar. The first two, owing to impurities, are more laxative than golden syrup, but all contain besides sugar-acids, extractives, salts, and more or less impurities.

Heat applied to sugar makes it change its crystalline form. When strongly heated it melts into a yellowish liquid, and on cooling it does not crystallise, but forms a transparent, brittle mass-familiar as barley sugar. Sugar candy is made by extremely slow crystallisation. Caramel is made by heating refined cane sugar to about $400^{\mathrm{c}} \mathrm{F}$., when it is melted, browned, and converted into a non-crystallisable fluid with a distinctive "caramel" flavour. Caramel may be added to insipid invalid foods such as milk, custard, farina, arrowroot, and the like.

Confectionery and sweets are made from cane sugar or glucose (grape sugar), with the addition of butter or other fats, nuts, fruits, starch, and flavouring extracts. Sweets in moderation are good for growing children. There is no proof that sugar is harmful to the healthy, although doubtless 
sweets which adhere to the teeth undergo fermentation with the production of acids which attack the teeth.

(b) Maltose- - Though one of the same group of sugars as cane, etc., it varies very considerably in chemical and physical properties. When taken in the form of malt extract the sugar is less apt to irritate the stomach, and although not capable of direct absorption as such, maltose may yet be regarded as a partially digested form of carbohydrate. Malt sugar is formed in the process of malting. The grain is roasted in a kiln till it show's signs of sprouting, when the temperature is raised to arrest further growth. The grain is now called malt, and is brownish, some of the starch having been changed into dextrin and part of it into sugar. The object of the malting is to convert the insoluble starch into the soluble sugar and dextrin (see Malt Extracts, p. 178).

(c) Lactose, or milk sugar, is the carbohydrate of milk. It differs from cane sugar in its flavour, being almost tasteless. It is hardly possible to ferment it by yeasts. It is therefore very useful in cases of stomach derangement with fermentation. It is readily split up by micro-organisms to form lactic acid.

(d) Mannite is obtained from the sweet juice of the stems of the ash trec; it is found also in bectroots and some other vegetables. Like sucrose, it crystallises and is white. It does not ferment with yeast. It is laxative, and may be used in diabetes, not being excreted in the urine as glucose.

2. Glucose, or grape sugar, is present in almost all fruits, in some in abunclant quantities. In peaches, pineapples, and strawberries it is found with cane sugar, and in grapes and cherrics it is combined with other varieties. Grape sugar is known by the name of dextrose. When grapes are dried to form raisins, the little dried masses on the outside are dextrose. Commercial glucose is usually obtained by boiling starch with acid, and it is sold in a syrupy form. When heated it turns brown and is used as sugar-colouring. Glucose mixed with egg albumin is largely employed by confectioners in the preparation of icing and fondants.

Leinlense, or fruit sugar, is found in most fruits; it is difficult to cry'stallise. It is now sold under the name of "Diabetin," for the use of diabetics, on the ground that it is better borne 
than any other form of sugar. Diabetin is swceter than canc sugar, and has a somewhat fruity taste. It may be taken in considerable quantities without disordering digestion, as saccharin is apt to do.

3. Invert Sugar is a mixture of dextrose and levulose. It can be preparcd from cane sugar by the action of ferments, or by boiling. Inversion goes on rapidly if cane sugar is boiled with fruit juice. A large proportion of cane sugar is converted into invert sugar in the process of jam-making. Honey is "an invert sugar" prepared by bees from the cane sugar of flowers; the insect transforms a part of the sugar into dextrose. Honey is a vegetable product manufactured by an insect, and contains besides the sugar-wax, gum, pigment, and odorous substances. Honey was more in demand for swectening before the discovery of sugar-refining. It is a wholesome, fattening food. Artificial honeycombs are now made from paraffin stamped into cells, which allows the bees more time for the storage of honey. Run honey is mixed with fluid glucose and sold as honey; it is innocuous, but should be sold at a cheaper rate. Honey gathered from poisonous flowers has occasioned symptoms of poisoning.

Saccharin and dulcin (sucrol) are chemical substitutes for sugar. They have many hundred times the sweetening power of sugar, but are of no use as foods. They are used to replace sugar as a flavouring agent in diabetes, gout, and obesity.

\section{Vegetable Foods Proper.}

Almost every part of plants furnishes food, but more especially seeds, roots, stems, leaves. These may be classified as follows :-

$A$. Seeds and Fruits.

(a) Cereals. - Wheat, oats, maize, etc.

(b) Pulses.-Peas, beans, lentils.

(c) Fruits and Nuts.-Oranges, almonds, walnuts.

$B$. TUBERS ANI ROOTS.

Tubers.-Potatoes, Jerusalem artichokes, yams.

Roots.-Carrots, turnips, radishes.

$C$. Stems and Leaves.

Green Vegetables. 


\section{A. Seeds and Fruits.}

\section{CEREAIS.}

(17) The Cereals, from Ceres; goddess of corn, comprise all grains or corn-bearing plants. They are really grasses cultivated so as to develop the maximum of food material with a minimum of husk-the growth of millet, lentils, and barley being prehistoric in origin. In geographical distribution they extend over the whole globe-sorghum and millet growing at the tropics, while barley, oats, and rye are grown in the extreme north of Europe. The seeds dry easily, and can be stored and shipped without loss. They contain from 5 to 14 per cent. nitrogenous matters, chiefly in the form of gluten, while the bulk of the grain consists of starch, the whole enclosed in a covering of cellulose. The proportion of fat varies in different members of the group. It is interesting to note that it tends to be most abundant in those cereals which grow in the temperate or cold zones, e.g., oats, whereas in cereals of tropical growth, e.g. rice, there is hardly any present. Wheat and rye, owing to peculiarities in their gluten, are the only ones suitable for breadmaking, but all of them can be made into cakes, porridge, puddings, or soup.

The process of grinding first removes the outer coats of cellulose, and an unbroken meal or flour is obtained. The gluten lies next the outer surface. The salts in grains amount to about 2 per cent. This amount depends largely on the kind of soil and manure employed-they consist chiefly of phosphates of soda and potash, with lime and magnesia, and a little silica and iron. The organic salts are almost absent.

The average composition of cereals is as follows:-

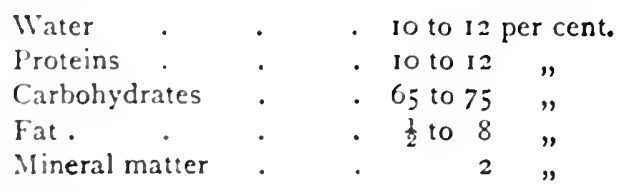

The average composition of the more important individual cereals may be taken as follows:- 


\section{Composition of Cereals.}

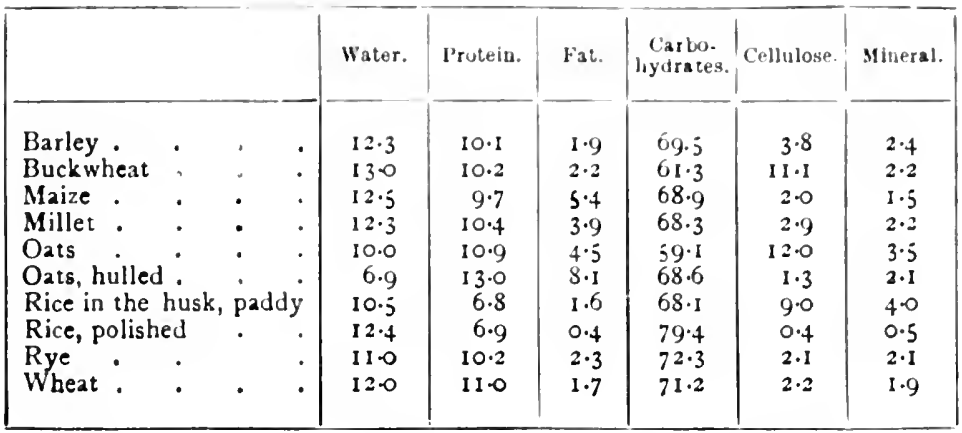

Parkes gives the following order of merit of the common grains, in respect of proximate principles :-

\begin{tabular}{|l|l|l|l|}
\hline Proteins. & Fats. & Starch. & Salts. \\
\cline { 2 - 3 } Wheat & Oats & Rice & Barley \\
Barley & Maize & Maize & Oats \\
Rye & Barley & Wheat & Wheat \\
Oats & Rye & Rye & Rye \\
Maize & Wheat & Oats & Maize \\
Rice & Rice & Barley & Rice \\
\hline
\end{tabular}

The cereals contain a great excess of carbohydrate, and mankind has instinctively added fat and protein; so that we eat butter with bread, milk with porridge, and make cereal puddings up with eggs and milk.

Wheat.-The first place among the cereals must be assigned to wheat-it is estimated that 6 bushels per head each year are consumed. There are two varieties, summer and winter wheat. The following is the average composition :-

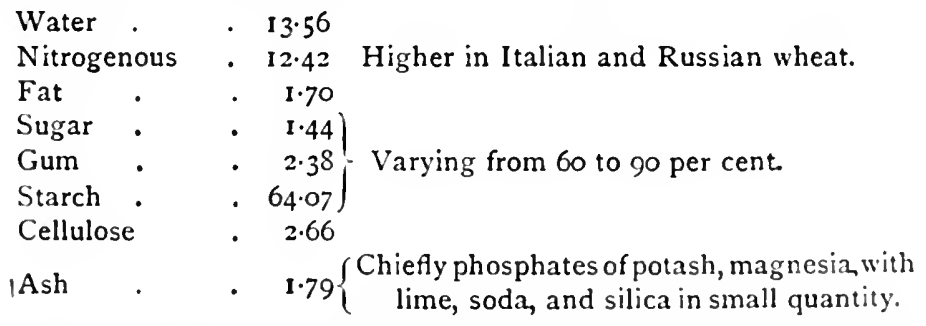

Russian wheat is richer in nitrogenous matters, ranging up to $2 I_{\frac{1}{2}}$ per cent. The hard Italian and Hungarian wheats 
are also rich in nitrogenous matters, containing soluble albumin as sluten. In order to transform wheat grains into a useful domestic substance, the grains have to undergo the process of grinding or milling. It is necessary, in order to follow the processes of grinding, to have some knowledge of the different parts of the wheat grain. These are:-

1. The husk, or cuticle.

2. Kernel, or food supply:

3. Germ, or young plant.

The husk consists of three layers, consisting mainly of cellulose with some pigment. When the wheat is decorticated the product is known as bran. Wheat-bran contains about 15 per cent. nitrogen, 3.5 per cent. of fatty matter, and 6 to 7 per cent. mineral matter, mainly phosphates; all of which materials should be nutritious, but very little bran can be absorbed, and it is irritating except to patients with a robust digestion. The kernel or endosperm: this consists of the nutritive matcrial for the young embryo, and makes up $S_{5}$ per cent. of the grain. Microscopically it is found to consist of a honeycomb of cellulose, into which is packed starch cells and gluten granules. Gluten is a mixture of proteins, viz., gliadin and glutenin, which have the peculiar property of becoming viscid when mixed with water. This important fcature will be mentioned again under Breadmaking. The relative proportions of starch and gluten differ in different kinds of wheat. It may be said that the hard, translucent, horny grains are rich in gluten, while those that are soft, opaque, and floury on scction are rich in starch.

The germ or young plant represents $I_{2}^{\frac{1}{2}}$ per cent. of the wholc grain. This is very rich in nitrogen and fat. The germ in removed as well as the bran in the preparation of flour, for the following reasons:-The abundant supply of fat in the germ may become rancid, and so spoil the flour, and the soluble proteins present are apt to act on the starch of the flour, converting part of it into soluble forms (dextrose and sugar), which darken in colour in the oven and detract from the appearance of the cooked flour.

Thus, in the process of milling to which the wheat is subjected, its different parts are broken up and various mill 
products are produced. The unter coats yields bran, fine pollards, sharps, and middlings; the germ is removed as offal, while the flour is derived solely from the kernel.

Flour, according to the amount of grinding, is yellowish white, from the presence of gluten; or pure white, in which case it is likely to contain little except starch. Good flour should have a pleasant smell, and should have no acid or rancid taste. It should not contain more than 15.2 per cent. water. The flour itself is classified and divided into two parts: the larger part, known as "bakers" or "household," and a smaller portion, very white in colour, and therefore poor in proteins, known as "patents"; from the latter, genuine Vienna bread is made, and also the best class of fancy breads and pastry.

The "bakers" or "household" flours are still further divided, but as they are again blended before being sold, it is not necessary to follow the commercial terms.

By removing the germ and the bran, the most useful constituents of the wheat are lost, viz., germ protein and fat, and the bran minerals and protein matter. Whole wheaten meal baked is more nutritious, much better flavoured, but is apt to be irritating on account of the indigestible outer coat, consisting of cellulose and silica, etc., and while it is useful as a laxative its use has not become general.

Other flours are obtainable where only the two outer layers of the husk are removed. Bread made from these is not nearly so indigestible as bread made from whole wheaten meal.

Two patent processes have also been devised to prevent the waste. Smith's patent takes the separated germ and partially cooks it by means of superheated steam. This kills the ferment, which otherwise acts on the starch and at the same time sterilises the fat, and so prevents it becoming rancid. The germ so heated is ground to a fine meal, and of this one part is added to three of ordinary flour, and the mixture is known as Hovis flour. It is much richer in protein and fat than ordinary flour. There are now several germ breads in the market, in all of which the germ is treated much along these lines. The Frame food process treats the bran. The bran is boiled under high pressure, the mineral matters and 
part of the nitrogen are recovered. The watery cxtract is filtered and evaporated to dryness. This is Frame food extract. This extract forms the basis of preparations prepared by the Frame Food Manufacturing Company.

This brings us now to the cooking of flour, or breadmaking; but before taking up this point, I would direct special attention to the present-clay methods, largely in vogue, of artificially bleaching flour. This is really a form of adulteration.

\section{Cookery of Flour.}

(a) Breadmaking.-The making of bread is possibly the most important of all cooking processes now in use.

Bread is a mixed food containing fat, protein, salts, sugar, and starch; it does not contain enough fat to be a perfect food, and hence the almost universal custom of using butter with it.

The chemical composition of bread is thus given by Atwater:-

\begin{tabular}{|c|c|c|c|}
\hline & Water. & Protein. & Salts. \\
\hline $\begin{array}{l}\text { White Bread } \\
\text { Brown Bread }\end{array}$ & $\begin{array}{l}35.4 \\
400\end{array}$ & $\begin{array}{l}9.5 \\
5.0\end{array}$ & $\begin{array}{l}1 \cdot 1 \\
1.9\end{array}$ \\
\hline
\end{tabular}

The whole process of breadmaking aims at converting the dough (flour and water) into a porous mass.

Dough is prepared by kneading together by hand or machinery the necessary proportions of flour and warm water. A pound of bread is made from $\frac{3}{4} \mathrm{lb}$. of flour by the arldition of 25 per cent. of water. The porosity of bread, which distinguishes it from biscuit, is obtained by the disengagement within the mass of carbonic acid gas, according to one of three methods:-(I) Fermentation, the carbonic acid gas being produced by the use of yeast, or by a leaven of dough already fermenting; (2) by the use of baking powders, the ordinary domestic baking powder being bicarbonate of soda and tartaric acid; and (3) by the use of carbonic acid gas under pressure, by means of machinery, giving aerated bread. 


\section{The Adulteration of Flour by Bleaching.}

All who appreciate the value of pure food will welcome the announcement made by the President of the Local Government Board a short time ago, that a Bill was in preparation designed to render illegal the bleaching of flour and the addition of phosphates as "flour improvers." It is not generally known that the bulk of flour used in this country is not the natural product of the wheat, but is flour which has been submitted to various forms of special treatment for the purpose of whitening it and otherwise increasing its commercial value, these processes being, there is good reason to believe, not without risk to the consumer. In view of a recent test case on "Bleached Flour" which has created widespread interest in the milling and baking trades, the present work is an opportune time for laying before the profession a short account of the process of blcaching.

The United States Government have previously taken up the subject of Bleached Flour. A public hearing on this subject was held by the Secretary of Agriculture and the Board of Food and Drug Inspection in I90S, and at this hearing those who favoured the bleaching process and those who were opposed to it were given equal opportunities to be heard. The conclusion was arrived at that flour bleached by nitrous oxide fumes was an adulterated product, and its sale in the United States is now illegal. In this country, the subject was first seriously taken up by $\mathrm{Dr}$ Wilson, Medical Officer of Health for Lanarkshire, and as a result of representations made to the Local Government Board in 1909, that body undertook an investigation into the subject, the results of this investigation being embodied in two reports, "On the Bleaching of Flour and the addition of so-called 'Improvers' to Flour," by Dr J. M. Hamill, and "On the Chemical Changes produced in Flour by Bleaching," by Dr E. W. Monier-Williams.

Dr Hamill's report, which was adverse to the process of bleaching, aroused widespread interest in the trade, meetings of millers and of bakers being held at which the bleaching of flour was specially discussed. At a meeting of the National Association of British and Irish Millers, held in April I9II, the following resolution was made and agreed to: "That in the opinion of the Association wheaten flour sold as such, without any qualifying designation, should be the unbleached and untreated product of properly cleaned and 'conditioned' wheat only." At a later date, the Council of the National Association of Master Bakers appointed a Committee to report on flour treatment, and this Committee arrived at the conclusion that the bleaching of flour was objectionable, and recommended that no bleached flour should be sold to the bakers without the fact that it is so bleached being disclosed.

The case which was recently concluded in the Sheriff-Court of Lanarkshire is of interest and importance to the public. This was a prosecution at the instance of the County Council of Lanarkshire against Uddingston Co-operative Society, charging the respondents with having sold for $1 \mathrm{lb}$. of flour a quantity of material which purported to be flour but which was not genuine flour, in respect that it had been bleached with peroxicle of nitrogen, a poisonous noxious gas, and contained 3.43 parts or thereby of nitrites per million parts of 
Anur, which was in excess of that found in genuine flour. The prosecution was the first of its kiml in scotland, and bemg a test case, it has aroused miversal interest in the milling and baking trades. After a lenglly hearing, shesiff shennan found the charge not proven. His conclusions that the prosecution was based on apprehended evils rather than proved deterioration. and that no pronf had been tendered of deleterious results due to bleaching, will appeal to most medical men as sound. Jut it must be borne in mind that in the circumstances there can be no direct and conclusive proof as to the prejudicial effects of bleached flour as an article of diet. The indirect evidence, however, is conclusive that flour so treated is not so easily digested and is therefore less nutritive, and, in the interests of growing children more particularly, it should not be substituted for the grenuine product of the wheat.

Rice flour boilcd is sometimes added in breadmaking, causing the bread to become more adhesive and to hold more water. Hence bakers sometimes resort to this means to make their bread heavier when it is sold by weight.

Fresh-baked bread is less digestible than stale bread, the moist new bread forming a tenacious mass in the mouth which is not readily penetrated by the saliva and other digestive juices. Stale bread crumbles into small particles and is easily attacked. Similarly, the crust is more digestible than the interior part of the loaf.

Spoiled bread.-Bread may be unfit for use from being made with adulterated or old flour, sour from bad flour, bitter from yeast, and may be sodden from insufficient fermentation; and it may grow mouldy from exposure to warm, damp air when it is moist.

\section{Digestion, Absorption, and Nutritive Value of Bread.}

The digestion of bread commences in the mouth, where, under the influence of the saliva, the starches are converted into dextrin and maltose. Thorough mastication is all-important for this process. The crust of bread, and also various special forms of bread, such as rusk, are more easily digested, because their starch has been already partly converted in the process of manufacture. New brcad is indigestible because of its liability to form doughy masses, which interfere with the ferment getting proper access to the ingredients. Bread is very well absorbed; the proteins in bread, however, are less completely absorbed than are the proteins in meat. Brown bread and wholemeal breads are less completely absorbed, on account of their greater richness in cellulose. The nutritive value of bread is considerable. The ratio of 
proteins and carbohydrates $(I: S)$ is too low to be a perfect food, and its deficiency in fat has already been referred to. Various mears are adopted to increase the nutritive value of bread, e.g., baking the bread with skimmed milk, adding pease meal, meat, or cascin. A good example of a bread with increased nutritive valuc is Hovis, a germ bread containing extra proteins and also fat (p. 89).

\section{Varieties of Breads.}

Bakers produce various types of loaves-pan, househoid french, cottage, etc. The chief difference is the type of crust and the porosity of the bread. The pan loaf is generally the most porous, and conscquently makes the best toast.

Toast is bread browned by heat in front of an open fire, the starch being partly converted into dextrin in the process. The additional caramel or flavour and dryness acquired lessen the time of digcstion of toasted as compared with fresh bread by about one-third. A slice of bread if cut sufficiently thin toasts dry and crisp throughout, but if thick the outer layers are scorched while the mass within may become softer than before toasting.

Baked bread.-Slices of bread put into a cool oven and slowly dried, and very slightly browned, make a very pleasant change. The slow baking transforms the starch into dextrin. The bread is hard and needs a great deal of mastication, and with a plentiful supply of butter makes an excellent food for children. Many rusk biscuits are prepared in this way.

Dinner toast.-Another method of presenting bread to people with weak digestion is by giving very thin slices of bread dipped in milk and slowly browned in the oven.

Buttered dry toast is still another way of serving bread. The crisp toast is buttered when hot, and the fat droplets penetrate it. This is a good method of giving an extra supply of butter.

Brown breads. -This is an clastic term, meaning that a certain proportion of bran or germ, or of both, have becn added to the flour. It is also applied to brearl mate from whole-wheat meal. Any bread made with the addition of bran is richer in mineral constituents. Another difference is 
the amount of water present. The protein of bran converts some of the starch into dextrin, and this keeps the brown bread moist. There is a smaller proportion of carbohydrates in brown as compared with white bread, and a larger amount of cellulose. For this reason brown bread is recommended in constipation.

Of the patent breads the most are of the brown variety. They are made from flours prepared by various patent processes. Somc are wholemeal breads, with the bran reduced to varying degrees of finencss. Others contain the germ in various proportions (see Hovis, p. S9).

Others are malted, e.g., Bermaline, Carr's, Veda, etc. The malting consists in adding malt extract. When the malt extract is mixed with the dough, the latter is ultimately converted into malt sugar and dextrin. This makes the bread keep moist, but its activity is stopped as soon as the bread is placed in the oven, the ferment being destroyed by the heat. Thus malted bread does not aid digestion of other starchy food.

Vienna bread is made from the whitest flour (the patents) fermented with compressed yeast, and milk often added to the dough. The crust is glazed by being subjected to the action of overheated steam before leaving the oven.

Pumpernickel is German black bread made with sour dough; it is somewhat laxative.

Zwicback is a thoroughly dry form of aerated bread which is very wholesome for invalids.

Gluten bread.-Bread made from gluten flour is useful where there is diabetes, and in some cases of obesity. It is very unappetising. The best breads contain 40 to 50 per cent. of gluten, but some only contain I 6 per cent. of gluten, and the rest starch. It can be toasted like ordinary bread.

Poluboskos (mcaning "much nourishment") is a gluten food which claims to contain only 0.4 per cent, of starch. It is given to diabetics in doses of one or two teaspoonfuls in milk.

Rusks may be regarded as a kind of toast. They are made in much the same way as brcad, with the addition of butter and milk, and sometimes sugar. They are twice passed through the oven, which thoroughly dries them. 
Biscuits are made from flour, but no yeast is used in the manufacture. They are made from fine starchy flour, and worked into dough, either with water, as ordinary ship biscuits, or with butter, milk, and sugar, in the case of table biscuits. All their starch is converted into dextrin, and many good infants' foods are made up largely of biscuit powder. Biscuits contain less water than bread, $\frac{3}{4} \mathrm{lb}$. biscuit being equivalent to $\mathbf{I} \mathrm{lb}$. bread. Biscuits are deficient in fat and salts, and are thus not a suitable diet for constant use. Biscuits claiming to be starch- and sugar-free are made, for use in obesity and diabetes.

The bread supplied to sailors at sea has to be of the unleavened sort, and takes the form of "ship biscuits" or "hard tack." These biscuits are exceedingly hard and tough, and require soaking before they can be eaten.

Most biscuits if kept long exposed to the air become exceedingly tasteless and soft, though they do not mould.

\section{Pastry and Puddings and Cakes.}

These are prepared in innumerable variety from flour, in various proportions, with milk, cream, butter, sugar, eggs, flavouring agents, nuts and fruits (such as currants, raisins, pineapple, cherries, ginger). The dough is usually raised by baking-powders or whipped white of egg; sometimes alcohol or yeast are used. For puddings a hot fire is used, and the mixture is either baked, boiled, or steamed, so that the flour is altered by the heat in much the same manner as in the manufacture of bread. The digestibility of these foods cannot be classified; they are rich, and on the whole not easily digested, except the farinaceous puddings. Sago, semolina, and the like, when simply made and thoroughly cooked, are useful in the feeding of invalids.

Pastry, even when well made and light, is a buttery compound, and the temperature at which it is cooked prevents the whole of the flour being properly cooked, and the uncooked buttery starch is almost always indigestible.

\section{Preparations of Wheat other than Flour.}

The wheat grain may be used as a food in its entirety. It is soaked in water till it swells up and bursts; it is then 
boiled in milk with the addition of sugar, so forming a nourishing dish called finmenty'.

Wheaten groats are made by crushing, and this can be macle into porridge, used like oatmeal.

Wheatend is a nutritious food containing all the wheat germ excepting the husk, and is finer than crushed wheat, and more easily digested. The starch granules are partially cooked. It is caten as a porridge.

Granose and Granola are flaky forms of the entire wheat grain. They are palatable and nutritious, are ready cooked, and are eaten with cream or hot milk.

Shredded wheat, Trisket, and pulled bread are all prepared much in the same way. The shredded wheat biscuit is made of wheat, thoroughly cleansed and cooked, and treated by machinery, which draws out the wheat kernels into long continuous filaments without separation of the parts. The shreds are folded into oblong biscuits, which are cooked at successive temperatures until they are quite dry and ready for use. They may be eaten with butter, or soaked in milk, cream, or soup. They are casily digested; they require mastication, and are quite palatable.

Farina is a general name meaning flour, but sometimes it is also applied to potato flour, which forms a jelly like arrowroot when cooked.

Farola is another granular preparation, but is made from the endosperm or germ, and is specially rich in proteins and mineral matters.

Florador, another granular wheat preparation, is recommended for puddings and shapes; it is certainly more nutritious than cornflour.

Semolina is prepared from the central part of hard wheat, and is rich in gluten. It contains about I I per cent. of protein, or half the amount contained in an equal weight of beef. It is thus a fairly rich nitrogenows food, and is used for making puddings and for thickening soups. It is also user extensirely in the manufacture of the alimentary pastes, such as macaroni.

Wacaroni, vermicelli, and spaghetti, etc., are made from mixing different fours rich in gluten (e.g. semolina). The fluur is made into a paste, kneaded, put into a cylinder the 
bottom of which is pierced with holes. A piston descends in the cylinder and the paste comes out from the perforations in the form of long tubes, which are cooled, cut in lengths, and dried. It contains i 6 to i 8 per cent. of gluten as against IO and I I per cent. in the case of white bread.

Weight for weight, macaroni may be regarded as not less valuable for fleshmaling purposes than beef or mutton. Most people can digest it easily and rapidly.

After thorough soaking, and when well cooked by boiling or stewing in milk or stock, it is very nutritious, and it is often agreeably combined with cheese. The other pastes are much the same in composition; they are wholesome, but tough, and require prolonged cooking.

\section{Other Cereals.}

Oats contains more protein and fat than flour and meal from other cereals. Maize meal is the most closely allied to it. Starch is present in proportion of about 38 per cent. The nitrogenous portions contain 94 per cent. protein, which is thus all available for tissue-building. There is great difficulty in completely getting rid of the husk, so a good deal of cellulose is left in the meal in the form of sharp particles. Oatmeal is obtainable in coarse, medium, and fine varieties, the two latter being those in household use. To those with a delicate digestion this makes oatmeal an unsuitable food; but for constipation oatmeal is an excellent article of diet. Oatmeal is an excellent food for the growing child. This may probably be explained by the stimulating effects of the oats on the thyroid gland (see Appendix). In some subjects it heats the blood, causing rashes and gastric derangement.

If oats are simply cleaned and ground, the result is oatmeal of various degrees of fineness. Oat flour, e.g. Scott's oat flour, is the product after the branny particles are removed - this is the best form for infants and invalids. Groats, e.g. Robinson's groats, consist of oats from which the husk has been entirely removed.

Rolling oats is another method of preparation instead of grinding. Rolled oats are more easily softened by conking; probabiy the great pressure between the rollers breaks 
down the cell envelopes. In some of the rolled oats preparations heat is also used. This requires less cooking in the house, and sterilises the fat, so that there is no fear of the abundant fat present turning sour and altering the flavour. "Rolled oats," Quaker oats, Arenine, Provost oats, and Porrage oats are all examples of this preparation.

Oatmeal is unfitted for breadmaking, owing to the absence of gluten. It is made into oatcakes by mixing the meal with water, fat in some form (dripping or butter), and salt. Made into cakes and baked on the girdle in the form of breadstuff, it is much used in Scotland as a breakfast breadstuff, and can either be home-made or bought in tins. Oatcake is as nutritious as bread, and contains a great deal higher food value.

Oatmeal needs prolonged boiling to soften the cellulose. For persons with limited digestive power oatmeal should be cooked so as to acquire a consistence which enables it to pour readily, and on cooling it should form a soft, gelatinous mass. (For making of gruel and porridge, see p. 296.)

Brose is an old Scotch dish made by stirring oatmeal into boiling water. It is not a food for a clelicate digestion.

A soupplateful of porridge is equivalent in protein to two slices of a large loaf $\frac{3}{4}$ to $I$ inch thick. If the bread is buttered, it would be equal in food value to a plateful of porridge and $\frac{1}{3}$ pint of good milk.

Maize or Corn may be dried, parched, and roasted, whole, or ground into meal of various degrees of fineness. Its chemical composition shows it to contain a considerable amount of fat and protein (three globulins, one or more albuminoids, and maize fibrine, or zcin) as well as starch, and it furnishes abundant energy and heat. It is very fattening both for man and the lower animals. There are innumerable varieties, but the common kinds are known as white, yellow, and red. As a fresh vegetable, sugar corn, unless eaten very young and tender, is indigestible, and canned corn is notoriously so-chiefly on account of the husk of the kernel. It may give rise to flatulency, indigestion, and diarrhea. When maize becomes mouldy it causes a disease known as "pellagra." The chief preparations are:- 
Cornmeal.-This is digestible, and like oatmeal somewhat laxative. It makes a dry, friable bread, for it contains no gluten. As compared with wheat flour, it contains more fat but is deficient in salt. It is not largely used in this country.

Polenta.-A maize meal largely used by the Italians.

Cornstarch is very white and soft; contains 53 per cent. of starch; contains proportionally little nourishment. May be used instead of arrowroot.

Indian meal is yellow, granular, and coarser than cornstarch.

Hominy, cerealine, and samp are preparations of broken or split maize of various degrees of fineness. Samp is very coarse, and can only be used when well boiled. The first two make excellent puddings.

Cornflour, maizina, oswego.-These are made from maize by washing away the protein and fat. They contain very small quantities of nitrogen, and are therefore only agreeable forms of starch, and are generally taken with a protein and fat, such as eggs or milk.

Popcorn.-A small variety of maize that is roasted and swells up and bursts; it is then known as popped popcorn; it is the basis of many sweetmeats.

Mush is made of well-ground Indian meal or cornmeal boiled in salted water. It mixes well with cream, and is very digestible and nutritious.

Buckwheat or blackwheat is used in Russia, Siberia, and Brittany. The meal has less protein and more carbohydrate than flour. It is usually eaten as porridge, and can be made into griddle cakes. It is not used in this country.

Millet or Sorghum is used in Africa, Southern Europe, and in China, but not in this country; it is similar in composition to buckwheat. White sorghum is a grass or corn, and can be converted into a flour- "dhoora"-much used in India. A fine quality of alcohol may be made from it. In the United States it is grown chiefly for molasses and syrup, and sugar is made from it.

Bread made from millet or sorghum meal when warm is fairly palatable and nutritious, and is used in China. When it grows cold it darkens and crumbles.

Rye may be said to stand very close to wheat in importance as a food. It is in use in Europe, and mainly in 
Germany. In Germany the rye production is double that of wheat, and in Russia it is even greater.

Rye flour yields a coarse, dark, less well-raised bread than wheat, but is equally nutritious, though not so digestible; it contains less gluten than wheaten bread, and it takes less time to raise and bake it, provided the oven is hot. If properly made it is easily assimilated, and to many people its flavour is agrecable.

kye is uften combined with wheat in France, under the name micil, and the Spaniards combine it with barley. Rye flour is poorer in protein than a wheat flour of a similar grade. It is very apt to be attacked by the fungus known as ergot, which causes the grair to swell up and become dark purple.

Rice is the poorest cereal in protein and lat, and contains 76 per cent. starch. Rice, when boiled, swells up and absorbs nearly five times its weight of water, while some of the mineral constituents are lost in the water. It should therefore be steamed, or if boiled the water it has been boiled in should be used as stock. Rice is only moderately easy of digestion, and often gives rise to flatulence; this is probably owing to the stomach not being the place to digest starch, and hence it takes a considerable time to leave the stomach.

Its poverty in protein and fat does not adapt it for an cxclusive food. It is rarely taken alone, but combined with other foods like meat or legumes rich in proteins, or made into puddings with eggs or milk.

It cannot be made into bread, but rice flour is often added to wheaten flour. Rice forms the staple food of about onethird of the human race. The whole grain is called paddy, and is coloured in various shades of yellow; when this coloured skin is removed the grain is known as rice. Ricewater makes a cooling drink (p. 35).

Barley contains more salt, fat, and cellulose than wheat, but less protein and carbohydrate. The ash of barley is rich in phosphates and iron. The proteins resemble those of oats, and do not form gluten but remain soluble; thus it cannot be made into bread, but is used as barley scones and cakes and barley meal porridge. 
In the preparation of barley the whole grain is ground to form barley meal. When stripped of the husk and roughly ground it is called pot barley or milled barley ; when the grains are further rounded and polished it is known as pearl barley. In the form of barley broth it forms a common article of dict.

Barley-water madie from pearl barley or Robinson's patent barley is a useful sedative in all irritable states of the urinary passages. Barlcy-water is often added to cow's milk in infant feeding.

\section{Legumes or Pulses.}

Peas, Beans, Lentils, Pea Nuts, Butter Bcans.

The ripe seeds of pulses rank next to cercals in importance as vegetable foods. They are especially rich in nitrogen, the chief proteins being legumin or vegetable casein. They are also rich in starch, but deficient in fats. They are richer in salts than in cercals, especially in potash and lime, but poorer in magnesia and phosphates.

The leading points in the composition of pulses may bc stated as follows :-

\section{Advantages.}

Rich in proteins.

Rich in carbohydrates.

Rich in salts.

\section{Disadvantages.}

Deficient in fats.

Contain much cellulose.

Dried peas, like dricd beans, contain a large amount of nourishment. In this respect dricd beans, dried peas, and lentils are practically equal, the peas and lentils containing rather less fat and more cellulose than the beans. Dried peas are not readily digested. Very special care is necessary in the cooking, so as to promote digestibility.

The protein present is rich in sulphur, which tends to produce sulphuretted hydrogen and similar compounds, so that a leguminous diet tends to cause flatulence. Pulses are rather indigestible on account of the leathery external envelope which they possess when old. Hence they require prolonged cooking in order to promote digestibility. They require to be cooked in soft water, since the lime and 
magnesia found in hard waters form insoluble compounds with legumin. An analysis of the chief pulses is given by baner as follows, the average composition of wheat being griven for comparison :-

\begin{tabular}{|c|c|c|c|c|c|c|c|}
\hline & & Water. & l'rotein. & Fat. & Starch. & Cellutose. & Ash. \\
\hline P'eas & . & $14 \cdot 3$ & 22.6 & $I \cdot 7$ & $53 \cdot 2$ & $5 \cdot 4$ & $2 \cdot 6$ \\
\hline Beans & . & $13 \cdot 6$ & $23 \cdot 1$ & $2 \cdot 2$ & 53.6 & 3.8 & 3.5 \\
\hline Lentils & . & 12.5 & $24 \cdot 8$ & I.S & $5+\cdot 7$ & $3 \cdot 5$ & $2 \cdot 4$ \\
\hline Wheat & . & 13.5 & 12.4 & $1 \cdot 7$ & 67.8 & 2.6 & $1 \cdot 7$ \\
\hline
\end{tabular}

It will be seen from the above table that their nutritive value is considerable, especially as regards the amount of proteins. They are a cheap and efficient method of supplementing the cleficiency of nitrogen in a vegetable diet, and on account of the large amount of proteins they contain, they are admirably adapted as food for the poorer classes. Their defects as compared with the cereals are their relative indigestibility, their unsuitability for breadmaking, and their less agrecable taste. About 6 per cent. of the ingested pea passes out unchanged, and starch cells giving a blue reaction with iodine are found in the fres.

The pea mut is not a nut but a legumen. It resembles nuts in the large percentage of fat in its composition. It is used largely as a diabetic food, and it also enters largely into the composition of the patent food "Nutrose."

Peas._-Varieties of fresh peas.-Fresh peas are sweetish, and should be cooked by boiling in water with a little salt; when old they lose water, become very dry, and require prolonged steeping so as to soften them. When old they lose their colour, and copper is sometimes added as a preservative, and cases of copper-poisoning have been ascribed to this source. Garden peas are sometimes served up in an immature state, with the pods included, as "haricots rus."

Dricd peas are met with in two forms, the split yellow pea and the dried whole green pea. Split peas are chiefly used to make pea soup; or are ground into pea flour or pease meal, from which pease brose and pease pudding are made. Pease brose is made from the fine flour of the white pea by forming it into a mass merely by the addition of boiling- 
water and a little salt. It is eaten with milk or butter, and is a good nourishing article of dict specially suitable for persons of a costive habit. Pease pudding is made by soaking a quart of peas in water for twelve hours, throwing away those then found floating on the top. The peas are then drained into a pudding cloth, put into cold water, and boiled for two to three hours till tender. They are then rubbed through a wire sicve. About one and a half to two ounces of butter with some pepper and salt are then added to the mass, which is then tied up again in a cloth clusted with flour, and boiled for another hour, when it is ready for serving. This is a cheap food for persons of robust digestion, but the cost of cooking adds materially to the price.

Beans.-There are several varietics. The chief are :-

(I) The lidney or haricot bean.

(2) The broad or Windsor bean.

(3) The scarlet rumner.

Haricot beans almost rank first among vegetables as a nourishing article of diet. It holds its own against the beef and mutton of the animal kingdom. By most stomachs haricots are more easily digested than meat, while the comparative cost is greatly in favour of the former. The average composition of the haricot bean is as follows :-

\begin{tabular}{|c|c|c|c|c|}
\hline & & & & Per cent \\
\hline Water . & - & - & - & 13.6 \\
\hline Proteins & & - & . & . $23 \cdot I$ \\
\hline Fats & • & . & . & - $2 \cdot 2$ \\
\hline Carbohydrates & & . & . & $53 \cdot 6$ \\
\hline Cellulose & & . & . & $3 \cdot 8$ \\
\hline Ash . & & & . & 3.5 \\
\hline
\end{tabular}

Haricot beans are only good when fresh, and the younger they are the better. When old they require prolonged boiling. If old beans are not tender after half an hour's boiling they should be made into a purée or pudding, dishes which are only suitable for a strong digestion. They must be eaten immediately after cooking. A stew made up of one part meat with ten parts of haricots is a much more nutritious and wholesome dish than a stew of all meat and no haricots. They are very useful for thickening soup or using as a salad flavoured by adding tomato or similar 
regctables. lieans form the basis of a great many useful vegretarian dishes.

The "scarlet rmmer" is chiefly used as a green vegetable, being served up in the pods under the name of "haricots rus."

Soya beans are specially rich in proteins, contain a large amount of hat, but are deficient in starch. They are largely used as a bread substitute in diabetes. Several varieties of cheese are made from its vegetable casein.

Lentils are one of the most nutritious pulses. Their general composition is as follows :-

\begin{tabular}{|c|c|c|c|c|}
\hline & & & & Per cent \\
\hline Water. & - & . & - & . $12 \cdot 5$ \\
\hline Proteins & & . & . & . $24 \cdot 8$ \\
\hline Fats. & . & . & . & . $\mathrm{r} .8$ \\
\hline Carbolyydrates & . & . & . & . 54.7 \\
\hline Cellose. & . & . & . & . 3.5 \\
\hline Ash . & . & . & . & $2 \cdot 4$ \\
\hline
\end{tabular}

They contain little sulphur, and are therefore less liable to cause flatulence than peas or beans. They have the further advantage of being specially rich in iron. There are two kinds of lentils, German and Egyptian. The former are green or olive coloured, the latter are red and smaller than the German. The German lentils are very savoury, and have a "meaty" flavour. Either kind can be used for making cxcellent soup and purée; like all legumes, they require to be steeped in water for twelve hours before boiling. They are sold as split lentils and also as lentil flour. They are an cconomical as well as a highly nutritious food.

Reíalenta arabica is a patent preparation composed largely of lentil flour, mixed with pea or bean meal, to which oat and barley meal are sometimes added.

Butter beans resemble small haricots, but are finer and boil down more quickly. They make a rich white soup, and may be used for savouries. They are also very good as a simple stew. 
Fruits, Nuts, and Fungl.

\begin{tabular}{|c|c|c|c|c|}
\hline \multicolumn{5}{|l|}{ Fruite } \\
\hline Fruits - & & Nuts- & & \\
\hline General composition & . 105 & Composition of . & - & \\
\hline Varieties of . & . 105 & Varieties of . & & \\
\hline Chemical composition & . 106 & Fungi - including & mushrooms & \\
\hline Uses of fruit . & . 107 & lichens, and algx & $x \quad \cdot$ & \\
\hline Fruits in detail. & . 108 & & & \\
\hline
\end{tabular}

\section{FRUITS.}

Fruits, speaking generally, are composed largely of water, with starches, sugar, organic acids, pectin, cellulose, essential oils, and ethers. Some fruits contain a little protein, chiefly as albumin. Fruit sugars are sucrose and invert sugar, containing dextrose and levulose in equal amounts.

Fruits are valued chiefly for the water in them and the vegetable acids, free or in combination, upon which depend their valuable properties as antiscorbutics. These acids are chiefly malic acid in apples, tartaric acid in grapes, and citric acid, found in lemons, oranges, and kindred fruits. They are generally combined with potash or soda so as to form acid salts. The organic acids in the case of fruit are rich in potash salts, and contain also those of lime, magnesia, and iron; apples, and more especially strawberries, have also much soda. Fruits all contain pectin, or vegetable jelly, cellulose, and an insoluble substance-pectose-which, by the action of a ferment in the plant, is converted into pectin in the process of ripening. This pectin forms the main constituent of fruit jellies.

Fruits may be classified as follows :-

I. Apple, pear, quince.

2. Orange, lemon, lime.

3. Stone fruits-e.g., plum, peach, apricot, cherry, olive, date.

4. Acid fruits-e.g., grape, gooseberry, currant, cranberry.

5. Fleshy fruits-e.g., strawberry, raspberry, blackberry, mulberry.

6. Pineapple, banana.

7. Nuts.

The composition of the edible part of fruits is given in 
the following table. The carbohydrates include sugar and cellulose and vegetable grums. As a greneral rule, it may be taken that about 60 per cent. of the total carbohydrates consists of fruit sugrar or levulose :-

\begin{tabular}{|c|c|c|c|c|c|c|c|}
\hline & & & Water. & Protein. & $\begin{array}{c}\text { Carbo. } \\
\text { hydrates. }\end{array}$ & Cellulose. & Acids. \\
\hline Apples . & . & . & 82.5 & 0.4 & 12.5 & $2 \cdot 7$ & 1.0 \\
\hline Apricots & . & . & 85.0 & $1 \cdot 1$ & 12.4 & $\ldots$ & 1.0 \\
\hline Bananas. & - & . & $7+0$ & $1 \cdot 5$ & 22.9 & 0.2 & $\ldots$ \\
\hline Blackberries & . & . & $85 \cdot 9$ & 0.9 & $2 \cdot 3$ & $5 \cdot 2$ & $\ldots$ \\
\hline Cherries . & . & . & 84.0 & 0.8 & 10.0 & 3.8 & 1.0 \\
\hline Cranberries & . & . & $86 \cdot 5$ & 0.5 & $3 \cdot 9$ & $6 \cdot 2$ & 2.0 \\
\hline Currants . & . & . & $85 \cdot 0$ & 0.4 & $7 \cdot 9$ & $4 \cdot 6$ & $1 \cdot 4$ \\
\hline Figs, dried. & . & . & $20 \cdot 0$ & $5 \cdot 5$ & $62 \cdot 8$ & $7 \cdot 3$ & $1 \cdot 2$ \\
\hline Goosebersier & • & . & 86.0 & 0.7 & 8.9 & $2 \cdot 7$ & $2 \cdot 5$ \\
\hline Grapes & • & - & $79 \cdot 0$ & 1.0 & 15.5 & $2 \cdot \vdots$ & 0.5 \\
\hline Lemons & • & . & $89 \cdot 3$ & I.O & $8 \cdot 3$ & $\ldots$ & $\ldots$ \\
\hline Nectarines. & . & . & 82.9 & 0.6 & $15 \cdot 9$ & $\ldots$ & $\ldots$ \\
\hline Oranges & • & . & 86.7 & 0.9 & 8.7 & I. 5 & 1.0 \\
\hline Peaches & . & . & 88.3 & 0.5 & $5 \cdot 8$ & $3 \cdot 4$ & 0.7 \\
\hline Pears. & - & . & 83.9 & 0.4 & II.5 & $3 \cdot 1$ & 0.1 \\
\hline Pineapples. & . & . & $89 \cdot 3$ & 0.4 & $9 \cdot 7$ & $\ldots$ & $\ldots$ \\
\hline Plums & . & & $78 \cdot 4$ & $1 \cdot 0$ & $14 \cdot 8$ & $4 \cdot 3$ & 1.0 \\
\hline Prunes, dried & . & . & $26 \cdot 4$ & $2 \cdot 4$ & 66.2 & $\ldots$ & $2 \cdot 7$ \\
\hline Raspberries & . & . & $84 \cdot 4$ & $1 \cdot 0$ & $5 \cdot 2$ & $7 \cdot 4$ & 1.4 \\
\hline Strawberries & . & . & $39 \cdot 1$ & $I .0$ & 6.3 & 2.2 & $1 \cdot 0$ \\
\hline
\end{tabular}

In the following table there are given the proportions between acid, sugar, and pectin in some common fruits :-

\begin{tabular}{|c|c|c|c|c|c|}
\hline & & & Acid. & Sugar. & Pectin. \\
\hline Apples & . & . & I & I I 2 & 5.6 \\
\hline Apricots. & . & . & 1 & $1 \cdot 7$ & 6.1 \\
\hline Blackberries & . & . & I & 3.7 & I.2 \\
\hline Currants. & . & . & 1 & $3 \cdot 0$ & 0.1 \\
\hline Gooseberries & . & . & I & 4.9 & 0.8 \\
\hline Grapes & . & . & I & 20.2 & $2 \cdot 0$ \\
\hline Peaches. & . & . & I & $2 \cdot 3$ & II.9 \\
\hline Plums . & . & . & I & 1.6 & $3 \cdot I$ \\
\hline Prunes . & . & . & I & $7 \cdot 0$ & $4 \cdot 4$ \\
\hline Raspberries & . & . & I & $2 \cdot 7$ & 1.0 \\
\hline Strawber ries & . & . & I & $4 \cdot 4$ & 0.1 \\
\hline
\end{tabular}

When to eat Fruit.-The laxative effects of fruit are most obtained if the fruit be taken alone the first thing in the morning on an empty stomach, half an hour before breakfast, with a little water. 
The Uses of Frnits are as follows:-To supply nourishment-the greatest amount is contained in the banana, date, fig, prune, and grape, this being due to the large proportion of sugar which they contain.

They are thirst-quenchers, and supply water, the most watery fruits being melons, oranges, lemons, limes, and grapes.

They possess well-marked antiscorbutic properties, especially those which have an abundant supply of potash salts as well as lime and magnesia-e.g., apples, lemons, limes, and oranges. There is also a diuretic influence, partly due to the water, but chiefly to the organic acids and salts, which stimulate the circulation and also probably the activity of the renal epithelium.

The acidity of the urine is lessened or even made alkaline by the ingestion of fruit, the alkaline salts are broken up in the blood or tissue, and re-formed into alkaline carbonate and as such are excreted. Their laxative action is duc to the cellulose and seed, and to the special influence of their organic ingredients: the best fruits to attack constipation are fresh apples, figs, oranges, grape fruit, prunes, and peaches.

Their digestibility depends on the fruit, its ripeness, freshness, and the personal idiosyncrasy of the consumer. The most easily digested are grapes, oranges, grape fruit, lemons, cooked apples, figs, peaches. Somewhat less digestible are water-melons, prunes, pears, apricots, bananas, raspberries, currants, pineapples. The best for invalids are juice of lemons, oranges, baked apples, pulped stewed prunes grapes, and pineapple juice.

Preserving and Cooking of Fruits. - This is most commonly done by drying, or by making jam, just before they are fully ripe. Dried fruits arc more nourishing, but less digestible. Of these mention may be made of currants and citrons; figs, prunes, raisins, sultanas, and dates contain much nourishment; all are preserved in their own sugar (glucose).

Evaporated apples, pears, peaches are preserved by the evaporation of the excess of water which they contain.

When dried fruits have become too hard they can be softened by pouring boiling-water over them and allowing 
them to soak for a few hours. Stewed fruits are much used; the cooking sterilises and softens the fruit.

Fruits are made into jams and jellies. The fruit is boiled with equal weight of sugar in the making of jams, and in the making of jellies $I 4 \quad 0 z$. to $I$ lb. are allowed for each pint of juice. If the cooking is carried out successfully the jelly and jam should stiffen from the pectose present. These conserves are good for children, satisfying the natural craving of children for sweets. They are wholesome, and their flavour may encourage the eating of more nutritious but less agreeable flavoured food, such as rice, semolina, etc.

Fruit syrups are made with about half as much sugar as fruit juice.

Fruit soups are common in Germany, and are prescribed in fevers when there is no diarrhoa. Bauer recommends soups "made by boiling fresh or dried fruits with water, with or without sugar, lemon peel, and freed from all solid residue by pressure."

When fruits are exposed to the sun and to considerable changes in temperature, they are liable to decompose and undergo fermentative changes which make them injurious to health. Insufficiently ripe, or over-ripe, soft, decomposing fruits are ccrtain to cause diarrhœa, colicky pains, cramp, and sometimes nausea and vomiting. Gastritis may be induced in young people by indulgence in unripe apples, pcars, cherries. This condition is best treated by a dose of castor oil to remove the irritating matter in the intestines.

Group I.-Apple, Pear, Quince.-Good apples are a wholesome fruit. They are useful for their antiscorbutic and also for their laxative properties. They should be given to invalids only when cooked. When well masticated they are one of the best forms of fruits for children, being specially valuable for cleansing the tecth. They are better avoided by the diabetic. Crab apples are used to make a jelly, with a distinctive sweet acid taste and beautiful colour.

Pears and quinces are less digestible than apples, and should not be given to invalids.

Guavas are a wholesome and nutritious fruit. Thcre are many varieties. In the tropics they are used largely, and 
they are imported into this country in the form of a table jelly.

Grour II.-Orange, Lemon, Lime, and Grape Fruit.Oranges and other members of this family are specially rich in free citric acid, and their chief value in therapeutics lies in their well-known antiscorbutic properties. Sweet oranges are eaten raw. Bitter oranges are used for making marmalade. When oranges or lemons are wanted for flavouring, as in Russian tea or lemonade, the juice alone should be used. Orange juice is laxative, especially for infants. Small unripe oranges, known as orange-berries, are used in making curaçao. Lemon juice is useful in cleansing the tongue and assuaging the thirst in fevers. It is also of value for imparting flavour to otherwise tasteless foods, such as rice or barley water. (For Lemonade drinks, see p. 276.) Lime juice, sweetened and unsweetened, is used largely as a beverage, especially in warm weather The shaddock and grape fruit are useful for their laxative and slightly diuretic properties, when taken early in the morning. The somewhat bitter taste may be disguised by the addition of sugar and a little brandy.

Group III., Stone Fruits.-Plum, Sloe, Damson, Greengage, Bullace, Peach, Apricot, Cherry, Olive, Date, and Prune. -Damsons, greengages, bullaces, and sloes may be regarded as varieties of the plum. Plums are a wholesome fruit when wholly ripe and not over-ripe. If consumed in the over-ripe or unripe state they are very liable to induce colic, diarrhoea, and other evidences of gastro-intestinal derangement. A special variety of plum forms, when dried, the medicinal prune. Common prunes are dried plums, and are largely used in desserts; they are useful for constipation. The ratio of sugar to free acid in plums is low, $1 \cdot 6: 1$, but in damsons it is higher, $7: \mathrm{I}$.

Peaches, apricots, and nectarines do not contain so much sugar as apples and some other fruits, and are useful in diabetes. Peaches contain less than 2 per cent. of sugar. These fruits lo not keep well; their juice has a distinctly laxative action in many subjects. Cherries, in this country, are eaten fresh, stewed in tarts, or preserved. Cherry brandy is made by mixing brandy with cherry juice. Maraschino is 
similarly prepared, specially fine sugar being employed in its preparation.

Dates are the fruit of the date palm. They rank in nutritious value with grapes; dried dates contain from 50 to 60 per cent. of sugar and allied substances. The fruit is eaten fresh or dricd, and in the latter state is made into flour. It forms a staplc article of diet to the Egyptians. Figs, though hardly a stone fruit, may conveniently be referred to here, since they rank with dates in nutritive properties. Dried figs are a highly nutritious carbohydrate food, containing from 50 to 60 per cent. of carbohydrate and 3 to 4 per cent. of protein.

Olives are little used in dietetics exccpt as appetisers. The taste is an acquired one. Olive oil is largely used as a salad dressing.

Group IV., Acid Fruits.-Grape, Gooseberry, Currant, Cranberry, etc.-Grapes are specially rich in sugar, in this respect resembling dates. The amount of sugar present is always high, and ranges from 10 to 30 per cent.; the ratio of sugar and acid in good grapes being $25: \mathrm{I}$; and in slightly sour grapes, IO: $\mathbf{I}$. The acid in grapes is mainly tartaric acid, combined with potash, lime, and magnesium. Grapes have laxative properties. The "grape cure" is sometimes employed for constipation and obesity (see p. $53 \mathrm{~S}$ ). Raisins are dried grapes, and are prepared in two ways, the finest-Muscatels - being dried on the growing plant; other varieties-Uxias-being dried after collection.

Currants, raspberries, barijerries, gooseberries, cranberries, blackberries, mulberries, all contain considerable free acid. The ratio of sugar and acid is, as a rule, about $4: 1$, and they are therefore eaten with sugar. They are used to make refreshing beverages, or to make jelly or jam.

These may be usefully employed, especially in the feeding of children. The fruits in the following section also come into the caterrory of acirl fruits.

GRoUP V., lileshy Finits.-Stranberry, Rasplerry, Blackbermy, Mulberry.-The ratio of sugar and free acid in strawberries ranges from 2 to 1 up to 7 to $I$ in the pineapple 
strawberry. They are rich in potash and soda salts. When taken in moderation, they are a wholesome and very agreeable food. Many people have an idiosyncrasy against them, manifested by the development of urticaria or gastrointestinal trouble. Gouty subjects should partake very sparingly. Strawberries have special value in the treatment of sprue (see p. 369).

Group VI.-Banana, Pineapple.-Bananas are very rich in carbohydrate, and for a fruit contain also a high proportion of protein. A diet consisting solely of this fruit will maintain life for long periods. In its ordinary form, however, it is too bulky to serve as the staple constitutent of food. Dried bananas are now imported into this country, and form a pleasant, highly nutritious dessert food. Dried bananas are also ground into a meal or flour, which has valuable properties as a food. It can be made into a thin gruel or porridge, and when taken with cream is a very nutritious foodstuff. The cheapness of bananas is another point which adds greatly to their value as an important food. Torrefied bananas ground down make a coffee which is a wonderfully good substitute for ordinary coffee.

Pineapple is one of the less digestible fruits, on account of its fibrous nature. Its juice is pleasant and wholesome, and has the power of digesting protein. It enters into the composition of Mosquera's beef meal.

\section{NuTs.}

Nuts contain a large quantity of fat, protein, some starch, and very little water. The shell forms on the average about half the nut. Nuts are not easily digested, owing to the dense cellulose framework which surround the kernel of the nut. They can, however, be bought prepared (cleaned), and can be ground down; in both cases this renders them more easily digestible. Protoid nuts, prepared by Christian, are an excellent sample of a highly nutritious and easily digested food. Most of the nuts are eaten raw, but chestnuts and cocoa-nuts, almonds and walnuts are used also in confectionery. For some specially prepared nut preparations and butters, see Vegetarian Cookcry, p. 522. 
The composition of the common nuts is given in the followng table. Their very high proportion of fat and proteins make them a very valuable foodstuff if carefully employed.

Composition of Nuts.

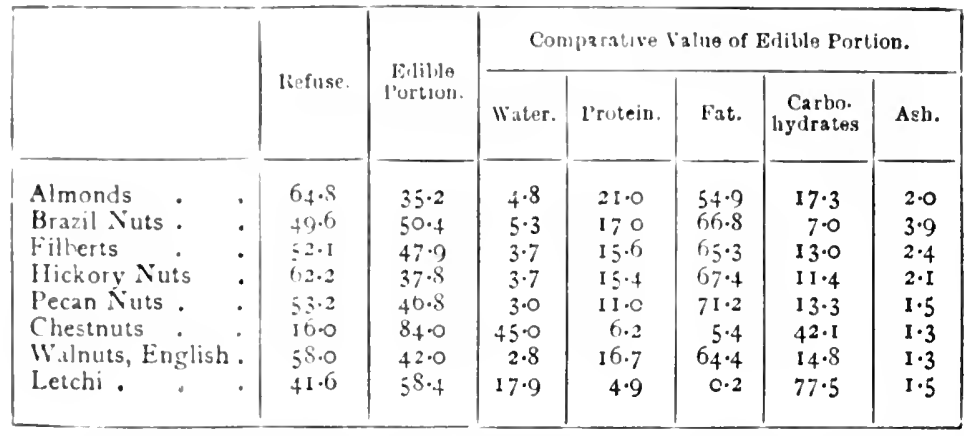

Almonds (swect and bitter) contain a large amount of fat and protein, but no starch and very little sugar. The small proportion of sugar makes them of great use in the treatment of diabetes. They are ground and made into almond cakes and biscuits. Salted almonds are eaten with dinner as an aid to digestion. Macaroons are a pleasant form of cake, composed of almonds and sugar. The bitter almonds contain hydrocyanic acid, and are only used medicinally.

II alnuts contain a large proportion of protein and fats; eaten freely between meals, they sometime have a very laxative effect. They are usually caten ripe and dry with dessert; the unripe fruit is made into walnut ketchup. The walnuts are taken before the shell has hardened; they are beaten to a pulp and the juice separated by straining; salt and vinegar are added, atso spices, and after considerable boiling down the ketchup is bottled and may be kept for years. The green walnut is used as a salad in France, mixed with onion, vincerar, salt, and pepper.

Chestnuts contain a small amount of oil and a large amount of carbohydrates. In Italy they form a valuable adjunct to the food supply. They may be boiled, roasted, or sround. When mixed with favourings and maize meal, they form prienta. Fiat cakes are marle from chestmut flour and water, and bakerl between flat strmes. The neal may be used for soups, puddings, and as the basis of the stuffing of poultry. 
Brazil nuts, pecan nuts, beech nuts, hazel nuts, hickory nuts, pine kernels, filberts, all contain much oil, and are imported in enormous quantities from Spain for the sake of their oil. Barcelona nuts are kiln dried before export, and keep indefinitely; if hazel nuts or their cultivated varieties, cobs and filberts, are not dried, they lose their flavour unless kept in airtight vessels. Butternuts easily become rancid after being shelled.

Cocoa-nuts are very indigestible even when thoroughly desiccated and grated. The nuts are eaten both ripe and unripe by the natives of the tropics, and the juice (cocoa-nut milk) is drawn out and drunk. They contain fully 70 per cent. of cocoa-nut oil or cocoa-butter, which is used as a food or for lighting and lubricating purposes. The butter is suitable for cooking, and can be used instead of margarine. Acorns are used as food in some countries. They are used like chestnuts, and like them contain starch. They are described as a very good fruit, savoury to the taste and healthful to the body.

Pistachio, a nut native to Syria, has a green-coloured kernel; it is much used on account of this for confectionery and for ices.

\section{Fungr.}

Fungi are largely employed as food in Southern Europe. They are eaten raw. They are also dried or preserved by cooking in vinegar, brine, or olive oil, which takes away the characteristic acrid taste of some of them. They are fairly rich in nitrogenous matter, but experimental observations have shown that this is imperfectly absorbed. They also contain fat, sugar (mannite and dextrose), fungic acid, and an acrid ingredient. They are used in this country chiefly for their flavour, and also for pickling and making ketchup.

A good brief description of the poisonous fungi is given by Knight as follows:-

Poisonous fungi are comparatively few, but as they closely resemble the edible forms, some distinctions must be observed. The common notion that poisonous fungi might be detected by discolouring a silver spoon, owing to the presence in them of sulphur compounds, is unreliable. The poisonous varieties are recognised generally by their high colour, scaly or spotted 
surface, and flesh cither tough or watery. They usually grow in clusters upon wet or shady ground. On bruising they show a play of colours and yicld a pungent mith, while their taste is bitter or burning the throat; on drying they become bluish. The poisonous matters in these belong to the class of narcotico-irritants, and cases of poisoning are best treated by the free use of emetics and castor oil. Edible fungi, on the other hand, are seldom high-coloured, scaly, or spotted, but are generally red or brownish. They break with a brittle fracture, retain their colour on drying, and grow best upon open, dir pastures. They have an agreeable smell and taste, but in some species any acrid taste may be dissipated by heat.

The chief edible fungi are the common mushroom generally used for making savouries and ketchup. The latter is made from the common mushroom by breaking it into small pieces and mixing with salt, which reduces it to an almost liquid state, then straining and boiling down to half the bulk. Spices of different kinds are added, and occasionally wine.

Lichens.-Iceland moss is a lichen found in Arctic regions. It contains 70 to So per cent. of a starch (lichenin) which is not very casily digested. Its nutritive value is therefore of a low order.

Algæ.-Irish or carrageen moss is a seaweed. The chief ingredients present is a vegetable jelly, the chemical composition of which is not fully known. It is specially noteworthy for the manufacture of a pleasant drink, made by adding cold water in the proportion of half an ounce of carrageen and 3 pints of water, then boiling and straining. It may be flavoured by spices if desired. If more carrageen is employed, the result is a mucilage which yields a jelly on boiling, which may be used as a nutritious and pleasant article of food which is fairly easily digested.

\section{B. Roots and Tubers.}

The roots and tubers used for food comprise the potato, turnip, carrot, parsilip, artichoke, onion, with the different plants yiclding arrowroot, tapioca, and sago. The main nourishment of these plants is stored up almost entirely in the form of carbohyclrates, chiefly starch. They contain very 
little protein and fat, and are therefore vastly inferior in nutritive value to the cereals and pulses. Some of the members of this group contain vegetable acid chiefly combined with potash, and these salts give them their recognised antiscorbutic properties. A considerable amount of the salts, however, is usually lost in the process of cooking.

The potato is the most important member of this group. About 95 per cent. of the potato consists of water and starch, the rest of the solids being made of fibre, sugar, vegetable jelly, and pectin. It is very poor in nitrogen, and contains practically no fat. The richness of the potato in starch-about 20 per cent.-is its most marked characteristic, starch being largely extracted from potatoes for commercial purposes. Of the total amount of nitrogen in potatoes only one-half is in the form of protein, the remaining half being in the form of ammonia compounds, e.g. asparagin, which are not available for food. Owing to this poverty in protein and fat, potatoes are not suitable as an exclusive food, but they are a valuable adjunct to other foods rich in nitrogen. In the process of cooking the albuminous juices are coagulated, the starch granules swell up and absorb the watery juices, and the potash assumes a mealy appearance. In this form it is easily digested. If the changes described do not take place, as happens with young potatoes, the potato has a more solid and waxy consistence, and in this form is much less digestible. As ordinarily cooked, some of the salts are lost, and to avoid this potatoes should be cooked in their jackets, or else steamed. The relatively large amount of alkaline salts in potatoes makes them specially useful in the treatment of scurvy.

The sweet potato is not used as an article of diet in this country, but is largely used in France, Spain, and the United States. It contains about I6 per cent. of starch, and Io per cent. of sugar. It is too sweet to eat with meat as a vegetable. It is a most wholesome article of diet.

The yam is a tuber of a tropical climbing plant. It contains much starch. When cooked it bccomes mealy and like the potato in flavour.

Beetroot.-Beet contains so to 90 per cent. of starch and 
sugar, and is one of the chief sources of cane sugar. Young bects are eaten boiled, and served with salad or eaten with vincgar.

The tums. - The nutritive value of the turnip is very sinall. It contains about 91 per cent. of water, and 5 to 6 per cent. of carbohydrates, chicfly in the form of pectin bodies, and about I per cent. of nitrogenous substances, most of this being in non-albuminoid form. Turnips have a marked tendency to cause flatulence.

Carrots are more nutritious than turnips, having about $S$ to Io per cent. of carbohydrates, chiefly in the form of sugar. They are not readily digested nor easily absorbed.

Parsnips closely resemble carrots in composition. They are rich in starch and sigar, the latter being largely lost in the process of cooking.

Jerusalem artichoke is a tuber. Like turnips, it contains no starch, but is rich in carbohydrates, chiefly a variety of sugar belonging to the gummy series. It has a sweet taste, and remains watery after cooking. It is of no great importance as a food, but is of value for making good soups and sauces.

Onions are of value both as flavouring agents and as vegetables. They impart a strong typical odour to the breath, due to the presence of a pungent oil. The large Spanish onions are used as food. They have a moderate laxative action, due to their richness in cellulose.

Armaroot is derived from the tuber of a West Indian plant (Haranta amolinacea). The roots are dried and pulverisecl to a fine starchy flour, which consists of practically pure starch, with $\mathrm{I} 5$ to 20 per cent. of water. Its quality is judged by its whiteness, and by the ease from which there is made from it a firm, transparent, pleasant-tasting jelly, which remains firm and of good taste for three to four days.

It is easily digested and very completely absorbed, and is therefore of special value in the treatment of diarrhoea and some gastro-intestinal derangements. In cases where there is clifficulty in digesting starches or sugars, arrowroot is an unsuitable food. It is also used to thicken clear meat soups and extracts.

Tapioca.-Tapioca is also a pure starch obtained from 
the tuber of Wanihol ulilissima, cultivated in South America. Its grains are small. It contains over $\$ 5$ per cent. of starch. It is not quite so easily digested and absorbed as arrowroot. It is useful for adding to soups, and for making into pudding with milk.

Sago is another starch obtained from the pith of the stems of several species of palm. In its composition and uses it is similar to tapioca.

\section{Stems and Leaves-Green Vegetables.}

Green vegetables are even less nutritious than roots; and are chicfly valued for their mineral salts, especially salts of potassium, and as a source of ballast, their indigestible residue stimulating intestinal movements. These vegetables contain about 90 per cent. of water and only from $I_{2}^{1}$ to 3 per cent. of nitrogenous matter, probably only half of this consisting of protein (sec table). In addition they contain cellulose in large amount, chlorophyll, sugars, gum, pectin, and sometimes traces of fat.

Composition of Vegetables.

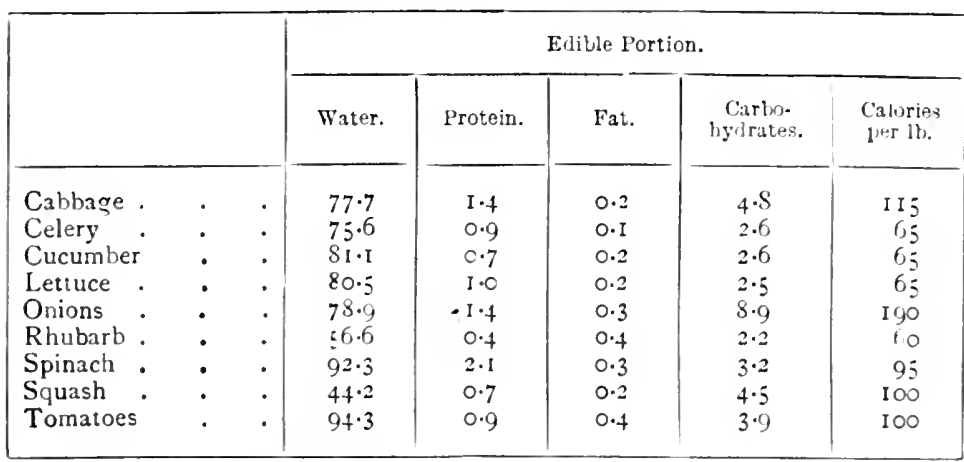

The young vegetable has a bitter flavour and is more digestible than an old one. As age advances they become tough and stringy from the increase in cellulose. Their digestibility is increased by careful cultivation in suitable scril. They should be eaten fresh, for owing to the large quantity of water which they hold, they soon dry when stored, and so loose their freshness. Celery and winter cabbage are exceptions, as they may be kept for weeks. Before use they should be carefully cleaned, not only by removal of dead and 
decaying parts, but by careful washing and soaking in salt and water: the latter to kill any embryos of tapeworms, etc.

Vegetables as a whole are not very easily digested, on account of the large amount of cellulose. In the process of cooking, vegretables gain much water and lose some of the carbohydrates and proteins, and much of their salts. As the nutritive value and digestibility of vegetables depend largely on their careful cooking, and special attention should be clirected to this, a short account of the best methods of preparation is given later (p. I22).

The Crucifere tribe of green vegetable, to which the cabbage and its varictics belong, furnish a large proportion of the vegetables for table use.

Cabbages. - There are many varicties, but they all contain a large quantity of sulphur, which tends to cause flatulence, hence they are not suitable for invalids. When fresh and tender, cabbage is a wholesome food for the healthy, and has decided antiscorbutic properties. When young, they can be caten raw with vinegar. They may be used in broth, or boiled and made into a purée.

Cauliflower is the flower of a variety of cabbage grown large and tender by cultivation. It is one of the most easily digested green vegetables. It is boiled and eaten with white sauce or cheese sauce; or if shredded down and dressed with vinegar and oil, it can be added to salad, and it is also used as a pickle. Broccoli is a variety of cauliflower, but inferior in flavour.

"Greens" or Kale have open heads" of leaves. German greens are the most delicate. They should be boiled and mashed like cabbage.

Seakale are the tender young sprouts of the sea cabbage grown in the dark, so that there is no chlorophyll. The presence of the green colouring matter gives a disagrecable acrid taste. When properly cultivated they are as easy to digest as the cauliflower.

Brussels sprouts are clusters of leaves resembling miniature cabbages growing in the axils of the main leaves. They are very nice when thoroughly cooked.

Savoy is another variety of cabbage.

Sauevkraut, a German dish. The leaves of the white 
cabbage, when fully grown, are taken out, layers of salt lairl between them and pressed; this bruises the leaves and squeeres out the juice; it is then set aside until fermentation commences. It is generally eaten boiled, like fresh cabbage.

Celery is much cultivated for the blanched leaf-stalks or for the root. It is eaten raw, alone or in salad. It nuy be cooked in milk and used as a vegetable, or used in the flavouring of soup. It can also be made into a puréc, and used as celery cream.

It is not casily digested, but its aromatic flavour makes it very popular. Celery salt and celery sceds are much used as flavourings. It has a great reputation for rheumatism; the reason for this is not quite clear.

Green artichole.-A cultivated thistle. The heads are cut before they expand. They are either boiled or eaten raw with salt and pepper. The vegetable contains tannin, and is easily digested, but has a curious flarour and is not in common use.

Asparagus is considered a great delicacy, and was even cultivated by the Romans. There are two varieties, white and green-the green is probably the finest. This vegetable possesses a very delicate flavour, and is much appreciated by invalids. The seeds are sometimes used on the Continent instead of coffee. The ingestion of asparagus has a diurctic effect, largety increasing the quantity and imparting a strong and disagreeable odour to the urine; it appears within one hour after it is eaten, and may persist from twelve to twenty hours. It is due to a sulphur product, a methyl mercaptan which is formed in the intestine during digestion and is excreted by the urine.

Spinach is a favourite vegetable, but contains no nutriment. It is used for improving the complexion, and it is certainly of benefit in relieving chronic constipation. If the leaves are young and tender, and if they are cooked until they are quite soft and then rubbed through a sicve, it is a very easily digested vegetable.

"Beet tops" turmip tops, and dandelion leaves can all be used in the same way as spinach.

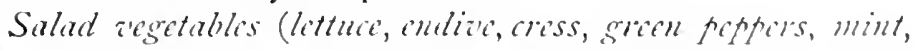
tarragon, parsley, cherril, borage, chive, horse-ralish, ite.). This 
is a sroup of regetables, lettuce being the chief type, the leave of which are caten raw. These are not very easily digested, they are cooling, antiscorbutic, nutritious, and gently laxative. They furnish a pleasant varicty during a meal. They are usually eaten with oil and vinegar or some other salad dressing. Some of these salad vegetables are used for pickles and relishes as well as for salad. They stimulate the digestive secretions and give a fllip to the appetite.

Union fimily are all nutritious-containing a quantity of nitrogenous matcrials and sugar in the colloid form as well as a pungent oil rich in sulphur, to which they owe their pungency and smell. The parts used are the bulb, young leaves, and seedlings.

Onions when scalcled, i.e., covered with boiling-water and a pinch of salt, are not nearly so strong in flavour as unscalded ones. Boiling makes them much milder in taste than when raw. Onions are valuable as blood-purifier. They are clible as fresh vegetables, e.g., spring onions in salads, and after long keeping are useful as flavouring agent for salads, stews, and soup, etc. There are a good many varieties.

The onion proper is of two sizes: the strong, small, onion largely used for flavouring; and the Spanish onion, much milder in flavour. Syboes are the young seedlings, and much esteemed for soups and stews. Shallot or eschalot is a delicate onion with a strong taste, but wanting the pungent smell of onion. Chizes, a smaller variety, where the lcaves and bulb are both used. The Welsh onion or cibot is larger than the chive, and is also valued for its tender leaves. Leek bclongs to the same class, and the leaves and bulb are also both used.

All onions impart a strong typical odour to the breath. It appears in two or three hours, and may persist for twentyfour hours or more. This is due to volatile substance absorbed by the blood from the digestive tract and excreted by the lungs.

Garlic belongs to the onion family, but instead of having a bulb it is composed of small bulbs known as "cloves." In Spain it forms part of every dish, and is very nutritious. Used as a condiment, it is stimulant and tonic and aids digestion. Garlic odour is due to oil of garlic, which is a sulphide of allyl, found also in watercress and radishes. 
Rhubarl is composed of the stems of the leaves, and is used more as a dessert, being eaten with sugar and cream. Its flavour is tart; cooking renders it soft and easily digrested. It tends to produce calcium oxalate in the urine when eaten to excess, and it is not good lor suuty and rheumatic people.

Tomato, although a fruit, is generally used as a vegetable. It is becoming very much appreciated. It may be caten raw with green salad vegetables, or alone with pepper and salt; it can be baked, fried, stuffed, and used in innumerable ways. The skin should be avoided, the pulp only being eaten. As a flavouring agent, such as tomato sauce, tomato ketchup, tomato beans, an enormous amount of tomatoes are canned every year; they retain more of their original flavour than do most other vegetables treated in this way.

Egg plant is allicd to the tomato, but contains many seeds and is not so casily digested.

Vegetable marrow is the best-known member of the gourd family in the British Isles. The pumpkin is a large-sized variety, and so is the squash. Marrow is a succulent wholesome vegetable with an agreeable flarour. It may be baked, boiled, or stuffed, or made into prescrves. It is an easily digested vegetable.

Cucumbers are mainly caten raw, they are generally used in salad. Immature young cucumbers are pickled as gherkins. Cucumber may be cooked and served in the same way as vegetable marrow, and is then easily digested.

Melon is more of a fruit, but belongs also to the cucumber family. It is more a drink than a food, since the solids only amount to 5 per cent. The juice of the water-melon makes an agreeable cooling drink. Melons are caten raw either with sugar or with ginger and pepper. The seeds of the Indian melon (kaukoor) contain a great deal of starch and vegetable fat; they are ground into meal.

In health, vegetables, and especially green vegetables, should enter into the daily dictary, as their richncss in alkaline salts malies them a useful food, and at the same time gives them valuable antiscorbutic propertics. As has been indicated, their nutritive value is very low. Their relative indigestibility, on account of the large amount of cellulose 
present, and liability of the latter to undergo abnormal fermentation, restricts their value as a food for invalids.

The following are a few good methods of preparing vege. tables for those with weali digestion :-

\section{Spinach.}

One of the most easily digested regetables if properly cooked. The preliminary difficulty in thorouglyly cleaning spinach and the removing of the tough stalks are the two important points in its preparation. It also recluces cnormously in cooking, and $I$ lb. will make a very small dish. Doulnle the leaves lengthways and strip off the stalks, then wasls the spimach thoroughly in several waters until all the grit is removed; place it in a saucepan zuthout any water except that which adheres to the leaves, sprinkle it with salt, and put the lid on the pan. Spinach is the only green vegetable which is cooked with the lid on the pan, as no water is used. Were the lid off, the spinach might burn from evaporation. Cook until it is quite tender for twenty or thirty minutes, stirring it occasionally with a spoon. When ready, drain off the water in a fine wire sieve with a basin below, then remove the basin and rub the spinach through the sieve on to a plate. Scrape the sieve well beneatl. Return the spinach to a saucepan with a small piece of butter, pepper and salt, stir over the fire until thoroughly hot, add a squeeze of lemon juice or a little cream. This can be eaten with small pieces of toast or fried bread. If served with a poached egg upon it, it forms a very light and easily digested dish.

\section{Boilid Lettuce.}

Wash a couple of lettuces thoroughly, and remove any discoloured leaves, or let them lie in water for a short time. Drain the water off and put them in a pan of boiling water and a little salt. Boil quickly for about twenty minutes, when they should be quite tender. Keep the lid off the pan. Remove any scum that rises. When cooked, drain, and chop up the leaves on a board. Return to the saucepan with a small piece of butter, pepper, and more salt if required.

\section{Tomatoes.}

These have most flavour when baked, but can be boiled or stewed. Wipe them first and remove the stalks. I'ut them on a greased baking tin or freproof dish, a little pepper and salt, and cover with a piece of greased kitchen paper. lake for ten minutes until they feel soft; lift on to a clean hot dish, and serve.

\section{Steamed Asparagus.}

Trim the asparagus, and steam by putting it in a jam-pot nearly filled with boiling water, placed in a large saucepan half-full of boiling water and lightly covered. The asparagus will take nearly an hour to 
cook in this manner. Serve with a sauce made of $\mathbf{I}$ nunce of melted butter, I tablespoonful of cream, the yolk of an egrg, and 5 drops of lemon juice. Stir the mixture for a few minutes over the fire until thoroughly warmed.

$$
\text { Celery', Seakale, Young Leeks. }
$$

For celery, choose it when fresh and crisp. Remove the coarse outside leaves, as they can be used for flavouring. Put away the root, separate the stalks, wash and brush them well in cold water, and scrape off any brown or discoloured parts with a knife; cut the stalks equal length, tie them together with tape (string would cut througly), and throw them into a basin of clean water, and allow to soak in this for a few moments before cooking.

To cook all these vegetables :-

Place in a saucepan of freshly boiling mixture of equal parts of milk and water and a little salt. Boil with the lid off for about half an hour, when they will be quite tender. Drain well, remove the tape, and serve on a small piece of toast. This is not meant to be eaten, but it is for the purpose of more thoroughly drawing the moisture from the vegetables. All these vegetables can be served with a little well-made white sauce poured round them. If improperly made this sauce is a compound of uncooked flour and milk, and is indigestible.

\section{White Sauce.}

$\frac{1}{4}$ ounce butter. $\frac{1}{4}$ ounce flour.
I gill of milk or white meat stock.

Squeeze lemon juice.

\section{Pinch of salt.}

Take a small lined saucepan; rinse it out first with cold water to prevent the sauce sticking to the foot of it, and melt in it the butter cver the fire, being careful it does not brown. Then add the flour, and mix with a wooden spoon until smooth; cook it for a minute or two over the fire to give it a glossy appearance. Draw the pan to the side of the fire, add the milk or stock, and then stir constantly over the fire until boiling. Boil for two or three minutes in order to thoroughly cook the flour, and season to taste.

\section{Cauliflower.}

Select a young cauliflower with a firm close head. Trim off the thick part of the stalk and nearly all the leaves. Split the stalk, so that the water may get in and cook it well. Wash in cold water, and let it lie in fresh water and $\mathrm{I}$ teaspoonful vinegar to draw out any insects. Have on the fire a deep saucepan three-quarters full of briskly boiling water, add salt to it, and put the cauliflower in head downwards. Let it boil from twenty minutes to half an hour, until the flower feels tender but nct broken up. When ready, lift it out and drain for a minute or two on a sieve, and then serve with white sauce or white sauce and grated l'armesan cheese. 


\section{Oninns.}

Spanish onions are by far the best for eating as a dish, the flavour not being so pungent. W'hen onions are plain foiled they are best served on dry toast without any sauce. A large Spanish onion takes about three hours' boiling to become tender. To bake onions, the onion should be partly boiled, and then placed on a baking tin with a little butter and basted occasionally. When finished they should be of a nice brown colour. If softened by two hours' boiling, one hour in the oven will be sufficient. To stew, place a large Spanish onion in a saucer at the hottom of the saucevan, and put sufficient equal parts of milk and water to reach the edge of the siucer. Keep the lid of the saucepan tightly closed, and let it steam about three and a half hours until quite tender. The water trom the onion will prevent the necessity of adding fresh water.

\section{Tegitable Marrou.}

Wash the marrow, cut it in quarters, remove the seeds, and peel it very thinly If large, cut it into neat-sized pieces and throw them into cold water until wanted. I'lace the marrow into a saucepan of salted water ( 1 dessertspoonful of salt to the quart). Boil gently with the lid on the pan for half an hour or more until the marrow feels tender when pierced with a fork. Drain well in a colander, and serve in a hot vegetable dish with white sauce poured over it. The marrow may be boiled in milk, the milk afterwards used for making the sauce. 


\section{CHAPTER VII}

MINERAL CONSTITUENTS OF FOOD-FOOD ACCESSORIES

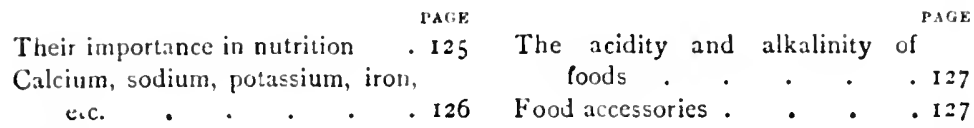

MINERAL salts are of very great importance in nutrition. This will readily be understood if we bear in mind that analysis of the tissues yields 5 per cent. of ash. Death occurs in a few weeks if salts are cut out of the diet. The two most important salts are calcium phosphate, which enters largely into the composition of bones, and sodium chloride, which occurs in all the tissues and fluids of the body. Mineral substances are of great value as tissue-builders, and indirectly are sources of energy. We have no very precise knowledge as to the exact amount required daily, but we know that an ordinary mixed diet contains sufficient for the body requirements. Salts enter the blood in organic combination, and much importance attacines to the special form in which the different mineral substances are combined with the other food constituents. They pass into the blood as a rule unchanged by digestion. The chief mineral constituents are calcium, sodium, potassium, magnesium, and iron; phosphorus, chlorine, and sulphur; traces of silica, iodine, fluorine.

The chicf uses of the salts may be summarised as follows :-

I. They enter into the composition of the tissues, e.g. the bones and teeth.

2. They subserve special functions, such as the iron in hamoglobin, calcium in coagulation of the blood, and 123 
sodium chloride in the production of hydrochloric acid in gastric digestion.

3. They exercise a powerful influence on the chemical composition of the blood, this being effected by their influence on processes of sccretion and excretion.

4. They control the rate of absorption by osmosis.

The order in which foods stand as regards richness in salts is as follows :-

(1) l'ulses and cereals rank first; (2) vegetables; (3) meat comes next; and (4) fruits and nuts contain the least amount of salts.

Cralcium.-Foods rich in lime are milk, cggs, cereals (especially rice), vegetables (especially asparagus and spinach), and clrinking-water, when that is of the hard variety. Foods poor in lime are meat, fish, potatoes, and fruits. An adequate supply of foods rich in lime is essential, and more especially during the growing period. Deficiency of lime leads to softness of the bones, and changes of a rachitic-like nature. Excess of lime salts in the diet is supposed to predispose to renal and vesical calculi. Reference may here be made to oxalic acid, which is present in food as oxalate of lime. It occurs specially in tea, coffec, rhubarb, spinach, and pepper. Cereal foods contain little; this knowledge is of value in the treatment of calculus.

Sodium and Potassium.-Salts of sodium are specially required for the fluids of the body, salts of potassium for the cellular constituents, notably the red-blood corpuscles and muscles. Vegetable foods are, as a rule, rich in potassium salts; animal foods, on the other hand, have a larger proportion of sodium salts. Green vegretables and fruits are the chief sources of these salts, these foods being valuable on account of their containing vergetable acids with which the minerals are combined, the presence of the salts tending to maintain a proper degree of alkalinity of the blood. A deficiency of alkaline salts in foods leads to scurvy. Sodium chloride is the most important salt. It supplies chlorine for the production of the hydrochloric acid of the gastric juice, it stimulates appetite, it promotes renal secretion, and it induces thirst, which is of value in encouraging the drinking of fluid. On an average mure than 10 grammes are taken in the daily 
dictary, this representing an amount which is far in excess of the actual body requirements. This excess of salt above the real requirements is more particularly observed in people who live largely on vegetarian foods. There is an ample supply of salt in a mixed dict without adding salt as an extra. There is no certain evidence that the excess of salt ordinarily taken is on the one hand of special value, or on the other injurious. The therapeutic effects of a salt-free diet are described on p. $4 \mathrm{I} 6$.

Iron.-Beef, eggs, oatmeal, and lentils have a relatively large amount of iron; milk and its derivatives are poor in iron. A prolonged milk regime leads to anæmia in some people. Iron exists in food in organic combination. A knowledge of the amount of iron in the food is of little practical value, since we cannot influence the state of the blood as regards iron by that means alone. Iron is of value in chalybeate waters.

Phosphorus. - Mcat and vegetables are rich in phosphorus. It occurs usually in organic form, and to a less extent in inorganic form as phosphates of the alkalis and earths. It is especially valuable for growing children.

\section{Acidity and Alkalinity of Foods.}

Foods may be classified according to the reaction of the ash left after incineration, into acid, neutral, or alkaline foods. Foods which give an acid reaction include meat, oats, barley, wheat, eggs, and rice; an alkaline reaction is given by milk, peas, and beans, potatoes, lemon and orange juice; animal fats and sugar have a neutral reaction. According to Wright, a deficiency of foods which yield an alkaline ash is a cause of scurvy.

\section{Food Accessories.}

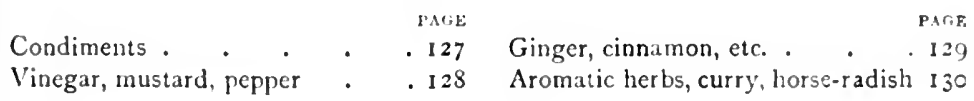

\section{Condiments.}

A large number of sapid substances are added to the foods to stimulate the saliva and gastric juices. They add flavour, and relieve the monotony of dict. 
It is casy to fall into the habit of taking condiments to cxcess, especially vinegar, pickles, and strong curries. This is sometimes met with in the case of Anglo-Indians. If used in excess they may over-stimulate gastric secretion and derange the intestinal digestion.

\section{Flavourings.}

Those in enmmon use are salt, vincgar, mustard, pepper.

linegar.-Among all the different condiments there is none so uscful as vinegar. Its flavour is stimulating, and in addition vinegar has an important action in softening the fibres of hard meat and the cellulose of green vegetables hence it is eaten with lamb in the form of mint sauce, with salmon as vinegar sauce, and is also added to salads. Vinegar is acetic acid; it can be made from wine, beer, various fruits, and from the distillation of wood. Good French vinegar contains 5 per cent. of acetic acid. Genuine vincgar is produced by oxiclation of alcohol by a fungus (Mycoderma acti); wood vinegar is produced by the destructive distillalion of wood, the product bcing often coloured by burnt sugar. This lacks the volatile ethers which characterise pure vincgar. Malt vinegar ought to be made from the fermentation of malt, but it is frequently made from dilute spirit got from sugar or molasses. Vinegar has also an antiscptic and preservative action-and it is largely used for pickling fish, oysters, and vegetables.

Vinegar enters largely into sauces-Worcester sauce, Yorkshire relish, ketchup, etc. These are useful to give flarour to an insipid dish, or to add to soup. Taken in moderation they are harmless. For invalids for whom strong sauces are not desirable, a little harmless flavouring can be added to the food by boiling a few aromatic herbs, e.s., parsley or mint with water, adding pepper and salt.

Mustard simply stimulates the salivary and gastric glands, and thus increases the digestive juices. Mustard owes its propertics to an oil of mustard which is in combination with a nitrogenous ferment; from these, on the addition of water, the oil is gradually formed, hence mustard should be made freshly so as to secure the full flavour. It is used to 
advantage in moderation in salad dressings and with cold meat. Mustard seeds ground would be unpalatable, hence the commercial article is always diluted with starch. Its use as a counter-irritant applied to the skin is well known, and a useful cmetic can be readily prepared by adding a tablespoonful of mustard to a tumbler of lukewarm ivater.

Pepper occurs as peppercorns, the natural berrics in their dried and shrivelled state; also as black pepper, where the whole berry is dried and ground for use. White pepper is made from the same berry, ground after the outer husk has been removed. The pungent property is clue to a volatile oil containing peperine; this is more irritating than oil of mustard.

Cayenne pepper is made from the crushed pod of various species of capsicum. The red pods of the capsicum are used in pickles, and are called chilies. It is a strong irritant to both skin and mucous membrane. It is generally eaten with raw oysters and whitebait. It is used as a substitute for alcohol for dipsomaniacs, and is used as a tincture to relieve the drink craving.

Spices are solely of value in griving variety of taste to food. Tasteless farinaceous foods can be made attractive by spicing. The simplest flavourings are vanilla, ginger, and cimmamon, and these may be used for invalids and children.

Ginger is a rhizome or underground stem; it contains starch, which malies the substance a food as well as a condiment.

The rhizome is scraped and dried, and sold as "root ginger," or it is afterwards powdered and sold as powdered ginger. The young roots boiled and preserved in syrup constitute preserved ginger, or if the substance is boiled in sugar it becomes crystallised ginger. Ginger owes its properties to oil of ginger, from which the essence of ginger is made; this is much used in flavouring and in the making of ginger beer, syrup ginger, and acrated water. Homebrewed ginger beer is made from ginger roots, sugrar, lemons, cream of tartar along with yeast, and bottled before fermentation is complete. Ginger wine is made like ginger beer, with the addition of spirit, and, like true wines, improves with 
kceping. Its action may be described as stimulating and carminative.

Cinnamon.-An aromatic; it owes its properties to oil of cinnamon, which is got from the bark of a small tree. Its action is tonic, stomachic, and carminative; it is also a strong disinfectant and germicidc. Its odour and flavour are delightful, and it is used medicinally and as a flavouring agent.

Nutmegs and mace are got from the same plant. Mace is the surrounding membrane of the nut. They are aromatic substances imparting a very characteristic flavour.

Cloves are flower buds of a plant taken and dried. About one-fiftl or one-sixth of their weight consists of oil of cloves, and to this they owe their hot taste and characteristic smell.

Allspice-Jamaica pepper, or pimento, is a fruit grown in the West Indies. The name comes from the aroma resembling a mixture of cloves, cinnamon, or nutmeg. Like cloves, it is aromatic.

Caraway seeds are from an umbelliferous plant; they are carminatives and tonics. Oil of caraway is given for flatulence. They are used in confectionery and for flavouring cordials.

Coriander secds are carminative and aromatic, and used in the same way as caraway seeds.

Vanilla is obtained from vanilla beans, the pods of an orchid grown in Mexico and other tropical regions. Its cssence makes a very agreeable flavouring agent for puddings, custards, and ices. Its chief use is in the manufacture of chocolate.

Aromatic herbs are used for flavouring in various ways. These are: parsley, chopped and added to soup or sauce; mint, either spearmint, used in mint sauce, or peppermint, an aromatic carminative much used; thyme and marjoram, used for seasoning; sage, chiefly used in the stuffing of geese; dill, a member of the umbellifera-the leaves are used to flavour pickles, and the fruit made into dill water makes a favourite carminative for infants; fermel is another herb of the same family, used as a flavouring for salads and sauces.

Curry powders of various sorts are prepared by mixing 
strong aromatics and condiments with starchy substances. It owes its peculiar odour and bright colour to the presence of turmeric, a varicty of ginger largely cultivated in the East Indies. Thorough cooking is absolutely necessary to develop the full flavour of the various ingredients in curry powder. Two recipes for curry powder may be given (Knight):-

I.

Turmeric powder .

Coriander seed powder

Black pepper . . 4 "

Fenugreek . . . 2 "

Ginger . . . 2 "

Cayenne . . . $\frac{1}{2}$ "

Cinnamon seeds . . . $\frac{1}{2}$ "
2.

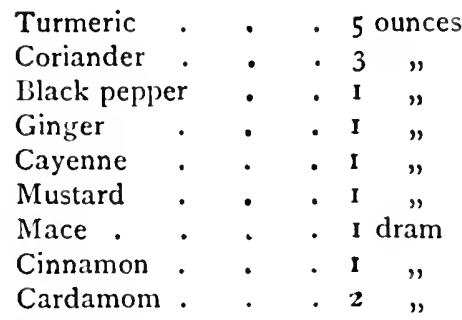

Horse-radish is a condiment which increases the saliva; may be eaten shredded down with meat or oyster, or made into a piquant sauce. 


\section{CHAPTER VIII}

HEVER.ALS-W.TTEK-AERATED WATERS-TEA, ETC.$\triangle \mathrm{LCOHOL}$

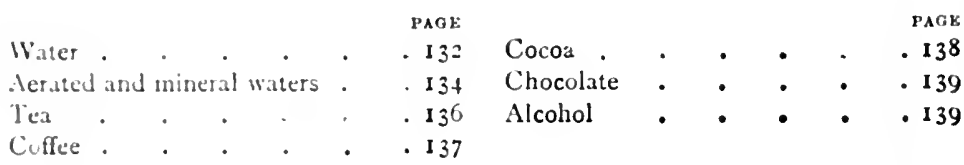

Water.-Water is indispensable to life. About twothirds of the total body-weight is composed of water, and water also enters largely into the composition of all foodstuffs. It is useful as a solvent, carrying nutrient material to the tissues and effete material to be eliminated by the kidneys and skin.

Daily requirements.-On an average, about 4 pints of water may be taken as the daily requirements of the tissues, of which about one-fourth is ordinarily taken in solid food. The best way of supplying water to the body is by drinking it in its pure state, when its useful solvent and eliminant properties can be fully utilised. The equivalent of the 4 pints ingested is excreted daily, 50 per cent. being voided in the urine, about 28 per cent. by the skin, 20 per cent. by the lungs, and 2 per cent. by the faeces. The amount of water required daily in fluid form varies with the amount of loss by the excretory organs, skin, kidneys, and lungs; and this in turn depends to an important extent on the outside temperature, on the amount of muscular activity, and on the nature of the food. In hot weather there is a free diaphoresis, and more fluicl is called for ; whereas in cold weather the skin is less active, and less fluid is necessary. Active muscular cxercise promotes diaphoresis and diurcsis, hence 
abundance of nuirl is desirable. If the rlict is a solid and dry one, and rich in nitrogen, more water is necessary, in order to eliminate the extra amount of urea and other nitrogenous products; whereas if vegctables and fresh fruits enter larsely into the dietary, less water is required. Natural foods which are specially rich in water are milk and succulcnt fruits, such as grapes, oranges, melons, and plums; also vegetables, such as cucumbers, tomatoes, and salads. All vegetables contain more water than meats, and fresh fruits as a rule contain more water than vegetables.

The effects of drinking water on the tissues. - The ingestion, even of a large amount of water, has very little effect on the tissues other than of a temporary character, this being due to the remarkable tendency on the part of the blood to maintain cquilibrium as regards its composition. After the ingestion of a large amount of water the blood is very temporarily diluted, the blood-pressure slightly raised, and, in proportion as the latter is prescnt, there is a slightly increased activity of the heart muscle. These effects quickly subside, coincidently with the rapid withdrawal of the water from the tissues by means of the kidneys and skin. Metabolism of proteins is not notably affected.

Deficiency of water a common dietetic error-One of the commonest dietetic errors is taking too little water. The important influence of water on nutrition is shown by a study of the influence of water starvation. Water starvation leads very specdily to the development of thirst, a dryness of the mucous membranes, constipation, defective absorption from the gastro-intestinal tract, with resulting impaired nutrition, emaciation, muscular weakness, convulsions, coma, and death. It is important to bear in mind that many patients are willing to take water in the form of a tablewater who will not readily take it in the form of ordinary drinking-water.

Drinking-waters are spoken of as hard and soft, according to the proportion of mineral matters present in the water. Hard water contains excess of lime salts, the drinking of which may induce constipation, indigestion, and disturbance of the general health. In some people the use of hard water in the cooking of food is sufficient to upset the general 
health. By boiling the water, its hardness, which is duc to the presence of earthy carbonates, is diminished, as the carbonic acid which assists in holding the carbonates in solution is driven off. Boiling is also the most effective way of ridding the water of organic impurities. Boiled water when cooled has an insipid taste, but this may be largely got rid of by subsequent aeration in a gazogene, or by simply shaking up the water with air in a stoppered bottle.

Vater, then, is an indispensable beverage. It is absorbed quickly, and as rapidly climinated. As a general rule, it may be said that at least $I_{2} \frac{1}{2}$ to 2 pints of pure water should be taken daily. This amount, it may be added, is considerably in excess of that taken by the average man. A useful method of prescribing water is to give a full tumblerful of hot or cold water on an empty stomach-

(a) The first thing in the morning;

(b) An hour before the midday meal; and

(c) The last thing at night.

The adclition of water to the dietary is a valuable therapeutic agent in many diseases. Special value attaches to its use in fevers, where it assists in eliminating the toxins by means of the kidneys and skin. Further reference to its use in disease will be found in the sections dealing with individual diseases.

Aerated and Mineral Waters.-Artificial aerated waters are made by charging water with carbonic acid gas at high pressure. The chief varieties of artificial aerated waters are as follows :-

I. Acrated distilled water, e.g. Salutaris water. Here all the mineral substances have been removed by distillation prior to being charged with gas.

2. Ordinary water impregnated with carbonic acid gas.

3. Alkaline waters, such as soda, potash, or lithia water. These contain on an average about 5 to IO grs. of alkaline salt to the bottle.

4. Seltzer water, an imitation of the natural mincral water of Seltzcr (in Nassau). This contains common salt, bicarbonate of soda, carbonate of magnesia, and hydrochloric acid. 
5. Sweetened waters, sich as lemonade, ginger beer, ginger ale, and the like. It is important to note that these are very acid drinks, and also rich in sugar.

Natural Mineral Waters.-Mineral waters are frequently taken as substitutes for ordinary water. They differ from ordinary water in the greater amount of gascous and solid matters they contain. The gaseous constituents are mainly carbonic acid gas, and in much lesser degrees sulphide of hydrogen; the solid constituents are salts of sodium, potassium, magnesium, aluminium, iron, iodine, bromine, chlorine, and sulphur. Some waters have a purgative action, others a laxative, and others a diuretic effect, according to their composition. For ordinary table use a water must not contain more than I per cent. of mineral matter, otherwise the specific effect of the saline ingredients present may be obtained.

The natural mineral waters most largely used as tablewaters in this country are Apollinaris, Johannis, Seltwer, Kronthal, St Galmier, and Vichy (Celestin). These are all alkaline, well-aerated waters, containing carbonate of lime and soda, and also sodium chloride. According to their chemical composition, mineral waters may be classified as follows :--

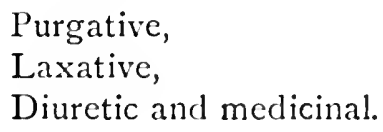

The purgative waters are characterised by the large amount of sodium sulphate and magnesium sulphate in this composition, the chief among these being Apenta, IIunjadi Janos, Friederichshall, Kissingen, Iranz Josef. These are bitter waters.

The laxative waters are less rich in the salts which induce active peristalsis of the bowels. These include waters of Harrogate, Kissingen, Kronthal, Seltzer, IViesbaden, Contrexeville. These are relatively rich in sodium chloride.

The diuretic and medicinal waters include the ordinary table-waters above mentioned, also special waters rich in bromine, iodine, iron, and sulphur, which are found in different health resorts. 
Wses of mineral ibaters.-When taken before meals, waters containing carbonic acid hate a soothing effect on the gastric mucous membranc. It the same time, carbonic acid acts as a stimulant to the morements of the stomach, and may thus aid digestion. If taken in excess, all carbonated waters are apt to produce incligestion, with flatulent distension of the stomach or bowel. The slight allialinity of some of the table-waters has led to their being used to neutralise the acidity of some of the more acicl wines. In practice we find that many patients will not readily take ordinary water, but are willing to take an alkaline table-water. P'robably the greatest use of acrated and simple mineral water in therapentics is to be found in the treatment of this class of patient. Many of the natural mincral waters have been found to be distinctly radio-active, and recent observations suggest that some therapeutic value may attach to this property. In this respect the natural mineral waters have a distinct advantage over the artifically prepared waters. The sweetened mincral waters have no therapeutic value; they may be pleasant drinks to people in health, but should be avoided by gouty and theumatic subjects, on account of the acid and sugar present in their composition.

lieverages may be classed into the following two aroups:-

1. Those whose stimulant qualities depend on an alkaloid, c.g., tca, coffec, cocoa, kola, coca.

2. Throse whose stimulant qualities depend on alcohol, e.g., spirits, wine, beer.

These will be in turn considered.

Tea is a preparation made from the lcaves of the young shoots of an evergreen plant, "Thea." It is grown chiefly in China, India, and Ceylon. There are two varietics, black and green tea. In the former the leaves are allowed partly to decompose, and the black colour is duc to their incipient decay due to fermentation. As in the process of fermentation the tannic acid becomes less soluble, black tea contains much less tannic acid than green tea, with the result that black tea has now the market practically to itself. The chief ingredients of tea are caffeine, tannin, and traces of 
volatile oils. The average composition of tea may be siven as follows :-

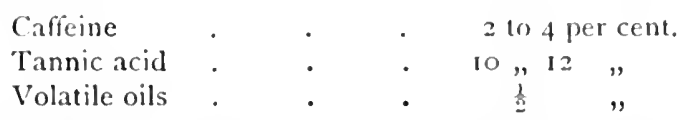

Extractives and gummy substances are present in small amount. As a general rule, we may say that China teas have a delicate flavour, with little astringency; Indian teas have more body and astringency; Ceylon teas are also rich in caffeine, but not so strong as Indian teas. Most ordinary teas arc blends.

Composition of an infusion.-As caffeine is very soluble, all the caffeine present is dissolved at once on the addition of hot water. Tannin is much less soluble, the result being that prolonged boiling increases the amount of tannin present in the solution. This is specially truc of all the cheaper teas. In some high-class China teas, costing 5 s. per lb., the proportion of tannin extracted may not be appreciably greater after ten or fiftecn minutes' infusion. On an average, it may be said that a teacupful of tca, after a few minutes' infusion, contains about I gr. of caffeine to rather more than 2 grs. of tannic acid. Tea should be prepared with water that has just come to the boil, and is best after from three to five minutes' infusion. If extracted too long, it contains more tannin, and a greater proportion of bitter principles. It is important that the water used should not be too hard or too soft. Excessive hardness may be neutralised by adding a pinch of soda to the tcapot. A very soft water cxtracts more fully the bitter principle from the leaves.

Tea is not a food, but a pleasant beverage which has a stimulating effect on the nervous system. If made with boiling milk it possesses nutritive properties. When taken to excess it deranges the digestive, the cardio-vascular, and the central nervous systems. Various symptoms of indigcstion, excitability, slecplessness, anæmia, constipation, and rapid, fecble pulse are the chicf symptoms induced by excessive indulgence.

Coffee is prepared from the seeds of Caffea arabica, the seeds being stripped of their covering and lried, and specially prepared by a roasting process, in which the berrics lose 
ahout 20 per cent. of their weinht hy water, and about half the caffeine present in their composition. The roasting process sets free a volatile oil which imparts the characteristic aroma of coffec. After grinding this volatile oil tends to disappear; hence the importance of using freshly ground coffec. The essential constituents of coffee are :-

Caffeine.

Tamnin and caffeo-tannic acid.

Fat.
Gummy matters.

Cellulose.

Ash.

The relative proportion of these is shown in the following tabular analysis $(13) y(h):-$

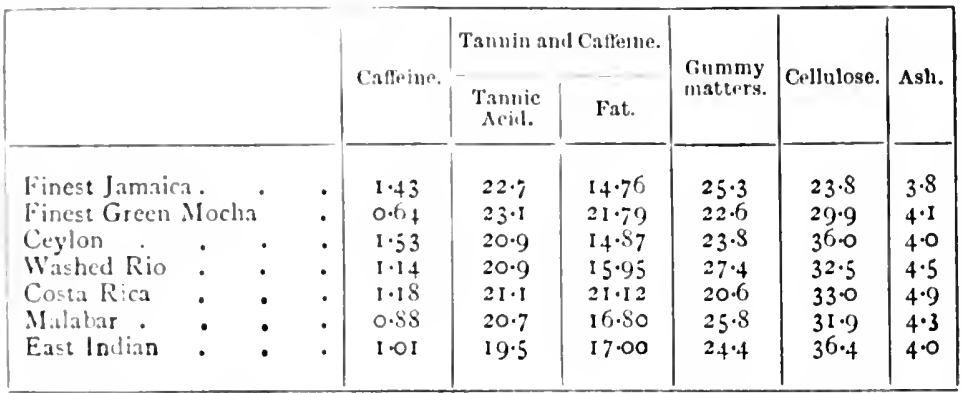

When coffec is made by infusion, in the ordinary ways of this country, there is extracted about 20 per cent. To obtain the full strength of the coffee, the example of the East should be followed, and the beverage prepared by infusion and decoction combined. When so prepared, coffee should yield fully onc-third of its weight of extract. Like tea, coffee is not a food, except for the milk and sugar added to it. As ordinarily prepared, the amount of caffeine and tannin in a cup of coffee is very similar to that in a cup of tea. The most common adulterant is chicory, and many people prefer coffee with a chicory flavour. It differs from coffee in having very little caffeine, tannin, or volatile oil, and it is much richer in sugar, having over ro per cent. of sugar, whereas ground coffee has less than I per cent.

Cocoa is prepared from the seeds of Theobroma cacao, deprived of their outer pulp and roasted, in which form, as in the coffee bean, the starch of the seed is changed into dextrin. The peculiar aroma is due to a volatile oil. The striking feature in its composition is the high percentage of fat. It is 
also rich in starch and albuminous matter, one-fifth of the latter, however, being of an indigestible nature. Konigg grives the following analysis:-

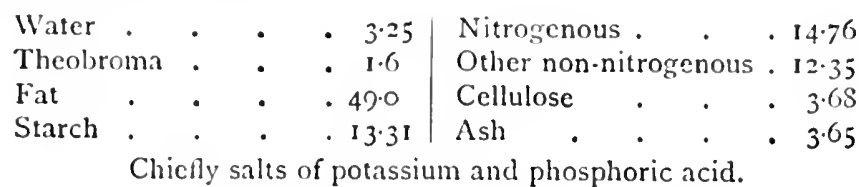

In many commercial cocoas there is a large addition of sugar and starch. Cocoa thus ranks as a foodstuff of distinct value. By reason of the large amount of sugar and fat present, if used in excess, it is liable to upset digestion. When not too rich, it forms a nutritious drink especially useful for children and convalescents. The special preparation of cocoa advertised by Sandow contains less fat than most other cocoas, and is on that account a valuable preparation for many subjects with a delicate digestion.

The kernels when finely ground constitute cocoa nibs; if boiled in water for about two hours and the fluid strained off, a decoction of pure unadulterated cocoa is obtained which is a nutritious and easily digested drink. For children and invalids peptonised cocoas are undoubtedly the best forms. Savory \& Moore and Allenbury supply good brands.

A "fortified cocoa" can be prepared as follows :-

I teaspoonful of peptonised cocoa.

2 tablespoonfuls of milk sugar. $\frac{1}{2}$ cup of water.

I ounce of cream.

IMix the cocoa and sugar, add the water, and boil for four or five minutes; then add the cream, plain or whipped.

Chocolate is cocoa to which has been added starch, sugar, and flavouring substances, generally vanilla. It contains about 1.5 per cent. of theobromine, 15 per cent. of fat, about 60 per cent. of sugar, and 5 per cent. of nitrogenous substances.

\section{Plain Chocolate (a good make).}

To $\frac{1}{2}$ oz. allow $\frac{1}{2}$ pint of water and $\frac{1}{2}$ pint of milk. Make the milk and water hot, break the chocolate into small pieces, add it, and stir until quite dissolved. Bring to boiling point, then strain, and serve with sugar. (Excellent drink in cold weather.) 
Alcohol.

\begin{tabular}{|c|c|c|c|c|c|}
\hline & & ank & & & PAne \\
\hline Ineroduction & - & .1341 & M.alt liquors. & - & .145 \\
\hline Genctil effers & . & .141 & Wines . & . & .147 \\
\hline Nilure and $5 x$ ure & - & .143 & Therapeutic uses & - & . 151 \\
\hline Sppirits. & - & . 144 & & & \\
\hline
\end{tabular}

Introduction. - 1 remarkabie change has occurred in the past twenty years in the attitude of the medical profession on the question of the value of alcohol in the treatment of disease. Whereas formerly wines and spirits were largely used in the treatment of many acute and chronic discases, the present tendency is more and more to discard alcohol in the treatment of discasc. This change in the custom of the profession is very well shown by a reference to the following figures. In the year I 890 , the annual cost of wines and spirits per occupied bed in the Royal Infirmary of Elinburgh was I2s. IO d.- IOs. for spirits, and 2s. IO! d. for wines. In 1908 , the annual cost was is. per head per annum for spirits, and nothing for wines.

Adlditional evidence of the general trend of medical opinion upon this matter is found in the steady fall in the amount of alcohol used in seven of the London hospitals in the past forty years. Quoting from a diagram in Horsley ancl Sturge's book on Alcohol and the Human Body, we find that whereas in 1862 the cost of alcohol for the year in the seren main London hospitals was a little under $£ 8000$, in I $y 02$ the cost is under $£_{3000}$. The extent of this decrease is enhancerl by the fact that in the later period a very much larger number of patients were treated than in the earlier years. This decrease of alcohol has been seen alike in surgical and medical cases. In surgery it is probable that the development of the antiseptic system has been to a great extent responsible for the diminished use of alcohol in recent ycars. The only surgrical condition in which alcohol is still considered by some to be of use is "shock," and even here it is largely giving place to other forms of stimulant. The decrease of alcohol in meclical cases is very well illustrated by a reference to its use in fevers, which are generally the main class of discase for which alcohol has in the past been 
extensively used. In the year ISgt the cost of stimulants in the hospitals under the Metropolitan Asylums Board, London (quoted by Horsley), was Is. 4d. per head; in 1904 this had fallen to 4 d., a very pronounced reduction. This reaction against the prescribing of alcohol in the treatment of discase has been very general, both in this country and abroad. There is little doubt that this movement is in the right direction.

The reason for this change is found in the fuller knowledge we now possess of the unfavourable effects of alcohol, on the structure, function, and resisting power of the body generally, and also to some extent to the recent discovery of valuable medicinal substances which have taken the place of alcohol in the treatment of certain diseases. While the use of alcohol in the treatment of disease is now very restricted, there is no question as to its undoubted value in the treatment of certain diseases, more especially in their critical stages, and we have to consider shortly the physiological effects of alcohol, its therapeutic uses, and the composition and characteristics of the leading alcoholic beverages.

General effects.-Alcohol is a general stimulant, small doses exciting, larger doses paralysing the nervous system, beginning with the higher centres; it also stimulates the cardio-vascular system, accelerating the circulation, but not notably increasing the force of the heart. In large doses the blood-vessels are paralysed, thus becoming dilated, resulting in a fall of the body temperature. It also stimulates primary digestion to a slight extent, due to its influence on the gastric vessels, and on the muscle wall of the stomach. It does not increase the amount of the gastric juice. Alcohol cannot be regarded as a food. It is beyond the province of this work to describe in full the toxic effects of alcohol, it will suffice to refer briefly to the facts regarding it which bear on its use in the treatment of disease.

Is Alcohol a Food?-Influcnce on metabolism.-When taken in moderate amount, alcohol is completely oxidised in the tissues; when taken in larger amounts, it esciples unoxidised with the breath and mrne. It is therefore clear that alcohol can furnish energy to the organism, and in virtue of this, alcohol is by some writers regarded as a foud. There 
is no loubt, however, that the fact of a substance being burnt up in the body with the liberation of a certain amount of cnergy does not entitle it to be regarded as a food. Alcohol docs not produce energy for muscular work; on the contrary, the reverse is the case. It is not a physiological source of heat production, because the heat produced by its oxidation is at once lost by the marked dissipation and loss of heat which occurs through the skin. Alcohol possesses no power of reparing tissue. Liebig, the renowned chemist, stated that 9 quarts of the best ale contain as much nourishment as would lie on the end of a table knife. And lastly, there is little or no evidence that alcohol has any effect in the prevention of tissuc waste. We must, therefore, conclude that when judged by the requisite standards alcohol cannot be regarded as a food. It may be true that in a very acute illness a patient may live for some days on nothing but large quantities of whisky, brandy, or champagne, and may apparently not emaciate in that time as much as he would have done if he had been living merely on his own tissues; but even if this be so, it does not justify us in regarding alcohol as in any real sense a food.

A further effect of alcohol has to be noted, viz., alcohol as a cause of deficient oxidation of tissue. In virtue of its affinity for oxygen it interferes with the process of oxidation in the tissues, and so leads to fatty degeneration and infiltration of the tissues. Hence the obesity observed in many subjects who take alcohol to excess.

Action of alcohol on the cardio-iascular system.-D Small doses increase the frequency of the heart-beat, partly indirectly through stimulating the gastric mucous membrane, and partly directly through acting on the nerves and muscles of the heart. There is no evidence, however, that alcohol strengthens the force of the heart-beat; on the contrary, the available experimental evidence rather points in the opposite direction. In disease, however, when the heart is beating quickly but feebly, alcohol may diminish the number of beats, and at the same time increase its force. Alcohol dilates the peripheral blood-vessels, with the result that more heat is given off by radiation than is produced by its own combustion, so that the body temperature is lowered. It is therefore a mistake to take alcohol in any form with the object of 
"keeping out the cold," as the initial feelings of warmth are soon followed by a lowered temperature from the increased radiation of heat from the skin that immediately ensucs. If taken in excess, a state of chronic congestion of the peripheral vessels is induced, hence the purplish appearance of the face seen in subjects who take much alcohol. Degenerative changes in the vessels are also induced by the immoderate use of alcohol in any form.

Action on the nervous system.-Alcohol induces a temporary initial stimulation or excitation of the central nervous system. It is now known, however, that this is the result of a deadening of the higher centres, and is in no sense due to a real stimulant action, as was formerly supposed. The effects of small quantities of alcohol on the more highly specialised functions of idealism, reasoning, etc., have been very minutely investigated in a very ingenious manner in recent years by Kraepelin, whose researches have clearly proved that there is no real quickening of brain activity under alcohol, but the reverse.

Action on the digestive system.--The chief effect of alcohol when taken in small doses is to increase the motility of the stomach, and thus indirectly stimulate digestion. There is no evidence that it otherwise improves the powers of digestion.

Action upon the muscular system.-As in the case of the nervous system, there is an initial apparent increase in the muscular activity. This is not a real increase, however. An interesting experiment on the sustaining power of alcohol was made upon three British regiments, and reported in 1899 (quoted by Thompson). The men were subjected to fatiguing exercises. To one regiment a ration of whisky was allowed, to a second a ration of malt liquor, and to the third no alcohol. The men taking whisky exhibited more energy for about four days than either of the other groups, but then became fatigued and weak; whereas those taking none steadily gained in endurance, and those taking malt liquor showed an intermediate condition. Alcohol is usually forbidden to athletes in training, for although it may temporarily lessen muscular fatigue, it soon reduces the power of endurance. 
Alcohol-Nature and Source.-Alcohol is obtained from fersnentation of grape sugar by means of yeast. The source of the grape sugar is grain, especially barley, grapes, and in some instances potatoes-the different kinds of alcoholic liquors obtained depending to some extent on the particular kind of sugar, and also the special yeast employed. The various by-products in the process of fermentation also materially influence the nature of the product. The strength of alcoholic liquors is usually expressed as the percentage of alcohol by volume, the percentage of alcohol by volume in some of the commoner alcoholic beverages being roughly as follows:-

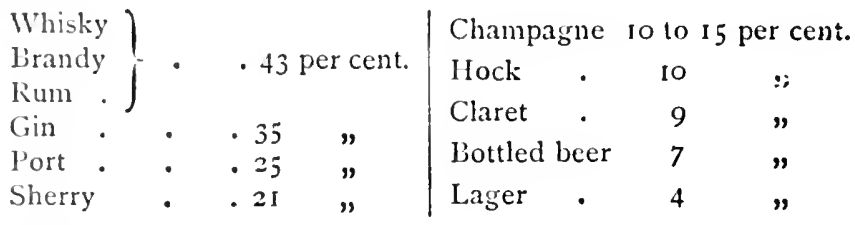

IVe have to consider shortly the three different classes of alcoholic beverages: spirits, malt liquors, and wines.

Spirits.-Spirits are obtained by distillation of the products of fermentation of different saccharine substances, the alcohol and various volatile substances being separated by distillation. Distillation of malted barley furnishes whishy, malted grape yiclds brondy, and malted molasses give rum as a clistillation product, the flavour in each instance being due to the by-products of fermentation. The by-products can be entirely removed by means of patent stills, leaving an almost pure spirit, known as silent spirit, because its source cannot be traced. Amongst the by-products of fermentation there are alcohols in a higher series, a mixture of which is known as fusel oil (amyl alcohol). Fusel oil is the last product of distillation, and it is formed especially when spirit is made from grain or potatoes instead of malt. It should be noted that all spirits are free of sugar, and all have a very low degree of acirlity : brandy with I gr. per ounce (reckoned as tartaric acid), and whisky and gin having only 2 gr. per ounce.

Whisky.-Whisky is a spirit made from malt, or malt and grain. It is of two kinds. Malt whisky, made in pot stills, and grain whisky, made in patent stills, ordinary whisky being 
usually a blend of the two. In the case of malt whisky the by-products of distillation give the whisky a raw and disagreeable taste ; this, however, gradually mcllows, the percentage of alcohol diminishing by 5 to $S$ per cent. in the course of a few years. Irish malt whisky differs from Scotch whisky in being prepared from a mixture of malted barley with unmalted grain, the malt not being dried over peat, as in the manufacture of Scotch whisky.

Grain whisky is made from a mixture of grains, barlcy, rye, and maize, with a little malt to convert the starch into sugar. It is distilled in patent stills, in order to separate to a large extent the by-products of fermentation, including fusel oil. Its method of manufacture makes it soon ready for use, and, unlike malt whisky, it does not improve on keeping. Most commercial whiskies are blends of malt and grain whisky. In recent years, the introduction of patent stills and the extended scale of manufacture has led to an increase in the amount of potato and grain spirit, and it is in these spirits, made from unaltered starch, that fusel oil is spccially found. The legal limit for dilution of whisky is 42.7 alcohol by volume.

Brandy.-Genuine brandy is a product of the grape, and is prepared from the distillation of wine. Good brandy lieeps on improving, due to the formation of the volatile ethers. Most commercial brandies, however, are not genuine brandies, but are made from silent spirit, the product of potato or grain coloured with burnt sugar, and flavoured by special essences in imitation of genuine brandy. The aicoholic strength of brandy and whisky is the same. Good malt whisky is more likely to be pure than brandy, and it has the advantage of being much cheaper.

Rum is the product of distillation of fermented molasses obtained in the manufacture of raw sugar, the by-products of fermentation giving rum its characteristic flavour. The best varieties are made from fermentation of the juice of sugar cane; much of the commercial rum is made, as in the case of brandy, from silent spirit, flavoured with special essences, the colour being imparted to it by the addition of burnt sugar. The alcoholic strength of rum is rather greater than whisky - about 50 to 60 per cent. by volune.

Gin is a product of fermentation of a mash of rye and 
malt, and clistillation of the product, juniper berries, a little salt, and occasionally hops being added in the final distillation. Gentuine gin is made in Holland. Much of the commercial sin is made, as in the case of brandy and rum, from silent spirit, flaroured with juniper berries, salt, turpentine, etc. The legal strength of gin is 37 per cent. by volume, the usual strength being about 50 per cent. A sweetened and diluted gin goes by the name of Old Tom. Unlike the other spirits, it is not coloured by the presence of oil of juniper or similar oils, which cause a milkiness when diluted with water, since they are insoluble in water. The oil of juniper gives gin distinct diuretic properties.

Liqueurs are spirits sweetened with cane sugar, and flaroured with aromatic or other herbs or essences. The proportion of alcohol in them is high, ranging from 35 to over 55 per cent.; they are usually rich in sugar, such liqueurs as Chartreuse, Kümmel, Anisette, and Benedictine having about 30 per cent. of cane sugar in their composition.

Beer is the product of fermentation of malt (barley) with hops. In the preparation of most commercial beers, however, cheaper substitutes for malt are employed. Those include potatoes, maize, and rice. The quality of beer depends largely on the temperature at which the "mashing" is carried out, the higher the temperature the greater the proportion of malt sugar in the beer; also on the temperature at which the fermentation process is conducted; as this is usually high, most of the sugar is broken up, and beer is, therefore, fairly rich in alcohol. In Germany the fermentation is carricd out at a lower temperature, with the result that German beers contain less alcohol and more carbonic acid. A light beer is one which contains more malt and less hops, and in its preparation the malt is dried at a higher temperature. Some beers, $c . g$. India pale ale, are very thoroughly fermented, and therefore contain very little sugar. The essential substances in beer are four in number: alcohols, sugars, free acids, and bitters. The proportion of alcohol varies from about 2 to 7 or $S$ per cent. in the stronger British beers (Bass's and M'Ewan's).

Stout and Porter are made in the same way as beer, but the malt is first subjected to a roasting process, 
which induces the formation of caramel, to which the colour is due. Caramel is added artificially in the preparation of many commercial liquors. Porter is a mixture of dubious composition, containing often liquorice, treacle, linseed, etc.

The approximate composition of beer is given in the following table :-

\begin{tabular}{|l|l|c|c|c|c|c|c|}
\hline & Water. & $\begin{array}{c}\text { Alcohol. } \\
\text { Per cent. } \\
\text { per vol. }\end{array}$ & $\begin{array}{c}\text { Total } \\
\text { Extract. }\end{array}$ & Protein. & Sugar. & Acidity. & Ash \\
\hline $\begin{array}{c}\text { English ale and } \\
\text { porter }\end{array}$ & $59 . \mathrm{I}$ & 4.89 & 6.03 & 0.53 & 0.84 & $0.3 \mathrm{I}$ & $0.3 \mathrm{I}$ \\
\hline
\end{tabular}

The composition of stout is given as follows (Lancet analysis):-

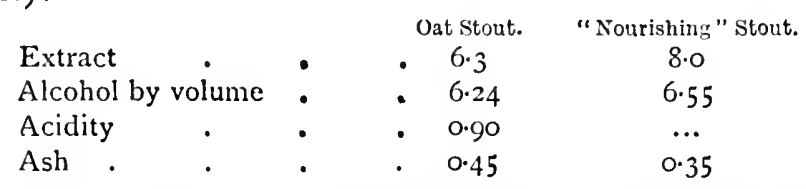

On an average, it may be taken that the chief ingredients of a pint (20 ounces) of good bottled beer is as follows :-

$\begin{array}{lll}\text { Alcohol . } & \text { I fluid ounce. Free acids . - } 25 \text { grains } \\ \text { Extract . . I to } 2 \text { " } & \text { Salts . - } 13 \text { " }\end{array}$

Wine.-Wine is (or should be) the product of the juice of the grape by fermentation. When so prepared, it is an alcoholic solution varying in strength from 6 to 25 volumes per cent., and containing flavouring and other substances. The chicf chemical constituents of the juice are sugar, for fermentation of alcohol; organic acids or their salts, chiefly of tartaric, citric, or malic acid; and albuminous substances. The stones or seeds furnish essential oils, which are largely responsible for the bouquet of wines, and the skins and stones furnish pigments and tannin. The quality of wine depends on the amount of sugar and albumin in the juice. In the process of fermentation the ycast germs split up the sugar, with the formation of alcohol. If there is a small amount of sugar and a large amount of albumin in the juice, fermentation goes on till all the sugar is split up. This furnishes a 
dry winc with a slightly acid taste, c.g. hock. If, on the other hand, there is a large amount of sugar and much smaller amount of albumin, the fermentation is less complete, some sugar is left in the winc, as in "swect wines." When as a result of fermentation the proportion of alcohol has risen to I 5 per cent. by volume, the process of fermentation is arrested by the alcohol, hence a natural wine never contains more than I 5 per cent. alcohol. Wines are often fortificd by the addition of spirit. This has the twofold effect of adding to their strength and preserving them from further fermentation, and so preventing the production of acetic and other acids.

Red Wines.-Darls grapes are used in the making of red wines, the slins and stones being left to ferment with the pulp, to which they yield tannin, pigment, and cxtractives. The average composition of red wines may be taken as follow's :-

Alcohol . 8 to ir per cent. Acids . $5, .65$ "

Sugar . . . 5 per cent. Tannin and pigment 11 to 2 ,

White Wines are usually made from white grapes. They are produced in great variety, and they have as a rule a rather higher percentage of alcohol than red wines.

General Composition of Wines.-The important ingredients in wines, from the medical point of view, are the following :-

$$
\begin{aligned}
& \text { Alcohol, } \\
& \text { Acids, }
\end{aligned}
$$

Sugars, Ethers.

There are in addition slight amounts of extractives, chiefly of a carbohydrate nature, and of glycerine, produced in the process of fermentation, but these are of little practical importance.

Alcohols.-The amount of alcohol (cthylic) present in wines ranges from $S$ to I I per cent. or thereby in the case of natural red wines, to 20 per cent. or more in fortified wines, c.s. port. All natural wines are comparatively poor in alcohol, and thus readily undergo the acetic fermentation. A fortified wine therefore leeps better, subsequent fermentation being restrained. Amyl alcohol and other higher alcohols are present in traces even in sound wines. As is invariably 
the case when alcohol is formed by fermentation, carbonic acid gas is given off, and if a wine is bottled when this action is all over, the product is a "still wine"; if, on the other hand, the wine is bottled, like beer, before the fermentation is quite over, then the liquor becomes charged with carbonic acid gas, which effervesces or liberates, producing a "sparkling" wine. Sparkling wine may also be made on the principle of aerated waters, by passing carbon dioxide into the wine under pressure.

Acids. - In a good wine the total acidity should be not more than 0.3 to 0.7 per cent. The taste of a wine cannot be regarded as a critcrion of its acidity, as the acicl may be masked by a high proportion of sugar. The acidity is due to natural acids and acids produced by fermentation. The natural acids in wine are tartaric, tannic, and malic acid. Tartaric acid exists in combination with potassium in the form of potassium bitartrate. As the proportion of alcohol in wine increases with age, the bitartrate becomes less soluble, and settles out in the form of "tartar." The tannic acid in wine is responsible for the astringent taste of certain wines.

Acetic, formic, succinic, and other fatty acids are produced in wines by fermentation. Red wines usually contain rather more of these volatile acids than white wines. If present in excess, the wine is slightly "turned," that is, on its way to become vinegar.

According to Dupre, the amount of acid, reckoned as tartaric, in a bottle of wine is as follows :-

Claret . 65 to 77 grains. Sherry . 54 to 61 grains.
Hock $57 " 70 "$ Port. 49 . $62 "$,
Marsala". . . 39 to 46 grains.

Sugars.-A natural wine should contain about $\frac{1}{2}$ per cent. of sugar. Fortified wines may contain 2 per cent. or more, and sweet wines as much as 20 per cent. The following analysis is given by Dupre:-

\begin{tabular}{|c|c|c|c|c|c|c|}
\hline Hock. & . & - & I. 4 & to 8.6 & rain & er bottle. \\
\hline Claret. & . & e & II & $\Rightarrow \quad$ IS & , &, \\
\hline Sherry & - & - & 217 & $" 421$ & , & $"$ \\
\hline Port . & , & - & 221 & $" 519$ &, & $"$ \\
\hline Old Marsala & . & . & $3 S S$ & $" 451$ & ", & $"$ \\
\hline Sauterne & . & . & . & 125 & $"$ & , \\
\hline Champagne & . & • & 500 & grains d & own & almost nor \\
\hline
\end{tabular}


Ethers.-The ethers present in wine impart to it its bouquet. The volatile ethers are derived from the volatile acids, e.g. acetic acid; the fixed cthers are the product of the fixed acids, e.g. tartaric acids.

As already stated, wines are divided into two great classes, natural wines and fortified wines. The chicf natural wines are claret, hock, and the Hungarian, Italian, Australian, and Californian wines; the principal fortified wines being port, sherry, Marsala, Madeira, and, as a rule, champagne. A few short notes on these various wines are appended, attention being chicfly directed to the points of practical importance from the medical point of view, viz., the proportion of alcohol, sugar, and acid present in each.

Claret.-A natural wine containing from $\delta$ to $\mathrm{I} 3$ per cent. of alcohol, about $\frac{1}{4}$ per cent. of sugar, and about $\frac{1}{2}$ per cent. of acid.

Burgundy.-Similar to claret, rather higher percentage of alcohol as a rule, and richer in extractives, and has therefore more body. Chablis, a white Burgundy made from white grapes.

Hock.-Similar alcoholic strength to claret; only traces of sugar, and acidity about the same as clarct; very small amount of acetic acid; good kecping qualities.

Hungarian Wines.-Two varieties; red and white; alcoholic strength as in claret; almost free of sugar.

Italian Wines.-Red and white; rather low percentage of alcohol, and relatively high acidity.

Californian and Australian Wines.-Full-bodied natural wines; red and white varicty.

Port.-A fortified wine, containing from 15 to 20 per ccnt. of alcohol; full of body, on account of large amount of cxtractives; relatively low acidity, but good deal of tannic acid, which diminishes with age. Rich in sugar (from I to 6 per cent.), giving a strong, dry wine or strong, sweet wine respectively.

Sherry.-The white wine of Spain. A fortified wine; percentage of alcohol similar to port. Amount of sugar varies very greatly; may contain mere traces or as much as 4 per cent., giving a strong, dry wine or strong, sweet wine respectively. Low acidity; improves greatly with age. 
Madeira.-Similar to sherry; rich in volatile ethers. Dry and sweet varieties, as with port and sherry.

Marsala.-A Sicilian wine resembling sherry, but contains on an average more sugar; very slightly acid.

Champagne.-A fortified sparkling wine; may be dry or sweet. Sugar varies from nothing to 12 or 14 per cent. True dryness is the result of age, and is due to a very slow conversion of sugar into alcohol; in many commercial preparations the "dryness" is attained artificially, and really represents very varying degrees of acidity. Acidity, about $\frac{1}{2}$ per cent.; alcohol, about io to 12 per cent.

Cider and Perry.-Made from apple and pear respectively; very mildly alcoholic, 2 to $\$$ per cent. Sugar, 2 to .6 per cent.; slightly acid, - I to 6 per cent., chiefly malic acid. The more acid wines may contain as much as 20 grains of tartaric acid per tumblerful.

Medicated Wines. - Therc are several varieties of "medicated wines" in the market, such as "meat and malt wine," made from extract of meat, malt extract, and sherry or port; and "coca wine," made from cocoa leaves and sometimes cocaine. The use of these wines is to be strongly deprecated from every point of view.

It is, perhaps, hardly necessary to say that many of the cheap wines imported into this country are artificial, being made from cider or ordinary potato and grain spirit, flavoured with cenanthic ether, and coloured by aniline dyes or by vegetable cxtracts like madder, beetroot, or logwood. As an example, the following is a recipe for making "port" (Knight) :-

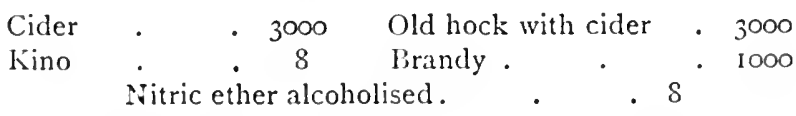

For the detection of these impurities, elaborate schemes are given in analytical works.

Therapeutic Uses of Alcohol.-As already indicated in the introduction to this section, alcohol is now very much less employed in the treatment of disease than it was some ten or twenty years ago. There is little doubt that this restriction in its use has not been attended with any disadrantagcous results to such patients as would in former yedrs have been 
frecly" "stimulated." On the contrary, there is reason to think that this altcration in the custom of the medical profession regarding the use of alcohol in discase has been a factor of some value in diminishing the number of those who ultimately fall a victim to its effects. We must, at the same time, recognise that alcohol is a very valuable therapeutic agent in the treatment of some discased conditions. These call for detailed consideration.

In acutc diseases.-In certain acute fevers, such as pneumonia, diphtheria, and the likc, when the circulation is distinctly failing, as shown by a rapid, weak, and irregular pulse, the administration of alcohol in doses of I dram to I ounce cvery two or four hours, according to the age of the pationt and the severity of the fever, is followed by a very matcrial improvement in the gencral condition of the patient. It should be noted, howcrer, that the proportion of cases of pncumonia which call for its administration is a really small onc. In the general run of cases occurring in healthy subjects of non-alcoholic habits there is no necessity to have recourse to stimulants. In exceptional cascs, however, and in those who have been previously addicted to its use, the frec use of stimulants is necessary. Diphtheria is such a trcacherous condition, and the risks of establishing a habit from its usc are here so remote, that it is advisable to have recourse to the use of stimulants if there is the least dissatisfaction with the general statc of the patient or the condition of his circulation. It may be given in doses of $I$ to 4 drams or thereby crery two or four hours, according to indications. In weal clderly subjects suffering from bronchitis with congestion of the lungs, and in clderly subjects with chronic heart discase, a little whisky, brandy, or dry champagne is reften of very great value as a stimulant. It may have at the same time a sclative effect on the nervous system, as it often tends to promotc slecp.

In chronic discases. - $\mathrm{Al}$ cohol is sometimes of considerable value in cases of failure of digestive power, as inclicated by inability to take and cnjoy food, and also in states of general weakness. Here it may be given in the form of a little whisky (1 ounce), twice or three times a clay with meals, or as a glass of dry champagne or other sound wine, given with 
luncheon and dinner. Great care is, howercr, necessary in prescribing alcohol in these cases, more especially in the case of female patients suffering from general nervous exhaustion, as these are so prone to become permanently addicted to its use. The use of all medicated wines, elixirs, and the like cannot be too strongly deprecated. A glass of beer or stout given with one or two meals daily for a time is occasionally of distinct value, acting as a bitter tonic, and at the same time supplying a relatively large amount of nutriment in a fluid form.

Gout and rheumatism.-Patients afflicted with gout or rheumatism are, speaking generally, better without alcohol in any form. This, however, is often a counscl of perfection, and as such impracticable. Such patients should thereforc be advised to abstain from malt liquors, and all wines rich in sugar, and also those with a high degree of acidity. Whisky is for them the safest drink; and after that a dry sherry or Madeira or sound claret, and these should not be taken every day.

As a tonic in conialescence.-In protracted convalescence from some acutc diseases, a glass of becr, a little whisky in water, or a glass of wine taken with the chicf meals, may improve the tone of the digestion and accelerate the rate of recovery. The advantages of these are perhaps best secn in some cases of influenza. 


\section{CHAPTER IX}

PATENT, PROPRIETARY, AND PREDIGESTED FOODS

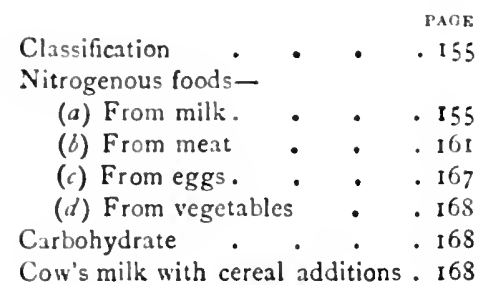

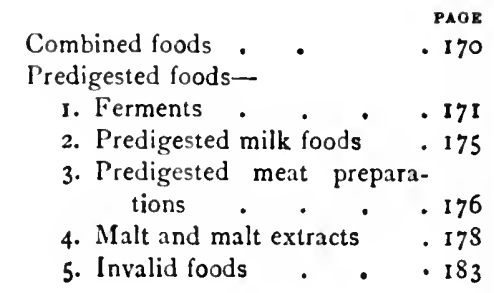

TIIERE are numerous patent and proprietary foods in the market, many of which are largely advertised and extensively used by the public and the profession. It is therefore necessary to investigate their claims. These foods are made by processes of concentration, evaporation, and condensation, from meat, eggs, milk and milk products, cereals, vegetables, fruits, and nuts. In some, partial or complete predigestion of the natural food is carried out. Some foods claim to be specially suitable for feeding infants and invalids, by being made less bulky, and simpler in composition, and therefore more digestible. Others claim simply to lose their bulk, and to be suitable for travellers and the like. With regard to the value of such foods, it may be definitely stated that proprietary foods are not necessary in health, but are of very great value in cases of sickness. At the same time it should be added that the more knowledge we possess of the composition of natural and proprietary foods, and of the effects of cooking natural foods, the less often will it be found necessary to have recourse to the more expensive patent preparations. In the following pages an account is given of the leading facts in the composition and uses of the best-known proprietary foods. The data given under the heading of composition have been taken partly from the results of 
the analysis recorded by the makers, and partly from the analyses of the individual foods published from the Lincet and other laboratories. Proprictary foods may be classified as follows:-

\section{Classification of Proprietary Foods-other than Predigested.}

A. Nitrogenous Foods.

I. Prepared from cow's milk.-( $a$ ) Condensed, with or without sugar; $(b)$ dried milk preparations; (c) modified milk.

2. From meat.-Meat teas, extracts, juices, powders.

3. From eggs, usually in combination with milk protein or animal protein.

4. From vegetables, either alone or in combination.

B. Cariohydrate Foods.

Starch, unchanged, or partially changed into soluble carbohydrates, or completely changed.

C. Cow's Milk witi Cereal additions.

D. Combined Foods.

\section{A. Nitrogenous Foods.}

(1) Foods prepared from Cow's Milk.

Condensed mill. - The importance of studying condensed milk is evident when we realise that we import $500,000 \mathrm{cwt}$. of it into this country every year, and that among the poorer classes there is no commoner substitute for cow's milk. The condensed milks are all made from cow's milk, either whole or skimmed. It is prepared by slowly evaporating the water off the millk by moderate heat in vacuo to the consistence of honey. As a rule, the milk is only reduced to onc-third of its original volume. Most brands of condensed milk have cane sugar added to help in its preservation. IVe have thus three types of condensed milk :-

Whole milk, condensed and unsweetened.

Whole milk, condensed and sweetened.

Skimmed milk, condensed and sweetened. 


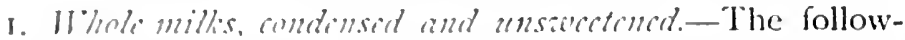
ing are the chief brands: Icleal, First Swiss, leacock, Viking, Hollanclia. Their composition is as follows :-

\begin{tabular}{|c|c|c|c|c|c|c|}
\hline & & & Water. & l'rotein. & Fat. & Inctoee. \\
\hline Ideal . & . & . & $6:-\infty 0$ & $8 \cdot 3$ & $12 \cdot 7$ & $16 . \infty 0$ \\
\hline First Swise & . & . & $62 \cdot 15$ & $9 \cdot 0$ & $11 \cdot 33$ & 1.4 .44 \\
\hline Pencock. & . & . & $6+05$ & $\cdots$ & 10.04 & $I \cdot 2 S$ \\
\hline Viking . & . & . & $\ldots$ & $8 \cdot 9$ & $9 \cdot 4$ & $\cdots$ \\
\hline Iollandia & . & . & 57.00 & $11 \cdot 3$ & $9 \cdot 8$ & 3.4 \\
\hline
\end{tabular}

These are prepared by cvaporation by heat sufficiently strons to render the milk sterile, so that no preservative materials are added. This milk is open to the same objections as the use of sterilised milk, but it is better for infants than those forms of condensed milk in which preservation is secured by the addition of too large a proportion of cane sugar. A dilution with two parts of water makes the mixture approximate more or less closely to cow's milk Further dilution and the addition of cream and sugar are necessary to make the fluid at all similar in composition to human milk.

The unswectened milks tend to so bad quickly when opened. For this reason they should be kept in a cold place after being opened, and the smallest size of tin should be procured.

2. Whole milks, condensed and swcetcned. - These are made from whole milk, with the addition of cane sugar to such an extent that the cane sugar added is grcater than the solids of the milk-its function is to act as a prescrvative. The following is the composition of some of the best brands :-

\begin{tabular}{|c|c|c|c|c|c|c|}
\hline & & Solids. & Protein. & Fat. & $\begin{array}{l}\text { Milk } \\
\text { Sugar. }\end{array}$ & $\begin{array}{l}\text { Cane } \\
\text { Singar. }\end{array}$ \\
\hline Nestlé & . & $77 \cdot 2$ & $9 \cdot 7$ & $13 \cdot 7$ & 15.0 & $37 \cdot 2$ \\
\hline Rose. & . & 76.6 & $8 \cdot 3$ & $12 \cdot 4$ & $17 \cdot 6$ & $36 \cdot I$ \\
\hline Milkmaid. & . & $76 \cdot 3$ & $9 \cdot 7$ & 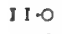 & $14 \cdot 6$ & $38 \cdot 7$ \\
\hline I. ull Weight & • & $76 \cdot 5$ & I $2 \cdot 3$ & I 1.0 & $13 \cdot 5$ & $37 \cdot 2$ \\
\hline Anglo-Swiss & . & 74.4 & 8.8 & 10.8 & 16.0 & $37 \cdot 1$ \\
\hline
\end{tabular}

On account of the large amount of sugar present in these 
preparations, in order to make the milk palatable a degree of dilution is required which makes it impossible for the resulting misture to be at all like cow's milk in its proportion of protein and fat.

Humanised condensed mill is prepared by the addition of cream and lactose, before condensation, in such quantities as to form a solution when suitably dilute equivalent to human milk in percentage composition.

3. Sweetened and condensed skimmed milk.-The chief characteristic of the condensed separated milks is its poverty in fat - as a rule, not exceeding $I .5$ per cent. When suitably diluted these milks are very deficient both in protein and fat, and are thus foods not well adapted for infant feeding. Such brands may be useful as food for culinary purposes and for addition to tea, but should certainly never be given to infants.

Advantages and disadvantages of condensed milks.-Condensed millis are more easily digested than cow's miik, due to the fact that in the process of preparation the casein is altered in some way unfavourable to the development of a hard curd. For this rcason, condensed milk is occasionally of much value in the treatment of infants who are unable to digest ordinary milk. The great popularity of condensed milk is chicfly due to the ease with which the infant's meal is prepared. The disadvantages are marked. They contain, as a rule, too little fat. The unsweetened mills are alone satisfactory in this respect. In suitable cases this can be remedied by the addition of cod-liver oil to the diet. In the dilution recommended they are usually deficient in protcin, this holds good very specially for the skimmed milk preparation. This deficiency may be remedied by the administration of protein in other forms, c.g. egg albumin. Further, they are not fresh foods. They all lack the important "antiscorbutic" element present in fresh milk. This can to some extent be counteracted by adding to the dietary a little fruit juice every second day. The nutritive value of any preparation depends on the quality of the milk, the desree of condensation, the addition of cream (if any), and the amount of cane sugar added. It need hardly be added that only the best brands should be 
used. It should also be noted that condensed milks are expensive in comparison with ordinary milk. As a rough computation, it may be said that the price of the milk diluted and ready for use works out at $4 \mathrm{~d}$. per pint.

Dricd milk preparations. - There are a large number of preparations of dried milk in the market; they belong to various groups :-

I. Milk poivders, composed of milk modified by the abstraction of casein or addition of sugar, or both. Allenbury No I Food is a food of this sort-it is made from cow's milk from which the excess of casein has been removed and the deficiency of sugar and fat corrected. It is free from starch, and is often very useful during the first three months of infant life, when a temporary change from fresh cow's milk mixture is indicated.

2. Dried milk, made from whole or skimmed milks. Whole milk dried is sold as Glaxo (Nalhan \& Co.), and Lacvitam (Prideaux), at Is. to Is. 3 d. per lb. Dried skimmed milk is sold as Lacumen, at $5 \mathrm{~d}$. to $9 \mathrm{~d}$. per lb.

3. Cascin preparations. - There are a large number of these preparations. The nutritive value is high, containing as a rule over 90 per cent. of pure protein. Their great value consists in that they can be added to other foods, thus "fortifying" them with protein. The preparations are tasteless, compact, easily digested, and soluble. Their solubility enables them to be added to other food, such as soups, jellies, milk puddings, greatly raising the nutritive value of the diet.

Dried cascin is a product of the Protene Company, and forms the basis of many of the patented preparations. It is in the market as Protene flour. Casein is purin-free, does not clot, and is easily digested and absorbed. It is indicated in all affections in which additional protein is needed, and is useful as a means of giving phosphorus in organic combination. It is specially valuable in acid dyspepsia, the protein fixing the acid.

Casein combined with ammonia is sold as Eucasin, and with sodium as Nutrosc. Sanose is a mixture of casein 80 per cent. and egg albumin 20 per cent. Sanatogen is a 
valuable casein preparation with 5 per cent. sodium glycerophosphate added.

Plasmon is a tasteless, odourless, white powder, entirely soluble in water; it is casein of milk made into a readily soluble powder by the addition of an alkali, and it contains phosphorus in organic form. It is one of the cheapest of the dried milk preparations.

One teaspoonful of plasmon powder is equivalent to the protein value of about 2 pints of milk. Plasmon is best added to soups, milk gravy, etc., after it has been dissolved.

$$
\left.\begin{array}{l}
\text { Plasmon, } 3 \text { teaspoonfuls. } \\
\text { Water (tepid), } \frac{1}{2} \text { pint. }
\end{array}\right\} \text { Prepared plasmon. }
$$

Add 3 tablespoonfuls of tepid water to the plasmon, stir and rub into a paste; then gradually add the tepid water, place on the fire, bring to the boil, stirring well all the time, and boil for two minutes. This can now be added to milk or other liquid beverage. When cold, the dissolved plasmon will form into a jelly, which when whisked will turn into a thick cream. The jelly or cream can be added to all food-liquid or solid.

\section{Plasmon Milk (hot).}

Plasmon, 3 teaspoonfuls. Water, 3 ounces.
Milk, 1 pint.

In a clean enamelled saucepan mix the plasmon into a smooth paste with the tepid water, then place on the fire, stir in gradually the pint of milk and boil all together for two minutes, stirring continuously.

\section{Plasmon Milk (cold).}

Dissolve the plasmon as directed above, then stir in slowly the pint of milk until all is well mixed, and allow to cool.

\section{Plasmon Snow Cream.}

Dissolve the plasmon as above. When cold, whisk the jelly thoroughly for a few minutes, and a beautiful firm snow cream will result. Sugar, flavourings, or cream may be added during the whisking, which allows a large variety of dishes to be prepared. If the plasmon be dissolved with milk instead of water, the snow cream is richer, and can be made into a very nutritious ice cream.

\section{Plasmon Porridge}

is simply ordinary porridge to which has been added I teaspoonful of dissolved plasmon to every plate of porridge, and then boiled.

\section{Plasmon Butter.}

A teaspoonful of plasmon may be thoroughly kneaded into $\frac{1}{4} \mathrm{lb}$. of butter, and be used for making sandwiches. 
The following articles are also on the market already combined with plasmon-plasmon cocoa, chocolate, arrowroot, vats, tea, biscuits, blancmange custard.

Cismmen (Pricleaus) is a white, flake-like powder, odourless, tasteless, and soluble, and miscible with ordinary food and drink. It is free from starch and sugar, and keeps indefinitely. It is combined with other foods in much the same way as plasmon is. A diabetic milli can be made from it by the addition of water, a weak alkali, and saccharin.

Protin and Tilie are also similar preparations.

All these casein foods are of great service in improving the protein value of the diet. They are superior to meat preparations. They are useful in the treatment of acute fevers, diabetes, and many conditions of debility. They have a special value in the treatment of hyperchlorhydria, as the casein fixes the acid more effectively than other forms of protein.

Modifud milk-milk laboratorics.-The establishment of milk laboratories is a recent development of practical value for the feeding of infants. The milk is designated modified milk, the process consisting in separating the chief components of cow's milk and recombining them, to the proportion present in human milk. This system of feeding infants is known as percentage feeding, and was first introduced by Rotch, in America. In order to prepare modified milk by Rotch's method, we require:-(I) Pure cream containing the fat; (2) pure milk containing the albuminoids and no fat; (3) distilled water; (4) a 20-per-cent. solution of milk sugar, made fresh daily with distilled water; (5) lime-water.

As an example of prescribed diet of modified milk, Rotch gives the following prescription :-

For Girl cet. 6 years-Caturrhal Jaundice.

$\begin{array}{llll}\text { B. Fat } & \text {. } & \cdot & 0.50 \\ \text { Milk sugar } & \cdot & \cdot & 6.00 \\ \text { Albuminoids } & . & . & 4.00\end{array}$

Give 4 ounces every 2 hours. Send 12 tubes, each 4 ounces. Lime-water, 1,6 .

Various preparations of modified milk are sold as humanised milk. These consist of ordinary milk which has 
been modified in some way, as by the addition of cream or whey, or by a reduction in the amount of casein and the addition of lactalbumin, albumins, or peptones.

buddised milk:-The addition of peroxide of hydrogen to milk has been worked out scientifically as well as practically by Dr Budda of Copenhagen. It is claimed that by the use of the nascent oxygen, as evolved from peroxide of hydrogen in contact with milk at a suitable temperature, the milk is rendered practically sterile, and that its nutritive properties otherwise are unaltered. This milk is prepared on a commercial basis, at a cost very little in excess of ordinary milk. It is as yet too soon to say whether the claims for this preparation are as well founded as is claimed for it. Some cases of well-marked scurvy have been ascribed to its use.

\section{(2) Foods Prepared from Meat.}

These exist under the name of meat teas, meat extracts, meat juices, peptones, peptonoids, dried meat powders, and lozenges. A large number of meat preparations do not contain the nutritive constitutents of meat, or only contain them in very small proportions; on the other hand, they contain large amounts of extractives which may derange digestion and impair the action of the kidneys. Meat contains on an average about 20 per cent. of protein. It is, therefore, impossible to concentrate meat down to less than one-fifth of its bulk, if the total nutritive value of the protein is to be retained. When it is stated that $\mathrm{I}$ lb. of meat extract is equal to $34 \mathrm{lbs}$. of meat, it should be clearly understood that $\mathrm{I} \mathrm{lb}$. of the extract contains only the whole flavouring matter from $34 \mathrm{lbs}$. of meat, and nothing more. These extractives have no nutritive value as tissue-builders or energy producers, but have some value as stimulants of the digestive secretions and for removing temporarily muscular fatigue. Such preparations, therefore, as contain little or none of the nutritive constitutents of meat are to be regarded as flavouring agents rather than as foods. If given in too large amount they may induce thirst, diarrhcea, and other evidences of deranged health. It will 
be convenient to discuss these preparations in the following order :-

I. Meat teas and meat extracts.

2. Meat juices.

3. Meat powders and lozenges.

4. Partially digested preparations.

Meat teas and meat crtracts. - A meat tea or meat extract is prepared by cutting up the meat into small pieces, heating slowly in water, then boiling quickly; the product is then strained, the protein (which is coagulated by heat and which forms a mutritive sediment) is thrown away, and the result is a fluid with an agreeable flavour, consisting of water, extractives, salts, and a very small amount of gelatine. One pound of lean beef extracted with I pint of water, yields about 25 to 30 ounces of good beef-tea, which contains about $1:$ per cent. of protein and extractives. Some commercial meat teas are strengthened by the addition of some of the shredded-down meat fibres. Meat teas are often made from one of the proprietary meat extracts in place of fresh meat, and a meat tea so prepared compares very favourably with the home-made preparations, alike as to flavour, stimulating properties, and expense. The better known of these preparations are as follows :-

Mason's home-made beef-tea. Composition-

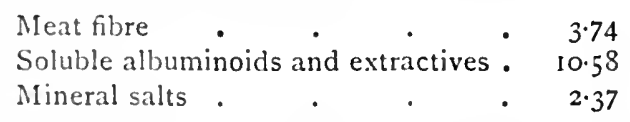

The directions are:-Dilute a tinful with a pint of water. This reduces the nutritive value to one-third, and brings it in strength to much the same proportion as in good homemade beef-tea. The cost works out at about $3 \frac{1}{2} \mathrm{~d}$. a pint. A comparison of the cost of this with that of other preparations may be given in tabular form:-

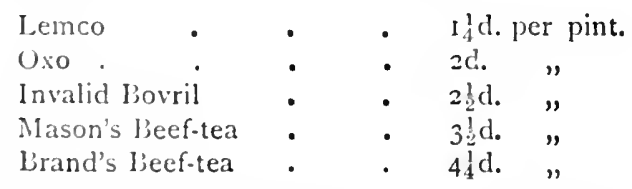

The cost of home-made beef-tea varies with the quality of meat used. One pound of meat yields $I_{2} \frac{1}{2}$ pints, and the cost 
can be calculated from the quality of beef. On the whole, home-made beef-teas as ordinarily prepared are more expensive than those made from the above meat extracts. All beef-teas have little nutritive value, but are useful stimulants. They are therefore an expensive form of diet. In fevers and certain debilitating conditions associated with impaired digestion, poor appetite, and furred tongue, the patient can take a hot, clear, more or less nutritive drink more readily than any other form of food. The rest to the digestive organs associated with the use of such a diet for twenty-four or forty-eight hours will be helpful in restoring the patient's capacity to digest and assimilate a really nutritive diet such as milk.

Of the pure meat extracts, Liebig's is the most representative: $34 \mathrm{lbs}$. of pure beef yield I lb. of extract, which makes 70 pints of beef-tea, each pint containing the extractives from $\frac{1}{2} \mathrm{lb}$. of meat. The composition of the extract is roughly as follows:-

$\begin{array}{llll}\text { Moisture } & - & - & 16 \text { to } 21 \text { per cent. } \\ \text { Mineral salts } & - & - & 18 \text { to } 22 ", \\ \text { Extractives } & - & - & 56 \text { to } 60 "\end{array}$

It contains no protein and no fat. Numerous modifications of Liebig's process have been introduced since it was recognised that the fluid had practically no nutritive value. These modifications consist in the addition of meat fibre, so as to give the extract some definite nutritive value. The following table gives the approximate composition of the chief meat extracts :-

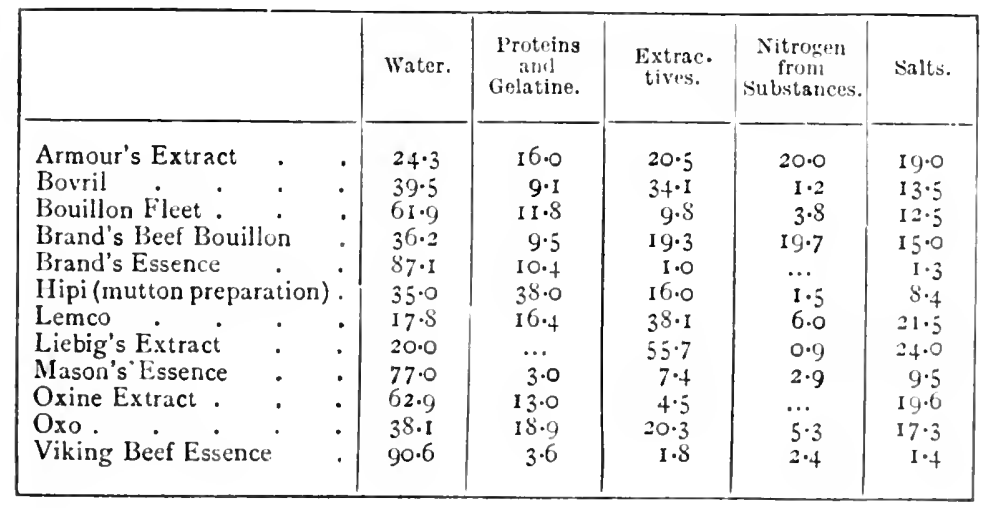


These extracts have consilerable value as stimulating, and in proportion to the protin frisent, nutritive beverages. They can advantageously be used to adel to other foodstuffs. The following recipes will be found useful :-

\section{Extract Soup.}

Make according to directions, and add albumin water (p. 47), made from the white of one or two eggrs.

\section{Eitract Soup.}

leat up ergs, place it in a soup bowl and pour over it a pint of hot (not boiling) extract soup, as directed.

\section{Milk Bowril.}

The taste of milk can be completely disfruised by making Invalid liovril or other meat extract as directed on the bottles, but using boiling milk instead of water.

\section{Extract Custard.}

Take "Milk Hovril" and to this add one or two eggrs as directed under Custards, boiled and baked (p. 49), and a delightfully flavoured dish is prepared.

\section{Mcat Juice with Mill.}

Three-quarter pound rump steak of fillet of beef free from fat, 1 pint of milk. Armour's beef extract or any other meat extract for flavouring.

Pass the steak through a fine mincing machine, or scrape very finely; this should give $7 \mathrm{oz}$. of meat pulp. Mix thoroughly with the milk, and pass through a fine strainer or muslin. This should give about a pint of fluid of the consistency of cream. Half a teaspoonful of extract is to be used for flavouring.

The preparation can be warmed by standing the vessel in hot water; excessive heat causes curdling (coagrulation).

There are a number of methods of cooking eggs with meat extracts-which make a pleasant variety.

\section{Stcamcd Egg.}

1 fresh egg.

$\frac{1}{2}$ teaspoonful of meat extract. Salt

Grease a cup, into this add the milk in which the extract has been dissolved; break the egry gently and drop it in ; sprinkle over with salt. I'lace the cup in a saucepan and pour enough boiling water to come up half-way. Boil slowly for ten minutes, and turn on to a slice of toast or buttered toast, and serve hot.

\section{Sacroury Scrambled Eggrs.}

Beat up an egry ; to this add $\frac{1}{2}$ ounce of milk to which has been added a $\frac{1}{2}$ teaspoonful meat extract. Nelt a little butter in a saucepan, and 
when thoroughly hot pour in the egre and milk mixture; keep beating with a fork until the eys has set. Serve on slice of hot butiered toast.

\section{Savoury Veal felly.}

A pint of jellied veal stock, I egrg, I teaspoonful meat extract. Melt the veal stock, dissolve the meat extract, and beat up the egs. Mix the three ingredients, add salt to taste. Place in a basin, and when cold a nicely flavoured jelly will turn out.

Meat juices.-Meat juices are quite different from the extracts. They consist of the fluid substance contained in the muscle fibre. They are prepared by extracting the juice by strong pressure, and subsequently concentrating the product by evaporation in vacuo. Heat has to be avoided, as it coagulates the soluble proteins. The process is expensive, and the product is liable to decomposition. Glycerine, salt, or other preservative is added. A true meat juice should yield a spectrum of oxyhæmoglobin.

Home-made fresh meat juice is cheaper, and, on account of its freshness, more valuable than the proprietary preparations. The blood-red colour characteristic of many of the meat juices is repugnant to many patients. This difficulty can be overcome by serving in a red glass or cup. The preparation of home-made beef juice is given on p. 77 .

The approximate composition of the beef juices is given in the table (Sutherland):-

\begin{tabular}{|c|c|c|c|c|c|}
\hline & Water. & $\begin{array}{l}\text { Proteins } \\
\text { and } \\
\text { Gelitine. }\end{array}$ & $\begin{array}{l}\text { Extrac. } \\
\text { tives. }\end{array}$ & $\begin{array}{c}\text { Nitrogen } \\
\text { from } \\
\text { substalces. }\end{array}$ & $\begin{array}{c}\text { Mineral } \\
\text { Substances. }\end{array}$ \\
\hline Armour's Beef Juice & $74 \cdot \mathrm{I}$ & $8 \cdot 3$ & 9.5 & & $7 \cdot 5$ \\
\hline Armour's Soluble Beef . & 23.0 & $33 \cdot 3^{1}$ & 13.4 & 6.7 & 13.2 \\
\hline Bovinine . . & $8 I .0$ & I 3.9 & $3 \cdot 4$ & $\ldots$ & I.O \\
\hline Bovril Beef Juice. & $52 \cdot 0$ & $7 \cdot 2$ & 1.4 .0 & 20.7 & $5 \cdot 9$ \\
\hline Brand's Meat Juice & $59 \cdot \mathrm{I}$ & $15 \cdot t^{2}$ & $16 \cdot 5$ & $\ldots$ & 8.8 \\
\hline Burgoyne's Meat Juice. & $+9 \cdot 5$ & $13 \cdot 0^{3}$ & $8 \cdot 1$ & $\ldots$ & $14 \cdot 2$ \\
\hline Esco leef Juice . & $52 \cdot 4$ & 7.6 & $5 \cdot 9$ & $13 \cdot 6$ & 20.3 \\
\hline Lipton's Fluid Beef & 42.9 & $22 \cdot 1^{4}$ & 18.7 & $\ldots$ & 16.2 \\
\hline Liquor Cirnis . & $5^{6.0}$ & 6.9 & $5 \cdot 0$ & $28 \cdot 4$ & $3 \cdot 5$ \\
\hline Puro . . . & $3^{6.6}$ & $30 \cdot 3$ & $19 \cdot 1$ & $\ldots$ & $9 \cdot 7$ \\
\hline Valentine's Beef Juice & 60.3 & 0.5 & $29 \cdot 1$ & $\ldots$ & $11 \cdot 3$ \\
\hline Vitalia Meat Juice & 66.5 & $21 \cdot 0$ & $6 \cdot 0$ & $\ldots$ & $6 \cdot 5$ \\
\hline IVyeth's Meat Juice & 44.8 & $35 \cdot 0^{5}$ & $\ldots$ & $\ldots$ & $17 \cdot 1$ \\
\hline
\end{tabular}

1 Thirty.two per rent. soluble. a Five per cent. coagulable. 3 Three ler ceut. coa duble. 4 Six jer cent. cuagulable.

Puro is extremely rich in protein, which is present in the 
form of egs albumin. It is a dark brown fluid, becoming red on the addition of water. Its colour is repugnant to many patients, but the flavour is agreeable. However, if such a food is necessary, it is cheaper and just as efficacious to take the white of an $\mathrm{cgg}$ (which contain approximately I 2 per cent. of egg albumin), with this prepare albumin water (p. 47), and add to it either a few drops of meat cxtract or home-made beef-tca. In this way a nourishing fuid rich in protein is prepared, at a much less cost than by the use of the proprictary preparations.

Bowinine is one of the cheapest meat juice preparations, it contains a large proportion of protein, and when examined with the spectroscope gives the spectrum of methremoglobin. It probably consists of blood and slycerine. There is no doubt its nutritive value is high, but its flavour is not very agrecable. The amount of coagulable protein is much less in Brand's beef juice, Bovril Company's juices, Liquor carnis, and Wyeth's, though all show signs of unaltered blood and may rightly be regarded as uncooked juices.

Special attention may be made of Valentine's meat juice, which according to Chittenden only contains .55 per cent. proteins, and has therefore no more claim to being a nourishing meat juice than many of the beef extracts and soups.

Vinsep is made of blood, boric acid, and a little alcohol, and contains $I \sigma$ per cent. of protein; the flavour is not agrccable. Alcoholic compounds of meat extracts should all be condemned-even if strengthened with malt or other carbohydrate food. These are apt to induce the alcoholic habit.

Dried Meat Powders. - These can be made at home by mincing cold boiled beef, drying it thoroughly in a slow oven, and grinding it up in a coffee-nut mill. These can also be bought in the form of various proprietary foods, such as Brand's nutrient powder, l'emmican, Mosquera beef meal, Meatox, and others. In the preparation of a meat powder, nothing is removed except the water of the fresh meat and the tough, stringy, and indigestible portion rejected in sifting. One ounce of the powder is equivalent in nutritive value to 4 ounces of fresh lean meat. A meat powder may be utilised to increase the nutritive value of soup, or given in the form of sandwiches. 
Pemmican.-To every fifty parts of powdered meat forty parts of fat are added, the resulting product being a food rich in both proteins and fat.

Mosquera leef meal is a preparation of high nutritive value. It contains 90 per cent. of nutritive inaterial, 13 per cent. of this being fat. The meat is partially digested by the ferment of pineapple juice.

Meatox is a powdered beef which contains above 75 per cent. of nutritive matter.

Brand's nutrient powder consists of powdered muscle fibre from which the moisture has been removed at a temperature below the coagulation point of the muscle proteins; it is readily digested and assimilated. Reference is later made to Somatose, a similar preparation, in which the proteins are partly transformed into albumoses.

Marvis is a dried fish powder, consisting largely of proteins; it can be used in the same way as other meat powders.

Meat lozenges, beef-tea tabloids, and all combinations of meat extracts with orher foodstuffs are not to be commendecl. They are quite useless as a food, and are simply concentrated salts and extractives.

\section{(3) Proprietary Foods made with Esrss.}

These exist usually as combinations with milk proteins, animal proteins, and fat ; the most useful are the following:Virol, made from marrow fat, yolk of cggg, egg-shells, malt extract, and lemon juice, is a palatable preparation of considerable nutritive value. The maker's analysis gives the composition as 20 per cent. of fat and 60 per cent. of malt extract. Virvis is a similar preparation of much the same composition. Sanose is a powder consisting of about So per cent. casein and 20 per cent. of albumose, derived from white of egg. Muffler's food, sold by the Aylesbury Dairy Company, consists of desiccated milk, powdered white of egg, wheaten flour, and lactose. Puro, a meat juice preparation (p. 165), contains much egg albumin. The preparation prepared by Brand, termed Fever food, is most nutritious; it consists of essence of beef, eggs, and cream. In appearance it resembles custard, and has a very agreeable flavour, 
which is quite distinct from the meaty Mavour of the beef juices and extracts.

(4) Proprictary Foods madi from Vegctable Proteins.

The chief vegetable protein foods are:-Aleuron, prepared from the proteins of wheat-a white, tasteless, fairly soluble preparation; also Aleuronat, a yellowish-brown powder, almost insoluble in water. These are extremely rich in protein, fairly cheap, and are valuable in the feeding of diabetics. Glidine, a concentrated protein food is prepared wholly from wheat; it is absolutely free from carbohydrate, and is casily digested and assimilated. L.egumin, a vegetable casein, is made from pulses, and is a useful vegetable protein food. Roborit is made from cereals; it is the most soluble of all the vegetable protein preparations. Tropon and lisox are two preparations of recent introduction, in which the protein of vegetables is combined with the protein of animals, chiefly fish. They are used chiefly stirred up in thick soups and purécs. Further reference is made to proprietary vegetable preparations in the vegetarian section, under Nut meats, and Nut butters (p. 522).

\section{B. Carbohydrate Foods.}

Many of these foods are made from wheat flour or mixed flours, and consist of practically unchanged starch.

As examples, mention may be made of Albany food, Marr's food, Ridge's, Robinson's patent barley, Scott's oat flour, Hovis oats, Quaker oats, and other varieties. Sometimes the flour is baked, the heat converting a small amount of the carbohydrates into a soluble form. In other foods of the same hind a small amount of fat and a pulse food are adderl, e.g., Falona, consisting of baked cereals and bran flour; also lutrox, made from cercals and a pea flour. Sugar may also be added, as in Frame food (sec p. S9). The composition of these fouds is given in the table on the following page.

\section{Cow's Milk with Cereal Additions.}

Mention must be made of some proprietary foods made with cow's milk to which has been added carbohydrate from cereals. There are three varieties:-

I. Foods with the starch practically unchanged. 


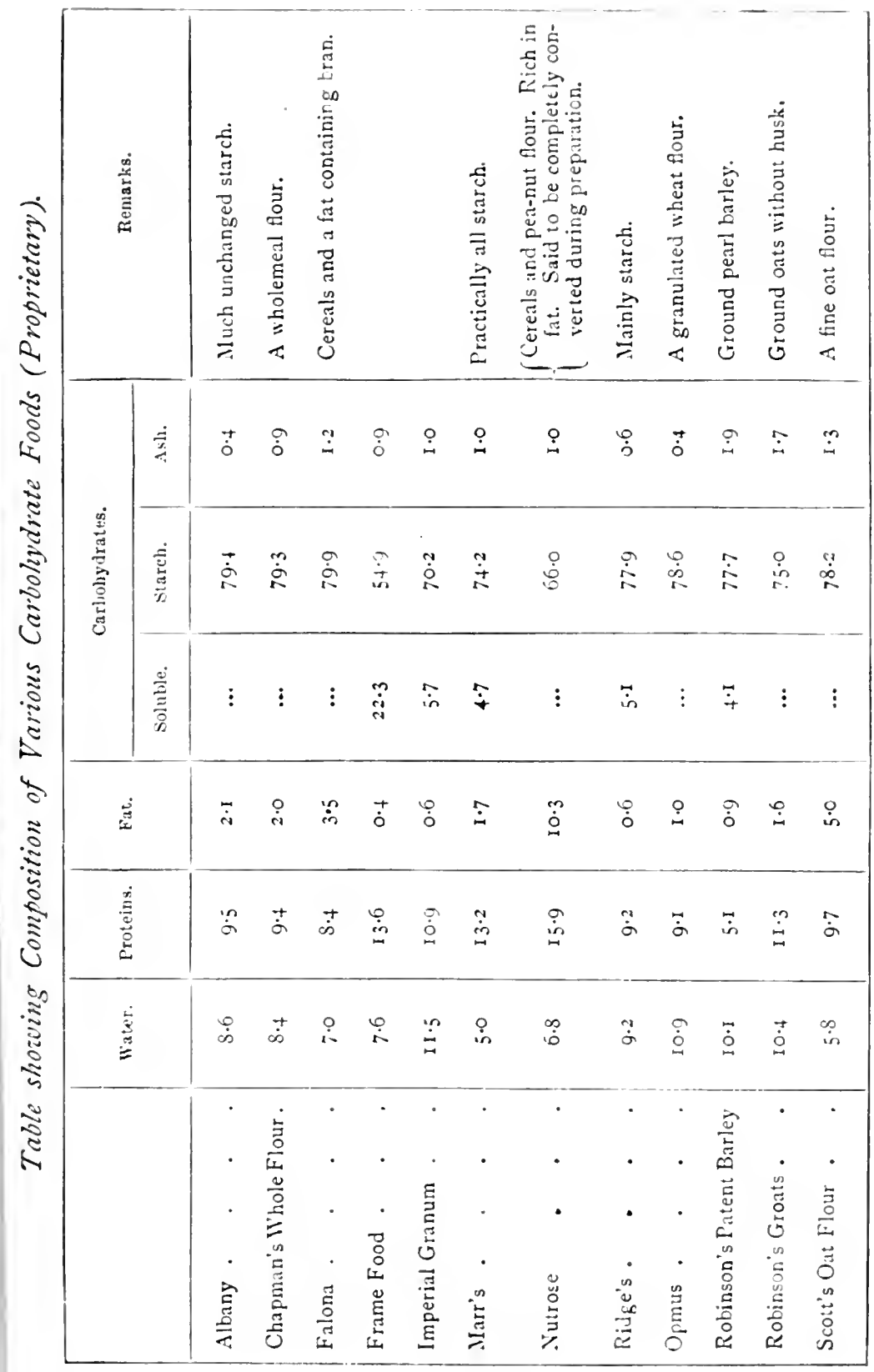


2. Fonds with the starch partly or entirely converted into soluble carbohyedrates.

3. Foods partially predigested.

Fonds arith the starch fratically unchanged.-The chicf ingredients of these foods are condensed milk, baked wheat flour, and sugar. These foods are rich in starch and sugar and deficient in fat and proteins, and from their composition are unsuitable foods for infants. The chief varicties are AngloSwiss, Amcrican-Swiss, and Franco-Swiss foods.

\begin{tabular}{|c|c|c|c|c|c|c|c|}
\hline & \multirow{2}{*}{ 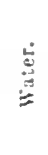 } & \multirow{2}{*}{$\begin{array}{l}\dot{E} \\
\text { 产 } \\
\text { 总 }\end{array}$} & \multirow[b]{2}{*}{ is } & \multicolumn{2}{|c|}{ Carlouluglrates. } & \multirow[b]{2}{*}{ 富 } & \multirow[b]{2}{*}{ Remarks. } \\
\hline & & & & 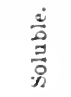 & $\begin{array}{l}\text { 离 } \\
\text { 范 }\end{array}$ & & \\
\hline Anglo-Swiss. & $6 \cdot 5$ & $10 \cdot 26$ & 4.95 & $46 \cdot 4$ & 29.4 & 2.02 & Much cane sugar. \\
\hline Americ.n-Swiss & $5 \cdot 6$ & 10.54 & 5.81 & $+5 \cdot 3$ & $30 \cdot 0$ & $\mathrm{I} \cdot 2$ & " \\
\hline Franco-Swiss. & $4 \cdot 4$ & 13.0 & $3 \cdot 70$ & 46.0 & $30 \cdot 8$ & $1 \cdot 4$ & \\
\hline Muffler's Food. & $5 \cdot 6$ & $14 \cdot 3$ & $5 \cdot 8$ & $27 \cdot 4$ & $44 \cdot 4$ & & $\left\{\begin{array}{c}\text { Contains powdered } \\
\text { white of egg. }\end{array}\right.$ \\
\hline
\end{tabular}

Combination Foods. - Virol is a good cxample of a combined food. It is made from malt extract, marrow fat, yolk of egg and egg-shells, and lemon juice. Its approximate composition is as follows:-

\begin{tabular}{|c|c|c|c|c|}
\hline Water. & Proteln. & Fat. & $\begin{array}{c}\text { Carbolydrates, } \\
\text { Solutle. }\end{array}$ & Ash. \\
\hline 24.0 & $4 \cdot 1$ & 10.7 & 59.2 & $\mathrm{I} \cdot 8$ \\
\hline
\end{tabular}

This is an excellent preparation. Cremalto is a mixture of Ieronshire cream and malt, with the following composition :-

\begin{tabular}{|c|c|c|c|c|}
\hline Water. & I'roteln. & Fat. & Carboliydrates. & Ash. \\
\hline 22.2 & $6 \cdot 4$ & 20.2 & $44 \cdot 6$ & $\mathrm{I} \cdot 7$ \\
\hline
\end{tabular}

Pemmican consists of the dried product of the best beef and fat, in the proportion of 50 of the former and 40 of the latter. This is also a useful compound. Mostelle grape juice is a nutritive, wholesome, non-alcoholic drink, made 
from the pure fruit of the grape, procured by pasteurisation before fermentation has taken place. It contains about 25 per cent. of sugar, and has a very low degrec of acidity: This may be used to replace fresh fruit if the latter is not availabls.

\section{Classification of Predigested Preparations.}

I. Ferments for predigesting foods at home.

2. Predigested proprictary milk foods, either alone or in combination with starch.

3. Predigested proprictary meat preparations.

4. Malt and malt extracts.

5. Malted foods, in which starch is partially changed or completely changed into soluble carbohydrates. "Invalid foods."

I. Ferments.-In the prcparation of predigested foods two classes of agents have to be relied upon: the action of the digestive ferments, of which pepsin and pancreatic extract are best known, and which act upon the proteins and carbohydrates of the food; and sccondly, the vegetable ferment diastase or malt, which has the property of converting starch, an insoluble substance, into the soluble sugar maltose.

The digestive ferments find their use in the following directions- $(a)$ as therapeutic agents, being used as remedies for indigestion; (b) as peptonising agents, for the artificial digestion of food. These ferments are obtained by simple infusion of the fresh gland or the sccreting membrane, and in the proper media behave in the same manner as the natural juices. They may be dried and made into powders. These digestive ferments possess enormous energy, being capable, even when only in an infusion, of converting into solution many thousand times their weight of alimentary substance. Pepsin is found only to be active in an acid medium, pancreatic ferments in neutral, alkaline, and feebly acid solutions. The dried powders are preferable to the fluid preparations, being more constant in their action. An additional point of importance is that the dried powders hardly effect the flavour of the food treated, while the infusions all tend to impart their peculiar repulsive taste to the food. 
Pepsin can be aclministered by the month to aid fecble digrestion or to relicre indisestion, but it is not available for peptonising ford for the sick, its action being restricted to albuminnus substances in an acid medium. This has to be remembered, since the words peptonised and peptone are crroneously associated with pepsin. Practically all predigestion of foods is donc with pancreatic ferments. lincreatic cxtract contains a ferment capable of transforming proteins into peptones like pepsin, but it acts in a neutral or allialine or faintly acid medium ; another ferment, trypsin, has a special power in digesting milk; there is in adilition a starch-digesting principle.

l'eptonised fools should only be employed when it is necessary to assist the digcstive organs for a time by giving the alimentary canal some degree of physiological rest.

They are indicated in many acute diseases associated with impairment in the gastric functions, such as gastric ulcer, cancer of the stomach, and some severe constitutional diseases in which irritability of the stomach is a prominent featurc. Some of the so-called humanised milks arc prepared by partial peptonisation or pancrcatisation of the milk proteins.

Pepsin in the form of pepsin powder or tablets, Pepsencia (Fairchild's), or Liquor pepticus (Benger's) is administered directly after a meal, and is not mixed with the food before being swallowed, bccause, as alrcady explained, to get it to act on the food the pepsin must be mixed with dilute hydrochloric acicl, and this spoils the flavour of the food.

Savory \& Moorc have produced a saline cssence of pancreatine, and saline essence of pepsin; these have an agrecable kctchup odour and flavour, and may be used with roast meat or fowl as a sance, or a small quantity may be ardecrl to becf-tea, soup, or broth. In actually peptonising milk and forels by mcans of pancreatic forments there are several reliable preparations that may be cmployed. Liquor pancreaticus (Benger's), Allenbury's Extractum pancreaticum and peptonising powders, and byno pancreatin are all reliable; the latter can be userl either for peptonising food or can be taken with meals. Fairchild's " \%ymine" powder and peptonising tubes are always rcliable. Savory \& Moore manufacture 
peptonisine pellets, each weighing 5 grammes. This form of powder does not require a large excess of allialli, and the flavour of the foodstuff is hardly altered.

All these peptonising preparations give full directions for their use on their wrappings; in addition the followings recipes may be given:-

\section{Peptonised Milk.}

I pint milk. 1 pint water.

2 teaspoonfuls Liquor pancreaticus.

20 grs. (1) small teaspoon) bicarbonate of soda.

Allow the milk to stand. Skim off the cream. Dilute the skimmed milk with i pint of water, and heat to a temperature of $140^{\circ} \mathrm{F}$. Mix with the warm milk the Liquor pancreaticus and $20 \mathrm{grs}$. of bicarbonate of soda. The mixture is poured into a covered jar, with a tea-cosy over it, and put near the fire. Let this stand for one and a half hours. Ijring the mixture to the boil for two or three minutes to arrest any further fermentative action, which will make the milk unpalatable. Now add the cream that was removed, and it is ready for use.

When peptonised by the cold process described below, the milk has no taste or evidence of the presence of the peptonising agcnt, and is especially suitable for dyspeptics.

Method.-Mix the peptonising ayent in cold water and cold milk as above, and immediately place the bottle on ice without subjecting it to any heat. When neeled, pour out the required portion, and use in the same manner as ordinary milk.

It is recommended to try the milk by the cold process in those cases in which food is not quickly digested, and in which the digestive functions are impaired or evein practically suspended. It has been found in many such cases that the peptonising principle exerts sufficient action upon the milk in the stomach to ensure its digestion and proper assimilation.

\section{Effervescent Peptonised Milk.}

Put some finely crushed ice in a glass and then half-fill it with A pollinaris, Vichy, or carbonated water as preferred, and then quickly pour in the peptonised milk and drink during effervescence. Ieptonised milkmay be made agreeable to many patients by serving with a little grated nutmeg, swcetened, or flavoured with a little brandy.

Peptonised Gruels are acted upon by the ferment, the 
starch being transformed into sugar, and the albuminoid matters are peptonised.

The gruel may be made from any farinaccous article in use-oatmeal, Quaker oats, etc. The gruel should be thoroughly well boiled. It is placed in a covered jar when it is below the temperature of $140^{\circ} \mathrm{F}$, the pancreatising agent is added, and the jug is covered and kept warm as before. After standing two hours, boil the mixture for five minutes, and then carefully strain.

\section{Peptonised Milk Gmel.}

This was a favourite preparation of Sir W. Roberts. It is an artifically digested milk, and forms a complete and highly nutritious food for weak digestions.

A thick gruel is made from farinaceous material (see p. 296). To the boiling gruel add an equal quantity of cold milk. This will then have a temperature of about $140^{\circ} \mathrm{F}$. To each pint of the milk gruel add 3 teaspoonfuls of Liquor pancreaticus and $20 \mathrm{grs}$. of sodiurn bicarbonate (or other peptonising agent). Let it stand covered in a warm place for two hours, boil for five minutes, and then strain. The peculiar flavour of predigested milk is quite masked by this process, and most invalids will take it without the least objection.

\section{Peptonised Milk Lemonade.}

Juice of I lemon.

1 gill peptonised milk.
I gill effervescing water.

I tablespoonful o: sugar and rice.

Fill a small tumbler one-third full of crushed ice, add the water, lemon juice, and the sugar to the ice, and fill up the glass with milk.

\section{Peptonised Mill Punch.}

Take a small tumbler and fill it about one-third full of crushed ice, pour on to this a tablespoonful of St Croix rum, and half a tablespoonful of brandy' then fill the glass with peptonised milk, stir it well, sweeten to taste, and sprinkle over the top of the mixture a little grated nutmeg.

\section{Peptonised Meat.}

Add 4 ounces of minced meat to $\frac{1}{2}$ a pint of water, and gradually bring to the boil. Then add $\frac{1}{2}$ a pint of cold water, so as to reduce the temperature to about $140^{\circ} \mathrm{F}$, and add $30 \mathrm{grs}$. of Zymine or other peptonisingr agent, and zo grs. of bicarbonate of soda. Keep warm for three hours and the meat will be peptonised.

\section{Peptonised Meat, Broths, and Teas.}

$\frac{1}{2} \mathrm{lb}$. lean beef, finely minced. I pint water.
I tablespoonful Liquor pancreaticus. 20 grs. bicarbonate of soda.

Mix together and simmer slowly for one and a half hours; when it has cooled down to $140^{\circ} \mathrm{F}$, add Liquor pancreaticus; keep it warm under 
a cosy for two hours; occasionally shake it up, then decant off the liquid portion and boil for five minutes.

This has a relative value in nitrogenous materials almost equal to milk. The tea can be flavoured with celery seed or vegetables, or thickened with sago, breadcrumbs, etc. (see p. 75).

Peptonised Soups, Blancmanges, and Jellies. - With a little ingenuity a variety of peptonised dishes can be obtained. There is no difficulty in doing this if it is always remembered that any peptonised fluid after standing at most two hours must be boiled, in order that the action of the ferment may be arrested. For the making of soups, use peptonised gruel (p. I73) instead of water. For the making of blancmanges, peptonised mill is added to the cream. For jellies, mix the Liquor pancreaticus with gelatine in the proportion of 2 teaspoonfuls to the pint, allow it to stand for one and a half hours in a warm place, and then check the further action by boiling.

\section{Peptonised Oyster Soup.}

Take half a dozen large oysters with their juice, and $\frac{1}{2}$ a pint of water. Heat in a saucepan until they have boiled briskly for a few minutes. Pour off the broth and set aside.

Mince the oysters finely, and reduce them to a paste with a potato masher. Place the oysters in a jar with the broth that has been set aside, and add Liquor pancreaticus 2 teaspoonfuls, sodium bicarbonate $15 \mathrm{grs}$. Let the jar stand in hot water or in a warm place for one and a half hours, then pour into a saucepan, and add $\frac{1}{2}$ a pint of milk. Heat over the fire slowly to boiling point, flavour with salt and pepper, and serve hot. Any undigested oysters may be strained out. The milk will be sufficiently digested during the few minutes which will elapse before the mixture boils, if heated gradually.

2. Predigested Milk Products.-Mention must be first made of Fairchild's peptogenic milk powder. By means of this powder and process cow's milk is so modified as to conform remarkably to normal mother's milk, thus affording a food for infants exactly suited to the powers of infant digestion; the amount of the predigesting process can be gradually reduced until the infant can digest normal mill:. Savory \& Moore supply a number of concentrated peptonised milli preparations-viz., condensed peptonised milk peptonised cocoa and milli, a really excellent and highly 
nourishing preparation; Café zylak, a peptonised coffee and milk (this when diluted with hot water makes a superior cup of café au lait); milk chocolate peptonised is a specially grood sweetmeat for children; all are palatable and nutritious foods, which can be very readily prepared. Some of the milk companies prepare a predigested milk, and predisested varieties are sold under the name of Loeflund's peptonised milk and liaclihaus mitk. These are not to be recommended, as there is no means of knowing how far the predigestion has been carried.

Mill in combination with cereals with the starch partly or cntirly conicrted into soluble carbohydrates.-The chief foods in this group are given in the table on the following page, which gives also the composition.

From the point of view of infant foods these foods have all the disadvantages of condensed milk, in respect of lack of freshness and deficiency of fat. The chief difference between these and condensed milk preparations is the form of the soluble carbohydrates in place of the cane sugrar.

3. Predigested Meats and Peptones.-The advantages of having a meat nutriment which contains the albumins in a soluble and readily assimilable form is obvious in the treatment of those patients in whom the digestive powers are more or less in abcyance, either in acute or chronic medical conditions or in some surgical emergencies. Predigested soups and meats can be prepared at home (see p. 175 ); there are also many preparations in the market in which the jroteins have been largely converted into albumins and peptones. These include various preparations of peptones, peptonoids, fluid meats, meat jellies, and meat powders The strong meaty odour and bitter taste of the peptones is an objection to their use to many patients. A further difficulty sometimes cncountered is the occurrence of vomiting and diarrhoea induced by the albuminoids and peptones. The composition of the various preparations varies widely, the amount of protein-albumins and peptones--varying from .5 per cent. in Valentine's meat juice, to over 70 per cent. in Somatose. In some of the preparations, e.g. Carnrick's, a large amount of carbohydrate is present, this being derived 


\begin{tabular}{|c|c|c|c|c|c|c|c|c|c|}
\hline 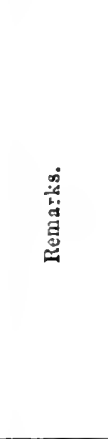 & 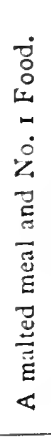 & 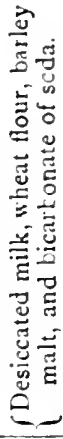 & 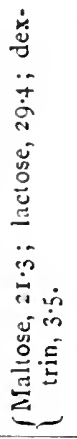 & 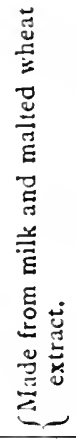 & 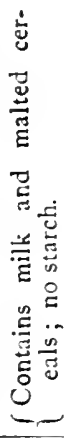 & 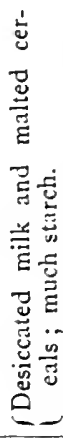 & 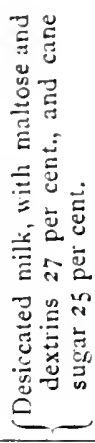 & 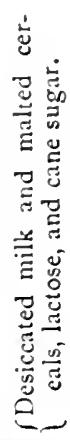 & 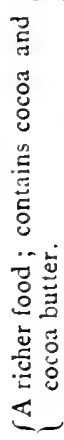 \\
\hline 离 & $\stackrel{m}{m}$ & $\stackrel{\infty}{i}$ & $\ddot{\dot{n}}$ & $\stackrel{\varphi}{i}$ & $\stackrel{\vec{i}}{\dot{d}}$ & $\stackrel{\circ}{\longrightarrow}$ & $\stackrel{\text { i }}{\circ}$ & $\stackrel{+}{m}$ & $\stackrel{n}{m}$ \\
\hline \multirow{2}{*}{ 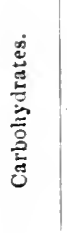 } & $\vdots$ & $\vec{o}$ & $\vdots$ & $\vdots$ & $\stackrel{\circ}{\circ}$ & $\stackrel{a}{\circ}$ & $\begin{array}{l}\stackrel{n}{m} \\
\stackrel{n}{n}\end{array}$ & $\stackrel{\tilde{D}}{\tilde{D}}$ & $\stackrel{m}{\ddot{\Xi}}$ \\
\hline & $\overrightarrow{\dot{i}}$ & $\stackrel{1}{\tilde{\theta}}$ & 辛 & 苟 & $\vdots$ & $\vdots$ & $\begin{array}{l}\dot{d} \\
\dot{D}\end{array}$ & $\stackrel{\varphi}{i n}$ & $\ddot{a}$ \\
\hline 总 & $\stackrel{m}{\dot{d}}$ & $\stackrel{\infty}{\dot{\infty}}$ & $\stackrel{\infty}{\stackrel{\sim}{\sharp}}$ & $\stackrel{?}{\ddot{n}}$ & $\vec{i}$ & $\stackrel{\varphi}{\text { in }}$ & $\ddot{n}$ & $\stackrel{\circ}{i n}$ & مי \\
\hline 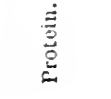 & $\ddot{\sigma}$ & $\stackrel{+}{\dot{\omega}}$ & $\stackrel{\circ}{\rightarrow}$ & $\ddot{\circ}$ & $\overrightarrow{\dot{m}}$ & $\stackrel{1}{\infty}$ & $\ddot{\dot{I}}$ & $\vec{b}$ & 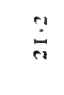 \\
\hline \multirow[t]{2}{*}{ 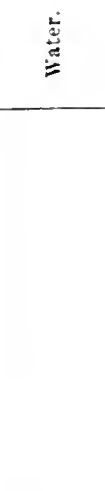 } & is & $\stackrel{\sim}{i}$ & $\stackrel{\dot{m}}{\dot{m}}$ & $\begin{array}{l}\ddot{+} \\
\ddot{+}\end{array}$ & $\stackrel{0}{\circ}$ & $\stackrel{\infty}{\infty}$ & $\stackrel{\infty}{i}$ & $\stackrel{\circ}{n}$ & $\dot{q}$ \\
\hline & 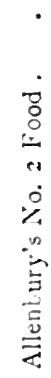 & 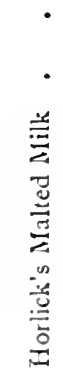 & 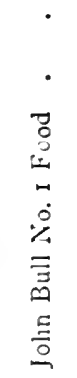 & 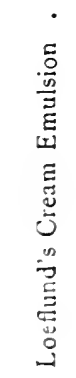 & 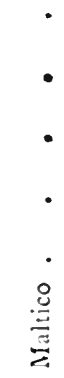 & 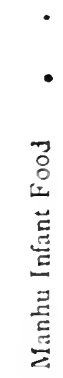 & 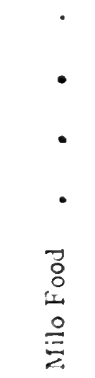 & 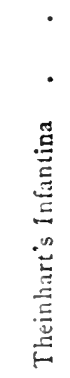 & 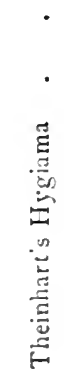 \\
\hline
\end{tabular}


from wheat. The approximate composition of the chief peptone preparations is given in the table on p. I79.

Somotosi is a meat preparation in which the albumin of the meat is mainly converted into albuminoids. It is a sreyish powder, freely soluble in water, forming a practically tasteless solution. It contains from 60 to 70 per cent. of protein. It can be given in water, in tea, in soup, or in milk, in which it readily dissolves. One teapoonful is equal to about a $\frac{1}{2}$ ounce of lean meat. It costs Is. Sd. per ounce, and yiclds from that amount only as much nourishment as is present in about a $\mathrm{lb}$. of beef. It is a valuable preparation for increasing the nutritive value of other foods. Somatose is supplicel in three forms: (a) somatose; (b) iron somatose, an organic combination of somatose and iron; (c) milk somatose, which contains somewhere about 5 per cent. of tamnin.

Sanory \& Moore's meat peptone is another useful concentrated form of nourishment. It possesses a full, meaty flavour. It may be used as soup, or spread between bread and butter as sandwiches.

Benger's peptonised jellies. - These consist of meat and chicken respectively, boiled and digested by means of the tryptic ferment in the Liquor pancreaticus, by which means almost all the flesh is converted into soluble bodies. The fluid is then made into a jelly by the use of gelatine. These jellies can be used culd, or dissolved with hot water to form a soup.

I'anopeptone is made from both meat and cereals, and claims to contain the nutritive principles of beef and bread.

4. Malt Extracts-Diastase and Maltose.-Diastase or malt is a regetable ferment which has the property of converting starch into the soluble maltose. In nature it is the action of diastase which causes the ripening of fruits and vegetables by converting their starches into dextrins and sugars. Diastase is soluble in water and weak alcohol, and insoluble in strong alcohol; it is much more powerful than the ferments in saliva and the starch-splitting ferment of the pancreatic juice. It acts in alkaline solutions, but unlike the above ferments it continues to act in acid media, hence its action is not disturbed by the gastric juice. 


\begin{tabular}{|c|c|}
\hline 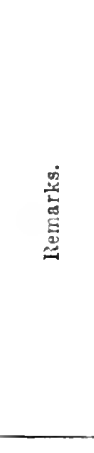 & 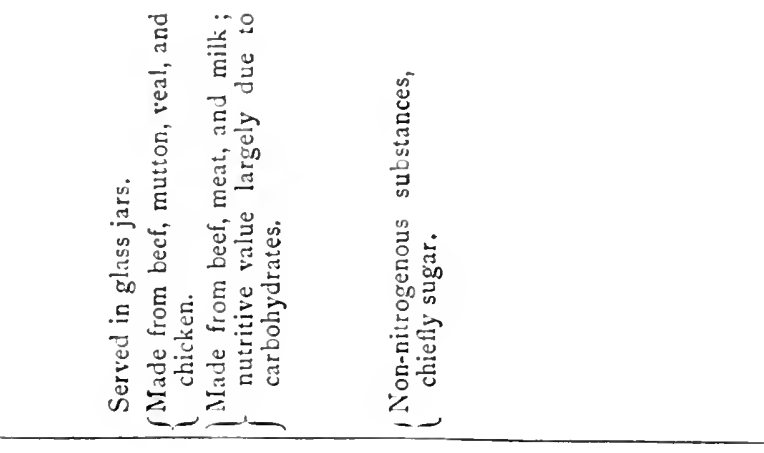 \\
\hline 荡 & 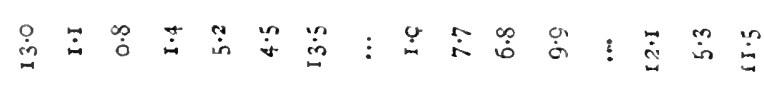 \\
\hline 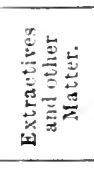 & 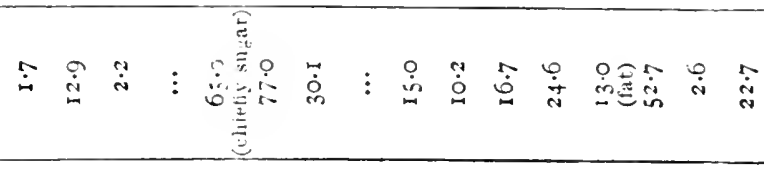 \\
\hline 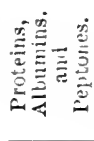 & 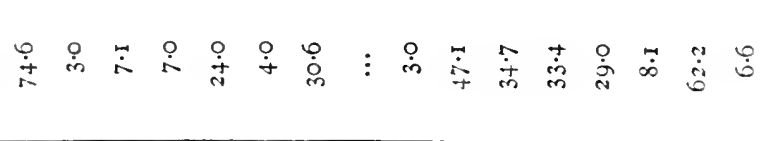 \\
\hline 总 & 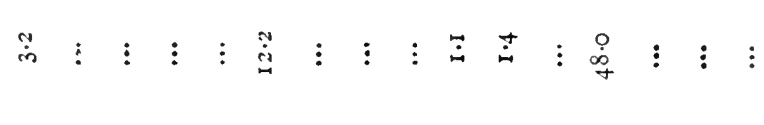 \\
\hline 总 & 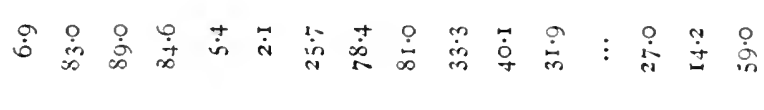 \\
\hline & 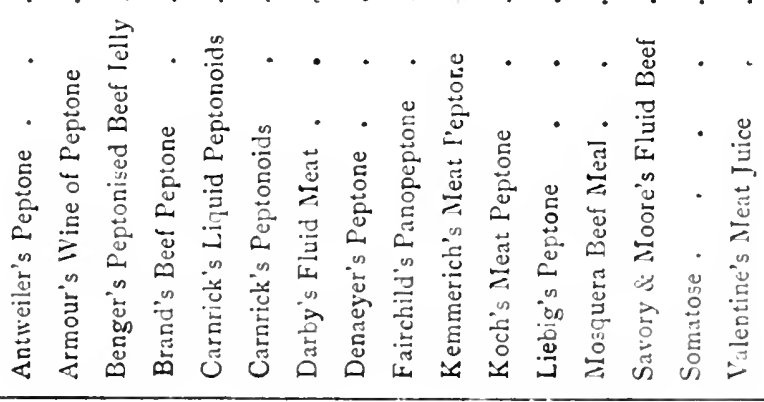 \\
\hline
\end{tabular}


Farinaceous meal of any kind mixed with onc-eighth of its weight of ground malt forms a highly digestible combination. These malted foods are in great demand for the feeding of invalids and children in any condition where the digestive power has been weakened, $c$ s.s., convalescence from fever, tuberculosis, sepsis, neurasthenia, and disorders of digestion. Malt extracts can also be made and added to any ordinary farinaceous dish.

Malt extracts are malt infusions evaporated down in arace at a low temperature in order not to elestroy the diastatic ferment; this malies them expensive. The average percentage composition of malt extracts is as follows:-

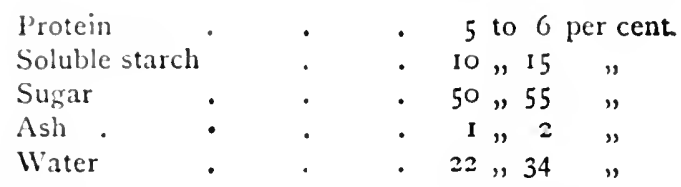

Malt extracts and maited foods in general are simply predigested starches, with other nutritive substances as above. A variety of malt extracts and malted foods are in the market, and these are of decided value in the treatment of many subacute and chronic diseases, such as neurasthenia, tuberculosis, and some forms of gouty dyspepsia. As foods they are, however, deficient in fats and proteins. A useful combination would be a farinaceous meal of any kind mixed with one-cighth of its weight of ground malt. The chief proprietary extracts of malt are :-

I. Kepler's malt cxtract is a thick, treacly preparation, and can be given in teaspoonful doses after meals in milk or sodawater, or it may be spread on any form of starchy food. This type of extract is a very grood one to mix with cod-liver oil. It is rich in diastase.

2. Hoff's malt extract (or Homax) is given as a wineglassful witl meals. It is a liquid preparation not unlike beer, and to many people is more easily taken than the sticky preparation. It can be taken diluted with water, soda-ivater, or milk. It contains considerable cliastase, and not more than so per cent. of alcohol. In the author's experience it is of special value in the treatment of some forms of indigestion in gusty subjects. 
3. Trommer's diastatic crtract of malt, marle from barley malt-very syrupy in consistence, and sweet. A teasponful dose at first is enough to start with.

4. Mrltine is made from three cereals-barley, wheat, and oats. It is rich in diastase. It is frequently given mixed with equal parts of wheat or barley flour, the mixture being used as a diluent of milk. It may be taken after meals, either plain or in various combinations, such as cod-liver oil, hypophosphites, ctc.

Bynin, a fluid malt cxtract prepared by Allen \& Hanbury.

In the desiccated malt extracts all the water has been removed, e.g. Curtis' desiccated malt cxtract and Gramalt.

Malt may also be made as an infusion at home, and can be prepared freshly; it is much cheaper than the preparations above mentioned.

\section{Malt Infusion (Sir W. Robcrts).}

Crushed malt, 3 ounces.

Cold water, 竞 pint.

Mix the malt thoroughly with the cold water in a jug. Let the mixture stand nine hours. Decant off the liquicl carefully, and strain this through muslin until it comes out clear and bright.

This has a colour like dark sherry, and a faint maltish taste.

It should be freshly made, as it is liable to ferment.

\section{Malted Gruel.}

The gruel may be made of any farinaceous substances-oatmeal, Quaker oats, Farina, arrowroot, barley or lentil flour, preferably those from prepared flour. (For method of making gruel, see p. 296.)

When cool enough to swallow, add the malt infusion or an extract of malt. About one tablespoonful of the infusion or a teaspoonful of the extract is sufficient to digest a plateful of gruel. The action is very rapid, and in a few moments the gruel becomes thin from the transformation of starch and maltose.

The malted proprictary foods in the market may be only partly converted (as in Table A, p. IS2), into dextrins, maltose, and dextrose.

In some members of this group (Table A), the starch is iittle altered; in others, Allenbury's No. 3, Hovis babies' No. 2, and Moseley's food (Table B), considerable conversion has taken place; and it is stated that some of them, e.g. Coomb's malted food, are completely changed during the preparation, and thercfore rank as completely malted foods. Mcllin's food, 
182 PATENT, PROPRIETARY, AND PREDIGESTED FOODS

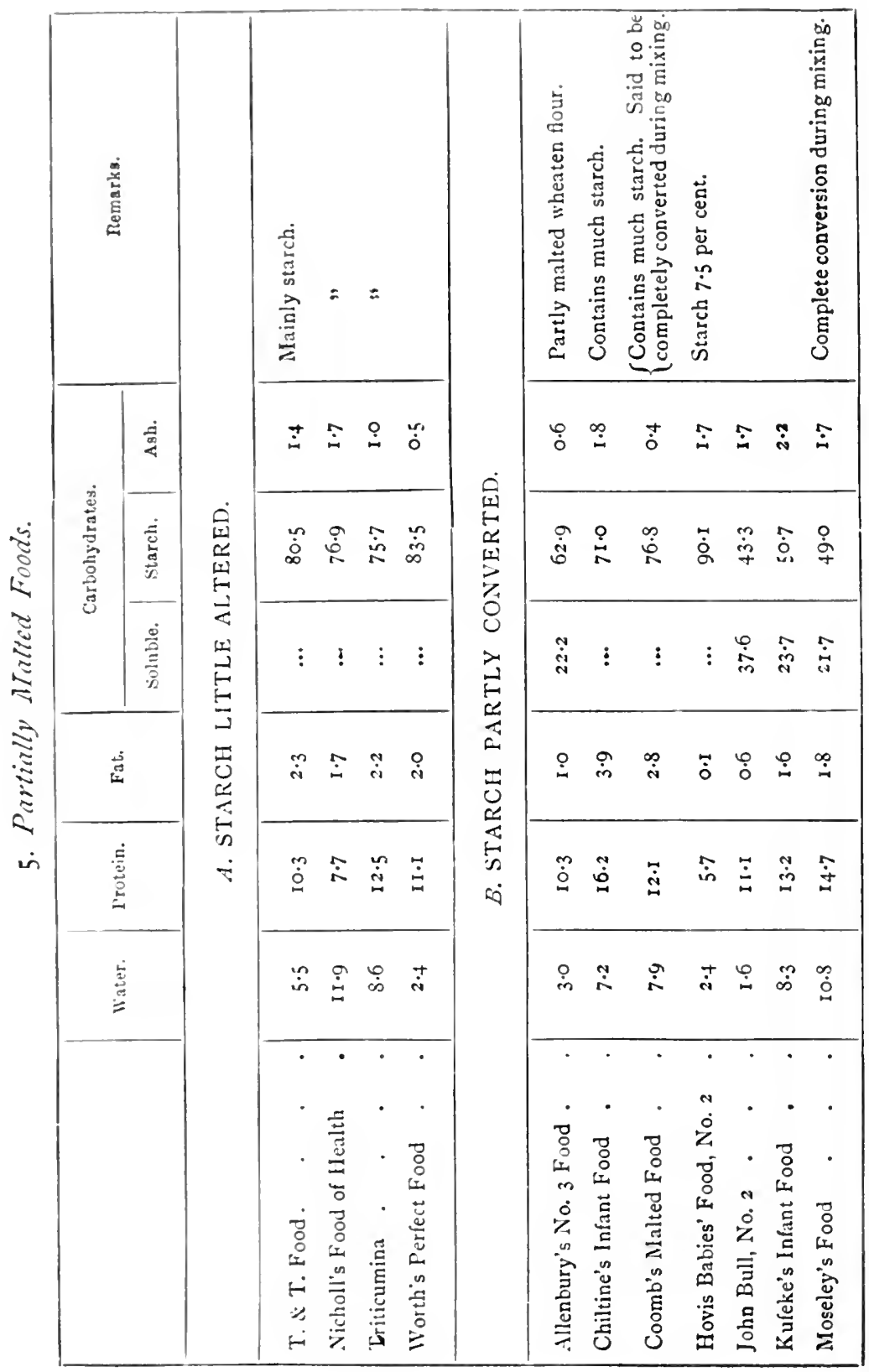


Horlick's food, Hovis babics' food, No. I, are cxamples of completely malted foods.

Of foods which are completely malted or nearly so, the best are Mellin's, Ilorlicli's, laget's malted farina, Chiltine maltose food, Diastased farina, Hovis babies' food, No. I. The composition of these is given in the following table:C. STARCH COMPLETELY CONVERTED.

\begin{tabular}{|c|c|c|c|c|c|c|}
\hline & \multirow{2}{*}{ Water. } & \multirow{2}{*}{ Protein. } & \multirow{2}{*}{ Fat. } & \multicolumn{2}{|c|}{ Carboliydrates. } & \multirow{2}{*}{ Ash. } \\
\hline & & & & Soluble. & Starch. & \\
\hline Chiltine Maltose Food & $4 \cdot 6$ & $5 \cdot 3$ & 0.2 & 87.6 & $\ldots$ & $2 \cdot 2$ \\
\hline Diastased Farina & $8 \cdot 3$ & 7.6 & $\mathrm{I} \cdot 3$ & $8 \mathrm{I} \cdot 7$ & $\ldots$ & $I \cdot I$ \\
\hline Horlick's Malted Food . & $9 \cdot 7$ & 10.7 & 0.3 & 76.8 & $2 \cdot 2$ & $\ldots$ \\
\hline Hovis Babies' Food, No. I . & $3 \cdot 7$ & $7 \cdot 7$ & 0.2 & 86.6 & ... & 1.8 \\
\hline Mellin's Food (maker's analysis) & $5 \cdot \dot{6}$ & $7 \cdot 5$ & 0.3 & $59 \cdot 6$ & $\ldots$ & $5 \cdot 6$ \\
\hline
\end{tabular}

5. Invalid Foods.--These are a group of foods of various composition that are of great use in the dietary of invalids.

Benger's food contains ferments which convert the proteins and starch during the preparation. It consists of cooked wheaten meal, to which is added the natural digestive ferment of the pancreas.

\begin{tabular}{|c|c|c|c|c|c|}
\hline Water. & Protein. & Fat. & \multicolumn{2}{|c|}{ Carboliydrates. } & \multirow{2}{*}{ Ash. } \\
\hline II.2 & I O.4 & I.I & 9.9 & 66.3 & 0.9 \\
\hline
\end{tabular}

When mixed with warm milk, as recommended, the car. bohydrates are nearly all converted into soluble dextrin and sugar, and the proteins are also partially peptoniscd. This is certainly one of the most useful proprietary foods on the market. It is specially useful in the feeding of wcakly infants, and in cases of acute gastric intestinal derangements such as typhoid fever and malnutrition generally.

benger's pancreatised lentil flour is specially prepared for children and invalids. Lentils form a highly nutritious food, being rich in nitrogenous matter, and the method of preparation of the flour makes it casy of digestion.

Savory \& Moore's best food for invalids. - The manufacture 
of this fond was originally sugrested by Licbig, but the process has since been much improved. The flour is specially prepared and then partially malted. On mixing in the manner described on the label of directions, the diastase converts the carbohydrates into soluble forms. It is very digestible, and may be given in all cases in which a milk diet is indicated. Its pleasant malty flavour makes it a favourite food.

Sarere is another nutrient food prepared by Savory \& Moore. The carbohydrates are partially malted and contain active diastase, assisting enfeebled digestive function. The milk and cereal proteins are not peptonised, so that the digestive apparatus has little work to perform.

Allenbury's malted food, No. 3, like the above, is a furinaccous food which requires the addition of cow's milk. It is a partially digested food composed chiefly of carefully cooked wheaten flour; to this is added malt in a soluble form. This food, though intended primarily for the use of infants after the fifth or sixth month, is of great value for invalids and convalescent patients who require a light and easily digested diet.

Carmrick's soluble food is another preparation in this class:-

\begin{tabular}{|c|c|c|c|c|c|}
\hline \multirow{2}{*}{ Water. } & \multirow{2}{*}{ Protein. } & \multirow{2}{*}{ Fat. } & \multicolumn{2}{|c|}{ Carlohydrates. } & \multirow{2}{*}{ Ash. } \\
\hline & & & Soluble. & Starch. & \\
\hline $5 \cdot 17$ & 16.6 & $5 \cdot 5$ & $28 \cdot 1$ & $41 \cdot 5$ & $3 \cdot 0$ \\
\hline
\end{tabular}

It consists of desiccated milk, malted wheat flour, and milk sugar. In the preparation the starch granules are partially digested, but much starch remains unchanged. This preparation is not so valuable as those mentioned above, as the latter have the advantage of being made with fresh milk.

By the use of the above-mentioned foods in combination with milk, a variety of dishes can be made. The special directions for each food are detailed on the tins, but the following notes will be found useful:-

\section{Invalid Food.}

1 ounce of invalid food.

4 tablespoonfuls of cold milk.

ŝ pint boiling mik. 
Mix the food into a paste with 4 tablespoonfuls of cold milk. Add this gradually to the ? pint of milk, which should be almost boiling; keep stirring all the time. Set aside in a warm place for twenty minutes; then boil the whole for a minute, stirring all the time, and strain if necessary. This can now be taken as an invalid food, or used in the making of various dishes. The following are useful recipes.

\section{Custard Pudding.}

1 pint of invalid food made with milk.
2 eggs.
2 teaspoonfuls of sugar.

Prepare the food according to direction on the tin ; after it has cooled, add to it the sugar and the eggs well beaten. Pour into a greased picdish and bake in a moderate oven from ten to fifteen minutes. Flavouring, such as nutmeg, cinnamon, or grated lemon rind, may be added. It can be served hot or cold.

\section{Batter Pudding.}

$\frac{1}{2}$ pint of invalid food made with milk.
2 eggs.
A pinch of salt.

Take the prepared food and let it boil up. Allow to cool, add the salt and eggs, well beaten. Pour the mixture into a well-greased basin, cover with greased paper, and steam slowly for half an hour. Do not fill the basin too full, as the pudding will rise. When ready it will be firm to the touch. It can be served with sugar, preserves, or meat gravy.

\section{Invalid Food Jelly.}

$\frac{1}{2}$ pint of invalid food with milk. $\frac{1}{2}$ ounce French leaf gelatine. 2 teaspoonfuls of castor sugar, and flavouring.

Make the invalid food. Add while hot the gelatine, and stir over the fire until dissolved. Add the sugar and any suitable flavouring-port, sherry wine, lemon, vanilla. Pour into a wetted mould until set. Turn out and serve cold.

\section{To prepare Peptonised Cocoa and Mill with Invalid Food.}

Take I tablespoonful of the food ( $\frac{3}{4}$ ounce) and 1 or 2 teaspoonfuls of cocoa (any good brand). Nix together in a basin and add gradually $S$ tablespoonfuls of cold water. Then add slowly a pint of boiling milk and water (say half and half). Set aside to digest for ten or fifteen minutes, then pour into a clean saucepan and bring to the boil. When cool it is ready. Sweeten to taste. Take half the above quantities for a breakfast cup.

The natural digestive principles contained in the Benger's food digest the cocoa as well as the milk with which it is mixed. The Benger's food is also partially digested.

\section{Inwalid Food with Chocolite.}

Prepare the food in the usual way according to the directions on every tin, then add your chocolate grated. Those who are not fond of 
chocolate may relish the food better if it is flavoured with cinnamon, and for this an inch or so of cinnamon stick will be sufficient for a breakfastcup of invalid food. Others again prefer the flavour of lemon, and in this case a small piece of lemon rind, pared off very thinly, is better than essence of lemon.

In these ways one is able to vary the taste of the food to please even the nost fastidious invalid.

\section{Invalid Food and Raw Erg.}

Beat up a fresh egg to a froth, then add the prepared food, gradually stirring the while. Brandy, sugar, or other flavouring may be added if desired.

N.B. - The prepared food should not be hotter than can be sipped comfortably, when the egg is added.

\section{Arrowroot Pudding, made with Prepared Invalid Food.}

I tablespoonful arrowroot.

2 teaspoonfuls sugar.

$\frac{1}{2}$ pint prepared invalid food.

Method.-Mix the arrowroot with a little cold water, add the prepared food to the mixture whilst stirring; return the whole to a saucepan and boil three or four minutes, add the sugar and nutmeg, beat up the egg and add to the mixture. Pour into a buttered dish and bake in a slow oven.

9. Qucen Pudding, made with Prepared Invalid Food.

$\frac{1}{3}$ pint prepared food.

I ounce butter.

2 eggs.
I tablespoonful jam.

2 tablespoonfuls castor sugar.

$\frac{1}{3}$ pint of white breadcrumbs.

Flavour with vanilla or lemon rind.

Method.-Mix the breadcrumbs, I tablespoonful sugar and butter, together in a basin, pour over these the prepared food, stir in the yolks of the eggs, previously well beaten, and the flavouring; pour the whole into a buttered dish, and bake twenty or thirty minutes, or until set. Then spread the jam on the top, beat up the whites of eggs to a stiff froth, add to them the remainder of the sugar, pile this on the top of the pudding, and return to the oven until set. Serve hot or cold.

10. Sago Pudding, made with Prepared Invalid Food.
I ounce of sago.
A little grated lemon rind.
I ounce of castor sugar.
A pinch of salt.
tounce butter.
$\frac{1}{2}$ pint of water.
冬 pint prepared food.

Method.-Put the sago into a saucepan with the water and salt, and slowly simmer for iwenty minutes to half an hour. Then add the prepared food, sugar, lemon rind, and the egg, previously well beaten. Pour into a buttered dish and bake in a slow oven for about half an hour. Semolina may be used instead of sago if preferred. 


\title{
CHAPTER $\mathrm{X}$
}

\author{
FOOD PRESERVATIVES, FOOD ADULTERATION, AND \\ DISEASES CAUSED BY FOOD
}

\section{Food Preservatives}

\author{
PAGE \\ I. Drying, smoking, and salting . I 87 \\ 2. Freezing and cold storage. I 88 \\ 3. Exclusion of air-canned foods. I 89 \\ 4. Antiseptic and preservative sub- \\ PAOE \\ stances . . . . I 89 \\ General effects of prescrvatives . I 89 \\ Food adulteration . . . Igo
}

Preserven foods of all kinds now enter so largely into the daily dietaries of nearly all classes of the community that some reference must be made to the different methods of preservation of foods, and to their effects on the nutritive value of the food.

\section{Drying, Smoking, and Salting.}

(a) Dried foods. - Milk, vegetables, and fruits are preserved in this way. The watery constituents of the food may be partially removed, as in the case of condensed milk, or completely removed, as in the desiccated form, where the dried powder is used to increase the nutritive properties of other foods. Tea and coffee are examples of foodstuffs prepared in this way, so also are peas, beans, grapes (raisins), apples, prunes, and figs. Sugar or salt are frequently employed to aid the drying and to assist in preventing the decomposition of the food. Pemmican is a good example of a concentrated food of a mixed kind. It consists of slices of meat cut and dried in the sun, to which is added fat, sugar, and dried fruit.

(b) Smoked food.-The process of smoking is applied to beef, fish, tongue, ham, and bacon. It consists in hanging 
the meat in a chamber, in which the air is saturated with wood smoke, the antiscptic substances derived from the combustion of the wool impresnating the outer layers of the meat and so prescrving the whole. This process is usually employecl after salting. Meat so prepared is not so easily digested as fresh meat.

(c) Salting-The addition of salt to meat or fish absorbs the moisture, and dries and preserves the meat. In the process some of the extractives and salts of the meat may be removed. Food so prepared is rather less nutritious and digestible than fresh meats. Salted meat requires prolonged cooking.

\section{Freezing and Cold Storage.}

(a) The process of freeing consists in subjecting meat to a temperature of about $26^{\circ} \mathrm{F}$. below zero, the meat when hard being transferred to a refrigerating chamber. Meat so prepared can be kept almost indefinitely. Frozen meat should be cooked when thawed, as decomposition sets in more readily than in non-frozen meat. Frozen meat loses some of its nutritive value in cooking, this loss being greater than in the case of non-frozen meat; it also loses a little delicacy of flavour. These disadvantages, however, are more than outweighed by the diminished cost.

(b) Treatment by refrigeration.-Here the meat is not actually frozen, but is kept in chambers maintained at a temperature a few degrecs above freezing point. The temperature is maintained by a draught of cold air. This process involves less alteration in the meat than freezing. In addition to meat, fish, eggs, fruits, and vegetables can be so treated.

\section{Exclusion of Air-Canned Foods.}

The decomposition of all foods is prevented or retarded by exclucling air from the food. This is done by the process of canning, or by varnishing the food, or by covering it with a substance of an impermeable nature, such as melted fat.

Canned foods are very extensively used at the present time. The food is first made sterile by heat, or by the use of chemicals-the latter method being often abused in the 
hands of unscrupulous people. After the fresh food is placcd in the new tin can, the lid is soldered on, leaving a minute hole on the top for the escape of air and steam. 'The can is then immersed in a bath of boiling fluid which has a higher boiling point than the water in the food. The latter boils, expels at first air, then stcam, and so cooks the food, rendering it ascptic. The lid is then soldered, so as to render the can airtight. It should be noted, however, that the presence of anaerobic bacteria in the food may induce decomposition of the food so treated. Canned foods are on the whole less digestible and also less tasty than fresh foods. It has also to be borne in mind that some people may have an idiosyncrasy to the preservative used. The possibility of the occurrence of copper, tin, lcad, or zinc poisoning from the prolonged use of canned meats must be borne in mind. The ingredients in many foods have a solvent action on the cans, as a result of which toxic symptoms are set up.

\section{Antiseptic and Preservative Substances.}

A large number of substances are used for this purpose. Many of these are innocuous, e.g., sugar, salt, oil, and vinegar; others are harmless in minute doses, but injurious in the amounts that are occasionally present, such as salicylic acid, formalin, borax, sulphuric acid.

The process of food adulteration has called for legislative action, but the condition is not always easily detected by any analytical method. It has been shown experimentally that the addition of boric acid to the food in the proportion of $\frac{1}{2}$ per cent. is not injurious to health; this would be equivalent to the consumption of about $7 \frac{1}{2}$ grains of boric acid daily. In conditions where the excretory functions of the kidneys or bowcls are defective, smaller amounts of salicylic acid, borax, formalin, and the like in the food would produce injurious results more readily than under normal conditions. The injurious results that may be induced are gastro-intestinal derangement, albuminuria, and an impaiment in the general health.

Gencral affects of preservatives on the food.-- Gencrally speaking, the effects of preservatives are to render the food a little less nutritious, probably by interfering with the normal 
action of the digestive ferments. In some cases the food is rendered less tasty, and its nutritive value thereby impaired.

\section{Food Aduiteration.}

Food may be adultcrated cither by the fraudulent substitutes of cheaper foods, or by the addition of substances which have a deletcrious action. The objects arrived at by the manufacturer who engages in this malpractice are-(I) to increase the bulk of the food; (2) to give an erroneous impression as to the strength of the food; and (3) to alter the appearance in a manner favourable to the manufacturer. An instructive table illustrating the extent to which adulteration of food was practised in America prior to the passing of the Pure Foods Act is given by Thompson as follows. This shows that about 40 per cent. of foodstuffs were adulterated. The forms in which food may be adulterated are legion. As common cxamples, mention may be made of wheat flour with bran, milk with water and sugar, powdered sugar with barium sulphate, honey with glucose, coffee with sugar and caramel, oleo-margarine as butter, pickles with copper and iron; wines and liquors with hamatoxylin, alum, and other salts; olive oil with cotton-seed oil. The adulteration of flour by bleaching is fully dealt with on p. 90.

Table illustrating Adulteration of Foods.

\begin{tabular}{|c|c|c|c|c|}
\hline & & 'lutal. & Adulterated. & Unadulterated. \\
\hline Baking-powder & . & $50^{\circ}$ & 45 & II \\
\hline Butter. . & . & 147 & 29 & 118 \\
\hline Canned Goods & . & 6 & $\ldots$ & 6 \\
\hline Catsups, Pickles & - & 57 & 45 & 12 \\
\hline Coffee. & - $\quad$. & 3 & I & 2 \\
\hline Cornstarch . & - & I & $\ldots$ & I \\
\hline Flour (Wheat) & . & 20 & $\ldots$ & 20 \\
\hline Jellics, Preserves & . & 23 & 18 & 5 \\
\hline Lard, & . . . & 40 & II & 29 \\
\hline Milk (Sweet and B & rmilk) & 150 & 35 & 115 \\
\hline Mince Meat & . $\quad$. & 7 & 7 & $\ldots$ \\
\hline Oleo-margarine & . & 18 & 16 & 2 \\
\hline Olive Oil & . & 2 & 1 & 1 \\
\hline Pepper, Spices, eto & . . . & 14 & 11 & 3 \\
\hline Sweet Cider and $\mathrm{C}$ & e Juice & 3 & 3 & $\ldots$ \\
\hline Syrups, Honey, an & ugrar. & 50 & 9 & 41 \\
\hline Vinegar & · & 126 & 59 & 67 \\
\hline
\end{tabular}


3. Diseases caused by food.

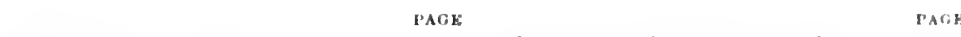

Ptomaine poisoning . . . I91 Food-poisoning due to grains . 192

food-poisoning due to poisoned

non-putrelying meat . . I9I

Foods containing parasites or their embryos . . . 192

In other sections we have considered diseased conditions induced by over-feeding, over-drinking, and under-feeding; reference must now be made to some special diseases dependent on dietetic sources.

Ptomaine Poisoning.- This may arise from tainted meat, milk, or fish, more especially shellfish. I'tomaines are alkaloidal substances produced by decomposition, or putrefaction of proteins under the influence of bacterial action. The bacilli specially associated with meat-poisoning include some members of the anaerobic group, e.g. Bacillus botulinus, which occurs notably in tainted ham and sausages; also bacilli of the protein group, such as Bacillus butyricus, which normally cause putrefaction in wholesome food; and various members of the para-typhoid group, especially the Bacillus enteritidis of Gärtner. Serious and even dangerous symptoms - pain, sickness, vomiting, collapse-may arise from eating food tainted as above. In the case of poisoning from eating tainted fish or mussels, the symptoms may arise within an hour or two, and affect mainly the central nervous system. Ptomaine poisoning more commonly arises from eating canned meats which have stood some time after opening. In these cases it may not be easy to determine whether the poison is derived from the tainted meat, or is due to metallic poisoning from ingredients used in the process of tinning. It is well also to keep in view the possibility that it is the result of the "preservative" used. In addition to meat-milk, cream, ice cream, and cheese may also be tainted and induce acute ptomaine poisoning. In connection with ptomaine poisoning, it is important to keep in mind the frequency with which idiosyncrasy is met with to special articles of diet, such as shellfish, strawberries, and the like.

liood-poisoning due to poisoned non-putrefling mat.Reference must be mate to the occasional uccurrence of cases of this kind, e.g., turkey eating deadly nightshade leaves, 
followed by symptoms of atropine poisoning in the human subject; grouse and hares have been known to be poisoned through eating the tender shoots of the laurel and rhododendron shrubs; oysters similarly may be the cause of typhoid, from being taken from contaminated oyster-beds.

lood-poisoning due to grains.-Mouldy flour and unripe srains when old develop poisons from decomposition of their sluten. The more common diseases that are so induced are ergotism and pellagra. The symptoms of ergotism may be of a gangrenous or convulsive character, and are due to the action of the fungus Claviceps purpurca, which grows on rye. Pellagra is a disease of Southern Europe which arises from eating fermented unripe maize or Indian corn made into polcnta. It is characterised by an erythema of the skin accompanied by severe mental symptoms. The disease is said to be preventable by the addition of salt to the cornmeal.

Lathyrism is a condition analagous to ergotism and pellagra, but resulting from the adulteration of flour with a srain called the chick-pea vetch; it is met with in India, Italy, and France.

Foods containing parasites or thcir embryos.-Food sometimes serves as the medium for the introduction of parasites or their embryos, such as tapeworm, roundworm, echinococcus, and trichina. The chief source of infection is the use of raw or imperfectly cooked flesh, a rarer source being the ingestion of vegretables that have been tainted from the excrement of infected animals. Trichinosis is acquired from eating ham or pork infected with the parasites. It may be a serious, and is sometimes a fatal disease. 


\section{CHAPTER XI}

\section{DIET AT DIFFERENT I'ERIODS OF LIFE}

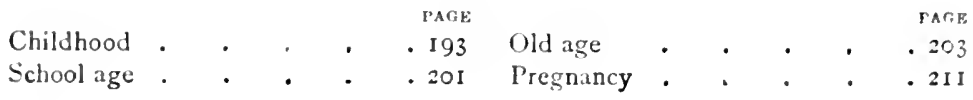

\section{Diet during Childhood, from Two Years to Seven Years of Age.}

\begin{tabular}{|c|c|c|c|c|}
\hline & PAGE & & & PAGE \\
\hline Importance of promoting mastica & & Meat foods . . & & . 198 \\
\hline tion $\quad . \quad . \quad . \quad$. & . 193 & Foods to be avoided & - & . 199 \\
\hline Normal weights and heights & . 195 & Daily dietary & - & . 199 \\
\hline The food requirements of children & n 195 & Diet for a "gouty" child & & .200 \\
\hline Proteins, fats, carbohydrates. & . 196 & Diet for a child predispo & sed tc & \\
\hline Milk, eggs, bread foods & . 196 & tuberculosis . . & . & .200 \\
\hline Cereals, vegetables, fruits & . 198 & Diet for a "nervous" child & - & .201 \\
\hline 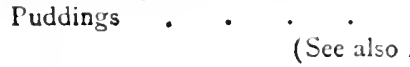 & $\begin{array}{l}\text { I98 } \\
\text { Infant }\end{array}$ & ng, p. 226.) & & \\
\hline
\end{tabular}

A COMmon fault in the feeding of children is giving a diet which consists too largely of pultaceous foodstuffs, which require little or no mastication. Such foodstuffs are usually of a kind which lead to acid fermentation. Serious consequences follow this defective system of feeding. In the first place the muscles of mastication and the jaws are imperfectly developed, with the result that the post-nasal space is small in size and liable to be further encroached on by excess of lymphoid tissue (adenoids), with resulting unfavourable effects on the growth and general nutrition of the child Secondly, the carbohydrates of the food lodge round the tecth and undergo acid fermentation, with resulting dental caries. A first essential in the feeding of children, therefore, is to see that the food is of a nature that demands mastica- 
tion. At eatch meal the child should receive one or other of the following articles of diet, baked bread (slice of ordinary bread placed in a quick oven until it is quite dry and crisp), milk toast (thin slice of stale bread dipped in milk and baked in a slow oven until it is brown), unsweetened rusks, unswectencel biscuits, oatcakes, unfircd bread (Christian's, p. 529), apples, bananas, and nuts. As these forms of administering cirbohyclrates tend to lessen the bulk of food consumed, it is important to supplement it by extra fat or sugar. The latter is unfarourable to the tecth, and an extra supply of fat or cream should therefore be given. After a meal which contains much carbohydrate in the form of cakes, or sweets, the acid in the mouth may advantageously be neutralised by the salts present in a little raw fruit, such as apples, bananas, or nuts.

There is another point of great importance in the diet of childien at this period of life that is usually lost sight of, viz., the necessity of adapting the diet to the diathesis of the child. The diet of a child of tuberculous stock, of say five years of age, is different from that of a gouty child of the same age. This point is one of great practical importance. The former child is usually of comparatively feeble development, shows relatively little muscular activity, is slightly anamic, and altogether forms a marked contrast to the welldeveloped, muscular, active child of good colour that is characteristic of the gouty diathesis. Attention will first be directed to the dictetic management of the average child, une with no specially pronounced cliathetic tendency, and thereafter to the diet appropriate to the child of gouty stock, to the highly nervous child, and to children predisposed to tuberculosis.

From two years of age onwards the normal child has a well-developed digestive apparatus and a keen appetite, and is well able to digest most foodstuffs if given in moderation. The tecth by this time are through the gum, and it is of the greatest importance that they should get a dict which levelops the art of mastication. The movement of the jaws in mastication in growing children promotes the development of the muscles of the tongue, palate, and naso-pharynx; it, at the same time, favours the normal development of the nasal 
and naso-pharyngeal cavities, which is of so great importance for the purposes of respiration and general nutrition. Too much importance, therefore, cannot be devoted to the question of a proper dict in the developing period.

The following table gives the average weights and heights of children at different ages. It should be borne in mind that these averages are calculated from tables of the weights and heights of a large number of persons, and though accurate as a general guide, are not necessarily true for each person. A deviation of I 5 per cent. in either direction from the standard is not seriously regarded. Of more importance than the actual weight is the proportion between beight and weight. Care must be taken that patients who are weighed periodically should always be weighed under precisely corresponding conditions as to scales, clothes, etc.

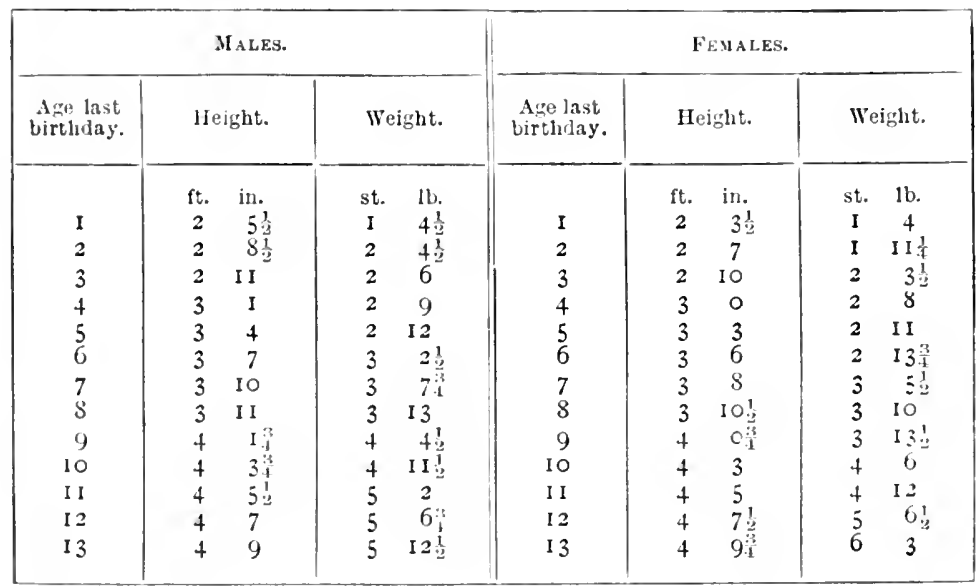

The Food Requirements of Children.-The quantity of food required by children is out of proportion to their size and weight, for the following reasons: the rapid growth taking place requires muscle-forming protein material for the constructive processes; the incessant activity calls for an abundant supply of energy-producing food-carbohydrates and fat: the loss of heat in children is more rapid than adults, and an abundant supply of heat-forming foorl is necessary. The general principles of treatment are as follows:-

1. An abundant supply of protein, carbohyclrate and fat. 
2. The meals to be given at regular hours, nothing being given in the interval.

3. The diet should be simple, nothing being necessary to tickle the palate or stimulate the appetite.

4. The dict should include a sufficient amount of hard food, so that the habit of proper mastication may be acquired

Protins are best supplicl in the forms of milk, eggs, and the proteins in the various cereals and legumes. The proteins of red meat and white meat are very appetising, and much relished by children, but they should be used sparingly. Iish, chicken, and rabbit are preferable to red meats. Meat soups thickened with various cereals and vegetables may be recommended.

Milk should be the great standby; in the feeding of children the allowance of 2 to 3 pints of milk daily, according to age, is not at all too much for a child. Some of this can be taken plain, some mixed with cocoa to make a hot drink, and the remainder used in the cooking of gruels, puddings, custards, etc.

Carbohydrates are mainly supplied by bread in all its varieties, also by the different cereals, and by vegetables properly prepared.

Fats.-Crcam, butter, bacon fat, dripping, suet, yolk of egg, are all forms in which fat can be presented to children in an appetising form. Fat is a most important element in the food of children at this period of life. Cream and butter are cxcellent forms of administering fat to growing children. From I to 3 ounces of cream may be given daily, this being given in the form of creamy milk, or with puddings or stewed fruit. Bacon fat and marrow fat are excellent forms of fat administration. Good recipes are here given :-

\section{bacon Kashors.}

Choose a piece from the back or streaky part of the pig for these. Remove the rind (which should be reserved for the stock pot), and cut the baron in ary thin, even slices, with a very sharp knife. These may be fried, toasted, or batied.

Tir fry hiconn. Plare the slices in a cold frying-pan and cook until the fat is transparent, iurning the rashers once or twice. It must be cooked slowly or the fat will become scorched and toasted. If not wanted crisp 
and dry, turn the slices before they look rlear, and remove them hefore all the fat is run out.

Toasted bacon is easily done by means of a l)utrh oven of a toaster or toasting-fork in front of the fire, putting a plate underneath to catch the fat. The fat of the bacon when cooked should look transparent and: crisp. The flavour of toasted bacon is superiol to that which is fried or baked.

Baked bacon.-Melt a little fat in a dipping tin; when quite hot but not scorching, lay in the slices of bacon. Place them overlapping each other so that the fat of one piece rests on the lean of another; cook about ten minutes in a good oven.

Bacon rolls, which are used as a garnish for many dishes, are made by cutting the bacon very thin, then rolling the slices up neatly, and slipping several together on a thin skewer. These should be baked or toasted.

Bacon should be served on a hot-water dish if possible, and it may be served on small pieces of bread which have been fried in the bacon fat. Eggs and bacon served together are too rich a dish for invalids, and not necessary for children.

\section{Marow Bones.}

Ingredients: Marrow bones, flour, dry toast. Saw the bones into short lengths, cover the ends with a paste made of flour and water, tie them in a floured cloth, and boil from one and three-quarters to two hours. Remove the cloth and crust, set the bones upright on a dish covered with a hot napkin, and serve with dry toast.

\section{Marrow Toasi.}

Marrow from two beef bones, buttered toast, salt and pepper. Soak the marrow in tepid water for two hours. About fifteen minutes before the dish is wanted, cut the marrow into inch lengths, place them in cold water, and bring rapidly to boiling point and drain well. Have some squares of very hot, well-buttered toast, put the marrow on them, breaking it up and spreading it with a fork, and season with salt and pepper. Place the toast before the fire or in a hot oven until the marrow is thoroughly melted. Then serve as hot as possible. When savoury marrow is prepared, sprinkle the above with chopped parslcy, chives, and lemon juice, just before serving

Eggs are excellent for children; given every day, a child tires of them, and in some children they cause "biliousness." Very occasionally children cannot take eggs.

Bread and biscuits form the staple method of administering carbohydrates. The bread should never be new. It should be given twice daily as dry, crisp toast, or as baked bread, as these promote mastication. Dry, crisp rolls are also advisable. New scones and buns are not advisable, but on 
the second day are very gond if toasted. These different bread fouls promote mastication, if care be taken to see that the child is not allowed to swill them down with fluid. Plain biscuits shonld always be available, but rich sweet varieties should only occasionally be given. Plain sponge cake and biscuits are also allowable. But all rich cakes with fruit, rich butter pastry, and heavily iced calies should be withheld.

Cerials. Almost any kind of cereal may be given for breakfast, and a sufficient variety should be given to prevent the child tiring of them. The following may be recommended:-Oatmeal, whole-wheat flour, as Wheaten groats or Artox, Hominy, puffed rice; pease flour, lentil flour, maize flour, are also good. (See also Cereals and Legumes, pp. S6, IOI.)

Vegetables may be given for dinner, such as plain boiled or mashed potatoes, plain boiled and well-cooked cauliflower, spinach, cabbage, or lettuce rubbed smoothly down and well boiled.

Meat foods.-Fish of the white varieties, boiled, broiled, and fried, are always allowable. Chicken and rabbit may be given twice a week. Beef and mutton boiled and roasted is quite digestible, but it is generally advisable not to start with red meats until towards the end of this period.

Broths and soups should not be made too strong, or thickened with meat purie; but meat stock can be added to good vegetablc soup made with carrots, turnips, onions, leeks, potatoes, lentils, peas. This may be thickened with barley, rice, tapioca, groats, sago, macaroni, yolk of egg, cream. A nourishing fish soup can be prepared and thickened by adding a purée of the fish.

Puddings should be taken once daily, the most suitable being custards, plain, baked, or boiled; milk puddings of different grains made with or without eggs; jelly (lemon or orange or other fresh fruit); curds with cream. Suet puddings are less digestible, and should certainly not be given frequently:

Frits are roorl for chillren; the fresh juice contains propertics which are good for the bloorl, and they contain sugar in an easily assimilable form. Some fruit should be taken daily. Of fresh fruits, oranges, apples, grapes, bananas, may be taken, avoiding the skin and stones. 
The fresh berries-raspberries, red and white currants, brambles, etc.-are best cooked and the juice eaten with a pudding. Strawberries should be given very sparingly, as in many children they disagree.

Stewed fruit-apples, pruncs, rhubarb, apricots, pears-mav all be given as an agreeable change to the milk puddings.

Sugar.-The growing child demands sugar, and usually shows a great craving for it. It is best to supply this in the form of swect pudding or stewed fruit. Honey, syrup, jam, eaten with bread and biscuits, are also good. A little good chocolate or pure plain toffec drop can do no harm in moderation, but the indiscriminate partaking of confectionery is prejudicial to the teeth and to the generai nutrition.

It will be convenient at this stage to indicate the special articles of food which may with advantage be withheld from children under seven years of age.

Meats._Sausage, pork, salted fish, corned beef, goose, kidney, liver, stewed meats.

Vegetables.-Fried vegetables of all varieties, raw or fried onions, raw cclery, radishes, lettuce, cucumbers, beetroots.

Bread and cakes.-All newly baked bread, rolls, scones, buns. All rice cakes containing dried fruits and thick icings. tion.

Dessert.-Candies, pies, tarts, pastry of every descrip-

Drinks.-Tea, coffec, wine, becr, cider.

The following dict shect is aclopted for a child at this period of life. The actual amount of the foodstuffs to be given will vary with the age and size of the patient :-

\section{Meals.}

If child awake early (6 to 6.30 A. 31 .)-Drink of milk, a piece of dry' bread, or plain biscuit.

Breakfast: 8 A.M.-

Milk to drink, or cocoa made with milk.

A well-cooked cereal with salt and cream (no sugar or syrup).

Toasted bread and butter (with crusts), a little jam.

This should be a sufficient breakfast for children up to seven years, but if more is found necessary it should not be more than an esr. boiled, poached, or scrambled, or a little fish. A little fresh fruit may be taken after breakfast or during the forenoon. 
During the forenoon, about 11 A.M., a drink of milk and a biscuit is advisable, or fruit ma! be laken.

Dinncr-Milk wo drink and toast to eat (with crusts); and a two-course dinner as follows. As the child get older, soup and a more liberal supply of vegetables may be added.

$\begin{array}{cclcc}1 & 2 & 3 & 4 & 5 \\ \text { Soup, well } & \text { Esgr with } & \text { Fish, } & \text { Chicken } & \text { Roast meat, } \\ \text { thickened, } & \text { a vegetable, } & \text { Potatoes, } & \text { or rabbit, } & \text { Potatoes, } \\ \text { Milk pudding. Junket. } & \text { Suet pud- } & \text { Stewed fruit. } & \text { Custard. } \\ & & & \end{array}$

Tea-Milk, or milk and cocoa; bread and butter, biscuits, plain scone, jam.

Supper-Milk and bread and butter, with a cereal (e.s.gruel).

The child should be taught to eat slowly, and to chew the food well. In this connection attention may again be directed to the importance of such articles of diet as crusts of bread, crisp rolls, and the like being given daily, care being taken that the child chews the food and does not merely wash it down with fluid. The importance of this can hardly be overestimated. The quantity of food depends largely on the appetite of the child. The appetite should not be forced.

If the food is not all taken, it is well to wait until the next meal. Loss of appetite is often an indication that the digestive organs require a rest. This rule does not apply to sick children.

Diet for a "Gouty" Child.-In families where there is a marked gouty tendency the diet of the children should be carefully regulated, since it is certain that with care much can be done to eradicate the tendency. The special points to observe are:-(I) The necessity of bringing up the child very largely on a lacto-vegetarian diet; red meats of all kinds should be withheld, or, at most, given very occasionally; and (2) sugar and foodstuffs rich in sugar should be given sparingly. If the child is carcfully dieted along these lines during the growing period, he will be much less prone to develop gouty symptoms in later life (see also p. 526).

Diet for Children predisposed to Tuberculosis. - In families where there is a marked tendency to tuberculous disease the question of diet is a highly important one, since, as in the case of gout, much can be done to eradicate the tendency. The special feature about the diet in such cases is 
the necessity of an increased amount of animal protein food, and more especially meat or raw-meat juice. The beneficial effects of a properly planned dictary in these cases are very remarkable. Necdless to say, the appropriate diet must be continued for many months, or even for a ycar or two, if the best results are to be obtained. The following dict sheet is adopted for a child of five or six years of age with a strong hereditary tendency to tuberculosis :-

Diet for a child of five years, of tubcrculous stock.-This dietary contains a more liberal supply of animal proteins in the form of milk, eggs, meat, and soup than an ordinary diet, the diet.including 2 pints of milk, and meat foods at least three times daily. This point should be insisted on and continued during the growing period.

6.30 A.M.-Milk, biscuit and butter.

Breakfast-Milk, butter, bread, egg, fish, or bacon.

Lunch-Cup of soup (meat stock), or egg flip.

Dinner-

Soup, with raw

meat,

and vegetable,

Curds and cream, Stewed fruit cream,

Glass of milk.

Glass of milk.
Fish, with sauce, potato, Bread sauce, Custard pudding, Vegetablc, Glass of milk.
Chicken, Blancmange cream, Glass of milk.

Tea-Milk, bread and butter.

Supper-Good meat soup, thickened with milk; or egg, or meat purée, or lentil purée.

Diet for the "Nervous" Child.-In children, where there is a family history of nervous disorders, including mental derangements, careful regard must be paid to the diet. It must essentially be of a non-stimulating character; meats and meat foods must be withheld, milk, farinaceous foods, fruits, and vegetables forming the dietary. The diet should be of the lacto-vegetarian character described on p. 526.

\section{Diet during School Life.}

During this stage of life the rapid growth and incessant activity still continue, and to this is now added the brainwork. It thus follows that growing boys and girls require a large amount of nourishing food. 
If a child has been wisely brought up and has a duly proportioned amount of work and play and slecp, his appetite is the best guile to the amount of food required. The appetitc of a child that has been pampered, and has not been brought up on plain, wholesome food is not a reliable guide to the amount of food required.

A very important point in the dict of young subjects is that of not starving the growing child in any one foodstuff. A requisite amount of protcins, fats, and carbohydrates is essential. To stint is very often to starve, therefore in arranging the dict the meals should be at regular intervals, threc good meals being given daily. A due amount of considcration must be given to the whole dict. Abundance of milk, a fair supply of fresh meat, and a liberal amount of vesctables and fruits, are the cssentials in the dictary of this period. The question of hours is important. Brealifast should be punctual, to allow the child to have time to eat a good hearty meal, and have time before starting for school to get the bowels attended to. Day scholars are often much upset through neglect of this wholesome rulc. The meals should not be bolted, ample time being taken to effect proper mastication of the food The following dictary may be recommended :-

The breakfast should be the heartiest meal of the day. Begin with a small plate of porridge and glass of milk; this followed by an egg or fish, bread and buter, or toast and butter, and tea or coffee largely made with hot milk; jam or marmalade and oatcake.

11.30 A.M.-A dry biscuit and a drink of milk (not hot scones, buns, or pastry); a little fresh fruit, $e g$., apple, orange, or banana.

Dinner, in the middle of the day, should consist of soup, meat, vegelables, and pudding. The soup does not require to be made of rich meat stock-lentil, pea, broth, or rice soup are all excellent, giving a good foundation for the meat course.

Meat. - Roast, boiled meat, and stews are the best, served always with potatoes and a vegetable.

Pudding should be varied: suet puddings with fruit or jam, milk puddings, or stewed fruit. A glass of milk may be given with this meal, and as much bread as the child wishes to take.

Tea should not be later than 5.30 P.M. - to consist of :

Heverace, milk or cocoa (not tea as a rule); as much plain bread and toast as the child can eat; plain cake, sometimes an egg, or $\mathrm{t}$ sh, or potted meat, marmalade, jam, or honey. 
Supper. - $\Lambda$ drink of milk and a biscuit is all that is necessary. $\Lambda$ large supper is not advisable. It is better for all children to go to berl with the stomach comparatively empty.

In growing boys and girls with a tuberculous tendency, special care is necessary in regard to their feeding. A practical difficulty sometimes encountered is fastidiousness of appetite or want of appetite. The particular point to be attended to here is the administration of ample proteins in the form of milk, eggs, and meat. These cases demand ample fresh air, little mental work, and appetising foods (see also p. $42 \mathrm{I}$ ).

With regard to alcohol, it cannot be too strongly emphasised that alcohol in every form should be avoided by the growing boy. The habit of allowing schoolboys beer regularly or occasionally is a very pernicious one.

\section{Diet in Old Age.}

PAGE PAGE Principles of treatment . . . 203 Points re individual foodstuffs . 205 A typical dietary . . . . 20t Liquids and stimulants . . 210

Diet in old Age.-Increasing years are associated with diminishing activity and a lessening demand for energy. Less nourishment must therefore be taken in proportion as age advances, or the individual will suffer. If a man of sixty continue to take the same abundant breakfast, substantial lunch, and heavy dinner, which he indulged in at the age of thirty or forty, it will lead to serious trouble. He may. accumulate fat which will still further diminish his general activity, and will lead to serious heart mischief. Or he will develop various symptoms of gout or rheumatism, which will be in turn associated with evidences of kidney weakness and marked liability to apoplexy. We must bear in mind that the tissues in later life have less power to eliminate, and that the excretory activity of organs like the kidneys diminishes with increasing years. The amount of food therefore consumed in old age must be proportionate to the lessened demand of the tissue, and to the diminished powers of elimination. The total intake of food must ie reduced. For the same reasons a man of seventy requires less food than a man of sixty years of age, and an octogenarian less than a man of seventy. It is often difficult to get the relatives of 
an old man to belicve that it is inadvisable to "support" the weight of years by liberal feeding. The attempts to strengthen the old man by giving extra nourishment in the form of strong beef-teas, egg flips, and the like, cannot be too strongly deprecated. Such liberal feeding merely goes to orercharge the blood with impurities, and to accelerate the decay of the tissues. Given a fair constitution, the use of a physiological dict in old age promotes a comfortable life, and is attended by a freclom from serious trouble which is of the greatest advantage both to the individual and to his relatives. It will be convenient to give the guiding rules for the dictetic management of a person of seventy years of age. Care has to be taken in the following directions:-

i. To restrict the total amount of food.

ii. To make the diet simple and nutritious, avoiding excess of animal food.

iii. To pay special attention to the form of administration of carbohydrates; old people are spccially prone to flatulence.

Diet.-The food should be given at short intervals, say five to six times in twenty-four hours; the diet should be simple; by this it is to be understood that not only is the quantity of foor taken to be gradually diminished in proportion to decreased activity of body and mind, but that not more than two or three different forms of food should be served at any onc meal. There is no objection to variety in the choice of foods. All food must be in a form admitting of easy mastication.

Any system of diet must be varied according to the circumstances and personal idiosyncrasies of the individual, but the following arrangement of meals can be recommended. If the patient is markedly obese, the diet must be restricted and modified along the lines laid down for Obesity on P. 500.

6 A.M. - Cup of tea freshly made; nothing to be eaten with it.

Dreakfast: 8.30 A.M.-A small cup of tea or coffee; breadstuff should not be hot rolls, or indigestible new bread; eggs or fish cooked in various well-known ways. 
Lunch: I or 1.30 P.M.-Fish and a farinaceous pudding; or, fish and biscuits and cheese. It is, in most cases, better to reserve the meat or fowl to the evening meal.

4 P.M.-A cup of freshly made tea.

Dinner: 7 P.M. - Should generally commence with a little soup, a vegetable purée, or a good fish soup (vide inf $r a$ ).

Fowl or game, red meat only occasionally, and one dish of vegetable. Pudding of a light, farinaceous variety, or stewed fruit.

IO P.M.-A cup of good consomme, or beef-tea or chicken tea, with a thin slice of toasted bread, is a very good thing tor an old person just as they get into bed.

Milk and cream.-Cream is a capital substitute for other forms of fatty food, and should be taken with tea and pudding.

Milk, if it can be digested, should always form a part of the dietary of the aged; the tendency should be to increase the amount of milk used as the vegetables and fruits are diminished. Milk is, of course, used in the cooking of gruels and farinaceous foods. As a beverage, milk can be taken with cocoa or coffee, or warmed and taken with a little saline or effervescing water.

Bread.-White or brown bread should always be toasted, and some forms of bread are found to be more digestible than others, e.g. a "pan loaf." The toast should be thoroughly toasted through, and quite brittle; two to three slices crisply toasted should be sufficient. Dry biscuits and rusks have also special value in the diet of the aged (see also p. 93).

Butter.-Fresh butter is the most wholesome of all fat foods; I ounce being taken in some form in the twentyfour hours.

Soups.-The light forms of consommé, vegetable purées, and fish soup are all appreciated when taken in small quantity. Rich animal purées, hare soup, kidney soup, ox-tail and turtle, all throw too much strain on the digestive glands, and should be avoided. (See also Soups for the Gouty, P. $44_{4}$ S.)

Chicken, veal, and beef-teas may all be used for the light supper meal at night. A few additional recipes may be given for useful soups. These are supplementary to those recommended under the section on Convalescent Dict (p. 302), which have also special value in the dictary of the agred. 
Brunoise soup.

I carrot, young.

th turnip, young.

zleaves celery.

lower of small cauliflower.

I onion.

2 ounces of stale bread, toasted.

I ounce butter.

1 pint water.

I pint milk.

I teaspoonful salt.

l'epper.

Stew the ingredients, except the toast, together for one hour, then break the toast in pieces, add it to the rest, and stew all together for another hour. Pass all through the sieve, and return to the stewpan to get hot.

\section{Lentil Soup.}

Wash the lentils thoroughly in cold water, and add the lentils to water in the proportion of $3 \mathrm{Hb}$. lentils to a gallon of water or of second stock. Add pepper, salt, onion, turnips, carrot, and celery. Boil all for three or four hours. Pass through fine wire sieve or colander, put on a few minutes to heat, and send to table with toast cut in dice. A little curry powder may be added if desired.

This soup is somewhat flatulent to those of weak digestion, but if made with Benger's pancreatised lentil flour and without the additional vegetables, it will be found very acceptable to the most delicate stomach.

l'ea soup served with dried mint, and haricot bean soup, can be made in the same way.

\section{Potato Soup.}

$\begin{array}{ll}\text { I llb. potatoes. } & \text { I ounce butter. } \\ \text { I leek. } & \text { I pint milk. } \\ \text { I onion. } & \text { I pint water. }\end{array}$

Stew the potatoes, put then with leek, onion, and butter into a pint of boiling water in a stewpan. Boil until the vegetables are soft, then pass them through a sieve, adding a pint of hot milk. I'ut them all into the stewpan until it boils, then serve. Serve with dice of fried bread.

\section{Rice and Tomato Soup.}

I pint of mutton, veal, or chicken broth.

3 fresh tomatoes.

I dessertsponouful l'atna rice.

A little salt.

Put the broth into a clean lined saucepan, with the rice well washed, and the tomatoes wiped and cut in slices. Boil slowly for half an hour, stirring occasionally. Then rub through a hair or fine wire sieve. Heat agrain, season to taste, and it is ready for serving.

Fish. - Find are allowable for old people. The oily fishes -such as salmon, herring, mackerel-are the only ones that are apt to disargrec with digestion, unless taken in small quantities. 
In addition to the usual methods of boiling, frying, and baking fish already described, a variety of dishes may be made from this class of food that are found to be appetising as well as quite satisfying.

\section{Boiled Cod or Boiled Hladidock Roes.}

Wash the roe well; then weigh it and tie it up in a piece of muslin or a pudding cloth. Put it into a saucepan or fish kettle, with enough boiling water to cover it. Add I teaspoonful of vinegar and $\frac{1}{2}$ teaspoonful of salt to each quart of water. Boil slowly, allowing twenty minutes to the pound, or until the roe feels quite firm to the touch. Lift out, drain well, and serve as much as will be required at one time. It can be served with plain cold butter or white sauce.

\section{Grilled and Fried Roe.}

The roe must be boiled first. When it is cold cut into slices half an inch thick with a sharp knife.

To grill, grease the grill or gridiron with a little butter, and make it quite hot. Lay the slices of roe on it, and broil in front of a clear fire for five or seven minutes. Serve this very hot.

To fry, melt I ounce butter in a frying-pan when smoking hot; put in the pieces of roe. Fry them a nice brown colour on both sides. When ready, lift out and drain on a piece of double paper. Serve very hot.

\section{Fish Baked in Batter.}

$\frac{1}{4}$ lb. uncooked fish, haddock, or sole.

I ounce flour.

$\frac{1}{2}$ gill milk.

1 egg.

$\frac{1}{2}$ ounce butter.

Pepper, salt, and lemon juice.

First make the batter; rub the flour through a wire sieve, make it free from lumps, and put it into a basin. Beat up the egrg with a fork and add it to the flour; beat with a wooden spoon until quite smooth and free from lumps. Then add the milk and beat for a few minutes longer. The more the batter is beaten the lighter it will be.

Have the fish free from skin and bone, and cut into small pieces. Lay these at the foot of a small greased pie-dish, and season with pepper, salt, and a squeeze of lemon juice. Pour the butter over, and put the rest of the butter in small pieces on the top. Allow this to stand for a few minutes before cooking; this gives time for the flour in the batter to swell, and it will be lighter when baked. Bake in a quick oven from twelve to fifteen minutes until well risen and nicely browned. Serve at once, as the batter ciuickly talls.

\section{Fried Haddock and Tomatoes.}

I dried haddock.

2 tomatoes.

I small onion.

1 ounce butter.

Penper, salt, and parsley.

Soul: the fish for three hours; then skin it. Take out all tlie bones, 
and break up the fish into faties. Slice the onion and tomatoes; chop up the parsley; sprinkle with pepper and salt, and cook all in the butter until yuite soft; then add the fish, and cook for ten minutes longer. Disls up in a border of boiled rice or mashed potatoes.

\section{Fish Soufle.}

$\$$ uncooked fish.

$\frac{1}{2}$ ounce butter.

sounce flour. $\frac{1}{2}$ gill fish stock or milk.

2 eggs.

Pepper, salt, and lemon juice.

First make a panada with the butter, flour, and fish. This is done by melting the butter in a small saucepan, adding the flour, and mixing until it is smooth with a wooden spoon. Then pour on the milk or fish stock, and stir until the mixture is thick and free from lumps, and leaves the sides of the pan quite clean.

Scrape the fish down finely with a knife. Put the panada into a mortar with the fish, seasoning, and yolks of egrgs. Jound well together and rub through a sieve. Beat up the whites of eggs to a stiff froth, and stir lightly into the fish mixture with an iron spoon. Pour into a greased basin, which should be only half full. Cover with a greased paper. Steam for twenty minutes. When firm, lift it out and turn out on a hot plate.

\section{Curried Fish.}

A very nice way of having fish is to curry it and serve it with a border of rice. The following ingredients should be put into the curry :-

I lb. fish.

2 ounces fat or butter.

I tablespoonful flour.

1 teaspoonful lemon juice or vinegar. Salt and pepper.
I apple, or stick of rhubarb.

I small onion.

I tablespoonful curry powder.

\section{Scalloped Fish. \\ 1 lb. cold cooked fish. \\ Breadcrumbs. \\ I ounce butter. \\ l'epper and salt.}

\section{Fish stock or milk}

liutter a scallop shell of fireproof china; sprinkle on it a layer of breadcrumbs; then a liyer of fish broken up into pieces; some pepper, salt, and piece of butter. Cover this with more breadcrumbs and bits of butter, and pour on a few drops of fish liquor or milk. Bake ten minutes.

\section{kedgerec.}

ib. cold fish or dried haddock.

I ounce butter.

ilb. boiled rice.

Cayenne pepper and salt.

$1 \mathrm{egg}$.

Wash and boil the rice; boil the egg very hard; break the fish into pieces and carefully remove all the bones; take the esgr, break off the shell, and cut the whites into sinall square pieces. When the boiled rice is dry melt the butter in a stewpan, atd the rice, then the fish, chopped white of egrg, cayenne pepper and salt. Mix them well together and serve on a hot dish, and sprinkle the yolk of egres over it. 


\section{Stermed Sole or Whiting.}

Skin and fillet the fish ; wash and dry the fillets, and put in a jam-pot which is placed in a saucepan half-full of boiling water. Cover tightly, and let it boil for ten minutes. Mix I ounce of butter with I ounce of flour in saucepan over the fire. Add I gill of milk and licpuor from the fish, and cook for ten minutes, stirring well. Pour this sauce over the fillets, and garnish with slice of lemon.

Meat Dishes.-Chicken and tongue are usefu! in the dietary of the aged. The receipts in the Convalescent section (pp. 305 ct scq.) may be supplemented by the following :-

\section{Chicken Purce.}

Remove all the skin and bones from a part of roast chicken. Chop the meat and pound it in a mortar, and rub through a sieve. Take the bones of the chicken, boil for several hours with onion, carrot, two leaves of celery, and enough water to cover them. Strain through a sieve, and remove all the fat. Add the pounded meat, and simmer until it is sufficiently thick. Add $\frac{1}{2}$ gill of cream, a few drops of lemon juice, and a small lump of sugar.

\section{Creme de Volaille.}

Melt $\frac{1}{2}$ ounce of butter and $\frac{1}{2}$ ounce of flour in a saucepan, and add $\frac{1}{2}$ gill of white stock. Take the flesh of half a chicken, chop, pound it, and rub it through a sieve. When the sauce is cool, add one egg, $\frac{1}{2}$ pint of cream, and mix well together. Put into buttered mould; steam for quarter of an hour.

\section{Tonsue.}

In choosing a tongue, find out how long it has been pickled or smoked. Select one with smooth skin, which denotes it being young and tender. If a dried one and rather hard, soak it at least for twelve hours previous to cooking it; if, however, the tongue is fresh from the pickle, two or three hours will be sufficient for it to remain to soak. Wash the tongue well, and trim it neatly at the root. Put the tongue into a stewpan with plenty of cold water and a bunch of savoury herbs, and a few pieces of vegetable for flavouring; let it gradually come to the boil, skim well, and simmer very gently until tender. A large smoked tongue will take four to four and a half hours, a small unsmoked one would take about two to two and a half hours. When the tongue is terder, take it up, plunge it into cold water, and then skin it carefully. If to be eaten hot, cover the tongue with greased paper after skinning, and heat in the oven for a few minutes. Then glaze it or cover with browned breadcrumbs. Garnish with greens and tufts of cauliflower, and serve good brown sauce in a sauce-boat. If to be eaten cold, after stewing turn it into shape on a board by fastening it down at root and tip with fine skewers, and leave it until cold. Glaze it or not as prefened. Put a frill round the :oot, garnish with paisley, a id serve. 
Vegetables and Fruits._Old people are very apt to give up vergetables, owing to their Batulent properties. This practice is not it rood onc, for if persisted in, some minor symptoms of scurvy not infrequently develop. Everything depends on the form in which the vegetables are administercd, and on the annumt and nature of the other ingredients of the meal.

A small quantity of potato should be taken every day if possible, and also a certain amount of well-cooked vegetables. Spinach, stewed lettuce, stewed or baked tomatoes, vegetable marrow, cucumber, boiled or stewed celery, seakalc, asparagus, lecks, the flower of cauliflower, large Spanish onions, and French beans are all suitable. Uncooked vegetables as partaken of in salads are not very satisfactory, since they are apt to cause fermentation. The same holds good for cabbage, srecns, brusscls sprouts, turnips, parsnips, and old carrots. For methods of preparation of the vegetables, see p. 122.

Fruit taken in small quantity is also permissible. It is best to take it cooked, either stewed or baked, and eaten with cream. This gets over the difficulty of eating a crisp apple when the teeth are imperfect.

In stewing fruit, if cane sugar is added by the cook the resultant product is very apt to turn acid. It is therefore better to neutralise the acidity with an alkali rather than to attempt to mask the flavour with sugar. Thus, to cach pound of fruit add as much bicarbonate of soda as will lic on a shilling. The bitterness of the fruit will be gone, and the natural flavour of the fruit will become apparent, which is usually cuite swect cnough. If this simple method be adopted, many old people will find they can enjoy stewed fruit without the annoynce of acidity or heartburn afterwards.

If there is a desire for sweetness, saccharin can take the place of sugar. The usual rule, however, will be found that the desire for swectness disappears, and that food with a relish has to be provided instead.

Liquids.-Very weak tea is generally best at breakfast, with a good proportion of milk and cream. This should be drunk at the conclusion of the meal. At lunch a cup of coffec and milk, or cocsa and milk may be taken, or a glass of water may be taten after the meal is finished. 
Stimulants in Old Age.- The question of the arlvisibility or not of giving stimulants to old people depends largely on the previous habits of each individual. In the case of these who have not been accustomed to liquor in any form, no advantage is to be gained by recommending it-they are better without it. For those who have been accustomed to indulge in a little wine or spirits, a small amount of alcohol may be advisable daily. This should be given with the chief meal of the day. A tablespoonful of whisky in a little water or table-water is probably the best form in which the stimulant may be administered. There is no reason why a glass of sound wine of any variety should not occasionally be taken in place of the whisky, but it is not advisable to take wine daily-this almost inevitably lcads to manifestations of "rheumatism" or deranged digestion.

\section{Diet during Pregnancy.}

PAGE PAGE

General directions . . . $21 \mathrm{I}$ Diet during the puerperium . . 213

Diet adiuped to modify the size of

the child . . . . . 212

Diet during abnormal pregnancy . 214

Diet during Pregnancy.-A good mixed lietary is the one best adapted for the normal pregnant woman. If the bowels are kept regular, and if the patient take the requisite amount of fresh air and excrcise, no special dietary precautions are called for. Too much importance cannot be laid on the necessity of preventing constipation, and on the value of fresh air and exercise for the parturient woman. In many pregnant women, however, it is advisable to modify the dict. The necessity for this is shown by the presence of certain symptoms or physical signs in the patient which indicate the existence of a special strain on the kidney's and other organs of excretion. Thus, morning sickness in an exaggerated degree, albuminuria, and dropsy are serious symptoms in pregnancy, and their presence calls for very special attention being directed to the diet. In these circumstances the lightest possible diet, one that throws the least strain on the kidneys and other glands, must be given. Such a regime is a milk diet. In severe cases it may be necessary 
t. have recoure in an cxc'usive milk regime; in less severe cases, a diet of milli, bread, farinaceous foods and fruits may suffice, while in the milder forms of derangement all that is necessary is that the patient should avoid red meats and richer dishes of all kinds, and live on the lacto-vegetarian diet described on p. 526. The quantity of nourishment must not exceed what is usually required by a healthy woman; the meals should be taken at regular intervals, and all indigestible articles of food and any that are known to disagree with the patient should be avoided. The morning sickness and pyrosis of presnant woman are not markedly affected by diet, small simple meals at frequent intervals are the best.

In the later months it is necessary to take food in smaller quantities, more frequently, since over-distension of the stomach causes discomfort, owing to the size and position of the uterus. "Longings" for particular foods, so far as they are kept within reasonable bounds, can be gratified; but there is no evidence that the refusal to satisfy unreasonable caprices has any cffect on the physical or mental development of the child.

I'regnancy may be associated with glycosuria, diabetes, heart disease, tuberculosis, obesity, and other disorders. These must be treated along the lines laid down in these sections. In glycosuria and diabetes, special restrictions are called for in the sugars and starchy foods; in heart disease, on account of the dangers associated with over-distension of the stomach from flatulence or food, very special care is necessary in recrard to the forms in which starchy foods are taken, and also to the amount and nature of the fluid taken with meals. In tuberculosis a special supply of protein is called for, but the extra strain thrown on the kidneys by a diet rich in protein food must be kept in view. Pregnancy complicated by obesity should be treated by gentle exercises, massage over the abdomen, and a careful restriction of the carbohydricies and fluids in the dietary. Further details on these points will be fourd in the sections dealin with these diseases.

Diet adopted to modify the Size of the Child.-The trend of modern thousht, experience, and to a certain extent scientific research, tend to show that diet to a certain extent can modify the maternal and foetal lissues in such a way as to 
make the labour more easy, and to increase the probability of a viable child being born. This is of special importance in the case of women who have a small pelvis, and who have in consequence of the dangers associated with this, given birth to one or more still-born children.

According to Prochownick, Paton, and other investigators, a diet deficient in carbohydrates and fluids will result in a small child, which is otherwise perfectly developed. Prochownick claims that with a conjugate diameter of $8 \mathrm{~cm}$. a difficult labour can be obviated, and even induction of premature labour can be rendered unnecessary. A special dict should be begun three months before labour is expected, and should be rigidly followed out, more particularly for the last two months. The diet he recommends is as follows:-

\section{Breakfast-}

- Small cup of coffee, 3 ounces.

Breadstuff, 3 ounce, with a little butter.

\section{Dinner-}

Meat, eggs, or fish, with a little sauce.

Green vegetables, prepared with cream.

Salad cheese.

Supper, much as Dinner-I to $1 \frac{1}{2}$ ounces of bread with butter.

(Water, soups, potatoes, desserts, sugar, and beer are strictly with held.)

Thirst is complained of during the earlier part of this treatment, but passes off. The large amount of animal food was objected to by some patients. All the confinements reported were much casier than on former occasions, even when the child was large and fat. All the children were born alive. The children were usually lean at birth, with the bones of the head unusually mobile; they were apparently mature in every way, and in the majority of cases the chili sained normally after birth, and the diet had apparently exercised no injurious effect whatever on the child, or on the mother during pregnancy or the lactation period. On such a diet it is cssential that the condition of the urine should be carefully observed, the amount of urea and the presence or absence of albumin in the urine being specially noted. Unlike what might have been expected, it was found that this diet did not apparently favour the onset of eclampsia.

Diet during the Puerperium. - After labour the exhaustion 
of the patient may he relieved by the administration of a cup of heef-tea or warm milk, and for the first twenty-four hours the dict should be restricted to milk and beef-tca. During the sccond day it is advisable to kecp mainly to fluid food, with a little bread and butter. After a thorough clearing out of the bowels has been effected, there is no reason why we should not begin a light convalescent diet, including plenty milk. The amount of milk and milk foods can be overdone; the addition of one good meat meal a day (rump-steak, grilled chop, or underdone roast beef) is advantagcous for the milk supply, probably on account of its stimulating effect on the thy roid gland (sec Appendix). No benefit is obtained either to the mother or infant by attempting to stuff the patient.

Diet during Abnormal Pregnancy.-The diet for cases complicated by heart discase, glycosuria, diabetes, and tuberculosis has already been referred to. The pernicious vomiting of pregnancy is a condition which may be very intractable. In barl cases it is essential to kecp the patient at complete rest, and administer food in little more than teaspoonful doses at a time. Milk and beef-tea preparations strengthened by the addition of plasmon, sanatogen, or other concentrated foodstuffs are the mainstay in trcatment. In exceptional cases nothing arrests the vomiting, and it becomes necessary to terminate the pregnancy by inducing labour. Pronounced sulivation is another conclition which is occasionally a troublesome feature in pregnancy: There is no evidence that dict plays any special rôle in connection with this; a lactovegetarian diet is probably the best. The dietetic treatment of chove in pregnancy is on the same lines as for chorea in the non-pregnant indiviclual. Any mental disorders developiner during pregnancy should be treated by a meat-frec dict, the ford consisting of milk, farinaccous foods, and fruits.

Special attention must be paid to the albuminuria of fresumey'. This is frequently only discovered by the practitioner in the crourse of his cxamination of the water; in its earlier stages the patient may show no symptoms, but later there is great liability in celampsia. The dict for this condition is the milk dict of acute nephritis (p. 4IO). 


\section{CHAPTER XII}

UNDER-FEEIING ANI) OVER-FEEDING

\begin{tabular}{|c|c|c|c|c|c|}
\hline & & & PAOE & & PAnR \\
\hline $\begin{array}{l}\text { Uner-reeding } \\
\text { Illustrative }\end{array}$ & chear. & nutritious & .215 & Wver-feeding and over-drinking & $\begin{aligned}-217 \\
218\end{aligned}$ \\
\hline dietaries & . & . & .216 & $\begin{array}{c}\text { General rules for prescribing } \\
\text { dietary }\end{array}$ & 219 \\
\hline
\end{tabular}

Under-feeding.-The effects of under-fecding may reveal themselves as a result of, on the one hand, an insufficient diet, and, on the other, an ill-balanced one. The latter is the more common cause, as owing to the lack of knowledge among people of the poorer classes as to the principles and practice of sound feeding, children are often fed on a relatively expensive and innutritious or actually injurious dictary. For these patients some reference may be here made to various cheap and good sources of food supply. The most useful foods are the following : oatmeal, meat of the cheaper varietics, herrings, skimmed milk, cheese of the cheaper sorts, lentils, peas, and margarine. Of these, oatmeal is the most usefu!, especially during the growing period.

Meat may be quite who'esome and nutritious and yet of an inferior quality. The flesh of cows is commonly sold at a low price. For strong soups and stews there is no arliantage in choosing the best quality of meats. Foreign meats are now imported in large amount, and it is by no means easy to tell the difference between home-fed and foreign mutton. The latter is considerably cheaper than the former. The cheap parts of beef are "thick flank,", which is coarse in fibre, contains no bone and little fat, and is sold at a reasonable price, and is a good, cconomical piece for pies, puddings, and stewing. The "thin flank" is also cheap, but is rather fatty. It is best salted and pickled, and caten culd "Leg of meat" is also low in price, and is good for slow stewing and for soupmaking. "Brisket" is also gool for 215 
stewing, and is cheap. Ox check is a cheap and nutritious food. Allowance must always be made for the amount of bone in the meat purchased. Thus, ribs of beef are cheaper than hecfstcak, but there are 2 to $3 \mathrm{oz}$ of bone in the pound. kump-stcak, becfsteak, and loin are all solid, without any bone One shilling will purchase 2 lbs. of loin, I lb. of beefsteak, or 12 oz. rump-stcak. Of mutton, the leg is the most economical joint; though higher in price than shoulder, it contains less bone and fat, and cuts up better. Sheep's head makes excellent broth, and also supplies a fair amount of good meat. Hagris made from "pluck" is one of the cheapest forms of numishment. l'ig yiclds a cheap food in the form of pig's "check" and pig's "trotters"; other parts are rather expensive. Sheep's trotters and pig's trotters yield a gelatine of considerable value as a food, because of its protein-sparing properties.

Of fish, herring-c.g., kippers, bloaters, red herrings-are the cheapest fish. Sprats, ecls, mackerel, pilchards, ling, and John Dory are other varicties of cheap nourishing foods.

Oi vegetables, pulses are the most economical and nourishing. Peas, beans, and lentils are to be commended. Of fruits, mention may be made of rhubarb, apples, oranges, and bananas. An intelligent housewife selects her vegetables and fruits from those which are at the time plentiful and cheap.

\section{Illustratiz'c Cheap Dicturies.}

Brakfast-Cereal-Porridge and skimmed milk.

Dinner-To be selected from the following :-

Soup made from-

(I) Peas, beans, or lentils.

(2) Sheep's head, flavoured with rice or barley and vegetables, turnip, or cabbage.

(3) Fish soup made from cod's head or "trimmings."

Meat courses selected from-

(a) Liver, tripe, neck of foreign mutton, mince (made up with breadcrumbs and potatoes).

(b) Fish, either haddock fried in batter, herrings with potatoes, ling or John Dory fried in batter or made intc fish potato pie.

Bread with skimmed milk, margarine or dripping toast, and cheap skimmed milk varieties of cheese.

iupper, selected from-

Bread and butter, cocoa, cheese as above, fried potatoes, or porridge and skimmed mik. 
Such articles of diet as egress, sardines, and pastry forrels, which are largely bonght by the working-classes, cannot be regarded as cheop good foods.

From an ill-balanced diet.-This is a common cause of under-feeding. As cxamples of diseased conditions arising from this cause, we find ancmia induced by a diet consisting largely of tea and bread, to the exclusion of good animal foods; scurvy from a dictary deficient in fresh fruit or vegetables; and rickets from deficiency of fat, proteins, and salts, with excess of carbohydrates. Under-feeding lowers the resistance of the tissues to disease generally. More particularly, a deficiency of animal protein foodmeat, egrgs, and pure milk-is a predisposing cause to tuberculosis.

\section{Over-feeding and Over-drinking.}

Insufficient attention is sometimes paid to the effects of over-drinking in forming dietaries. Quite apart from the abuse of alcohol in the form of whisky, beer, and the like, ill-health not infrequently results from excessive tea or coffee drinking, more especially the former. It is no uncommon thing to find patients who drink tea in large quantity, three, four, or five times daily, the tea not being freshly prepared, which increases its liability to cause ill-health in the form of palpitations, indigestion, anemia, insomnia, and general weakness. In patients with atony or dilatation of the stomach special precautions have to be taken not to over-distend that organ by excess of fluid.

The injurious effects of over-eating are of far-reaching importance. It has been said that more harm results from over-eating than by over-drinking. Be that as it may, there is no question that over-indulgence of the appetite is the most important factor in the development of many serious diseases. Occasionally the excessive ingestion of protcin food induces a temporary albuminuria; similarly, glycosuria, pentosuria, and obesity arises from over-indulgence in sugary and starchy foods. Apart from these conditions, however, there is no question that prolonged over-eating tends to promote serious disease of the cardiac, vascular, and renal systems, and is also an important factor in 
the derelnpment of the common discases of metabrismgout and rheumatism. It cannot be too strongly emphasised that very many of the cases ordinarily met with of heart disease, kidney discase, cerebral hamorrhage, and the like, are a direct outcome of long-continued errors in feeding. These points are more fully dealt with in the sections dealing with these various disorders. Excess of proteins, and more especially animal proteins, is, gencrally speaking, a more serious defect than excess of carbohydrates and fat. This is due to the fact previously pointed out, that proteins are incompletcly oxidised, and any increase in the products of imperfect metabolism of proteins tends to the accumulation of the waste products in the blood, and these act as poisons, acting injuriously in the different directions already indicated. In this connection we must bear in mind that an cxcess of carbohydrates and of fats may produce similar results through shielding the proteins from complete oxidation.

There is no end to the forms in which over-eating is met with in everyday practice. The appropriate dietary for any given case can only be framed after full knowledge of the feeding habits of each individual. In this connection it is wise not to lay too much stress on what the patient says. Few will admit that they habitually over-eat, and the most that many gourmands will admit is that they "enjoy their food." The patient's statements have therefore to be qualified by the impression gained by the practitioner from the general appearance and history of the patient. The writer finds it useful to get the patient to give in writing a full statement of his or her ordinary diet for one or two days.

A word should be said about seasonal over-indulgence. To err is human, and to err occasionally in feeding is not only human, but is for the time being exceedingly pleasant. In the spring-time the advent of vegetables leads to a slight over-indulgence, with resulting development of indigestion, or, as in the case of rhubarb, to calculus formation. In early summer the too frequent indulgence in the luscious sugar-coated strawberry induces lumbago, neuritis, pruritus, and other so-called gouty manifestations. Similarly, in the autumn, ill-health may arise from too freely partaking of pears, plums, and other autumn fruits. 
It may be useful to give a few general rules that should be kept in mind when framing a dictary.

\section{General Rules to be kept in mind when framing a Dietary in Disease.}

(a) Directions should not be of a general nature; all directions should be made specific, and in writing.

(b) The relation of the meals to rest, excrcise, and work should be clearly defined.

(c) The quality and quantity of fluid ingested may be as important a consideration as the solid constituents of food.

(d) Keep in mind that in many instances the patient is simply giving free play to his appetite, and all that is necessary is to get him to stop over-cating. This may require a little tact, as in (e).

(e) Begin by cutting off some of the "extras" in the dietary. Tell the patient that these are bad for him. These may not in themselves be injurious, but as a part of the whole they are throwing an unnecessary strain on the digestive functions.

(f) The patient's previous experience of the food recommended should be investigated. Regard must be paid to any idiosyncrasy, if such really exist.

$(g)$ All meals should be taken slowly, special attention being directed to efficient mastication of the food.

(h) It may be advisable to make any radical change in diet slowly; a return to a normal diet should certainly be made gradually.

(i) If you decide to put the patient on a special system of diet, and more especially a restricted diet, and a satisfactory result is not obtained within two or three weeks, the diet is unsuitable and should be changed.

(j) Keep in mind the scason of the year with its associated proclivity to over-indulgence in certain articles of dict, especially fruits.

(k) The application of the pancreatic reaction in the urine is of value in inclicating whether the sugars and starches should be specially restricted (p. 377). 


\section{CHAP'TER XIII}

\section{LENERAI, SERVING OF FOOD FOR INVALIDS-RECTAL FEEDING}

TIF manner in which the food is served is of great practical importance. A meal served in a careless, slovenly manner may disgust the patient and seriously retard convalescence.

Everything should be scrved as daintily as possible, the dishes, glasses, and traycloth being thoroughly clean. To most invalids the meals are the events of the day, and too much care cannot be exercised to ensure that all the details should be done in as attractive a way as possible. Patients should not, as a rule, be consulted as to their meals, but there should be an endeavour to ascertain beforehand what the patient likes. Any particular fancy as to sweetness or otherwise should be remembered. Untouched food should never be left in an invalid's room, but should be put aside in a cool place; and no food should be cooked or prepared in the invalid's presence if it can be done elsewhere. Food should never be tasted in presence of the patient, and it should not be cooled by being blown upon, as this naturally disgusts the paticnt.

In the case of helpless patients who cannot feed themselves, nourishment may be given by the spoon or the feedingcup. When the patient is very helpless, a useful device is to pull out the check, by inserting the finger between the gum and the cheek, and thus introduce the fluid nourishment slowly at one side. A teaspoon is the most convenient size of spoon for child-feeding, and a dessertspoon for the adult. As to drinking-cups, the shape made with three handles is very convenient for the patient to use when feeding himself; 
but when the services of a nurse are required, a small boatshaped fecling-cup with a curved spout, and about 3 inches of rubber tubing attached, is the most useful. In the case of the latter, great care must be taken to maintain thorough cleanliness of the apparatus in use.

In feeding with a spoon or feeding-cup, it is certainly easier for the patient to have the head raised, if this is permissible; the nurse in these cases passes the left arm under the pillow on which the patient is lying, and gently raises the head.

\section{Rectal Feeding.}

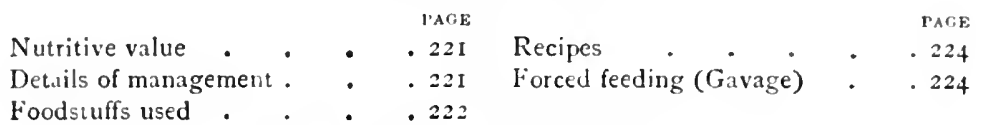

Artificial fecding-rectal alimentation.-Rectal feeding is a method of alimentation of great value in the treatment of some diseases. It is indicated in many disorders of the stomach or other part of the upper alimentary tract, such as gastric ulcer, cesophageal and gastric cancer, and acute gastritis resulting from the action of corrosive and other poisons. It is also useful in cases of prolonged reflex vomiting, such as occurs in some cases of pregnancy, and in other conditions in which the power of absorbing food is temporarily suspended, as in cases of severe cerebral hemorrhage and the like. A vast amount of investigation has been carried out on the subject of the amount of proteins, fats, and carbohydrates that are absorbed from the large bowel, when food is introduced into the system in this way. The results obtained from these investigations are somewhat conflicting, and are not always in accord with the results of clinical experience. This much is certain: sufficient nourishment can be absorbed from rectal alimentation to maintain life and fair nutrition even for some weeks; and as in the great majority of cases it is not necessary to have recourse to this system of feeding for more than eight or ten days at the outset, it is certain that rectal alimentation, when carefully carried out, is of very great value in treatment.

Details of management.-Great care is nccessary with 
regard to certain details in the management. In the first place, it is essential to clear out the bowel as a preliminary measure. All mucus and frecs must be removed by an injection of soap and water, preferably followed by an enema of plain water. In the next place, the nutrient enemata must be carefully regulated, both in number and amount, so as to diminish the irritation in the bowel and avoid excessive peristalsis. The nutrient cnema should be preferably given by a long flexible tube, which is inserted, in the case of adults, $S$ or 10 inches into the bowel. By this method the injection is less likely to be rejected, and the food constituents are absorbed into the inferior mesenteric vcin, from whence they pass to the liver via the portal vein, in place of passing direct into the inferior vena cava, as they do when brought into contact with the lowest part of the rectum only. Not more than 4 to 6 ounces should be given at a time, the patient being instructed not to strain during administration. The patient should lie on his left side with his hips raised. Care must be taken not to inject air. The temperature of the food is important, it should range from 95 to $100^{\circ} \mathrm{F}$. If too hot or too cold, absorption is interfered with, and undue peristalsis may be induced. As a general rule, the frequency of administration should not exceed one every six hours. The bowel should be thoroughly cleansed out once daily, the tube being connected with a funnel to a height of 2 to 3 feet. The addition of ten to twenty drops of tincture of opium to the nutrient enema once a day, or every sccond day, is of value in diminishing the irritation in the bowel.

Foodstuffs cmployed.-All the various classes of food may be employed in rectal feeding. Proteins are supplied in the form of milk, white of egg, meat juice, peptones, and various concentrated protein foods such as Plasmon, Protene, and Somatose. Carbohydrates are given in the form of lactose in milk, dextrose in its pure form, and grape sugar (glucose). Care has to be cxercised not to administer too niuch sugar, as this may induce pain and diarrhoea. Not more than from 4 to 6 ounces of a 10 per cent. solution of sugar should be given. Starch may also be employed, and appears to be fairly well absorbed, even when given in the raw state. Fats 
have a inore restricted value, and the best form of administration is the yolk of egrss. The recent investigations of Koester have shown that more than 50 per cent. of cream is absorbed when emulsionised with Pancreon.

Reference must be made to the digestion and absorption of nourishment from the bowel. There is little or no power of digestion in the large bowel, hence protein foods should always be administered in a predigested form. l'ancreatised preparations are here of the greatest value (see p. 173).

Probably about one-fourth of the nutriment required by the body can be absorbed by the large bowel, and this suffices to tide patients over a critical period, extending it may be over several weeks. Absorption of all the food constituents in the enema is facilitated by the addition of common salt, this probably being due to the action of the saline in inducing reverse peristalsis. From $\frac{1}{2}$ to I teaspoonful of common salt should therefore be added to each nutrient enema. The recent investigations of Boyd and others appear to show that protein foods are less completely absorbed than has hitherto been supposed, and increasing attention is now being directed to the special value of the sugars when given in pure form. Dextrose and glucose should therefore enter largely into the dietary of a patient who is being fed entirely by the bowel. The chief food constituents of value for rectal alimentation may be tabulated as follows :-

Proteins.
Milk.
Beef juice.
White of eggs.
Concentrated proteins,
such as l'lasmon,
Somatose, and the
like.

Carboliyirates.

Dextrose.

Milk sugar.
Fats.

Yolks of egors.

As the addition of common salt facilitates absorption of the nutrient elements of food, a good pinch of salt should be added to each nutrient enema. The addition of alcohol, notably in the form of whisky or brandy, is also of much value in treatment. Some authorities attach more value to the use of the injection of 15 to 20 ounces of normal saline, containing from to to I ounce of pune dextrose, twice or thrice 
daily, than to the use of ordinary nutrient enemata. The following series of recipes will be found of value :--

1. Plain milk.

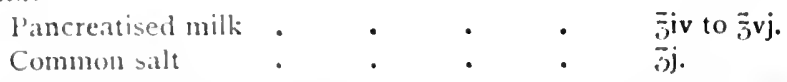

2. Milk in combination awith esrys, meat proparations, sugar, and stimulants, e.g.-
(is) l'ancreatised milk
Whites of a egrys
Comnon salt
jij of milk sugar may be added.
jiv to $\bar{j} \mathrm{vj}$.
3j.

(b) l'ancreatised milk and pancreatised beef

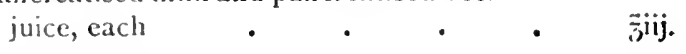

(c) Pancreatised milk • • • • • • •

heaten-up egg

Brandy or whisky (diluted with equal amount of

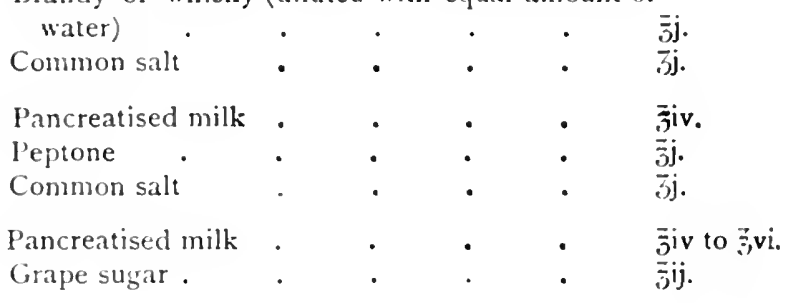

3. Dextrose. This may be given either in nomal saline, or as a constituent of a nutrient enema, as follows:-
(a) Dextrose
Normal saline
(b) Dextrose
l'ancreatised milk.
l'ancreatised milk . . . . Biv to 3 vj.

As already stated, the total amount of nourishment absorbed from the judicious use of these encmata is very small. But it amply suffices in the great majority of cases to tide the patient over a critical period in his illncss.

Nutrient suppositories. - There are numerous nutrient suppositories in the market, their chief basis being peptone. These are not as a rule readily absorbed, and their use is rarcly advisable.

liorced fecding by the stomach tube (Gavage).-In 
asylum practice and in certain medical affections of the tonguc, pharynx, and esophagus which render deglutition impossible, recourse is had to forced fecding by the stomach tube. This is inserted either through the nose or mouth, and food is administered two or three times in twenty-four hours. Milk, eggs, beef juices, and concentrated meat teas are suitable foods for administration. A good mixture to employ consists of I pint of mill;, one egg, I ounce of milk sugar, and a pinch of common salt. This mixture can be fortified if desired by the addition of a dried milk preparation, e.g., Plasmon, Somatose (p. 15S). The food should be introduced slowly.

In nasal foeding the above rules apply. The apparatus is simple: the small glass barrel of a urethral syringe with about 10 inches of narrow rubber tubing attached. This is well oiled, and passed gently along the floor of the nose in a backward and slightly outward direction; it slips over the posterior surface of the velum palati, and from thence into the pharynx and gullet. Patients soon become tolerant of this method, provided there is no obstruction in the nasal passages. 


\section{CHAPTER XIV}

\section{INFANT LEEDING-DIET IN FIRST TWO YEARS OF LIFE ${ }^{1}$}

\section{A. Infant Feeding in Health}

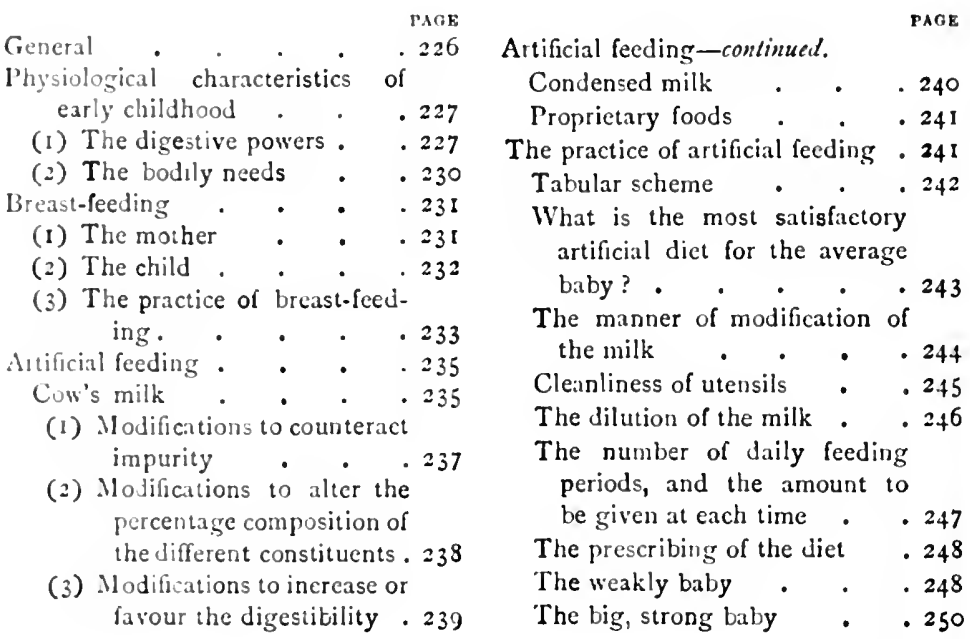

In all civilised countries the subject of infant feeding has, of late years, been attracting much attention, and in Germany, France, America, and our own country much has been done to unravel medical difficulties, to avert unnecessary sources of evil, and to grapple with many of those social and economic problems which are so intimately bound up with the supply and administration of nourishment for the young child.

In our own country, all the different conclitions connected with the subject - the conditions of life, of food-supply, climate, 1 Ly Dr Dingwall Fordyce. 
environment in general-all, naturally, vary to a certain extent from those in other countries.

Thus, while at the base of the subject of the scientific practice of the feeding of infants and young children there rest broad laws applicable on all occasions, yet it is not surprising to find that the methods successfully cmployed in one country vary considerably from those employed in another, where the various factors entering into the life of the child are modified to a considerable degree. The broad basal laws, the scientific principles, are, however, such as demand consideration and recognition from all medical men to whose charge is entrusted the medical supervision of carly childhood.

Physiological Characteristics of Early Childhood-(I) The digestive powers. - At the period of birth, and immediately after it, the secretion of saliva by the infant is small in amount. As the weeks pass, this amount rapidly increases, and by the time the infant is two or three months old the secretion is free. Yet its digestive power is still limited, and its composition is different to that in adults. The starchsplitting ferment, ptyalin, is a constituent of the salivary secretion which is present in extremely minute quantities during the early weelss and months of life; as life advances it increases in amount-by the third or fourth month it may be present in quite considerable quantities, and at about the period of the commencement of the primary dentition (the sixth to the tenth month) it increases rapidly to large proportions. Starch, therefore, if occurring in the infant's food, will, up to at least the sixth month of life, pass into the stomach very largely unaltered by the salivary secretion; while, after this period, the average infant will be found to possess, in its saliva, the means of initiating the digestion of a not inconsiderable amount of starchy food.

During the early months of life the natural food of the infant is his mother's milk. This milk is obtained by the process of sucking from the maternal breast; mastication is unnecessary, the jaws are not called upon for active exercise, and the secretion of saliva is comparatively small in amount and poor in digestive capacity. With the development and eruption of teeth, marlied changes occur. The 
masticatory powers now call for development, the jaws demand exercise for proper srowth, and the digestive quality and the quantity of the saliva increase marliedly. With the eruption of succeeding teeth the masticatory and digestive capabilitics progressively increase, and by the end of the sccond year are in an advaneed stage of development.

The position of the stomach in infancy is more upright than that which it ultimately assumes, and as a consequence the regurgitation of the gastric contents is a simple process. Of the ingredicnts of the gastric juice, rennin is present from birth in considerable amount; while pepsin and hydrochloric acil, though secreted shortly after birth, are present at first in only small amount. The digestive powers of the gastric juice are therefore at first very limited, and it appears that at this period the greater part of digestion is carricd on in the intestine. The reaction between human milk and rennin results in but very fine curd-formation, and, consequently, a large quantity of the milk passes rapidly through the pylorus to undergo the major part of digestion in the small intestine. The gastric mucous membrane is sensitive and intolerant of the presence of forcign bodies, particularly during the carly months of life, and large, tough curdssuch as those of cow's milk-and, at a later period, lumps of food or irritating liquids are badly borne, and usually quickly rejected by vomiting.

The secretion of bile is, on the other hand, free from birth onwards. The liver is comparatively large at birth, its activity considerable, and its digestive powers well developed. Likewise, the digestive powers of the pancreatic secretion are considerable, with this marked limitation, however-the starch-digesting power is largely in abcyance. Amylopsin in the pancreatic juice, like ptyalin in the saliva, is, during the carly months of life, chicfly conspicuous by its absence; the bodily powers of digesting starch develop gradually only after birth, and, until the period of the commencement of the first dentition, are cxtremely limited. In the small intestine the greater part of digestion takes place. The intestines in infancy are very frecly movable, and as this is a period when musculat spasm and muscular inco-ordination are of common occurrence, it is readily seen how vomiting, 
diarrhea, and intussusception easily occur. Fxamination of the faces of a breast-fed infant shows that bacteria are present in abundance, and that they are mostly positive in reaction to Gram's stain. Bucillus bifulus is here the dominant form (Herter); it is anti-putrefactive, does not attack protein, and forms lactic acid on sugar media.

A variety of other organisms are also present, among them Bacillus coli (Gram negative) and Bacillus lactis arogenes.

In the case of bottle-fed infants the number of bacterial forms present is greater than in breast-fed infants, and the dominant type is not the Bacillus bifidus but the Bacillus coli. The difference in the bacterial flora in the two cases is important, because of the tendency of Bacillus coli to further putrefactive changes.

In both breast- and bottle-fed babies very little putrefactive decomposition ordinarily occurs in the intestine, and it is well here to note that milk has a restraining effect upon intestinal putrefactive processes. With an increased and varied diet different bacterial conditions are obtained in the intestine, although putrefactive processes as compared with adult life are not active. During the first few weeks of life the infant has three or four movements of the bowcls daily; later, two movements daily are common. It is important to note the character of these stools : they consist of some 2 or 3 ounces of a light yellow, homogencous, semisolid fluid, with a faintly acid reaction to litmus paper.

As regards the digestive processes, from the point of view of the foodstuffs it has been shown that the power of the newborn baby to digest starch is very limited. Normally this power gradually increases in amount until the period of the first dentition, when its development takes place rapidly. Sugar is readily digested cven in early infancy, and forms an important part of the infant's diet. The readiness with which it undergoes fermentative change-more particularly under the action of the lactic acid bacillus-results in its tendency, when present in excess in the food, to cause gastro-intestinal disturbance, and such disturbances associated with, or caused by, fermentative processes are, consequently, common in early childhood.

Fat and carbohydrate are the chief sources of animal 
heat: in the adult the value of fat in this respect is, in an ordinary diet, markedly less than that of carbohydrate; in the infant the conditions are reversed, fat being of greater value than carbohydrate. Fat is urgently needed by the body cells in childhood; it is as a rule readily digested at this period, and it assists in the absorption of mincral salts.

At no period of life are the differences between the varictics of protein more clearly demonstrated than in carliest infancy. The greater bulk of the curd resulting from the ingestion of cow's mille compared with that of luman milk is largely due to the difference in the relative proportions of the protein constituents in the two milks, and is a cause of many of the difficulties associated with the artificial feeding of infants. The digestive functions of the stomach are constantly stimulated to fuller development as ase advances, owing to the ever-changing amount and quality of the fluid secreted and the consequent changing reactions between it and the milk. By the period of the first dentition all the digestive juices are fully active, and are secreted freely; the stomach is capable of containing larger meals, and the intervals between meals can be considerably lengthened. The anatomical peculiarities of the infant stomach have become less marked, the susceptibility of the gastro-intestinal mucous membrane to local sources of irritation is much diminished, and the general muscular tone has developed considerably.

(2) The bodily necds. - In practice, the correct recognition of the individual influences which affect the amount of food required, and of the nature of these influences, is necessary for the regulation of a suitable dictary.

Of such factors bodily growth is one of the most important. In childhood, assimilative powers are great and growth is active-so powerful, indeed, is this tendency towards nitrogenretention that even in times of illness, when the child is receiving a meagre dict, poor in protein, and cmaciation is occurring, yet nitrogen is retained by the cells, and growth takes place.

In the case of a child the calls of the organism for growth necessitate an ample diet, and, more particularly, an adequate supply of nitrogenous material. Owing to the great 
surface extent of the child in relation to his bulk, and the consequent considerable loss of heat, his need of a relatively large supply of non-nitrogenous fond as compared with the adult is also marked. In this relation, as has previously been noted, fat is of geater value than carbohydrate to the infant, and thus we find that abundance of fat is onc of the chicf characteristics of the food in infancy and carly childhood.

Breast-feeding.-(I) The mother.-In the case of all healthy mothers, even when it is unlikely that the period of suckling will be long-continued, the full extent of this period should be utilised. Every day of suckling granted to the infant during the first few weeks of life is of immense service to it.

Maternal mill supplies an easily digested form of nourishment to the infant, and one which is specially designed to mect its needs until such time as an artificial diet can readily be made use of. The health of the mother during pregnancy and lactation is, consequently, of the greatest importance. During the first few days after birth a small amount of fluid, colostrum, is secreted by the maternal mammary glands. This fluid differs in composition from the later milk and serves as a preparation for its ingestion.

About the third day after birth the secretion of milk becomes established, and the process of suckling stimulates this secretion. So much is this the case that it is possible for a mother to suckle her infant for a much longer time than is good cither for the health of her infant or herself.

Human milk is a fluid of varying composition, and for practical purposes the following figures suffice:-

Approximate Percentage Composition of Human Mill.

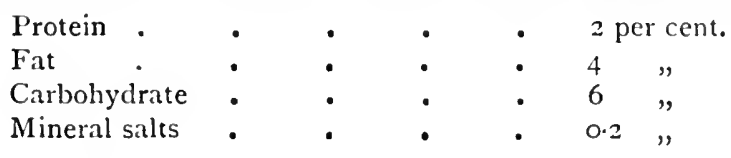

The protein present is largely in the form of albumin, with cascinogen in half this quantity, this caseinogen being peculiar in that it yields no carbohydrate when split up by 
digestion, and onntains no nuclein. It forms the curd when acted on be renuin.

Milk sitric: in ynulity during each act of suckling; at its commencement the percentise of fat is low and of protein high, while towards the close the reverse is the case; and the frequency of suckling also affects the quality of the milk.

The diet of the mother and the condition of her general health naturally exert a most powerful influence on the composition of her milk. The nursing mother requires a liberal diet of plain food with abundance of milk; she should avoid alcohol, and as a rule all highly spiced or indigestible forms of food. It is possible for a mother in poor health to suckle and rear a healthy infant, yet such a condition is uncommon and the procedure usually inadvisable.

Transitory attacks of acute illness of minor degree have, as a rule, no marked effect upon the milk. If her condition demands it, there is no reason to hesitate in giving any drug to a nursing mother, as it is the long-continued administration of a drug which nay injuriously affect the infant through the milk.

The return of menstruation is not uncommon during lactation, and, as a rule, this is an occurrence of no importance to either mother or child. It is not a sign of ill-health on the part of the mother, and though occasionally the child's digestion is disturbed at this period, yet partial or complete artificial feeding for the few day's readily counteracts this, and weaning is never called for unless there are also definite signs of ill-health on the part of the mother or the child. Pregnancy may occur during lactation, though it is uncommon before the eighth month, and it is always advisable to commence weaning when this occurs.

Suckling is also contra-indicated when the mother is the subject of serious chronic, organic, or infective disease, of acute mammary affections, and, usually, of serious acute illness.

Wet-nursing is a custom little practised in this country. The social and other difficulties necessarily associated with the procedure are great; yet when these can be overcome, the advantage to the weakly or wasted infant of a diet of human milk is often very marked.

(2) The child.-The capacity of the infant stomach is at 
birth about I fluirl ounce; but as in early infancy the curd which is formed in the stomach by mother's mill is very soft and floculent, and passes reatlily thrumb the pyloris, a larger quantity than this can be taken at one feeding. At the age of six months the stomach capacity is about 6 ounces; but as, with advancing age, the secretory powers of the stomach have increased, and their reaction with the milk become somewhat more complicated as a provision for the development of the digestive powers, so the resulting curd becomes ever more solid, and passes less rapidly through the pylorus.

The infant demands that all its sustenance should be derived from its mother up till the close of the eighth month of life, while the value of maternal nursing is greatest in the early days and wecks.

It is important to determine periorlically how an infant is thriving, and this is best done by ascertaining the weight of the child and kecping a record of it. When possible, it is well to weigh the infant weekly for the first six months, and every second week during the next six months. A record of continuous gain in weight cloes not necessarily mean that the infant is growing and developing satisfactorily, though for satisfactory growth and development increase of weight is essential. During the first week of life there is usually a loss of weight amounting to perhaps 6 ounces. Thereafter there is a steady gain in weight, interrupted at times it may be by slight functional disturbances. It is useful to remember that an average baby ( 721 lbs.) doubles its weight at six months ( 15 lbs.), and trebles it at twelve months (22.

(3) The practice of breast-fecding.-During the first two or three clays of life the infant is put to the breast six-hourly as a rule, for a period of five to ten minutes at a time. It thereby obtains colostrum, and the process of sucliling stimulates milksecretion in the breasts. In addition small quantities of warm, boiled water should be given frequently.

The training of the infant should commence as soon as the maternal milk-secretion is established, and regularity in the occurrence of nursing periods and limitation of the time of nursing are, from the first, all-important.

During the first month the infant is given the breast at 
interrals of two hours cluring the day (cight nursing periods), and twice during the night. Each mursing period is limited to fifteen minutes, and the infant should be wakened if necessary at the regular time.

During the second and third months the breast is given at intervals of two and a half hours during the day (seven nursing periods), and once at night. At this time the infant will sleep five or six hours at night without feeding. During the third, fourth, and fifth months the infant is given the breast at intervals of three hours during the day (six nursing periods), and once at night.

After the fifth month the breast is given at intervals of three hours during the day (six nursing periods), and it is unnecessary at night.

The plan of mixed fecling must be adopted when the maternal secretion of milk is insufficient, or when the state of her general health renders it inadvisable that she should bear the whole strain of nursing. In the early days of lactation a little artificial assistance such as this may scrve to render full maternal suckling possible later. It is also not infrequently necessary, from social or other reasons, in cases where both mother and infant are healthy, to supplement mother's milk with artificial food. The mother may be able to suckle her child only during part of the day, or during the night and not during the day. Whatever the period of suckling be, the hours for feeding must be adhered to. The infant here begins with a milk-and-water mixture corresponding in strength to that for an infant four or six weeks younger, and this mixture is gradually strengthened till it is of suitable strength for the infant of that particular age (p. 242).

Weaning, when possible, should be a gradual process.

At the beginning of the ninth month one of the nursing periods in the morning is omitted and an artificial feed is substituted : after two or three days the substitution of another feer-in the afternoon-is made, and gradually the infant is entircly weaned from the maternal breast. It is always advisable during lactation to accustom the infant to the bottle-in case sudden weaning may at any time become necessary-by offering it once a day a bottlc containing warm, boiled water. 
Artificial Feeding.-In the cvent of mother's milk being unavailable for the infant, it becomes essential to provide a substitute for it, and we look first naturally to the mills of other mammals. Animals, other than the cow, from which milk may be obtained for the nutrition of the infant, are the ass, the goat, and the mare; but for all practical purposes cow's milk is of pre-cminent importance.

The chief characteristics of mother's milk are purity, ready digestibility, and suitability for adequate nutrition and development; and though cow's milk is lacling in many particulars, yet it is the nearest natural substitute for mother's milk. All patent and artificial foods are wanting in the essential quality of freshness. None contain the elements of the foodstuffs necessary for the infant's healthy nutrition, in a form so closely resembling mother's milk, as does cow's milk; many differ from it very markedly in quality, many are deficicnt in certain constituents, and many contain totally unsuitable constituents.

The composition of cow's milk varies according to many of the conditions of life of the animal, and thus the milk from a herd is more constant in composition than that from a single cow. The milk of Jersey, Guernsey, and Alderney cows is, as a rule, unsuitable for infant fecding, because it contains a high percentage amount of fat, and the nature of this fat is more unlike the fat of human milk than is the fat in the milk of other breeds of cows.

In comparing the average composition of human milk and cow's milk the following figures are sufficiently accurate for all practical purposes, as the variations in the composition of commercial milk are wide.

Comparison of the Perentage Composition of Human and Cow's Mill.

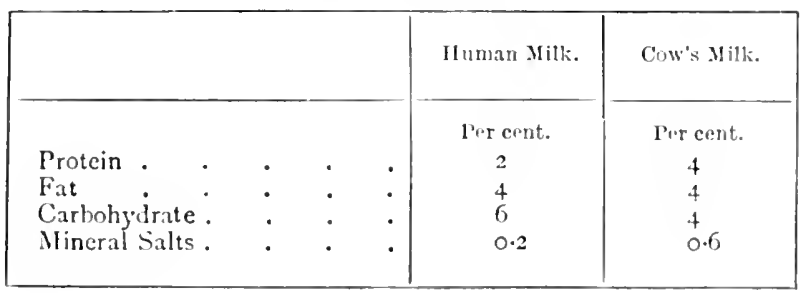


The varictics of protein present in cow's milk are, like those in human mill, chicfly cascinogen and lactalbumin, but they are present in clouble the amount of those in human milk. The difference between the protein of the two milks is not, however, merely the amount. The bulk of the protein present in maternal milk consists of lactalbumin, whereas in cow's milk it consists of cascinogen.

Although the amount of fat in cow's milk is approximately the same as that in human milk, yet it differs from the latter in chemical composition and is not so readily digested. Sugar occurs in solution, as in human milk, but in considerably less quantity, and thus, associated with an cxcess of protein, there is a deficiency of carbohydrate in cow's milk.

The salts in cow's milk are about three times as plentiful as in human milk; but as they occur largely in states of combination different from those found in human milk, their absorption takes place less readily.

Cow's milk, as supplied to the infant, is impure and stale. Fresh milk possesses the property of inhibiting bacterial development, and this power is considerable where the infant receives its mother's milk. Fresh cow's milk has slight power in this respect; but milk which is old, or milk which has been heated, lacks the power, while milk which has been merely frozen after milking retains it to some degree. Owing to the fact that lactic acid bacilli swarm in cow's milk, this milk when stale becomes sour; but even before a degree of sourness has been reached which is readily appreciable by the examiner, these bacilli may have caused such changes in the milk as to have rendered it very indigestible for the infant. Practically all milk as drawn from the udder of the cow contains many bacteria, and milk is a fluid in which bacteria grow readily. The presence of lactic acid bacilli tends to hincler the growth of other organisms, and in the case of an infant large numbers of bacteria are always dangerous, quite irrespective of their nature.

Tuberculosis is a very common disease among cows, and in the milk of infected animals tubercle bacilli are very frequently found. These bacilli from a bovine source are undoubtedly capable of causing tuberculosis in the human being; yet, while milk containing them is a dangerous food 
for the infant, a still more dangerous means of infection is through contamination of cow's milk with tubercle bacilli from a human source-c.g. sputum.

With the object of remedying or minimising the disadvantages attendant on artificial feeding, various methods of modification of the milk are commonly employed, and these may be suitably grouped under the following three headings :-

I. Modifications to counteract impurity.

2. Modifications to alter the percentage composition of the different constituents.

3. Modifications to increase or favour its digestibility.

1. Modifications to counteract impurity.-The danger from impurity of milk is obviated by the application of heat, and to this end various degrees of heat are employed.

Thus we may pasteurise, i.e., heat to a temperature of $150^{\circ}-160^{\circ} \mathrm{F}$. for twenty or thirty minutes; or scald, i.e., heat to boiling-point; or sterilise, i.c., expose the milk to a temperature of $212^{\circ} \mathrm{F}$. for forty minutes-in each case rapid cooling succeeding the application of heat.

For practical purposes, scalding is the most satisfactory procedure. The effect of pasteurisation is uncertain, and prolonged sterilisation causes marked changes in the composition of the milk, without satisfactory compensatory advantages in the matter of sterility.

The effects of the three processes may be summarised shortly as follows :-

The Results of the Application of Heat to Milk.

\begin{tabular}{|c|c|c|}
\hline Pasteuriserl Milk. & Boiled Milk. & Sterilised Milk. \\
\hline $\begin{array}{l}\text { I. Partial destruclion of } \\
\text { bacteria. } \\
\text { 2. } \\
\text { 3. } \\
\text { 4........ } \\
\text { 4. } \\
\text { 5. Slight precipitation of } \\
\text { calcium sults. } \\
\text { 6. Probahle destruction } \\
\text { of ferments. }\end{array}$ & $\begin{array}{l}\text { Approximate sterility. } \\
\text { Partial coagulation of } \\
\text { protein. } \\
\text {......... } \\
\text { Greater precipitation of } \\
\text { calcium silts. } \\
\text { Destruction of ferments. }\end{array}$ & $\begin{array}{l}\text { Sterility. } \\
\text { Large coagulation of } \\
\text { protein. } \\
\text { Interference with fit } \\
\text { cmulsion. } \\
\text { Caramelisation of lac- } \\
\text { tose. } \\
\text { Large prccipitation of } \\
\text { calcium salts. } \\
\text { Destruction of ferments. }\end{array}$ \\
\hline
\end{tabular}


Consequent on the above changes induced in the milk by the different degrees of heat, alterations occur in its digestion. With large precipitation of calcium salts, remin curd forms slowly in the stomach, and, consequently, is a softer and more flocculent curd the higher the clegree of heat to which the milk has been subjected. The flocculent curd of highly heated milk is not so fitted for gastric digestion as that of milk heated at a lower temperature, and it passes more readily onwards to the intestine.

2. Modifications of the perentage composition of milk.-The usual and most satisfactory method of carrying out this modification is to dilute milk with water, and add cream and sugar. By this means the protein percentage is reduced, while the fat and carbohydrate content is retained. It is unwise to give an infant, for any length of time, a mixture weaker than one part of milk and two parts of water. With such dilution the protein percentage is largely reduced, yet the initial relative preponderance of caseinogen in the protein was such that it is still present in larger quantities than in human milk.

Other diluents frequently employed are lime-water and barley-water. Lime-water, besides acting as a diluent, alters to a slight extent the proportion of lime salts present in the mixture, and also serves to render the mixture more alkaline. This last action is the most important, because rennin only acts in the presence of an acid, and consequently its action is delayed, and a less dense curd is formed in the stomach.

Barley-water contains minute amounts of protein, fat, and mincral salts, and a more considerable, though still small, amount of starch. It consequently possesses a small nutritive value, the most of which, however, is due to its starch content. The power of the infant to digest starch is comparatively weak, though it varies considerably in different children. It is, consequently, always advisable to know the strength of the barley-water which is being employed, and a uscful method for its preparation is to add I tablespoonful of prepared barley flour to I pint of water, boil for twenty minutes, and male up with water again to a pint. The barleywater so prepared contains rather less than $x$ per cent. of starch.

Milk may also be mudified by scparating it into its constituents-whey, cream, lactose, and water-and subsequently 
mixing them again, with or without the addition of fresh mills. Such a method of procedure is termed "the percentage method," and for its satisfactory conduct requires knowledge of the original richness of the milk. Lacking such knowledge, accurate percentage modifications are impossible, but the principle underlying the procedure is that which must guide us in our prescription of all milli-mixtures (sce p. 242).

3. Modifications to increase or favour the digestibility of milk.-13y the addition of sodium citrate to milk, many of the soluble calcium salts are precipitated, and as a result a smaller and softer rennin curd is formed in the stomach. One grain of sodium citrate added to I ounce of pure milk, or to so much of a milk mixture as contains I ounce of milk, serves partially to prevent rennin action, while 2 grains prevents it entircly.

By means of "peptonising powders," consisting of pancreatic extract and bicarbonate of soda, artificial predigestion of milk can be obtained, more or less completc, according to the length of time which the powders are allowed to act.

The method of employment is simple, and consists in mixing the powder with the milk, and placing the bottle con. taining the mixture in water at a temperature of $110^{\circ} \mathrm{F}$. for the length of time desired. Thus, after twenty minutes' heating, partial digestion occurs, and there is no bitter taste in the milk; while the longer it is heated-up to two hoursthe more complete is the digestive process, and the more marked becomes the development of a bitter taste.

Various other preparations of milk as well as a varicty of foods, are frequently used in the feeding of young children.

Buttermilk has practically the same protein and inorganic salt content as the ordinary milk: it contains, however, extremcly little fat, and a diminished amount of sugar, as some of the sugar has been changed into lactic acid. Its two chief characteristics are, consequently, a small amount of fat and a large amount of lactic acid. This milk is very digestible, and may be griven to the infant in the raw condition, whereby the benefit due to the presence of living lactic acid bacilli will be obtained. It is also frepuently given mixed with flour and sugar and then boiled, and in such a case the characteristics of the food are its porerty in fat, its acidity, and its high carbohydrate content. 
Condensed milli is cow's milk from which, as a rule, about two-thirds of the water has been removed by heating and evaporation; but as the composition of the original cow's milk is very variable, the composition of different brands of condensed milk is also variable. In addition to condensation of the milk, there is frequently also the addition to it of cane sugar, and we meet, therefore, with three types of condensed milk:-

I. Condensed whole milk, unsweetened.

2. Condensed whole milk, sweetened.

3. Condensed skinmed milk, swectened.

It is obvious that for the use of the infant all types require plentiful dilution. Twofold dilution with water restores the original composition of the milk, with or without, according to the type, the addition of cane sugar. Further dilution, to make the amount of protein approximately correspond to that in mother's milk, results in the amount of fat being reduced to a minimum. The vast majority of all condensed milks are artificially sweetened with cane sugar, and their two outstanding characteristics are, accordingly, lack of fat and abundance of sugar (see p. I 57 ).

Of such milks, two of the best are Nestlés and Milkmaid. What is their place in the fecding of the infant? In ordinary circumstances these milks are altogether undesirable as part of the dict of a healthy infant. When freely cliluted and mixed with cream, the sugar and fat content of the mixture may be rendered satisfactory, but in such a case the protein content is utterly insufficient. If, on the other hand, the amount of protein present is to be satisfactory the quantity of carbohydrate is necessarily excessive. In extraordinary circumstances, however, they have a definite value, and for short periods form a safe and satisfactory dict. For searoyages and railway travelling, when milk from a WalkerGordon dairy ${ }^{1}$ is not readily obtainable, they are excellent forms of nourishment, as are also the Allenbury foods, and in certain conditions of delicacy and discase in infancy to be incintioned later, their conployment is of great value.

1 From such dairies sterilised milk can be obtained, modifed according to prescription. 
An immense number of proprictary infant foods are now on the market, and their composition varics widcly. Some are intended as substitutes for cow's milk, and some as additions to it. For the infant under nine months of age the latter are not only unnecessary but harmful; for an older child, hovever, most of them form a useful and readily digested addition to the diet.

Those forms intended to be used as substitutes for milk are more suitable than the others for young infants, but even with their cmployment there are associated many drawbacks. All lack the antiscorbutic property, and none are so suitable in composition as carefully modificd cow's milk. When the employment of one of these foods is preferred to other methods of fecling the infant, Allenbury No. I is probably the best food for an infant during the first two or three months of life.

For older children, i.e. over three months of age, the most suitable foods are Allenbury No. 2 and Horlick's malted milk.

These three foods-Allenbury, Nos. I and 2, and Horlick's malted milk-are intended as substitutes for cow's milk; they consist of desiccated mill with a small amount of cereal-the starch of which is largely converted into malt sugar, and for use they are mixed with water.

Many foods, however, contain no milk in their composition, and are intended as additions to cow's milk. All such foods are composed of cereals, i.e. powdered grain, and are consequently rich in starch. In the case of Mellin's food the starch is completely converted into malt sugar, as is also the case in Hovis No. I; in Savory \& Moore's food, Benger's food, and Allenbury No. 3 it is partially converted; while in most of the other foods the starch remains almost entirely unconverted. (See also Chapter IX., p. 154.)

The Practice of Artificial Feeding.-Cow's milk, boiled (scalded) and suitably modified, is, however, the best artificial food obtainable for the infant.

This modification as a matter of routine consists of dilution with water, and the addition of cream and sugar; further modification is necessary in special circumstances, and may consist of the addition of sodium bicarbonate sodium citrate, gruel, etc. 
Before going into any cletails of diet, I grive the following table, which shows succinctly the dict likely to prove satisfactory for the arerage healthy infunt :-

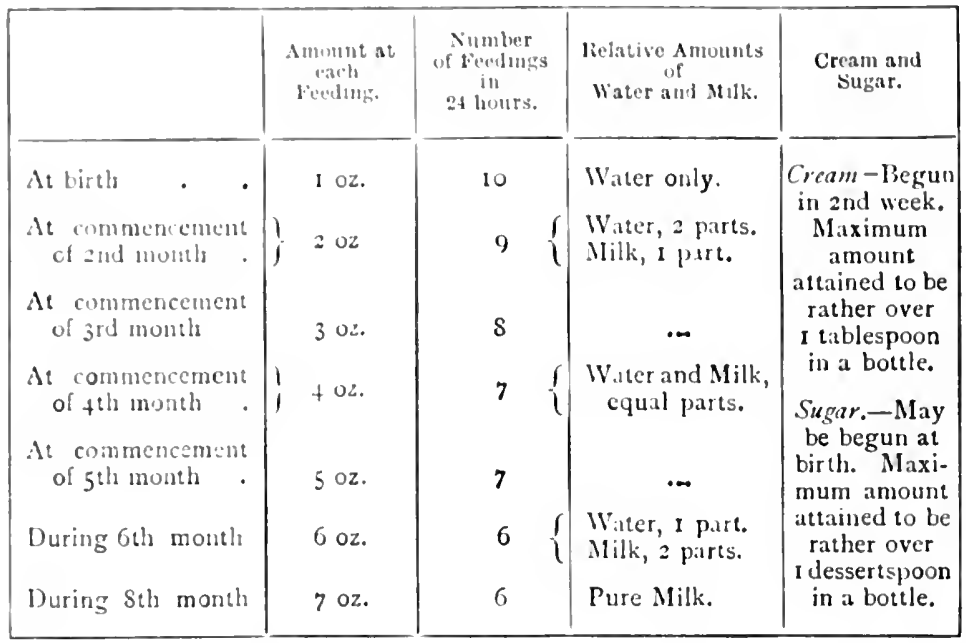

In the foregoing table the amount of food to be given at each feeding for babies of different ages has been placed in the first column. The figures are only valuable as a general guide, but as such-as an approximate indication of the capacity of the infant stomach-they are certainly of practical use.

In the second column there are placed the number of meals which are to be given in the twenty-four hours-for the first two months the infant is fed twice at night, and afterwards till the sixth month once at night.

In the third column it has to be understood that the food of tine infant gradually passes from one strength to the next as age advances.

In the final column it is noted that the amount of cream and sugar administered-which to begin with should be very small (p. 245)-should for a baby under nine months of age never exceed the quantities therein mentioned. The sugar is preferably milk sugar, but cane sugar is also quite satisfactory.

The infant at birth whose future destiny largely depends 
upon the contents of its feeling-bottle, requires most careful supervision. breast-nursing is the ideal condition for the child, but in the vast majority of cases, artificial feeding can be conducted to a satisfactory issue without any serious difficulties. The digestive capabilities of the infant are broal and elastic, and capable of suiting themsclves, within limits, to the nourishment presented to them. And this very power is too often its own undoing. Infant feeding is a simple branch of medicine compared with many others; simple, that is to say, in its successful practice, though not, perhaps, in its scicnce. But the subject demands intelligent attention, a little thought, and some clinical experience, and without the two former the latter is totally inefficient. The accoucheur is, as a rule, professedly blissfully ignorant of everything in comnection with the subject. The baby introduced by him to the troubles of this world is relegated to some female guardian, "to be fed on Allenbury No. I," "Horlick's malted milk," "boiled milli and water," or its nourishment may depend on the particular fad of that particular female. A little later the general practitioner, or it may be the peeliatric physician, is called in when trouble has commenced, and such an infant starts with a heavy handicap.

Or it may be the general practitioner is acting accoucheur, or he secs the infant at, or shortly after, birth, in which case its chances are much more hopeful. Prevention is always better than cure; but with regard to the digestive functions of the young infant, the alternative-cure-is not infrequently only a possibility. Catastrophes are apt to occur suddenly and with violence, and the issue is taken out of our hands ere ever we are able to influence it. When entrusted with the charge of an infant's dict, we must know what we want to do, how we ought to do it, and see, so far as we can, that our method is carried into practice. To achieve these objects we have, first of all, to decicle on the form or forms of nourishment which we consider most suitable, and in making this decision it is absolutely insufficient to be suided by hearsay, fashion, or chance. Definite linowleclge of the peculiarities and various reactions of different foods or milks, or on the other hand, wide clinical experience-one or other, but preferably both-inust be the driving force controlling 
the decision. No back-door rush to a proprietary food is justifiable, when used as an arenuc of escape from isnorance.

l'roprictary foods, as is well known, are very largely used in this country in the rearing of healthy children. Many of the foods themselves are most cxcellent, and, in the hands of different practitioners, give consistently good results. When these foods are definitcly chosen by the pliysician from among the various means at his disposal for the rearing of the infant, with a due appreciation of their composition, charactcristics, and peculiarities, and are deliberately employed by him as being the best existent form of nourishment available, one may question the validity of his reasoning and possibly the reliability of his opinion as regards the healthiness of his patients, but the manner of his practice is above all reproach. He has definite, valid reasons for what he does, and these, combined with his clinical results are, to his mind, convincing, or at least sufficient. The scicnce of infant feeding, the scientific substitution for mother's milk of a substance sufficient in all respects for the needs of the infant, is itself in its infancy; circumstances differ in different countries and in different localitics, and our knowledge is not yet so profound that any one line of action can be singled out as definitely the best; but in this country at the present day, for the average healthy infant, suitably modificd cow's milk and water is in my opinion the most satisfactory diet.

$W_{C}$ settle, then, in our own mind that this average baby is to be reared on suitable modifications of cow's milk and water. What do we mean by "suitable modifications"? How is the milli to be modificd? Is it to be used raw or heated? And if heated, to what degree, and for what length of time?

Owing to the many sources and forms of contamination of cow's milk which have previously been alluded to, and which, consequently, do not call for recapitulation, raw cow's milk cannot, as a rule, be considered a safe food for a young infant. Doubtless, in certain parts of the country and from a few dairies in towns, milk can be obtained approximately clean, but for the great majority of infants, the possibility of injury resulting from contaminated milk is too great to 
justify the physician in prohibiting the application of heat to it. And the drawbacks associated with this process of heating are not in themselves sufficient to warrant such a prohibition.

Rickets and scurvy are both discases which have been attributed at times to the boiling of the infant's milk, but there is no reason to believe that, given a milk or milkmixture of adequate composition, the application to it of a reasonable degree and time of heating will produce such conditions.

It is an unfortmate neccssity we have to face, that the probability of cow's milk being scriously contaminated is so great, the danger must be obviated by boiling the milk. The process of pasteurisation has no advantages over that of scalding; and the latter, as being the more definite procedure, we consequently recommend. The infant's mill;, then, obtained from a reputable dairy (preferably from cows tuberculin-tested), requires to be scalded before use. This process of scalding consists in placing the mills in an open dish on the fire, leaving it there till it commences to boil, removing it, putting a cover on the dish, and cooling the milk rapidly by setting the dish in cold water. The whole of the milk for the infant's use can be treated in this way on its arrival from the dairy, and it can be modified later as required, in which case the cream and water will require separate scalding.

Or, on the other hand, the total amount of milk, cream, water, and sugar required for the infant in the course of the day may be mixed together, scalded, and then stored for use. This latter is usually the more convenient method. Immediately after the process has been carried through, the milkmixture is divided into quantities such as the infant is to receive at each feeding period, and into a properly sterilised bottle this quantity is poured. The bottle is then sealed with a rubber cap, and placed in a cool situation till required by the infant, when it is gently warmed by being set in warm water. Care of the mills in the house is of the utmost importance, and contamination must be most zealously guarded against. The bottles, also, and the teats must, likewise, be carefully chosen and attentively looked after. The bottle 
should be as simple as possible: it should have no rigidly defined neck, and no internal angles or corners. The neck must not be so narrow as to prevent the ready entrance of a brush to cleanse the interior: it may be an upright bottle with sloping neck and rounded internal curves at the bottom, or it may be a boat-shaped bottle. Either must be thoroughly rinsed and brushed out with boiling water after use, placed in weak boracic or sola solution, and washed out once more with boiled water before being used again. The rubber teats require like careful treatment.

So much, then, for the modification of the milk by heat and its subsequent prevention from contamination. How about the further modification of its composition? Water, as has previously been pointed out, is the best diluent, and cream and white sugar are added as desired. In the case of maternal suckling, the infant, during the first day or two of life, receives from the breast a modificd form of milkcolostrum-which contains only a sniall amount of readily absorbed nourishment, and which acts as a mild purgative. To our artificially fed infant, therefore, during these first few days we give no milk, but only water with a little sugar dissolved in it, and by the third day feeding with milkmixture is commenced. Realising as we do that cow's milk is an unnatural form of nourishment, we accordingly, though confidently expecting that its digestion and assimilation will be ready, and that no untoward results will ensue, wish to commence with as simple a form of food as possible, and to add the ingredicnts of our milk-mixture one at a time.

Accordingly; on the third day, we add milk to the sugar and water. How much mills and how much water? Rather more than a tablespoonful of water to each teaspoonful of milk, and, with this, just a pinch of sugar. As the days go by and the infant kecps well, we gradually increase the strength of the milk, until by the end of the first week the infant is given a mixture of one part of milk to two parts of water.

All going well and the infant being hungry, and, perhaps, with a tendency to constipation, we add to our mixture during the second weck a little cream. How much? To begin with, very little-a teaspoonful in the twenty-four hours 
-and, if this addition proves satisfactory, the amount may be gradually and slowly increased. From this stage rmwards -from the stage when the baby first receives a mixture of milk, water, cream, and sugar-the mixture is slowly and steadily increased in strength.

Thus, while according to the table already given, the mixture consists of two parts water and one part milk at the beginning of the second month, during the second and third months it is gradually strengthened, until at the commencement of the fourth month it consists of equal parts of milk and water, and so on thereafter. In the same manner the amount of cream and sugar is gradually increased.

Should the proportion of the different elements of the mixture be altered separatcly or simultancously? Always scparately. Here again we guard against unnecessary ignorance in the event of digestive disturbance. If we strengthen the mixture in all or several of its clements simultaneously, and the infant becomes ill, we cannot say with certainty which element is causing the trouble-whether it is the fat, the sugar, or the protein. On the other hand, by increasing each separately, we have a guide to direct us in the event of digestive disturbance. As age advances, then, we gradually strengthen our mixture in all directions, and we increase each element of it separately. But is this all we do? Is this the only possible way of strengthening the nourishment? How about the total amount of food to be given in the course of the day, and the amount at each feed?

Obviously, we can increase the amount of nourishment we are giving, not mercly by strengthening the mixture but otherwise, or also by increasing the amount. Just as it is unwise to increase the elements of the mixture simultaneously, so is it unwise to increase the amount and the strength of the mixture at the same time. During the first two days we give the infant an occasional teaspoonful of boiled water, or of a dilute sugar solution, and on the third day commence fecding with 3 tablespoonfuls of the milk-mixture at each fecding period. This amount at each feeding we continue throughout the first fortnight, and then gradually increase, till by the beginning of the second month the infant receives 2 ounces at each feed, and thereafter the amount is gradually. 
increased, as set fowth in the table. Ant the number of feeds in the course of the twenty-four hours? We must always strictly enjoin that a minimum interial of two hours must elapse between two succeeding feeds. Human milli passes readily through the pylurus, cow's milk less readily, and even in the case of the most dilute solutions of the latter we calculate that the stomach is not empty until about one and a half hours after a feed. To give the stomach necessary rest, then, a minimum interval of two hours must be demanded, this interval gradually lengthening as the amount and strength of the mixture increases.

Thus, during the first month ten feedings are given, eight during the day at intervals of two hours, and two during the night; by the end of the third month the number of feedings is reduced to seven, of which six are given during the day at intervals of two and a half hours, and one at night; during the sixth month, six feedings are given, all during the day at intervals of three hours, and this procedure is continued thereafter.

The prescribing of the dict.-So much for the dict of the average healthy infant, but how are we to prescribe it? In the first place we do well to remember that we have to prescribe it. A written prescription somewhat after the following form is essential in every case :-

3 tablespoonfuls milk

3 tablespoonfuls water

I teaspoonful cream

1 leaspoonful white sugar

To be scalded, and serve as one feed.

Six bottles to be griven during the day (a feeding period never to exceed fifteen minutes) at intervals of two and a half hours, and one botile at night.

Or else this may be stated otherwise as-

21 tablespoonfuls milk

21 tablespoonfuls water

7 teaspoonfuls ream 7 leaspoonfuls white sugar

This mixture is to be scalded and divided into seven feeds.

Six bottles to be given during the day (a feeding period never to exceed fifteen minutes) at intervals of 1 wo and a half hours, and one botule at night.

The a'cakly baby. - In the preceding few pages the diet to be recommended for an atrerige healthy infant has been briefly 
outlined. But some healthy infants are markerlly below the averasge, and others just as markedly above it: they differ from it as regards nutritional nceds, and ats regards digrestive capabilities. We meet, on the one hand, with the unusually small and weak, or the premature infant. The premature infant is frequently mable to suck satisfactorily, and, when possible, the secretion of the maternal breast should be drawn off and given to the infant by the spoon. If, however, artificial fecling is nccessary, the infant should be fed by the spoon every hour or one and a half hours, according to its age and strength. It is usually wise to commence with I tablespoonful of sugar and water ( 1 teaspoonful of white sugar in I pint of boiled water) crery hour for a day or two, and afterwards to add $\frac{2}{2}$ teaspoonful of peptonised milk to cach feeding, and to feed every one and a half hours instead of every hour. The amount of milk is, later on, graclually increased, and the degree of peptonisation gradually decreased. It is frequently advisable to add two or three drops of brandy to each fecd. In some cases very dilute condensed milk (I dram Nestlés milk in 3 ounces of water), given in small quantities ( $\frac{1}{2}$ ounce) hourly, is also very useful as the initial food.

In the case of an infant which is merely undersized, the food should be that suitable for a younger infant, and, as a rule, it should be adapted more with regard to the weight than the age of the infant.

This, however, docs not always result successfully, and when satisfactory gain in weight is not attained, the food must be increased in amount or quality, or some other change must be made. The methods most likely to be successful in such a case are two in number: either a cereal sruel (thick barley water, p. 34, or oatmeal gruel, p. 296) may be added to the milli-mixture, or the milli-mixture may be replaced by Nestlé's milk (one of the best varictics of condensed whole milk sweetened). When the infant is receiving a milk-mixture of a composition suited to its asc, and, consequently, somewhat over-strong when consideration is had of its weight, when there are no symptoms of digestive disturbance, and when there is not satisfartory gain in weight, in such a case add a cereal gruel to the food, replace the water 
with barley-water. When, howerer, the infant shows in any manner that the digestive powers are being highly taxed, while the addition of a cereal gruel may prove of value, it is usually advisable rather to have recourse at once to Nestlés condensed milk. Give this milk in the proportion of I teaspoonful of the milk to 6 tablespoonfuls of water, and, of this, give at each feeding time the amount suited to the age of the child. This mixture should be continued for ten days, a fortnight, or even longer, and then, if all gocs well, cow's milk is gradually added to it. Now, in these two changes-the change from a cow's milk-nixture to Nestlés milk, and later the addition to this latter of cow's milk-an important principle in infant fecding is involved, and it is this:

In altering the dict of an infant, when the change to be made is that from a food of higher nutritive value and greater digestive strain to that of a lower value and less strain, the alteration may be made suddenly; but when the alteration is in the reverse direction, it must be undertaken slowly and stcp by step.

The big, strong baby.-In the case of a big, strong infant, the quantitics and the strength of the food previously mentioned are insufficient for his needs; the milk-mixture must be more rapidly strengthened, a cereal gruel may be added to it, and to the infant of six months of arge and over, a malted food, such as Horlick's malted milk, may be given once or eren twice daily. 


\section{CHAPTER XV}

\section{INEANT FEEDING-DIET IN FIRST TWO YEARS \\ Ol: L,IFE-continued \\ B. Infant Feeding in Disease, and Diet to Close of the Second Year}

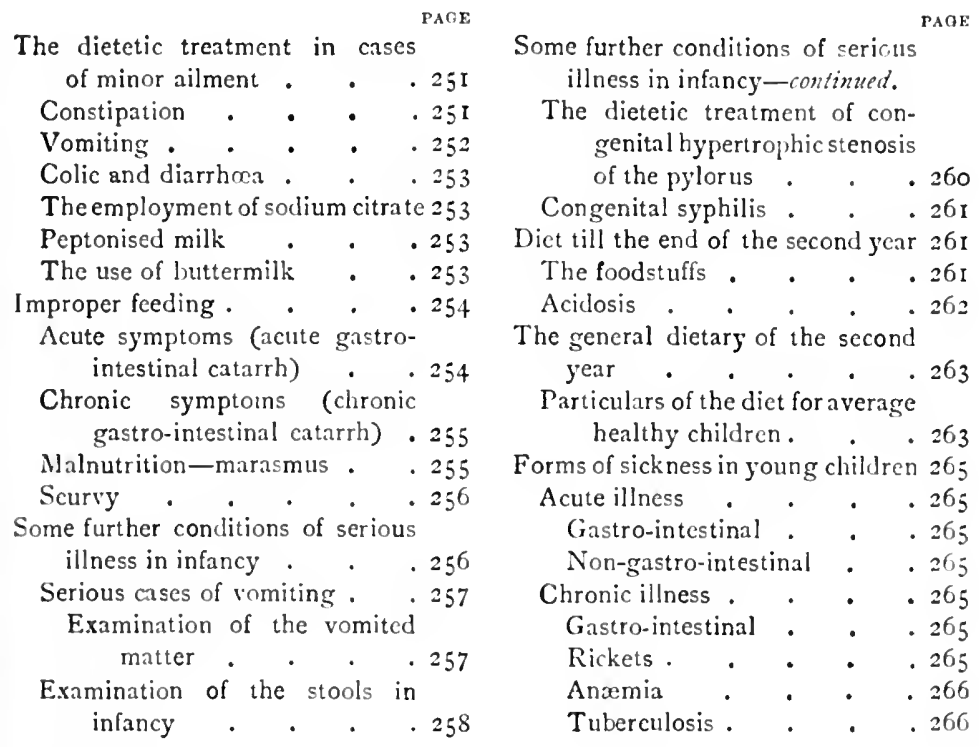

\section{The Dietetic Treatment in cases of Minor Ailment.-}

Of minor ailments occurring in infancy, constifation is one of the commonest, and in its treatment dict is all-important.

Constipation frequently occurs in infants who are apparently suitably fed, and in all cases it is necessary to cxclude 
any local affection of the rectum or anus. Iabit is important in the prophylaxis of constipation, and carcful training is always valuable in its cure. The addition of a dilute cereal sruel, such as barley-water, to the food, an increase in the amount of cream, a change from milk sugar to cane sugar, a tablesponful of a fresh fruit juice thrice daily-all are important dietctic methods of countcracting this condition in the case of bottle-fed infarits. The employment of citrated milk is frequently associated with the condition of constipation, and the addition of sodium citrate to milk-mixtures must alway's be only a temporary expedient.

In other cases variation of the food is frequently useful, and a teaspoonful of a proprictary food, such as Benger or Mellin, adcled to one or two of the bottles in the day, may prove very satisfactory.

The condition is not uncommon among breast-fed infants, and in such cases the digestion and the diet of the mother must in the first place be carefully attended to. Constipation occurs when the baby is not getting enough food, and when its food is not strong enough; in both cases the remedy is simple, when the cause of the condition is recognised.

Encmata should not be continued in routine use. There is a great tendency, when the practice is once started, to continue, daily, syringing out the infant's rectum. This is distinctly inadvisable, and when the condition is not amenable to treatment by dictetic measures, olive oil (I dram) or cascara ( $5 \mathrm{~m}$.) thrice daily, are more satisfactory.

Vomiting may occur through over-filling of the stomach in cases where the amount of food is too large, or it may be due to the infant drinking too quickly; both conditions, when reconnised, are obviously readily remedied. All infants occasionally rcgurgitate a small quantity of fluid soon after drinking. This condition must not be allowed to continue, as a habit of vomiting is readily developed in certain infants and is often very difficult to treat. If the amount of fluid given at each feeding-time is not too large, and if the infant does not drink too quickly, it is usually sufficient, to stop the habit of regurgitation in carly cases, to prop the upper part of the baby's body up in the cot after feeding, 
and to avoid rocking, nursing, or moving him about. The chief cause of serious vomiting is irritability of the stomach, due to the presence in it of undigested or unsuitable food, and such cases are dealt with on pages 256 to 258 .

Colic and diarrhea, due, it may be, to a chill, or to some temporary indiscretion in the diet, require, in the first place, satisfactory cleansing of the contents of the alimentary tract, and this is most satisfactorily brought about by a dose of castor oil. Thereafter, for twenty-four or thirty-six hours, the infant is given a food considerably weaker than it was accustomed to; then gradually a full diet is regained. The addition of sodium citrate to the milk-mixture is frequently a valuable dietctic means of treatment (p. 239). It is of use in a variety of conditions. An infant may have to be wcaned suddenly, while still in the early months of infancy, owing to the illness of the mother, and this infant may at first bcar badly a diet consisting of a cow's milk-mixture. By adding sodium citrate, a milk-mixture of adequate strength can, however, be more readily tolerated, and the infant's nutrition satisfactorily maintained. Again, when breast-nursing has been irregular, when, perhaps, in addition, a proprictary food has been given occasionally, and when, in all probability, the digestive powers of the infant have been somewhat irregularly developed, it is, as a rule, wise to commence milk-feeding with a citrated milk. Or, when a strong infant is recovering from an attack of acute gastro-enteric catarrh, citration of a milk-mixture may permit of stronger and more satisfactory food being given early; while to any infant recovering from such an attack, citrated milk is one of the steps which may be taken on the way to resain a natural dict (p. 255).

The indications for the predigestion or peptonisation of a mill-mixture are acute illness, high ferer, and in many cases those already mentioned in which sodium citrate is of use.

In chronic conditions peptonised milk is, however, of less value practically than theoretically it ought to be, and not infrequently citration of the milk proves more satisfactory (p. 239).

buttermilk, prepared naturally or by artificial means, is a valuable form of diet in certain cases. It is, however, not yet possible to lay down any very definite rules as to the 
cases in which it should be griven. When given raw, its outstanding characteristics are its porerty in fat, and the presence in it of living lactic acid bacilli, and, theoretically, it should accordingly be griven in those cases in which there is difficulty in fat digestion, and in which we wish to extend the area of the lactic acid flora. The ordinary putrefactive changes in milk occurring in the digestive tract take place through the agency of organisms acting in an alkaline medium, and the presence of large numbers of lactic acid bacilli in the milk prevent the action of these organisms.

I have found buttermill--raw commercial buttermilk - of marked value in cases of summer infective diarrhoea. being a food of low nutritive value, it is well to add to it as the symptoms improve a small amount of barley or oatmeal flour, and as there is a tendency for the infant to become so accustomed to this form of nourishment as to render it unwilling to return to a more suitable diet, the administration of the buttermilk should be of as temporary a nature as possible (p. 239).

Improper Feeding. - The results of improper feeding may display themselves as acute or as chronic symptoms, c.g. acute or chronic gastro-intestinal catarrh. Such conditions may be brought about by other causes also, but, as improper feeding is by far the most common cause, it is convenient to consider the dietetic treatment under this heading. When the condition is acute, one must recognise that the alimentary canal of this infant is intolerant of food; its digestive power is disordered and, for the time being, inactive; its gastrointestinal tract is unduly irritable, and constantly irritated by obnoxious contents; digestion is at a standstill; diarrhoea and vomiting constantly drain away the strength; vitality is at a low ebb. The two primary indications are to sustain the infant's strength, and to remove the irritating contents of the alimentary canal. No attempts to administer food are, for the time being, permissible, and the length of time during which the administration of food is refrained from, and the nature of the food first griven, must depend upon the age of the child and the severity of the condition. A purgative and an cnema are always called for; it may be necessary to wash out the stomach; transfusion with saline solution is always 
advisable, and brandy well diluted (30 drops in 2 ounce of water) may be given by the mouth.

In commencing nourishment the steps must be very gradual by which we regain the dietetic normal. At the commencement, albumin water and brandy $(5 \mathrm{~m}$.) are given to the infant frecly-hourly. With improvement in the conditiondiminution of diarrhcea, absence of vomiting, disappearance of felled, toxic facies-whey is substituted for the albumin water. The period during which all milk or crean is excluded from the dict of the young infant in severe cases lasts several days, and it is always prudent to wait for marked improvement in the facies and number of stools beforc making such addition. On the other hand, it must be remembered that an infant on a dict of whey and brandy is apt to pass numerous liquid stools, and if the general appearance is otherwise satisfactory some more satisfying form of nourishment is called for. A small amount of cream is now added to the food, and an infant of about three months of age now gets $2 \frac{1}{2}$ or 3 ounces of whey with $\frac{1}{2}$ dram of cream every two hours, brandy being continued if necessary. The amount of cream is slowly increased day by day for two or three days, and this mixture is then replaced by dilute fully citrated milk (I part of milk, 2 parts of water, 2 grains of sodium citrate, to each ounce of milk), or by clilute peptonised (forty minutes) mills. Thereafter the normal diet is gradually regained.

In cases, however, where in spite of acule digestive disorder the general condition of the infant is fairly satisfactory, after six, eight, or ten hours of abstention from milk: food, feeding may be recommenced with a dilute mill.

When the symptoms are chronic, gradual correction of the causal dictetic impropriety may suffice, but usually more than this is necessary. The digestive powers have, in some manner, been over-taxed, and they must, consequently, be partially and temporarily rested. To this end the food must, in the first instance, be restricted in all its elements, and only gradually strengthened. Many of these cases are extremely intractable, and marked malnutrition occurs. The term marasmus is sometimes used to denote a condition of extreme malnutrition whatever the cause may be; it is 
frequently used in connection with cases of extreme malnutrition due to prolonged improper feeding or long-standing digestive disorder; it also, however, appears to apply to a conclition due to inherent weakness of the digestive powers, and in these latter cases it is occasionally found that small doses of thyroid extract (1 grain to $\frac{1}{2}$ grain) thrice daily give bəneficial results.

In all cases of malnutrition or marasmus, to enable us to judge of the dictetic means most likely to restore or improve the infant's health, we have first of all to seek by all means in our power to discover any underlying cause for the condition. The history must be fully cntered into; syphilis, tuberculosis, cmpycma, ctc., carefully excluded, the previous dict of the infant closely considered in conjunction with his present condition, the nature of his stools, vomit, etc. The history may supply us with a hint as to the foodstuff probably at fault, or it may be impossible to lay our finger on any one factor which more than another seems to have brought about the condition. IVe consequently strive to find the directions in which the infant's digestion is stronger, and to avoid those in which it is weaker. To do so we commence with a food likely to be well within his digestive capacity-it may be whey and brandy-gradually strengthen and add the various milk ingredients to this, kecping a careful eye on the nature of the stools. In many cases $\frac{1}{2}$ grain of grey powder, given night and morning, proves of great value.

It is well to allude here to the condition of scurvy. The infant suffering from early scurvy not infrequently shows no marked physical signs, and displays no definitely characteristic symptoms; it, however, refuses food, or is unable to digest it. In these cases arrangement of the dict is of no avail unless the scorbutic condition is first treated with fruit juices, when digestive difficulties will greatly diminish (sce also p. 392).

Some further Conditions of Serious Inness in Infancy.Vomiting has prcviously been alluded to as onc of the minor ailments of infancy. The act is an casy onc; it is a common symptom in a wide varicty of conditions, and its nature and significance vary considerably. The common cause of 
scrious a'omiting is irritability of the stomach, due to the presence in it of undigested or unsuitable food. It may be that there is excess of sugar, of fat, or of protein, of one or of all in the food; the vomit and the stools require careful cxamination, and treatment has to be conducted on the lines already laid down.

Now, what may we learn from examination of the vomited matcrial, and what from cxamination of the stools?

With regard to the vomit, it is important in the first place to recognise the manner of the act of vomiting and its relation to the taking of food. Thus the gastric contents may, after a feed, gently trickle out of the corners of the mouth, or they may be forcibly shot out in a strcam to some considerable distance; or vomiting may occur twenty, thirty, or sixty minutes after a meal; or the vomiting may occur so irregularly as to have no definite relationship to the taking of food. This last condition is that present when cerebral or meningeal affections lie at the root of the evil, and to it I shall not again refer; romiting as a symptom of acute diseases, such as intestinal obstruction, is also not a condition which permits of dietetic treatment.

The romiting of early infancy, caused by digestive disorder, is, as a rule, not marliedly forcible; the muscular system in general, and the muscular coat of the stomach in particular, is largeiy undeveloped, the upright position of the stomach renders reçurgitation easy, and consequently, in order to evacuate its contents, 120 great gastric force is called for. When, however, the muscular wall of the stomach and of the pylorus is abnormally developed or increased, the process of vomiting tends to be much more forcible, and if the food is unable to pass through the pylorus, shortly after a meal very forcible ejection of the gastric contents takes place. Such is the condition of affairs in the affection known as congenital hypertrophy of the pylorus; the vomiting in the carly stages always occurs shortly after taking food, and the nature of the vomiting is a more important diagnostic sign than the character of the vomit, as, especially in its later stages, the condition is likely to be complicated with disturbance of gastric digcstion. When, on the other hand, digestive disturbance is the 
primary cause of the condition, examination of the romited matter may gire assistance, and although in many instances such cxamination does not greatly facilitate our diagnosis as to the food element with which the disturbance has arisen, and morcover, while in most cases there probably is already difficulty in dealing with all food substances, yet this examination should never be omitted, and is an additional point of possible assistance to us.

Vomiting may be originally duc to indigestion caused by abnormal changes in the protein, fat, or sugar of the food occurring in the stomach. In sugar indigestion the vomiting is usually accompanied by much eructation of gas, and the romited matcrial is extremcly acid: when fat is at fault, the vomited matter has a peculiarly sour and acrid odour; and when the protein is the cause of the vomiting, tough curds are vomited, usually, however, with a considerable degree of acidity or sourness. Examination of the vomited material is, of course, only one point in our diagnosis, another point is inamination of the stools. Here again we have to realise that it is often quite impossible to say what has been the cxciting cause of the condition, as the process, once initiated, has caused disturbance of many or of all the digestive functions.

For clinical and practical purposes our methods of examination of the stools are markedly restricted in number, and, in the main, consist in accurate observation and simple chemical reactions. In the case of a healthy breast-fed infant, the stools are acid to litmus-paper, owing to the presence of volatile fatty acids, and more especially to the presence of free lactic acid; when the infant is fed on cow's milk the reaction shows signs of a certain degree of protein putrcfaction, and is, consequently, faintly alkaline. In cases of feeding with buttermilk, unless there is much carbohydrate mixed with the milk, the reaction of the stools is naturally alkaline, owing to the presence of ammonia. The ycllowish colour of a "normal" stool is undoubtedly subject to considerable variation; it varies within the bounds of normality according to the composition of the milk or mills-mixture cmployed as food, the amount and activity of the digestive juices, and on the degree of bacterial action which talses 
place during its progress through the alimentary canal. Thus, with a large amount of carbohydrate in the diet, the stools tend to be brown; with an amount of fat bordering on the maximum "normal," or with a tendency to inefficient fat digestion, the colour becomes more grey; while with an excessive degrec of protein putrefaction and intestinal bacterial action, the stools bccome quickly and markedly green on exposure to the air. In cases where the stools are green, this colour is due to oxidation of the normal colouring matter of the frees-bilirubin-into biliverdin; such a change is a very frequent accompaniment of various forms of food disturbance, and is very largely brought about by bacterial action. Along with the administration of calomel, green stools are common, the explanation of this apparently being the increased alkalinity brought about in the upper bowel; with various other drugs the colour of the fxces, as in aduits, is also affected. Of abnormal constituents, blood is recognisable, as in the case of adults. A small amount of mucus is common in the stools of healthy children, more especially when there is a tendency to constipation, or when the amount of ingested protein material is greater than the digestive juices are capable of dealing with. Much mucus means irritation of the intestinal walls through food or bacteria; the mucus is usually from the large intestine, but when it comes from the small intestine, it occurs as small flakes in a liquid motion.

Fat in the stools occasionally occurs as greasy, opalescent molecules, frequently more or less closely connected with true protein curd, and thus gives to the casual observer an appearance of somewhat massive curds in the stool.

When associated with diarrhcea, fat appears in the stools as yellow lumps in a green fluid motion. Frothy, liquid stools are common along with fermeritative changes in the alimentary canal, and are frequently due to excess of carbohydrate in the food.

In the great majority of cases of ordinary infantile diarrnœa, when this diarrhoea is at all profuse, the stools show the following characteristics:-They are acid to litmus-paper, green and watery in appearance and consistence; they contain numerous white solid curds, and there is constantly present a 
distinct amount of mucus, which, however, varies considerably in quantity. Towards the diagnosis of the primary cause of the digestive disturbance these stools give, I think, no assist. ance; they indicate, on the other hand, disturbance of all digestive functions, and emphasise the necessity of digestive rest. When treatment has been commenced, however, examination of the stools is doubly important. By their appcarance we are greatly assisted in judging of the wisdom of our dictetic treatment and of the form of food constituents which: we may safely increase.

In the digestive disturbances of infancy vomiting is usually associated with a certain degree of diarrhoea in the important condition to which I have already alluded, however-conrenital pyloric stenosis-this is not the case, and vomiting here is usually associated with constipation.

The medical treatment of these cases is practically entirely dictetic.

As a consequence of the abnormal condition at the pylorus, food passes with difficulty from the stomach into the duorlenum, the hypertrophied stomach wall attempts to forcibly press it through, but its efforts largely result in merely producing vomiting. Some of the milk remains in the stomach, and, in the course of time, fermentation occurs, irritation of the gastric mucous membrane succeeds, and a Sastric catarrh is set up.

Medical treatment is naturally most successful when the condition is recognised early, and when, consequently, suitable dictetic procedures are adopted before the development of secondary catarrhal conditions, which in themselves increase the tendency to muscular spasm.

Food should be given in small quantities frequently. The best form of food is mother's milk, but when this is not obtainable, a fully peptonised or fully citrated milk-mixture should be griven in tablespoonful cioses, hourly. As the condition improves, the amount at each fecding period a:d the intervals between these periods may be gradually increased.

A very important aid to treatment consists in washing out the stomach. This procedure is usually called for however early the case is seen, and is always necessary when secondary catarrh has been set up. 
The fluid used may be plain sterilised water or slightly' alkaline water, and the proceciure is to be carried out daily.

In the condition known as summer diarrhoea, infective diarrhœa, or acute gastro-enteric infection, the dictetic treatment has to be carried out very largely along the lines already mentioned, when speaking of the acute symptoms resulting from improper feeding (p. 254).

The rearing of an infant suffering from congenital syphilis is not, infrequently, a matter of the greatest difficulty. Most syphilitic children brought up on breast milk, and regularly treated with grey powder, do extremely well, and many artificially reared infants also do well when carefully treatcd. But deprivation of its mother's milk is a much more scrious matter for a syphilitic than for a non-syphilitic child, and the artificial rearing of these children is frequently a matter which taxes to the utmost the resources of the physician.

\section{Diet till the End of the Second Year.}

During the latter three or four months of the first ycar, the milk should be strengthened by some farinaccous food. Most of the proprictary infant foods can now be used with advantage, and are a useful means of adding sugar and starch to the food and of lending variety to the dict (sce p. 154).

Carbohydrate can, however, be usefully added to the diet in another form. The infant has reached an age at which he demands something to chew, and also at which the eruption of teeth and the development of the jaws is in active process.

A crust of stale bread is now a valuable part of the dict, and it is well to spread this crust freely with butter. Other than milk, which still forms the bulk of the diet, and occasionally a portion of a raw egg, animal food is not adrisable at this time.

During the sccond year, however, animal food in the form of soup, gravy, fish, and minced meat comes to occupy a large and important place in the dietary. Such food is rich in protein, and is a valuable means of sccuring healthy development. 
Carbohydrates at this perind, as in later life, are readily digested and readily absorbed. For these reasons it is obvious that carbohychate is a very valuable form of foodstuff in childhood. But carbohydrate is apt to be given in cxcess at this time, and sooner or later bacterial fermentation sets in, with its resulting gastro-intestinal symptoms.

Fat is still an important element in the diet, and is usually readily digested in the form of cream or butter. Cream, butter, and eggs are valuable forms of nourishment for the child, and care must be taken that their place is not usurped to any cxtent by increase in the amount of carbohydrate. But, on the other hand, excess of fat in the food is also associated with danger, and is intimately connected with the extremely complex subject of "acidosis" in children. The exact explanation of this condition is unknown. It is invariably associated with the presence of acctone in the urine, and minor degrees of this condition of acetonuria are extremely common.

Owing to the vomiting which accompanies the scrious acute condition of acidosis, it is frequently impossible to give the child anything by the stomach. If solution of sodium bicarbonate ( 15 grains, hourly, for six hours) is not retained, the stomach must be washed out, normal saline solution injected subcutaneously, and attcmpts made to inject the alkaline solution intravenously if it is still rejected by the stomach.

In the minor cases of acetonuria a purgative should be administered, the diet restricted to milk diluted according to the age and general condition of the child, and alkalis given freely.

With the resumption of a fuller diet, care must be taken to see that the various food constituents occur in their right proportions.

On the other hand, the importance of a sufficiency of fat in the food has been frequently alluded to, and will be considered more particularly later, in connection with the subject of rickets.

In any ordinary diet salts are present in abundance, and during the first two years of life it is important that they should be obtained from milk, which is rich in three of the 
substances most necessary at this period-calcium, potassium, and phosphorus. Some of the more important sources of iron are vegetable substances, such as oatmeal, also meat and eggs.

Most healthy children eat more than is absolutely necessary for their bodily requirements, and a small surplus amount of food in general cannot be regarded as other than sood for the child. Habitual under-feeding is undoubtedly markedly injurious.

The General Dietary of the Second Year.-What is the average diet for the average child? What is his food to consist of? How often is he to be fed in the course of the day? How much food is he to get at one time?

Before particularising, it is useful to briefly survey the diet for the period. At the age of twelve months and throughout the second year the baby is to be given five meals in the day, although in many cases four are sufficient before the end of the second year is reached. Between meal-times water may be allowed in moderation, but it is of the utmost importance that the hours for feeding be strictly observed, and that no food be given in the intervals. Throughout the second year the child should receive 2 pints of milk a day, a certain amount of which he obtains in the form of milk puddings, whereby he also receives farinaccous food. At this time also he should be given eggs, plain soup or gravy, with a little breadcrumb or mashed potato; and about the eightecntin month a little minced meat or fish. Now also some well-boiled green vegetable should be added to his dict. The digestive powers at this period are comparatively limited, but the child is growing and developing rapidly in every direction: he demands variations in his food and in the nature of the foodstuffs, and it is unwise, for many reasons, to limit his dict to those articles which are most readily and fully digestible.

Stewed fruit, bread and butter, porridge and milk, are valuable forms of food at this period, and animal protein other than that in milk should be given once daily in the form of mincerl meat, fish, or egrs.

About the close of the cighth month of life weaning should be commenced in the case of a breast-fed infant, and by the 
twelfh month, at latest, breast-nursing should entirely cease. Whencerer pessible, the infint, on weaning from the breast, should be fed from a cup and have no intermediate period of buttle-feceling.

At the ninth month the fecling of the average infant is approximately as follow: - Food is given six times during the day, at, say 7 A.M., IO A.M., I P.M., 4 P.M., 7 P.M., IO P.M. At each of these periods the food consists of 6 to $S$ ounces of milk, with I kessertspoonful to I tablespoonful of cream. Along with the second and fifth meals there is given a crust of stale bread or a piece of toast well toasted. The milk of the third and fourth meals is strengthened with a tablespoonful of a cercal or of a proprictary food, such as Mcllin's, or of some food such as Farola. In addition, a little fresh fruit juice suitably swectened may be given occasionally, and, should the infant desire it, water may be given freely between meals.

by the tielfth month the food can usually be conveniently given at five meal periods, at, approximately, 7 A.M., IO A.M., 2 I.M., 5 P.M., 9 P.M. The food is to consist of about 2 pints of milk and 2 ounces of cream, thickened with some food, such as Farola. A crust of bread or a piece of toast covered with a little butter is allowed at any meal. Twice a week, at the midday meal, half a raw egg is beaten up in the milk.

from the taifth till the isghtechth month, thin porridge and milk or bread in milk forms a suitable breakfast. For the sccond moal, a good drink of milk-about half a pintand a buttered crust suffice. The third meal consists of cither plain soup, with a thin half-slice of bread and butter and a drink of milk; or, a lightly boiled egg, a tablespoonful of mashed potatoes and butter, and a drink of milk; or, a little gravy and breadcrumbs, with a milk pudding. The fourth meal consists of a drink of milk and a buttered crust, and the last meal of the day, of mills thickened with a cereal.

By' the eightecuth month many infants will do with four meals daily instead of five, and thereafter, till the close of the second year, four meals are usually sufficient. During this period minced meat, fish, and well-cooked vegetables are adeled to the dictary, and these should be given at the meal in the middle of the day.

In the case of all healthy children varicty in the diet is 
important, and to this end it is always wise to allow the mother or nurse a certain reasonable latitule in the ordering and nature of the food, but only in the case of healthy children. Strictly forbid alcohol, tea, coffee, salad, pickles, and all such condiments; salted food, canned food, raw vegetables, pastry, nuts, and unripe fruit.

Forms of Sickness in Young Children.-For delicate children or for sick children, the diet must be prescribed in detail and in writing.

During acute illness, at this period the food must consist solely of milk, and it is always well to give the milk diluted with a third or a fourth of its bulk of water or of lime-water.

When the condition is primarily gastro-intestinal, even milk must be temporarily withheld. In these cases immediate treatment is purgative and stimulant, associated in most cases with gastric lavage and hypodermic saline injection. Water is the essential dietetic constituent here; the dictetic ladder must be slowly climbed, rung by rung, and in many cases no milk should be given until the temperature is approximately normal. In the serious condition of mucous colitis some form of milk poor in curd is often useful, and Nestlé's milk (I dram in 4 ounces water) given frequently in small quantities is a satisfactory form.

When the primary condition, on the other hand, is nongastro-intestinal, milk diluted about one-third can, as a rule, be given almost from the commencement. It is inadvisable to give more than $I \frac{1}{2}$ pints of milk in the twenty-four hours to an infant of two years old, but frequent drinks of water are bencficial. Theoretically, milk in these cases should always $\mathrm{b} \approx$ peptonised, but this is often quite unnecessary: this procedure should, however, always be carricd out when for any reason in the past history, weakness of the digestive powers is to be feared, and, of course, immediately it is suspected that non-peptonised milk is unsuited to the infant.

Of chronic illnesses at this period, gastro-intestinal conditions are very common, and are to be treated along the lines already laid down. This is the time of life when rickets occurs, and the rachitic child requires careful dictetic treatment. He requires regulation of his feeding times, he almost certainly requires restriction of the amount of carbo- 
hydrate fond which he is recciving, and he usually requires more milk and less of whaterer form of improper food it has been his attendant's pleasure to give him. As a rule, the digestive processes in these children are disturbed to a greater or less extent, and caution in the dict is the first indication. Along with reduction of the carbohydrate element in the food and climination of improper forms of food, gradual digestive improvement occurs, fat in the form of cream, butter, and eggs should be increased in amount, and the protein element in the food well sustained.

Excess of carbohydrate in the food, and more particularly of starch, is the chicf cause of rickets. The presence of abnormal amounts of this foodstuff interferes with the digestion of fat, and though lack of fat in the food frequently causes rickets, yet very often rickets occurs although there is an ample amount of fat present in the milk-mixture, and in these cases the condition is usually due to carbohydrate excess. In treating the case, then, while it is extremely important that an ample supply of fat be given, care must also be taken that the amount of carbohydrate is strictly limited.

For many cases of ancemia occurring at this period dietetic treatment is all-important, and, in most, dietetic errors succeeded by gastro-intestinal disorders lic at the root of the evil.

To detail the treatment in these cases, therefore, would signify recapitulation of the rules already laid down as applicable to infant-fecding in general.

To no one foodstuff alone can the condition be ascribed. The whole environment, method of life, and dietetic history must be carefully considered, and it has to be remembered that an important factor in the causation of the condition may have been a dietetic error in connection with any of the food constituents.

Finally, this is the period of life when the earliest, or it may be only the premonitory, signs and symptoms of tuberculous infection disclose themselves, and this, consequently; must be the time when most strenuous measures are undertaken to counteract the infection. Of such measures, not the least important is a plentiful supply of fat in the dict, and cream, butter, eggs, and cod-liver oil must be given to the verge of the child's capacity to utilise them satisfactorily. 


\section{CHAPTER XVI}

DIETARY IN FEVERS AND ACUTE INFECTIVE DISEASES

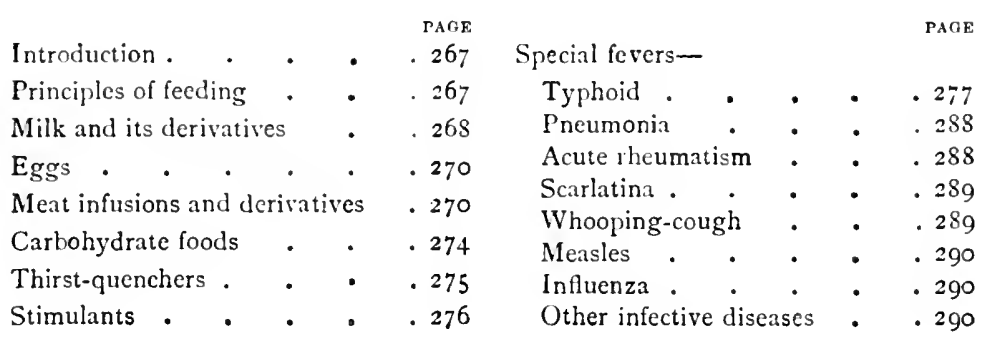

A HIGH temperature acts on all the tissues of the body, causing alteration in normal metabolic processes, and derangement, morc or less severe, of the whole alimentary tract. Associated with the high temperature there is rapid wasting of the albuminous tissues, with an increased combustion of the structural elements of the body.

As a consequence of this, there is an excessive excretion of urea, which is climinated in the urine, but which may for a time accumulate in the blood. There is, also, although to a less degrec, an increased excretion of carbonic acid.

At the same time, the functions of the digestive and assimilative organs are gravely disturbed. There are morbid changes affecting the peptic and other secreting glands in the digestive tract. These changes are usually accompanicd by loss of appetite, and even disgust for food, which, if administcred, is often vomited.

Principles of Feeding.-The following are the guiding principles in treatment :-

I. An adequate supply of albumins, carbohydrates and 
selatines must be given, to neutralise the increased combustion in the tissues resulting from the high temperature.

2. No food should be administered which cannot be readily absorbed and assimilated, for if the enfeebled digestive organs are overloaded, the undigested food will undergo fermentative changes, which will lead to gastro-intestinal irritation. With suitable feeding, the wasting is less, the patient does not become so reduced, and, consequently, the convalescence is more rapid.

3. An abundance of fluid should be given. This overcomes the dry and parched sensation in the throat and fauces, washes out through the kidncys the waste matter produced by the increased rate of metabolism, and promotes the elimination of the toxins.

4. Food must be given in measured quantitics at regular intervals, and should be daintily served.

It is specially important to attend to the toilet of the mouth in fever. Regular cleansing of the mouth and teeth with an antiseptic mouth-wash at least three or four times daily checks fermentative processes, and enables the patient to take his food to the best advantage.

Food, in all cases of pyrexia, should be administered in the fluid form, the quantity small, from 3 to 4 ounces at a time, and given at short intervals (every one and a half to two and a half hours) during the clay. At night, if the strength is being well maintained, simple drinks to quench the thirst are all that is required; by this arrangement the digestive organs obtain rest.

The dict must be selected from the following substances, viz.-milk, whey, eggs, meat teas, meat infusions, meat juices, meat extracts, soups, meat jellies, calf's-foot jelly, grape sugar, starches, fruit juices, fruit soup, and beverages of low nutritional valuc. This dict may be suitably varied by changing the flavouring substances.

Milk and its Derivatives.-Milk is pre-eminently the diet for the febrile state. It is also the most convenient form of food, but it must be borne in mind that milk forms a solid curd when acted on by the gastric juice. On this account some persons, even in health, find milk indigestible.

If there is any doubt of the milk being thoroughly 
satisfactory and fresh, it should be scalded. The necessary dilution of the milk depends greatly on the digestive powers of the patient. The effect of the diluent on the milk and its action on the density of the curd have alrcady been considered (p. 33). The milk may be griven hot or cold, but it is best to be slightly warmed. The following methods may be adopted :-

(a) Simple dilution with boiling water, clear or thick barley-water (p. 34), toast, or rice-water, in the proportion of equal parts.

(b) Dilution with an effervescent water-milk and Vichy or Vals water, cqual parts, or milk one part with two portions of potash, soda, or Apollinaris water. In some patients effervescent drinks set up distension of the stomach and troublesome flatulence; this quickly subsides when the aerated water is stopped.

(c) Dilution and mixture with an alkali. This method is advisable if there is pain and flatulence after the simply diluted milk. The addition of 10 grains of soda bicarbonate and o grains common salt, added to equal parts milk and water, often prevents pain and lessens the constipation. Limewater, in the proporticn of one part lime-water to three parts of milk, is useful if there is pain and a tendency to diarrhoea. As to quantity, 2 ounces of the milk, diluted as recommended, may be given every one and a half hours. If this does not disagree, the amount may be increased. Three to four pints of milk daily are readily taken by most adult patients. In those cases where a milk regime for a lengthy period is necessary, attention should be directed to the points in its administration (referred to on p. 278).

Repugnance to milk can be overcome by modifying the flavour of the milk; for example, tea can be infused with boiled milk, or a very weak cocoa made with Allenbury's milk cocoa can be specially recommended for this. Horlick's malted milk made with milk is very palatable. A small amount, c.g. $\frac{1}{2}$ a teaspoonful of a meat extract such as bovril, Oxo, Lemco, or Vigoral, added to a cup of warm milk or milk and water, is an excellent way of varying the flavour.

(d) Modifuations of milk. - Occasionally cases occur where diluted milk is not digested, and wohy will then be 
found useful. It will also be found an agrecable change in the monoteny of a milk diet. The proportions and method of preparation are described in detail on parge 40. Whey is practically milk minus the curd and fat, which have been got rid of by a process of coagulation and straining. Its nutritive value may be increased by the addition of strong beef-tea, raw-meat juice, cegrewater, or Plasmon. Koumiss and Kephir, fermented millis (p. +4), can sometimes be retained by an irritable stomach when everything else is rejected.

Eggs._Eges form another permissible food, but ought not to be allowed too freely. They may be given as a drink, either alone or in combination with milk, or may be used to fortify other nourishment. As fluid food is preferable for pyrexial patients, egrgs are best administered raw. The liglutest form of egg drink is an egg beaten up, added to 3 ounces of very hot water, strained and flavoured with vanilla essence or cinmamon, and slightly sweetened. Another form of egrg drink, more stimulating and nourishing, is described on page 47 , where milk and sherry are added to the exer. Egg flip, ricl or plain (p. $4 \$$ ), is the white of egg adled, when well beaten up, to mills or cream, and flavoured. A switclied egrs also may be added to a cup of tea or coffec. A whole esce, beaten up with three times as much water, strained, and atded to light broth or clear soup, is also very nonrishing. Cintion.-Do not add the egg to boiling soup, or it will curdle. Albumin water (p. 47), added to a clear soup or to at cup of Bovril is nourishing and very pleasant.

The patent preparation of Brand's termed "Iever food" is most nutritive; it consists of essence of beef, eggs, and cream. In appearance it resembles custard, and has a very agrecable flavour which is quite distinct from the meaty flavours of the becf juices and extracts.

Meat Infusions, Juices, Extracts, etc.-This group of foods is largely administered, and their usefulness is universally admitterl. The actual nutritive value of most of the beef-teas and clear soup is low, but a French authority has pointed out that the most suitable diet for febrile maladies is one that contains only a small quantity of albuminous matter; and it is the possession of the saline principles (chloride and sulphate of potassium, etc.), dissolved in a 
large amount of water, which constitute the chief recommendation of broths and beef-teas. In the selection of a beef-tea or beef essence, it is far better to use a carefully prepared home-made beef-tea than any of the expensive patented becf-teas and meat juices, which are purchased at great cost in the belief that they are strengthening. In a previous chapter, p. 75, full directions are given for the preparation of "teas" (beef, mutton, and veal and chicken). There are two methods described; method I is preferable for fever patients, as the flavour is less concentrated. When the "tea" has been made in the closed jars, as described under method 2, it is rather strong for most fever patients.

Special attention should be given to the means of thickening the teas (p. 76) with tapioca, breadcrumbs, baked flour, arrowroot, oatmeal, and yolk of an egg; the last mentioned being specially pleasant to a paticnt who is improving. The nutritive value of the food may be greatly increased by the addition of one or more of these substances.

Vegetable flavouring can also be added by cooking vegetables with the meat and straining carefully, without in any way injuring the digestibility of the food. Proprietary beef extracts, essences, and juices (p. I6I) may also be given, but are not so satisfactory for fever patients as well-cliluted foods.

Gelatine is another important item in the dict of these cases. By itself it has not the same nutritive value as the albuminates, and in any case it is nccessary to prescribe it in considerable quantities to attain the same end. Gelatine is not a tissue-builder, but it is a means of saving the albuminous waste from the tissues. From this point of view gelatine cannot be too strongly recommended. Gelatine may be administered in the form of a clear soup_- "consommé" -or may be given as a meat jelly, call's-foot jelly, or as a sweet jelly.

\section{Clear Soup or Consommé.}

I quart of first stock. (See Stockmaking, p. 74. This should be in the form of a good jelly.)

6 ounces lean, juicy beef.

I lump of sugar.

I white and shell of eggr.

Method.-Carefully remove all fat from the top of the stock, and put 
it into a clean-lined saucepan. Wipe the beef with a damp cloth, and shred it down fincly as you would for beef-tea, removing all fat and skin. Adel this to the stock, with the white of the egg and the shell well washed and crushed. Whisk these over the fire with a wire whisk until the soup just comes to hoiling-point. Then remove the whisk, and let it boil well up. 1)raw the pan to the side of the fire, where the soup will keep warm but not simmer, and cover it with a plate. Let it stand there from ten to fifteen minutes. Tie a clean cloth on to the four legs of a chair turned upside down, letting it fall slightly in the middle so as to form a bag. l'our some boiling water through the cloth into a basin to thoroughly heat the cloth. I'lace a clean, dry basin underneath, and pour the soup gently through the cloth. The soup will not be clear the first time, so change the basin and pour the soup through again, repeating this process until the soup runs through quite clear. In repeating, add a lump of sugar, which makes the soup sparkle.

This soup can be varied by the addition of different garnishes, $c \cdot s$. :-

\section{Consommé and Egg.}

I quart of consommé. $1 \mathrm{egg}$.

Method.-Put the clear soup into a saucepan, and bring it to the boil. lieat un the egg in a small cup or basin with a fork, and pour it slowly into the boiling soup, stirring all the time with a spoon. The egg will curdlc in the soup, and look like threads of yellow.

\section{Consommé with Custard.}
I pint clear soup.
I yolk of egrg.
$\frac{1}{4}$ gill of clear soup.
lepper and salt.

Take yolk of cyrs and a small portion of the white, heat up with $\frac{1}{4}$ gill of the clear soup, and season with pepper and salt, and strain into a greased egg-cup. Cover with greased paper, and steam very slowly for ten minutes, or until the custard feels firm to the touch; let it cool, and turn it out. Cut it into small dice. l'ut these in tureen, and pour boiling lot consomne over tham.

Meat, veal, or chicken jelly can be obtained from preparing the meat and chicken, as in bcef-tea No. 2 (p. 76), and serving it cold. Also the beef essence (1. 77) served cold makes a very nice jelly, but can only be taken in very small quantitics, as it is very concentrated.
1 lb. veal.
Veal Jelly.
2 thin slices of turnip.
1 teacup of water.
rinch of salt.

Slice the veal very thinly, and place a layer of it in a jar with a layer 
of thinly sliced turnip, and repeat this until all is used up; add the salt and water, cover the jar, put it in a saucepan with boiling water to reach up half-way, and simmer for four hours. Strain and serve cold. It will be in a strong jelly.

Sweet jelly may be made from calves' fect or from gelatine. Calfs-foot jelly is troublesome to make, but if thoroughly well made it is much more delicate in flavour than gelatine jelly. Both methods are given.

$$
\text { Calf's-foot Jelly (Sweet). }
$$

I ox foot or two calf's feet.

$\frac{1}{2}$ lb. sugar.

4 eggs.

4 lemons.
I blade mace.

I inch cinnamon stick.

4 cloves.

2 glasses sherry wine.

2 quarts of water.

Two calf's feet are equal to one ox foot, and make the same quantity of jelly; they are prepared in the same way as the ox foot, but need not be boiled quite so long. Get the ox foot broken across several times; split it up between the toes; take out the piece of fat between the toes and all the marrow from the bones. First blanch the foot, by thoroughly washing, cover with cold water, and bring it to the boil. Now place it in a basin of cold water, and scrape well.

After again rinsing in cold water, put it on in a clean pot with 2 quarts of cold water, bringing it to the boil and skimming it well, and boil very gently for about eight hours. If very gently simmered by the side of the fire, the stock does not reduce too much. Strain it into a basin, either through a towel or a sieve, and stand aside to get quite cold. There should be six breakfastcupfuls of stock. When quite cold, remove all the fat from the top ; this must be done very carefully.

Now put the stock into a clean saucepan, add the sugar, the flavourings broken into small pieces, the lemon rind very thinly pared off, the juice strained, two eggs and the whites of the other two eggs beaten up and a little egrg-shell crushed up.

Put this on the fire and whisk briskly until it comes to boilingpoint. Allow it to boil very gently about seven minutes. Withdraw from the fire, cover it with the lid, and allow it to settle for five or ten minutes.

Have a flannel or felt jelly-bag hanging up. l'our a good deal of boiling water through the bag, to warm and cleanse it. When the water has all run out, put a clean basin under the bag and pour the jelly in. lour the jelly twice through the bas, when the jelly should be clear and a brilliant colour. This jelly is excellent without wine. But if wine is used, it is best put into the saucepan just before the jelly is poured into the bag. 
Iline Jilly' (Sweet Wine Jelly from gelatine).

$1 \frac{1}{b}$ ounces French sheet gelatine.

3 sills cold water.

sill lemon juice.

$\frac{1}{2}$ : ill sherry wine.

I tablespoonful brand?:
3 ounces loaf sugar.

Rind of 1 lemon, cut.

2 or 3 cloves.

I inch cinnamon stick.

White and shell of $1 \mathrm{egg}$.

The proportion of gelaine is 2 ounces to I quart.

put all the ingredients into a lined saucepan; whisk until they boil; remove to the side of fire when the scum begins to rise to the top. Cover the top of the pan with a plate, and allow it to stand fifteen minutes. Strain through a hot jelly cloth; run through three or four times till clear, and when cold, mould in a scalded wet mould.

\section{Whipped Jelly.}

Melt the jelly by standing the basin containing it in a saucepan of hot water. When dissolved, put into a large basin; with whisk whip it until it is quite cold, and should become a firm froth and perfectly white. liy varying the ingredients in the wine jelly, a good many different forms cin be obtained, e.g.-

\section{Port Wine Jelly.}

Take 3 gills port wine, I gill water, and I tablespoonful of red-currant jelly, instead of the sherry wine, lemon juice, and the large amount of water.

\section{Orange and Lemon Jellies}

are made by substituting orange or lemon juice for the wine.

Farinaceous Foods containing carbohydrates in the form of starch or sugar can be given in moderation. Thin oatmeal and barley gruel carefully strained and flavoured with salt or sugar is useful (sce p. 296). Arrowroot and Farola are also of value (for preparation, see p. 297).

Malt cxtract, granulated, dissolved in warm water or milk, or with an effervescing water, is good. These supply srape sugar (maltose), soluble dextrin, and a small quantity of soluble albuminoids (see pp). I $7 \&$ ct scq.). Among proprietary fouds, Benger's food is one of the most useful preparations, especially for cases of continued fever. Small quantities of arrowoot, ground rice, and well-baked flour can also be added to clear soup or becf-tea. Great care must be talien not to matic the soup too thick.

\section{Binled Flour.}

Spread some white four thinly on a dish, bake it in a moderate oven for about an hour, until it is at delicate colour. Take it out and place it on a sheet of kitchen paper; when cool, roll it smooth with a rolling-pin, pass it through a wire sieve, and then keep it in a canister or bottle. 
Grape sugar, which is a kind of predigested carbohydrate, is strongly recommended, and may be added to farinaceous foods, and may also be used to sweeten beverages.

Fruit juice, especially the juice of grapes and oranges, is quite admissible, and is usually much appreciated. Special stress should be laid on the point that in grapes the skins and stones are carefully removed, and in oranges that only the juice and pulp are eaten. Fruit soups are commended as agreeable and useful. They are made by boiling fresh or dried fruits with water, with or without the addition of sugar, lemon peel, and freed from the solid residue by pressing and straining.

Thirst-quenchers.-For thirst an abundance of refreshing drinks should be permitted. These all have a very low nutritive value. If made with barley (p. 34) or rice-water instead of plain water, the nutritive value is slimhtly increased. Again, the addition of a teaspoonful of milk sugar or lactose to the pint increases the value considerably without affecting the flavour. Iced water should not be forgotten as being always much appreciated by fever patients.

\section{Rice-Water.}

Take 2 ounces of rice in an enamelled saucepan, with 3 pints of water, and boil for two and a half hours. Stir it frequently and skim carefully. Strain into a jug through a fine wire sieve, and rub through the glutinous parts, but not the hard portion. Add flavouring to taste.

\section{Apple-Water. \\ I lb. apples. $\quad \frac{1}{2}$ lb. brown sugar. \\ I gallon boiling water.}

Cut up the apples into quarters; take them and put into the jug with brown sugar, and pour the boiling water over it. Let it stand until cold; pulp the apples and the fluid through the colander. Bottle for use; do not cork the bottle; keep it in a cool place.

\section{Apple Toast Water.}

Tonst a piece of bread slowly until it gets quite black. Placed in a jur of alple water for three-(puarters of an hour, then strained, makes a very nice and refreshing drink.

\section{Aptele barley and atple lice-lliter.}

boil ! $1 \mathrm{lb}$. of rice or $1 \mathrm{lb}$. of barley, blend with the apple-water, and then strain. 
In spring and summer, rhubarb, green gooseberries, black and red currants, and raspberries may all be made into nice cooling drinks, if used in the same proportion.

\section{Imperial Drink.}

tounce cream of tartar. Juice of 1 lemon.

2 tablespoonfuls of sifted sugar.

Place the ingredients in a jug, pour over a quart of boiling water, and cover until cold.

\section{Lemonade.}

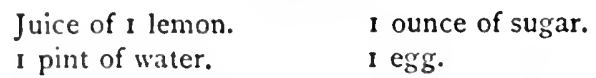

Dissolve the sugar in the water; add the juice of the lemon; beat up the white of egg, and add this.

This makes a very palatable drink, with slight nutritive value.

\section{Lemonade (2).}

4 lemons. $\quad \frac{1}{4} \mathrm{lb}$. of loaf sugar. 3 pints boiling water.

Rub some sugar on the rinds of two of the lemons until it is yellow. Strain the juice of the four lemons; put the sugar and juice into a jug, and pour it over the water. Cover it until it is cold.

\section{Orangeade.}

$\begin{array}{ll}2 \text { oranges. } & 2 \text { or } 3 \text { lumps of sugar. } \\ \text { Juice of } 1 \text { lemon. } & 1 \text { pint of boiling water. }\end{array}$

Wipe the oranges with a damp cloth, and peel the rind of one of them very thinly. Put this into a jug with sugar, and strain in the orange and lemon juice. Pour on the freshly boiled water. Cover closely until cold, and then strain.

\section{Black-Cumant Drink.}

2 tablespoonfuls black-currant jam. I teaspoonful arrowroot.

Take the black-currant jam and boil it in a quart of water. Cover it and stew gently for half an hour, then strain it, and set the liquor again on the fire. Mix the arrowroot in cold water, pour over it the boiling liquor and keep stirring. Then let it get quite cold. (This is a very pleasant drink, and specially nice for an inflamed throat.)

Tea and coffec freshly made with milk may be given also as beverages with a certain food valuc. (These are better withheld until pyrexia is gone.) Peptonised foods are not usually called for in fever cases. They are described in Chapter IX.

Stimulants.-The arlviability of administering or withholding stimulants depends entirely on the condition of the patient. The indications for its administration are as 
follows:- After a long continued pyrcxia, if the circulation shows signs of failure, the pulse becoming weak and irregular; or if the digestive powers flas, with sordes forming on the lips, with a foul tonguc and loss of appetite. Hyperpyrexia may also neccssitatc the use of alcohol.

Champagne, brandy, or whisky may be used; the two latter are the best in the acute stages. It may be given in plain water, in milk, or in an effervescing water. When ordered, the exact quantity should be stated: it is best given at regular intervals by day and night. A half to one ounce every two or three hours is usually sufficient; it is seldom necessary or advisable to give more than 6 ounces in twenty. four hours to an adult. A larger quantity causes overstimulation; this can be recognised by a feeling of discomfort, a bad taste in the mouth, and an offensive breath. Children show a distinct toleration for relatively large doses of alcohol. In cases of vomiting, dry champagne is often the best form of stimulant.

\section{Typhoid or Enteric Fever.}

Introduction . $\quad . \quad . \quad .277$ Other systems of feeding-

A milk regime $\quad . \quad . \quad 278$

Details of . . . . . 279

Indications for increasing the diet

in convalescence. . . $28 \mathrm{r}$

Value of water-drinking $\quad . \quad 284$

Dietetic treatment of complications 284

A liberal diet, with solid food from the outset. .285

Modification of this system . 286

Treatment on the empty bowel theory . . . 286

Starvation diet . . . . 287

In no disease is the question of diet of greater importance than in typhoid fever. The disease is a serious one, on account of its usually protracted nature, with its corresponding drain on the patient's general strength. It is, therefore, of paramount importance to maintain the strength of the patient, but in doing so due regard must be paid to the lesion in the intestine (ulceration) which is usually present, and also to the impaired digestive powers of the patient. At the same time wc must recognise that it is perhaps more true of this discase than of any other that we must treat the patient and not the disease. The truth of this is shown by a reference to the different systems of diet 
that have proved undoubtedly successful in its treatment. Some recognised authorities find good results from the use of a fairly full dict containing much solid food, throughout the whole course of the illness; others adhere to the timehonoured system of a milk diet during the acute phases of the discase. Both systems appear to be equally successful, and from this we may conclude that the diet has to bc judged more from the nature and amount of the residue which it leaves in the small intestines than from the form in which it is taken into the stomach. It is probable that in certain cases a residue of undigested solid curd from an exclusive milk regime produces much more local and general disturbances of an unfavourable nature than the residue from a fish, chicken, or meat diet. In this connection it must also be borne in mind that in some cases the local lesion in the bowel is of a very slight character, there being littic or no demonstrable ulceration. In the present state of our knowledge it may be said that the most judicious system of feeding is that which relies largely on a milk regime. We shall therefore first describe this system in detail, and thereafter consider the other dictetic regimes that are recommended.

Milk regime.-Milk should form the chief food, and much attention to detail is necessary in its administration. It is specially important to closely watch the stools. If the motions contain undigested curd, it is clear that the amount of milk given or the form in which it is administered are unsuitable, and an immediate change in the diet is called for on account of the risks to the patient from the mechanical presence of lumpy curds, and from the abdominal distension from the fermentative changes in the food. If attention be paid to the following points, milk will seldom fail as a dict in typhoid fever. It should be given well diluted, it should be administered at regular intervals only, the total amount should not exceed from 2 to 3 pints per day, and the motions should be inspected daily for the presence of undigested curds.

The milk should be diluted with plain hot water in the proportion of one to three, or one to four. The warmth of the mixture assists digestion by not chilling the stomach, and the dilution prevents the curd being too hard. If the bowels are costive, fluid magnesia (Dinneford's) can be used as the 
diluent and added to the warmed milk; if the bowels have a tendency to be loose, lime-water is the best diluent. The amount of milk administered in twenty-four honrs is important. It must never be used as a quencher of thirst, but always as a food; it must be taken at regular intervals and in stated amounts. The prescribed quantity should be taken at the proper time, and no milk should be allowed to stand at the bedside; this precaution ensures the stomach having time to empty itself. The amount of milk given should be limited; 3 ounces every two hours, i.e. under 2 pints in the twenty-four hours, is enough at first; if this does not cause curd in the stools the quantity may be increased up to 3 or 4 ounces every two hours. No interval of longer than three to three and a half hours should be allowed during the night without food.

The presence of undigested curd, whether in large masses or flakes, shows that either sufficient attention to detail in the administration is not being observed, or that the patient is getting more milk than he can digest. A reduction of $\frac{1}{2}$ ounce from the two-hourly feeds will often be sufficient to stop the presence of curd, and the improved digestion will probably put an end to the slight diarrhcea that may be present. If this does not prove sufficient, malted milk may be used, or the milk may be partially or completely peptonised. These modifications in the manner of administration are helpful in patients troubled with meteorism. Whey is a good substitute for milk if the latter is not tolerated. During this period very special attention is necessary to the toilet of the mouth.

Milk dict is very monotonous, and if a patient is not suffering from diarrhœa or blood in the stools, there is no reason why this monotony should not be relieved after twentyfour hours by the administration of some of the meat broths. An allowance of chicken or beef-tea or clear consommé is much appreciated, and can be given well salted. Most enteric cases crave for salt, and there is no reason why it should not be supplied. The actual food value of these preparations is small, but they help digestion by acting as stimulants. A well-recognised method of administering the meat-tea juices is to give a daily allowance of a pint, divided 
into three portions. One portion should be given as the dinner meal, the second portion, wiven hot about 9 o'clock, helps tise patient to so to slecp, and the third quantity may be given in the early hours of the morning.

If diarricea is persistent, the warm meat-broths tend only to aggravate it; it is then better to use raw-meat juice, or one of the many meat extracts on the market. Meat juice may be prepared at home, and given in 2 teaspoonfuls, slightly salted. The meat extracts should be given cold, and mixed with a little water. Bovinine and Wyeth's meat juice are excellent, but the strong meaty flavour is much disliked by some patients. Brand's chicken jelly is very agrecable, and so is home-made chicken essence.

\section{DIET SHEET 1.}

The following dietary is suitable for the acute stage :-

3 A.M. - Chicken tca (hot), 7 ounces, with 3 ounces milk; or

Bovinine and 3 ounces milk.

5 A.M.-Milk, 3 ounces, hot water, I ounce.

7 A.M.-Milk, 3 ounces, hot water, I ounce.

9 A.M.-Milk, 3 ounces, hot water, 1 ounce.

I I A.M.-Milk, 3 ounces, hot water, I ounce.

I P.M. - Hot beef-tea, 7 ounces, milk, 3 ounces; or

Chicken essence and milk.

3 P.M.-Milk, 3 ounces, hot water, 1 ounce.

5 P.M.-Milk, 3 ounces, hot water, 1 ounce; or

Cup of tea, with 3 ounces milk, freshly made.

7 P.M.-Milk, 3 ounces, hot water, I ounce.

9 P.M.-Hot chicken tea, 7 ounces, milk, 3 ounces ; or

Valentine's beef juice, 2 teaspoonfuls, and milk, 3 ounces.

II P.M.-Milk, 3 ounces, hot water, I ounce.

I A.M.-Milk, 3 ounces, hot water, 1 ounce (if awake).

When there is excessive wasting, or if the fever is very prolonged, or if there has been a relapse after a prolonged first attack, the nutritive value of the diet should be increased. The prepared proteins, e.g., Plasmon, Somatose, Protene, Sanatogen, may be added, 2 to 4 teaspoonfuls being given in the twenty-four hours (see p. 158 ). Albumin water added to the milk will be found uscful. Also half an egg added to milk may be given twice daily in the form of custard boiled or baked, or as egg flip. A small amount of well-boiled sago or arrowroot may be given in the chicken tea. Calfs- 
foot jelly (p. 273), with fruit or wine flavouring, or blancmange made with milk may be given (p. 301 ).

\section{DIET SHEET II.}

Diet chart for a case of prolonged fever, or for relapse with much fever.

3 A.M.-Chicken tea, 8 ounces.

5 A.M.-Milk (diluted), 3 ounces, with prepared Plasmon, I ounce (p. 159).

7 A.M.-Milk, 3 ounces, and albumin water.

9 A.M.-Milk, 3 ounces, and half-beaten egg.

I P.M.-Chicken-broth tea, 8 ounces, and I ounce Plasmon (hot) salted.

3 P.ar.-Milk, 3 ounces, and albumin water.

5 P.M.-Calf's-foot jelly, or milk blancmange.

7 P.M.-Milk (diluted), 3 ounces.

9 P.M.-Milk, 3 ounces, and half egg (as baked custard).

I I P.M.-Chicken tea, thickened arrowroot, $S$ ounces (salted), I ounce Plasmon.

I A.M.-Milk, 3 ounces, diluted (if awake).

Indications for increasing the diet in convalescunce.Assuming a patient has satisfactorily passed through his fever, and his temperature is approaching the normal line, when is the first increase of diet to be made? Much depends upon the circumstances of the individual case. Unless he is really hungry, there is no particular advantage in making any addition to the diet till the temperature is steadily normal. By "real hunger" is to be unclerstood a genuine craving for food; that is to say, it is not enough for the patient to reply that he is hungry when asked. He must volunteer the information himself. If his hunger is real, and all precautions to satisfy a false appetite have already been taken, some addition to his food may be allowed when his temperature is normal in the mornings, the evening readings being disregarded. Should his diet, up to this point, have consisted exclusively of milk and meat broths, with a few extras that may have been permitted in prolonged cases, it is obvious that, before he is allowed solid food, he must be content with semi-solids and "sloppy" materials. Benger's food or boiled bread and milk (p. 439) are usually the first additions, and the effect of even this slight incrcase of diet on the temperature of the patient should be carefully noted. If the morning temperature remains normal, 
the bread and milk is continued for two or three days, the amount given being gradually increased, and a little wellmakle wathour porridge being adeled to give variety. Diet Sheet 111 . is a very suitable dict for carly convalescence.

\section{DIET SHEET III.}

Early convalescence, the morning temperature being normal for five or six days.

3 A.M.-Beef consommé, ro ounces.

5 A.M.-Milk, 6 to ro ounces.

7 A.M.-Bread and milk, with milk (special, p. 439).

9 A.M. - Tea, thin bread and butter; no crusts.

11 A.M.-Milk, 6 to 10 ounces.

I P.M. - Chicken tea, thickened with sago (later, some form of powdered fish, e.g. a soufflé in cream); milk pudding or jelly.

3 P.M.-Calfs-foot jelly (lemon, orange, sherry).

5 P.M.-Milk, 6 to 10 ounces.

7 P.M.-Gruel, made from oatmeal, barley meal, or wheat ; eaten with milk and cream.

9 P.M.-Beef-tea, 10 ounces.

I I P.M.-Milk, 6 to ro ources (if a wake).

I A.M.-Milk, $\delta$ ounces (if awake).

By this time the evening temperature has also frequently settled; but even if not, another increase may be safely tried, always provided there has been no rise above normal in the mornings. At this stage the first solids may be given, a sponge biscuit or a small amount of light sponge cake being a quite suitable substance to experiment with. If this is tolerated, on the following day a very small quantity of white fish may be allowed. This should be boiled or steamed, and all skin should be carefully removed. The best fish for this purpose is whiting or sole, but in hospital practice fresh haddock forms an admirable substitute. A very thin finger of bread, from which all crust has been cut, may be given with the fish. On the following day, always assuming the morning temperature remains steadily normal, a little thin bread and butter may be allowed at breakfast and tea time, the patient still receiving a reasonable quantity of milk at definite intervals, and beef or chicken tea being continued exactly as before. For three or four days this diet may be continued, the amount of food given being cautiously 
increased, and such additions as a little baked custard pudding or some well-boilcd milk pudding may be permitted. A sood dietary for this stage is presented in the folluwing diet sheet :-

\section{DIET SHEET IV.}

\section{Full convalescent.}

6 A.M.-Tea with milk, bread and butter.

8 A.s.-Oatflour gruel, with milk and cream. 10. jo A.M.-Milk with half egg, beaten.

I P.M.-Soup (strained), Io ounces.

Fish, or chicken.

Milk-pudding and stewed fruit, or jelly, or custard; eaten with cream.

4. ̧̧o P.M.-Tea, boiled egg, bread and butter, jelly, sponge cake. 7 r.M. - Cornflour, arrowroot, or semolina, made with milk; eaten with cream, bread and butter.

Io P.M.-Hot beef-tea.

Should the morning temperature rise above normal, it is wiser to go back to the fluid diet at once, until, at least, the cause of the pyrexia has been ascertained. It is quite possible, of course, that the cause may lie elsewhere than in the diet. Constipation, for instance, is often troublesome at this stage, and the temperature of the enteric convalescent, being extremely mobile, is very readily affected by it. Such complications, moreover, as phlebitis, otitis media, and superficial skin abscesses may supervene in convalescence and cause some degree of fever. In such instances it is rarely necessary to makc much modification in the diet, and, the pyrexia being satisfactorily accounted for, the appetite of the patient may be taken as a rough guide to the amount of food required.

Should, however, the addition of solids to the dietary leave the temperature quite unaffected, after a few days of steady increase in the amount of food given, a further step may be taken and the patient allowed a little of the breast or wing of a chicken. Patients, as a rule, are ready to begin this from three to five days after their first allowance of fish. With the chicken may be given a little mashed potato, which may be added when the diet is still limited to fish. A little stewed fruit may now be added. This diet is maintained till all chances of relapse are over, after 
which (say after a fortnight's normal temperature) there is no reason why meat should not be allowed in moderation. In moderation, indeed, success in the dieting of an enteric patient usually lies. As much varicty of food as possible should be given, but at first only in small amounts.

Value of water-drinking in typhoid fever.-Thirst should be assuaged by the drinking of a large amount of plain water, from 4 to 6 pints of water being given daily. In addition to assuaging thirst, an abundance of water-drinking promotes elimination of the toxins. When an insufficient amount of water is taken, the tongue gets very dry, even when the mouth is being carefully attended to. Aerated waters should be aroided, as tending to induce flatulence. Imperial drink (p. 276 ), or an acidulated drink made with a few drops of hydrochloric acid and a little syrup of lemons, are also of value in allaying thirst. Weak tea made with milk is permissible, except in cases troubled with insomnia.

Dietctic treatment of complications. - This has alrcady been incidentally referred to, so far as regards the troublesome complications of constipation, diarrhœa, and meteorism. In the treatment of constipation the addition of fluid magnesia to the milk, and of beef-tea to the diet, will prove serviceable; diarrhee may be combated by the use of lime-water as a diluent in place of plain water. If this does not suffice, the milk should be peptonised, and the amount given should be considerably reduced. Beef-tca snould be withdrawn from the diet until the diarrhœa has disappeared. Meteorism is not a common complication in cases that are judiciously fed. It may be combated by peptonising and pancreating the milk, and by making more use of beef-tea and chicken jelly. If necessary, the amount of milk may be for the time reduced, or skimmed milk or whey may be substituted.

Hamorhage is treated by starvation for thirty-six hours, and thereafter the administration of teaspoonful doses of concentrated foods every three hours. Peptonised milk and chicken jelly are the best foods for early administration. If no return of symptoms develop, the amount of these are gradually increased, and also the frequency of administration. At the end of the third day the patient may, in favourable cases, be getting a diet consisting of 10 ounces of peptonised 
milk, $\frac{1}{2}$ ounce of chicken jelly or meat juice, administered in small amounts every two hours. If this is well borne, the dict can be increased daily with fair rapidity.

The question of the use of stimulants in cases of namorrhage is a very important one. They should be withheld unless the condition of the patient is one of great collapse, with an extremely feeble pulse. Under these circumstances brandy should be administered in not more than teaspoonful doses at frequent intervals, the effect of this being very closcly watched, so as to avoid risk of overstimulation with a recurrence of the blceding.

In the event of perforation occurring, the dietetic treatment for the first few days after opcration should take the form of rectal alimentation. Injections of saline, $\delta$ to 10 ounces, with the addition of dextrose, are of special value. Thereafter oral administration may be begun, a start bcing made with very small quantities of peptonised milk, chicken jelly, raw-meat juice, given every hour.

Other systems of feeding.-The system of feeding already outlined may be taken as the one gencrally recognised as the most suitable for the feeding of typhoid fever cases. Reference must, however, be paid to other systems which have found favour with recognised authorities.

Liberal diet, with solid food from the outset.- This treatment was introduced by a Russian physician, Bushuyev. I I is method is to allow solid food to all who can take it, from the moment they come under observation. The following is the dietary suggested by him for the acute stage :-

7 A.M. - Tea, with a roll.

S A.M.-Oatmeal, barley, or wheat liquid porridge, with butter (about 13 fluid ounces).

9 A.M.-One or two boiled eggs, hard or soft as the patient prefers.

10-11 A.M.-A glass (about 7 ounces) of milk, a roll, half a cutlet, or a piece of boiled meat.

12-12.30 P.M.-A plate (about 7 ounces) of chicken soup, or ordinary soup, and a cupful of jelly.

3 P.M. - Tea, with a roll.

6 1'.M. - A cup of chicken or beef-tea, semolina pudding or milk, and a bit of chicken.

$S$ 1.M.-Milk, with a roll.

During the night-Coffee or tea, with milk, two to four times; colfee with cognac. 
It will be observed that the above dietary is a strikingly liberal one. While it has given good results in a large series of cases, and does not appear to have been prejudicial in any recorded cases, it should certainly not be adopted as a routine method. Other authorities, and more especially Amcrican physicians, have adopted this system of feeding in a less prominent and more rational manner. They have found, in experimenting with a more varied diet, that no harm accrued from giving meat and milk, beef-tea thickened in various ways, and mill puddings, during the acute stage. Those who have cxperimented with this more varied diet hare not found that its use was followed by a relapse more frequently than the ordinary system of feeding by an almost exclusive mills regime.

Many American authorities approve of a full diet along the following lines :-

I. Milk in various forms, such as hot or cold, with or without salt; may be diluted with lime-water, magnesia, or plain water, or with the aerated waters, c.g., Apollinaris, Vichy, soda-water. Peptogenic milk, or peptonised milk, milk with white of egg, buttermilk, koumiss, whey; milk with tea, coffee, or cocoa.

2. Soups-beef, veal, chicken, tomato, potato, oyster, mutton, pea, bean; carefully strained and thickened with rice flour, arrowroot flour, milk cream, egg, or barley.

3. Horlick's malted milk, Mellin's food, Somatose, etc.

4. Leef juice, meat juices, Bovinine peptonoids.

5. Gruels (strained), barley-water, toast-water, and albumin water.

6. Egrgs, soft boiled, raw, or with egg flip.

7. Finely minced beef, scraped beef, oyster, well-boiled puddings, blancmange, and jellies.

A liberal dictary is a very important factor in the treatment of convalescence. As soon as the morning temperature is satisfactory, solid food should be increasingly given, provided the pationt be genuincly hungry. This increased dietary is not only of spccial service in the treatment of convalescence in cases running a normal course; it may be of great service in cases which show a prolonged swinging temperature in the convalescent period.

Dictictic treatment on the cmpty bowel theory.-Ewart has drawn special attention to the advantages of a diet which leaves little or no residuum. According to this view, the 
ulceration is regarded as a preventable condition, rather than an integral part of the disease. A grood deal can be said in favour of this view. The dietary recommencled consists in from $2 \frac{1}{2}$ to 4 pints of whey in the twenty-four hours, common salt being added in the proportion of 10 to I 5 grains to each half-pint, in order to correct the deficiency in mineral salts in an ordinary milk diet. This diet is continued for three or four days. At the end of this period, sugar, albumin, and cream are successively added to the dietary-sugar, in the form of lactose, 2 drams to each half-pint of whey; albumin, in the form of white of egg, which may be given peptonised; and fat, in the form of cream, either taken alone, or in the whey, or as yolk of egg. Maltine is also useful. Thin vegetable soups, fruit juices, and jellics are also recommended. In determining each addition to the diet, we must be guided by the presence or absence of meteorism, the state of the stools, and the general condition of the patient.

Starvation treatment.-With the object of securing complete rest for the affected part of the intestines, and effectually excluding the possibility of fermentation of partially digested food, some writers have recommended systems of feeding which are really treatment by starvation. Thus it has been recommended that the treatment should be entirely rectal, a lemonade drink being the only food given by the mouth. A similar line of treatment has been advocated by Williams. In some cases this author gives water only for days at a time, and he regards half a pint of milk in the twenty-four hours as a liberal diet, which he seldom exceeds until the temperature is normal. In the hands of other clinicians this system of treatment has been found to answer remarkably well in certain cases. The patients so treated have not wasted any more than the patients more liberally fed, which scems to prove that in the latter the food was not being assimilated, and that, therefore, no advantage was gained by its administration. The main lesson which the success of this starvation treatment should convey is the advisability of judiciously starving the patient for a few clays at the ontset of the illness in cases where the power of digestion and assinilation is in abeyance, as revealed by marked gastric and intestinal disturbance. 
Pneumonia or Pneumonic Fever.-In this acute condition, the diet must be fluid and light, and adapted to the enfecbled digestive powers. (The general directions on p. 267 apply.) The food should be griven in small quantities and at short intervals. During the fever the total quantity of liquid food in twenty-four hours should not excecd 3 to 4 pints; cold water may be allowed freely in addition. Milk diluted in various ways is the staple dict. If the stomach is irritable, whey in some form is preferable, e.g., whey and egg-water, whey and cream, or whey and white wine with cream. Any of the beef-tea and soup group (pp. 75 and 270) may be used; beef-tea is best given as directed on page 76 . Freshly made tea, with cream and a strip of toast or sponge rusk to eat with it, is allowable. Milk flavoured with coffec is an excellent stimulant, and is very refreshing in the morning after a bad night. Fresh fruit juice (grapes, oranges) is much appreciated.

As soon as the fever has abated, the patient may be placed on a convalescent dietary. In judging of the disappearance of the fever, we must remember that the fall of temperature may be a pseudo crisis, and not a real crisis. In the general run of cases, alcohol in any form is not called for. In clderly people and in alcoholic subjects the use of stimulants is more frequently indicated. The early routine use of alcohol in these cases cannot be too strongly deprecated. When the heart's action becomes weak, irregular, and intermittent, and the general condition of the patient indicates increasing weakness, a stimulant is called for. It may be given in the form of whisky, brancly, or champagne. An average dose would be $?$ ounce of whisky in twice the amount of water every four hours. In exceptional cases, when distinct benefit is apparently resulting from the stimulant, a considerably larger amount of whisky or brandy may be administered.

Rheumatic Fever-Acute Rheumatism.-The diet for acute rheumatism is the dict of acute fever (p. 267). Strong meat soups, however, should not be given until convalescence is well advanced. The paticnt should be encouraged to drink a large amount of fluids, which allays thirst and promotes elimination of the rhemmatic poison. The imperial drink is a refreshing bererage. 
Scarlet Fever. - In uncomplicated cases the usual fever dictary, with a liberal supply of cold water or lemonade, is sufficient. It is important to keep in view the tendency to the development of acute nephritis, usually about the third week of the illness. The following is a good regime :-

(I) For the first four days the nourishment should consist exclusively of milk, with possibly the addition of some lemonade and soda-water. Plain water may be given freely.

(2) For the next four days an egg and any form of farinaceous food may be added.

(3) During the remaining four days the diet may include some weak broth, fish, fruit, and vegetables (see Convalescent Diet, p. 293).

(4) After this period, poultry, game, and meat may be gradually allowed, and the food administered as freely as desired. In young children and in adolescents it is surprising what amount of food can be consumed with impunity in cases when the diet has been restricted as above during the initial stages of the illness. On the other hand, the administration of a liberal mixed dietary in the initial stages of the disease is prone to induce nephritis, with albuminuria, etc.

If the condition is complicated with severe faucial ulceration, or submaxillary swelling, and swallowing is painful, the food administered should be of the most nourishing character, and given in small bulk, e.g., eggs and milk, rawmeat juice, beef or chicken essence. In some cases it is necessary to have recourse to nasal feeding. The onset of albuminuria necessitates an exclusive milk regime. Cardiac weakness calls for a liberal use of stimulants.

Whooping-Cough.-During the whole course of the illness, milk, light soups, and farinaceous foods should form the chief ingredients of the dietary. In cases in which the vomiting is persistent and the paroxysms severe, the child may become greatly weakened. Under these circumstances the child should be fed with custards, rich egg flip, beef and chicken essences, fortified with Plasmon, which should be given after each paroxysm. The quantity should not be large, but must be regulated by the length of time between the fits. In very troublesome cases great benefit may be obtained by substituting whey for 
diluted milk. Treatment of these patients in the open air makes them much easier to feed.

Measles.-The general directions for a fever dietary apply. During convalescence, special care is necessary in the case of young and weakly children. The too early administration of a strong meat or vegetable soup may induce a severe and troublesome diarrhoea.

Influenza.-The dietetic treatment of influcnza varies according to the presence or absence of $(a)$ pyrexia and $(b)$ gastro-intestinal derangement. The leading indication is to have recourse to a generous dietary as soon as the acute stages of the disease are passed. In febrile cases the rules laid down under fever dietary apply. As soon as the fever has abated, a convalescent diet may be given. In other cases a generous dietary is called for from the outset. The appetite of these patients usually requires to be tempted, and assistance in the selection and preparation of suitable foods will be found in the section on Dict during Convalescence. Care must be talien in prescribing alcohol in any form in this discase. It is usually uncalled for, but in certain cases recovery is accelerated by the judicious use of a small quantity of whisky, champagne, or Burgundy, which should be given once or twice a day with meals.

Diphtheria.- The diet in diphtheria is the diet of acute fever. As soon as the temperature is normal, soft solids may be given. Occasionally, even in the acute stages, semi-solids are swallowed with greater ease than liquids, in which case the soups can be thickened with tapioca, sago, or arrowroot. The stock, carefully skimmed from fat, may be given in its jelly form. Veal jelly, custard, and curds are also valuable. In cases with much faucial trouble, nasal feeding may be necessary (see p. 225). If intubation or tracheotomy have been required, it is wiser to have recourse to nasal feeding, owing to the risks of inhalation pneumonia. Stimulants are frequently arlisable, and may be given in I to 2 teaspoonfuls of whisky, either diluted with water, or added to the egg flip.

Smallpox. - The general directions for feeding fever patients are again applicable. There should be an abundance of fluids, and the foodstuffs should be those which give 
least trouble to the digestion. Cold drinks may be given liberally. Patients are usually quite ready for their food; if vomiting is persistent, nourishment must be given in small quantitics, and in a concentrated form-eggs, essences, beef jellies; if no nourishment is retained, nutrient enemata should be administered. As the confluent form is exhausting, a gencrous dietary is called for (see Diet in Convalesence, p. 292). Stimulants must be freely administered if the pulse becomes feeble and rapid.

Tonsillitis (Quinsy) is best treated by a milk and beef-tea regime (p. 268). Semi-solid diets are sometimes taken more easily than fluids, and in these cases the semi-solid diet for dysphagia (p. 438) may be recommended.

Typhus.-Owing to the condition of the mouth and tongue, and in order to promote the elimination of toxines, these patients require a large quantity of fluid. It is absolutely necessary to supply water in abundance; this may be given simply as cold water, or as one of the mineral watersSalutaris or Apollinaris. The water should be forced on these patients, as they are sometimes unable to ask for it; a quantity of five to six pints in twenty-four hours is advisable.

The digestion is much impaired, and a milk and meat soup dietary, such as outlined on page 268 for fevers in general, should be given. When there is great debility and manifest failure of strength, the more concentrated nourishment, such as essence of meat, or chicken, egg fip, or the prepared artifical foods, such as Wyeth's beef juice, Bovinine, Brand's beef jelly, are necessary. The food in such cases is best administered in small quantities every hour and a half. A dried milk preparation may also be used to further fortify the food (p. 158 ).

Malarin.-The febrile stages of malarin calls for the administration of the fever dietary, p. 268 ; in the later stages the diet in convalescence (p. 292) or the light diet summarised on p. 548 is applicable. 


\section{CHAP'TER XVII}

DIET DURING CONVALESCENCE

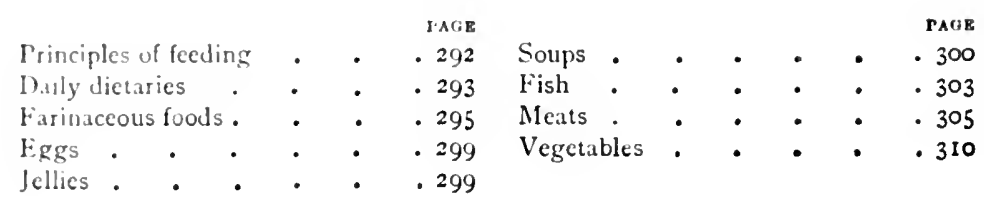

Diet during Convalescence.-The digcstive tract being more or less weakened in all cases of acute illness, patients convalescing from an acute discase may be regarded as dyspeptics for the time being. Great care is therefore necessary in regard to both the quantity and quality of the food. The digestive capacity of convalescents, however, varies widcly. There is, for instance, the healthy young adult recovering from some sharp attack of infective fever, in whom the digestive organs are only weakened, not organically affected. His convalescence is rapid, and he is sum capablc of eating and digesting everything. In this class of case there is no necessity to try and tempt the appetite; the food can be simply prepared; the danger is that the paticnt will overeat. On the other hand, the patient may be a delicate child recovering from scarlatina, complicated by nephritis. Here it would be absolutcly wrong if we did not limit the quantity, and give very strict injunctions as to the quality of the food. Similarly, after typhoid fever, when convalescence is established, a mass of undigested food, e.g., potatoes or a piece of unmasticated meat, may cause a relaysc, by setting up irritation in some recently ulcerated patch.

At first, in all cases, the fever diet should be continued, the milk and beef-tea being gradually reduced, and thickened 
beef-teas and soups, egg drinks, and various jellies being mainly given. This can be extended to include the more easily digested starches, either in the form of some invalid food, e.g., a simple, well-cooked gruel, malted gruel, or Benger's or Savory \& Moore's invalid food. The next advance would include lightly cooked egss, either plain boiled, poached, scrambled, or in the form of a custard; or combined, as in milk puddings, with a farinaceous food. For breadstuffs, thin slices of toast, the crusty portion of a Vienna roll, sweetened and unsweetened rusks, toasted sponge, finger biscuits, rice biscuits, and plain biscuits may be recommended. Many of the malted breads now on the market, such as Veda, Hovis, Bermaline, Bipsine, etc., are quite permissible, care being taken that the bread is not new (see Bread).

As the strength of the patient increases a more liberal diet is given, fish, sweetbreads, chicken, game, pigeons, rabbits, being gradually added to the dietary. Then follow mince, beef quenelles, eye of a tender loin chop, a slice of tender beefsteak, or a small piece from the undercut of a lightly. cooked sirloin of beef, or a slice from a leg of mutton. The patient should always be reminded of the necessity of eating slowly, and masticating well. Vegetables and fruits must be cautiously added to the dietary.

The following seven days' dietary is sketched to give an indication of what is permissible. Doubtless, in some cases a more rapid return to ordinary diet could be made, while in others the change would require to be more gradually effected. This scheme of dietary is followed by an account of the manner of preparation of farinaceous and other foodstuffs of special value in convalescence.

\section{Seven Day's' Dietary.}

First Day.

7 A.M.-If awake early, a small cup of freshly made tea, with cream.

8.30 A.M.-Milk and thick barley-water, half a slice of toast, cut in fingers.

II. 30 A.M.-Calfs-foot jelly, about 2 ounces.

I P.M. -

Thick beef-tea (Egg and tapioca groût, p. 77).

A few grapes (juice and pulp only). 
4 I.M. Cup of tea, with milk and cream, thin slice of bread and butter.

6. 30 l'.M. (up of lienser's food (or other invalid foods).

9 1....-Cup of heef-teil (method 1, p. 76).

\section{Second Day.}

7 A.M. - A small cup of coffec, with milk.

8. 30 A.M. - Malted gruel.

11.30 A.M.-Milk and soda-water, with plain biscuits.

I 1'.M. -

Beef-tea purée (p. 77), with strip of toast.

Blancmange.

4 P.M. -

Cup of tea, with milk and cream.

I slice bread and butter.

1 sponge finger.

6.30 P.M.-I'lain egg flip (p. 48), with biscuits.

9) H.M. - Cup of chicken soup or chicken jelly.

\section{Third Day.}

7 A.M.-A small cup of freshly-made tea, with cream and small half-slice toast.

8.30 A.M. : Breakfast-Saucerful of oatmeal gruel, with cream and a little piece of Vienna roll (crusty part).

11.30 A.M.-A teacupful of beef-tea (unthickened), either hot or cold.

1 P.M. -

Steamed whiting, half-slice of bread.

Semolina or ground rice pudding.

4 P.M. -

Potash and milk, with rice biscuit or sponge cake.

A little fruit.

6. 30 P.M. - An invalid food, in any form (see p. 183).

9 P.M. - Some variety of meat tea or infusion.

\section{Fourth Day.}

8 A.M. -

Saucerful of hominy porridge or barley-meal gruel, etc.

A small cup of tea, toast, and a very little butter.

11.30 A.M.-A teacupful of chicken tea, with milk and potash or a little fruit.

1.30 P.M. -

Baked or steamed fish (p. 306).

Spinach.

Apple cream.

4 P.M.-P'otash and milk, or a small cup of fresh tea, bread and butter, and sponge cake.

6.30 P.M.-Peptonised cocoa and milk, or custard.

9 P.M. - Some variety of meat infusion, c.g. veal tea. 
8 A.M. -

Fifth Day

A lightly-boiled egre, toast or roll with butter.

A small cup of tea.

II.jo A.M.-Teacupful of soup, or a little fruit, and a drink of milk and potash.

I. 30 P.M. -

Rabbit, chicken (roast), two slices from breast, or pigeon served with bread sauce.

A small helping of vegretable, $c_{\text {:s. }}$., stewed vegetable marrow or caulifower, not potatoes.

Pudding-apples cooked in water sago, eaten with cream.

6.jo P.M.-Oysters (p. 305).

9 P.M.-Some variety of soup.

S A.M.-

\section{Sixth Day.}

A piece of boiled or steamed haddock, whiting, or sole

Tea, bread or toast and butter.

I I A.M.-Soup, or eggs drink.

I. 30 P.M. -

Sweetbread or tripe.

Vegetable, stewed tomato (pulp only).

Stewed fruit with custard.

4 P.M.-Afternoon tea (avoiding rich cakes and pastry).

6 P.M.-

Poached egg on toast or spinach.

Milk and potash.

9 P.M.-Cup of soup.

8 A.M.-

Seventh Day.

A few rolls of well-fried streaky bacon.

Toast and tea.

I I. 30 A.M. -

Egg flip, or soup, or milk and potash.

Fruit.

1.30 P.HI. -

A small slice of tender roast mutton, or the eye of a tender mutton chop.

Vegetable.

Jelly.

4.30 P.M.-Afternoon tea (avoiding rich cakes and pastry).

6.30 P.M. -

Fish.

Milk pudding.

9 P.M. - Cup of so:'p.

Farinaceous Foods.-The value of different farinaceous foods is often much interfered with by defective cooking. 
In the preparation of sructs and other farinaceous foods, prolonged boiling is required in order to burst the starch sranules. The stomach can do very little with uncooked, starchy' food. There are now many half-cookcd cereal preparations in the market which do not require such prolonged cooking (sec pp. I6S, i $S_{3}$ ).

\section{Oatmeal Gruel.}

I tablespoonful fine oatmeal. $\quad \frac{1}{2}$ pint cold water.

Salt or sugar.

Put the oatmeal into a clean basin and pour the water over it. Cover the basin and let it stand for at least half an hour, stirring occasionally, then straining the liquid off into a small clean saucepan, pressing the oatmeal as dry as possible. Stir the strained liquid over the fire until boiling, and let it boil from fifteen to twenty minutes. The thickness of the gruel is very much a matter of taste; if too thick add more water, or if too thin use more oatmeal. Season with salt or sugar. The addition of a little cream is a great advantage, improving the taste and increasing the nutritive value.

\section{Milk Gruel. \\ 1 tablespoonful fine oatmeal. \\ $\frac{1}{2}$ pint milk.}

Salt or sugar.

Macle in the same way as last recipe, except that milk is used instead of water.

\section{Malted Gruel.}

This gruel may be made of any of the farinaceous substances-Quaker oats, Farina, arrowront, barley, or lentil flour. Make in the same way as oatmeal gruel. When cold enough to swallow, add the malt infusion or an extract of malt; about I tablespoonfu! of the infusion or a teaspoonful of the extract is sufficient to digest a plateful of gruel. The action is very rapid, and in a few moments the gruel becomes thin from the transformation of the starch into maltose.

\section{Barley-Meal Gruel.}

I dessertspoonfui barley-meal.

is pint milk.
A small piece of butter.

Sugar or salt.

Mix the milk very gradually with the meal, stirring until quite smooth. Take a small lined saucepan, and after rinsing with cold water, pour the barley and milk into it. Stir constantly over the fire until boiling, let it boil ten minutes, season, and serve very hoc.

\section{Port I'zne Gruel.}

Nake a gruel with oatmeal or barley-meal and water, then thin it down with a glass of port wine; heat thoroushly, but do not boil again. 


\title{
Caudle.
}

Beat up an egg to a froth, add a glass of sherry and half a pint of hot gruel; flavour with lemon peel, nutmeg, and sugar.

\section{Water Arrowroot or Cornflour.}

$\frac{1}{2}$ ounce arrowroot or cornflour. $\frac{1}{2}$ pint cold water.
I teaspoonful of sugar.

Seasoning, either nutmeg, sherry, or brandy.

Put the arrowroot into a small basin, add to it a tablespoonful of cold water, break it with a wooden spoon until quite smooth. Then pour on the rest of the water, mix well, and pour into a small lined saucepan. Stir this over the fire until it boils and thickens, then let it boil for ten minutes to thoroughly cook the arrowroot. Sweeten to taste, and serve in a cup or small basin. A little nutmeg may be grated on the top, and wine or cream added if desired.

\section{Milk Arrowroot or Milk Cornflour.}

\section{臬 ounce arrowroot or cornflour. $\quad \frac{1}{2}$ pint milk.}

$$
\frac{1}{2} \text { teaspoonful of sugar. }
$$

Make as above, using milk instead of water.

\section{Water Sago or Tapioca.}

\author{
$\frac{1}{2}$ ounce sago or tapioca. \\ $\frac{3}{4}$ pint cold water. \\ Sugar, brandy, or fruit juice \\ to taste.
}

Place the sago and water into an enamelled saucepan, and boil gently for an hour and a quarter, adding a little water to make up for evaporation. Skim when it comes to the boil, and stir frequently. Sweeten to taste; this may be flavoured with brandy or sherry, or may have added to it a purée of prunes with a glass of claret, or stewed apples with a few cloves.

Farinaceous or Milk Puddings.-In the following recipes we have boiled farinaccous foods which are further cooked by baking; eggs can be added if desired. The presence of eggs in a pudding greatly improves the flavour and appearance, but they make it richer and more difficult to digest. The essential for a good milk pudding is to have the starchy food sufficiently boiled, and the eggs lightly cooked. It is best to beat up the white of the egr separately, as this introduces air into the pudding and causes it to rise. For flavouring, the most suitable substances are fresh lemon rind or juice, essence of vanilla, grated nutmeg, and ground cinnamon.

\section{Arrowroot or Cornflour Pudding.}

\pm ounce arrowroot or corntiour.

joint milk.
I egg.

I teaspoonful of sugar 
Make in the same way as arrowroot and milk (p. 297), and thoroughly boil the mixture for ten minutes. Kemove the pan from the fire, add the sugar and any favouring. Separate the yolk from the white, add the yolk to the arrowroot whenever it has sliglutly cooled, add a pinch of salt to the white, and beat it up to a stiff froth. Stir this lightly into the mixture, and pour into a greased pie-dish, wiping round the edges of the dish. Bake in a moderate oven until well risen, and of a nice light brown colour. Sprinkle some white sugar over it and serve at once, as it soon falls if allowed to stand.

\author{
Semolina or Ground Rice Pudding. \\ 3 ounce semolina or ground rice. \\ I teaspoonful of sugar. \\ $1 \mathrm{egg}$. \\ 1 pint milk.
}

Put the grain into a small lined saucepan, and the milk with it. Stir these over the fire with a wooden spoon until boiling, and boil for a few minutes until the semolina swells and thickens. Remove the pan from the fire, add susar and seasoning, and when it has cooled, mix the yolk of the egg well into it. Beat up the white on a plate to a stiff froth and mix into pudding, pour into a pie-dish and bake for ten minutes, sprinkle with sugar, and serve at once.

Rice Pudding.
$\begin{array}{ll}\text { I nunce whole rice. } & \text { I teaspoonful of sugar. } \\ \text { I pint milk. } & \text { I egg. }\end{array}$

Flavouring as required.

Wash the rice thoroughly in water; put it into a lined saucepan with cold water to cover it ; bring it to the boil, and pour the water off. This helps to burst the rice more quickly. Then pour in the milk, and let the rice simmer by the fire until quite soft; add the yoke of the egg and the white as described in the last recipe, and bake in a well-greased pie-dish.

\title{
Tapioca and Sago Pulding.
}

3 ounce tapioca or sago.

is pint cold milk.

\section{Flavouring.}

1 egg.

I teaspoonful of sugar.

If small cruslied tapioca or sago is used, the directions are the same as for semolina pudding. If not, the recipe is as follows:-

Cover the grain with milk, and soak for an hour. Rinse out a small lined saucepan, turn the tapioca and milk into it, and stir over the fire until it comes to the boil. Then simmer slowly until it turns clear, stirring every now and then. This takes from twenty to thirty minutes. If it becomes too thick while cooking, add a little more milk. Then finish off the pudding with eggs, etc., as in semolina. (For water sago or tapioca, see p. 297.)

\section{Bialed bread and Butter Pudding.}

I or 2 slices thin bread and butter.

I teaspoonful sugar.

$\frac{1}{2}$ pint milk.

Crated nutmeg. 
Cut some bread and butter rather thin, remove the crusts, and rue into pieces about an inch square. Lay these into a small greased piedish, making the dish just about half full ; beat up the egg in a small basin and add the nutmes, sugar, and milk. Mix well together and pour over the bread in the pie-dish. Allow the pudding to stand about ten minutes until the bread gets thoroughly saturated, then bake in a moderate oven from ten to fifteen minutes until nicely browned on the top. Sprinkle with sugar.

Eggs may be given raw or cooked. The method of giving raw eggs is described on p. 47. When given alone they may be given as prairic oyster, boiled egg, poached egg, scrambled egg, or baked egg. They can be added to soups as thickenings, e.g., thick beef-tca, consommé with egg, consommé with custard (p. 48).

The following recipes may be used for custards :-

\section{Custard Sauce.}

$\begin{array}{cc}2 \text { yolks of egg. } & \text { I dessertspoonful sugar } \\ \text { I white of egg. } & \frac{1}{2} \text { pint milk. } \\ \text { A few drops of flavouring. }\end{array}$

Rinse out a small lined saucepan with cold water, and put the milk into it, and let it heat over the fire. Put the yolks and white of egg into a basin with sugar, and mix them well together with a wooden spoon. Then pour the hot milk gradually on to them, stirring all the time and mixing thoroughly. Return all to the saucepan, and stir very carefully over the fire until the sauce thickens. On no account must it be allowed to boil, or it will curdle. Have ready at hand a clean basin and strainer. As soon as the sauce shows signs of thickening, and it is almost boiling, remove the pan from the fire, continue stirring for a few moments, and then strain into a basin. Add flavouring to taste-lemon, vanilla, nutmeg, or cinnamon. This can be made richer by increasing the proportion of yolks to white. It can be served as sauce, or in a custard glass, with flavouring grated on the top.

\section{Baked Custard.}

2 yolks and $\mathrm{I}$ white of egs.

I gill of milk.
I teaspoonful of sugar

Flavouring.

Beat up the eggs in a basin with the sugar and flavouring; pour in the milk and mix again; strain the custard into a greased pie-dish. Stand the pie-dish in a Yorkshire pudding-dish with some cold water round it. Bake in a moderate oven from fifteen to twenty minutes until firm and nicely browned. A thin slice of sponge cake may be placed on the top of the custard before baking. 
Omelets.-Ferss may also be advantageously used as omelets, ats follow:-

\section{How to make an Omelet.}

For an omelet of 2 eggrs, break them into a bowl, add salt and pepper, and beat them with a fork for about a minute, not longer as a rule. When the egrgs are sufficiently beaten they "run" off the fork in a homogeneous liquid, without any glutinous appearance. It is not necessary to beat for several minutes, with the idea that the more the egys are beaten the lighter the omelet. This is a great mistake, as too much beating causes eggs to lose their consistency. It is, however, better to beat too much than too little. Place the pan on the fire to warm it, put in a small piece of butter-about the size of a hazel-nut for an omelet of 2 or 3 eggrs. Add the contents of the bowl when the butter steams. If this precaution is taken, the omelet will not catch, as the high temperature of the butter isolates the eggs. It is therefore a mistake to shake the egrgs directly they are poured into the pan. But a second or two later, the fork must be passed round the sides of the pan to loosen the eggs, and then they are worked in all directions with the back of the fork as if they were scrambled. When they are sufficiently cooked they look in fact almost like scrambled eggs; but now the omelet is shaken on to one side of the pan, and with the fork one half is folled on the other and slid on to the dish. The shape of the omelet is thus obtained without difficulty, and the heat of one half just finishes the cooking of the other as it rests upon it.

\section{Swect Omelets.}

\section{A.-Omelet Souphé (Srucct).}

White sugar, I tablespoonful. Pinch of salt.
2 eggs.

A little powdered vanilla.

Take two bowls. Put into one of them I teaspoonful of white sugar; into the other a pinch of salt. Break 2 eggs, separate the yolks, and drop one yolk at a time into the bowl containing the sugar; whip them well with a wooden spoon and they becone creamy like a mayonnaise. Add a little powdered vanilla to another $\frac{1}{2}$ teaspoonful of sugar, and mix with the yolks. I'ut the whites of the eggs into the bowl containing the salt, and whip into a stiff froth. Mix with the yolks as lightly as possible, and pour the contents into a buttered dish in the shape of a pyramid. Cover it with sifted sugar and leave it for three or four minutes on the side of the stove. Then put it into the oven for ten to twelve minutes, turning the dish occasionally to colour it on all sides. Make two or three incisions with a knife, and serve immediately. This omelet must be eaten as soon as it is cooked, or it loses both its shape and its delicacy. 


\title{
B.-Snowball Eggs.
}

3 eggs.

I $\frac{1}{2}$ tablespoonfuls powdered white sugar.
I pint of milk.

Rind of lemon, or vanilla.

Sugar to taste.

Place 1 pint of milk in a saucepan on the fire with the rind of a lemon or a little vanilla, and sufficient white sugar to sweeten.

break 3 egrss, separating the white from the yolk. Put is teaspoonfuls of powdered white sugar on a plate. Beat the whites of the eggs into a stiff froth, adding a small pinch of salt. When sufficiently stiff add the sugar, and mix briskly. Take a teaspoonful of this mixture and throw it into the boiling milk in the saucepan; turn it three minutes later; remove it with a skimmer and place it on a dish. Take as many spoonfuls of the white of egg as remain and cook them in a similar manner, three or four at a time. (If the white has been beaten sufficiently stiffly, when cooked each spoonful will be a compact mass.) Dress the snowballs in a pyramid on a dish. Pour the remainder of the milk from the saucepan into the yolks of the eggs; put this mixture into another saucepan on the fire, turn it constantly with a spoon, and let it thicken without boiling. Pass it through a strainer, and when cold pour it over the snowballs in the dish.

\section{Savoury Omelets.}

\section{A.-Omelei with Tomatocs.}

Break the eggs into a bowl, with salt and pepper; beat them for a few minutes with a fork, place the omelet pan on the fire to warm, add a lump of butter. When the butter steams pour in the eggs. Make little incisions with a fork to let the heat reach the eggs in all parts; pass a knife round the edge of the pan to prevent the eggs from "sticking"; fold one half on the other as soon as they begin to get firm, and shake the omelet on to a hot dish. Pour over it a good tomato sauce.

\section{B.-Bread Ontelet.}

Put $\mathrm{I}$ tablespoonful of crumbled bread into a saucepan with $\frac{1}{2}$ gill of cream, salt, pepper, and nutmeg. When the bread is swollen with the cream, break 3 eggs, beat them, and make an omelet.

Jeliies.-Jellics are a pleasant change to the ordinary milky foods, and are much appreciated by invalids.

The directions for calfs-foot jelly and plain gelatine jelly are given on page 273. They may be taken with whipped cream, which increases thcir value as a food substance.

\author{
Cream Jelly or Blancmange. \\ I gill of inilk. \\ $\$$ ounce isinglass. \\ I gill of cream. \\ Rind of lemon.
}

I ounce sugar. 
Kinse out a small saucepan and put into it the milk, isinglass, and thinly-pecled rind of half a lemon. Let this stand by the sicte of the fire until the isinglass is dissolved and the milk well flavoured with the lemon. Stir acasionally to prevent hoiling. Add the sugar, and strain into a basin to keep back the lemon rind. Add the crean, and stir occasionally until ncatrly cold. If not stirred, the milk and cream will separate. lour into a small basin that has been rinsed out with cold water, and place in a cool position to set. Turn out and serve with a little red-or black-currant jelly.

$$
\text { Egg Jelly. }
$$

I ounce selatine.

$1 \mathrm{egrar}$.
3 ounces lump sugar.

it pint cold water.

$\$$ pint orange or lemon juice.

Soak the grelatime in water for twenty minutes. Rub the sugar on the oranges to extract colour and flarour. P'ut the sugar, gelatine, and water into a clean saucepan, and stir it over a slow heat until quite dissolved. Then add the juice (strained), let it just get hot, remove it from the fire, have the eag ready beaten in a basin, pour the jelly over it gradually, stirring well. Let it cool, stirring a few times to let it mix thoroughly with the egr. Pour into a small basin that has been rinsed in cold water to set. Turn out and serve with a little cream.

Soups.-The following recipes are those in which the ingredients are not too rich for the digestive capacity of convalescent patients. They form a delightful change after the monotony of the beef-teas and extracts. These recipes are also usefu! for the dietary of the aged (see p. 203).

\section{Froth-Mution, Chicken, or Veal.}

1 b. neck or knuckle of mutton or real, or I chicken.

2 pints cold water.
I dessertspoonful of rice.

I teaspoonful chopped parsley.

I teaspoonful salt.

Wipe the meat well with a damp cloth. Cut into small pieces and remove it from the bone, and take away as much fat as possible. Put meat, bones, water, and salt into a clean-lined pan, put on the lid, and hring it very slowly to the boil. Remove with an iron spoon all the scum that rises. Simmer slowly for four hours, skimming when necessary. When cold, remove all the fat. Return it to a saucepan well washed. Allow it to cook again for twenty minutes, until the rice is soft. Add the parsley at the last, and it is ready for serving.

Tapioca srodit or arrowroot may be used for thickening instead of rice.

\section{rice Soup.}

I pint of mutton, veal, or chicken soup.

I tablespoonful of Patna rice.

Yolk of egg.

I tablespoonful of cream.

Strain the broth and remove all the fat from it; put it into a clean saucepan with the rice well washed, and boil till the rice is perfectly soft. 
Then rub all through a fine sieve, rinse out the pan, and return the soup to it. Beat up the yolk and cream with a fork, strain them into the soup, and stir carefully over the fire until thoroughly hot, but it must not be allowed to boil. Tapiocat or sago may be used instead of rice to thicken with. Also three tomatoes might be boiled with the rice, and then rubbed through the sieve. This would make a tomato soup.

\section{Rabbit Soup.}

\begin{tabular}{ll} 
I rabbit. & $\frac{1}{2}$ ounce flour. \\
I $\frac{1}{2}$ pints cold water. & A few pieces of parsley. \\
$\frac{1}{2}$ pint milk. & I bay leaf. \\
$\frac{1}{2}$ ounce butter. & 6 peppercorns. \\
\multicolumn{1}{l}{$\frac{1}{2}$ teaspoonful of salt. }
\end{tabular}

Wash and clean the rabbit well. Let it lie in salt and water for halt an hour. Lift out, dry it, and cut into joints. Cut the flesh into small pieces, and chop the bones. Put all these into a saucepan with cold water, with bay leaf, parsley, salt, and peppercorns. Bring to boil and skim well. Simmer slowly from five to six hours; then strain through a fine sieve. Put the meat into a mortar; pound it well with a little liquid, and rub it through a wire sieve. Rinse out the pan; melt in it the butter; add the flour, and mix till smooth. Then add the sieved meat, soup, and milk, and stir until boiling. Boil for ten minutes.

\section{Game Soup.}

I bird (grouse, pigeon, woodcock, $\frac{1}{2}$ teaspoonful arrowroot. partridge), or the remains of game. A pinch of celery seed, pepper, $\frac{1}{4} \mathrm{lb}$. lean, juicy meat.

I pint cold water.

Wipe the game and meat with a cloth; shred the meat as for beeftea ; cut the game into neat pieces. l'ut all these into a lined saucepan, with cold water and seasoning; bring slowly to the boil, and skim thoroughly. Allow the soup to simmer for four hours. Strain and allow to cool, and then remove the fat. Mix the arrowroot with cold water; add this to the soup. Boil for two or three minutes, until the arrowroot turns quict clear.

\section{Fish Soup.}

Small haddock or whiting, or 3 gills or I pint cold water. piece of cod.

$\frac{1}{2}$ ounce butter.

$\frac{1}{2}$ ounce flour. I gill of milk.

I yolk of egg and $\frac{1}{2}$ gill cream.

I teaspoonful finely chopped parsley.

Wash and scrape the fish very clean; see that there is no black skin lining the inside parts. Remove the eyes. Cut the fish across into several pieces, and put them in a lined saucepan. Cover the fish with cold water, and add the salt. Bring to the boil and skim. After the fish has boiled for a few minutes, lift out a few nice little pieces of fish free from skin and bone, and reserve them for serving in the soup at the 
end. Allow the rest to simmer from three-quarters to one hour. Then strain through a wire sieve, and rul some of the white pieces through. kinse out the pan the soup was cooked in. Melt in it the butter; add the hour, and mix these two smoothly together, being careful they do not brown. Then pour on the soup that has been sieved, and stir until boiling. lieat the yolk of egg and cream and milk together; and, when the soup is off the boil, beat these ingredients into it; then strain through a fine strainer, stirring all the time. Do not let the soup boil after the eggr is added, or it will curdle. The pieces of fish that were reserved and the chopjed parsley are now added.

\section{Oyster Soup.}

I dozen oysters.

I gill cream.

1 pint fish stock or white stock.

I ounce butter.

I ounce flour.

Pinch of cayenne.

I egg.

A few drops of anchovy essence.

A squeeze of lemon juice.

White pepper and salt.

Place the oysters in a small saucepan with their own liquor, bring them almost to the boil, then strain. Beard the oysters (that is, remove the piece like a fringe that encircles them), cut them in two, and put them aside for stewing in the soup. Put the beards into a saucepan with the liquor and the stock, and let them simmer for half an hour, to extract all the flavour from them. If the stock is not previously well favoured, small pieces of the different flavouring vegetables (p. 74) should also be cooked in it. Strain through a fine hair sieve or piece of muslin, and rinse out the saucepan ready for usc. First melt in it the butter, being careful it does not brown, add to it the flour, and mix together until quite smooth. Pour on the stock, and stir constantly over the fire until boiling. Skim if necessary. Season to taste with a little white pepper, salt, anchovy essence, and pinch of cayenne. Beat up the yolk of eggs in a basin with the cream, strain into the soup. When off the boil, stir all the time. Place oysters in the soup tureen, pour the soup over them, and serve.

\section{Veal Soupt.}

I lib. veal.

I small hunckle of veal.

6 breakfastcupfuls water.
I tablespoonful tapioca groût.

I gill cream.

Yolks of 2 eggrs.

\section{2 square inches of turnip.}

Cut the veal up in small pieces, and break the knuckle up well. Put all on with the cold water. Hring to the boil, and skim carefully; add the turnip cut into small pieces, and boil steadily for at least five hours. Strain the soup, then add the tapioca previously soaked in cold water, and again boil for fifteen minutes, stirring frequently. Place the yolks and cream in a basin, and stir well. Gradually add the hot soup to the yolk and crean mixture, stirring constantly to prevent curdling, and scason to taste. 
Fish.-Raw oysters, whiting, haddock, and sole are the most easily digested members of the fish group, and as such should come first in the dietary (see also Chapter V. and p. 207).

\title{
Oysters au Naturel.
}

\author{
Oysters. \\ Pepper and salt. \\ Cayenne. \\ Lemon juice.
}

Open the oysters carefully and serve them in their shells. Scason with pepper, salt, and a pinch of cayenne. Garnish with parsley or cut lemon. Serve directly they are opened, or the flavour will be spoilt. They are best eaten with a little brown bread and butter. Oysters may be peptonised and then given, and are an excellent and easily digested food (p. 175).

This is richer and not so digestible as above, but is quite suitable for many convalescent patients :-

\section{Oysters Scalloped.}

$\begin{array}{ll}\frac{1}{2} \text { dozen oysters. } & \text { Breadcrumbs. } \\ \frac{1}{2} \text { ounce butter. } & \text { Pepper and salt. }\end{array}$

Lemon juice.

Put the oysters and their liquor into a small saucepan, and bring them to the boil. Remove the beards from the oysters, and strain the liquor. Grease china or well-washed oyster shells. Sprinkle into each dish a few breadcrumbs, then put in three oysters into each shell. Season to taste with pepper and salt. Pour over a little oyster liquor. Cover with more breadcrumbs. Pour some melted butter over the top. Brown in the oven or in front of the fire, and serve very hot.

The white fish can be steamed and served without any sauce, or stewed in a little milk and served with a white sauce, as follows :-

\section{White Sauce (French).}

$\begin{array}{ll}\frac{1}{2} \text { ounce butter. } & \frac{1}{2} \text { gill cream. } \\ \frac{1}{2} \text { ounce flour. } & \text { Pepper and salt. }\end{array}$

Small $\frac{1}{2}$ pint fish stock or seasoned milk.

Method.-Melt the butter in a lined saucepan, add the flour, and mix smoothly with a wooden spoon. Cook for four minutes over the fire, but do not brown. Draw the pan to the side of the fire, and add the stock or milk gradually, then return to the fire, and stir constantly until boiling. Add the cream and seasoning, and boil for a minute or two longer. Remove the pan from the fire before adding the lemon juice, and strain before using. More or less milk may be added according to the thickness of the sauce required. If considered too rich, the cream may be omitted.

Siasoned Milk.-Put as much milk as is required into a lined sauce- 
pan, with a small piece of carrot, turnip, onion, and a few parsley stalks. let the pan stand by the side of the fire until the milk is well seasoned, then strain and cool before using.

Sleamed Fish. - This is the lightest and simplest mode of cooking fish for an invalid.

I filleted haddock, whiting, or sole.

A small piece of butter.

A pinch of salt and white pepper.

$\Lambda$ squecze of lemon juice.

Cut the fillets of fish into neat-sized pieces; grease a soup-plate or muffin-dish with a little butter, and place the fish on this. Sprinkle with a little salt and white pepper if it is allowed, and squeeze over some Icmon juice, which helps to keep the fish firm and white. Cover the fish with a piece of greased white paper, and then with a lid or basin. Place this over a pan half-full of boiling water, secing that the plate fits well on the pan. Keep the water in the pan boiling, so that there may be plenty of steam, and cook from twenty to thirty minutes, until the fish loses its clear, transparent appearance and looks quite whitc. If the pieces are thich, it is better to turn them while cooking. The liquid that is on the plate when the fish is cooked is the juice from the fish, and should be scried with it. Serve the fish with a little plain cold butter and a piece of plain bread or toast.

\section{Stewed Fish.}

I filleted fish, whiting, haddock, sole, plaice.

I tablespoonful breadcrumbs.

I teaspoonful chopped parsicy.

I gill cold water.

I gill milk.

I ounce butter.

White pepper.

Wipe the fish with a damp cloth and cut it into small, neat pieces. Rinse out a lined saucepan with water, and place the pieces of fish at the foot. Sprinkle over them a little salt and white pepper, pour in the milk and water; put the lid on the pan, and let the fish cook slowly by the side of the fire until it is ready, which will be in about fifteen minutes. 1) not overcook, or the fish will be hard. Lift out the pieces of fish on to the plate on which they are to be served, and keep them hot. Add the breadcrumbs and the butter to the water and milk in the pan. Stir over the fire for a few minutes until the breadcrumbs swell and thicken the sauce. Sprinkle in the parsley, and then pour this sauce over the fish.

\section{Lalied Fish.}

\& Ib. uncooked fish.

2 tablespoonfuls breadcrumbs.

Pepper, salt, and a little lemon juice.
I egg.

$\frac{1}{2}$ gill milk.

$\frac{1}{2}$ ounce butter.

Grease a small pie-dish with a little of the butter. Have the fish free from the skin and bone, and cut it into neat pieces. Lay half of these pieces at the foot of the pie-dish, sprinkle over them a little white pepper, salt, and a squeeze of lemon juice, and then put on a layer of breadcrumbs. Next, put in the rest of the fish, seasoning, and more crumbs. Leat up the egg in a small basin, add the milk to it, and strain this into 
the pie-dish. Put the rest of the butter in small pieces on the top and wipe round the edges of the pie-dish, and bake in the oven until nicely browned.

Fried Fish.-Nothing is nicer for an invalid than a really well-fried fillet of sole or small whiting, with a slice of lemon to squecze over it.

I sole.

\section{Soles to Fry.}

A little flour.

\section{Pepper and salt.}

Eggr and breadcrumbs.

Frying fat.

Skin and fillet the fish, and wipe the fillets with a clamp cloth. Trim neatly and cut across in slanting direction into two or three pieces. Dip each piece in flour mixed with pepper and salt, then egg and breadcrumbs, and fry in boiling fat until well browned. Drain on kitchen paper and serve very hot. Garnish with lemon (see method of wet frying, p. 6o).

Small whitings and haddocks, small flounders and plaice, can be cooked whole in this way. Large flounders, plaice, and haddocks are better filleted whole.

\section{Quenelle of Fish.}

I lb. haddock.

I slice bread. $\frac{1}{2}$ ounce butter.
I teacupful milk.

I teaspoonful parsley.

I egg and I yolk.

\section{Pepper and salt.}

Remove the skin and bones from the haddock, and scrape it down, putting aside any part that is not white. Soak the breadcrumbs in milk, and when quite soaked, strain and place in a small saucepan with the butter, parsley, and the yolk of one egg, and stir over the fire till it becomes a thick paste. Put it in a mortar with the fish, and powder it into a smooth paste; mix in thoroughly a beaten up egg, also pepper and salt. Place in a buttered shape and steam for an hour and a half.

Meats.-Of this class of food, poultry (e.g. chicken and turkey), game (e.g. pheasant and partridge), tripe, sweetbreads, and rabbit are the most easily digested. They can be served in the ustual manner of roasting, boiling, or stewing. Tripe and sweetbreads form most excellent dishes, and only reqtire to be more thoroughly known to be appreciated. Beef and mtitton may be served as "minced beef," "meat-juice mince," or beef quenelles, and are very digestible; multon chops, roast leg of mutton, grilled rumpsteak, repuire more digestive power.

A few extra recipes for the preparation of chicken, game, 
rabbits, and swectbreals are given, and also the method of preparing and serving tripe.

\title{
Eroiled Chicken.
}

I small chicken.

I ounce butter.

Pepper and salt.

Irepare a young chicken for roasting, split it down the back, lay it open, ancl take only half at a time. Rub the piece of chicken over with a little butter to keep the skin from cracking, and season with pepper and salt. Grease the gridiron and make it thoroughly hot. Lay the chicken on it with the cut side down to begin with; broil either on the sop of or before a clear fire for about half an hour. When ccoked, lift on to a very hot plate, and rub the rest of the butter over it. Serve with rolls of bacon round it. If broiling an older fowl, it must be partially cooked first, either by boiling or roasting. It may be eaten with or without bread sauce, made as follows :-

\author{
Bread Sauce. \\ 2 ounces breadcrumbs. $\frac{1}{2}$ pint water. \\ $\frac{1}{2}$ ounce butter. I tablespoonful cream or milk. \\ Salt and pepper.
}

Pour hot water over the breadcrumbs, cover with a plate, and when quite cool, mash it and put in a pan with the butter, cream, salt and pepper. Mix all well together and simmer till hot.

\begin{tabular}{l}
\multicolumn{2}{c}{ Chicken Souflé. } \\
$\begin{array}{ll}\text { Breast of chicken. } & \text { 1 } \\
\text { I gill cream. } & \text { I egg. }\end{array}$
\end{tabular}

I'epper and salt to taste.

Skin the breast of the chicken, chop it finely, pound well in mortar; melt the butter, and stir it into the flour with a tablespoonful of cream. Let it come to the boil, and pour over the pounded chicken, add seasonIngr, pound together, and rub through a wire sieve. Switch the remaining cream until stiff, mix gently with other ingredients; butter some cups, half-fill with the mixture, cover the cups with kitchen paper, and set in stewpan half full of boiling water. Steam for fifteen minutes. Serve with white sauce. The boiling water should only come half-way up the cups while stcaming.

\section{Chicken or Veal Panada.}

i tb. breast of chicken, or $\frac{1}{4} \mathrm{lb}$. fillet of veal. I tablespoonful cold water. I tablespoonful cream. A pinch of salt.

Wipe the meat and cut it into small pieces; free it from fat and skin. Hace it in a cup with a pincl of salt and cold water. Tie over it a sreased whise pitper, and stcam slowly from one to one and a half hours. Then lift it out, place the contents of the cup in a mortar, pound 
well, and rub throngh a sieve. Put the sieved mixture into a pan, add the cream, and heat thoroughly. This may be served on a piece of toast, or taken coll.

\section{Rugnit of Iniel or Rivbit.}

Take the wings and breast of a fowl or the back and legs of a rabbit, soak in hot water for five minutes, then put into a jug with salt and mace, or peppercorns. Cover with milk, seal the jar closely, set in an oven, and bake for three hours. Take out the meat. I'our the milk into a basin to cool, so that the fat may be easily removed. Before serving, warm in a cup set in hot water, or warm a little of the meat in the milk, and serve with thin toast or water biscuits.

\section{Stewed Partrilge.}

$\begin{array}{ll}\text { I partridge. } & \text { I blade of mace. } \\ \frac{1}{2} \text { ounce butter. } & \text { Lemon. } \\ \text { I teaspoonful of flour. } & \text { Pepper and salt. }\end{array}$

Cut the partridge into joints and take out the largest bones. Put the butter into a small stewpan; when it gets hot put in the best parts of the partridge and fry it very carefully, then add to this a small bit of lemon peel, a small bit of mace, and pepper and salt; add the flour and I teacupful of water, and the bones that were removed. When this all boils up, put on the lid, and let it all stew slowly for three-quarters of an hour, or till tender. Take up the best bits on a dish and strain the gravy over them. All game is easily digested when cooked in this way.

Tripe.-Methods of preparing:-The best varieties of tripe are those known as the "blanket" (because it has a folded appearance), and the dark variety known as the "monk's hood"; these are best for invalids on account of their tenderness. The other sorts are known as the "book" and the "honeycomb."

If tripe is properly prepared, it is a most delicately flavoured and casily digested article of food, and should be in more constant use than it is at present. It requires, however, very careful cleaning and boiling. In Scotland prepared tripe camnot be purchased at the butcher's, so it is necessary to understand the whole process. Tripe sold in England has generally had a preliminary boiling.

First wash and scrub in several waters and scrape it with a knife, pulling away any pieces of fat from it. Cut it into picces and put it into a clean saucepan with cold witer to cover it, and bring it to the boil. This is called blanching, and is repeated until the water in which the tripe was boiled loses all its heavy smell. This may require to be 
done four or five times. Then rinse the saucepan well, put in the tripe with cold water to cover it, bring to the boil, and couls sluwly for ten 20 twelve hours. If cooked too quickly the tripe will harden. When sufficiently cooked, it ousht to be so tender that it will pull casily to pieces. Pour it out into a basin and cover it with the liquor in which it was cooked. This prevents it becoming hard and dry. It can then be made up in any way desired.

The water in which the tripe is boiled should never be thrown away, as it contains a certain amount of nourishment. It is sometimes served as an invalid jelly.

The prepared tripe can be stewed in various sauces for fifteen minutes, and served in one of the following ways:-

I. Tripe stewed in white sauce and onions, and served with sippets of toast.

2. Tripe stewed in a thick tomato sauce, and served with little rolls of bacon and croquettes of fried bread.

3. Tripe heated in a good curry sauce, and served with a border of rice.

4. Baked Tripe-_Grease a small pie-dish, and put the tripe, with thin square pieces of bread and butter, into this, in alternate layers. The last layer should be bread, with the buttered side up. Beat up an egg in a basin until it is frothy, add it to half a gill of tripe liquor, and season with pepper and salt. Strain this into the pie-dish, and then wipe round the edge of the dish with a cloth. Let the mixture stand for ten minutes, until the mixture gets thoroughly soaked. Bake in a moderate oven for about fifteen minutes until nicely browned. Serve hot.

Sweetbreads. - There are two varieties of sweetbreadthe "throat" sweetbread (thymus gland) and the "stomach" sweetbread (pancreas). The latter is much more digestible. Lamb's swectbreads are very tender. This article of food must be nicely prepared, or it is very unappetising. The difficulty is to clcar off all the connective tissue and fat from between the lobules.

Soak the sweetbread in cold water for one or two hours. Then put it into a saucepan with cold water to cover it. Bring to the buil, and boil for five minutes. Then lift it out and place in a basin of cold water to cool it. This preserves the colour of the sweetbread. Then, with great care, remove from it all the fat and skin, pulling them off with the fingers. It is now ready for cooking. 


\section{Braised Sweetbreads.}

Prepare the sweethreads as above. Braise them for one and a half hours-that is, place the sweetbreads unbroken into a saucepan containing a little onion, carrot, turnip, celery, savoury herbs, and seasoning; add a little meat stock, just enough to cover the meat; cover with paper and a well-fitting licl. At the end of the time take them out, brown in the oven, and serve on a piece of fried toast or a bed of mashed potatoes. Pour a good sauce round them, such as Italienne, made as follows :-

\section{Sauce Italienne.}

1 ounce flour.

I ounce butter.

I bay leaf.

Onion and sprig parsley.

1 gill sherry.

$\frac{1}{2}$ pint second stock.

Melt the butter; fry the herbs and onions and flour to a good brown colour. Add the sherry, and allow it to cook a few minutes; add the stock when boiling, and allow to simmer for an hour. Strain the sauce before pouring round the sweetbreads.

\section{Stewed Swectbreads.}

\section{I stomach sweetbread. I teaspoonful arrowrooi. I gill white stock. I tablespoonful cream.}

White pepper and salt.

Break the prepared sweetbread into small pieces of equal size; put them into a small lined stewpan with the stock; put on the lid, and allow it to simmer slowly until tender.

When cooked, lift the pieces of sweetbread out, place them on a neat square of toast on a hot dish, and keep them warm. Break the arrowroot into a small basin with a little cold water, and add it to the stock in the pan. Stir over the fire until boiling, and boil for five minutes, so as to cook the arrowroot. Add cream, and season to taste. Pour the sauce over the sweetbread, and serve very hot.

See also recipe in diabetic feeding (p. 487) for sweetbreads and tomatoes.

Red Meat.-A slice of plain roasted mutton or becf, or a lightly grilled chop or steak, are easily digested. The following recipes will be found useful :-

\section{Minced Beef.}

$\frac{1}{2} \mathrm{lb}$. best rump-steak.

$\frac{1}{2}$ pint cold water.
Pepper and salt.

Sippets of toast.

Either get the butcher to mince the steak, or, after removing all the fat and connective tissue, put it through the mincing machine.

Never buy so-called mince collops from the shop for an invalid; there is always too much fat in it.

Take a small lined stewpan; put the minced beef into it, with half the water and the seasoning. Put the pan on the stove, and pound the 
meat well until it loses its raw appearance. Then add the rest of the water: simmer genly hy the fire for twenty minutes. Do not allow the meat to cook too ylickly, or it hecomes hard. kemove any grease that may rise on if, and serve very hot. Carnish the dish with some neat sippets of toasted bread.

\section{Meat-Juice lince.}

16. best rump-steak.

I small piece of butter.

Pepper and salt.

Take the meat and rub through the hair sieve until all the red juicy part has gone through; scrape the bottom of the sieve. Melt a very litile piece of the butter in a small frying-pan; toss the meat juice in it for three or four minutes, until it loses its red colour. Flavour, and serve with toast. This looks just like mince, but as none of the fibre is present, it is very digrestible. This meat-juice mince can be made more easily digestible by omitting the butter, and adopting the following method:Take the scraped meat, and add a teaspoonful of beef-tea or simple stock, and stir in an iron pan for three or four minutes, when the juice granulates and becomes brown in colour. If an enamel pan is used, the meat has a very unappetising appearance.

$\begin{array}{lc} & \text { Beef Quenelles. } \\ \text { I lb. beefsteak. } & \text { Salt and pepper to taste. } \\ \text { Breadcrumbs. } & \text { I egg. }\end{array}$

2 tablespoonfuls stock.

Pound the beefsteak, half a teacupful of breadcrumbs, salt and pepper, egr and stock well in a mortar, rub through sieve, shape with tablespoons, and poach in shallow pan for ten minutes in boiling water. Serve with sippets of toast, and pour a gravy made of thickened beef-tea round the quenelles.

Vegetables.-The following are the most suitable vegetables for convalescent patients:-Spinach, boiled lettuce, baked tomatoes, steamed asparagus, stewed celery, seakale, young leeks, cauliflower, onions, and vegetable marrow. The most suitable methods of cooking these vegetables have been described on p. 122. All these vegetables can be served with a little well-made white sauce served round them. This sauce must be properly made, as described on o. 123 .

\section{Rice and Macaroni.}

These carbohydrates are the basis of many nourishing and easily digested Italian dishes. In cooking, the directions for boiling rice and macaroni should be closely followed.

\section{I'lain Boiled Rice.}

Wash well some l'atna rice in several waters until the last water looks quite clean. If there is a pot for steaming the rice in, it is best to use this, 
but if not, boil the rice in a saucepan of boiling water containing salt, which is in the proportion of I teaspoonful to the quart. Boil quickly with the lid off, stirring it frequently with a fork to prevent it sticking to the pan. Cook from ten to fifteen minutes until the grain will rub down easily when one is tested between the finger and thumb. Strain through sieve or strainer, and finish the cooking by drying it, either by putting it into the saucepan by the side of the fire, or putting it on to a plate in a moderate oven. While drying, stir lightly with a fork every now and then to keep the grains separate.

N.B. - The water in which the rice has been boiled contains the best part of the rice, so it should not be thrown away, but kept for the stock pot.

\section{Italian Rice (Cheese and Rice).}

Plain boil the rice as directed above. After straining the rice, pour it back into a pan. Put a sufficient quantity of butter into a frying-pan; when the butter is melted add the rice, and mix well together for two or three minutes. Place the rice in a dish, and cover with grated Parmesan cheese.

Milan Rice (Rice with Meat Extract).

Place a bit of butter in a saucepan; when melted, throw in the rice ( 2 oz. is sufficient for one person). Mix rapidly with a wooden spoon to prevent burning. When the rice begins to colour, moisten with good stock, by degrees, until the rice is thoroughly cooked. Then add a small teaspoonful of any meat extract. Mix with it salt, pepper, and grated Parmesan cheese, about I oz. A little of the cheese is mixed with the rice and the remainder served separately.

\section{Boiled Macuroni.}

Break the macaroni into short lengths, and throw it into a saucepan of freshly boiling water with salt in it.

Boil quickly with the lid off the pan until it has thoroughly swclled and is tender. Stir occasionally, to prevent it sticking. The time depends on the variety of the macaroni-the large pipe will take about half an hour, the small much longer. Keep it well covered with water. When ready, drain, and this may either be served plain with meat, or it may be put back into the saucepan with enough stock to cover it and allow to stew for half an hour.

The pulp of a fresh tomato rubbed through a sieve may also be added to this. 


\section{CHAPTER XVIII}

\section{DISEASES OF TIIE STOMACII}

\begin{tabular}{|c|c|c|c|c|c|c|}
\hline & & & PAOK & & & PAQE \\
\hline Indigestion . & . & - & . 314 & Gastrorhexis . & - & $\cdot 337$ \\
\hline Indigestion in children & . & • & - 320 & Dilated stomach & $\cdot$ & $\cdot 339$ \\
\hline Gastric catarrh & - & . & . 322 & Cancer of the stomach & . & . 343 \\
\hline Hyperchlorhydria. & - & • & - 326 & Gastroptosis & - & - 344 \\
\hline Gastric ulcer . & - & - & - 330 & & & \\
\hline
\end{tabular}

Diagnosis of the cause . . . - 3r5 Practical points in dietetic manage-

Diagnosis of functional cases . 316 ment . . . . . 318

UNDER the vague term indigestion there is comprised a number of disorders which have one feature in common, e.g., the inability to digest ordinary food in the painless, unconscious manner characteristic of health. This indigestion may show itself in a number of different ways. Pain or discomfort after meals is one of the most prominent symptoms; this may be severe or slight in character; it may occur immediately after the ingestion of food, or some hours later. Heartburn and watcrbrash are other manifestations which are often very distressing. Flatulence is another prominent symptom; this may take the form of belching up of wind, or of passage of flatus by the bowel, or of a tightness and oppression in the abdomen. Loss of appetite, nausea, general physical and mental depression, and derangement of the bowels, especially constipation, are other subjective symptoms commonly met with. It must be recognised that indigestion is merely a symptom. It may be a symptom of -

I. Chronic constitutional disease in which the digestion is involved secondarily, e.g. tuberculosis; or it may result from 
2. I.ocal disease in the stomach, intestines, or other viscus, of an organic nature; or

3. Iocal discase in the stomach or intestines of a functional character. By that we mean that no structural change is present, so far as can be determined by our present methods of investigation. It is probable that this group depends on alterations in the gastric and intestinal secretions of a nature not yet fully understood.

A few words may be said on the diagnosis of the cause of indigestion.

Diagnosis of the cause of indigestion. - An accurate diagnosis of the cause of indigestion must precede any attempts at its remedial treatment by means of diet. Keeping in view the points already laid down, we must first determine whether the indigestion is an expression of a chronic constitutional derangement. The most important constitutional conditions which give rise to indigestion are tuberculosis, chronic renal disease, and heart disease. In every case, therefore, we must exclude them as the cause; if found to be secondary to one of these conditions, the treatment has to be directed to the primary condition (q.\%). Tuberculosis is frequently the cause of indigestion in young people; and with regard to this it should be borne in mind that the indigestion may be an early symptom of the tuberculosis, and may precede by many months the development of active tuberculous disease in the lungs or elsewhere. Chronic renal disease is often responsible for symptoms of indigestion in adult and elderly subjects; it is not infrequent in practice to find that the existence of chronic renal disease is ascertained for the first time by the routine cxamination of the urine in cases in which the symptoms have been entirely those of "indigestion." In the case of organic heart discase, severe anxmia, rheumatoid arthritis, and some other disorders, we are less likely to overlook the true nature of the indigestion than in cases of tuberculosis and renal disease already referred to.

The second point is to determine whether the indigestion is the result of an organic lesion of the stomach or bowel, or 
other organ. If we exclude acute gastritis, which is not a canse of indigestion in the ordinary sense, the conditions to which attention must be directed are the following:-

1. Lesions in the stomach or duodenum, especially gastric or duodenal ulcer, hyperchlorhydria, dilatation of the stomach, and chronic gastric calarrh; the last mentioned, it should be noted, may be associated with malignant disease.

2. Appendicitis. Pain in the epigastrium and other symptoms of indigestion may be present, and may be the chicf indications of appendicular mischief.

3. Catarrh of the gall-bladder or bile-ducts, often associated with some pancreatic discase.

4. Floating kidncy, and various uterine and ovarian disorders may be the cause of the "indigestion."

It is very important to keep these points in mind. If we do so, we will avoid a mistake by no means infrequently madc, of treating certain cases-as examples of "functional indigestion "-for weeks or months, with little or no success, which are later cured by other clinicians who have detected the undcrlying cause in the appendix, kidney, or uterus, etc.

Diagnosis of functional indigestion.-Having now determined that the indigestion is not secondary to some chronic constitutional disease, and further, that it is not dependent, so far as can be ascertained, on organic disease of the stomach or other organ, we now conclude that it is of "functional" origin. By that we mean that it depends, not on any demonstrable standard change, but on some alteration in the secretions of the gastric or intestinal juice, or in the muscle of the stomach wall, of a nature not yet fully understood. Thus the gastric secretion may be increased in amount or reduced below the normal. When it is increased we have the condition of hyperchlorhydria, which is probably the only type of "functional indigestion" which admits of accurate differentiation. The symptoms of this hyperchlorhydria are quite distinctive, and are the subject of spccial consideration on p. 326. This hypcrchlorhydria is often associated with motor insufficiency of the stomach wall, revealed by a state of dilatation of the stomach, hence the 
inclusion of this in the organic group above described. There remains a very large group of cases which hardly admit, in our present knowledge, of more accurate classification than that of functional dyspepsia or indigestion. The causation of these will soon be shortly considered, the existing cause in the majority of cases being dietetic crrors.

Imperfect mastication, defective state of the tecth, hurried irregular meals of an ill-balanced nature, and constipation are probably the most important causal factors. By their action, singly or in combination, the digestive functions are seriously impaired, with the resulting clinical features characteristic of indigestion. Among the dietetic errors which are frequently responsible, mention may be made of excessive tea-drinking, immoderate use of starchy foods, over-indulgence in sweets, and occasionally excess of meat foods. Excess of tea, excess of sweets, and too great use of starchy foods is more frequently the cause of the indigestion seen in young women; in men, excess of tea, or of meat, or of starchy foods is also responsible, and their unfavourable action is in them often intensified by over-indulgence in tobacco or alcohol. Reference should be made to the value of the carcful examination of the urine as an aid in diagnosis in certain cases of indigestion. In cases in which the urine gives a marked pancreatic reaction, the indication is to restrict to a marked degree the farinaceous and saccharine foods.

It must be clearly recognised that there are cases of functional indigestion which are not dependent on any dietetic error, but are the result of a temporary lowering of the general nervous tone of the individual. Such cases are cured by measures directed to the improvement of general health, without special reference to dietetic conditions; such measures as rest, change of air, and general tonic treatment atone sufficing to get rid of the indigestion. In the treatment of the general run of cases it is essential to point out that complete rest in bed for a week or two or longer, and attention to the bowels, are points of cardinal importance in the treatment. Clinical experience shows that not a few cases which have been diagnosed, after full consideration, as cases of functional indigestion, are really cases of organic disease. In some respects this is not a matter of great 
moment, as in cases of doubt the dictetic treatment of the two conditions is essentially the same.

Principles in the dictetic treatment. - In the slighter cases all that is required is to correct the defects in the dietary, which may be ascertained from a careful inquiry into the dictetic history of the patient. Tea must be reduced or climinated from the dictary, sweets should be cut off, bread and starchy foods must be reduced, and all indigestible articles of food should be avoided. In cases where meat foods have been taken three or four times daily, these must be reduced, and a lacto-vegetarian regimen substituted. If these points are attended to, and three simple meals a day prescribed, recovery soon takes place.

In the more scvere cases the above will not suffice." Then complete rest in bed for some weeks is essential, and the dict from the outset has to be adapted to the digestive capacity of the patient. It may be neccssary to begin with a dict of I, 2 , or 3 pints of milk in the twenty-four hours, which may require to be given diluted or peptonised. As the state of digestion improves, beef-tea, bread, milk puddings are cautiously added to the dictary. In some cases it is useful to add some extract of malt. If the symptoms persist in spite of treatment carried out carefully along these lines, it may point to the conclusion that the case is one of organic disease-ulcer of stomach or duodenum-which will only be cured by operative treatment.

Reference has already been made to the value of cxtract of malt in ccrtain cases. This is more particularly applicable to ccrtain cases of a gouty nature, in which the symptoms are in all probability the result of defective pancreatic activity. Malt may be given in the form of Maltine, Extract of malt, and IHomax. The last-mentioned preparation has very special value in this class of case.

The only other point to which it is necessary to draw attention is to cases in which flatulence is the predominant feature. In these cases, in addition to attention to diet along the lines already indicated, it is essential to specially restrict the vegetables and pulse fords.

Practical Rules in the Treatment of Dyspepsia.-(a) small meals, slowly and deliberately caten, is the first 
cssential. The meals should be small, and very moderate in quantity. A dict should be selected that gives the necessary nourishment with the least labour to the stomach. It is important to remember that the digestive function begins in the mouth. Thorough mastication is, therefore, of paramount importance. Particular attention should also be directed to the state of the teeth.

(b) A sufficient amount of time should be allowed betwecn meals to permit of complete digestion of one meal before the next is taken. When on a fluid diet, and only very small quantities being taken at a time, the meals must be taken more frequently, two and a half to three-hourly; but when solid food is taken, four to five hours should at least clapse before the next meal. This is especially important in dyspepsia in elderly subjects.

(c) Avoid sitting down to food immediately after hard physical or mental work, and do not return to work irnmediately after a meal, rest for half an hour.

(d) A few notes on the most suitable type of food may be added :-

It is exceedingly important that the food of the dyspeptic should be carefully and skilfully cooked. Of the meats, the shorter-fibred and more easily digested meats and fish should be sclected. Chicken, turkey, pheasant, partridge, swectbread, tripe, mutton, are better than beef, goose, duck, wild fowl, veal, or pork. Laınb and rabbit are not so digestible as is often assumed. Of the fish, the white varieties, as sole, whiting, plaice, flounder, are the best, and fish is best grilled, or plainly boiled or steamed. For cooking, if the meat is tender, grilling is the best method; underdone roast is also good.

As to sauces, it is best for dyspeptics to avoid rich sauces entirely; and when butter is required, as with fish, to use plain fresh butter.

Fat in some forms is difficult to digest. Grilled fat bacon eaten with dry toast is easily digested, tasty, and a good form of fatty food. When taken with bread and yolk of cgg it makes a nutritive and compact meal. 13readstuffs saturated with butter, such as buttered toast, hot scones, muffins, pastry, are not easily digested, the saturation with fat preventing the 
gastric juice getting at it, with the result that these foods undergo abnormal fermentative changes.

Some varieties of bread are indigestible, but often when complained about it will be found that the patient is taking too much. A digestible brcad is one that is not new, which breaks short, is open and crumbs easily (pan loaf); scones and wholemeal bread are often very troublesome for people with fecble digestive power (see Bread, p. 93).

Swect dishes are apt to undergo acid fermentation, and unripe acid fruits, nuts, and the hard coverings of vegetables containing much cellulose are difficult of digestion and must be avoided. Vegetables should be smoothly mashed, or reduced to the form of purées, especially all green vegetables.

Tea or coffee do not always cause indigestion, but are apt to do so in some persons. If they do cause indigestion they should never be taken with or soon after food, but a cup of freshly made tea or coffee three or four hours after a meal will not unfrequently be found to promote the final stage of stomach digestion. No food, however, should be eaten at the same time. Light China teas are much less likely to cause dyspepsia than the stronger Indian kinds. There are other varieties of so-called digestive teas on the market, which are reputed to contain little tannin, e.g. Typho-Tips.

Chronic Intestinal Indigestion in Children.-The clinical picture of a child suffering from chronic indigestion is a varied one. The child may be well nourished, but more commonly it shows wasting, often in marked degree. Listlessness and a seneral physical and mental apathy are prominent features, and these are associated with loss of appetite, distaste for ordinary food, and often a distinct degree of anæmia. A derangement of the bowels is usually present, the bowels being constipated or loose, the motions being offensive and containing undigested foodstuffs. In rare cases the anæmia may become very pronounced, the condition becoming one of severe anxmia, the treatment of which is discussed in the section on Diseases of the Blood.

The condition arises from over-fecding or injudicious fceding of long duration. Too much tea, excess of sweets, and the too liberal indulgence in carbohyclrate foods, especially bread and starchy puddings, are commonly noted causes; 
in the chiddren of gouty parents the main defect is usually a general excess of all the foodstuffs, more especially farinaceous or meat foods (see also Foorl Fever, p. 350). Some cases are associated with hyperchlorlyydria, and in these cases treatment must be conducted along the lines laid down for that condition. Whatever the cause may be the indications for treatment can be clearly defined.

Treatment.- The whole digestive tract must get a rest, by the administration of only small quantities of the most easily digested foodstuffs given in fluicl form. The benefits of this treatment are often more quickly obtained by keeping the patient in bed for a few days, and clearing out the bowel thoroughly as a preliminary measure.

The diet at the outset should consist of peptonised whey, weak beef-tca, or weak mutton, veal, and chicken soup, given in 3 to 4 ounce feeds, with net more than a finger of crisp toast. In some cases breadstuffs are better withheld till later. In twenty-four or thirty-six hours, skimmed milk, plain or peptonised, may be added to the dict, which may also include chicken jelly, meat juice, and the like. Ordinary milk, plain or peptonised, may soon be given, but the effect of it must be carefully observed both on the patient's symptoms and on the condition of the stools. If it is well tolerated it may then be fortified by the addition of white of egg, Plasmon, Protene, and Sanatogen, and by the addition of simply. prepared fish, chicken, or sweetbread. Carbohydrates must be added very cautiously, beginning with a little crisp toast, rusk, or stale bread, going on to a plain milk pudding or prepared invalid food-Savory \& Moore's, Benger's, or Allenbury food (p. I $8_{3}$ ). There is frequently some difficulty in the digestion of carbohydrates, and this may be orercome by the administration of Extract of malt or Maltine. As the state of digestion improves, fat is cautiously added in the form of butter, cream, and yolk of eggs.

To prevent a recurrence.-Special care must be taken with the subsequent feeding of the child. The amount of farinaccous foods and sweets must be carefully regulated, and excess in either avoided. Particular attention must be clirecter to the thorough mastication of the food. This is of value in two directions. It imitates the normal digestive process in the 
mouth, and so favours a healthy sastric and intestinal digestion; and it diminishes the risk of eating to excess. Food must, therefore, be selected which promotes mastication. Beef and mutton should be siven in the form of roast or boiled, and not mince meat; and the child should be encourarged to take crusts, crisp toatst, hard biscuits, and other foods which reguire chewing.

A diet suitable for a child of seven is here given. It must be observed that the number of meals is restricted, no food is siven between meals, and the carbohychates and fats are especially reduced.

\section{S.A.M. : Prialifast-}

$$
\text { Dict. }
$$

Cup of milk and hot water (unsweetened), allowing ro ounces of milk.

lit of fish ; or ham or tongue.

Slice of toast, and a couple of rusks or Vienna roll and a very little butter.

12.jo: Dinner-

Milk, 6 to 8 ounces diluted.

A good helping $\left\{\begin{array}{l}\text { Fish, with white sauce and potato; or } \\ \text { Chicken, with bread sauce or cauliflower ; or } \\ \text { Roast mutton, gravy, and a vegetable (cabbage } \\ \text { purće). }\end{array}\right.$

l'udding, milk pudding, with stewed fruit; or custard, with raw apple; or jelly, or a meringue; only a little sugar and cream.

1)ry toast or rusks, given as much as the child requires.

4 1.M.-Milk, 10 ounces; bread and butter, limited to I slice ; rusks and dry biscuit, as much as child will takc. Sweet cakes to be taken very sparingly.

6.30 P....-Cup of soup, thickened with well-boiled sago, macaroni, vermicelli, or barley.

Slice of toast.

\section{Gastric Catarrh-Gastritis.}

Gatric Citarth-

Acute gastric catarrh . . 322

Chronic grastric citarth . . 324
Gastric catarrh (contunued)-

Gastric catarrh in children

PAGE

325

The incligestion associated with gastric catarrh, and more particularly in its acute form, is distinguished from other forms of indigestion by the suddenness of its onset, and by the fact that a definite cause can usually be assigned for it. The most cummon caluses are irritating or toxic 
articles of food, and excessive indulgence in alcohol. Contributory causes are defective mastication, hurried meals, and septic state of the teeth. It must be borne in mind that an acute gastritis may be an early symptom of one of the infective fevers, and a late symptom in advanced cardiac or renal disease. In some cases the catarrh spreads to the duodenum and bile-ducts, inducing jaundice, and to the small and large intestines, inducing diarrhoea.

Dictctic tratment of acute gastric catarrh.-Complete rest in bed, with the application of hot fomentations to the abdomen, will give some relief. All food should be withheld for the first twenty-four to thirty-six hours, the nourishment being restricted to the administration of 10 to 15 ounces of normal saline by the bowel every six hours. If the patient is collapsed, it may be advisable to give an ounce of whisky or brandy with each saline injection. Thirst may be relieved by the administration of teaspoonful sips of hot water, or, if preferred, the patient may be given ice to suck. After thirty-six hours, milk is given in 4 to 6 ounce doses, diluted one-third with lime-water or barley-water; I to I pints may be given in the first twenty-four hours. Milk should be gradually increased by lessening the amount of dilution, and the addition of albumin water, whey, and rawbeef juice. On the third or fourth day, an addition to the food of arrowroot (thoroughly well boiled) or invalid food, crisp toast, or rusks may be made. After this, some of the milk may be used for making into blancmange, or added to an esg, forming a custard, a good meat tea (p. 75) or clear soup, and an egg, lightly boiled or scrambled-i.c., about the fourth or fifth day the diet may be as follows :-

8 A.11.-

I cup of milk, flavoured with tea.

Crisp toast, half-slice.

I0.30 A.M.-Cup of clear consommé and toast.

I l'..I.-

I lightly-boiled egg, with toast.

6 ounces milk.

4 1.M. -

A cup of tea, flavoured with milk.

Crisp biscuit.

7 r.u.-Blancmange or custard (baked).

9.jo P.M.-Cup of chicken tea. 
The diet is aradually increased by the addition of bread, eggs, fish, and chiclien, and in farourable cases the patient may, at the end of ten clays, be taking a full convalescent diet (p. 295). In cases where the acute gastritis has supervened on a chronic catarrh, the prosress may be slower, as there is usually in these cases some slight dilatation of the stomach, with corresponding weakness in the digestive secretions (see Chronic Gastritis).

Dietctic tratment of chronic sastric catarrh.-Chronic sastric catiorh may be primary, when it results from longcontinued excesses in eating and drinking, aggravated ustrally by hurried and irregular meals, and by scptic state of the tecth; it may be secondary, as in advanced heart discrase, chronic renal disease, cirrhosis of the liver, and hyperchlorhyclia. In the latter group the treatment has to be nore particularly directed to the primary disease.

Complete rest in bed for some days is advisable, and a diet of the blandest form is indicated. This should be an exclusive milk diet; about 2 pints of milk, diluted one-third with barley-water, may form the sole food for the first fortyeight hours. In view of the enfeebled state of the gastric secretions, often associated with vomiting, it is sometimes achisable to grive the milk peptonised. In cases where the plain milk is for any reason impossible, koumiss, Kephir, or whey may be substituted. Buttermilk is a useful addition to this dict, and should be given in Io-ounce doses twice daily: The diet should be kept fluid until the patien' is able to take about 2 pints of milk, or its equivalent, without discomfort. The diet is then added to very cautiously. The digestion is enfecbled, so that the addition of carbohydrates is very apt to cause flatulence. They are best given in the form of a predigested foodstuff, e.g., Benger's or Allenbury. Only easily digested proteins should be given, e.g., white of e'sg, meat juice, Plasmon, and Somatose. These may be arranged in the following way:-

S.30 A.M.-Milk, 8 ounces, with Plasmon.

11 A.M.--Milk bovril (p. jo), or Allenbury.

1.3० 1...1.-

Veal jelly and dry toast ; or

curds and cream. 


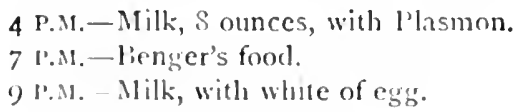

Iater, more egs, fish, chiclien, underdone meat, butter and toast, and peptonised cocoa may be added. The diet must be kept exceedingly simple, and it is necessary to forbid sugar, spiced condiments, alcohol. Tea and coffec can only be permitted if used as flavouring agents.

S A.M.-

Peptonised cocoa and milk.

Toast and butter, or stale crisp roll.

I I A.M.-Cup of clear consommé or a meat tea, and ounce of prepared Plasmon (p. 1 59).

I. 3 O P.M.-

Snall cup of chicken or fish soup.

Fish, chicken, tripe, sweetbread, with one well-cooked vegetable.

Stewed apples.

4 P.M.-

Cup of milk tea.

Dry sponge cake or biscuit.

7 P.M. -

Steamed fish, or scrambled egg, or chicken souffé.

Toast and butter.

Small cup of hot milk.

9.30 P.M. - Consommé or beef-tea.

The diet should be maintained for some weeks along the lines laid down. Thereafter a gradual return to ordinary dict may be effected. Alcohol in all its forms must be avoided, and the patient must realise the necessity of kecping to a simple ordinary dict, avoiding rich dishes, condiments, excess of tea or coffec, and other stimulating foods.

Acute gastric irritation in children.-This condition is usnally associated with some gastric catarrh. It arises from an error in diet, and more especially from too many sweets, unripe fruit, or a general excess of foodstuffs. It is important to note that the children of gouty stock are especially liable to attacks of gastric catarrh from chill.

The treatment is simple. All food should be withheld for twelve to twenty-four hours, during which thirst may be allayed by sipping hot water. A dose of castor oil or other aperient should be given at the outset. In older children, 
where there is a distinct history of the recent ingestion of umwholesome food, an emetic may be useful. After twelve to twonty-four hours' starvation, a little weak beef-tea, or chicken, mutton, or veal somp may be given, with a thin wafer of toast. If this is well borne, mills in cliluted form may be adeled to the dictary, not more than 2 to 3 ounces being given at a time. The lighter forms of milk pudding and a little fish or chicken can soon be given, the recovery of the patient being usually a rapid one.

In cases of gastric catarrh which develop after a chill, the recovery may be more slow (see also Food Fever, p. 350). This may necessitate a day or two in bed, and the use of peptonised milk, albumin water, and the weaker beef-teas. In these patients a preliminary starvation cure for twentyfour hours is usually advantageous. In the rare cases in which the child is prostrate from excessive vomiting, stimulants may be advisable, champagne being probably the most useful form, given in doses of $\frac{1}{2}$ to $I$ ounce, according to the age of the child.

\section{Hyperehlorhydria.}

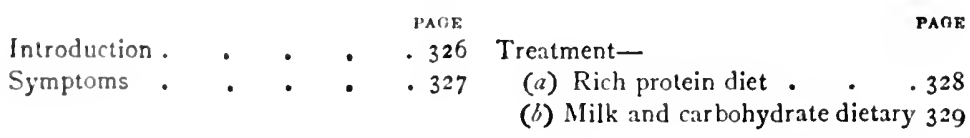

Hyperacidity or Hyperchlorhydria.-Probably the commonest form of indigestion is that associated with and dependent on a hyperacidity of gastric juice (hyperchlorhydria). This condition occurs most commonly in young adults, especially men; some marked examples are met with in schoolboy's. In its later stages it is associated with other pathological conditions, such as (I) slight dilatation of the stomach; (2) gastric catarrh, with excessive secretion of mucus; and (3) spasm of the pyloric end of the stomach, of an intermittent character. It is not infrequently associated with a gastric or duodenal ulcer. The symptoms produced by hyperacility are burning pains in the region of the stomach, heartburn, flatulence, cructation of acid food, 
and, as a rulc, constipation. The pain has characteristic features. It occurs from one and a half to two hours after food; it is relieved by food-hence the term hunger painand also by the administration of alkali, $c . g$. bicarbonate of soda or carbonate of magnesia; and, further, the pain develops after a meal of easily digested food as quickly as it does after a heavy meal. Another feature of the pain, in bad cases, is its liability to occur during the night, some hours after the last meal. In these cases the pain may be of a very severe, paroxysmal character, closely resembling the pain of biliary colic.

The cause of this condition is unknown. It is believed that it may arise from long-continued errors in diet, especially the excessive use of protein food, hurried, irregular meals, imperfect mastication, injudicious use of stimulants and tobacco-more particularly in constipated subjects.

Treatment.-Complete rest in bed for one or two wecks or more is an important factor in treatment. Under its influence the gastric pains may greatly diminish, and the general condition of the patient improve. The bowels should be freely opened by a dose of calomel, followed by a morning saline of strength sufficient to clcar the bowels out thoroughly. An occasional saline is also of value in the later treatment. In some cases associated with dilatation of the stomach much benefit is obtained from washing out the stomach nightly. Attention to the toilet of the mouth and thorough mastication are important factors in treatment.

The chief principle in the dietetic treatment is the use of such articles of food as combine most readily with the excess of acid. Protein foods meet this requircment. Milk, eggs, and meat should bulk largely in the dictary. It is sometimes contended, on the supposition that cxcessive use of protein has been responsible for inducing the discase, that it is inadvisable to continue a regime which, while relieving the symptoms, perpetuates the disease; and the supporters of this view recommend a dict less rich in protcin, one containing farinaccous foods suitably combined with protein. This objection is really more theorctical than practical; 
and, in sencral, it may be said that a dict relatively rich in protein is presminemty the diet for this disease. Large doses of alkialis, is bicarbonate of soda or carbonate of mannesial, siven in 30 to 40 errain doses about two hours after food, neutralise the hyperacid state of the gastric secretion, and are a valuable adjunct in treatment.

Fats tend to lessen the acidity of the gastric contents, and are therefore to be commended; they are best given in the form of butter and cream. Milk is valuable, in virtue of its being an efficient acid neutraliscr; it is best given with the addition of lime-water, in proportion of one part lime-water and four parts milk. Foods rich in carbohydrates are to be taken sparingly, because free acid appears in the stomach soon after their administration, which interferes with the normal conversion of the starch under the influence of the salisa. The addition of a liquid extract of malt to the food aids the digestion in these cases, and sometimes has a remarkable effect in at once relicving the pain.

The most suitable vegetables are spinach and cabbage, flower of cauliflower, asparagus, stewed onions, vegetable marrow; and potatoes, peas, carrots, turnips may usually be given in moderation in the form of purées. The amount of salt taken in the dict should be restricted, since there is reason to belicve that the addition of much sodium chloride favours the formation of hydrogen chloride (hydrochloric acid) in the gastric secretion.

The following dietaries are given as the most appropriate for the treatument. No. I., a rich protein diet, is the one to be most commended; No. II., a less rich protein diet, in which the farinaceous frods are combined with proteins, has advantages in certain cases where the previous history of the patient points clearly to the long-continued excessive use of protein fouds as a causal factor in the disease.

It will be observed that in both of these diets simplicity is aimed at, cutting off or restricting the amount of stimulating articles of dict, such as tea, coffee, alcohol, mustard, pepruer, and vinegar; soups are not allowed because of their bulk, and, in the main, their poor nutritious valuc; pastry and salvouries are forbidden. 
DIET I.

Breakfast-

Rich Protin liet.

Milk, flavoured with tea.

Two eggrs, or steamed fish, or slice of cold tongue, or slice of boiled bacon; one slice toast.

II A.M.-Milk, $\frac{1}{2}$ pint ; or Hoff's malt extract (Homax); a biscuit.

Lunch-

Steak or mutton chop (grilled), or roast chicken; cauliflower or stewed onions; slice of toast.

4. 30 P.M.-Tea made with milk, and a little cream.

7 P.M.-Alternative diets $\left\{\begin{array}{c}\text { Fish and chicken; meat and cheese savoury; } \\ \text { meat and entrée. }\end{array}\right.$

9. 30 P.M. -Glass of milk.

DIET II.

Milk and Carbohydrate Diet.

8.30 A.M.-

Coffee or cocoa, with plenty of milk.

Bread, toast, roll, or rusk.

Butter, honey, jam, or marmalade.

II A.M.-Milk, and one egg beaten up.

I.3O P.M. -

Meat, fish, chicken, game, sweetbread; no vegetable.

Pudding - milk pudding, or stewed fruit or jelly.

Cheese, biscuit, and butter.

4 P.M. - Milk tea, and one rusk or biscuit.

7.3O P.M. -

Small bowl of clear consommé (p. 271 ).

Fish or meat, one vegetable, potato, spinach.

Pudding-jelly, custard, blancmange.

Cheese, biscuits, and butter ; light cheese savoury.

9.30 P.M.-Milk diluted, in all half a pint.

In persistent cases of long standing, when the general nutrition of the patient is below par on account of his or her attempts to correct the condition by adopting a semistarvation diet, it is advisable to put the patient to bed for ten to fourteen days, and for the first week give an exclusive milk diet-2 to 4 pints of milk daily. A daily dose of Carlsbad salts given on an empty stomach the first thing in the 
morning, should also he given. In the second week the diet may be extented by the gradual addition of eggs and malted farinaceous fouds, mill: still forming the staple of the dietary.

\section{Gastric Ulcer.}

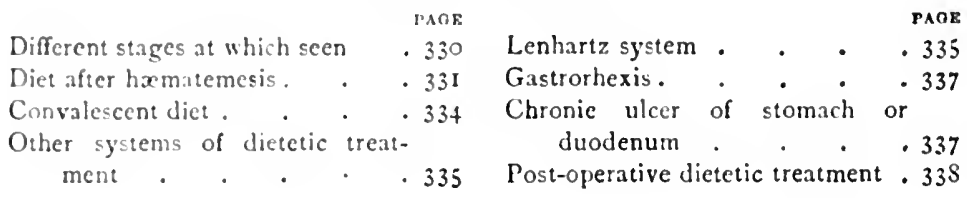

In typical cases the diagnosis of a gastric ulcer is easy. Typical cases are those in which hematemesis has occurred as a sequel to symptoms of acutc or chronic indigestion, which may have becn of months or years duration. Atypical cases, however, are common, and in this the diagnosis is often a matter of difficulty. Some of the patients in both groups have to seck relief ultimately at the hands of the surscon. Medical treatment is sufficient in the majority of cases, and in the medical treatment the most important factor is the diet. The dietctic treatment will necessarily vary with the actual condition of the patient when first seen. Thus, the patient may be seen immediatcly after hæmatemesis, her condition being one of prostration and collapse; or she may be seen some days or even weeks after the bleeding, by which time the ulcer may have largely healcd, and the general condition of the patient is greatly improved. In other cases the patient only comes under observation for chronic symptoms, the condition pointing more or less clearly to a chronic ulcer, the treatment of which is primarily surgical. Yet, again, the condition may be one in which the practitioner is only justified in suspecting the cxistence of an ulcer, the treatment of the case being, however, essentially the same as for gastric ulcer. Lastly, the case may come under observation for the sequele of old ulcerations, adhesions in the neighbourhood of the pylorus, with possibly some pyloric narrowing. In the last-mentioned group the symptoms are mainly those of gastric ulcer, and this treatment, as a rule, is surgical rather than medical. 
The general principles of dictetic treatment in these cases will now be discussed.

Dietetic treatment of gastric ular after hamatemesis.-The principle underlying the treatment of a case of hamatemesis from gastric ulcer is to give the stomach rest. This should be as complete as possible. The patient is kept in bed, absolutely recumbent. If there is the least doubt about the bowels being open, an enema of soap and water should be given, and if necessary repeated, so as to thoroughly clean out the bowel. No food is given by the mouth for the first three or four days, during this period the patient is fed by the bowel. Rectal feeding, if it is to be continued for days or longer, requires great care and attention to details. The food given may be in the form of home-made preparations, consisting of peptonised gruels, and meat teas, eggs, milk, and brandy, or injections of normal saline solution containing $I$ ounce of dextrose in 10 ounces of fluid. The nourishment should not be given oftener than six-hourly, even when nothing is being taken by the mouth. Preference should always be given to foods made at home, rather than the so-called nutrient suppositories. (For fuller details on Rectal Alimentation, see p. 22I.) If great thirst is complained of, an injection of 10 to 20 ounces of normal saline is given by the bowcl; and in cases where the hamorrhage has been very severe, and the state of the paticnt is one of great prostration, an intravenous injection of saline may be administered. It is probably better not to allow the patient small pieces of ice to suck, as the swallowing of the saliva induces slight peristalsis of the stomach, which may interfere with the natural healing powers of the ulcer. The dry, uncomfortable condition of the mouth may be alleviated by moistening the lips, gums, and tongue with hot water, provided there is no recurrence of the hæmorrhage. On the third or fourth day a little food may be given by the mouth. To begin with, a tablespoonful of milk diluted by one-third or onc-half with barley-water or lime-water may be administered. If necessary this should be peptonised, but as a rule this is unnecessary. If the result is satisfactory, and no pain or sickness is set up by it, this may be repeated cvery two hours. The main 
nourishment of the patient is still, however, derived from the rectal feeding. The amount of food given by the mouth is added to daily. (In the fifth or sixth day after the hamorhage the paticnt mily in favourable cases be taking from 1 to 1 pints of milk, diluted one-third, in the twenty-four hours, this being given in small doses every two hours. The following gives in tabular form the dietary after hamatemesis, the stomach having had complete rest for the first three or four days.

Dictary in Hematemesis from Gastric Ulcer.

\begin{tabular}{|c|c|c|c|c|c|c|}
\hline $\begin{array}{l}\text { Feeding } \\
\text { ly Motuld. }\end{array}$ & Dilution. & $\begin{array}{l}\text { Quantity } \\
\text { per feedl. }\end{array}$ & $\begin{array}{c}\text { Time } \\
\text { interval. }\end{array}$ & $\begin{array}{l}\text { Number } \\
\text { of feeds. } \\
24 \text { hours. }\end{array}$ & $\begin{array}{l}\text { Quantity } \\
\text { in } \\
24 \text { lours } \\
\text { of } \\
\text { mixture. }\end{array}$ & $\begin{array}{c}\text { Rectal } \\
\text { injections. }\end{array}$ \\
\hline $\begin{array}{c}\text { Is d day, } \\
\text { cold }\end{array}$ & $\begin{array}{l}\text { Pints. } \\
\text { Milk . . . I } \\
\text { Barley-water I }\end{array}$ & $\sum_{2}^{0}$ & $\begin{array}{l}\text { If vurly. } \\
2\end{array}$ & 9 & $\begin{array}{c}\text { Pints. } \\
\text { I }\end{array}$ & As above. \\
\hline $\begin{array}{l}\text { 2nd day, } \\
\text { cold }\end{array}$ & $\begin{array}{l}\text { Milk • . I } \\
\text { Barley-water I }\end{array}$ & \} & $2 x$ & 9 & It & $\cdots$ \\
\hline $\begin{array}{l}3 \text { rdday, body } \\
\text { temperature }\end{array}$ & $\begin{array}{l}\text { Milk . I } \\
\text { Barley-water I }\end{array}$ & \} & 3 & 6 & $\mathrm{I}_{2}^{1}$ & Reduce. \\
\hline $4^{\text {th }}$ day & $\begin{array}{ll}\text { Milk } & \cdot \\
\text { Water } & \cdot \\
\end{array}$ & \} & 3 & 6 & 2 & Reduce. \\
\hline sth day & $\begin{array}{l}\text { Milk : } 3 \\
\text { Water : I }\end{array}$ & \} & 3 & 6 & \{ & $\begin{array}{l}\text { Continue as } \\
4^{\text {th day. }}\end{array}$ \\
\hline Sth day & $\begin{array}{l}\text { Milk } \\
\text { Witter }\end{array} \cdot$. I & j & 3 & 6 & 2 & $\begin{array}{l}\text { Continue as } \\
\text { 4th day. }\end{array}$ \\
\hline
\end{tabular}

Pain and romiting are the guides to treatment. If either of these recur, it is an indication to reduce the diet, and subsequently to increase it more slowly. If the progress is in all respects satisfactory, the milk may be gradually strengthened by the addition of Plasmon, Cascin, Protene, or Sanatogenthe first named being probably the most valuable-I to 2 teaspoonfuls of Plasmon being stirred into a paste with 1 to 2 ounces of tepid water, which is then added to the milk. This may be given three times in the twenty-four hours. Towards the end of the sccond week the patient is now taking about 2 pints of milk with half an ounce of Plasmon or other protein food in the twenty-four hours, and at this stage a cup of milk, 
beef-tea, a little chicken jelly, or raw-meat juice may be given twice daily for a change. It is now possible to abandon the rectal feeding, and gradually increase the nourishment griven by the mouth. This is done by the addition of Benger's food, cornflour, arrowroot, or breadcrumbs and milk specially prepared (p. 439). At the end of the third week of mouth administration, beef-tea, meat extracts, white of egg, and such preparations as Wyeth's meat juice or Brand's essence may be utilised. The lighter forms of milk pudding may also be given. These should be given tentatively; a recurrence of pain or discomfort after administration indicates the nccessity of still withholding protcin in these forms. At this stage the daily diet would comprise 2 to 3 pints of milk, diluted one-third, the white of one or two eggs, some chicken jelly, and a beef-tea preparation. In the fourth week, eggs, fish, and chicken may be gradually added to the dict, which may be farther increased by the addition of soups and a little vegetable. If the addition of fish or chicken leads to a recurrence of the abdominal pain, these should be further deferred, and the regime in use in the tinird week should be continued. There is, however, very seldom any difficulty with fish and chicken diet at this stage, provided these are given in the most suitable forms.

The diet suited to the different periods may be given in the following tabular form:-

\section{Diet at end of first week of oral feeding.}

Two pints of milk, diluted, one part in six, given in 6 ounces supplied every three hours, six meals daily: This is an insufficient diet, and requires to be supplemented with one rectal meal daily.

\section{Diet during second aitek.}

During the sccond weck of oral feeding one of two courses may be adopted-cither cautiously increase by the addition of a simple nutritious protein dictary of egss and meat extracts, or keep the patient on milk and carbohydrates. If there is hyperacidity, the former is probably the better plan. 
Protein and Wilk.

7 A.M-Milk, 6 ounces, slightly diluted.

S.3o A.M.-Milk and beaten-up egs, $S$ ounces.

I $\mathrm{A.M}$ - licef juice, t ounce (p. 78 ). I M.M.Mlilk borril, 6 ounces ( $p$. 164).

4 1'.M.-Custard, S ounces.

7 1'.M.- Junket and cream.

10 1.M. - licef-tea, wuh toast.
Carbohydrate and Milk.

7 A.M.-Milk, 6 ounces, and 3 teaspoonfuls l'lasmon, diluted.

S. 30 A.M.-Benger's food with milk, 6 ounces; thin slice of bread.

12 A.M. - Milk with Plasmon, and cocoa for flavour; bread and butter.

4 P.M.-Arrowroot boiled with milk and cream; milk (diluted), 6 ounces.

S P.M.-lienger's food and milk (diluted), and I ounce prepared Plasmon, or junket and cream. so 1.M.-Milk (diluted); bread and butter.

\section{Dict towards and of the third week.}

7 A.M.-Milk, with biscuit, so ounces.

9 A.M. -

Cocoa made with milk, $S$ ounces.

Bread and butter-toast and butter.

I P.M. -

Soup from a vegetable stock, thickened with milk and cream, 8 ounces; or a weak meat broth, all the vegetables carefully strained.

Light milk pudding or custard, or blancmange.

Milk to drink, $S$ ounces.

4 1.M.-Milk, S ounces, flavoured with freshly made weak tea; a little cream, sponge biscuit, or rusk.

$7 \mathrm{PMA}-$

Soup, as under the I o'clock meal; or a boiled or scrambled egg.

l'udding - a custard, junket, or well-made milk pudding (p. 297).

101 1..M.-Milk, S ounces, with Horlick's malted milk, spongre biscuit, or rusk.

This dict may with advantage be maintained for a week or longer, if there is the slightest pain or discomfort with the food. In the majority of cases the following convalescent diet may be griven in the fourth week:-

\section{Concalescent dict.}

\section{Bircalifast-}

Milk, 8 ounces, flavoured with tea, coffec, or cocoa.

Bread and butter, or toast, or rusk.

Egg (boiled, poached, or scrambled).

11 A.M. - Milk, $\delta$ to 10 ounces, or milk with Horlick's malted milk, and a b.scuit. 
Lunch-

Entrées, oysters, fish (steamed or plain boiled); or souffé, or creams ; or

Chicken or game souflie, or cream; tripe, or sweetbread; one vegetable, potato (mashed), cauliflower, etc.

Milk pudding or custard, or a light savoury made with eggs.

Milk, 8 ounces; dry toast.

4.3o P.M. - Freshly made tea, with milk and a biscuit.

Dinner-

A light soup-consommé, strained mutton broth, or chicken soup; or vegetable stock thickened with milk or cream.

A meat course, as under Lunch, with one vegetable.

Milk pudding, with cream.

9.30 P.M.-Benger's food, with milk.

According to some physicians the rate of increase in the above dict sheets is unduly quick. These would aim at giving the diet allowed at end of fourth week not sooner than the end of the sixth week. Such a slow rate of increase is not as a rule necessary, and the rate of increase indicated in the diet list will be found generally applicable.

Other systems of dictetic treatment.-In igo I Lenhartz adrocated a system of feeding for gastric ulcer based on a radically different principle. He contends that the use of rectal feeding and an exclusive milk diet does not give the stomach the rest that the advocates of these measures claim for them, and that it is better to use a food rich in protein, so as to neutralise the excess of acid that is frequently present in these cases. He recommended immediate feeding and a rapid daily increase of food. For the first week the dict is taken from eggs, milk, and a little sugar; in the second week, chopped meat, milk rice, butter, raw ham and zwicback are added; and at the end of fourteen days the patients are taking a highly nutritive diet, with a caloric value of over 3000 calories. On the first day, 8 to ro ounces of iced mills with two beaten eggs are given in spoonful doses; on the third day, 20 ounces of milk and four eggs, and 20 grammes ${ }^{1}$ of sugar beaten up in the eggs; on the sixth day, six eggs, 30 grammes of sugar, and $I_{2} \frac{1}{2}$ to 2 pints of milk, with raw chopped neat from the dietary. On the eighth day the dict is increased to eight egrgs, 40 granmes of sugar, 2 to $2 !$ pints of milk, raw chopped meat, one piece of zwicback,

${ }^{1}$ I ounce avoirdupois $=28.35$ grammes. 
and milk rice. The amount of food is sradually increased in the second weck, until on the fourteenth day the patient is taking cight egrgs, 50 grammes of sugar, 21 pints of milk, raw chopped meat, milk rice, zwicback, and in addition some raw ham and butter. According to this dictary, the food siven on the first, eighth, and fourteenth days after the hrematemesis is as follows:-

Lenhartz dict-First day (all food iced).

7 A.M. - Milk and Vichy, equal parts, $2 \frac{1}{2}$ ounces.

9 A.M. - Milk and Vichy, and half egrs (beaten), = ounces.

II A.M.-Mlik and Vichy, $2 \frac{1}{2}$ ounces.

I P.N. - Milk and albumin water (1 egg), $2 \frac{1}{2}$ ounces.

3 r.M. - Milk and Vichy, $2 \frac{1}{2}$ ounces.

5 P.M. - Milk and Vichy, $2 \frac{1}{2}$ ounces.

9 P.M. - Milk and Vichy and half egg, 2o ounces.

\section{Lenhartz dict-Eighth day.}

7 A.M.-Milk, with 2 eggs beaten up, $S$ ounces (sweetened).

9 A.M. - Milk ( 8 ounces), lightly boiled eggr, and toast.

if A.M. - Custard (with I egg, to ounces milk, and sugar).

I P.M.-Raw-beef (scraped) sandwiches; 8 ounces milk.

3 P.M.-Lenger's food, with milk ( 8 ounces).

5 P.M.-Custard, 8 ounces.

7 P.M. - L Light farinaceous pudding, with milk.

9 P.M.-Raw-beef sandwich and milk.

\section{Lenharta-Full cona'alescent dict (Fourtecnth day).}

Have to supply 8 eggs (4 cooked, 4 beaten-up raw), sugar, milk (4 to 5 pints), raw beef, milk with a cercal, bread, meat, butter, made up as follows :-

7 A.M.-.Milk (I ounce), with eggs, beaten up.

9) A.M. -

Milk-flavoured tea, cocoa, coffee.

Ham, tongue, or eggs ; bread and butter.

It A.M.-Kaw-meat sandwiches, with milk (I ounce).

1 I'..31.-

Milk soup, thickened with egg and cream.

Eggs in form of panada, soufflé, omelet, savoury.

Fish or chicken (made as cream, souffle, or quenelles).

Milk pudding, custard, blancmange-all made with eggs and milk and sugar.

Milk to drink.

4 P.M.-Milk ( 1 ounce), sweet biscuit or sponge cake.

7 P.N. - Same as Binner.

10.jo P.M.M-Milk, with beaten-up egg. 
The author of this treatment claims, from observation of a large number of cases, that the results are equally satisfactory, and more speedily attained than by the system of graduated fecding which is in general use. The writer has had no practical experience of this specially liberal regime, but in a slightly modificd form it has given excellent results in some cascs.

Gastrorhexis. - It is convenient here to refer to the dietetic treatment of cases of hamorrhage from the stomach, unassociated with the presence of an ulcer. This occurs especially in young women, the bleeding being due to a small crosion in one of the capillaries of the gastric mucous membrane. The bleeding is usually small in amount, but may be considerable, the condition then being almost indistinguishable from that of gastric ulcer. The absence of defined localised abdominal pain and of antecedent symptoms of indigestion in gastrorhexis are of value in the diagnosis. Further, gastrorhexis is more prone to occur at or about the menstrual period, when the blecding may be vicarious in character. The dietetic treatment of the two diseases is different; whereas in gastric ulcer it is, as a rule, advisable to increase the diet slowly after the manner already indicated, in gastrorhexis the diet can be increased rapidly, the patient being able to take at the end of ten days to a fortnight the same diet as is recommended for a case of gastric ulcer at the end of the fifth weck.

\section{Chronic Ulcer of the Stomach or Duodenum.}

The diagnosis of a chronic gastric or duodenal ulcer is often a very difficult matter. In some cases the symptoms, physical signs, and past history of the patient point conclusively to the existence of an ulcer, and in thesc circumstances the treatment is essentially surgical. In many cases, however, it is by no means casy to say whether the condition is due to a gastric ulcer or to a so-called functional derangement of the stomach (hyperchlorhydria), and in the latter case the dietetic treatment is of very great importancc. If medical and dietetic means fail, reliable evidence is thereby afforded of the condition being one calling for operative treatment. Operative means (gastro-enterostomy) gives immediate and usually per- 
manent relicf. It is very striking to observe after a case of chronic ulccr has becin treated for weeks or even months with all kinds of light dietaries with littic or no success, the immediate and as a rule permanent relicf which follows the operation of sastro-enterostomy. In this connection reference may be made to the post-operative elictetic treatment of these cases.

Post-operative dietetic tratment of chronic gastric ulcer.For the first twenty-four hours all food is withheld, the no.nishment being restricted to the administration of 10 to I 2 ounces of normal saline per rectum every four hours. On the second day milk is administered, diluted onc-half or one-third with water or barley-water, and as much as one pint may be given in the twenty-four hours, with 6 to $s$ ounces of beef-tea. On the third day the amount of milk and beef-tea can usually be doubled, and a couple of eggs may be added to the dictary. Various invalid foods (like Benger's, Allenbury:) can be made use of if desired, and also proprictary meat preparations. A dose of calomel followed by a morning saline should be given on the third night. On the fourth day a slice of bread and a light milk pudding can be added, and on the following day a little porridge and small amount of chicken or fish souffle may be given once or twice in the course of the twenty-four hours. In tabular form this dictary is as follows:-

\section{Chronic ulceration of stomach, post-operative dict.}

Ist dity.-Milk diluted ( 1 and 1 ) with lime-water or barley-water; give

I ounce every hour $=24$ ounces $=\mathrm{I} 2$ ounces milk.

$2 n d$ day.-Nilk diluted ( 4 to $\mathrm{I}$ ) as above-5 ounces every two hoursnine meals, 45 ounces $=14$ pints milk.

3rd day.-Same dilution as second day; add to every second feed, smal! quantity of carbohydrate-arrowroot, lienger's, Allenbury.

At the end of a week a full carbohydrate diet may be reached (p. 334).

Hy the end of the second week, fish and chicken (pounded) and eggs may be given.

By the end of three weeks the full convalescent gastric ulcer dict can be taken, and this should be maintained for some months after the operation, as follows :-

Jircakfast-l'orridge and milk, and bread and butter, and cup of tea.

Dinner-Clear soup, fish or chicken, and one vegetable.

Milk pudding or stewed fruit.

Tea-Tea and bread and butter, with cake.

Supper-Fish or chicken, or mill: and biced and butter. 


\section{Dilated Stomach.}

PACE

Introduction . . . . 333

Gencral points in manugement . $\quad 339$

Principles of dietetic treatment . 339
Dietaries-

(a) In severe cases, at rest. $3+1$

(b) In less severe cases. . $34^{2}$

The treatment of dilated stomach varies according to the cause. The dilatation may be the result of obstruction at the pyloric end of the stomach-obstructive form-which is most commonly due to malignant discase, simple ulceration, or chronic inflammation with adhesions in and around the pylorus; or there may be dilatation with little or no pyloric obstruction-non-olstructive form-which may result from (a) a primary defect in the stomach itself, $\operatorname{cog}$. hyperchlorhydria, or (b) from some general constitutional weakness, such as neurasthenia, anæmia, tuberculosis, or other debilitating illness.

Dilatation of obstructive origin.-The treatment is here mainly surgical. If the cause of the obstruction cannot be removed, the dietetic treatment of the dilatation must be conducted along the lines to be hereafter indicated (1).34I).

Dilatation of non-obstructive origin.-We have in the first place to keep in vicw the fact that the dilatation may be the result of a primary disorder of the stomach, or it may be merely an expression of the general want of muscular tone present in any debilitating illness.

The primary disorder of the stomach is most commonly of the nature of a chronic gastric catarrh resulting from excessive eating and drinking, and more especially from the injudicious use of alcoholic drinks; another common cause is hyperchlorhydria, which is frequently associated with a lesser degree of dilatation. Of the general diseases which induce dilatation of the stomach in varying degree, special mention should be made of neurasthenia, severe anxmia, tuberculosis, and advanced renal disease ; in these conditions the diet is adapted to the general clisease; it is not as a rule necessary to pay special attention to the stomach itsclf.

Before considering the dietetic treatment, reference may be made to other points in treatment which bear clirectly on the question of food and its digestion. Complete rest in bed 
for two th three wecks is essential at the outset of treatment in serere cases. A septic state of the teeth is often an important predisposing cause, and sometimes an exciting cause of the sastric catarrh which has led to the dilatation; it is therefore essential that the tecth should be thoroughly attended to. An atonic condition of the bowel with constipation is a frequent complication of dilated stomach, and among the measures adopted to relieve this, special mention should be made of massage and physical cxcrcises specially adapted to strengthen the tone of the abdominal muscles. Mild counter-irritation, by means of mustard plaster or small blisters, is often of great value. If there is cvidence of an untisually septic state of the intestinal contents, as shown by marked fotor of the stools, this should so far as possible be currected by the judicious use of agents which modify this, more especially the various preparations of lactic acid bacilli (p. 540). And, lastly, the use of lavage-washing out the stomach cach night or cvery alternate night for a weck or two, or it may be longer, is often of the greatest service in treatment. The removal by lavage of the numerous toxic fermentation products which accumulate in a dilated stomach leaves the mucous membrane in a healthicr condition, and gives an impetus to a more satisfactory digestion of foodstuffs.

Gineral principles in dictctic tratment.-The general principles of treatment are quite clearly defined. We must give the maximum of rest possible to the damaged organ. IV. must give the stomach as much rest as possible consistent with siving an amount of nourishment adequate to the patient's condition. This must be done by reducing the total bull of food, by diminishing the amount of solids in the dictary, and riving the food in concentrated form. For the sane reatson the liquids must be restricted, as they mechanically distend the stomach and over-dilute the gastric juice. In casces of morlerate sererity, not more than from 20 to 30 ounces of fluid should be taken in the twenty-four hours. All effervescing beverages should be avoided; and stimulants are as a rule contra-indicated.

At the outset, in very marked cases it may be advisable to give no fluid by the mouth, but relieve thirst by ice, and supply the requisite amount of fluid to the tissues by rectal 
injection of normal saline. Foods have to be of the unfermentulle arriety. Farinaceous foods are therefore given in very restricted amounts, proteins forming the chicf basis of the dictary. In this connection it is important to bear in mind that Lactose is an unfermentable sugar, and advantage may be taken of this to supply carbohydrate in this form. Vegetables which are not readily converted into a semi-fluid or pultaceous form in the stomach should not be allowed; and as green vegetables come under this category their use has to be carefully restricted, and special precaution talien with regard to the cooking and the form in which they are presented. No stimulants should be given, such as alcohol, tea, coffec, spices, and condiments. Starchy foods should also be avoided. The meals should be small in amount and frequently administered, and in severe cases a complete hour's rest after meals should be enjoined. In the obstructive forms of dilatation which are not amenable to surgical treatment, peptonised and pancreatised foods are of special value (p. I 7 I). Two illustrative dictaries are appended, suitable for a severe case under complete rest and a less severe case respectively.

Diet in dilated stomach-severe form.-In severe cases a complete rest for the stomach for forty-eight hours is advisable, rectal saline injections being administered.

A milk dict is not suitable-a dry diet is advisable so as to reduce the bulk, the fluid being restricted to 20 to 30 ounces of fluid by the mouth in twenty-four hours. To quench thirst, rectal injection of salines may be commended.

Food should be taken hot; meals should be small and frecuent. All the nourishment given should be of the highest nutritive value, and the more easily digested the better. It must be slowly masticated, to allow of oral digestion to proceed as far as possible. Meat should take the form of underdone steak, chop, or roast, sweetbreads, oysters; green vegetables are bulliy, and not as a rule suitable.

Rest for an hour after the three large meals is a useful measure.

Ontline of Treatment-I. Mainly Protein diet. 8 A.N.-

Milk or peptonised-miik cocoa, 5 ounces, not more.

Fish (steamed), or boiled egg ; toast and butter. 
IC. ;O A.M. -

Sandwiches mate of l'lasmon and raw meat, t ib.

Milk, 5 munces.

1 P.M. -

Sweetbreads conked with cream; or

Chicken cream, or soufflic ; or

Oysters, or raw-meat mince, $\frac{1}{2} \mathrm{lb}$.

Toast and butter.

Mitk, 5 ounces.

4 P.M. -

Kaw-meat soup, 5 ounces, containing i lb. of raw meat scraped ; or

Savoury custard (p. 49).

7 P.N. -

Fish (steamed); soufte, pudding, or cream ; or

Figg and cheese custard (milk, 5 ounces); or

Cheese souffic:

930 I'.N. -

Veal or chicken jelly (p. 165), with Plasmon added; or

Allenbury food and milk, 5 ounces, with Plasmon.

As the condition of dilatation improves, chicken, mutton, same may be allowed, all being well masticated, also blancmanges, jellies, and cream, potato puréc, and vegetable souffés.

The carbohydrates must be introduced with great caution, the predigested ones coming first (p. I $S_{3}$ ).

In some cases where the power of digesting proteins is diminished, the carbohydrates may have to form a larger portion of the diet, notwithstanding the flatulence they may induce, as follows:-

\section{I1. Mainly Carboludrate diet.}

S A.M.-Milk, 5 ounces; loast and butles.

Gruel with cream and H'lasmon, and Malt extract (p. i $\$ 1$ ). I0. 30 A.M. - Milk, 5 ounces, and 1 eggr (scrambled) and toast.

1 P.M. -

Milk, 5 ounces ; custard, flavoured with Bovril, cheese, or sugar ; or

Raw-beef juice mince, $\frac{1}{2} \mathrm{lb}$., and slice of toast.

4.30 P.M.-Milk, 5 ounces, with I'lasmon, flavoured with peptonised cocoa. 7.30 1'....-Allenlury food and milk, 5 ounces.

9) 1י.M.-Beef-tea or chicken tea, 5 ounces, thickened with egg or cream.

Somatose, Carmrick's peptonoids, Fairchild's panopeptone, Denacycr's albumose-peptone mixture, may be used in the place of some of the milk.

Dict in dilated stomach-less severe form-patient going about. - The meals to be caten slowly, and the paticnt to rest for fully one hour after breakfast, lunch, and dinner, etc. 
8 A.M. -

Milk or milk rocon, 5 ounces.

Toast and butter, one and a half slices.

Egrg or fish, or crisply fried bacon.

IO. 30 A.M.-

Milk with Plasmon, 5 ounces.

Panopeptone, I tablespoonful ; rusk or dry biscuit ; or

Raw-neat sandwich.

I P.M.-

Milk, 5 ounces, with a slice of toast and butter, and a two-course dinner, from the following :-

Fish. Chicken. Raw-beef juice.

Blancmange. Fruit purce with crean. Savoury custard, or Vegetable puréc.

4 P.M.-Egg beaten up in 5 ounces milk.

7 P.M.-Same as I o'clock Lunch.

9.30 P.M. - Cup of soup thickened with egg or Plasmon.

In convalescence the diet should be largely dry, little fluid being given with meals. The meals should be fairly concentrated, thoroughly masticated, and slowly eaten. Farinaceous foodstuffs should be very cautiously adeled to the dietary.

With obstructive conditions any dietetic treatment is only a preliminary to operative treatment.

The carbohydrate should be given as Lactose, adding I tablespoonful of mills sugar in $S$ ounces of milk. Peptonised and pancreatised foods are of the greatest value, especially Peptonised milk, Panopeptone, Brancl's peptonised jelly, Benger's beef jelly (peptonised), Valentine's meat juice (see Predigested Foods, p. I 76$)$.

\section{Cancer of the Stomach.}

In inoperable cases of cancer of the stomach the treatment is purely palliative. There is usually associated some degree of gastric catarrh, or dilatation of the stomach, which increases the difficulties in the dictetic treatment. In cases accompanicd with hæmorthage, the dietetic treatment must be conducted along the lines laid down for gastric ulcer. In other cases, we aim at giving the most nourishing diet that is tolerated by the patient's cnfeebled digestive capacity. The dict must be simple and nutritious, and should be given in small quantities at short intervals. Milk, chicken 
tea, meat broths, may be largely used; tea, coffee, and buttcrmilk ate useful as accessory articles of dict. The more casily eligested forms of meat foods, such as sweetbread, tripe, chicken, and the lighter forms of fish, are all suitable in the earlier stages. Of the vegetables, spinach, flower of cauliflower, and Portuguese onions are the most to be commended. Among bread foods, preference should be given to toast, rusks, and stale dry bread; and puddings made from the invalid foods, and custards and jellies (p. 185), are the most suitable. The pulp of good grapes and various fruit juices are a pleasant change. Any liking which the patient expresses for an article of food should be acceled to, unless there are the strongest reasons for withholding it. It is often surprising what these patients are able to take without any apparent gastric or other disturbance. In the later stages the diet has to be chiefly fluid, consisting of milk, beef-tea, and the like, which may be fortified by the ardlition of white of egg, Plasmon, Protene, or other concentrated foodstuff. A little whisky or brandy is of great value as an aid to digestion in these cases.

\section{Diet in Gastroptosis and Enteroptosis.}

The treatment of the downward displacement of the stomach and bowels characteristic of gastroptosis and enteroptosis is mainly mechanical, consisting of bandages, massage, and in some cases surgical procedure. These conditions are frequently accompanied by a degree of rilatation of the stomach and intestines, and by a condition of gencral neurasthenia, and when these are present the treatment must be mainly directed to them (q.v.). The symptoms produced by the displacement of these hollow viscera are mainly those of indigestion, notably a sense of weight, fullness and oppression, eructations, with nausea and vomiting. The principles of dietctic treatment are similar to those in dilatation of the stomach. Rest in bed, with general tonic treatinent and massage, are important factors in the preliminary treatment. Thorough mastication anrl slow eating should be insisted upon. The meals should be of moderate bulk, taken at regular intervals, and nothing should be taken between meals. The cliet should be largely 
a dry one, little fluid being taken with the meals. Light and easily digested foodstuffs only should be taken, special care being taken with regard to the amount and nature of the carbohydrate foods. Buttermilk may be recommended as an accessory article of diet, for its favourable influence on fermentative processes in the bowcl. Measures must be taken to correct the constipation usually present, e.g., massage and the use of suitable aperients (see also Dilatation of Stomach, and Neurasthenia).

\section{The Dietetic After-treatment of Operations.}

Diet is one of the most important points in the aftertreatment of abdominal and other major operations. For the first twenty-four hours little or nothing should be given except small quantities of hot water, to which a little bicarbonate of soda may be added, and a rectal injection of saline, IO to 15 ounces. These allay thirst and relieve sickness. On the second day, and until the bowels have been freely opened, usually on the third day, liquid food only should be given, and it should be of a nature little likely to cause flatulence. Milk, diluted, is ordinarily given, but it frequently disagrees.

One of the safest and most reliable diets is albumin water (p. 47). Two pints of albumin water in twenty-four hours represents a fair anount of nutritive material, and are easily digested and non-irritating. Prepared Plasmon (p. 159) is another very useful preparation, and may be given in 2-ounce feeds every three hours. Grape sugar is strongly recommended by Gilford in the form of raisin tea, prepared as follows :Take $\frac{1}{4} \mathrm{lb}$. of raisins, chop them up finely, cover well with boiling water, stew for about two hours, and filter off the fluid. This tea may be mixed with water, and taken either hot or cold; it may also be combined with albumin water or prepared Plasmon, making a nutritive, easily digested, and non-fermentative food. After the bowels have been freely opened, the diet may include an invalid food (p. 183), gruel, bread and butter, a clear soup, e.g., chicken, beef-tea, or consommé, and cup of tea. The diet can then be increased along the lines suggested in the section on Convalescence, p. 294 . 


\section{CHAPTER XIX}

DIET IN IISEASES OF TIL INTESTINE

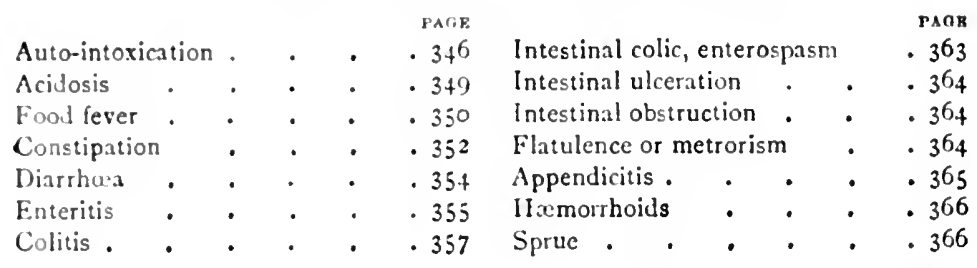

Intestinal Fermentation and Putrefaction-Auto-intoxication.-Intestinal auto-intoxication is a toxemia resulting from the absorption of abnormal food products under the influence of bacterial action. Intestinal auto-intoxication is responsible for a group of miscellancous toxamias which include cases of anxmia, headaches, neuralgia, neuritis, arterio-sclerosis, rheumatism, neurasthenia, and other conditions. Some symptoms are in part mechanical, due to pressure from gas. The toxins may frequently be recognised in the stomach contents (various organic acids), in the urine (excess of ethereal sulphates), and in the breath (acetone and hydrogen sulphide gas). Alcoholic fermentation of the foodstuffs may also occur. The bowels are frequently constipated, and the motions may be ill-formed and very offensive in character. The toxic products produced as a result of fermentation of carbohydrate foods are chicfly $\mathrm{CO}_{2}$, and various organic acids, such as lactic acid, acetic acid, butyric acid, and to a less extent formic and valerianic acid and acetone. The end-products of decomposition of carbohydrate foods are $\mathrm{CO}_{2}$ and water, and no fermentation products are recovered from the urine with the exception of oxalic acid in oxaluria. The toxic products arising from the abnomal decomposition of proteins under the influence of bacterial 
action are various nitrogen and sulphur compounds, chicfly of the aromatic series, $c_{\mathrm{s}}$. , indol, phenol, skatol, and hydrogen sulphide gas (see p. IG). Other less important products are neurin, lecithin, and cystin. The excess of nitrogen and sulphur in these putrefactive products are eliminated in the urine as ethereal sulphates, and their presence may be detected in the urine.

The dietetic treatment of cases of auto-intoxication is of the first importance. The fermentation cases should be treated with a diet chicfly protein in character. The dict should comprise various meat soups, fish, chicken, eggs, tripc, swectbread, and scraped beef; farinaceous foods being restricted to dry toast, stale bread, and rusks. The diet must be carefully planned, the food given at regular intervals, and no food of any kind given between meals. The free use of plain water or other diluent should be encouraged. It is necessary to point out the importance of proper attention being paid to mastication of the food, to the state of the teeth, and the careful regulation of the bowels as essential points in the treatment. The spccial value of the soured milk treatment and of various lactic acid bacilli is separately considered on p. 540. The following dietary is appropriate to cases of auto-intoxication resulting from the abnormal fermentation of carbohydrate foods :-

7 A.M.-Tumblerful of hot water.

8 A.M. : Breakfast-

Tea, I cup without sugar, and milk, not cream.

Good helping of fried bacon or fish, or eggs (plain, poached, or scrambled); or cold ham, or cold tongue, or grilled kidney.

I slice of thin crisp toast, with very little butter.

It A.M._I tumblerful of soured milk, with plain sweet biscuit.

I P.M. : Lunch-

(a) Fish, or chicken, or game; or chop, steak, or roast beef, or roast mutton.

(b) Biscuits, or dry roll with cheese, and with butter ; cup of coffee. 4. 3o P.M. - Cup of soured milk, and half-slice sponge cake or biscuit.

\section{P.M.: Dinner-}

Clear soup, unthickened.

Meat as at Lunch, without vegetables; dry toast, and a simple gravy.

Pudding in form of custard, curds, jelly, cream, or stewed fruit, without added sugar; no coffee.

Io P.M.-Drink of hot water. 
The pufrefuction cases are treated with a lacto-vergetarian diet. Neat, and especially red meats, are for the time cut off from the dietary. Meat soups are similarly withheld. Eggs are also excluded. The diet should comprise bread and milk, farinaceous foods, green vecretables, and fruits. An appropriate dict sheet is here given :-

7.30 A.M. - Tumblerful of hot water.

8 A.M.: Breakfast-

Cereal-c. 4 ., porridge, Hominy, Quaker oats, with cream.

Toast or roll with butter, and a little marmalade if desired.

I cup of tea.

II A.M.-I glass of soured milk with biscuit.

I P'.M.: I.tunich-

Egrg in some form, or vegetable savoury, e.s., cauliflower au gratin, macaroni cheese, tomato savoury.

Plain milk pudding with cream.

4 P.M. - r cup of soured milk, with piece of sponge cake.

7 P.s.: Dinner-

l'egetable or milk stock soup, c.s., tomato, artichoke, potato, lentil, or onion.

Fish occasionally, or egg in some form if not taken at Lunch, or vegetable savoury.

Pudding-simple pudding, or stewed fruit; no savouries and no coffec.

ro P.M.-Tumblerful of hot water.

Foods forlidden in all cases.-Patients who are specially prone to intestinal auto-intoxication have a relatively weak digestive power. Their diet must therefore be a simple one. All foods which are difficult to digest should be excluded from the dietary, and the various "extras" which can be indulged in with impunity by healthy subjects must be rigorously withheld. The following articles should only be griven in the most restricted amounts:- Marmalade, jams, sugar, sweets, and confectionery; pastry, sweet cakes, new bread, and hot rolls; made-up dishes of all kinds, and all canned foods; pickles, sauces, spices, caviare, and rich gravies, lobsters, mushrooms, shrimps, sardines, salmon, mackerel, raisins, nuts, pears, and all preserved fruits. 
Acidosis, or acid intoxication-

Nature of the condition

Dietetic treatment in slight cases 349
Acidosis, or acid intoxicationcontrmued.

Dietetic treatment in severe cases 350

Acidosis, or Acid Intoxication. - Acidosis, or acid intoxication, is a clinical condition occasionally met with in children. The condition is one to which increasing attention is now being paid. It is a toxamia which is recognised by the peculiar smell of acetone in the breath, the presence of acetone in the urine and romit, and in some cases diacetic acid in the urine-conditions similar to those met with in diabetes.

The symptoms may be very slight or very serious. In the slighter cases the symptoms are those of minor gastrointestinal trouble; the child is off his food, the bowels are deranged, the tongue is furred, and the child is generally off colour. The breath has the distinctive odour of acetone. In the very severe cases, sudden, uncontrollable vomiting is the most prominent symptom, accompanicd by constant nausea, retching, and great prostration. These latter cases may be rapidly fatal.

The cause of the condition is unknown. It is believed to be closely dependent on dictetic conditions, but there is great diversity of opinion as to the defects in the diet which may be responsible. It has been variously ascribed to excess of protein, excess of carbohydrates, and excess of fats, this excess being not necessarily absolute, but only relative to the digestive power of the individual. In the writer's view the carbohydrates are chiefly at fault, and the digestive disturbance is mainly the result of deranged pancreatic activity.

Dietetic treatment of the slighter degrees.-A close examination of some cascs of acute gastric irritation, chronic indigestion, intestinal indigestion, and food fever will show that these are associated with acctone in the breath, due to acid intoxication. IVe may therefore conclude that there is a very close relationship between these different conditions. This close relationship is further reflected in the treatment. If the dict in use be carefully studied, it will be found that it is unsuited to the age of the child. It will either have been excessive in amount, or there may have 
been a special excess of farinaceous foods and sweets. Correction has to be made accordingly.

The diet must be a simple one, made up largely of protein foods, carbohydrates and fats being restricted. Breakfast should comprise skimmed mill, fish, ham, or tongue, and stale bread or toast, with a little butter. Dinner. - A bowl of clear soup, fish, or chicken, or meat, green vegetables (no potatoes), with toast or rusk; no puddings. A cup of warm diluted milk, with half a slice of toast, may be given for tea; and the Eacming meal should consist of a cup of beef-tea, thickened with Plasmon, and a rusk.

The addition of Extract of malt to the diet is often useful, and the administration of large doses of allali, e.g. bicarbonate of soda (20 to 30 grains), is a valuable remedial measurc.

Dictetic treatment of sevcre cases. - In bad cases the vomiting may be so severe as to preclude the oral administration of food. Nutrient enemata may be necessary, and should consist of peptonised milk, glucose, white of egg, and brandy. Thirst is troublesome, and may be relieved by sips of hot or cold water, or barley-water. When the symptoms mitigate, foorl of the most easily digested kind is administered. Skimmed milk, peptonised, and perhaps fortified by the addition of Plasmon, white of $\mathrm{cgg}$, or Allenbury food, should first be tried. Weak beef-tea, chicken jelly, veal, mutton, and chicken soup may also be utilised. Crisp toast should be the first bread food allowed. A striking feature in these cases is the remarkably sudden recovery often shown. The romiting and other symptoms may sucklenly disappear after a good night's rest, and the patient experiences a sensation of hunger. It is a curious fiact that the recovery of the digestive powers appears to take place crincidently, as after the sudden recovery of appetite the patient can digest almost everything. It is, however, arlvisable to licep the patient on a light diet for at least a weck, and for a loner time subsequently to pay special attention to the amount and nature of the farinaceous foods and silects. Extract of malt is of great valuc as a digestive tonic in thesc cases.

Food Fever. - Linder the term "food fever," Eustace 
Smith has described a condition in children characterised by the following clinical features. The child is suddenly attacked with acute fever, associated with manifestations of gastro-intestinal derangement, vomiting, diarrhox, headache, furred tongue, and general malaise. The stools are frothy, ill-formed, and offensive. The fever lasts, as a rule, some days, but may persist for a week or two. This conclition is chiefly seen in children of a neurotic or gouty temperament, and occurs between the ages of three and twelve years.

This condition is one of acute gastric and intestinal catarrh, its distinctive feature being the liability to recurrence. It arises from indiscretions in the dictary, especially the cxcessive consumption of farinaceous foods and sweets, which undergo fermentative changes in the bowels, with resulting absorption of toxins, which are responsible for the fever.

The dictetic treatment consists in restricting or cutting off for a time farinaccous foods and sweets. Starvation for the first twenty-four hours may be advisable, and so long as the fever is high, the patient should be on a febrile diet. The diet generally should be selected from skimmed milk, fish, tonguc, chicken, meat, eggs, stale bread, toast, rusks, and green vegetables. Plain milk, farinaceous puddings, pastry, sweets of all kinds, acid fruits, sweet drinks, and root vegetables should be withheld during the attack. The administration of Malt extract may prove advantageous. A suitable diet sheet is appended :-

Dietary during an attack, which may last for a week or longer in modified form.

Breakfast-

Cup of skimmed milk, 8 ounces, diluted with hot water (no sugar).

Slice of tongue or ham.

Stale bread and butter, or toast and butter.

IO.jo A.M.-Dry rusk, with butter; drink of water.

\section{Dinner-}

Soup, beef-tea, chicken tea, consommé of veal or beef unthickened.

A helping of fish or poultry, or chop or steak, plainly cooked, and plain clear gravy.

Green vegetable (sprouts, cabbage, cauliflower, boiled onions, or leeks); no white soup.

(Avoid puddings, bread and butter, and biscuits and butter.) 
T:a-

Cup of skimmed milk, or weak tea made with skimmed milk.

Slice of toast, or dry biscuit or rusk.

8 P.M. - Cup of carefully skimmed beef-tea, with half-slice of toast.

After the attack is over, the return to the use of starchy fonds must be made very gradually, and it should be remembered that these subjects have a limited power of digesting carbohydrate foods; these are sometimes classified as cases of intestinal indigestion.

Constipation.-Food is a factor of some importance in the tratment of constipation. Food may promote peristalsis through a mechanical action, as in the case of foods rich in cellulose, which leave a large residue in the intestine; or it may infuence the bowel by a chemical action, through the agency of the organic acids produced by bacterial decomposition of the carbohydrates and cellulose of the food, as in the case of vegetables and fruits. Among foods rich in cellulose, green vegetables, oatmeal, and wholemeal bread occupy a prominent place, and these should enter largely into the diet of constipated suljects. Fruits are also of great value, more especially figs, prunes, dates, apples, pears, oranges, and peaches. Fruit should be taken once or twice a day; it may be taken fresh or stewed, and it is best taken on an empty stomach the first thing in the morning. Fat is useful as a lubricant, and the patient should be encouraged to take plenty butter and cream. A little marmalade, honey, or treacle taken at breakfast has a useful aperient action. A common fault in the dietary of constipated subjects is a deficiency in fluid, and patients should therefore be encouraged to drink 2 to 3 pints of fluid in the day, one tumblerful of hot or cold water being taken the first thing in the morning. Excess of meat and excess of tca are factors in the development of constipation, and the amount of these must be restricted. The main points in the dietary for constipation may be represented as follows :-

Meat foods should be restricted to one meat meal for dinner.

Tea should be taken in moderation, not more than two cups daily. 
Foods rich in cellulose should bulk largely in the dictary e.g., porridgc, especially that made from Scotch oatmeal and Quaker oats, wholemeal bread.

Vegetables, especially green vegetables, should be taken frcely.

Fruits have a useful aperient action.

Fats.-The taking of fat should be encouraged, as in the form of butter or cream.

Water-drinking is in many cases a useful corrective of constipation. Cider and malt liquor have a slight aperient action; red wines have the reverse.

Milk is constipating to the majority of individuals, but in exceptional cases it has a laxative action. Buttermilk has a laxative effect.

There are many factors at work in the development of constipation, and these require attention as well as the diet. Lack of exercise, too sedentary habits, matetudinal hurry, are important contributory causes. Defective education of children as to the acquirement of the regular habit of going to stool is often the primary cause; this can to some extent be corrected by cultivating regularity in habit in later life. In looking for recovery from constipation in long-standing cases it is essential to point out to the patient the necessity of patience, and the long-continued use of a diet adapted to the condition. Massage and suitable exercises are important aids in treatment.

The following is a suitable dietary for a case of constipation. Importance should be directed to the necessity of taking the food slowly, and of thorough mastication.

7 A.M. - Tumblerful of cold or hot water.

8 A.N.-

A little fruit taken before breakfast.

Bowl of porridge made from Scotch oatmeal, with liberal supply of milk and cream.

Cup of tea ; toast or rolls, butter and marmalade.

I P.M -

Broth.

Bread and cheese; wholemeal bread, with liberal supply of butter. Stewed prunes. 4. 3 P.M. - Cup of tea, and thin slice of bread and butter. 
7 P.M.-Plain three-course dinner. Either soup, meat, and pudding; or fish, meat, and pudding ; including plenty green vegetables, and stewed fruit.

Io P.M.-Tumblerful of hot water.

Diarrhœa.-It is probable that all forms of diarrhoea, with the exception of the diarrhoa of pure nervous origin, are dependent on the pathogenic action of the bacteria which are usually present in the bowels. Thesc bacteria are divisible into two great groups-(I) a large group, which abound in the small intestine, the crecum, and first part of the colon, which decompose the carbohydrates, with resulting formation of organic acids. These organic acids normally neutralise the alkaline intestinal juices and keep the contents of the small intestinc acid. It is further believed that this acidity is of value in restraining the action of the putrefactive proteindecomposing bacteria to be now referred to; and (2) a large group of protein-decomposing organisms (Bacillus coli and others) which abound normally in the lower two-thirds of the colon, but under pathological conditions are present in the higher parts of the digestive tract. In all probability the diarrho:a which follows the ingestion of some irritating article of food results not from the direct action of the foodstuff, but from its indircet action in promoting abnormal bacterial growth. The different forms of inflammation (cnteritis) and ulccration of the small and large intestines are undoubtedly of bacterial origin. These will be referred to later.

Diarrhoea may result from excessive fermentation and acidity in the small intestine, a condition which induces loosening of the bowels, flatulence, and colicky pains, or it may result from abnormal decomposition of proteins, due to excessive activity of the putrefactive bacteria. These are two distinct clinical types which can sometimes be differentiated. The former group must be treated by a reduction of the carbohydrates, and their replacement by proteins and fats; the latter require a milk or lacto-vegetarian dict for their correction. It must be recognised, however, that it is frequently impossible to decide whether the diarrhoea has its origin mainly in the small or the large intestine, and the condition has to be treated on the following general lines. 
An attempt must be made to recognise the cause of the diarrhœa, which must be removed. In this, seek to determine whether the diarrhœea results from the derangement of the normal digestion of the carbohydrates in the small intestine, or of the proteins in the large intestine, as the dietetic treatment for the two varies in the manner already indicated. A study of the previous dictetic history of the patient, and of the nature of the symptoms and of the stools, will be of value in this direction. In cases of so-called "acid dliarrhœa," the stools are very loose, acid, and usually yellow and frothy. In all forms the chief aim in treatment is to prescribe a diet of the least irritating character, one which will leave as little unabsorbed residue as possible. Articles of diet rich in cellulose-vegetables, fruits, coarse breadstuffs, malt liquors, and sugar-should be avoided. If the diarrhoa be severe, complete rest in bed is essential, and it may be necessary to withhold all food for a day or two, nothing being given but a little barley-water to allay the thirst.

When the symptoms have quietened down, or in milder cases from the outset, the diet should consist of arrowroot, cornflour, rice, sago, one of the patent cercal foods (p. $18_{3}$ ), and milk. Milk must be given cautiously, and its effect noted on the stools; it is best given with lime-water, in proportion of three to one, to start with. Raw-meat juice, white of egg, the pulp of underdone meat, and special protein preparations, such as Panopeptone and Plasmon, are also useful. Thirst may be allayed by ice, cold weak tea, diluted red wine, or a lemonade drink.

Nervous Diarrhœa and Lienteric Diarrhœa.-There are subjects in whom the entrance of food into the stomach excites an undue peristalsis of the whole bowel, with resulting diarrhœa (lienteric diarrhœa). Diarrhœea of essentially nervous origin is not uncommon, and this may be accompanied by a sudden influx of fluid into the bowel, with resulting profuse and liquid stools. There are many forms of nervous diarrhoea. None of them are specially influenced by diet. The condition must be treated on general lines. Frequently the patient is the best judge of his diet.

Catarrhal Enteritis.-For all practical purposes the 
diarrhoea of catarrhal enteritis may be regarded as merely an exacseration of the condition (p. 354) already cliscussed. It is undotrbtedly of bacterial origin. It is frequently sccondary to and an extension of acute or chronic gastritis. The condition may be acute or chronic. Assistance in framing the appropriate dict may be gained from a study of the stools. They may be very thin and almost colourless; they may be large, pultaceous, and frothy, arising from too much carbohydrate foods; they may be exceedingly offensive, susgesting putrefaction of protein material. In the former instance the carbohydrates are restricted, the diet consisting of cgg-white, albumin water, whey, raw-meat juice, lanopeptone, arrowroot made with water, barlcy"water, and weak tea; in the latter we give milk diluted with limewater, buttermilk, arrowroot made with milk, cornflour, and various cereal preparations. A dict sheet for each of these conditions in its acute stage is appended :-

\section{Diet in Acute Enteritis.}

\section{Protein dict.}

6 A.M. - 2 drams of a meat juice.

8. 30 A.M. -8 ounces whey, with albumin water.

I0. 30 A.M.-Panopeptone, 竞 ounce in alkaline water.

I 13.M.-Arrowront, boiled i 5 mins. with water, eaten with cream and $\frac{1}{2}$ ounce brandy.

4 P.M.-Albumin water, added to cup of weak tea.

6.30 P.M.-10 ounces chicken tea, thickened with arrowroot.

7. 30 P.M. W. Weat essence or jelly.

11 P.M.-Panopeptone.
Carbohydrate diet.

6 M.M.-Milk with lime-water, 10 ounces, 4 to 1 .

8.30 A.M.-Benger's food, made with milk.

I A.M.-Buttermilk, 10 ounces.

I P.M.-Arrowroot, boiled with milk, flavoured with brandy or cinnamon.

4 1.M. - Tea made with milk; halfslice toast.

6.30 P.M.-Benger's food custard.

I I P.M.-Io ounces milk, with limewater.

In chronic cases we similarly seck to determine whether the condition arises from a defect in the carbohydrate digestion or in the protein. The experience of the patient will be of value in enabling us to form a correct opinion on this point. Having ascertained this, a diet of a largely protein character or of a largely carbohydrate character is prescribed according to circumstances (see pp. 347, 348). 
Colitis.-All forms of colitis are the result of bacterial or parasitic influences. In most cases of acute intestinal catarrh resulting from toxic articles of food, there is an associated inflammatory state of the colon; in these cases a mild degree of colitis is present. This catarrh of the colon readily subsides under the treatment laid down for the correction of the diseased state of the small intestinc (p. 356). There is a large group of affections, however, in which the catarrh involves the colon primarily, and here all grades of severity of the disease are met with. Four clinical types are recognised :-

I. Simple colitis, acute and chronic.

2. Ulcerative, acute and chronic.

3. Dysentery, acute and chronic.

4. Mucous colitis, or muco-membranous colitis (see p. 360).

It is probable that ulcerative colitis and dysentery are really one and the same condition.

The treatment of the different forms of colitis is difficult, and sometimes unsatisfactory. The patient requires to exercise considerable patience in regard to treatment.

Principles of treatment.-Complete rest in bed is essential. Care must be taken that the bowel has been thoroughly emptied by a cathartic or by enema. At the outset the diet should be restricted to fluid foods, and especially milk. Plain milk is not at this stage suitable, but may be given diluted with water or lime-water in proportions of three to one. Where the diluted milk is found unsuitable, skimmed milk, whey, or koumiss may be well borne. Thirst is best relieved by sipping teaspoonfuls of hot water or by sucking ice. As soon as the more acute symptoms have passed off, milk diluted with lime-water, curds, or milk blancmange, Plasmon, yolk of egg, various invalid foods such as Allenbury, Savory \& Moore's, and Benger's, and arrowroot, sago, and other simple farinaceous foods, may be added to the diet. Soured milk is also advantageous in some cases. Proteins in the form of fish, chicken, sweetbread, and tripe are then added to the diet. Fatty foods, green vegetables, raw fruits, and any of the less digestible foodstuffs should be avoided for a long time after the disappearance of the acute symptoms. The following dietaries are given as 
being appropriate to the onset of the disease, and at the end of the first week of an acute colitis of arerage severity :-

\section{Diet in Colitis (Acute).}

At onset of diserse.

21 pints of milk in twenty-four hours should be given, slightly warmed, as follows:-

Every two hours about 5 ounces of sweet milk, either in the form of milk diluted with water or lime-water, or an equal amount of whey, koumiss, skimmed or soured milk.

The mitk may sometimes be fortified by the addition of albumin water (white of $2 \operatorname{eggs}$ ), or I'lasmon, I to 2 drims daily.
At end of first week.

6 A.M.-Milk, 5 to to ounces, diluted wilh lime-water.

S A.M.-Milk, 5 to 10 ounces, with yolk of egg.

I I A.M. - Soured milk, 5 to 10 ounces.

I 1.M. -

Rice soup (strained), with yolk of egg.

Milk blancmange, made with isinglass ; or

Arrowroot, well boiled, with milk.

3 P.M. - Milk, 5 ounces, with Plasmon.

5 P.M.-Whey, 5 ounces, with yolk of egg.

7 P.M. -

Benger's food, Io ounces, with Plasmon; or

Mutton broth, boiled barley (strained), and yolk of egg. 9 P.M.-Milk, 5 to ro ounces.

Diet in chronic colitis.-Great care is necessary in selecting the diet for these cases. The condition has usually been of long standing, and the patient's attention may be unduly concentrated on the state of his digestion, with the result that he has cut off one article of food after another, and may be living on a semi-starvation dietary. The keynote to the successful treatment is simplicity. It is not, as a rulc, necessary to cut off either the proteins, fats, or carbohydrates. It is, however, essential to cut off all the extras in an ordinary dictary, and for each meal to be made up of one or at most two dishes, which must be simply prepared. Lavage on the Plombiere system, is frequently of great value. In certain patients with hypochondriacal tendencies it is better avoided. In most cases it is best to give during the first week of treatment the diet for acute colitis (supra). The following points 
will be found of value in prescribing the different meals for these cases after this preliminary course of treatment is over :-

7 A.M. - Small glass of milk (warmed).

\section{Breakfast-}

Lightly boiled egg, toast and butter, weak tea with milk (small cup); or Tender streaky bacon, toast (no butter), weak tea with milk (small cup); or

Steamed fish, bread and butter, weak tea with milk (small cup); or Slice of tongue or lean ham, weak tea with milk (small cup).

(Avoid sugar unless in very small amount, jam, marmalade, hot scones, and oatcake.)

I A.M. - Small cup of clear soup, with strips of toast.

\section{Lunch-}

Fish (fried or steamed, one of the white varieties); potato ; or

Chicken (roasted or boiled), with bread sauce; or

Tripe or sweetbread; or

Broiled chop or steak, or slice of roast beef or mutton, and one plain vegetable.

4.30 P.M.-Cup of freshly made tea, rice biscuit, rusk, or sponge cake.

\section{Dinner-}

Not more than two courses.

Soup-any simple good soup (not broth, unless strained); hare, kidney, oxtail, and mulligatawny should be avoided.

Meat, fish, or chicken as above, with one vegetable.

Pudding - a milk pudding made with egg, a souffé, custard, cieam, or jelly.

No suet puddings or pastry.

No extras such as dessert, fruits, sweets, nuts, or pickles.

9.30 P.Mr_C Cup of Benger's food if desired.

Dysentery.-The dietetic treatment of acute and chronic dysentery is the same as for acute and chronic colitis. Commencing with a mild starvation diet, we make use of milk (diluted or peptonised), whey or koumiss, and pass from these to thin broths thickened with well-boiled starches, e.g., arrowroot, cornflour, potato flour, sago, and tapioca. As a rule, until the tongue cleans, barley-water, rice-water, egg albumin water, thin chicken or mutton broth, rice- or barleywater in which chicken has been boiled, or chicken jelly, constitute the most appropriate foods. When the tongue has cleaned, milk (at first diluted or peptonised), or raw egg and milk may be gradually introduced, and along with rice- or 
barley-water should be for many days the staple and only food. L'nlike the simpler forms of colitis, a fluid or semi-fluid diet, as described on pp. $2 S I$ and 358 , must be continued for a long time. This is a difficulty in the treatment, as the patients get restive under the restrictions.

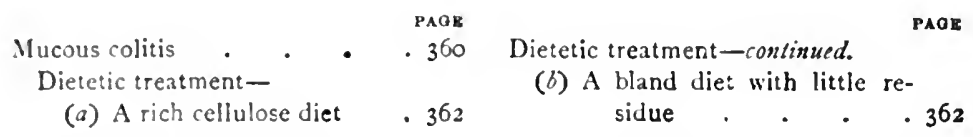

Mucous Colitis, or Muco-membranous Colitis. - In health the small amount of mucin secreted by the lining membrane of the colon has a lubricating effect, which is of some value in promoting normal peristalsis, and so preventing constipation. In disease there may be marked hypersecretion of mucin, as in the condition under consideration. Mucous colitis is characterised by the occasional passage by the bowel of a large amount of mucinoid material, which is often present in the form of large tubular casts. The stools are usually frequent and very fotid, and in some cases contain a little blood. In other cases the bowels are notably constipated, and they are usually so in the intervals between the attacks. The attacks are accompanied by a varying degree of abdominal pain-cnterospasm. This may be slight, as in the form of slight tenesmus, or may be very severe, simulating the pain present in acute appendicitis. The condition is a serious one, and very troublesome to treat. It is serious, because it is so often associated with a marked degree of hypochondriasis from which the patient can with difficulty be aroused; it is troublesome, because in many cases it is complicated by gastric neurasthenia and general inanition, from which the recovery is at the best slow. The etiology of the disease is unknown. It is by some regarded as of nervous origin, a secretion neurosis; by others as a distinct catarrh, probably of bacterial origin. The latter is, in all probability, the correct explanation; it is a form of catarrh to which people of a nervous temperament are more than usually susceptible.

Dietetic treatment.- The first point which the practitioner 
should recognise and seek to impress on the patient is the fact that in the great majority of instances the patient's condition is not nearly so serious as he imagines. The attention of the patient should be clirected away from the continual daily personal cxamination of the dejecta; and it should be explained to him that some excess of mucin in the stool is frequently present in health, and may be of no pathological consequence whatever. Attention should bc more particularly directed to correcting the form and odour of the freces, which are usually ill-formed, pultaceous, and foetid. The diet must be framed to diminish the abnormal fermentative and putrefactive changes which are responsible for this condition. To this end two distinct types of dietary have been recommended: one, a coarse cellulose dietary which leaves a large residue in the intestines; the other, a bland diet which leaves little residue. The former may be beneficial in cases where constipation is a marked feature; its favourable action is, however, probably due to the diminished protein putrefaction associated with its use: the favourable effect of the bland diet, which leaves little residue, is in all probability due to the reduction in the fermentation of carbohydrates, and to the lessened strain on the digestion in general. At the outset of treatment complete rest in bed is for a time advisable.

Meat foods, and more especially red meat, should be restricted or in some cases avoided; fats should be taken as freely as the state of digestive power will allow; fruits are valuable, but little or no sugar should be added to them. The dict should be essentially simple, free of spices and condiments, and all extras carefully avoided. Alcohol in all its forms is, as a rule, inadvisable. Extract of malt preparations are of great value in some cases where there is deficient power of digesting carbohydrates, and much benefit is often derived from the use of various intestinal antiseptics, especially the lactic acid bacilli group. Lavage is also of value in many cases, but in others its use is distinctly disadvantageous. Two illustrative dietaries are here given; the first is arranged on the system of the coarse cellulose diet recommended by Von Noorden, the sccond illustrates the bland nutritious diet which leaves little 
residue. The author's practical expericnce has led him to conclude that, if the points referred to in the text are duly regarded, and if a course of treatment for acute colitis (p. 358 ) is first carricd out for eight or ten days, a judicious compromise gives the most satisfactory results.

\section{Cellulose dict for Mucous Colitis.}

7 A.M.-

Hot water, $\frac{1}{2}$ pint; with apples, oranges, bananas, figs, grapes, strawberries, gooseberrics, etc., in their season.

S. 30 A.M.-

Tea, coffee, or cocoa, made with milk, one cup.

Fat bacon, fish, or eggs.

Brown wholemeal bread (toast), 2 slices.

Butter, honey, raspberry, strawberry, or black-currant jam. Lunch-

Egg savoury; vegetable dish, e.g., baked tomatoes, beans and tomatoes, artichokes, salads, green, or with beetroot and celery.

Small allowance of water; brown bread.

4.30 P.Mr. -

Tea, with brown bread and butter.

Vegetable soup-celery, turnip, onion, carrot ; broth ; bean soup.

Fish (fried or steamed), with bread or toast.

Vegetable dish, as at Lunch.

Fruit (stewed), made into fritters or soufflé, with cream.

Water to drink.

9 P.M.-Glass of hot water; rusk, or wholemeal biscuit.

\section{Bland diet for Mucous Colitis.}

7 A.M.-Hot water, $\frac{1}{2}$ pint.

8 A.M. - Milk, diluted with hot water or weak tea.

White bread-pan loaf, and not new.

Butter, honey, jam, or jelly.

Eggr or fat bacon.

II A.M.-Hot milk, 冬 pint.

I P.M. -

Vegetable stock, thickened with cream and milk, $\frac{1}{2}$ pint ; toast.

Milk pudding, made with egg and breadcrumbs, sago, tapioca, macaroni; or

Custard or blancmange, flavoured with fresh fruit juice.

4.30 P.M. -

Milk, flavoured with tea or cocoa, I cup.

Bread and butter, toast and butter, or sponge cake-a small supply. 
7 P.M. -

Vegetable stock soup, e.g., lentil, pea, milk (also p. 206).

Fish or egg or oysters.

Vegetable-potato purée, or balls, or fritters; spinach, or cauliflower or vegetable souffle, with beans or peas, celery, cream.

Milk pudding or blancmange, with cream and fruit juice.

Bread or toast.

Io P.M.-Warm milk alone, or with Horlick's malted milk,

In some cases it is beneficial to commence the treatment with a diet of skimmed milk (2 pints), buttermilk ( 1 pint), with the whites of two eggs in the twenty-four hours, continuing this regime for six or eight days. In cases where the rich cellulose diet gives at the outset good results, too frequently this diet must be modified on account of the flatulence to which it may give rise. The patient must be told that immediate results are not to be cxpected, as the rate of recovery is usually slow. At the same time every effort must be made to counteract the hypochondriacal condition frequently present in these patients. Undue attention must not be paid to the patient's own ideas as to what is good or bad for him, as his ideas are often merely fanciful. If the colitis be associated with gastric neurasthenia, and pain in the stomach follows the ingestion of any solid food, an exclusive milk regimen should be given for some days. Gain in weight is the most important criterion of success in treatment.

Intestinal Colic (Enterospasm).-Intestinal colic may result from constipation, or from enteritis or colitis, and more particularly from that form of colitis known as mucous colitis. The dietetic treatment therefore varies with the cause. If due to constipation, the diet should be one rich in cellulose, as given on page 352. If due to catarrh of the bowel, the diet should be a bland one, containing a large amount of fat in the form of butter and cream. The following diet is appropriate: it has ample nutritious material, and leaves a scanty residue :-

\section{Breakfast-}

Milk, flavoured with cocoa.

Small bowl of gruel, with cream.

Slice of toast and butter. 


\section{Lunch-}

Vegetahle soup, thickened with milk and eggr.

Milk pudeling or custard, with cream ; or slewed apples or prunes.

liread or toast and butter.

\section{Dinner-}

Vegetable soup-potato, lentil, or vegetable stock, thickened with milk.

Fish or egg, mashed potato, and a vegetable.

Milk pudding or fruit jelly, blancmange, with cream.

Intestinal Ulceration. - The dietetic treatment of gastric ulcer has already been fully cliscussed (p. 330). The dietetic treatment of duodenal ulcer is essentially the same as that for gastric ulcer; when associated with hyperchlorhydria, as it frequently is, the dietetic treatment must be adapted accordingly.

Tuberculous Ulceration.-The dietetic treatment of tubcrculous ulceration of the bowel is often one of great difficulty. When marked ulceration of the bowel has developed, the general condition of the patient is usually a very grave one. Milk and milk foods should form the basis of the dietary, and it is often necessary to give the milk peptonised and diluted with lime-water. Whey, skim milk, and koumiss are useful forms of administration. Extra nourishment may be given by fortifying the milk with white of egre, Plasmon, or Allenbury food, with the addition of a little Extract of malt. Beef-teas are useful if they do not induce diarrhœea, and chicken jelly may be given. (See also dict on pp. 433 and 44 r.)

Intestinal Obstruction. - The treatment of intestinal obstruction is essentially surgical, unless in cases due to constipation. In acute cases, all foods should be withheld until after the operation. Thirst may be allayed by sipping ice, or washing out the mouth with hot water, or water acidulated with a few drops of lemon. In cases where the operation is deferred longer than twenty-four hours, it may be advisable to administer salines, glucose solutions, and other foodstuffs by the bowel.

In chronic cases the aim is to give a diet that will be casily digested and largely absorbed, leaving little residue. The food should be given in small amounts, and at frequent intervals-every two and a half to three hours. The follow- 
ing foods are of special value in these cases:-Milk, plain, diluted, or peptonised, and strengthened by the addition of Plasmon, white of egg, or invalid food, Bovinine, chicken or veal jeliy, beef or mutton tea, l'anopeptone, Brand's chicken jelly. (For post-operative treatment, see p. 345.)

Flatulence or Meteorism.-A flatulent distension of the bowel, with accompanying unpleasant noises (borborysmi), is met with occasionally in young subjects, especially women, and in the later years of life. There may be no other symptoms of indigestion.

Treatment should be directed to improving the gereral health in every way by the administration of general tonics. Those patients are usually of a nervous temperament, and the condition is aggravated by the attention devoted to it. The diet should be simple and nutritious, farinaceous foods and sweets should be restricted to a great extent, and the bowels must be carefully regulated. The daily administration of some buttermilk or some physiologically active preparation of lactic acid bacilli will be found of value in treatment.

In elderly subjects similar rules of treatment apply. Benefit is also obtained by largely restricting the amount of fluids and soups given at meals. A dry diet is therefore useful, fluid being given on an empty stomach an hour before food. Such articles of food as new bread, scones, potatoes, cabbage, sprouts, uncooked fruit or cooked fruit eaten with much sugar, aerated waters, and beer should be avoided. The dry diet recommended on p. 407 will be found helpful.

Appendicitis.-At the commencement of an attacli of appendicitis, or at any rate when the patient first comes under observation, it may be impossible to say whether perforation or gangrene has occurred.

In the event of perforation or gangrene having talien place, it is very important that the stomach and intestines should be as motionless as possible, and this can only be attained by withholding food altogether for twenty-four hours or more, by which time the actual condition of affairs may have been determined. If laparotomy is performed, the subsequent dietetic treatment should be cautiously along the lines laid down for post-operative treatment after abdominal operation, which is given in detail on pp. $33 \$$ and 345 . 
If it be decided that no immediate operation is necessary, 4 ounces of fuid nourishment may be given cvery two hours, the food consisting of milk diluted one in three with plain water, egg albumin, weak beef or mutton tea. From eight to ten feeds should be given in the course of the twenty-four hours. After a day or so of this diet, when the pain and fever have largely subsided, and all fear of localised suppuration or seneral infection is over, the diet can be rapidly increased by the addition of gruels made from oatflour, or barley-meal, or prepared invalid food (Benger's or Allenbury); also some of the Plasmon preparations, lightly cooked egg, scraped beef, and fish.

If the attack subsicles, and if the appendix is not removed, the question arises as to whether diet will prevent a recurrence of the attacks. A correct dict will certainly greatly diminish the risk of fresh attacks. The diet must be a simple one, not too rich or varied, and should contain little of the canned food preparations. It must be free from excess of foodstuffs that are prone to fermentation or putrefaction. Hence moderation in the amount both of the carbohydrates and proteins in the food is essential. Thorough mastication, attention to the bowels, and the use of various lactic acid bacilli preparations may be mentioned as adjuvant factors in the prophylaxis.

Hæmorrhoids. - Hæmorrinoids may result from any cause which interferes with the proper return of the venous blood from the vessels in the lower part of the rectum. Among the more common causal factors, mention may be made of a sedentary occupation, constipation, pregnancy, and intemperance in food and drink, causing chronic congestion of the liver. Whatever the cause, it is essential that the bowels be kept thoroughly regular by the judicious use of mild aperients. With regard to diet, alcohol in all its forms should be avoicled; large rich meals should not be indulged in; three simple meals a day should be taken. Red meats and condiments of all kinds should be restricted, the diet being largely a lacto-vegetarian one, with fish and chicken as the main meat foods. For inveterate cases, with a liability to recurring inflammation, a diet framed on the following lines will be found suitable:- 
Breakfast-

Porridge and cream.

Tea, bread and butter and marmalade.

Cup of tea.

Lunch-

Vegetable soup.

Fish or chicken, and a vegetable.

Glass of buttermilk.

Dinner-

Clear soup.

Light entrée, e.g. chicken cream with vegetable.

Stewed fruit and cream, or blancmange or jelly.

Sprue.-Various methods of dieting have been advocated, and are used either singly or in combination. These may be classified as follows :-

I. The milk diet.

2. The meat diet.

3. The fruit diet.

4. The mixed diet.

In all cases the boweis should in the first itstance be cleaned out by a dose of castor oil. Should pyorrhoea alveolaris or other condition of oral sepsis be present, as is often the case in this disease, appropriate local treatment must be carried out. Complete rest in bed and warmth are of the utmost importance in treatment.

The milk diet.-This regime is the most generally applicable and effective in this disease. Much attention to detail is essential for its successful application. Written directions are supplied to the patient as follows (Manson and Daniels) :-

I. Fresh milk, slightly warmed, to be the only food and drink.

2. The milk to be taken at intervals of two or three hours, in divided quantities up to the aggregate amount of 3 pints in the twenty-four hours.

3. The milk must never be taken hurriedly, but slowly sipped with a spoon or sucked through a strand or fine glass tube, in imitation of the natural way of ingesting wilk. 
4. After each feed the mouth must be rinsed out with an alkaline or antiseptic wash, and the tecth lightly brushed.

5. Unless the paticnt-is icry weak, sleep must not be disturbed for feeding purposes.

6. If at any time there is a fecling of nausea or a want of appetite, one or more fecds should be intermitted.

7. Throughout the treatment the patient's weight should be taken every three or four day's, and accurately recorded.

If after a thorough trial of this treatment for a week there is no marked improvement, the diet must be modified. If, on the contrary, as is usually the case, improvement is marked, attempts to increase the amount of milk must not be made too soon; nor, indeed, till the patient clamours for more food and the motions are solid. In this case, increase to the extent of half a pint per diem may be allowed every two or three days. Not until six weeks after the stools are formed, and the soreness of the mouth and the abdominal distension have disappeared, may any attempt be made to add to the dietary. If things go well, the following may be carefully introduced:-Fruit, especially strawberries or bananas mashed up with a portion of the milk; raw or underdone cggs; well-boiled arrowroot, rice-water or barley-water; rusk, crisp thin toast; custard, malted artificial food, stewed apple, chicken broth in which rice has been boiled and strained out; pounded chicken, chicken cream or panada; boiled sole or turbot; boiled, mashed, and afterwards balled potato; and so gradually, after several months, reverting to regular meals and ordinary diet, not for a long time introducing anything but the simplest and most digestible of food, and avoiding alcohol and beef, and unnecessary fluid at meals.

The milk treatment as above described may fail; but before admitting failure, ccrtain modifications of it should be tried,

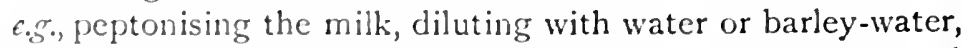
the use of whey, skimmed milk, koumiss, or buttermilk; and occasionally benefit is derived from the addition of a little fruit, especially of strawberries. 
The meat regime.-This regime is commenced with teaspoonful, gradually increased to tablespoonful, doses of carefully prepared meat juice. If this is well borne, scraped meat, and later minced and lightly cooked meat, may be gradually introduced. At first, an ounce or two of meat is given every three or four hours; if this agrees, the quantity is increased, and the intervals between the meals lengthened, until a pound or more is taken in the twenty-four hours, in three or four meals. Thin, crisp toast may be taken with the meat, and hot water in small quantities, taken slowly, from one and a half to two hours after the meal. The return to a normal dict after a course of meat treatment should be as gradual and tentative as after the milk treatment. Very great benefit sometimes accrues from alternating the milk and meat treatment, e.g. alternating the two every four days. This is a point of great practical importance.

The fruit treatment. - A diet of milk and strawberries, the amounts of both being gradually raised to 5 pints of the former and $3 \mathrm{lbs}$. of the latter, sometimes tends to a rapid and permanent cure of sprue. When good strawberries are not available, bananas form a fair, though inferior substitute. The fruit, which must be ripe, must be reduced to a pulp and thoroughly incorporated with the milk. Other fruit treatments have been advocated.

The mixed diet treatment has already been referred to. Special mention may again be made of the value of the system of alternating the diets in the manner described. 


\section{CHAPTER XX}

DIET IN DISEASES OF TIIE LIVER AND PANCREAS

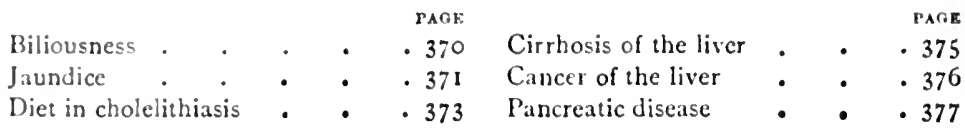

Biliousness.-The term biliousness is a loose one, employed more especially by the public to indicate their condition when they feel sick, off colour, headachy, and the romit contains bile. The cause of this condition is a duodenal and gastric catarrh, this catarrh being doubtless associated with a general congestion of the liver. This catarrh is doubtless of bacterial origin, previous dietetic exccsses on the patient's part being the primary factor in its development. In people predisposed to it, chill acts as an cxciting cause, more especially in gouty patients. The dietetic treatment is simple, and consists in starvation for twenty-four hours or so, aided by rest, and the use of a blue pill and saline purge. After a day's starvation the patient should live for a couple of days on the lightest simple food, c.g., beef-tea, chicken jelly, milk diluted, sruel, pounded fish or chicken, and toast or rusks. The later dietetic treatment consists in moderating the diet which has usually been excessive, making it simpler where it has previously been rich and varied, and especially restricting the amount of sweets. This advice is very frequently disregarded. The patients prefer the pleasures of the table, and rely on an annual visit to some spa for the correction of the functional disorders of the liver and other digestive glands induced by their immoderate eating and drinking. 
Jaundice.-One of the functions of bile is to aid in the digestion and absorption of fats. When from any reason bile is prevented from getting into the intestine, the absorption of fats is interfered with, a state of defective digestion is induced, and the amount of fat in the stools is greatly increased. One is not surprised, therefore, to find that patients with jaundice show a marked repugnance to fat. The diet should therefore contain little or no fat. The diet should be simple, and should be largely protein in character. Milk in the form of skimmed milk, whey, buttermilk, or koumiss; and beef juice, albumin water, and well-cooked barley-water should form the dietary in the more acute stages, and in cases with irritability of the stomach. Later, soups thickened with barley, or sago, or tapioca, the lighter forms of fish, and different varieties of lean meat, with toast or roll, may be added. The more easily digested vegetables and fruits may also be given, such as spinach, onions, asparagus tops, and the flower of cauliflower, stewed apples, prunes, and figs. Potatoes should be given sparingly, and are best given cooked in their jackets, either boiled or steamed. With regard to fluids, the drinking of plain water or alkaline water should be encouraged; as much as 2 pints, or more at the outset, should be taken daily. Tea and coffee may be given in moderate amount; all stimulants should be withheld unless specially indicated. During convalescence the patient should be cautioned against eating to excess, or taking rich, stimulating, or coarse articles of food; and special care should be taken with regard to his return to the use of fats and fatty foods. One of the extract of malt preparations, such as Extract of malt, Maltine, or Homax, is a useful aid to digestion of the carbohydrate foods. The principles of treatment outlined above are applicable to all cases of jaundice. It may be advisable to amplify this by giving detailed examples of a dietary appropriate to two distinct groups of clinical cases, such as simple catarrhal jaundice, and jaundice due to inoperable malignant disease.

Dict in simple catarrhal jaundice-early stases.-The diet here is of a fluid character, easily digested, largely protein in nature, and free of fats. Its nutritive value is small in amount, but is ample for the first three days or so of the 
illness. Its use will promote a speedy return to a more liberal regime.

7 A.M.-10 ounces mineral wates.

S A.M. -

Io ounces skimmed milk, thickened with white of egg or albumin water.

1 slice of loast without butter.

10 1.M. - 10 ounces buttermilk.

1 P.M. -

10 ounces clear soup thickened with Plasmon; or Islice of toast 10 ounces beef-tea thickened with meat juice; or 1 or roll.

Pudding (not made with egg), stewed fruit without cream; a little milk.

4 P.M. - Cup of tea with little sugar ; half-slice of toast.

6 P.M.-10 ounces skimmed milk; a little sherry may be added if desired, as a flavouring agent; an invalid food.

10 P.s.- to ounces mineral water.

As the stomach becomes tolerant and the appetite returns the diet can be gradually increased, as follows:-

7 A.M. - 10 ounces mineral water.

8.30 A.M.--

Freshly made tea, with very little milk.

Roll or crisply made toas!, no butter.

Fish ('teamed), or slice of ham, tongue, or chicken.

IO A.M.-10 ounces buttermilk; I sweet biscuit.

I P.M. -

Cup of barley or sago soup.

Fish (white, steamed or boiled) ; or

Chicken or pheasant (roast or boiled), slice from breast ; or

Rump-sicak, or tender eye of mutton chop ; or

Slice of roast beef or mutton, with gravy.

1 vegetable-spinach, or cauliflower, or stewed celery.

stewed fruit, eaten with milk and biscuit.

(Malt extract with Dinner.)

4 P.M.-Cup of tea; dry rusk, biscuit, or sponge cake.

7 M.M.-Two courses. Cup of soup, and a little meat or fish.

(.Malt extract with Supper.)

Ditt in Jaundice due to inoperable malignant disease. 7 A.M. 10 ounces plain water or mineral water.

8 A.M. -

Cup of weak tea, with little sugar.

Slice of toast or roll, with a little jam or marmalade; no butter.

Fish, ham, or cold tongue. 
I A.M. - to ounces mineral water, or an equal amount of buttermilk.

1 P.M.-

Bowl of clear soup.

Oysters, fish, chicken, or sweelbread, with small amount of mashed potato, and spinach, caulitlower, or asparagus.

Stewed fruit, with very little milk; no cream.

4 P.M.-Cup of weak tea, with little sugar, and half-slice of toast.

7 P.M. : Dinner (two courses). - Much the same as Lunch.

Steamed fish, or light entrée.

Custard, or curds, or stewed fruit.

A little alcohol, in the form of whisky or brandy.

In this dietary the fats are cut off, the carbohydrates are reduced, and a simple, easily digested diet of protein nature is given. There is no reason for withholding any article of food for which the patient expresses a wish, unless it be of a nature likely to derange or still further weaken his digestion. The meals should not be large.

As the disease progresses the patient becomes unable to digest the above, and a more fluid dietary, along lines similar to that adopted for the earlier stages of simple catarrhal jaundice must be given.

Diet in gall-stones.-The chief causes of gall-stones are inflammation of the bile-passages and gall-bladder, with resulting stagnation of bile. This inflammation of the bilepassages is usually the sequel to a catarrh of the duodenum, which has resulted from long-continued errors in feeding. In some cases it is not so much the amount and nature of the food that is at fault, as other conditions associated with that system of feeding, and more especially a sedentary life and constipation. The dietetic conditions which predispose to duodenal catarrh are excess of food, and more especially a rich, varied dietary containing a too liberal supply of sweets and starchy foods. The digestive powers in these patients are generally more than usually limited, and the first essential is that the dict must be simplified. The amount of fat in the dietary has to be reduced, because in these cases fat impedes digestion. Care has to be taken with the carbohydrates on account of the special rôle which the liver-the bile-producing organ-plays in their metabolism. All foods liable to putrefaction, such as over-ripe cheese, shellfish, and the like, should be avoided, because of 
the unfarnurable infuence on the growth of pathogenic bacteria in the bowel. Stimulants are better withheld, and water-drinking should be encouraged.

The meals shoull be giren at regular intervals, not too far apart, since the introduction of solicl food into the stomach prometes the flow of bile-four or five meals in the day. Too long fasting is therefore injurious. The following regime is adapted for a case of gall-stone disease in a middle-aged woman of stout tendency. Special mention may again be made of the value in treatment of exercise in the open air, exercises to promote the action of the abdominal muscies, and the judicious use of laxative salines.

7 A.M. -

Tumblerful of hot water, with I dram of sodium phosphate dissolved in it; or

A Carlsbad mixture. (A useful Carlsbad mixture can be made by dissolving 22 grains of sodium stalphate, 12 grains of sodium bicarbonate, and 10 grains of sodium chloride in a pint of water. Take $210+$ ounces at a time, once every fifteen minutes;

S A.M. repeat three times.)

One cup of tea, with little or no sugar.

One course of fish, ham and egg, or tongue.

One or one and a half slices of toast, or roll, with butter (jam and marmalade should only occasionally be taken).

11.30 A.M.-Tumblerful of water (either plain, carbonated, or alkaline water). 1 P.N.-

Fish or chicken soufflé.

Stewed fruit passed through a sieve, or bread and cheese.

4.30 P.N. -

Cup of tea, with little sugar.

Thin slice of bread and butter; no sweet cakes.

7 P.M. (Jlain three-course Dinner).-Either

$\begin{array}{lccc}\text { Soup, } & \text { or Fish, } & \text { or Fish or meat course, } & \text { or Soup, } \\ \text { Meat, } & \text { Entre, } & \text { Pudding, } & \text { Entrée, } \\ \text { Pudding; } & \text { Pudding; } & \text { Savoury; } & \text { Savoury. }\end{array}$

(The soup should preferably be clear, and not made from rich vegetable stock. A limited amount of potatoes and green vegetables may be given. Rich, oily salads should be avoided. The meat should be freshly cooked or cold-no rich sauces or gravies. Suet puddings and pastry should only occasionally be taken, the best puddings being stewed frus (without added sugar), custard, curds, jellies, blancmange. Extras in the form of fruits, nuts, and sweets should be avoided.)

to P.M.-Tumblerful of hot water. 
Cirrhosis of the Liver.-The most common cause of cirrhosis of the liver is long-continued indulgence in excess of alcohol. The use of highly seasoned foods may also induce it, more especially in children. It may also arise from chronic intestinal fermentation, resulting from the use of a diet which favours abnormal fermentative and putrefactive changes in the bowel. It is usually associated with some degree of chronic gastric catarrh.

The principles of dietetic treatment can be readily defined. Alcohol in every form must be avoided, until at least the later and incurable stage of the disease, when a stimulant may be advisable; all rich and stimulating foods should be withheld. Spices and condiments must be excluded from the dietary; fats and carbohydrates need to be restricted. The diet must be simple, and in the early stages should be largely a milk dietary, or a lacto-vegetarian regime. The bowels must be kept open by the judicious use of saline mineral water. The diet varies with the complications, more especially the presence of marked ascites. An appropriate diet sheet is here given for the early stages of the disease, and also for the later stages associated with pronounced ascites.

Cirrhosis of liver-early stages, without marked ascites.Here milk should form the basis of the dietary. It may be necessary to give it diluted or peptonised, or in the form of skimmed milk or koumiss, depending on the degree of derangement of gastric digestion:-

6 A.M. - 10 ounces of buttermilk.

8 A.M.-IO ounces of milk, thickened with white of egg; slice of toast.

II A.M.-Chicken or veal jelly; or soup thickened with sago, Farina, or barley.

I P.M. - IO ounces of beef-tea thickened with meat juice, with a dry roll ; or pounded fish, or fish soufflé.

4 P.M.-Io ounces of milk.

6 P.M.-An invalid food-Allenbury, Benger's, Savory \& Moore's.

9 P.M.-Cup of beef-tea thickened with Plasmon.

A course of six to eight days of this dietary will be of great value in relieving portal congestion, and inducing a healthier state of the whole digestive tract. At the end of this time the diet can be gradually increascd. 
Cirrhosis of the liver atith pronounced ascites.-Kceping in view the general principles previously laid down, a dry diet planned along the following lines is recommended:-

S A.M.-Cup of lea ; sandwich of potted chicken or raw meat ; or fish ; or, occasionally, lightly boiled egg.

II A.M. 6 ounces meat soup, thickened with Plasmon.

1.30 P.M.-

Fish quenelles; fish soufflé.

Pounded chicken, or scraped steak mince with toast.

A small glass of alkaline water.

4. 30 P.M. - Cup of buttermilk, or freshly made tea with milk; dry sponge cake.

7 P.M. - An invalid food, or light pudding.

(Malt extract twice daily.)

In recent years increasing attention has been directed to the occurrence of carrhosis of the liver in children, under conditions in which alcohol in all its forms can be excluded. These are cases of subacute yellow atrophy, which are in all probability due to a chronic infection from the intestines, arising in association with a catarrhal condition of the duodenum. In these cases it should be kept in mind that an exclusive milk diet, or a diet consisting of bread and milk and milk puddings, is often more indigestible and therefore more prone to maintain a catarrhal state of the bowel than a protein diet made up of becf-teas, pounded fish or chicken, with puddings in the form of custard, rather than farinaceous puddings. In these cases it will be found that the protein diet laid down for cases of intestinal catarrh will prove of value (p. 356 ).

Cancer of the Liver.-There is no special dietetic treatment for cancer of the liver. In the later stages the digestive powers of the patient are very greatly reduced, and the food must be given in very small amounts, frequently, and in the most easily digestible forms. Plain milk may be too strong, and should be diluted or peptonised. Skimmed milk, whey, and koumiss are serviceable varieties of milk. The nutritive value of the milk may, in suitable cases, be increased by the addition of Plasmon, white of egg, or small amount of one of the invalid foods. The addition of a little malt may be of valuc. Becf-tea or veal-tea, with chicken jelly, Bovinine, 
and similar preparations may all be utilised, as occasionally' one preparation is tolerated when the others induce nausea and vomiting. Pounded fish or chicken, milk puddings made with invalid food, and clear jellies should be given as freely as the state of digestion will allow. Among fruits, orange juice or a few grapes may be allowed. Stimulants in the form of brandy or whisky are of value in improving the digestive power and the general strength of the patient. An occasional day's rectal feeding, to give the stomach rest, is often advantagcous (p. 22 r).

Disease of the Pancreas. - Indigestion of pancreatic origin. - There is little definitely known about the relation of diet to pancreatic diseases, but recent advances in the pathology and treatment of pancreatic diseases clearly indicate the practical importance of this subject. It is known that there is one severe form of diabetes commonly associated with pathological changes in the pancreas, which is consequently spoken of as pancreatic diabetes. These cases run an unfavourable course, and are accompanied by much emaciation. In recent years Mayo Robson has added largely to our knowledge of the different forms of subacute and chronic inflammation of the gland; he has drawn attention to the comparative frequency of pancreatic disease, and to the clinical methods by which it may be recognised. One of these methods must be here alluded to, as in the writer's experience it is of distinct value in connection with dietetic treatment. The pancreatic reaction in the urine, a test devised by Cammidge for the recognition of inflammatory disease of the pancreas is here alluded to. The crystals are believed to be of the nature of a pentose. The writer has made an extensive investigation into the value of this test, based on the examination of the urine of some hundreds of cases of all kinds, medical and surgical, under different dietetic conditions, and the results have shown that while this test has no special value in the diagnosis of pancreatitis, as was at first supposed, it is of great value as an indication of the toleration limit of the body for carbohydrate foods. His observations on this test, since confirmed by many other observers, have shown that a positive reaction occurs in a very much larger number of "control" cases than was originally described by the 
author of the test, and that a positive reaction is in no way to be regarded as pathognomonic of pancreatitis, but simply as an indication of derangement of the function of the gland. Further, no clinical significance attaches to the presence of mere traces of a positive reaction as revealed by the presence of only a few crystals on microscopic examination, but much significance attaches to the presence of a marked positive reaction. As the pancreas is the organ most largely concerned in the metabolism of carbohydrates, we are probably justified in concluding that in the clinical conditions which give a pronounced pancreatic reaction in the urine, special attention should be directed to the restriction of the carbohydrates in the food, and practical experience amply confirms this. This view is in conformity with the experience of Mayo Robson, to the effect that not a few of the cases which can now be diagnosed with fair accuracy as subacute or chronic pancreatic disease ultimately develop true diabetes. The treatment of these conditions, whether due to functional or organic disease of the pancreas, is comparatively simple. The difficulty lies in their recognition, which is essential for their successful treatment. The following points will be found helpful in treatment :-

(a) Certain cases of "indigestion," with its varied manifestations, are accompanied by, and in the writer's opinion dependent upon, functional pancreatic disease, which is revealed by the presence of a pronounced pancreatic reaction in the urine. When these cases are appropriately dieted, recovery quickly takes place.

(b) Some cases characterised by neuritic-like pains, commonly regarded as of a rheumatic or gouty nature, are in reality dependent on defects in the pancreas, which can only be remedied by proper feeding. Defective circulation in the feet and hands, with coldness of extremities and liability to chilblains, are present in these patients. These cases are comparable, in minor degree, to the forms of neuritis which are met with in true diabetes.

(c) In cases of muscular and nervous asthenia, the primary fault is occasionally to be found in the pancreas. The author has seen cases of neurasthenia of very long standing, which had long resisted the ordinary treatment, recovering 
rapidly when the existence of this relationsinip was recognised, and the treatment directed accordingly.

General principles of treatment.-The two essential points in the dictetic treatment are to restrict the carbohydrates, and especially the sugars. Give a simple instead of a rich and varied dietary. The diet should be a mild, anti-diabetic one. Sugar, jams, and sweets of all kind should be reduced, or for a time cut off entirely. In many cases this alone suffices to get rid of the patient's symptoms. In others the starchy foods have also to be reduced; potatoes, suet puddings, starchy puddings, such as sago, arrowroot, etc., and perhaps breadstuffs, must be reduced, and their place taken by a more protein dietary. Custards and curds may take the place of the largely carbohydrate puddings. It is also advisable to exercise caution in the amount of fat taken in the forms of butter, cream, and the like. Spices, condiments, and extra articles of food in general should be avoided, as their presence increases the liability to the milder degree of duodenal catarrh which is so often present in these cases, and is the exciting cause of the pancreatic derangement. The addition of Extract of malt or Takadiastase is sometimes of value in aiding starch digestion. The dietary on p. 347 will be found suitable for the average case. 


\title{
CHAPTER XXI
}

\author{
AN.EMIA AND DISEASES OF THE BLOOD
}

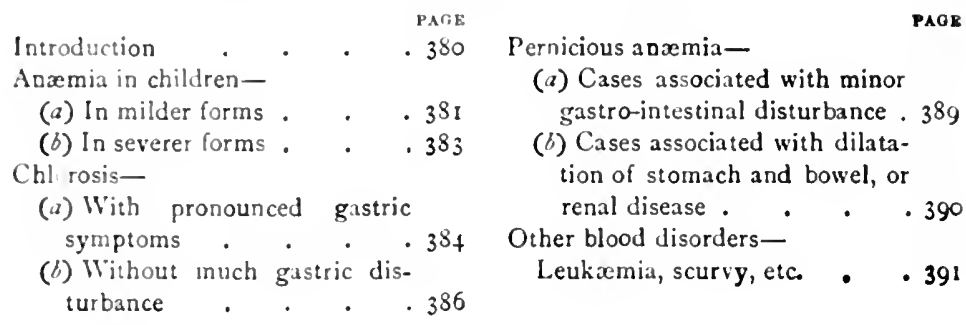

Ax.EMla may be secondary or primary. A secondary anxmia is one in which the blood disorder is the result of a known disease, such as cancer, tuberculosis, rheumatism; or it may result from a serious bleeding, direct loss of blood from hremorrhoids, uterine hemorrhage, and the like. A primary annmia is one in which no cause for the morbid condition of the blood can be defined. There is good reason, however, to believe that the majority of cases of primary anamia are the result of a toxamia, or an infection having its origin in the gastro-intestinal tract, and in these conditions the diet is a most important factor in treatment. The dictetic treatment of the various forms of secondary anamia calls for little comment here; when the cause has been removed, the blood condition rapidly improves under the influence of rest, fresh air, attention to the bowels, administration of iron and arsenic, with as full and generous a diet as the patient can assimilate. The treatment of the different forms of primary anæmia calls for detailed consideration. These may be considered under the following sections:- 
1. Anamia in children.

2. Chlorosis, or simple anxmia.

3. Pernicious or idiopathic anxmia.

4. Other blood disorders, $\epsilon . g$., leukemia, scurvy, etc.

Anæmia in Children.-There are two factors of special importance in the development of anxmia in children. These are (I) defective fecding, and (2) a chronic intestinal catarrh, which may be latent and only revealed by obscrvations of the stools. Many cases of severe anæmia in children are due to the long-continued use of a diet which is deficient in blood-forming elements, c.g., a dict consisting largcly of bread and butter, and pastry, with tea several times daily. This system of defective fecding predisposes to chronic gastrointestinal derangement, which, in turn, reacts unfavourably on the digestive powers of the child. The existence of chronic gastro-intestinal derangement in these cases is shown by the presence in varying degree of the following conditions-constipation, occasional diarrhœa, and, notably, unformed fotid stools, which may contain excess of mucus and undigested food. A contributing factor may be a septic condition of the mouth, due to discased teeth. Before considering in detail the dietetic treatment, reference may be made to some preliminary essentials in the management of these cases. These include :-

x. Thorough clearing out of the bowcls by a judiciously selected course of aperients, $\epsilon . g$., a course of calomcl, $\frac{1}{8}$ gr. to I gr., for sevcral nights according to age of child, followed on alternate mornings by a saline aperient.

2. Careful attention should be directed to the state of the mouth and tecth. All septic stumps should be removed, and an antiseptic mouth-wash used daily.

3. Complete rest in bed is, in some cases, essential to effect a specly and complete recovery.

4. Sunlight, fresh air, and thorough mastication of the food are important factors for successful treatment.

The milder degrees of ancmia.- The first point to determine in these cases is whether the condition is a sccondary 
anamia or a primary one. The common causes of sccondary anxmia in children are tuberculosis, rhcumatism, the infective fevers, $i \cdot g$., scarlet, diphtheria, and worms; if we find the anamia to be of secondary origin, the indication is to treat the cause. When, after careful examination of the child, nonc of the recognised causes of secondary anxmia are discovered, the conclusion is arrived at that the case is one of primary anemia.

The term "primary" anxmia merely means an anæmia of which the causation is at present unknown. While there is no precise knowledge of the cause of primary anæmia in children, there is abundant clinical evidence to suggest that it is very frequently associated with, and dependent on, a chronic gastro-intestinal disturbance of a nature which may have been sufficiently slight to have escaped the observation of the parents. Inquiry into the history of these patients will often indicate that, in addition to living under unfavourable conditions as to fresh air and sunlight, they have for long been injudiciously fed, the diet consisting too largely of tea, bread, and jam pastry, and the like, and containing too little milk, animal food, and fresh vegetables. In the milder degrees of ancemia recovery is speedily attained if we stop the unwholesome dietary that has been in use, and restore the proper balance of protein, fat, and carbohydrates in the food. To this end judicious use is made of milk, cream, meat juice, meat foods in moderation, fresh vegetables, and fruit. Complete rest in bed for a short time, careful attention to the bowels, and a diet planned along the following lines, will speedily effect a cure of the condition :-

\section{Anemia-Child at. Eight Ycars.}

Brcakfast-Bowl of porridge, gruel, or other cereal; milk, 10 ounces; slice of bread and butter, or toast and butter, or oatcake.

I A.M.-Cup of clear soup ( 8 ounces), to which has been added $\frac{1}{4}$ lb. of scraped raw meat; or

Cup of soup (8 ounces), thickened with yolk of egg and a little milk; a biscuit.

I 1.M.-A good two-course dinner, the meat being plainly cooked. Fish, or chicken, or meat, potatoes, and a vegetable. Light milk pudding, or a custard and stewed fruit. 
4.30 P.M.-A good, wholesome tea, plenty of milk to drink, toast, occasionally a bit of plain cake or a biscuit, butter, and a little jam or jelly. Bread foods should not be new.

Bedtime-A cup of soup ; or

A cup of peptonised cocoa or milk.

In seicre ancemias.-In more severe cases of anemia in children the treatment may be much more difficult. These may be similar in character to the pernicious anremias described on p. 388 ; they are usually associated with the passage of ill-formed, fotid stools. It may or it may not be possible to get the child to take a diet framed along the lines laid down above, but even if this is possible, no improvement results. The condition remains unchanged, or may get worse. A radical change of diet is then necessary. After a preliminary clearing-out of the bowel by one or two doses of grey powder and saline, a diet is selected which will throw the least strain on the digestive tract, and at the same time diminish the fermentative and putrefactive changes taking place in the bowel. For this purpose it is advisable to materially diminish the total amount of food given in the first few days. The carbohydrates are largely reduced, fats are excluded, plain milk is withheld as being for the time unsuitable, and the food is selected from skimmed milk, buttermilk, white of egg, meat juice, and a small quantity of bread or toast-not new.

Plasmon, Sanatogen, and various malted foods, such as Mellin's, Benger's, Allenbury's, or Savory \& Moore's food, may be used to strengthen the fluid nourishment. These greatly strengthen the nutritive value of the diet without adding much to its bulk or to its difficulty of digestion. The beef juice can be given in the form of the juice of $\frac{1}{4}$ to $\frac{1}{2}$ lb. good steak stirred into good soup, or as raw-beef mince browned by cooking for three minutes, or as scraped beef sandwiches. The white of egg may be given beaten up in the skimmed milk or beef-tea. The breadstuffs that may be allowed must be stale, and include the following:-Malted bread (not new); Bermaline, Hovis, or Veda; biscuits made of the same materials; a dry sponge cake or sweet rusk and plain toast. A little fruit juice may be given daily. 
The following dictary may be recommended as most suitable for a severe case of this kind in a child of six to seven years:-

6 A.M.-Skimmed milk, 8 ounces.

S A.M. -

Skimmed milk, 8 ounces, with white of egg beaten up.

Half-slice of baked bread.'

I A.M.-Raw-beef juice from 1 lb. of steak given in beef-tea (6 ounces). 1.30 P.M. . -

Skimmed milk, 8 ounces, with white of egg beaten up.

Half-slice stale bread or crisp toast.

4 P.M.-Buttermilk, 8 ounces, with toast.

6 P.M. -

Beef-tea or chicken tea.

Slice of toast.

If awake Jater, drink of skimmed milk, or buttermilk if readily taken.

Under this regime there may be an initial slight increase in the anxmia, but this will soon give place to an improvement which will steadily and in favourable cases will rapidly progress. There is at the same time an improvement in the condition of the stools, which soon lose the unformed $\mathrm{f}$ extid character formerly present. As a rule, in about eight or ten days the diet may be gradually increased by the addition of meat in the form of fish, chicken, or minced rumpsteak, more bread, and a milk pudding with a little cream. Later, well-boiled green vegetables may be added. The return to an ordinary diet should be accomplished very slowly, the stools being carcfully examined from time to time. The examination of the stools is the most important guide to the successful dietetic treatment of these cases.

Chlorosis.-Many cases of chlorosis are associated with marked subjective symptoms of gastric disturbance, such as scnsation of weight after food, flatulence, pain in the epigastric regions, and vomiting, and in these cases the possibility of the coexistence of a gastric or duodenal ulcer has to be borne in mind. In the majority of cases, however, these symptoms are absent. The treatment of these two

1 Baked bread is prepared by cutting a loaf of stale pan bread very thin, dipping the slices in milk, and placing in a cool oven to become thoroughly crisp and of a liglut brown colour. 
different groups will now be considered in detail, but reference may first be made to certain preliminary essentials in the treatment of all cases, viz. :-

1. A thorough clearing-out of the boucls by a judiciously selected course of aperients, or enemata of soap and water, or soap and water following small injections of olive oil. Frequently-administered enemata may be required to completely remove the scybalous masses which are so frequently present in cases of anremia. After the bowels have been cleared out, some tonic aperient medicine, e.g. cascara, should be administered daily.

2. Careful attention to the condition of the month and teeth.-A septic condition of the mouth and tceth is frequently present in chlorosis, and this should be remedied by appropriate means, the assistance of a dental surgeon being called in, if necessary, to get the mouth into a satisfactory condition.

3. Complete rest in bed. - In all pronounced cases, complete rest in bed for at least three to four weeks is essential to a speedy and complete recovery.

Chlorosis with pronounced gastric irritation.-In this condition there is marked hyperæsthesia of the gastric mucous membrane, sometimes associated with an excessive production of hydrochloric acid. The indications for treatment are therefore-(I) To give the stomach rest by giving easily digested food in very small quantity at a time, or it may be by withholding food altogether for twenty-four or forty-eight hours, nutrient enemata being substituted; and (2) Administering an alkali, c.g., bicarbonate of soda, io to 30 grs., with fluid nourishment. These indications are fulfilled in the following manner. Milk should be the staple dietary, and should be given diluted with potash, soda, lime-water, Vichy or Apollinaris water, I ounce of milk being given every hour. In some cases it may be advisable to give the milk peptonised. The amount of milk and the proportion of milk should be gradually increased until the patient is taking from 4 to 5 pints of milk in the twenty-four hours. This is best given in the form of 8 to 10 ounces every three hours. 
As soon as the gastric symptoms have subsided, other nourishment may be given, chiefly in the form of breadstuffs-dry toast, rusks, Vienna rolls, Veda bread; meat juice and beef-tea preparations, and lightly malted invalid foods, such as Sarory \& Moore's, Benger's, and Allenbury's food. These should be followed by simple farinaceous food, such as semolina, ground rice, arrowroot, and cornflour. The recently introduced preparations of "Puffed rice" and Granose flakes make an agrecable cliange to many patients. Protcin foods should be gradually added to the cliet: eggs, souffés, fish-steamed whiting, plaice, and flounders are the lightest -swectbread, chicken, fresh game, rabbit; later, mince, beef quenelles, and steak, the patient gradually passing on to the convalescent diet, fully described on page 387 . If flatulence is a promincnt feature, special care must be taken with the vegetables, the most suitable ones being cauliflower, spinach, and Portugal onions, potatoes being withlueld until digestion is stronger. Of the pulses, lentils may be given on account of their richness in iron; the pulscs, as a whole, however, are not very easily digested by these patients. At the end of four to six weeks, if the condition of the blood is now improved, the patient may pass to an unrestricted physiological diet, special warning being giren against the immoderate use of tea, any deficiency in protein and fat elements of food, and an cxcess of carbohydrates often in unsuitable forms. The addition of moderate quantities of fresh fruit and vegetables is of value both in gencral nutrition and for assisting to correct the tendency to constipation.

Dictary in Chlorosis, associated with Gastric Derangement.

\begin{tabular}{|c|c|c|c|}
\hline & $\begin{array}{l}\text { mmencement of } \\
\text { First Weck. }\end{array}$ & & Second Week. \\
\hline 6 & $\begin{array}{l}\text { Milk, io oz. (hot } \\
\text { or cold). }\end{array}$ & $\begin{array}{c}\text { A.M. } \\
6\end{array}$ & Milk, Io oz. \\
\hline 8 & $\begin{array}{l}\text { Gruel and milk, } \\
\text { Io oz. (a litule } \\
\text { cream;. }\end{array}$ & 8 & $\begin{array}{l}\text { Cup of tea ; or } \\
\text { Milk and cream. } \\
\text { White fish } \\
\text { (steamed); or } \\
\text { Lightly-boiled } \\
\text { egrg. }\end{array}$ \\
\hline
\end{tabular}

Third Week (Full Convalescent Diet). A.s.

6 Milk.

8 Ordinary light breakfast. Milk, 10 oz. 
CHLOROSIS

Commencement of First Week.

A.M.

I Milk, with egrs ; or Cup of soup.

P.M.

I. jo Milk pudding, made with I egg and milk, $10 \mathrm{oz}$; such as

Custard.

Semolina.

Sago.

Breadcrumbs.

Cornflour.

Ground rice.

4 Horlick's malted milk ; or

Peptonised cocoa (Allenbury's).

6.30 lienger's food; or

A I I e n bury's (salted).

Both made with milk.

9 Milk, $10 \mathrm{oz}$
Second Week.

A.M.

11 Cup of Bengrer's, and milk; or

Allenbury's or

Savory \& Moore.

P.M.

1.jo Soup (see page 302).

Chicken, with bread sauce ; or

White fish, with white sauce.

Slice of toast.

I vegetable (cauliflower, spinach, onion).

Pudding (not farinaceous).

4 Tea, with milk. Bread and butter.

6. jo Bowl of gruel; or Milk pudding, with milk and cream.

9 Cup of raw-beef soup or beeftea.
Third Week (Full

Convalescent Diet).

A.M.

11 Soup, with scraped beef ; or

Milk, with yolk of egg or egg flip.

P.M.

1.30 Soup.

Red meat, simply cooked.

Potatoes and a vegretable.

Pudding, with stewed fruit.

Cream.

4 Tea, with milk.

Bread and butter. plain cake.

7 Light two-course dinner.

Glass of milk ; or Soup.

Chlorosis without much gastric disturbance.-Rest in bed, attention to the toilet of the mouth, and the cure of constipation, already referred to, are of prime importance in treatment. After the first fow days, when the bowcls have been thoroughly cleared, the paticnt can be placed on a full convalescent diet-which includes meat, eggrs, good soup; in the vegetable kingdom, lentils contain a relatively large amount of iron, and can be judiciously made use of in the dictary. 
7 A.M.-Uncooked fruit-apples, figs, prunes, or raisins.

\section{Breakfast-}

Saucesful of porridge, with cream and milk.

Fish, egg, tongue, bacon, ham.

Cup of tea, with plentiful supply of milk.

1 A.M.-Cup of milk, or small cup of soup.

Lunch (two-course)-

1. Freshly-cooked fish, chicken, rabbit, sweetbread, red meat, with regetable.

2. Milk pudding, with stewed fruit.

Tea-Cup of tea (made with milk), bread and butter. No new scones.

Dinner (three-course meal)-

Freshly-cooked meats, with one vegetable.

Simple pudding or savoury.

$\begin{array}{llll}\text { Soup, } & \text { Meat, } & \text { Soup, } & \text { Fish, } \\ \text { Fish, } & \text { Pudding, } & \text { Meat, } & \text { Pudding, } \\ \text { Pudding. } & \text { Savoury. } & \text { Pudding. } & \text { Savoury. }\end{array}$

Io P.M. - Milk, one cup, with Horlick's malted milk.

Pernicious or Idiopathic Anæmia.-Pcrnicious or idiopathic anæmia is esscntially a disease of adult life. The cause is unknown; recent advances in our knowledge point to its being, in the vast majority of cases, the result of a chronic absorption of poisons from the intestinal tract. The history of the case usually reveals some gastric intestinal disorderconstipation, flatulence, deranged appetite-which has been induced or aggravated by a septic condition of the teeth and mouth (oral sepsis). An examination of the stools shows them to be unformed and foetid in character. The discase is a serious one, and frequently fatal. Diet is a very important factor in treatment. The following points are essential adjuvants in treatment:-

I. Complete rest in bed is essential.

2. Careful attention should be directed to the state of the mouth and teeth. All septic stumps should be removed, and an antiseptic mouth-wash used daily.

3. The bowels should be thoroughly cleaned out by the aid of one or two doses of calomel, followed by salts or by enemas of soap and water. 
4. The use of medicinal agents which arrest abnormal bacterial activity in the intestinal tract is usually indicated. These include various preparations of lactic acid bacilli-e.g., Lacto-bacilline, Sauerin, and, to a lesser extent among drugs, salol, sulpho-carbolate of soda, and calomel.

Dietetic treatment.-The diet has to be adapted alike as to the amount and nature of the foodstuffs used, to the impaired state of digestion, to the chronic catarrhal condition of the bowel, and to the correction of the abnormal bacterial activity in the small and large intestines, which are so important features of the discase. The indications for treatment are therefore the following:-

I. Foodstuffs must be of an easily digestible nature.

2. Farinaceous foods to be restricted, because of their liability to undergo abnormal fermentative changes.

3. Protein foods to be selected with care, so as to diminish putrefactive changes in the bowel.

The degree of bacterial infection from the bowel depends very largely on the amount of foodstuffs available for them. The multiplication and activity of the bacteria will be proportionate to the amount of foodstuffs presented to them. The aim in treatment is to give a diet of such size and quality as will be rapidly digested and absorbed, thus arresting abnormal bacterial activity in the small and large intestines.

In severe cases associated with gastro-intestinal derangement.-For the first few days a much restricted diet is advantageous. One and a half pints of skimmed milk, 1 pints of soured milk, and I pint of a meat tea, with two slices of crisp toast or unsweetened rusks, in the twenty-four hours, is a useful dietary for the first few days. This diet is best administered in quantities of $S$ to IO ounces every three hours. Under the influence of this regimen the appetite improves, the abdominal discomfort or pain abates, and the state of the motions becomes more satisfactory. The diet is then cautiously increased. This may be done by the gradual addition of easily digested protein in the form of white of egg, fresh milk, raw-meat juice, either prepared at 
home or the various meat juices in the market, Wyeth's, lichig's peptone, etce, or one of the varions malted foods, and raw oysters.

Animal food in the form of fish, chicken, sweetbread, pheasant, partridge, rabbit, or tripe; and puddings in the form of sweet jelly, milk jelly, blancmange, lemon sponge, curds, or custard are then added to the dietary. Plain mills puddings should come later, as they are a greater tax on the digestion than those mentioned. Fruit juice may be given in the form of refreshing beverages (p. 275). Special care must be taken with regard to the increase of the farinaceous foods and of vegetables. Simplicity in the meals gives the keynote to successful treatment. In cases associated with acute febrile disturbance it may be necessary to have recourse temporarily to the fever diet described on p. 268.

The following diet sheets may be recommended as being appropriate for a case of an adult man of average size, to be commenced after the few days' fluid dietary recommended above :-

6 A.M. -Milk, 10 ounces (hot or cold).

S A.M.-Cup of Benger's food made with milk, a little milk to drink, and a crisp slice of toast.

Il A.M.-Soured milk, 10 ounces; dry rusk.

1.30 1.M.-Beef-tea, chicken essence, etc., strengthened by the addition of white of egg, Protene, Plasmon, or Sanatogen, or by the addition of $\frac{1}{4} \mathrm{lb}$. raw scraped beef; slice of crisp toast or a roll.

4 P.M.-Cup of milk, or cup of tea made with boiling milk.

6) P.M. - Cup of buttermilk, with slightly sweetened biscuits.

8 P.M.-

Cup of Allenhury's or Benger's food made with milk ; or

Cup of Horlick's malted milk made with milk, and a slice of dry toast.

In cases with atony of the stomach and bowel with dilatation of the stomach, and also in cases complicated with renal disease and dropsical tendency, a very much smaller amount of liquid must be given and food must be administered in a morc concentrated form, as in the following diet list :-

6 A.M.-Chicken essence or jelly, 6 ounces; half-slice of toast.

8 A.M. - Cup of invalid food ; ald to this white of egg, well beaten. il A.M.-Soured milk, 10 ounces, and a plain dry biscuit. 
1.30 P.M. -

Fish or chicken souflé, or scraped beef mince.

Half-slice of toast.

4 P.M.-- Cup of tea made with milk, 6 ounces.

6 P.M.-Soured milk, to ounces, and a plain dry biscuit.

8 P.M.-Beef-tea, or strong soup thickened with egg and a little milk, or Plasmon, or Protene.

Later, when the gastro-intestinal condition has improved as shown by the state of the tongue, the return of appetite, and the more normal state of the motions, the diet must be made more liberal and varied, as follows :-

6 A.M. - Cup of tea made with milk, or a glass of hot milk.

8 A.M.-

White fish, or lightly boiled fresh egg.

产 pint hot milk.

Slice of crisp toast, or roll with butter; no jam or marmalade.

I I A.M.-Coured milk, $\frac{1}{2}$ pint, with biscuit.

I. 30 P.M. -

Clear soup, or meat tea, ro ounces.

Fish, chicken, game, sweetbread, rabbit, or tripe, simply cooked.

Half-slice toast, or rusk.

Pudding, to be preferably jelly, curds, custard, or a little stewed fruit with cream.

Tablespoonful of whisky, or glass of wine if desired.

4 P.M.-Cup of tea or peptonised cocoa, made with milk; one small piece of plain breadstuff.

6 P.M. - - $\frac{1}{2}$ pint of soured milk and a biscuit.

8 P.M.-Fish or chicken souffé, slice of toast or roll, glass of milk.

After eight or ten days of the above dietary it will usually be found that there has been a further improvement in the state of the digestive tract, shown by the complete disappearance of subjective symptoms, and a further improvement in the state of the stools. The total amount of food may now be increased, but the diet should be maintained along the lines inclicated. Farinaceous puddings, thick soups, pastry, and rich foods of all kinds should be avoided, or, at most, given in the most sparing amount.

Leukæmia.-The dietetic treatment of the different forms of leucocythæmia or leukæmia should be largely conducted along the lines laid down for the anamias. Subjective symptoms are often absent in the early stages of the chronic 
leukremias, but in the later stages disturbances are frequent. These take the form of loss of appetite, flatulence, sickness, constipation, which may alternate with diarrhœa, and the passage of ill-formed, foetid stools. Further, the great enlargement of the spleen which is frequently present may mechanically interfere with gastric digestion. As in the case of ancemias, it is essential $(a)$ to attend to the toilet of the mouth, setting rid of any septic foci there present, and (b) to avoid constipation by the use of suitable aperients.

In cases not associated aith gastric derangement, all that is required is to give the patient a light, nourishing diet; the meals to be simple, not too mixed, not too large, and to be free from all rich and over-stimulating articles of food. Red meats should be given sparingly; farinaceous foods to be restricted in anount; the use of milk, and especially buttermilk, should be encouraged. All meals should be taken at regular intervals, and nothing taken between meals.

In cases associated with derangement of digestion, the diet should be framed exactly along the lines laid down for pernicious anæmia on p. 389.

Scurvy.-The exact etiology of scurvy is unknown. It is variously ascribed to a deficiency in the potash salts of the food, to a deficiency in the alkalinity of the blood (acidosis), to ptomaine poisoning, and to a specific infection. Whatever the cause may be, it is known that a plentiful diet of fresh vegetables and of fresh meats cures the disease, and it is essentially therefore a dictetic disorder.

In this connection the important distinction between vegetable foodstuffs on the one hand, and meat and cereal foods on the other, must be borne in mind. The former contains an excess of base over mineral acid, the latter contains an excess of mineral acid over base. A diet which contains little or no vegetarian foods will therefore diminish the alkalinity of the blood, tending to produce a condition of acidosis, while a diet rich in vegetables will increase the alkalinity of the blood. In the sporadic cases of adult scurvy met with in this country, we invariably find that the diet has been radically defective in the following directions :(I) Vegetables and fruits have been absent, or taken in too fractional amounts; and (2) the meat foods taken have not 
been sufficiently of the fresh meat variety, tinned foods having been too largely used.

The condition can be easily cured. In severe cases associated with a painful septic state of the mouth and gums, frequently with diarrhœa or constipation, the food should be fluid or semi-solid, so long as mastication is difficult. For such a case, in a boy of twelve or fourteen years of age, the day's dietary may with advantage be-

Fresh milk, 2 to 3 pints, thickened with some invalid food.

Beef-tea, I pint, thickened with some fresh-meat juice, or the white of egg.

The juice of a lemon, or lime, or orange.

As soon as the difficulties in mastication have been overcome, the diet can be increased by the addition of red meat, white meat, and a liberal supply of vegetables. The nature of the vegetables is not material. Cabbage, lettuce, potatoes, cress, and onions are among the most useful, and among fruits, lemons, limes, oranges, and apples may be specially mentioned. A good lemonade drink is described on page 276. The lime juice should be reasonably fresh, as after being stored for a long time it partly decomposes into citric acid and carbonates, thereby losing much of its value. Infusion of malt has been credited with possessing valuable antiscorbutic properties; it must, however, be fresh. The following is a suitable dictary for an ordinary case of adult scurvy in which there is no marked gastric intestinal derangement :-

Breakfast-

Fruit, an apple or orange, taken half-hour before breakfast

Tea.

Bacon and eggs, or fish.

I I A.M.-Drink of lemonade and a biscuit.

Dinner-

Soup made from good vegetable stock.

Red or white meat, green vegetables, and potatoes.

Stewed fruit, or milk pudding.

Drink of fresh lime or lemon juice in water.

Tea-Tea, bread and butter.

\section{Supper-}

Fish or chicken.

Bread and cheese, and salad. 


\section{CHAPTER XXII}

\section{DIET IN ARTERIO-SCLEROSIS}

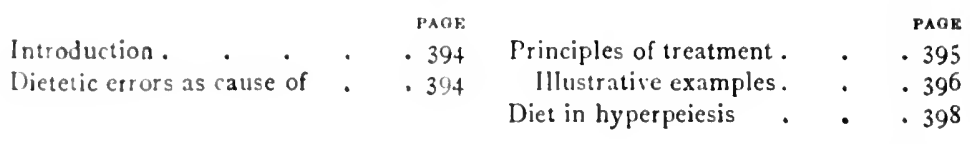

Introduction.-The general thickening of the arterial wall which is characteristic of arterio-sclerosis, is too commonly regarded as essentially a clisease of adult and later life. This condition, however, is very frequently present in young subjects, more especially in men who lead a life of physical strain, e.g. miners and athletes, and it is occasionally met with in young people in whom it has developed as a sequel of an acute infective disease. In its later stages it is usually associated with chronic renal or chronic cardiac disease, and in practice well-marked cases of arterial sclerosis are frequently met with which have cscaped recognition until the onset of symptoms of heart failure or of renal discase. The dietetic treatment in the earlier stages of the disease will now be considered.

Arterio-sclerosis is frequently but by no means invariably dependent on prolonged high blood-pressure, this increase of blood-pressure being due to the action of some poison or poisons in the circulation, which constrict the bloodvessels and induces hyperplasia of the vessel walls. The source of this poison is usually the intestinal tract. Diet undoubtedly plays an important part in the development of arterio-sclerosis, and we must, therefore, look upon diet as a factor with prophylactic and to some extent curative properties. Defective feeding may induce arterio-sclerosis in one of the following ways.

I. By the action of toxins produced by abnormal digestion 
of proteins and especially animal protein foods in the digestive tract, more particularly in constipated subjects.

2. By the action of toxins produced by abnormal fermentation of the carbohydrates of the food. In such cases flatulent dyspepsia and constipation are usually prominent clinical features. In these cases it is possible that the carbohydrates of the food are only indirectly the source of the poison, the toxin being derived from the protein clements of the food, the normal digestion of which has been deranged by the excess of carbohydrate food.

3. By the development of toxins produced either in the digestive tract or in the tissues from an cxcess of nutrient material - over-eating. Herc again constipation is an important predisposing factor (sec also Auto-intoxication, p. 346).

As the disease is insidious in its origin, and has, as a rule, been of long duration when the patient first comes under observation, it follows that the full beneficial effects of a more physiological diet may not be attained for many months. Treatment must therefore be prolonged over a lengthened period, the state of the blood-pressure serving as a useful guide in the treatment. In addition to diet, it is of the first importance to promote free and regular evacuation of the bowels, and to regulate, or it may be, forbid indulgence in alcohol and tobacco. The main principles to be followed in the dietetic treatment may be summarised as follows :-

(a) In young subjects there should be a marked restriction in the amount of animal protein foods. In some cases a prolonged course of an exclusive milk diet may be adopted with advantage.

(b) In adults and elderly subjects a restriction in the total amount of foods is important. Here also a diminution in the animal protein food is advisable.

(c) Drinking of fluid between meals should be encouraged. The urine of these patients is frequently concentrated, and deficient in quantity, and it is advisable to bring the specific gravity of the water down to about IoI6. This is best accomplished by ordering a measured amount of fluid, e.g., half a pint of plain water, hot 
or cold, Salutaris, or Apollinaris water to be taken the first thing in the morning and the last thing at night. If this does not suffice to bring down the specific gravity of the urine to 1016 or thereby, another half pint of fluid may be ordered to be taken an hour before lunch and dinner.

(d) Thorough mastication of the food, the prevention of oral sepsis, careful regulation of the bowels, with an occasional course of mercurials and salines, and abstinence or moderation in the use of alcohol and tobacco, are essential adjuvants in treatment.

A practical illustration of the foregoing points may be given by a reference to illustrative examples of the disease. ln the case of young subjects it may be advisable to prescribe a few weeks' complete rest in bed, with an exclusive milk dietary for this period. When this is not called for, the dietetic regime should be as follows :-

In a youth of 14 years of $a g c$, in whom the condition has developed as a sequel to an acute infective disease such as typhoid or scarlet fever. The chicf point here is a restriction in the amount of animal protein foods, and especially every variety of red meat. Special injunctions should be given as to thorough mastication of the food, and promotion of a regular action of the bowels.

Breakfist should be largely a farinaceous diet, consisting of porridge and milk, bread and milk, with perhaps fruit

Dinner-A simple three-course dinner, with fish, white meat (sweetbreads, tripe, rabbit), and red meat on alternate days.

Tea and Supper should comprise chiefly milk and breadstuffs. Eggs and cheese may be allowed occasionally. Weak tea may be taken in the earlier meal.

In a man at. 22.- It is not unusual to find that the routine diet of a young man with thickened vessels includes a large amount of meat foods taken three or four times daily, carbohydrates forming a relatively small proportion of the total food. In rarer cases the diet is too exclusively carbohydrate in character, and associated with the drinking of tea, three or four times daily, often with excess of sugar, jams, etc. Both of these extremes are to be avoided. In 
well-marked instances it is advisable to place the patient on a milk diet for a month or longer, rest from work and complete rest in bed being at the same time necessary. Subsequently, the chief point to attend to is to diminish the intake of meat foods, substituting soup, thickened with farinaccous substances, with vegetables and puddings. The meals should not exceed three in number. The drinking of water should be encouraged. Alcohol in every form is better withheld. Special injunctions should be given as to thorough mastication of the food, and the promotion of a regular action of the bowels. An appropriate dietary is appended :-

Breakfast.-Bowl of porridge and milk, tea, bread and butter, and jam.

Dinner.-A plain three-course dinner, in which white meat frequently takes the place of red meat.

Tea.-Tea, bread, butter, cheese, with an egg.

A regime along these lines should be continued permanently.

In an elderly subject.-Most elderly people eat more than they require, and more than is good for their arteries. It is thercfore advisable to give detailed instructions as to the amount and nature of the foodstuffs appropriate to the age, the body-weight, and the general circumstances of the patient as to work, social conditions, and the like. The leading points in dietetic treatment may here be summarised as :-

(a) An all-round restriction in the total amount of food consumed.

(b) Meat meals, and especially red-meat meals, should be reduced to not more than one meat meal a day. In many cases white meats only can be prescribed with advantage.

(c) Highly spiced foods should be avoided.

Some patients learn by expericnce that they enjoy the best health on a diet which is largely vegetarian in character. With regard to alcohol, no universl rule can be laid down. Speaking generally, it is better withheld; but for paticnts with fecble digestion, and for others who have long been accustomed to tal:c stimulants in strict modcration, it is 
sometimes advisable to recommend a glass of light wine or spirit to be taken with food.

It is important to bear in mind that there are occasionally met with cases of pronounced arterio-sclerosis, sometimes but not always associated with increased blood-pressure, who have not been in the least addicted to excess of animal protein foods, but who have lived very largely on a carbohydrate regime. In these cases, if there is reason to suspect the immoderate use of vegetable foods these should be restricted, as benefit may undoubtedly accrue thereby. It should be clearly understood that cases of pronounced arteriosclerosis are met with in which the diet does not appear to have been a factor of importance in the development of the diseasc.

Hyperpeiesis (increased Blood-pressure). - Reference must be made to an important class of case characterised by increased blood-pressure without obvious thickening of the vessel wall, a condition to which special attention has long been drawn by Clifford Allbutt. In these cases the longmaintained increased blood-pressure sooner or later induces marked thickening and degenerative changes in the arterial walls, and for practical purposes they may therefore be regarded as cases of arterial sclerosis. The dietetic treatment of these cases is a matter of great importance; the principles of treatment and the practical details being similar to those indicated for arterio-sclerosis. 


\section{CHAPTER XXIII}

\section{DIET IN DISEASES OF THE HEART}

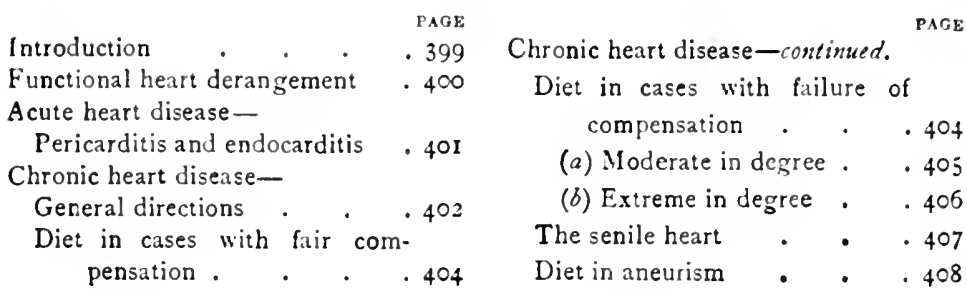

General Introduction.-It is probably no exaggeration to say that the majority of patients who complain of their heart are really suffering from a derangement of the stomach or liver, which has had its origin in dietetic crrors. This will emphasise to the reader the very important relationship which exists between the stomach and the heart, and at the same time will indicate the great importance of diet in the prevention and curative treatment of various cardiac disorders. Cardiac diseases are divided into two great groups, functional and organic. In the former there is a temporary derangement of the nervous and muscular mechanism of the heart; if there is any change in the structure of the heart, it is of a curable character. In the latter there is definite organic disease of the valves of the heart, or of the heart muscle. This is incurable; but when the tone of the heart is restored all the symptoms of the condition may disappear.

Organic disease may be acute or chronic. The acute diseases comprise inflammation of the covering of the heart (pericarditis), and of the lining membrane of the heart (endocarclitis), both of which are usually due to the poison of rheumatism, scarlet fever, or Bright's disease. The chronic diseases are the result of a chronic inflammation or degenera- 
tion of the valves of the heart or of the heart muscle. These may be the sequel to acute disease; more commonly they are the result of a primary degenerative change due to the poison of gout, alcohol, rheumatism, Bright's discase, arterial sclerosis, syphilis, and influenza. A particular type of chronic organic disease is known as the senile heart; this results from a fatty or a fibroid degeneration of the heart muscle in elderly subjects. A considerable amount of organic disease of the heart may be present without inducing symptoms, and it is only when the heart begins to fail that definite symptoms of heart mischief are manifested.

Threc cardinal features of heart disease are breathlessness, precordial discomfort or pain (angina), and palpitation. These are characteristic both of functional and organic disease, but are often most pronounced in functional disorders. In organic disease of the heart, symptoms may be few or absent, so long as the heart has been able to adapt itself by hypertrophy of muscle to the increased strain upon it; in other words, so long as compensation is established. There comes a time, however, when the compensatory mechanism fails, the heart muscle gives out, and the heart dilates, with the result that breathlessness, weakness, and other symptoms develop in proportion to the degree of dilatation. If this dilatation of the heart is very markedin other words, if there is a complete failure of compensation -it induces a pronounced venous congestion of the vessels of the stomach, liver, kidney, and lungs, with resulting gastric catarrh, deranged digestion, albuminuria, and bronchitis. The question of diet becomes one of very great importance in these cases.

Functional Heart Derangements.-As already indicated, the leading symptoms of functional disorder of the heart are precordial discomfort or pain, palpitation, and breathlessness. The more common causes of these derangements may be summarised as follows :-

I. Errors in diet-over-cating; hurried meals; excessive use of tea and alcohol.

2. Indigestion due to slight catarrh of the stomach or congestion of the liver, usually arising from an 
injudicious dietary, and more especially the too great use of starchy foods.

3. Nervous disorders, especially neurasthenia and hysteria.

4. Anremia and debility.

5. Extraneous poisons, e.g. tobacco and drugs.

We are only here concerned with the dietetic treatment of those cases which fall into the first two groups.

The first cssential in the treatment of these cases is to ascertain in what way the dietetic habits of the individual have been at fault. It may be that the patient has been in the habit of taking five or six meals a day, tea and starchy foods bulking very largely in the dictary. Irregularity of meal hours and hurried meals are responsible in other cases. Constipation is an important predisposing factor, and worry is often a contributory cause. These defects must, so far as possible, be got rid of. As a rule, no special system of diet is called for. If the above points are kept in view, three simple meals a day will speedily cure the condition.

Acute Heart Disease-Acute Pericarditis and Endocarditis.-These are acute febrile disorders, and the diet is essentially the diet of the febrile state. The most common cause of these affections is the poison of acute rheumatism, which induces rheumatic fever. The diet at the outset should be an cxclusive milk diet. From 3 to 4 pints of milk should be given in the twenty-four hours, diluted one-third or more with plain water or potash. This should be given in the form of $S$ to Io ounces every two hours. Abundance of fluid is essential to promote fluidity of the blood, sweating, and free diuresis. The patient should, therefore, be encouraged to make free use of alkaline drinks, I pint or more of plain water or potash or soda-water being taken at intervals in the twenty-four hours. If milk is not well taken, it may be peptonised, or it is sometimes well borne if citrate or bicarbonate of soda are added to it in the proportion of 2 to 3 grains to the ounce. In cases where there is a marked intolerance to the milk, we must have recourse to beef-teas and meat essences. These should not be strong, but may have their nutritive value increased by the addition 
of some protein food. Further details, with appropriate dietaries, will be found in the chapter dealing with acute fevers.

If stimulants are necessary, brandy and champagne are probably the most useful. These should be given in doses of $\frac{1}{2}$ and $I$ ounce of brandy, or $I$ and 2 ounces of champagne, once or twice daily.

Chronic Heart Disease.-The dict for patients with chronic organic heart disease usually requires more or less careful regulation, even before compensation is lost, for digestion is always more or less handicapped by the heart lesion, with its resulting venous stasis in the liver and other parts of the alimentary tract. After compensation is lost the question of cliet certainly becomes one of the most important factors in the treatment. The gaseously distended abdomen may press up the diaphragm and impede the already embarrassed respiration, thus occasioning great discomfort and restlessness. These symptoms can be greatly lessened and often entirely relieved by a carefully restricted and judiciously arranged dietary. The diet must be regulated to suit the condition of the patient and his special circumstances. General principles applicable to all cases are as follows :-

\section{General directions:-}

I. The meals should be small in amount. More should never be taken than the patient can easily digest. Over-distension of the stomach from food mechanically pushes up the diaphragm and displaces the heart, causing palpitation and dyspnoea. In addition, if the meals are too large, the residue of the digested food in the intestine ferments and causes flatulence.

2. The meals should be simple, and well cooked. A simple diet (i.e. not too large a variety of courses) throws less strain on the digestive functions, and also greatly diminishes the risk of eating to excess. Improperly prepared food is a cause of indigestion, and may itself produce flatulence and discomfort.

3. Long intervals between the meals should be ordered, and eating between meals should be strictly pro- 
hibited, as even a small portion of food taken while digestion is in progress may give rise to flatulence. The object of this restriction is to permit the stomach to have time to enabie it to completely get rid of one meal before it is again filled.

4. Three meals of about equal size should be taken in the twenty-four hours. The midday meal can be the richest, but the total bulk should be about the same in each.

5. The meals should be taken as dry as possible. This lessens the distension of the stomach and does not over-dilute the gastric juice; further, fluid ingested tends to dilate the vessels, to raise arterial tension, and to increase the work of the heart. Fluid need not be restricted to a very small amount unless special indications arise, but it should be taken mainly between meals and sipped siowly. Weak tea or coffee can be taken in small amount with breakfast, and alone for afternoon tea.

In a general way, it may be said that, in all cases in which compensation is satisfactorily established, a diet of plainly prepared food, unencumbered by too many detailed restrictions, is best, but a few nints may be here given as to foodstuffs.

All highly seasoned food and condiments are better omitted, as they tempt the appetite more than is necessary: Stews and badly fried foods are apt to cause derangement of the digestion.

It will also be found advisable to restrict the carbohydrates, especialiy the starches and sugars; they need not be strictly cut off, unless causing fermentation and flatulence. Toast, dry bread, rolls, biscuits, may be taken, but should never be eaten warm. Lightly made and well-cooked milk puddings can be taken, but pastry and suet puddings are not suitable. Of the vegetables, potatoes (not new), caluliflower, spinach, vegetable marrow and cucumber, stewed tomatoes (the pulp only, boiled onions, stewed celery, asparagus tops, are all easily digested. The root vegetables and stalks of the green vegetables above mentioned should be avoided.

Alcohol is not necessary in the early stages of heart dis- 
easc, and if later indicated on account of marked failure of compensation, small doses of good whisky or good old brandy may be giren in measured quantity twice daily. Wine and beer are better withleld.

Diet in auses with fair compensation.-The following dietary is suitable for a case of chronic heart disease in an adult subject, when the compensation is not seriously disturbed:-

\section{S.30 A.M. : Brealefast-}

Cup of tea or coffee (one cup).

Fish, egr (with or without bacon), ham, tongue, or grilled kidney.

Two half-slices of toast and a roll, with butter ; or

A half-slice of toast, oatcake, or crisp rusk, with butter.

I. 30 P.M. : Lunch-Alternative meals.

Fish and potato, Chicken and bread sauce Chop or steak,

Fruit, with cream, and cauliflower,

Cheese and biscuits, Custard,

Small cup of coffee. Cheese savoury,

Small cup of coffee.

Jelly or cream,

Fresh fruit,

Small cup of coffee.

\& P.M. - A cup of tea (nothing solid to take with it).

7 P.M.- I three-course dinner, much the same as given for Lunch.

Diet rules for failure of compensation.-With failing compensation there arise various digestive disorders. Loss of appetite, flatulence, constipation, are the subjective indications which result from the congested state of the liver, stomach, and bowels which are now present. In later stages, albuminuria develops from the venous congestion of the kiclneys, and the tissues may now become cedematous or water-logged, from the interference to the free return of blood to the heart.

Dict rules for failure of compensation.-The general dircetions already given should be closely adhered to. The diet varies according to the degree of severity of the heart failure. The dict appropriate to cases of moderate severity will first be cliscussed.

The patient, although ill, is not suffering from fever, and there is no necessity to place him upon a fluid diet given at short intervals. It is best to follow his usual habit, and continue having three meals a day. These should be, as before stater, small in amount, simple in character, well-cooked, and nutritive-arranged at sufficient intervals to permit of 
complete removal of one meal from the stomach before the entrance of the next into it. And, in addition, the meals should be as dry as possible; soup in these cases is better avoirlerl.

Breakfast is generally the best meal, as after the long rest there is more digestive capacity ; so with this meal a large cup of tea or coffee may be permitted, and a little carbohydrate foodstuff. China tea, apparently, is much better for a feeble digestion than Indian or Ceylon, and should, where available, be taken.

There is no need to give a tumbler of milk, cup of Bovril, or other food at I o'clock. It is better to let the patient sip slowly a glass of water about an hour before the next meal is due, at I or 2 o'clock. The midday meal should consist of chop or fish or fowl, with some carefully prepared green vegetable (p. 403), cooked with plenty of butter, and rubbed through a sieve. A second course of stewed fruit, sweetened with Saxin, and eaten with cream junket, or custard (baked or boiled) apple cream, lemon sponge, milk blancmange, jelly with cream. Creams flavoured in different ways are allowable. No pudding containing starch is to be allowed. A little cheese, eaten with butter, but no bread or biscuit, should be taken. Half an ounce of brandy or whisky may be allowed with the midday and evening meals.

At 5 o'clock a cup of Chinese tea, unsweetened, or with Saxin, may be drunk, but no breadstuff should be taken with it.

At 7 or 7.30 the evening meal should generally be a repetition of the midday one, but it is best to take chop or other red meat only at one of the meals. The vegetables mentioned above are allowable. A second course may be permitted, and may be followed by cheese, as before, if this agrees.

A glass of whisky or brandy in half a tumbler of hot water, or a small 令 pint of beef-tea, chicken tea, or good consommé may be taken after 10.30, but no breadstuff of any kind should be taken along with it. Three small meals will usually be ample for a cardiac sufferer; there is no question that any laxity from this diet will speedily show itself with increased flatulence.

Those patients who have been in the habit of taking dinner and high tea must give up the habit. It is very difficult to make them understand that the midday and cvening meal should be very much the same in quality and quantity.

An illustrative diet sheet is here given :-

8 to 8.30 : Breakfast-

I large cup of China tea, with plenty of milk and cream.

Thin crisp toast made from "pan loaf," or V'eda bread with butter and a little marmalade.

One of the following :-

Bacon (fat, crisply cooked), or fish (steamed or fried or rizzard) ; egg, plain boiled, scrambled, or poached; tongue, or potted meat. 
Midday meal and Earening meal-

Choice from-

1. Fish, rabbit, fowl, game, raw-beef mince, steak, chop, slice of roast beef or mutton (hot or cold).

2 Vegretalle: One selected from the following-

Greens-c.s., cabbage, lettuce, spinach, sprouts-boiled, rubbed through sieve, and heated in butter.

Vegretable marrow or cucumber (stewed).

Cauliflower and asparagus (tops only).

Celery (stewed).

Onions (Portugal)-long stewing.

3. Sweet-Stewed fruit, neutralised with soda bicarbonate, or soufflés sweetened with Saxin.

Roast apples, apple cream.

Custards (boiled or baked), with cream.

Junket, jelly creams

4. Cheese-Eaten with butter or cooked with eggs, if found to be digested.

Half a glass of whisky or brandy, with 4 ounces of alkaline water

Evenisg meal-A choice from $\mathbf{I}$ and 3 in the above midday meal. Two courses only to be taken. White meat in place of red meat should be taken once a day at the midday or evening meal. No cheese.

Diet for failure of compensation-advanced degree.-The feeding of the patient suffering from severe dilatation of the heart is often a very difficult matter. The liver is in a state of congestion, and unable to do its usual share in the digestive processes; the stomach is in a condition of catarrh, which has induccd complete loss of appetite, and often sickness and vomiting. In these circumstances it is sometimes advisable to give the stomach complete rest for forty-eight hours, and feed the patient entirely by the bowel (see p. 22I). In most cases the diet must for a time subsequently be entirely a fluid onc, and should comprise milk (plain or peptonised), koumiss, Kephir, various meat preparations, and invalid foods. The following dietary is given, so as to indicate the amount of food and the varicty of foodstuffs that may be recommended in these severe cases. The total nutritive value of this diet is small, but in many cases it is as much as the patient can possibly take for a week or two or more of his illness. In a few cases patients cannot even take as much as is given in this diet sheet, the amount of 
fuid that can be taken being about one-half of that indicated in this regimen. In all of these cases stimulants are advisable, preferably in the form of best quality whisky or brandy.

6 A.M. - Milk (peptonised), 2 ounces.

8 A.M.-Beef juice, 2 teaspoonfuls in a little aerated water.

IO A.M. - White wine whey, 2 ounces; or koumiss, 2 ounces.

12 A.M.-Allenbury food, 3 ounces.

2 P.M. - Beef juice, 2 teaspoonfuls, either given alone, or in a little brandy and water.

4 P.M.-Milk (peptonised), 2 ounces.

6 P.M.-A few teaspoonfuls of chicken jelly.

8 P.M.-Albumin water and milk, I ounce of each; or albumin water and koumiss.

Io P.M.-Allenbury food, 3 ounces, and brandy.

I2 P.M.-Beef juice.

I A.M.-Milk (peptonised), and brandy.

3.30 A.M.-Chicken jelly, a few teaspoonfuls.

The Senile Heart.-In elderly subjects suffering from heart disease, the general rules ahready given are the best guide in the treatment of such patients as are below their usual weight. A smaller number, however, are over their normal weight, and suffer more from breathlessness than the preceding class, these require careful dieting to reduce the obesity without reducing their strength. And for a third class, where the failure of compensation shows itself in dropsy of the tissues, a special "dry diet" is necessary.

Diet for heart disease in obese subjects.-This dietary is also appropriate to the general run of cases of angina pectoris, where there is no serious organic disease of the kidneys.

\section{Breakfast-}

Fluid restricted to 4 to 5 ounces-tea, milk, coffee, or cream, and seltzer water.

I slice of crisp toast with butter.

I poached or boiled egg, or I fillet of fish.

1.30 or 2 P.M.: Midday meal.-The principal meal of the day; should consist of two courses only.

$\left.\begin{array}{c}\text { Fish, } \\ \text { meat, and } \\ \text { I vegetable }\end{array}\right\}$ or $\left\{\begin{array}{l}\text { Fish and a potato. } \\ \text { Light pudding. }\end{array}\right.$ or $\left\{\begin{array}{l}\text { Meat and I vegetable. } \\ \text { Pudding. }\end{array}\right.$

(Fluid not to be more than 4 ounces of hot water.) 
5 P.M. - A small cup of Chma tea, freshly made, with cream and sugar.

7 1.M. : Fienins mal one course.

Fish, with toast; or heef fuice mince.

Chicken purie, with toast.

Saboury liovril custard.

Eggr in some form.

(Farinaccous foods better avoided.)

10 P.M. - b : tumbler of hot water.

Dry dict for dropsy (after Balfour).-

Breakfiast-

I slice of dry toast, no buter.

I cup freshly made tea with cream.

Dinner-

$\frac{1}{4}$ Ib. of rump-steak; or "eye" of 2 mutton chops; or an equal quantity of mutton (roasted) ; or beef, chicken, game, or fish ; as much dry toast as desired.

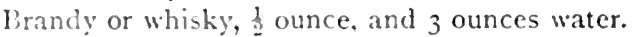

Sufper.-As much dry toast as is desired, along with $\frac{1}{2}$ ounce of brandy or whisky in 3 ounces of water; nothing more.

(It is not desirable that patients in this condition drink much, but if thirsty, they may be allowed to sip slowly 4 ounces of water an hour before meals.)

Aneurism.-Rest, a restricted diet with a limited amount of Auid, together with potassium iodide, form the chief points in the treatment of aneurism. The starvation diet recommended by Tufnell is only applicable in a very small proportion of cases. Tufnell's diet is as follows:-

Morning meal. -2 ounces of bread and butter, with 2 ounces of milk or cocoa.

Midilay meal. -3 or 4 ounces of meat, with 2 to 3 ounces of bread or potato, and 3 to $f$ ounces of water.

Evening meal.-2 ounces of bread and butter, with 2 ounces of milk or tea

This rigid regime is only advisable in well-nourished subjects, especially those with a plethoric tendency. It is quite unsuitable in debilitated subjects. In the latter there is sometimes an enfeebled digestion, and it may be advisable to have recourse at the outset, to a milk or lacto-vegetarian diet. The important points to attend to in framing the dictary in all cases are the following :-

I. Restriction in the amount of fluids of all kinds. Not more than from 20 to 30 ounces in the twenty-four hours. 
2. Meats and meat foods to be given in very sparing amount, the stimulating effects of these foods on the circulation being prejudicial.

3. A light, simple, nutritious diet, given thrice daily, with no food between meals. The meals should be much on the lines of the diet laid down on p. 548 .

4. Alcohol in all its forms is inadvisable, excepting in cases of feeble digestion where its use in small doses may prove beneficial. 


\section{CHAPTER XXIV}

\section{DIET IN RENAL DISEASE}

\begin{tabular}{|c|c|c|c|c|c|}
\hline & PAQE & & & & PAGE \\
\hline Indications for treatment . & .410 & Other renal disorders & • & & . 417 \\
\hline Bright's disease-Acute nephritis & - $4 \mathrm{II}$ & Lithæmia-gravel & & & - 418 \\
\hline Subacute and chronic nephritis & . 412 & Oxaluria . . & - & - & . 418 \\
\hline Use of a chloride-free diet. & . 416 & Phosphaturia. & . & . & \\
\hline
\end{tabular}

IN health the kidneys extract from the blood the excess of water, and the products of nitrogenous waste-urea, uric acid, etc. There is a definite relation between the quantity and quality of food ingested and the state of the urine. Thus a concentrated dry diet diminishes the amount of urine and renders it more acid; a liquid diet, e.g. milk, has diuretic properties, increasing the amount of urine voided. Animal foods and the more highly nitrogenous vegetable foods increase the amount of nitrogenous waste products in the urine, and also increase its acidity. Vegetable foods, on the other hand, lead to an increase in the salts of the urine; they tend to make it less acid, or even alkaline in reaction. A dry diet, and one which contains a high proportion of protein, throws a greater strain on the kidneys than one which contains much fluid and in which the proportion of protein foods is small in amount (see Appendix, p. 578). Advantage is taken of these facts in the treatment of nephritis and other kidney disorders, the indications in treatment being-(a) to lessen the amount of work thrown upon the kidneys; this is effected by diminishing the proteins, and especially the animal proteins, in the food; $(b)$ to avoid articles of food which during their excretion may irritate the diseased organs, such as alcohol in all its forms, spices, ginger, and the like; $(c)$ to maintain a permanent modification 
of the diet along these two lines from the time that the existence of renal disease has been detected.

Acute Nephritis.-General considerations. - It must be borne in mind that many cases of acute nephritis are not examples of a primary inflammation occurring in a previously healthy organ, but are really examples of an acute inflammation supervening in a patient who was previously the subject of subacute or chronic nephritis. It is important to recognise this, because care must be taken in all cases of chronic nephritis associated with an acute exacerbation of inflammation not to lessen the general strength of the patient by keeping him for too prolonged a period or an unduly. restricted dictary. The dietetic treatment of acute nephritis varies slightly according to the type of the disease, more especially as to the presence and severity of general dropsy. Attention will first be directed to the treatment of a simple, uncomplicated case of a primary acute nephritis, such as is associated with not more than a slight degree of cedema of the tissues.

Primary acute nephritis.-- In sthenic individuals all food should be withheld for the first twenty-four or thirty-six hours, during which diluents may be given in the form of plain water, potash or soda water, Salutaris, or Apollinaris water, to the extent of from 2 to 4 pints in the twenty-four hours. Barley-water, rice-water, or toast-water may be substituted if desired. Thereafter the diet should consist exclusively of milk, from I to 3 pints, increasing, it may be, up to 4 or 5 pints, in the twenty-four hours, diluted with an equal amount of water as above. In cases where milk is not readily digested, whey may be substituted with advantage, and, similarly, I pint or more of buttermilk in the twenty-four hours may advantageously replace an equal quantity of milk, the buttermilk allaying the thirst and improving the state of the digestive tract. The milk is more easily digested when administered in small quantities, esc. from $S$ to 10 ounces every one and a half hours. If there is difficulty with the digestion of milk, it may be given peptonised or pancreatised. As the general condition of the patient and the state of the urine improves, the milk may be reluced in amount and its nutritive value increased by the addition 
of Benger's food, Allenbury dict, Horlick's malted milk, Plasmon, or similar preparation; and, later, by the addition of bread and butter, milk puddings, fruits, and green begetables, with, if desired, a cup of tea. Meat in the form of fish, chicken, tripe, or sweetbread may be added to the diet, usually about the fourth week, and may be continued, provided its use is not followed by an exacerbation of symptoms - œdema, albuminuria, hæmaturia. Various vegetable soups, such as tomato soup, lentil or pea soup, are also useful at this period. A full ordinary diet should not be allowed for at least a month after the complete disappearance of albuminuria from the urine.

Acute nephritis, with pronounced anuria and anasarca.Here the amount of food and drink should be restricted to the smallest possible quantity, c.g., from 2 to 3 pints daily of milk diluted with carbonated water. Buttermilk may be substituted with advantage. This regime should be kept up for four or five days, by which time, in favourable cases, an improvement in the condition of the patient will allow of the treatment laid down in the preceding paragraphs.

Disadiantages of an caclusive milk dict, and means by which ovcreome.-Some patients show a marked intolerance for an exclusive milk diet, and for these the fermented milks, koumiss or Kephir, may be recommended. Such patients may be able to take buttermilk, whey, or various pancreatised preparations in place of ordinary milk. The addition of rice-water, barley-water, or oatmeal-water to the dietary promotes the toleration of a milk regime, and, in the same way, the administration of an imperial drink is of service. The constipating effects of a milk diet may be counteracted by the use of Philp's milk of magnesia, or Dinneford's fluid magnesia, or plain citrate or sulphate of magnesia. Any tendency to diarrhcea may be checked by the addition of lime-water.

Subacute and Chronic Nephritis, including Granular Contracted Kidney. - The principles underlying the dietetic treatment are essentially the same for the different varieties of subacute and chronic Bright's disease. One important essential in treatment is to bear in mind that the appropriate dietary for these cases frequently depends more on the 
general nutrition of the patient, and on the state of his carcliovascular system, than on the condition of the kidneys as revealed by the results of urinary analysis. The great indication in treatment is to relicve the strain on the kidneys so far as possible, compatible with the maintenance of a good condition of general nutrition and a satisfactory blood-pressure. In this connection reference may be made to the great importance of efficiently promoting the vicarious excretions of the skin and bowels in all forms of chronic nephritis. The dietetic treatment of a typical case of subacute or chronic nephritis will first be considered, and thereafter the modifications in this treatment that are called for in certain cases will be referred to.

Dietetic treatment of subacute or chronic nephritis, including renal cirrhosis. - The chief indication in treatment is to diminish the strain on the renal function by restricting the amount of animal protein food, especially meats, and by prohibiting the use of alcohol in all its forms. In sthenic individuals a prolonged course of a milk diet, or a lactovegetarian diet, should be recommended, the dict for these patients being similar to that recommended in cases of arterio-sclerosis (p. 394). The favourable results from this regime may be scen in an improved state of the urine, a lowering of the blood-pressure where that has been increased, and an improvement in the general condition of the patient. A suitable diet of a largely lacto-vegetarian character, appropriate to a working-man who is off work, or engaged in light work only, is as follows:-

Breakfast-Porridge and milk, tea, bread and butter.

Midday-Bowl of soup, 'bread and cheese, macaroni, vegetables, or fruit. Evening-Milk, egg, bread and butter, clieese or jam, and vegetables or fruit, if these were not taken at the midday meal. Eggs should be partaken of sparingly, and should not form a part of each day's dietary. White meats may later be added to the dietary, in the form of fish, chicken, tripe, or sweetbread. (See also Light Diet, $p .5+8$.)

In the case of well-to-do patients a grood alternative dietary is as follows :-

Breakfast-Café au lait, with plenty cream; Vienna rolls ur toast and butter, marmalade.

1 Made entirely from vegetable stock. 
Lismi - To be selected from the following (not more than two courses to be taken):-(a) Vegetable soup. (b) Steamed fish, fish souffé (made up with cheese or savoury sauce) ; or eggs occasionally in the form of omelet or souftle. (c) Light farinaceous pudding or stewed fruit, with cream.

Dinnir-kepetition of the midday meal, three courses, however, being allowed. Sweetbread, tripe, chicken, rabbit, or game may occasionally be allowed.

The use of red meats should be restricted, as there is no doubt that red meats are decidedly less suitable than white meats. Highly seasoned foods should also be avoided, since they tend to over-eating. Meat of any kind should not, as a rule, be allowed more than once daily. It will be noted that vegetable soups are recommended in the above diet sheets. Soups made from rich meat stocks should be avoided, because of the large amount of extractives present. Special attention may be drawn to the value of made-up dishes, in which an animal protein food is combined with carbohydrates, such as rice or macaroni, in varying proportions. Other vegetable savouries are given on page 528 . By this means the patient gets a mcat dish, but, on account of the smaller amount of animal protein, he gets it in a form which exerts a lesser strain on the tissues. The nature and amount of fluid to be allowed is important. Care must be taken that the diet should not be such as to induce a state of hydremic plethora, which would react unfavourably on the heart and circulation, and further aggravate and complicate the patient's general condition. Alcohol in all its forms should be prohibited; tea and coffec should only be given in small quantity, but the patient should be encouraged to drink fuids in the form of plain water, carbonated water, Salutaris, or Apollinaris water, preferably to be taken on an cmpty stomach. A good system is the administration of a large tumblerful of hot water, to be taken the last thing at night and first thing in the morning, and again an hour before the midday meal. Care must, however, be taken not to overload the system with fuid, the amount of fluid to be ordered being gatuged from a study of the amount of urine excreted and the condition of the bloud-pressure. Special care must be taken in this direction in cases associated with 
a distinct increase in the blood-pressure, and also in cases with general dropsy. Finally, it should be emphasised to patients with chronic nephritis that they should continue to have regard to their diet along the lines laid down above, even although all the subjective symptoms of renal disease may have disappeared. Attention will now be directed to the treatment of special cases.

Cases associatcd with threatened uremia.-Here the dictetic treatment is that given for acute nephritis. Food should be given in small quantity at a time, and in cases associated with vomiting or sickness should be given pancreatised.

Cases associated with marked impairment of general mutrition, ancmia with persistence of blood and albumin in the urine.-In this class of case it is important not to starve the patient in our attempt to improve the state of the kidneys. Experience has proved that occasionally a milk diet, or a lacto-vegetarian diet, fails to exercise its usual ameliorating effect on the state of the kidneys, as revealed by urinary analysis, and actual benefit accrues to the patient from the administration of a diet which contains a more liberal amount of animal protein food in the form of fish, chicken, and white meat than is allowed in the dictary given above. Those cases are, however, exceptional, and call for careful experimentation $w$ vith the diet. In this class of case the writer has found special benefit from the use of buttermilk and lactic acid bacilli.

Cases with marled increase in blood-pressure associated with dropsy.-A special point to attend to here is the amount of fluid to be allowed. This has already been alluded to, as has also the fact that close attention must be paid to the state of activity of the skin and bowels as important adjuvants in treatment.

Cases benefited by alcohol.-While alcohol is better withheld entirely in subacute and chronic nephritis, cases are occasionally met with in which the beneficial effects of a little alcohol on the weakened digestive tract or circulation more than outweigh the baneful effects which it exerts on the kidneys. In these patients half an ounce of whisky may be prescribed, to be taken once or twice daily, at meal times; Qut this should be discontinued as soon as possible. 


\section{Treatment of Chronic Nephritis by a Chloride-free} Diet.-In recent years attention has been directed to the therapeutic value of a diet prepared, cooked, and taken without salt, in the treatment of chronic nephritis, especially when associated with dropsy. Particular attention has been directed to this subject by Widal, and this system of treatment has been largely used by French clinicians. A salt-free dict is now one of the recognised dictaries in some of the leading Parisian hospitals. The same diet has been recommended for other morbid conditions, notably chronic heart clisease associated with dropsy, persistent diarrhcea, and cirrhosis of the liver with ascites. The rationale of a salt-free diet in cases of oedema and dropsy is fairly intelligible. Sodium chloride has a high osmotic equivalent, and it tends to retain fluid in the tissues. Its omission from the diet may therefore be expected to promote the elimination of dropsical effusions. The normal salt requirement in health is from I 5 to 30 grains daily, but the majority of persons consume about $\frac{1}{4}$ ounce or even considerably more. In the salt-free diet, foods are selected which contain the minimum of inorganic salts, and no salt is used in the cooking, or eaten as a condiment. A practically salt-free dietary is made up from the following articles of food:-Milk, bread made without salt, eggs, chicken cereals cooked without salt, butter, fruits, jellies, tea, and coffee. The results of treatment by a salt-free diet in cases of renal disease associated with dropsy have been by no means uniformly satisfactory in the hands of those who have tried this system. There is no question, however, that the beneficial effects of this treatment in some cases are quite remarkable, the results of treatment leaving no reasonable doubt as to the profound therapeutic value of a salt-free regime in these cases. In cases of nephritis, therefore, in which the dropsy of the tissues persists in spite of the application of the ordinary measures-dietetic and other-a dict which is largely chloride-free should certainly be tried. The following is an appropriate dietary, a little white meat cooked without salt being allowed occasionally.

Salt-free dietary.-No salt to be used in the cooking, or eaten at table. The best way to get over the difficulty of griving a salt-free diet is to make milk puddings made with 
eggs the staple, the flavouring being varied between vanilla, lemon, orange, nutmeg, cinnamon, chocolate.

\section{Breakfast-}

Porridge and cream, flavoured with syrup or sugar; or

Cup of tea with plenty milk; toast or roll specially prepared, and butter.

\section{Lunch-}

Eggs or prairie oysters, or egg flip, or sweet custard ; or

Roast chicken, with toast or roll as above; potato, or tomato.

Any farinaceous milk pudding, or jelly, or cream.

Afternoon Tea-Cup of tea, with wafer of toast or sponge biscuit.

Dinner-On same lines as Lunch; chicken not to be taken oftener than once a day.

In cases where a more rigid chloride-free dict than the above is tried without marked benefit specdily resulting from the treatment, the diet should not be indefinitcly continued, as the complete withdrawal of chloride of sodium from the food has occasionally been observed to aggravate the conditicn.

Dietetic Treatment of other Renal Disorders.-No special reference is necessary to the dietetic treatment of other renal disorders. These have all to be treated along the general lines indicated on p. 4 Io. One special point should, however, be noted. In conditions associated with pyelitis, attention should be directed to the reaction of the urine. Benefit is sometimes obtained by prescribing a diet rich in vegetable substances, so as to reduce the acidity of the urine. A meat meal should not be given more than once daily (see also p. 526). In cases of tuberculous disease it may be advisable to ignore to a great extent the condition of the urine, and to concentrate attention on the general condition of the patient.

Albuminuria is mercly a symptom, and as such hardly calls for consideration here. The first point to determine is whether the albuminuria is a result of demonstrable organic disease such as acute, subacute, or chronic nephritis, or whether it is of a so-called functional type such as occurs after exertion, or, in a few cases, during the height of digestion. The albuminuria of adolescence is closely related to the albuminuria of posture. When the albuminuria depends on organic kidney disease, the appropriate dietetic treatment should be carried out; in other cases, no special dietetic rules apply, 
with the exception of restricting the immoderate use of animal proteins, especially red meat and eggs.

Lithremia: Uric Acid Diathesis: Gravel.-The uric acid excreted in the urine is derived from two sources: from the food (exogenous purins), and from tissue metabolism (endogrenous purins). The former only can be influenced by diet. While the acidity of urine is not due to uric acid but to acid sodium phosphate, the deposition of uric acid occurs in an acid urine, and it may be desirable to make the urine temporarily neutral or slightly alkaline in reaction. In this connection it is important to note that milk and regetable food favour alkalinity of the urine, while meat foods tend to make the urine acid. The free use of fresh green vegetables should therefore be encouraged, as their alkaline salts are of value in tending to promote an alkaline state of the urine. Moreover, certain articles of dict are rich in purins, $\epsilon . g$., sweetbreads, thymus, tea, coffee, lentils, and meat, and these must be restricted or, it may be, withheld for a time. At the same time it must be borne in mind that an excessive meat diet is not by any means the sole cause of lithrmia; not infrequently the condition arises from the excessive use of farinaceous and saccharine foodstuffs. Abnormal decomposition of these foodstuffs in the intestine is followed by derangement of the liver function, with resultant changes in the blood and urine (lithæmia). Diluents have special value as general diuretics, and are further useful in correcting the catarrhal state of the pelvis of the kidney which is frequently present in these cases, and is a contributory factor in the ctiology of the condition. (See also Auto-intoxication, p. 346; Purin-free diet, P. 531 ; and Gout, p. 444.)

Oxaluria.-In oxaluria the greater part of the oxalic acid excreted in the urine in the form of oxalates is derived solely from the food or from the products of the decomposition of the food in the alimentary tract. The treatment of oxaluria consists, therefore, in withholding from the diet substances rich in oxalic acid, such as cocoa, black tea, spinach, tomatoes, rhubarb, pepper, sorrel, figs, strawberries, apples and pears, and in the administration of a diet little prone to fermentation and decomposition in the intestinal 
tract. Raw fruits and vegetables which contain citric, malic, and other organic acids have an important relation to the formation of oxalic acid. The dict appropriate to this condition, therefore, consists chicfly of various meat foods, milk, eggs without the yolk, and stale bread or rusks; this diet also acts beneficially by increasing the acidity of the urine due to increase of the acid phosphates, which help to keep the oxalates in solution. The free use of diluents, aided by small doses of sulphate of magnesia, is an important adjuvant to treatment. Dilute mineral acids, hydrochloric or nitro-hydrochloric, are of value if taken in 15 to $20 \mathrm{minim}$ doses immediately after food (see also Auto-intoxication, p. 346).

Phosphaturia.-The occurrence of phosphaturia is favoured by a diet rich in fruit and fresh green vegetables, and it is diminished by a diet from which these are excluded. Meat, eggs, milk, cheese, cercals, and legumes should therefore comprise the dietary in these cases. 


\title{
CHAPTER XXV
}

\author{
TUBERCULOSIS
}

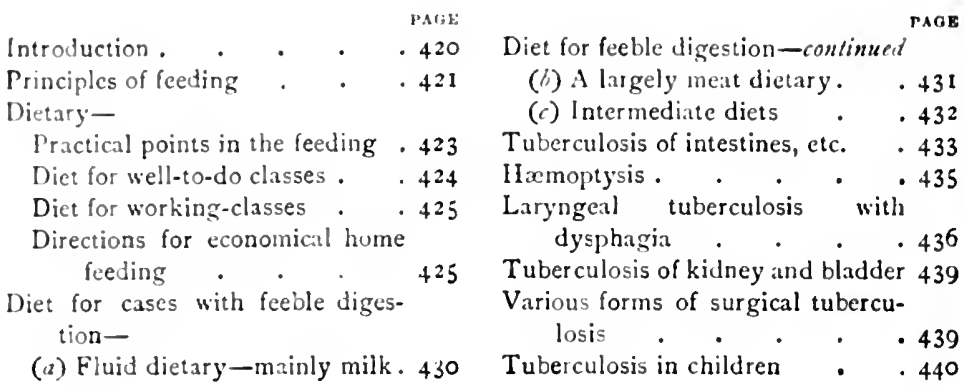

Introduction. - Tuberculosis is essentially a wasting disease, conspicuous features of the condition being loss of appetite, disturbed digestion, interference with assimilation, and a resultant loss of flesh-both muscle and adipose tissue. One essential in treatment, therefore, is to improve the resistant and recuperative powers of the body by gretting the patient to eat properly, and to eat a sufficient amount.

There is no hard and fast rule for the dieting in tuberculosis. The disease may show itself at all ages, and in many varied forms; the stage and severity of the disease, and the presence or absence of special complications, have to be considered. Thus the diet of a young subject affected with acute tuberculosis, where there is extensive and active mischief with fever, and general constitutional disturbance, differs from that of a patient whose weight is almost average for his height, and in whom there is a limited and quiescent lesion. Similarly, hæmoptysis, tuberculosis of larynx with difficulty in swallowing, dyspepsia due to general tuberculous intection, tuberculous enteritis with associated gastric disturbance, tuber- 
culosis of the kidney and urinary tract, the glandular enlargements due to tubercle, and the various surgical affections of bones and joints, all require a regimen of their own. It will be most convenient first to discuss the Principles of Feeding, and the dietetic treatment of tuberculosis generally, and after that to take up the special indications in tuberculosis of the various organs.

The Principles of Feeding.-In considering the principles of feeding it is necessary to refer to the importance of thorough oxygenation of the blood, a therapeutic factor which bears directly on the processes of general nutrition. As the proper method of oxygenating the blood is by the continual supply of fresh air and sunlight, the patient should, so far as possible, live in the fresh air day and night, irrespective of the weather. This promotes a good appetite, increases the digestive powers, and so enables the full effects of a judicious dietary to be obtained. A further important point is, that breathing should be carried out properly. It is of comparatively little value to put a child or young person who is a mouth-breather on to a proper dietary, if the oxygenating power of the blood and tissues is greatly below the normal, from a cause which can be readily removed. Breathing exercises, carried out in a systematic and thorough manner, are frequently of the greatest value in these cases.

As has been stated above, tuberculosis is a wasting disease, therefore the main point in the dietetic treatment is to increase the amount of food, so that the patient's weight shall increase and remain stationary at a little in excess of the patient's highest known weight before becoming infected with tuberculosis. There is great variety of opinions among sanatorium physicians as to the quantity of food necessary to do this, some believing in a process of forced feeding, in which a large excess of food is taken; this system is not to be commended. It is probably safe to assume that those physicians who use the lowest dietary standards consistent with satisfactory gain in weight are adopting the soundest lines of treatment.

While the food as a whole has to be increased, special importance attaches to the increase of the proteins and fats.

Bardswell and Chapman found that by increasing the 
ammunt of protein up to 150 grammes daily, i.e., by an increase of from 25 to 30 per cent. on the amount of protein found in a normal diet (Voit standard, see p. 20), the best results from a clinical and metabolic standpoint were obtained.

Increasing the intake of protein beyond this point, viz., 150 grammes daily, is not associated with any better clinical results, and the extra protein ingested is immediately excreted, throwing a considerable strain upon the excretory organs. With regard to fat and carbohydrates, in the large majority of tuberculous cases, the importance of energy-giving food is recognised, especially when the patient is much below the proper body-weight.

Fat is the best energy supplier, being less bulky, and it is as a rule more readily taken in these cases. For a tuberculous patient not engaged in active muscular exercise, an increase of 30 per cent. of the fat and carbohydrate foodstuffs usually suffices; if the patient is taking muscular exercise, a larger amount of these foodstuffs could be consumed.

As a rough estimate of the extent to which the nutritive material should exceed the normal diet of a non-tuberculous subject, it may be said that the diet in a case of tuberculosis should contain about one-third more. Of this third, the greater part should be given in the form of animal protein, and more especially meat, eggs, milk. Animal proteins are selected because there is good reason for believing that they have a very special value in the treatment of tuberculosis. The explanation of this special value is, I believe, to be found in part in the special influence of a diet rich in proteins on the thyroid gland, as shown by the results of experimental observations (p. 557). The fats and carbohydrates are mainly increased by the addition of milk, butter, cream, yolk of eggs. There is no special virtue in increasing the breadstuffs and farinaceous foods.

The general principles to be followed in the dietetic treatment of tuberculosis have been admirably summed up by Bardswell and Chapman as follows:-

I. The amount of protein in the physiological diet should be increased by 30 per cent., and this increase should be maintained until the disease is obsolete.

2. If the patient is under weight, the physiological diet 
should also be increased 30 per cent. in the purely enersy'giving foods, viz., either in fats or carbohydrates, or partly in each. This increase should be maintained until the weight becomes stationary at a few pounds in excess of the patient's highest known weight before becoming infected with tuberculosis. A decrease of 15 per cent. may then be made, and the diet, thus altered, should be continued until the disease is obsolete.

3. Patients with constitutional disturbance associated with anorexia or dyspepsia usually require a somewhat concentrated diet, so as to give the comparatively large amount of nourishment in a but slightly increased bulk of foodstuffs.

4. The meals should be well cooked, varied, and given as far as possible at considerable intervals, and reliance should be placed upon plain foodstuffs whenever possible; proprietary invalid foods should only be used when ordinary foods cannot be taken.

The Diet.-From the outset the patient must be impressed with the fact that the diet is of primary importance in the treatment of the disease, and must be kept up so long as the condition is present. Whenever the patient tends to grow careless, the injunctions concerning the diet must be repeated. Directions should not be given in a general way, but should be detailed, special mention being made of the food to be eaten and the food to be avoided. The hours for taking food and the amount to be taken should be carefully outlined. It is generally better to give written instructions concerning the diet, as the patient is apt to be forgetful, more especially if he has certain likes and dislikes.

The diet should be restricted to three good meals a day, with two snacks at suitably separated intervals. Thus if breakfast be at 9 A.M., lunch at I P.M., dinner at 7 P.M., a light snack may be allowed at 7 A.M. and at 4 P.M. It is unwise in such cases to allow further extras of any kind between meals. If the patient sleep well, it is better not to give anything by night. If wakeful, a cup of beef-tea or diluted warm milk may be allowed through the night. The food must be nicely prepared, daintily served, and varied as much as possible. It is not as a rule advisable to give much fluid at meal-times. Where the extra nourishment required 
is griven in the form of milk, not more than one tumblerful should be griven with meals. The quantity of food should be increased as appetite adrances; it is noteworthy that a patient in the most favourable conditions of fresh air and sunlight may be able to digest and assimilate an extra diet of six to eight raw eggs daily, whereas under less favourable conditions in a town, not more than one or two eggs daily could be assimilated without deranging the digestion.

Ainongst the aell-to-do class. - The cxtra nourishment required can be given either in the form of 3 pints of milk extra daily, or two to three eggs and 2 pints of milk, or as underdone red meat, 6 to $S$ ounces. More commonly it is supplied by a judicious combination of these foods. The eggs may be taken raw (p. 47), or added to milk or soup, or $\frac{1}{2} \mathrm{lb}$. raw meat or meat juice may be added to the daily dietary.

A typical dietary, framed for an average case of fair digestive capacity and free from complications, is here given. A choice is given for the chicf courses in the menu. It will be obscrved that the diet contains a restricted amount of bread, breadstuffs, suet puddings, and the like, which predispose to fermentative changes.

8 A.M. : Breakfast -

Cofiee, or cocoa, or tea, made mainly with milk-two breakfast cups.

One of the (E.ro-plain boiled, scrambled, or poached-one or two. following I Bacon, ham, tongue, herring or fish, meat rissoles.

Toast, two to three half-slices; roll or oatcake; plentiful supply of butter.

II A.M.-Milk, $\frac{1}{2}$ pint, to which may be added one or two raw eggs.

1 jo P.s. : Lunch-

Fish or entrée, an ordinary helping.

Meat-roast, grilled steak, or chop (rather underdone), and vegetable.

Custard, curds, stewed fruit and cream, souffés, or omelets.

MI Ih, 童 pint.

4 P.M. - Cup of tea with cream, bread and butter, slice of cake.

7 P.M.: Dinner-

Soup, about 8 ounces of clear consommé.

Fish or entrée.

Meat and seretable.

Pudding. Savoury, or biscuits and cheese. Milk, $\frac{1}{2}$ pint.

With any tendency to sleeplessness, a cup of clear soup is of special value, or a glass of hot milk taken at bedtime. 
If the custom of the patient is to take the chief meal of the day at midday, and a late meat tea, the evening meal may be as follows :-

Fish or egg.

Meat, ham, sausage, or brawn.

Cold sweet-such as cornflour shape, custard, or stewed fruit.

Milk, 多 pint, flavoured with cocoa or coffee.

Biscuits, butter, and cheese.

Amongst the working-classes.-Here the extra protein required may be got from the cheaper meats and fish, from skimmed milk, and from the pulses. The extra fat may be obtained in the form of margarine. The cost of the folluwing dietary works out at about is. the clay:-

Breakfast-

Bowl of well-boiled porridge, made with half milk and half water; milk, 辛 pint.

Bacon, egg, or fish.

Bread and butter.

Cocoa or coffee, made with milk-breakfast cup.

Dinner-

Meat, potatoes, and green vegetable.

Suet pudding, with jam, treacle, or stewed fruit.

Milk, $\frac{1}{2}$ pint (skimmed).

Tea-

Tea made with skimmed milk.

Bread and butter.

Supper-

Soup, made from pulses (lentil, pea, bean); or porridge and milk; or sausage, ham, or cold meat.

Bread and butter.

Milk, $\frac{1}{2}$ pint.

A still cheaper dietary may be necessary, and may be framed by using skimmed milk in place of sweet milk, margarine instead of butter, also by using the cheaper meats at $5 \mathrm{~d}$. to $8 \mathrm{~d}$. per pound, and making more use of lentils and the cheaper varicties of cheese.

The following directions will be found useful for the dietetic treatment of tuberculous patients of the poorer classes living under home conditions. These are taken from Bardswell's admirable work on this subject.

Directions for economical home feeding for patients lizing at home-for instance, those attending out-patient dipartments at hospitals, etc.-It is by no means easy to direct 
efficiently the dietetic treatment of tuberculous people belonging to the working-classes, mless they are immediately under supervision, $e^{\circ}$ in an institution. In our experience, the prescription of a definite diet to consumptive patients among the poorer classes is not satisfactory, as, for the most part, they have not the means at home of carrying out the instructions at all accurately.

We have obtained more satisfactory results in such cases after giving general directions, as under :-

You require to take much more food than you did before you became consumptive. Do not hurry over your meals; you will feel satisfied frequently before you have eaten cnough, and you must continue to eat, even when you do not want more food. Your appetite is no guide as to the amount you need. The best way to find out whether you are eating cnough is to weigh yourself every week, always at the same time of day, and in the same clothes. If you have not gained at least one pound during the week, you will know you have not been eating enough.

What food to buy, and how to cook it.-The following is intencled to give you a rough idea as to how you can arrange your meals most satisfactorily, and the amounts of the various foods you require :-

Breakfast.-1 pint of porridge, with milk and sugar; a rasher of bacon or a herring, etc.; a round of bread ; tea or coffee.

Dinner.-Two large chops, or a large plateful of meat, with plenty of potatoes; a teacupful of milk pudding, or a large slice of suet pudding, half a round of bread, and a glass of milk.

Tea.-At least three rounds of bread and butter, with jam ; or, if you can afford it, other relish.

Suffer.- $\frac{1}{2}$ pint of pea, bean, or lentil soup, or $\frac{1}{2}$ pint of porridge ; lwo rounds of bread, with sufficient cheese for both pieres; and a glass of milk.

If you take this diet, you ought to gain at least a pound a week in weight; but if you do not, your bcst course is to take more milk until your weight increases.

The above diet should cost you about 6s. 6d. per week, but you will require to be careful as to what you buy, and the following notes will probably be of service to you in 
showing you how to spend your money to the greatest advantage :-

Meat.-If you cannot afford to buy English mcat, buy the best forcign, which contains just as much nourishment, and will not cost you more than $6 \frac{1}{2} \mathrm{~d}$. per pound for the best joints. If you cannot afford to buy joints, you must be content to buy "pieces." Make full use of tripe, sausage, bullock's liver, and kidney, which are cheap and nutritious, but do not waste moncy on veal and lamb.

Butter.-Buy butter at is. a pound, if you can afford it, but if money is scarce, buy good margarine instead, at $6 \mathrm{~d}$. or $8 \mathrm{~d}$.

Milk.-You can always get new milk at $\mathbf{I} \frac{1}{2} \mathrm{~d}$. or $2 \mathrm{~d}$. per pint ; but if you cannot afford to buy much ncw milk, buy what you can afford, and make up with separated milk, which will cost you Id. or $1 \frac{1}{2} \mathrm{~d}$. per quart.

Cheese.-Dutch cheese will cost you $4 \frac{1}{2} \mathrm{~d}$. to $6 \frac{1}{2} \mathrm{~d}$, and American 6d. to $7 \mathrm{~d}$. Do not buy more expensive cheese, as you will get no more nourishment for the extra cost.

Eggs.-Except during the early summer, eggs are always an expensive form of food; therefore, do not spend more on them than you can help.

Oatmeal.-Oatmeal is one of the very best and cheapest foods you can have. Buy coarse Scotch oatmeal, Provost or Quaker oats, and have a plateful of porridge every morning; and, if you like it, occasionally at supper instead of the soup.

Dried Peas, Beans, and Lentils.-These, like oatmeal, are most valuable foods for you, and should be used every day, either boiled as a vegetable for dinner, or as a soup for supper. You can buy them at the grocer's; the peas and haricot beans will cost you $2 \frac{1}{2} \mathrm{~d}$. per pound or pint, and the lentils $2 \mathrm{~d}$.

Potatoes. - These are required every day, and you will save money if you buy at least a stone at a time.

Fish.-Buy fish instead of meat occasionally, for the sakc of a change-either cod, plaice, herrings, bloaters, Findon or fresh haddocks, or whatever fish is in season and cheap. Tinned salmon, at $5 \mathrm{~d}$. a tin, is a cheap and nutritious food, and makes a good change for supper. 
The following rough directions for cooking may be of IIEC:-

Porridge-Stir oatmeal gradually into boiling water, add a pinch of salt, and cook gently, stirring occasionally, for an hour (Quaker and Provost oats take only 20 minutes to cook). Allow 2 teacupfuls of water and 2 level tablespoonfuls of oatmeal to each man.

Lentil, Pea, or Bean Soup.-Soak the seeds in cold water overnight. Boil gently in plenty of water until soft ; the cooked seeds may either be eaten as a vegetable, or they may be beaten to a fine paste, or, better still, rubbed through a sieve; add a little of the liquid in which they were boiled, and a flavouring if required. To form a highly nutritious soup, allow 3 level tablespoonfuls of raw seeds for each man.

Suet Puddings.-(I) Allow I level tablespoonful of dripping, 3 level tablespoonfuls of flour, and a large pinch of baking-powder perman. Mix the dripping thoroughly with the flour and baking-powder. Make the whole into a paste with a little water, form into a roll, flour the surface, tie up tightly in a pudding-cloth, and boil for 2 or 3 hours. Serve with syrup, gravy, or jam.

(2) Or the above paste may be rolled out flat, and jam or syrup spread upon it. Roll, fold in the ends, flour the surface, tie tightly in the pudding-cloth, and boil for 2 or 3 hours.

(3) Allow 1 level tablespoonful of dripping, 3 level tablespoonfuls of flour, a large pinch of baking-powder, and a little sugar and fruit for each man. The fruit may be either currants, figs, or dates, chopped up finely, or raisins. Mix the flour and dripping and sugar, add the fruit, and make into a paste with a little water, flour the surface, and tie tightly in a cloth ; boil 2 or $\hat{3}$ hours. Instead of the fruit, a little syrup and a pinch of ground ginger may be used in the above mixture.

Milk Pudding.-Allow for each person 2 level teaspoonfuls of rice, sago, tapioca, etc., and $\frac{a}{3}$ pint of milk and a small teaspoonful of sugar. Put the rice, sugar, and milk, with a pinch of salt, into a pie-dish, and bake slowly in the oven for 2 or 3 hours.

Tuberculosis in Cases with Impaired Digestion.-Tuberculosis is frequently accompanied in its severer forms with anorexia, nausea, vomiting, and fever, and the question has to be faced how a patient with these symptoms can be got to take the above standard dictary.

Anorexia is a marked feature often met with in early tuberculous cases. This anorexia has developed gradually, and is associated with progressive loss of strength and weight, and the patient may be anæmic or obviously run down. In these early cases there is probably nothing organically wrong with the digestive organs. The best treatment for the condition is to place the patient under good hygienic conditions, 
with rest, continual supply of fresh air and sunlight, and at the same time give the generous diet above recommended, in spite of the absence of appetite. The result of this is a striking improvement in appetite, the patient soon acquiring the ability to digest and enjoy the food.

A second form of anorexia associated with much constitutional disturbance, e.g., high fever, sweating, is very difficult to feed. In itself, the fever accompanying the anorexia in tuberculosis cannot be regarded as a reason for reducing the amount of food. The patient, however, is often found to be quite unable to take the large bulky meals necessary for his condition, on account of the dyspepsia set up. The meals have then to be presented in a less bulky form, but still containing the necessary increase of protein. The anorexia accompanying a long-standing case of tuberculosis is generally due to impaired digestive power, and has, in addition, symptoms of distension and flatulence after meals, nausea, and vomiting. In these circumstances the increased protein must be supplied, but has to be given in the most easily digested form. In order to do this the food must be presented in smaller bulk, and it is better often to give the greater part in a fluid or cemi-solid form, solic food being diminished.

To effect this, ail joodstuffs having a large bulk and small nutritive value must be climinated from the diet, viz., potatoes, green vegetables, porridge, pulses, bread, suet puddings; and this must be replaced by other foodstuffs of equal value, but smaller bulk. This may be done by increasing the amount of animal foods, giving more raw-meat rissoles, mince, steak, chop, etc.; or the milk may be "fortified" by the addition of soluble casein preparations, such as Plasmon or Protene (see p. I 59). As much as I to $I_{\frac{1}{2}}$ ounces of these preparations can be given without causing any disturbance to digestion; and as I teaspoonful of Plasmon powder is equivalent to the protein value of 2 pints of milk, its value is obvious. Casein preparations are best added to soup or to milk puddings; when added to plain milk it alters the flavour. Plasmon bread and Plasmon biscuits can be bought readymade.

Eggs may be added to milk (e.g. egg flip, custard) or to 
soup, thus obtaining extra nourishment with little extra bulk

Kerii . Keat. - 1 lb. of scraped beef can very easily be added to a small cup of beef soup; or $\frac{1}{2} \mathrm{lb}$. scraped meat, made into sandwiches with tomatoes, is an exceedingly casy method for some patients to take the extra nourishment. Cream and yolk of egg are the best methods of getting in the necessary fat.

By the use of Benger's, Allenbury's, and other invalid foods, an easily digested starch can be prepared in many ways (p. $\left.18_{3}\right)$.

A few practical points that may heip in the feeding of these difficult cases are here given. Where there is vomiting or a feeling of nausea whenever the stomach is full, it is well to insist on the patient, in addition to resting before and after meals, to take the meal in the recumbent posture; this is sometimes of great value. A great distaste for sweet things is often present with the anorexia. In these circumstances it is well to reduce the sugar contained in the cooking by onehalf; the "invalid foods" are just as nice when flavoured with salt, and the puddings, when very slightly sweetened and well flavoured with lemon, will be quite readily taken. Variety is another most important matter when there is fever. A useful aid to improving the appetite is cold sponging of patients with pyrexia in the course of the hour before the meal; the temperature is temporarily improved, and this allows of the food being taken with less difficulty. This is specially useful before the evening meal.

The following dietaries are examples of diets that may be given when the patient's enfeebled digestion is unable to take the ordinary tuberculous diet :-

1. Fluid Dietary: mainly Milk.-This is advisable where the anorexia is persistent and severe. In place of giving the usual three large meals and two snack meals in the twentyfour hours, it is advisable to feed oftener and in smaller amounts; also, if the patient is wakeful, to give nourishment in the course of the night.

7 A.M. - Milk, $\frac{1}{2}$ pint.

8.30 A.M. -

Milk, $\frac{1}{2}$ pint ; with casein, $\frac{1}{2}$ oz., flavoured with coffee or cocoa.

Gruel made with milk, and eaten with cream. 
II A.M.-

Soup, thickened with 1 lb. raw beef, scraped; or

Soup, thickened with egg and cream; or

Milk, with egg.

I P.M.-

Chicken essence, or veal jelly, strengthered with casein, $\frac{1}{2}$ oz., and milk, $\frac{1}{2}$ pint ; or

Raw-meat mince, $\frac{1}{4}$ lb., with milk; or

Raw-meat rissoles, with milk; or

Raw-meat sandwiches, with milk.

3 P.M.-Milk, with egg, or thin custard.

5 P.M.-Milk tea, $\frac{1}{2}$ pint, with cream.

7 P.M.-

A meat juice, e.g., Wyeth's, Leube Rosenthal's meat solutions, mixed with port or Burgundy; or

Soup, with raw meat; or

Beef extract, with egg and milk, forming a custard ; or

Beef extract, made with milk and casein, $\frac{1}{2}$ pint ; or

Milk and arrowroot, with casein and cream, $\frac{1}{2}$ pint. (Brandy may be added.)

S P.M. - An invalid food, made with milk and casein, $\frac{1}{2}$ pint (see p. 183). I 1 P.M. - Milk and egg, or chicken tea with egg.

In very severe cases the milk may have to be peptonised or pancreatised; or fermented milk (koumiss or Kephir) is sometimes tolerated when ordinary milk causes digestive disturbance; whey, also, flavoured with sherry and fortified with casein and cream.

2. A largely Meat Dietary.-This is often of great assistance for a time in cases where dyspeptic symptoms follow the large mixed meals.

6 A.M.-Milk, 音 pint.

8 A.M.-

Milk, I pint, fortified with casein, $\frac{1}{2}$ oz., flavoured with coffee or cocoa (peptonised).

Slice of toast, with butter.

Bacon, ham, eggs, fish, meat rissoles, or steak (taking two things).

I A.M.-Glass of hot milk, with eggs, or raw-meat soup.

I P.M. : Lunch and Dinner-

Soup from strong stock, or fish soup, or helping of fish.

Mince lightly grilled, tender steak or chop; or slice of underdone sirloin of beef; or roast leg of mutton.

Stewed fruit and custard, or jelly with cream.

Toast ; glass of milk.

4 P.M. - Cup of milk-tea, toast and butter, or biscuit and butter.

Dinner-Much the same as Lunch. A little wine. 
Intermediate Dicts.-It is advisable occasionally to stop this largely meat dietary for a day or so, and give other foods, c.g., egg, fish, a little farinaccous food, and vegetables, just for a change. This gives the kidneys a rest, and diminishes the risk of the development of albuminuria, or other urinary troubles arising out of the large protein dict.

Tiue further dietaries may be given that are not so specialised as the mainly fluid and the mainly meat dict. They are both more concentrated than the ordinary standard dietary, and are useful steps in the process of getting a patient up to the standard dict.

(A) 7 A.M. - Milk, $\frac{1}{2}$ pint.

\section{Briakfast-}

Coffee or cocoa (pancreatised), made with milk, and $\frac{1}{2}$ oz. casein.

Well-boiled gruel, made with milk, eaten with cream, or bread and milk.

I egg, lightly cooked, and a small piece of toast and butter.

11 A.M. -

Soup, with raw beef; or three raw eggs (p. 424.)

Dinner-

Milk, $\frac{1}{2}$ pint ; toast, or rusks, and butter.

Fish soufflé, or cream, or quenelle; or

Pounded chicken, or cream, or soufflé ; or

Omelet, with chicken or fish.

Mince from scraped beef, or meat rissoles; or

\{ Raw-meat sandwiches.

Small helping of pudding.

4 P.M. - Tea made with milk.

6.30 P.M.-

Milk, 立 pint.

Choice of one light meat, solid, as under Lunch.

Custard, cream, or light soufflé.

Glass of wine.

9 P.M.-Invalid food, with casein.

Juring night-Milk, with egg.

(b) Breakfast-

Tea or coffee, with milk, two large cups, with casein.

Bacon, egrgs, fish, sausages, rissoles (two courses).

Toast; roll with butter.

II A.M.-

Milk, $\frac{1}{2}$ pint, with two raw eggs ; or

Soup, with raw beef. 
I P.M -

Soup from meat stock.

Fish, or entrée.

Meat, fowl, or game, with one vegetable.

Milk pudding with casein, or stewed fruit, custards, creams, or jelly.

Milk, $\frac{1}{2}$ pint, with bread or toast and butter.

+ P.M.-

Tea made with milk.

Bread, biscuits, and butter.

Dinner-

Milk, 立 pint.

Soup and meat, and a vegetable; or

Fish, entrée, and a vegetable.

Pudding, or a savoury containing casein or cream.

IO P.M. -

Milk, with egg; or

Soup with raw beef.

Tuberculosis of the various organs require special modifications of the standard dictaries.

Tuberculosis of the Intestine ${ }^{1}$-In addition to the general toxæmic state due to the tuberculous poison, we have to consider the inflamed, and it may be ulcerated, surface present in the bowel. Abdominal pain and diarrhœa are the chief symptoms. Nourishment in the blandest possible form should be given, and of such a kind as not to excite excessive peristalsis. To fulfil these requirements the foodstuffs must be fairly completely absorbed, and leave only a small amount of residue. The total bulk of food must be small, and the amount of fluid restricted. The food should be given in small quantity, at frequent intervals.

Milk must be given in small quantities, and is best pancreatised, or given with Benger's food or Allenbury's, which when prepared is partly digested and incapable of producing a hard curd.

Eggs are very suitable, and can be used freely. They may be given raw, lightly boiled, or poached, or in the form of custard, omelet, or souffé.

Cheese, if carefully dissolved and the acid neutralised with bicarbonate of soda, can then be used in the formation of many savoury dishes.

1 See also "Abdominal Tuberculosis," p. 44 I. 
Cream and butter should be given freely, and largely replace the carbohydrate as suppliers of energy.

Fish of the lighter varicties and carefully prepared, is useful (pp. 60, 207, 303).

Kaw llecat, either in soup, milk, or as sandwiches, is one of the best foods; raw-meat juice is easily absorbed, and leaves very little residue.

Underdone meat, as chop, steak, or slice from roast, mutton, or beef, is also easily digested. Well-done meat is not so easily digested.

Proprictary meat juices of various kinds (sec p. I65), given in liberal amount, are very suitable articles of foodstuff.

Clear meat consommé may be allowed in a small amount, also home-made meat jelly and essences (p. 77).

Bread should be dry or toasted, and some of the "infant" rusks and plain biscuits (cracknels), eaten with butter, are allowable.

The best class of puddlings are custards, omelets, soufflés, creams, and jelly; some of the lighter milk puddings are also permissible.

Tea, coffee, or pancreatised cocoa may be taken as a flavouring agent for the milk.

All the bulky foodstuffs, as porridge and other cereals, green and root vegetables, suet puddings, pastry, and fruit, are inadmissible.

The cascin preparations are apt to set up diarrhoa. An illustrative diet sheet is here given :-

\section{Dictary-}

6 A.M.-Two teaspoonfuls of Wyeth's beef juice in 2 ounces milk.

Breakfast-

Milk, 8 ounces, with coffee.

$\mathrm{Egg}$ omelet, or lightly boiled egg.

Toast and butter, roll, or two rusks.

11 A.M. - Soup with $\frac{1}{4} \mathrm{lb}$. raw beef, in all 8 ounces; or milk with 2

\section{Lunch-} raw eggs.

Milk, 8 ounces.

Underdone roast-meat or raw-meat sandwiches; or

Chicken cream, made with egg and cream.

Roll or toast.

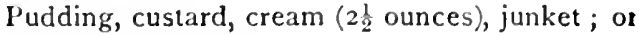

Savoury with cheese. 
4.30 P.M.-

Milk-tea ; or Benger's food, with one or more raw eggs.

Toast and butter.

\section{Dinner-}

Steamed fish (small helping), or savoury custard.

Underdone chop or steak (small helping).

Sweet pudding, with cream (2 늘 ounces); or

Cheese pudding.

IO P.M. -

Meat juice ; or

Bovril, milk ; or

Benger's food.

Hæmoptysis. - A slight hrmoptysis, nothing more than a discoloration of the sputum, is probably the result of some local congestion, and does not call for any change in the dietetic required. If, however, after a day or so extra rest, the discoloration continues or increases, the indication is to reduce the blood-pressure. This is best done by restricting the amount of fluid taken. Cut off the milk-supply to I pint, and give no tea, coffee, or cocoa, no soups, and for a few days reduce slightly the amount of solid food.

With a severe hæmoptysis, due to the rupture of a pulmonary aneurism or the ulceration of a blood-vessel, the blood-pressure should be reduced and maintained at a low level for some days after the bleeding has ceased. The amount of fluid given in the first twenty-four hours should be the minimum, I to 2 teaspoonfuls at a time, and not very often - more to allay the thirst than act as a food. The milk may be iced and the mouth washed out with iced water, or lumps of ice given to suck. Half-teaspoonfuls of very hot water are a good thirst-quencher. If the blood-pressure is being treated by free purgation with salts, the patient will probably suffer severely from thirst. On the second day the milk may be augmented by the addition of teaspoonfuls of beef juice in a little milk or water, and the quantity of milk may be I pint in the twenty-four hours.

After this, increase the diet, still griving it cold and in small quantities at a time, up to 1.1 pints of milk, 3 to 4 ounces of toast and butter, one egg, and $\frac{1}{4} \mathrm{lb}$. shredded meat in sandwiches. The diet should be steadily increased, and in 
about ten days after the hamorrhage the patient should be back to his standard dietary.

The following diet would probably be suitable about the fifth or sixth day, the food being given in small quantity every two hours :-

4 A.M.- Meat juice in milk, $1 \frac{1}{2}$ ounces.

6 A.M.-Milk, 4 ounces, ancl 2 teaspoonfuls of Plasmon.

S A.M.-

Egg beaten into I ounce of milk.

Half-slice of toast well buttered, or two biscuits buttered. to A.M. - Soup from good stock, with raw-meat juice (2 $\frac{1}{2}$ ounces). Noon.-Allenbury food made with milk, 3 ounces.

2 P.N. -

Raw-meat sandwiches, made with I ounce bread, I ounce meat, and butter ; or

Pounded chicken, $\hat{\jmath}$ ounces, and I ounce bread and butter ; or

Fish cream, 3 ounces, and $\mathbf{I}$ ounce bread and butter. 4 P.M.-Milk, 4 ounces, and I teaspoonful of Plasnon.

6 P.M. - Scrambled egg on toast.

S 1.M.-Custard, 3 ounces; or curds with cream, 3 ounces. Io P.M.-Milk with Plasmon, 4 ounces; one biscuit.

Noon.-Chicken essence or meat jelly, 2 ounces.

2.jo A.M.-Benger's food, 3 ounces.

Some authorities have a great belief in the value of rawmeat juice and raw meat in cases of hæmoptysis. Where there are a succession of hamorrhages and the patient's strength is much reduced, the diet must be increased, and the blood-pressure reduced if necessary by means other than diet.

Laryngeal Tuberculosis and Dysphagia.-There is no symptom that calls for special treatment in the earlier stages of laryngeal tuberculosis; it suffices to say that the same high standard of nutrition must be adopted as is necessary for tuberculosis generally. Even if slight pain on swallowing is complained of the patient should be urged to try and take the full standard diet, as in this way his chances of recovery are grcater. If any special articles of food are observed to cause more pain or discomfort than others, they should be discontinued and others substituted.

If, however, dysphagia is complained of to such an extent that the standarcl diet cannot be adopted, a diet composed of semi-sulids and fluids must be used until such improve- 
ment has taken place that the patient can return to an ordinary diet.

These laryngeal cases, complicated by dysphagia, require ingenuity and care in order to get in sufficient nourishment with the least suffering to the patient.

All foodstuffs should be given cold, and very often if the fluids are iced they are taken more easily.

All condiments such as pepper and mustard are irritating, and must be omitted.

Careful notice should be taken to see if any solid foods can be taken, and the diet should be carefully built up round these.

Semi-solid diets are often taken more readily than fluid diets, and these can be given in smaller bulk than a fluid diet, and therefore are less liable to cause dyspepsia.

When the pain on swallowing is very severe, the following plans may be tried to alleviate the pain of taking food:- $(a)$ Insufflation of the larynx with various anresthetic powders, orthoform or anæsthesin; or the larynx may be painted or sprayed by a IO or 20 per cent. cocaine solution, or with eucaine, menthol, and parolene a 20 or 30 per cent. may be employed for spraying with-will often allay pain sufficiently to allow of food being taken more readily.

The application of cold to the larynx by Leiter's laryngeal cell is often of distinct use-or a cold compress with ice may be applied. When there is difficulty in swallowing fluid, the Norris Wolfenden position may be assumed, i.e., the patient lying on the side, and liquid food taken through a tube from a cup placed slightly below the level of the mouth; or Wolfenden's position can be tried, viz., the patient lying on the face with the head over the couch, and sucking up food in the same way.

The food should be concentrated, and given at fairly frequent intervals, and in small quantity. The following diet and recipes will be found helpful :-

\section{A Fluid Diet for Dyspluagia :-}

8 A.M. - Thin gruel, made with milk and cream; or ; pint.
Invalid food, made with milk and cream

Io A.M. - Egg beaten up in milk, 4 pint.

I A.M.-Milk with Plasmon or Sanatogen, flavoured with cocoa, I pint. 
I P... - Velvet soup, \& pint (p. 439), with egg.

3 P.M.-Junket, I pint, with cream.

5 1.M.- Thin invalid food, 1 pint.

7 M.M. Milk bovril.

9 r.M.-Egg and milk, $\frac{1}{1}$ pint.

10 I.M.M-IBcef-lea, with 2 ounces raw meat, $\frac{1}{2}$ pint.

During night-Milk and Sanatogen, 1 pint.

The Aluid clietary for Anorexia of tuberculosis would also be found suitable (p. 430).

2. Simi-solid Diet for Dysphagia :-

7 A.M.-Milk, $\frac{1}{2}$ pint, with egg.

9 A.M. -

Arrowroot or cornflour milk, I pint, with cream.

Breadcrumbs and milk, I pint, with cream.

II A.M. -

Milk blancmange (p. 439).

Vanilla cream.

Iced regetable cream.

I I.M. -

Fish or chicken cream.

Fish or clicken souffé.

Beef quenelles.

Eggs, scrambled, with butter (four eggs).

3 P.M.-Curds with cream, and iced cream or jelly.

5 P.M-Bovil custard.

7 P.M. -

Velvet soup, I pint; or

Soup with raw-meat juice, I pint.

During night-Benger's food, I pint ; or

Cocoa and milk, I pint.

The following preparations are specially useful in dysphagia :-

Custards. - The custard is made with milk and eggs, as described. The milk used can be fortified with Plasmon, or casein, from $5^{j}$ to $j^{\text {iv }}$ to the pint. The flavouring can be varied-a sweet custard flavoured with vanilla or lemon, or nutmeg or grated chocolate, or sherry; or a savoury custard, made with the addition of Bovril or Bovinine, or a strong chicken essence, to the milk and eggs.

Cheese can also be added to the milk and eggs. Two ounces of grated American cheese, a pinch of bicarbonate of soda mixed with the milk and eggs, and either boiled or baked. 
Creams and blancmanges are much better taken by dysphagic patients when made with gelatine than with comflour or arrowroot.

Jellies, either in the form of a swect or savoury jelly, are well taken. Gelatinc, $\frac{1}{3}$ ounce added to I pint milk, will thicken it sufficiently to cnable a patient to take it without pain when the plain milk causcs much pain.

Curds and cream, freshly prepared, is sometimes more easily taken than milk.

Velvet soup.-A clear soup very blandly flavoured, fortified with I tablespoonful of Casumen to the pint, may have one or two eggs stirred in when very hot immediately before serving.

Fish souffe, or cream and chicken treated in the same method, can be taken.

Breadcrumbs and milk, strained, can be often taken. Boil half a round of bread crumbled down in $\frac{1}{2}$ pint of milk, strain through fine muslin, and serve.

Tuberculosis of Kidney and Bladder.-In tuberculosis of the kidney, bladder, or other part of the urinary tract, the feeding of the patient is a more difficult matter than in most other forms of tuberculosis. It is often impossible to give the amount of protein food desirable, because of the extra strain thrown on the kidneys by a diet rich in protein.

Special care has to be taken with the amount and nature of the animal protein foods given. Those meats should be given in carefully regulated amounts. Much assistance in framing the diet is derived from the examination of the urine. So long as the amount of protein being administered does not increase the amount of albumin or pus in the urine, the dict in use may safely be continued.

In general, it will be found that the most suitable diets for these cases are those indicated on p. 432. At the outset the lighter diet (p. 430) should be given; and if the condition of the patient and of the urine allow it, this may give place to the stronger diet on p. 424. In some cases it is necessary to largely ignore the state of the urine, and rather treat the general condition.

Various forms of Surgical Tuberculosis.-The dietetic treatment of tuberculosis of the lymphatic glands, the general health of the patient being good, is to place him in the 
best possible hygienic conditions, and at once begin the stanclard tuberculous dietary (q.i'). Probably it is best to give the extra nourishment in the form of 1 pint of milk, two raw egss, and $\frac{1}{2}$ lb. raw beef juice, in soup or sandwiches, per diem (p. 424).

In tuberculosis of bones and joints, the general state of the patient must be borne in mind; and if the patient is confined to bed, or unable to take any active exercise, probably the "largely meat dietary" (p. 431) will be found most casily digested.

Lupus and other tuberculous lesions of the skin call for nothing special in the dietary, except the importance of getting on to the standard dietary, and maintaining this dietary until the patient's weight becomes stationary at a few pounds in excess of the patient's highest known weight before becoming infected with tuberculosis.

Diet in Tuberculosis in Children.-The most common forms of tuberculosis in children are tuberculous peritonitis, enlargement of abdominal glands (tabes mesenterica), tuberculous enteritis, glandular tuberculosis, tuberculosis of bone, and pulmonary tuberculosis. The infection may arise through the food, or by inhalation from contaminated air. The majority of cases occur after two years of age. In the earlier stages the symptoms are often slight, consisting in a general lack of vigour, some degree of wasting, and anæmia. If the temperature be closely observed at this stage, it is found that there is some irregular pyrexia. It will be convenient to treat this subject in the following order:-

(a) Prophylactic treatment of Tuberculosis in general.

(b) Dietetic treatment of abdominal Tuberculosis.

The treatment of the other forms has to be conducted along the lines already laid down.

Prophylactic treatment. - This is especially important in the case of children with a family predisposition to tuberculosis. Here the general circumstances of the child, and also the dietary, must be arranged so as to maintain the healthiest possible condition of the gastro-intestinal tract. Everything which might promote gastro-intestinal derangement, and so allow penetration of the intestines by 
the tubercle bacillus, must be carefully avoided. Strict precautions are necessary in regard to the milk-supply. If the milk-supply is above suspicion, it is no doubt best for the child to take untreated milk, that is, milk which has not been boiled or sterilised. There is no question that the artificial treatment of milk by heat and other methods interferes to some extent with its properties as a food. It does so in all probability by altering some vital ingredient present in fresh milk. Since, however, the danger to the child from the use of artificially treated milk is considerably less than that from the use of fresh milk infected with tubercle, it is, as a rule, advisable to recommend the former. It should, however, be noted that the milk should not be sterilised in the manner sometimes done, by exposing it to a very high temperature for half an hour or more-it should simply be scalded.

An abundance of fresh food is an essential in treatment. Milk, eggs, fresh meat, meat juice, fresh vegetables, and fruit should enter largely into the dietary, and an extra amount daily should be insisted upon. Care must be exercised to prevent the immoderate use of farinaceous foods and sweets, which are prone to induce indigestion, and so lower the resistance of the bowels. Lastly, reference may be made to the importance of fresh air, by night as well as by day, regular meals, and thorough mastication of the food, as being factors of importance in the prophylactic trcatment.

Abdominal Tuberculosis. - This most frequently takes the form of tuberculous peritonitis, tuberculous ulceration of the bowel, or tuberculosis of the lymphatic glands (tabes mesenterica). The infection comes from the intestine or from the thoracic glands through the lymph channels. The great majority of cases occur after two years of age. The symptoms may be slight, such as a general lassitude, and some anæmia; in other cases wasting is a prominent feature; and in some cases diarrhœa, with the passage of blood and mucus, may have attracted the attention of the parent. Some degree of irregular temperature with slight pyrexia is frequently present. When the condition becomes well marked, abdominal distension is the chief feature, this arising from flatulent distension, atony of the bowel, and often catarrh and ulceration of the intestine. These 
conditions make the dietetic treatment one of some difficulty:

The special point to be attended to in the dietary is the necessity of the utmost care with regard to the administration of any of the readily fermentable foodstuffs. Bread and milk foods and farinaccous puddings are quite unsuitable for thesc patients; too often these entcr largely into the dietary. The bowels should as a preliminary be judiciously emptied by a dose of castor oil, given two nights in succession. If there is loss of appetite, with pain, the food should for a day or two be restricted to meat soups, chicken jelly, mutton, veal, or chicken tea, which can gradually be strengthened by the addition of Plasmon, Sanatosen, and raw-meat juice. It should be noted that diarrhoea is not a contra-indication to this diet, the looseness of the stools usually resulting from ulceration of the bowel or from fermentation of starchy foods. As soon as the patient can take it, more solid food is given in the form of pounded fish, or chicken, white of egg, and thin slices of toast or rusk. In patients whose appetite at night is deficient on account of the evening temperature, it may be advisable to give fluid food only at night, reserving the solid food for the two earlicr meals. When the appetite is restored it is better to give three meals a day only, and nothing but fluids between meals. In cases with feeble digestion and appetite, the more frequent use of smaller feeds is indicated. The following is an appropriate diet for a case of abdominal tuberculosis in a child, in whom the appetite is satisfactory :-

7 A.M. - Glass of milk and a Plasmon biscuit.

8 A.M. : Breakfast-

Milk; scrambled egg or steamed fish ; toast and butter.

II A.M. - 8 ounces meat soup, with juice from $\frac{1}{4} \mathrm{lb}$. raw beef.

\section{P.M. : Dinner-}

Red meat, broiled or roasted, hot or cold, clear gravy ; small helping of well-cooked vegetables, not potatoes; slice of dry toast.

Custard, hot or cold ; curds and cream ; cream or blancmange, in preference to starchy or suet puddings.

4.30 P.M.-Glass of milk and a biscuit. 


\section{Supper-}

Milk to drink.

Fish, egg, or chicken.

slice of toast.

Fatty foods, such as cream, yolk of eggss, and cod-liver oil and malt, are gradually added to the dietary. An examination of the state of the stools and a consideration of the symptoms will guide us in increasing or otherwise the amount of food administered. 


\title{
CHAPTER XXVI
}

\author{
GOUT, RHEUMATISM, AND RHEUMATOID ARTHRITIS
}

Gout

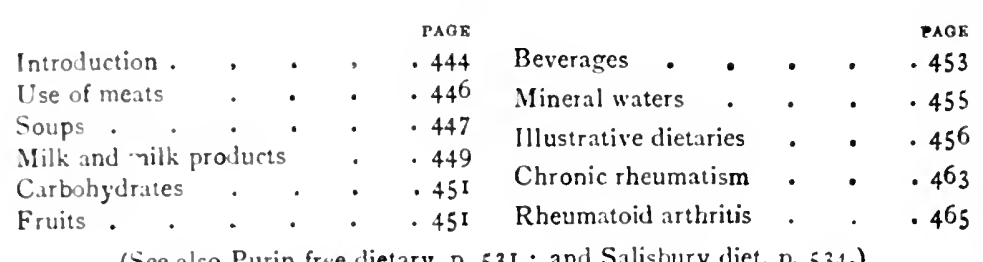

(See also Purin-frce dietary, p. 531 ; and Salisbury diet, p. 534.)

Introduction.-Derangements in the digestive system play an excechngly important rôle in the development both of acute and chronic gout, and these derangements usually depend either on immoderate eating or drinking, or on the ingestion of articles of diet especially unsuited to the individual. The relationship of these digestive disturbances to the phenomena of acute and chronic gout is an important one, and the importance of a well-regulated and healthy intestinal mucous membrane cannot be overestimated. Autointoxication or infection is certainly a primary factor in the disease, and has to be guarded against by careful dieting, healthy intestinal secretion, and normal intestinal evacuation. It is advisable to insist at all times on the clusest attention being paid to the action of the bowels. While we have yet to learn much about the secretory or excretory influence of the large intestine, we may safely assume that by judicious purgation much more is done than merely free the system of the undigested foodstuffs present in the gut. Not infrequently in the course of subacute or chronic gout there is developed a subacute or chronic catarrh of the gastric and 
intestinal mucosa, which in turn aggravates and complicates the general gouty state. Such a complication merely leads to a more strict application of the general principles of the dietetic treatment appropriate to the discase.

It is sometimes maintained that the influence of different food ingredients on the gouty constitution has been too much magnified, this asscrtion being based on two clinical factsfirstly, that a child fed entirely on milk may continue to excrete large quantitics of uric acid; and, sccondly, that an adult patient who has been excreting a similar excess on a light vegetarian diet may specdily improve and return to a normal excretion when his dict is changed to meat. This view is based on too narrow a conception of the problems. The little we know with certainty regarding gout seems to indicate that the radical defect is in the metabolism of the protcins of the food. The metabolic changes of the proteins of milk or vegetables are essentially similar to those in meat, and there is no reason to believe that the decomposition products arising from the normal metabolism of the one are in any way different from those in the other. Any differences there may be are those of degree and not of kind. Everything depends on the form in which the foodstuffs are presented. It sometimes strikes me that in this question of feeding we find an interesting analogy in the art of agriculture. A scientific farmer in the fceding of his land has not only to consider the natural quality of the soil, but also the climate, rainfall, and nature of the product desired. Of the food required by the growing plant the element nitrogen is also one of the mainstays, and it is usually provided in one of two forms-potassium nitrate or ammonium sulphate. Now it is by no means immaterial to him in which of these forms the land is fed. His choice depends on many things, one of the most important from our present point of view being their relative solubility. If the land is badly drained, and especially if the rainfall be considerable, he uses the less soluble ammonium sulphate in order to minimise the risk of the nitrogen being washed away and so rendered unavailable for the growth and maintenance of his grain. So it is with the human subject, but only in a more elaborate way. The individual qualities of the tissues, their drainage system, 
and the relative solubilities of the different food ingredients as commonly prepared, constantly demand careful considcration. The question of diet is certainly the paramount one. Its influence is profound, not only on the individual, but on the race, and its importance was well defined by Sir William Roberts, when he wrote that one generation of scientific dietetics would produce an influence upon humanity second only to a new creation of the race.

Meats, etc.-From the earliest times some writers have regarded all or at any rate most kinds of muscle food as injurious to the gouty, and as in other debated points in the subject history of the disease, many experimental observations have been brought forward to prove this point; but as a rule, these obseriations have been made in the much too narrow field of uric acid excretion. The most recent observations indicate that the commonly accepted view that a meat dict is associated with an increase in the uric acid excretion is an erroneous onc, and on the whole it may be taken as definitely shown, both by practical experience and theoretical cxperiments, that, as a rule, a gouty subject may take a measured quantity of meats in an easily digested form.

In the use of meats it is not only important that these should be taken in an easily assimilable form, but that they should not be accompanied by an undue admixture of other foodstuffs. It is held by some that in such cases the fact of the carbohydrates and fats being more readily oxidised in the tissues, leads to defective combustion of the albuminous foods. We must look for the cause of any injurious effects of meat more in its quality and in the form in which it is administered. If too little nitrogenous food be taken, an increased decomposition of nuclear-holding tissues may result, as has been proved in a case of complete starvation, in a subject in whom typical acute gout developed in the course of the observation.

We must, however, bear in mind that a strong meat dict, that is, meat twice or thrice claily, is an acid food, owing to the imperfect neutralising of the sulphuric and phosphoric acid present in the diet. This may be in part rectified by the consumption of the alkaline table-waters referred to later.

We have also to consider that the tastes and inclinations 
of the greater number of gouty subjects clemand a certain supply of meat, and, by taking it in moderate anount, the supply of nitrogenous food necessary for the maintenance of the albumin in the body is more readily obtained.

With regard to the different kinds of animal food, white meats, e.g. fish and chicken, are more suitable than red meats owing to their more ready digestibility, and also in the case of fish to the smaller proportion of nitrogen present in equal bulk. The confirmed gouty subject is wise to limit his consumption of red meat to one meal in the day or even less, and further, to make as a routine a selection of the red and white meats similar to that indicated in case Mrs D. (p. 460). The whole question of a meat diet is summed up in its digestibility, which in turn bears a definite ratio to the simplicity of the meal in which the meat is a component part. The temporary diet of meat and hot water (p. 534) which is of much value in suitable cases is a simple one, and to its simplicity we must largely look for an explanation of its beneficial effects. What has been said of meat holds also good for other animal foods. The various kinds of fish and game can all be taken by a gouty subject, but what must be specially attended to is the amount of admixture with other foods and drinks. Not infrequently innocent substances taken at the end of a highly nitrogenous mixed meal are regarded as the noxious agents, when in reality they have played a quite subordinate rôle. High game and very fatty meats should be avoided. The relationship of an excessive meat diet to gout is further considered on p. 6I2.

Under this heading a few practical points may be mentioned about the culinary aspects of soups, meats, and fish. It is impossible to overestimate the importance of this subject; the want of recognition of its importance is, in the writer's opinion, one of the causes of the very diverse differences of opinion entertained as to the beneficial or noxious influence of various dietetic substances.

Soups. - What soups may a gouty person partake of?

The answer to this question will depend on the digestive capacity, but in coming to a decision we must take into consideration some elementary points in the preparation of the various soups.

It has been stated that there are perhaps not less than 500 soups, but 
regarded analytically, there are only a few leading species from which the different varieties are produced by additions and combinations of flavours.

(a) A clear decoction of meat or bones which, when weak, forms a broth or a "tea," and when strong is a consommé or essence. These may be prepared from beef, veal, or mutton, and sometimes pork or ham.

(b) A similar decoction can be made from the various forms of fowl, game, and fish.

(c) A decoction of vegetables, including herbs, roots, grains, and farinaceous substances.

All of these soups may have added to them well-known dried Italian pastes, e.g. vermicelli or macaroni, and a consommé of meat or pork or game may be thickened with additions of a meat, fowl, or game purée respectively. In the same way the weaker broths furnish a basis for vegetable purées.

The following highly nitrogenous soups are not as a rule suitable articles of dict for the gouty :-Turtle, mock turtle, hare, kidney, oxtail, mulligatawny. If they are indulged in, the rest of the food and drink consumed at the same meal must be more carefully limited.

Cocky-leeky, giblet, and hotch-potch are almost stews, and should be considered as a meat course. In not a few cases all of these highly nitrogenous soups are contra-indicated.

The great fault to be found with soups usually served is that they are heavy, and contain too many ingredients. The average soup is made up with as many good things as possible, some to make it more nourishing, others to make it more palatable. This is all very well for the healthy, but where, as in gout, the digestive functions in the tissues and alimentary canal are readily disturbed, simple soups are required. The soups without thickening are therefore the most suitable. The thickenings in common use are purées of meat or fowl, flour, tapioca, yolks of eggs, etc.

Roast beef and mutton bones boiled with vegetables, and the fat carefully removed, make a good stock from which soup can be made for the gouty. Excellent soup can also be made from the water in which meat or fish has been boiled.

The various vegetable purées-spinach, artichoke, tomato, carrots, green peas, etc.-are excellent for this class of patient. They are sufficiently sustaining to prevent a feeling of hunger, and if well digested give a fair amount of nourishment. In the case of soups made from the pulses, their high nutritive value should influence the rest of the meal, and in some cases they are better avoided. A very good vegetarian stock can be made by extracting the "goodness " and flavouring from vegetables, the chief ones being onion, celery, carrot, and turnips. To do this take these vegetables and cut them into small pieces, place in a saucepan with sufficient water to cover them, and let them boil gently for several hours. The liquor when strained off is "stock," and can be flavoured with a small quantity of savoury herbs, pepper, salt, and ketchup, and can be coloured a nice brown with a few drops of Parisian essence.

A more detailed account of the methods of preparing the invalid soups (teas and essetices) will be found on p. 71. 
Meats.-Made-up meats are not suitable for the gouty, owing to the greater toughness of fibres induced by the second cooking, and also because of the admixture of rich sauces of various kinds which are usually added for palatability. Meats should be tencler and simply prepared. The best ways of preparing are, in order-broiling, steaning, roasting, boiling, baking, stewing, and frying. The last mentioned should be avoided, especially in the case of beef and mutton. Although lamb and veal possess less extractive value than other meats, and are on that ground commendable, yet the gelatinous nature of the fibres makes them more difficult of mastication, and therefore less digestible. If allowed, this danger must be pointed out with a view of obviating it. Tripe, sweetbreads, kidney, and liver may all be allowed for occasional use, provided the very special cleaning and careful cooking necessary are given effect to. Salted meats are rendered more indigestible in tine preparation, and should therefore be avoided. Bacon and ham are more digestible than pork. With regard to game, white flesh is more suitable than brown, and water-birds are more fatty than other game.

Fish.-Fish are well calculated to form a large proportion of the dietary of the gouty. They contain on an average one-third less nitrogen than an equivalent amount of ordinary meat, and usually contain little or no fat. Fat fishes (salmon, mackerel, eels, pilchards, red mullets) are equal in nitrogenous value to an equal amount of moderate fat beef. There is a very large proportion of water in the flesh of fish. When ordering, it is well to suggest those known to be in season and plentiful, as they will probably be in the best condition. As has already been mentioned, many nutritious soups can be made from them.

Meat and hot-water cure-Before leaving the subject of meat, reference may be made to the value of an exclusively red-meat diet in certain cases of chronic gout. The essentials of this treatment are the drinking of three to four pints of hot water daily, a pint to be taken before each meal, and the same quantity at bedtime, and the administration of one to three pounds of meat in the twenty-four hours. The details of this treatment are given elsewhere (p. 534).

Milk and Milk Products.-As in the case of various other foods, there is much difference of opinion as to the value or necessity of a diet composed largely of milk, milk products and vegetables. In many cases a course of a strict milk dict is the most suitable, particularly in young and otherwise healthy subjects, but it is much less suitable for adults and the aged. Milk is highly nutritious, and when it is easily digested and no undue fermentation processes induced by its use, a limited course of milk diet is to be commended, the 
amount and duration being regulated by the effects on the digestive system and by the attitude of the patient towards it. Alkalinity of the urine is favoured or increased by a full milk dict, yet an exclusively milk regime is probably in the main unfavourable. Howerer, there is no doubt that the children of gouty parents should be brought up systematically on a diet in which milk and its products are the staple, and meat given in very limited quantities. This is specially important in those by no means infrequent cases where there is, in addition, a marked neurotic strain in the family. With the active and fixed habits of later life a meat-free diet is very rarely practicable, and is very seldom called for.

Cream, forming as it does the most appropriate form of fatty food in the dietary of the aged, likewise constitutes an excellent form of fat administration in gouty subjects. It should preferably be taken with milk pudding or stewed fruit in an otherwise simple meal, or it may be used in the preparation of chicken crcam, fish cream, or in various combinations with vegetables, when it takes the place of butter.

Skimmed milk is more digestible than ordinary milk in all cases where fat is not readily digested, but in recommending it as a beverage or food regard must be paid to the amount of proteins and lactose present in it.

Who is a useful article in many cases. It is a pleasant and stimulating drink, with a certain food value from the lactalbumin, lactose, and mineral matter present. In some cases whey with cream make an admirable combination.

The pure cascinogen of milk, now prepared by the l'rotene Company in the form of a flour, and made into biscuits and bread, is an appropriatc form of protein administration. The taste, however, is an acquired one (p. 158).

Cheese. - There is no reason why cheese should be forbidden. The ill-effects frequently attributed to it arise from the manner in which it is taken at the end of a meal, already excessive and badly assorted. Being a rich, albuminous food, and varying in the proportion of fat present according to the varicty of cheese, it should not be taken in large guantity; it should be well masticated, and it 
should be carefully distributed through the various vegetables or breadstuffs of the meal.

It is well to recommend patients who are very fond of cheese to partake of one of the softer varieties, as, although less digestible, they are much less likely to be taken to excess (see p. 42).

Eggs.-Eggs are an excellent dish for the gouty, and should form one of the staple brealifast dishes. They also constitute a very appropriate food constituent for the children of gouty parents, in whom the consumption of meat, and especially red meats, should be very limited indeed. It is well to remember that a hard-boiled egg takes three hours, and a soft-boiled or raw one, from one and a half to two hours for complete digestion.

Carbohydrates. - The fact that gout is unknown in countries like Japan, where a strict vegetarian diet is common, clearly proves that, as a class, carbohydrates can by no means be the direct cause of the disturbance of metabolism characteristic of gout. On the other hand, taken in considerable amount and with rich, nitrogenous foodstuffs, their use is frequently accompanied by some evidence of local disturbance in the alimentary canal, or general disturbance of metabolism in the tissues, either of which may bc characteristic of a gouty condition. When this tendency is pronounced, the sum of the local and general effects produces typical gout in a more or less acute form, the manifestations depending on the age and constitution of the individual. In other subjects we find manifestations of irregular gout, and these, when well marked, may be regarded as equally typical of the gouty condition.

Carbohydrates, and especially those of the saccharine group, are as a class to be regarded as more potent noxious agents than meat. A good rule with regard to them is to reduce the amount and simplify their form. Much information as to the diet appropriate for cases of gouty clisorders may be obtained from the application of the test of the "pancreatic reaction in the urine" (see p. 377). A marked positive reaction is a special inclication to restrict the carbohydrate and saccharine foodstuffs.

Saccharine foods and dietetic accessories, i.s.e, jams 
marmalade, sugar, sweet cakes, are only to be partaken of occasionally and in small quantity, and in not a few cases, especially of stout adults, are to be studionsly avoided.

With regard to the strict vegetarian diet so eloquently advocated by Haig and others, the gond effects undoubtedly derived in many instances depend, in the writer's opinion, on the simplicity of the whole diet, with the limited quantity of the chief nitrogenous ingredients, these being the two primary essentials in the dietetic treatment of confirmed gout. The following illustration may be given (Haig):-

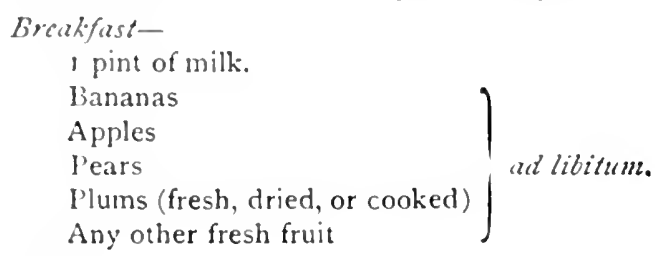

Lunch-

Vegetable soup made with milk.

I'late of potatoes (with butter, oil, or milk).

2 ounces cheese, eaten with potatoes and any other vegetables in season.

Stewed fruit or tart.

Fresh fruil

I pint of milk drunk during the meal.

\section{Dinner-}

Much as Lunch.

I pint of milk.

I ounce checse.

A close analysis of this diet, which is recommended for a person in health, shows that it is not quite so simple as at first sight apparent, and while a diet for the gouty framed on very similar lines is undoubtedly a very beneficial method of treatment in some cases, in others it is altogether unsuirable; see also "Lacto-vegetarian diet" (p. 520).

Popular belicf, partly supported by medical opinion, condemus potatocs, but if used in moderation, and cooked and served with due precaution, there is no reason for prohibiting them, cxcept in those special cases where they are definitely determined to be unsuited to the digestive capacity.

When new and moist they are indigestible; the best form is a well. boiled mealy potato in its skin, or the same put through a potato masher. A thoroughly well-baked potato is also good. When fried, or roasted in mutton dripping, or mashed with milk and butter, they are unsuitable in most cases. The other ronts-turnips, carrots, parsnips, radishes, beetroots (also rich in sugar), artichokes, also cabbages, curly greens, 
brussels sprouts, broccoli, and the green of caulithwer-should only be taken in small amount on account of their tendency to induce llatulemee, etc. The followng are more suitable: Spinach, flower of cauliflower, savoys, endive, lettuce, watercress, kale, leeks, onions, celery, cucumber, vegetable marrow, green peas, French beans. Asparagus has been condemned by some writers on account of the nucleins in the young shoots; also tomatoes and sorrel on account of the acids present; but, as many typically gouty subjects can partake of them freely, it is probable that these objections have only theoretical importance.

The green vegetables above mentioned can be freely partaken of in the form of salads, provided oily dressings and hard-boiled egrs are avoided. Mushrooms and truftles and other fungi are quite permissible in small quantities. The pulses (lentils, peas, beans, haricot beans) are not as a rule advisable, because it is not an easy matter to make the patient realise that their nutritive value is such that their use must influence markedly tine amount and quality of the other articles consumed.

With regard to puadings, the simpler the better. Milk puddings, such as rice, sago, semolina, ground rice, etc., should be made without eggs in many cases. Suet puddings of all kinds are as a class to be avoided, but if made with breadcrumbs in place of flour, well boiled, and unaccompanied by a heavy sauce, they may be taken. If custards and omelets, sweet or savoury, are taken, the nutritive value of the eggs must be recognised. Jellies, blancmanges, lemon sponge, and creams may be taken in very sparing amount, and, as with other foods, a wise discretion is necessary both by the physician and by the patient. Fruits of all kinds in themselves are permissible, but must be taken with caution, especially in later adult life, and it is well to bear in mind the old saying, "Fruit is golden in the morning, silver at midday, and lead at night." Much depends on the amount of sugar used in the cooking and the accessories used at table. Crystallised fruits are quite unsuitable on account of the large amount of sugar present. For the same reason special care has to be taken with regard to dried fruits, such as plums, raisins, dates, and figs.

Beverages.-To the confirmed gouty subject the question of what he may drink is sometimes a more important one than that of what he may eat. Alongside of this question there is another bearing on the time-relationship to meals -at which various liquids should or should not be taken. Thus, it is as a general rule advisable to recommend alcoholic stimulants only to be taken with meals; in other cases the consumption of fluids, of a non-alcoholic nature, may be wisely restricted mainly to the intervals between meals. Fluids may act prejudicially in two ways. In the first place, they may act injuriously in a mechanical way, i.c., by clogging 
the food elements, and at the same time diluting the digestive fuids, favour abnomal decomposition of the proteins and also carbohydrates. And, sccondly, they may, in virtue of a specific action, lead to faulty nitrogenous metabolism in the digestive tract, and secondarily, in the tissues.

Like the question of diet, it is impossible to lay down definite rules applicable to the disease. Everything depends on the age of the patient, his constitution, his previous history as to consumption of fluids of different kinds, the nature of the symptoms, and the reaction of the tissues to various fuids. Specially is this so with the use of alcoholic stimulants. While there is no doubt that the subjects of inherited gouty tendencies are better without any form of liquor, this is frequently not so in the case of the patients more or less habituated to the use of stimulants. In judging of the suitability of the various liquors, we must have regard to the usual methods of preparation of the individual bererages, e.g., beer, claret, champagne, etc., and to their common defects as recognised by experts in the trade (see p. I 47). With regard to alcoholic beverages, points already referred to are of supreme importance. The decision as to what any given subject can take, may only be arrived at after a careful study of the history, diet, and state of muscular activity in each case. There is no doubt that malt liquors and sweet wines are much more injurious than other liquors.

The sweet wines include champagne, Madeira, port, sherry, Malmsey, and Tokay; also porter, ale, and cider. Burgundy, Bordeaux, Rhine, and Moselle are almost void of sugar, and are therefore more suitable. The greater acidity of Burgundy and the Rhenish wines makes them, on the whole, less suitable than claret and Moselle wine.

German beer, e.g. lager, can frequently be taken with impunity when even one glass of the British beers will induce some acute disturbance.

The free consumption of water can be safely recommended to many, but not to all gouty subjects. In the case of stout adult plethoric subjects it may be advisable to restrict its use to early morning and late evening. The water is, as a rule, best taken on an cmpty stomach. With regard to tea, coffee, and cocoa, when suitably prepared these beverages may be 
partaken in moderate amount, but idiosyncrasies in their use are very often encountered. To some, cocoa is specially injurious, to others the daily consumption of coffee is soon followed by digestive and other disturbances, and in these cases special restrictions are called for. The amount of sugar allowed should be small. All sweet beverages should be restricted or cut off, more especially if they be in addition aerated.

The administration of the allialine and mineral waters is so closely related to the question of food and drink that special attention may be directed to it.

Mineral Waters.-The various waters in common use are recommended for one of the following reasons :-

i. A purely purgative action.

ii. A diuretic action.

iii. A diuretic and medicinal action.

Of the purgative zuaters.-Franz Joseph is one of the most palatable, and its action is mild. Apenta, a bitter and faintly sulphurated water, is also mild, and much favoured. Hunyadi Janos, Esculap, Friedrichshall, and Carlsbad are all bitter aperients, with a more powerful action, but are all suitable for occasional use. A teaspoonful each of sulphate of magnesia and sodium phosphate in half a tumbler of water may also be commended The action of these waters is hastened by admixture with hot water, and they should be taken the first thing in the morning. The continual daily use of any mincral water or saline purgative is not, however, desirable.

Of the diuretic waters.-Some are palatable, and are taken as table waters; others are specially suited for a short course of home treatment, and should be taken thrice daily on an empty stomach for a period of two or three weeks. The table-waters, which are aerated, include Apollinaris, Briresborn, Johannis, Seltzer, St Galmier, and Salutaris, which is a distilled water of English manufacture. The other group is represented by Contrexeville, a mild water containing sulphate of lime and magnesia, and Vichy water (bicarbonate of soda the main saline), of which there are several varieties. Célestins is the best known, but the Grand-Grille and 
Hauterive may also be employed with benefit. Sulis water from the springs at Bath is also useful.

Diuretic and medicinal action.-Occasionally the presence of anemia, rheumatism, or some pelvic disorder suggests the use of other waters. Thus Levico (arsenic and iron) is useful in aniemia. So also is Schwalbach (Weissenbrunn preferred) and La Bourbule, the former being especially useful in rheumatic cases. Kissingen, a saline gaseous aperient water, is valuable in various uterine and other pelvic disorders in gouty subjects.

The foregoing only represents a few of the mineral waters available; artificial representations of many of these and other waters are prepared in this country and sold in tabloid form.

Illustrations of Treatment.-From the foregoing outline of treatment it will be evident that the dietetic measures vary enormously with the different stages and very diverse manifestations of the disease. Every case of gout is a new problem in treatment. I have thought it well to give further point to this by recording in detail a series of illustrative cases, and have selected a few which have been under my observation for a lengthened interval, so that I am in the position to speak with accuracy of the effects of the different regime recommended in each case.

I. Mr A., xt. I6, schoolboy.-Marked hereditary history of gout.

i. Erythematous eruptions.

ii. Pharyngitis and tonsillitis.

iii. Nail disorders.

This case is selected to illustrate some clinical features of gout in the young subject, and also to emphasise the rational prophylactic treatment of the disease. The patient is a tall, big-boned, muscular subject whose weight is distinctly above the average for his height and years. He excels in athletics, being an adept football player, golfer, and swimmer. His home surroundings have been of the kind most favourable to the full indulgence of a keen appetite and sound digestion. His diet is plentiful and rich, and all his life he has been in the habit of drinking large quantities of milk independently of much nitrogenous food at ordinary meal-times. Scotch 
oatcakes, butter and jam are a special weakness. Ile is a total abstainer

The case admirably illustrates the treatmont appropriate to the disease. His symptoms develop after a slight or marked excess in diet, more especially if jams or other sweets have been largely consumed, on which occasions there has been no abatement in the amount of red meats and other nourishing foods. The occasions of these various congestive attacks in a young subject are probably, as with the paroxysms in adults, to be explained as the result of longstanding over-nutrition, with deficient elimination, and the excess immediately preceding the attack has merely strained the capacity of the tissues-intestinal viscera and general cell life-to breaking point. The general plan of treatment appropriate to such a case may be briefly summarised-

(i.) Moderation in diet-a slight all-round diminution of the total quantity of food consumed at each meal; the acquirement of self-control.

(ii.) Restriction and gradual cessation of the milk-drinking between foods, and also a diminution in the amount of fluid drunk at meal-times. His habit is to drink very large quantities of fluid at the different meals, which fluid would be more wisely taken in the intervals.

(iii.) Limitation of the jams, sweets, and fruits, of which he partakes inordinately, also care in the consumption of the various sweet summer beverages. (These patients are as a rule addicted to sweets of different kinds.)

(iv.) Daily satisfactory evacuation of the bowels, by artificial means if necessary. In any case, to be supplemented by an occasional saline (once in eight or ten days).

2. Mr B., æt. 26, mason.

\section{i. Chronic articular gout. \\ ii. Lithamia. \\ iii. Acute exacerbations.}

This case is selected to illustrate some points in the dietetic treatment of the discase in its more acute phases. The patient was a hospital one, and I have not the same knowledge of the later history in this case as of the others; but the points that I wish to emphasise are sufficiently 
brought out by the notes available. Enlike the others recorded, this putient was in the habit of passing large guantities of free uric acid, and he was thin, weak, and slightly cachectic in appearance.

After recovery from the acute attack patient was gradually put on a light hospital dict, as follows:-

breakfast-Porridge and milk, toast, tea, and frequently an egg.

Dinner-Soup, bread, and fowl, fish, ol red meat, with potatoes; or fish,

fowl, or meat and potatoes, with a pudding ; occasionally green vegetables.

Tea-Tea, bread and butter.

And in addition a cupful of milk was taken either alone or with soda-water twice daily. During this time patient was making a very slow recovery, being continuously very subject to sharp recurring pains in different regions, excessive weakness in the feet, hands, etc., and he was in this state when he left the hospital to go to the Convalescent Home for four weeks.

His diet then was as follows:-

1. Porridge, tea, bread and butter.

2. Fish or fowl, bread, potatoes, rice or other milk pudding.

3. 'Tea, bread and butter.

4. Porridge and milk.

The most important differences between this and his former dict were the absence of all soups, red meats, and green vegetables. Lnder this regime he improved very materially, and, for him, very rapidly. The pains diminished and soon disappeared; he gained $6 \frac{1}{2}$ lbs. in weight in four weeks. He now felt well.

On his return to hospital for further observation his diet was inadvertently changed back to his former hospital diet with immediate unfortunate results. The pains reappeared, the stiffness and weakness became accentuated, and at least one of the former weak spots became swollen, red, and tender within thirty-six hours after his return to hospital. His appetite and digestion remained apparently unaffected, the tongue was slightly furred, and the total amount of food consumed was actually less in amount than it had been at the Convalescent lfomc. No actual acute attack developed, but his whole inetabolism was deranged, and he lost $3 \frac{1}{4}$ lbs. within 
six days. Even allowing for the change of air incurred on his return to the hospital, the case wats a perfect picture of the profound influence of diet on the disease. If we analyse the altered circumstances which leel to the derangement of metabolism, there is no doubt that the soup was prejulicial, and mainly because it interfered with the normal local metabolism of the proteins in the diet. There is also every reason to believe that the mills taken in the course of the hospital diet was not calculated to give the various glandular secretions the rest requisite for their due functional activity. Other points there may be, but these will suffice. In gout, as in health, the tissues can cope with a range of dict within which no untoward effects result. The "convalescent" dict was the more physiological one, and a reference to its nature and amount clearly shows what nature is willing and able to do. Further, that diet could certainly be modified in different directions, e.g. to include vegetables without detriment so long as the necessary rearrangement of the diet was made.

There are not a few cases like this one in respect of the noxious influence of soup, but in this connection regard should be paid to the points in the composition of soup already referred to. With regard to the meat, this patient is an illustration of a type in which all red meats are better avoided. Whatever the exact cause may be, there are cases of gout when the reaction of the tissues to intestinal influences is more marked and more unfarourable if red meats are a component of the diet, and these should be dicted accordingly. But such cases are exceptional.

3. Mrs C., at. 32, married; two children.-Hereditary history of gout.

i. Neuralgia.

ii. Pains in great toe joints and legs.

iii. Acute grout.

This patient is a big, well-built woman of active bodily and mental habits, with keen appetite and excellent digestion, which she is in a position to gratify, although she does not eat immoderately. Her weight well exceeds the average for her height and years. She occasionally has a glass of claret to clinner, and takes very exceptionally a glass of beer to 
lunch. The latter is a beverage of which she is particularly fond, but she indulges very occasionally, as she has long recognised that it was prejudicial to her. This case illustrates well the ill-declared type of gout that is more frequently seen in Scotland than the truly typical form.

The special treatment may, then, be summarised as follows :-

(i.) A slight all-round restriction in the quantity of food consumed. The lunch to be mainly if not always a vegetable one, and red meats to be replaced by chicken or fish for dinner, once or twice in the week. Sweets of all kinds only to be partaken of sparingly. The principal meal to be taken dry; one small glass of claret to be taken occasionally at dinner if desired. Beer is better avoided in this case. Water to be drunk freely between meals, and a tumbler of hot water taken at night.

(ii.) More systematic exercise. Sharp walking or cycling in place of driving, supplemented by ten minutes' physical exercise daily, preferably after morning bath.

(iii.) Attention to the bowels. As the bowels move daily without an aperient, all that is required is the use of a mild yet active saline every week or ten days. Further measures will probably be necessary at the monthly periods, as the patient, like many others of a like habit of body, is prone to undue states of depression in the premenstrual period.

5. Mrs D., æt. 55.

i. Peripheral neuritis and vascular disturbances.

ii. Lumbago.

iii. Headaches.

iv. Tophi.

Mrs D. is a stout, typically gouty-looking subject, of plethoric habit, who has lived an active town life and has lived well. Of late years she has restricted her diet slightly, more, however, in accord with the teachings of her own experience than as a result of medical advice, which she secks but does not readily follow. There is a distinct hereditary history, a brother and two uncles being afflicted with well-defined gouty manifestations. Patient has on the whole been a very healthy woman; she has had ten children. 
Owing to the long-standing nature of the disease, with the associated greater instability of tissue metabolism and lessened power of resistance in the intestinal tract, the treatment will obviously differ in detail from any of those previously recorded. It may be well, in the first place, to give in full the diet which she has taken and finds well adapted to keep her free from gouty manifestations :-

Breakfast.-Avoiding kidneys, steak, liver, and all made-up dishes, and only taking one solid, e.g., fish of any kind (except salmon and fatty fishes which do not agree with her), one or two eggs, or bacon and egg; one breakfastcupful of freshly made tea with not more than one piece of sugar. Toasted bread, Vienna rolls, or other bread (not too new or doughy), with butter. Marmalade or jam to be taken only in very small quantity, and even then not to be taken every day.

Lunch, to be mainly vegetables. - Selections from the following: tomatoes cooked or raw, macaroni dressed in various ways, salads, celery, cauliflower au gratin. Bread, brown bread, Vienna rolls, or any form of unsweetened biscuit ; small piece of mild cheese, if desired. Small quantity of fruit, one of the following: an orange, raisins, apples, figs, dates, walnuts. Half an ounce of whisky in half a tumblerful of soda-water.

Afternoon Tea.-One or two small cups of tea, with a very thin slice of bread and butter, or a piece of very light cake. Very little solid should be taken, and especially no rich cakes.

Dinner.-The dinner to consist of three courses, to which fruit can be added, if not taken to lunch. The diet to be arranged on the following plan-

\begin{tabular}{lllll}
\multicolumn{1}{c}{ I } & \multicolumn{1}{c}{ 2 } & \multicolumn{1}{c}{3} & \multicolumn{1}{c}{4} & \multicolumn{1}{c}{5} \\
Soup, & Fish, & Soup, & Fish, & Soup, \\
Meat, & Meat, & Entrée, 1 & Meat, & Fish, \\
Pudding, & Savoury. & Pudding, & Pudding. & Savoury. \\
Fruit. & & Fruit. & &
\end{tabular}

Care has to be taken that on the nights when meat is taken the soup should be of a lighter character, e.g., clear brown, rice, or fish soup. Similarly on nights 2 and 4 , the fish should be of the lighter kind, e.g., whiting, haddock, or sole. On the 5 th night the soup can be richer, e.g. oxtail or kidney with a light fish, or the soup may be light and the fish more rich, e.g., turbot, halibut, or skate. No more than two vegetables are to be allowed, and then in sparing amount-a sauce to be reckoned as a vegetable. (Half an ounce of whisky in not more than half a tumblerful of water the only safe beverage for constant use.) Claret,

'Sweetbl ead, tipe, chicken, sabbit. 


\section{GOUT, RHEUMATISM, RHEUMATOID ARTHRITIS}

champagne, and whisky are the only drinks for which patient has any regard. The puddings recommended are milk puddings of various kinds, and stewed fruits made with small quantity of sugar.

Suet puddings only to be taken in sparing amotint, and then only when the other courses are of the lighter nature. Jellies and creams can be taken sparingly, meringues (a special weakness) to be avoided. Bananas and strawberries are best avoided. Simall cup of café noir prepared without sugar.

Are any medicinal remedies called for? As the patient is a sensible woman and fully appreciates the very small infucnce which drugs have exerted in her disease, none should be recommended with the exception of the constant use of a vegetable pill, and frequent use of the saline already referred to.

This case is a fair illustration of a not uncommon type in which the purcly vegetarian diet, so eloquently advocated by Haig, is not applicable in treatment, and even if it were advisable, there is not the remotest possibility of its being carried out. With regard to exercise, as the patient is of an active temperament, and has a considerable anount of muscular exercise in connection with her houschold duties and numerous outdoor interests, no further recommendations are called for. Further, it would be well for her to arrange to have her annual holiday occasionally at a health resort, where a full course of hydropathic treatment under medical directions will be useful in working off the effects of the occasional or frequent deviations from the paths of physiological righteousness, which may be regarded as a part of the clinical history of the disease; and in the intervals, and for the same purpose, an occasional course of diurctic remedies will be found of the greatest service.

Summary. - It may be well now to tabulate the principal points which should be kept in view in the general management of all cases.

1. When a hereditary tendency exists in children, habits of extreme sobriety in eating and drinking should be cultivated, and the diet should be mainly a milk, vegetarian, and light meat one (pp. 200, 526).

2. When the disease is established there is no routine treaiment, and the details will not be the same in any two 
cases. Attention should, however, be directed in turn to the following:-

(a) The diet and state of the digestive tract.

(b) The amount and nature of the exercise indulgerl in.

(c) The functional activity of the skin and kidneys.

(d) The state of the central nervous systcm.

3. The quantity of food should be determined by the amount of active excrcise. Threc meals a day only to be taken, and those to be of a simple character.

4. When in doubt as to which set of food constituents to cut off, begin with the carbohydrates, and especially the saccharine substances. In not a few cases the latter may require to be completely cut off, and in every instance special care must be exercised in the admixture of carbohydrates with the fats and nitrogenous foodstuffs. As already pointed out, the examination of the urine for "the pancreatic reaction" is of special value as a guide to dietetic treatment.

5. Thorough mastication of the food is all-important, and strict attention to the evacuation of the bowels a necessity (with, in addition, an occasional saline).

6. Fluids and beverages.-(a) Alcohol in any form is better avoided, except in subjects who are more or less habituated to its use, in which case the liquor taken should be the one which is known by the patient to be least detrimental to him. On no account should drinks be mixed. All sweet wines and malt liquors should be avoided, unless the patient is satisfied from careful observation that these are not prejudicial to him. The stimulant should be taken in a measured quantity and with meals.

(b) The free use of the alkaline table-waters is to be commended, care being taken that an excessive amount of fluid is not taken with the meals.

(c) A tumblerful of hot water at night and an occasional course of mineral waters taken on an empty stomach are useful eliminants.

\section{Chronic Rheumatism.}

The causation of chronic rheumatism is not exactly known. Our present knowledge indicates that an important 
factor in rhcumatism is a poisoning of the system by a poison absorbed from a litent catarrh, such as is frequently present in the digestive tract, uterus, bladder, or other mur ous membrane (see Auto-intoxication). In the presence of a weak spot of this kind, diet frequently acts as an exciting cause. It may do so in virtue of one or other of the following defects:-

1. Excess of animal protcin foods, such as is involved in taking a rich meat dict twice or thrice daily, with a resulting excessive putrefaction of proteins.

2. Excess of sugars, jams, etc., such as is involved in taking four or five cups of tea daily with much sugar, also marmalade and jams, sweets and chocolate, with abnormal fermentations as a sequel. The careful application to the urine of the test known as the pancreatic reaction (p. 377) is of great value as indicating whether there is any excess of farinaceous or saccharine foods.

3. Excess of fruits.

An excess in either of these directions may induce all the symptoms of chronic rheumatism. In a few cases the patient is aware that certain articles of diet induce his rheumatism, and under these circumstances the use of such foods or drinks should be avoided or restricted. There is no question that some rheumatic subjects keep themselves free from pain on a lacto-vegetarian diet (p. 520). No hard and fast rules can be laid down. In the investigation of rheumatic cases, careful attention must be directed to the dietary of the patient for a long time prior to the development of rheumatic symptoms. Has the patient indulged too freely in animal "protein foods" ? e.g., indulging in a rich red-meat dict twice or thrice daily. Has he been in the habit of taking a large amount of sugar, in the form of sugar in his tea, jam, fruit, and the like? Has he partaken of beer or other alcoholic liquors to an extent which is prejudicial to him? e.g., taking a little of beer daily to lunch over a lengthened period, when leading a comparatively sedentary life. And lastly, has there been in operation any contributory factor, such as constipation, the existence of which would be an important contributing factor? 
Most cases of rheumatism can be cured by these points. In conclusion one may formulate th general rules :-

I. The diet should be a simple one, taken a intervals, and eaten slowly. When the digestion is good and the appetite strong, a large amount of food may be taken provided it be of a simple nature. Speciai care must be taken to prevent constipation.

2. Any article of food or drink which the patients have good reason to believe detrimental should be withheld or taken in sparing amount. Their nature frequently gives a clue to the nature of the faulty metabolism present. In this connection it is important to note the periodic nature of the symptoms, e.g. recurrence of "rheumatism" at the fruit season.

3. More fluid should be taken. Most rheumatic subjects drink too little. The writer has had under his care a lady affected with chronic rheumatic pains who passed only from 6 to 8 ounces of urine daily. Similar cases are far from uncommon. Plain water, hot water night and morning, or Lithia water, to the extent of about 15 to 20 ounces (two tumblerfuls) should be taken daily, on an empty stomach.

4. If the patient can furnish no clue as to dietetic error, and if the pancreatic reaction of the urine is of a negative character, the best plan is as follows:(a) Reduce the diet, making it as simple as possible, and if that does not suffice, cut off meat foods, putting the patient on a lacto-vegetarian diet, care being at the same time taken that no excess of sugar is taken in the dietary. Special value in some cases attaches to the use of buttermilk, of which a detailed account is given on p. 540 .

\section{Rheumatoid Arthritis.}

There are few chronic diseases in which special attention to the gastro-intestinal tract by means of diet and other measures is of greater importance than that group of diseases comprised under the term Rheumatoid Arthritis. 
The discase is one which attacks young people, adults, and elderly subjects, and its onset may be acute, subacute, or chronic. The dietetic treatment will therefore vary according to the age of the patient and the stage of the disease. The cxact causation of this disorder is unknown, but there is good reason for believing that it is of bacterial origin, the source of the infection being the gastro-intestinal tract (including the oro-phary:x) or the genito-urinary tract. In support of the vicw that the sastro-intestinal tract is a source of the toximia, we have the fact that the stools are usually profomndly deranged, being for the most part ill-formed, pultaccous, and extremely fotid. Whether this derangement is a primary or secondary factor in the disease is for practical purposes inmaterial; the important point is to recognise its existence, and to aim at its correction by means of diet and other mcasures, since there is ample cridence that this can frequently be done, with a corresponding improvement in the symptoms, or apparent cure.

The view is often expressed by authoritative writers that there is an important distinction between gout and rheumatoid arthritis in regard to the dict appropriate to the two diseases, the former necessitating a "sparing" diet, the latter a "generous dietary." This distinction is only partially true, and much harm has, in the author's opinion, followed from the general adoption of a clictary based on the assumed correctness of this view. Cases of rheumatoid arthritis are frequently seen, which have previously been treated with little or no success on a "generous" dict, in which the substitution of a dietary of less than half the nutritive value is followed by a striking and permanent improvement. These are invariably cases in which the careful examination of the stools has shown an unusually septic condition of the alimentary tract, a state of affairs which, it should be added, may exist without subjective symptoms of gastro-intestinal disorder. More commonly, however, there is a history of constipation, diarrhoe, flatuicnce, discomfort after focd, or other symptoms of gastrointestinal derangement.

In many cases of rheumatoid arthritis, in which there is reason to belicve that the infection of the system is taking place from a nerglected catarrh of the uterus or bladder, there 
is an associated derangement of the large intestine, shown by the septic state of the intestinal evacuations, and in these cases it is of equal importance to pay special attention to the diet. In contrast to the large group of cases of rheumatoid arthritis referred to as having been fed, to their detriment, on an over-generous diet, reference must be made to other cases in which the reverse holds good. We occasionally see cases, often of an advanced character, in which the paticnts have dieted themselves on a "system," usually of a vegetarian or pseudo-vegetarian character, where the diet in use, either from its poor nutritive value or from its unfavourable influence on the growth of the intestinal bacteria, has accelerated the progress of the disease.

As already indicated, the onset of the disease may be acute, associated with a varying amount of febrile disturbance, which may persist for weeks; as a rule, however, the onset is slow and insidious. The dietetic treatment of the acute phase of the disease is the same as that for acute fever (see Chap. XVI.); the diet for the subacute and chronic stages of the disease is a more difficult matter. The one point which has to be kept in mind is that the patients have frequently been living on a diet which has been favourable to the pathogenic action of the bacteria which normally abound in the intestine, as a result of which poisonous substances are absorbed into the system, and the intestinal evacuations are at the same time foetid in character. The diet must be altered in a manner which will lead to a more satisfactory state of the intestinal contents, as revealed by the passage of healthy stools. The dict appropriate to any given case can only be determined after a careful inquiry has been made into the past history of the case. There is good reason to believe that a diet which is rich in meat and other rich albuminous foodstuffs promotes the multiplication of the intestinal bacteria in an unfavourable manner. Hence it is important to reduce the amount of meat, and more especially red meat, and further, to see that the meat when taken is given in a simple and easily digested form. There are some cases, however, which are beneficially treated in the early stages of the disease by a protein dietary, the protein being given in a simple and easily digested form (sce l'rotein dictary in 
Auto-intoxication, p. 347). We also know that a dict which is rich in vegetables, and especially green vegetables, leads to the formation of organic acids in the intestinal tract, which cxercise a restraining influence on the bacteria in the bowel. On these grounds a lacto-vegetarian diet is to be commended. Great care has, however, to be taken in the selection of this dict, because of the flatulence and other disturbance that may be induced by a too largely vegetarian regime. Again, we know that the digestive secretions are, as a rule, weakened in this disease, and hence the diet must be framed in such a way as to throw the minimum strain on the digestive functions, while supplying ample nutritious material for the needs of the tissues. Hence the diet should be simple, the proteins, fats, and carbohydrates all being presented in a form which is easily digested and assimilated. In some patients it is a useful plan to give for two or three days at the outset of treatment nothing but skimmed milk and buttermilk. The last general point to which I would direct attention is the value of soured milk as an article of diet in this disease. Metchnikoff has pointed out that lactic acid bacilli exercise a restraining influence on the pathogenic action of the Bacillus coli communis and other intestinal bacteria, and one of the forms in which this can be administered is buttermilk. In recent years soured milk has proved of decided value in the treatment of this disease. A fuller account of this regime is given on page 540 .

So long as there is intestinal derangement, as shown by the presence of fotid stools, with, it may be, constipation alternating with diarrhoea, the dietary should be framed along the following lines. Thorough mastication of the food, careful attention to the cleanliness of the teeth, and the avoidance of constipation, are of great importance in treatment.

8 A.M. : Breakfast.-Cup of tea or coffee, with little or no sugar; an egg, boiled, poached, not fried; or fish of a white variety, steamed, boiled or fried; or well-cooked bacon, not combined with egg; or slice of ham or tongue. Only one solid fool should be taken. A crisp roll, or slice of toast, or bread not too new, with a little butter; no marmalade or jam.

II A.M.-Half a pint of soured milk, with a biscuit. 
Dinner.-Restricted to two courses. Fish and meat on alternate days. Aroid oily fishes, and made-up meats. No sauces with the neat. One segetable only-cauliflower, celery, spinach, onion, or fresh beans. Potatoes and other tubers to be avoided. For puddingcustard, jelly, curds, stewed fruit, with little or no added sugar. Avoid milk puddings, pastry, suet, pancakes, and omelets. Half a pint of soured milk.

4.30 P.M.-Cup of tea, with little or no sugar; dry biscuit or rusk.

Supper.-Either a cereal, e.g., porridge or gruel with milk, and a little cream, or strong meat tea or chicken essence with toast. Half a pint of warm soured milk to be taken late at night.

As soon as the bowel condition is improved, the diet, which is, so far, a non-fermentative one, may be increased in variety and nutritive value by the addition of more breadstuffs and butter at breakfast, a third course, e.g., soup or biscuits and cheese to dinner, and the addition of fish or egg to the evening meal. As soon as possible, extra fat should be added in the form of cream and butter. 


\section{CHAPTER XXVII}

\section{GLICOSURIA AND DIABETES}

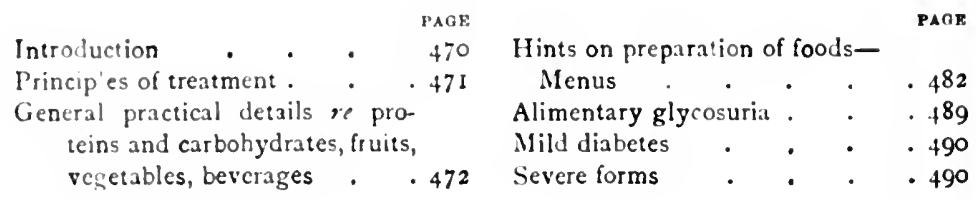

Introduction. - In health the ingestion of a mixed diet containing a moderate amount of sugar and starchy foods is not attended by the passage of sugar in the urine. The sugars and starches of the food undergo a series of chemical changes (sec pp. 9, 15 ), being burnt up in the tissues, and forming a source of energy and heat production. In disease there is a defect in the mechanism of digestion and assimilation of carbohydrate foods, with the result that sugar appears in the urine (glycosuria). Even under normal conditions the power of sugar destruction in the body is not unlimited, since if a large excess of sugar be taken in the food, sugar appears in the urine. This is known as alimentary glycosuria. In all probability this alimentary glycosuria is simply the mildest form of the diseased state which in an advanced stage is true diabetes, or diabetes mellitus. In this condition the sugar in the urine is derived from the starches of the food as well as from the sugars. Diabetes may be of a mild or a severe type. In the former the amount of sugar in the urine can be controlled to a very great extent by diet; in the latter, sugar continues to be excreted in the urine, it may be in large amount, even although the diet is free of sugar and starchy food.

In every case in which there is doubt as to the severity of the disease, recourse should be had to a test diet. If a diet 
free from carbohydrate (see later) does not cause the sugar to disappear from the urine, the patient is suffering from a severe form of the disease. Care must be exercised in the application of this test, and it is as a rule advisable not to apply this rigid test suddenly; the carbohydrates should be cut off from the diet gradually over a period of several days. In every case we must ascertain what amount of carbohydrate food the paticnt can tolerate without the appearance of sugar in the urine; in other words, given the presence of sugar in the urine, we must determine whether the condition is one of $(a)$ alimentary glycosuria, $(b)$ mild diabetes, or $(c)$ severe diabetes.

Principles of Treatment.-The main essential in treatment is to restrict so far as possible the amount of carbohydrates to the amount which the patient can assimilate without the appearance of sugar in the urine. This involves the use of foods rich in proteins and fats, and the restriction of, or it may be, the abstention from, all sugars and starchy foods. The deprivation of starchy foods in the form of bread and bread foods is a great trial to the patient. Most of the substitutes prescribed as diabetic foods are not very palatable; they are, further, expensive, and to many the restriction becomes so irksome that the strictness of the dietary has to be relaxed. The dict must not be regulated exclusively by its effects on the urine. On a given diet the sugar may steadily diminish, while at the same time the general condition of the patient deteriorates. Further, the type of the disease has to be considered. Thus the dietetic trcatment of diabetes in an obese adult or in an elderly subject is a simpler matter than the treatment of the severe form of the disease met with in young subjects in whom there is much wasting and general weakness. The weight of the patient is a very important guide in the treatment, and has to be continually noted throughout the progress of the disease. The toleration limit for carbohydrates is another factor to be noted. We must determine the extent to which the excretion of sugar can be affected by dietetic means. A further point that should be attended to is to make the changes in the dietary gradually; in many cases of diabetes there is danger associated with the sudden removal of carbohydrates. Lastly, it is important to make 
the food as appetising and varied as possible. Assistance in this direction will be found in the description of the Menus on pp. 48 I et seq.

In the successful dieting of diabetic patients the principle to follow is to exclude as much as possible the starches and sugars from the food; to replace these important articles of food by fat, which is also a hydrocarbon, so that the body may not lack entirely fuel food. To do this, and still allow the diet to be varied and appetising, requires a considerable knowledge of foodstuffs and cookery.

The main rules to be observed are as follows :-

I. No sugar or articles of food containing sugar.

2. Restriction of all foods that contain starch.

3. The great deficiency caused by the above restriction to be made up by fat, and not by excess of meat.

The lists on p. 473 give the allowable foods, and those that are not permissible, and upon this the menus are framed. It is unfortunately almost impossible to get a satisfactory diabetic diet that is not expensive.

In these tables we see that milk is allowed only in limited quantities, on account of the 4 per cent. of carbohydrate in the form of lactose. This is the most assimilable form of sugar, and in severe forms of diabetes, when there is much impairment of digestion, it is probably often the best food, on account of its protein, its richness in fat, and the solubility of its sugar. If milk is considered inadvisable, an artificial milk can be procured free from sugar (from Messrs Clay, Paget, \& Co., Ebury Street, Eaton Square, London; or Messrs Callard \& Co., Regent Street, London); this can be diluted with mineral water. Cream has mainly to replace milk in the special cookery, being almost free from lactose, and it has the great advantage in containing the most easily digested form of fat (see p. 40).

The following recipe of home-made artificial milk prepared from cream can be taken in unlimited quantity by diabetics, and is a most useful article of food :-

Sugar-free Milk.

Place 4 tablespoonfuls of cream in I pint of water. Mix well. Allow to stand for twelve hours. Then skim off the fat and place in a second 
Foods.

May cat

Butcher meat of all kinds except liver.

Tongue, ham, bacon, or other smoked, salted, dried, or cured meats.

Poultry, game.

Fish of all kinds, fresh, salted, or cured; shellfish, except the bodies of lobsters and crabs; mussels.

Animal soups, not thickened with any starchy materials; beefteas and broths.

Eggs, dressed in any way.

Cheese, cream cheeses, butter, cream.

Greens, spinach, turnip-tops, French beans, ${ }^{1}$ brussels sprouts, ${ }^{1}$ cauliflower. ${ }^{1}$

Broccoli, ${ }^{1}$ cabbage ${ }^{1}$, asparagus, ${ }^{1}$ seakale, ${ }^{1}$ vegetable marrow, lettuce, cucumber, tomatoes, mushrooms, mustard and cress, watercress, endive, spring onions, leeks, celery, rhubarb, pickles.

Oil, vinegar.

Savoury jelly ; jellies and custards, sweetened with saccharin; blancmanges made with isin. glass or gelatine.

All nuts, except chestnuts; olives.

\section{May not eat}

Sugar in any form.

Wheaten bread, and ordinary biscuits of all kinds.

Toast, rice, arrowroot, cornflour, oatmeal, sago, tapioca, macaroni, vermicelli.

Potatoes, carrots, parsnips, beetroot, peas, Spanish onions.

Pastry and puddings of all kinds, and honey.

All fruit, fresh and preserved, Liver. except lemons and unripe fruit.

Oysters.

Cockles and mussels, and crabs.

\section{Beverages. \\ May take}

Tea, coffee, cocoa from nibs; dry sherry, claret, dry Sauterne, Burgundy, Chablis, hock, brandy, whisky, and other unsweetened spirits; unsweetened aerated waters; milk (limited to I or I $\frac{1}{2}$ pints daily); Kephir, sugar-free milk.
May not take

Milk, except in limited quantities; sweet ales, porter, stout, cider ; all sweet wines, port, Tokay, champagne; liqueurs; fruit juices and syrups; cocoa and ordinary chocolate.

1 These should be boiled in a large amount of water. 
vessel ; to this add water (cautiously), a pinch of salt, a trace of saccharin, and a little white of egr, until the fluid has the consistence and colour of ordinary milk.

A second form of milk, containing only a little sugar, may be made by dissolving cream, and especially Devonshire clotted cream, in water.

A third artificial milk, practically free from sugar, can be made from Biogene powder and Milk albumin (Bonthron, 50 Glasshouse Street, London), as follows:-

To a glass of water a teaspoonful of cream and one or two tablespoonfuls of Biogene powder is added, and well mixed.

The supply of abundance of fat is often a difficulty, but fish and vegetables should be cooked and served with a liberal amount of butter. The fat of beef and mutton and bacon is very suitable. Many patients can readily take the fat of cold roasted beef, and ham, or bath chaps (pig's cheek); and large quantities of fatty food can be taken in this way. bone-marrow, which consists almost entirely of fatty material, may be used in the following ways:-

\section{Potted Meat.}

4 ounces of marrow-bone, 4 ounces shin of beef. Cut up the beef and marrow into small pieces; place in a jar, with a little onion and pepper and salt ; just cover with water. Stew gently in a slow oven for three to four hours, until the meat is quite soft.

Take out the meat and marrow, leaving the fluid in the jar. Pound the meat and marrow, or pass twice through the mincer until they are quite smooth. Add a little fluid from the jar in which they were cooked; add pepper, salt, and spice, and mix all together into a paste. Place in small pots, and cover with clarified butter, to preserve it.

\section{Grilled Marrow-bones.}

Saw the bones into short lengths. Cover the ends with a paste made of flour and water, tie them in a floured cloth, and boil one and threequarters to two hours. Remove the cloth and crusu, set the bones upright on a dish covered with a hot napkin, and serve with dry, crisp toast. Serve very hot.

Salmon, herrings, mackerel, sardines in oil, pâté de foie gras, cream cheeses, rich sauces made with eggs, oil, and cream (e.g. mayonnaise), are all useful. If the excess of fat in the food gives rise to dyspepsia, a small quantity of brandy and water after meals aids digestion. 
The want of sugar in the diet is greatly felt by most patients; - of the sugars, milk sugar (lactose), as in milk, is the least injurious; but the sweet flavour can be replaced by saccharin and Saxin (coal-tar products), these being intensely sweet only require to be used in very small quantities; prepared glycerinc is also available as a sweetening agent.

Starch being quite unsuitable for diabetics, means that all the breadstuffs are cut off, and this is a very great deprivation. Bread ordinarily contains about 50 per cent. carbohydrate and 2 per cent. sugar. Various bread substitutes, known as diabetic bread and biscuits, and claiming to contain only a small quantity of the starch, are to be obtained; but it should be noted that all reliable diabetic foodstuffs are expensive. The presence or absence of starch can easily be proved by the application of iodine and potassium iodide solution; if the breadstuff turns deep blueblack it contains a large amount of starch, and is little better than ordinary bread. The diabetic breads are made from bran, gluten, casein; and in recent years the oily nuts such as almond, cocoa-nut, hazel nut, and the soya bean have been largely used. The made-up breads, cakes, and biscuits can be procured direct from the makers (Blatchley, London; and Callard \& Co., London); or the ground nuts, etc., in the form of flour can be purchased and made up in the patient's own house.

Almond flour or desiccated cocoa-nut powder made into biscuits is very satisfactory, and they contain a very considerable quantity of fat. These both contain a little sugar, which is destroyed by the action of yeast in the preparation of the foods. Cocoa-nut, hazel nut, and pine seeds can also be procured in powder form, and made into biscuits and flavoured in various ways. Bran flour is another product which, if carefully prepared, is entirely free from starch; this can be bought by the pound, and made at home into bran cakes or bread.

Diabetic foods are either made up by the manufacturers or made at home from the specially prepared flours, as follows :-

The following albumins may be used for the preparation 
of bread substitutes, puldings, etc., or in the cooking of food in place of breadcrumbs:-

l'egetable albumins.-(I) Gluten flour, best specimens only contain 2 to 3 per cent. starch (as supplied by Messrs Bischof \& Brooke, 35 Brooke Street, Holburn, London, E.C.). (2) Glidine contains only 2.7 per cent. starch, or less (Messrs Menley $\&$ James, Farringdon Road, London, E.C.). (3) Aleuront contains only 7 per cent. of carbohydrates (Messrs Callard, Regent Street, London).

Milk albumins (all starch-free).-Protene (The Protene Co., 36 Welbeck Street, London, W.); Plasmon (Plasmon Co., 56 Duke Street, Grosvenor Square, London); Biogene (Mr Bonthron, 50 Glasshouse Street, London).

Milk albumins.-Sanatogen (The Sanatogen Co., I2 Chenies Street, London, W.C.).

\section{Bread Substitutes wohich are free from Starch and satisfactory chemically.}

(1) From Bonthron, 50 Glasshouse Street, London-

Casein biscuits (these are very palatable).

Casein bread.

Shortbread biscuits and Biobran drops.

Biogene wafers.

(2) From Callard \& Co., Regent Street, London-
Prolacto bread.
Cellulon bread.
Bran and almond bread.
Casoid bread.
Kalari biscuits.
Rislacto biscuits.

Casoid meal bread.

(3) From Protene Co., 36 Welbeck Street, LondonProtein bread. Protein biscuits.

Protein br: n bread.

(4) From Plasmon Co., 56 Duke Street, Grosvenor Square, LondonPlasmon diabetic biscuits.

(5) From Huntly \& Palmer's, Reading-Akoll biscuits.

(6) From Messrs R. Summer \& Co., of Liverpool-Tritumen bread. It is claimed that each roll contains as much assimilable albumin as 3 ounces of meat or four eggs.

(7) Brusson Jeune Co., Bedford Chambers, Covent Garden, London, prepare a crisp roll, not entirely free from starch, which is an excellent diabetic food.

\footnotetext{
Home-made Diabetic Breadstuffs. Almond Cake.

I ounce almond flour. 2 eggs.

Salt to taste.

Beat the whites of the eggs to a stiff froth, add the almond flour, and beat well together. Spread out into a buttered baking-tin about half an inch thick, and bake in a moderately quick oven from fifteen to
} twenty minutes. 
The mixture should be done quickly, and baked as soon as the ingredients are mixed.

These cakes are much improved by adding a small quantity of gluten flour.

\section{Cocoa-nut or Almond Cakes.}

4 ounces desiccated cocoa-nut, or almond flour.

I pinch of saccharin.
German yeast.

1 egg.

2 teaspoonfuls cream.

The almond flour is mixed into a paste with a little water and the German yeast. Allow the mixture to stand in a warm place for twenty minutes. Then add the egg, two teaspoonfuls of cream, and water sufficient to work the mixture. Divide into cakes and bake in a quick oven.

\section{Bran Cakes.}

4 ounces prepared bran flour.

I teaspoonful of bicarbonate of soda

\section{5 eggs.}

$\frac{1}{4}$ pint of warm milk.

2 ounces butter.

First mix the bicarbonate of soda with the bran flour, then beat up 2 ounces of butter in a warm basin, shake into it the dry ingredients, beating with a spoon all the time. Next beat up the five eggs in a separate basin before the fire until quite warm, and stir them gradually into the mixture of bran flour, soda, and butter. Beat up all well for ten minutes, and add gradually the warmed milk. Place in buttered tins, and bake in a brisk oven for about ten minutes. The cakes are done when they will turn out of the tins quite easily. This will make about five cakes the size of buns. The cakes can be cut into slices, buttered, and toasted.

Even more palatable cakes can be made with an equal mixture of bran and almond flour. The bran reduces the excessive richness of the almond flour and gives a pleasant flavour.

Bran Bread.

$\frac{1}{2} \mathrm{lb}$. bran (prepared).

2 ounces almond flour.

3 ounces butter.

6 eggs. $\frac{1}{2}$ pint milk.

2 teaspoonfuls of bicarbonate of soda.

I teaspoonful of tartaric acid.

Place the butter in a basin and beat it to a cream, then add the almonds, and well beat; add the eggs one at a time. Partly mix in the bran before adding the milk. Well mix the whole together, and place it in a well-buttered tin, and bake for an hour in moderate oven.

Gluten Bread.
I lb. gluten flour.
I ounce ground almonds.
$\frac{1}{4} \mathrm{lb}$. of prepared bran.
2 eggs.
1 ounce yeast.
Pinch of salt.

Make a sponge as for ordinary bread, and set it to rise. This will take about three-quarters of an hour. Then bake. 
The addition of a little ground almonds and 2 eggs is an improvement.

Gluten bread in slices, cut into small pieces, soaked in butter and toasted or fried, is very palatable, and will be found a useful article in the preparation of many dishes.

\section{Further Diretions for Home-made Bread Substitutes} (Williamson).

Protene Bread.

4 ounces of No. 2 Protene, ${ }^{1} 2$ ounces of butter, 2 eggs. Beat all together thoroughly. Divide so as to form 8 small cobs. Bake in oven.

\section{Protene and Cocoa-nut Bread.}

Mix together I tablespoonful of lukewarm water, $\frac{1}{4}$ ounce of German yeast, $\hat{3}$ tablespoonfuls of desiccated cocoa-nut powder. Cover and leave in a warm place for about twenty minutes, until it is spongy; then add 3 tablespoonfuls of bran protene, a pinch of salt, I egg well beaten up with a little milk. Mix all well together, place into tins, bake twenty minutes or longer.

\section{Cocoa-nut Cakes.}

I ounce of German yeast, 4 tablespoonfuls of lukewarm water, 16 ounces of desiccated cocoa-nut powder. Mix into a paste, adding a little more lukewarm water if necessary. Leave in a warm place for twenty minutes. Then add 2 eggs (beaten up in 3 or 4 tablespoonfuls of milk), and a little salt. Mix well. Place into 16 small dishes or tins (well greased). Bake in a moderate oven twenty or thirty minutes. These are the cheapest diabetic cakes.

Almond cakes may be made in a similar manner, using almond flour in place of cocoa-nut powder.

\section{Aleuront and Cocoa-nut Cakes.}

For the preparation of these cakes, 2 ounces of desiccated cocoa-nut powder are mixed with a little water containing a small quantity of German yeast. The mass is then formed into a kind of paste, and this is kept for half an hour or longer in a warm place. The small amount of sugrar contained in the cocoa-nut is almost entirely decomposed by the fermentation produced by the yeast, and the cocoa-nut paste becomes spongy. 2 ounces of Aleuront, I egg beaten up, and a small quantity of water, in which a little saccharin or Saxin has been dissolved, are now added to the cocoa-nut, and the whole well mixed until a paste is formed. This is spread out on a tin and divided into cakes, which are baked in a moderate oven for twenty or thirty minutes.

\section{Cocoa-nut and Plasmon Cakes.}

Mix together 2 tablespoonfuls of cocoa-nut powder, a little lukewarm water, and ! ounce of German yeast, so as to form a stiff paste. Allow

1 Xis. 2 Protene can be outained from The P'sutene Co., 36 Welbeck Strcet, London, W. 
to stand (covered) in a warm place for about ten minutes, until it becomes spongy, then add 3 tablespoonfuls of Plasmon, a pinch of salt, I tablespoonful of glycerine, and I egg well beaten up with a little milk. Mix all together. Divide into 4 to 8 tins. Bake for twenty minutes or more.

\section{Protene and Almond Bread.}

Mix $\frac{1}{4}$ ounce of German yeast with 2 tablespoonfuls of lukewarm water and $\mathrm{I}$ ounce of almond flour (ground almonds). Allow the mixture to stand in a warm place for ten minutes, then add 4 ounces of No. 2 Protene, I egg (beaten up), a little salt, I $\frac{1}{2}$ ounces of butter, and a little milk. Mix all well together with a fork, divide into cobs, or place into small tins, and bake.

\section{Glidine and Almond Cakes.}

3 tablespoonfuls of ground almonds; 3 tablespoonfuls of Glidine; $\frac{1}{2}$ teaspoonful of baking-powder. Mix all together. Beat up I egg in a little milk. Then mix all together. (If necessary, a little more milk may be added.) Place in small tins so as to make little cobs. Bake in a moderate oven twenty to thirty minutes. These cakes are soft, and taste best when buttered. They contain a very small amount of starch and sugar, but may be eaten in moderate amount by diabetic patients. The very small quantity of sugar may be destroyed by the action of yeast if the cakes are made in the following manner :-

Place 4 ounces of ground almonds in one vessel. Mix $\frac{1}{4}$ ounce of yeast in about 2 or 3 tablespoonfuls of lukewarm water, add this to the almonds, cover, leave it in a warm place for twenty minutes, until it becomes spongy. Then put 4 ounces of Glidine into a separate vessel with $\frac{1}{2}$ teaspoonful of baking-powder. In another vessel beat up I egg in a little milk. Then mix all well together (almonds, Glidine, and egg) into a light paste, and if too thick add a little more milk. Drop with a spoon into small pots or tart tins to make 6 or 7 cobs. Bake in a moderately hot oven for twenty minutes or longer.

These cakes may be taken in any quantity by all diabetic patients.

\section{Plasmon Biscuits.}

Plasmon 8 ounces, $\mathrm{I}$ egg beaten up in milk. Mix well together into a light paste. Divide into cakes and bake for ten minutes.

Bran and almond bread, almond bread, and gluten and almond bread may be prepared at the patient's home from flour supplied by Callard $\&$ Co. (London).

Most gluten bread contains so much starch that it is of little service. It should always be tested with iodine, and should be regarded as ordinary white bread, unless it is known to be one of the few specimens containing only a very small percentage of starch. When it is considered advisable to allow a diabetic patient a small quantity of white bread, 3 or 4 ounces daily - this may be replaced by an amount of gluten bread containing the same quantity of starch as the 3 ounces of ordinary bread. The bulk of this quantity of gluten bread will be much greater 
than that of the equivalent white bread. Many patients much prefer the small quantity of ordinary bread to its more bulky equivalent of gluten bread: but to some patients the more bulky gluten bread is more satisfying.

There are a few specimens of gluten flour (such as preparations supplied by Messrs R. O. Bischof \& Brooke, 35 Brooke Street, Holborn, London, E.C. ; and by J. Bonthron \& Co., and Callard \& Co., London, W.) which contain only 2 to 6 per cent. of starch. When the medical man has ascertained, by his own testing with iodine, that the gluten flour only contains a very small percentage of starch, it may be used freely for the preparation of bread, puddings, pancakes, according to directions supplied by the various firms (provided these directions do not recommend the addition of ordinary flour).

Diabetic spongecakes made from almond flour and sweetened with glycerine are excellent.

Gluten macaroni and gluten vermicelli are quite appetising articles.

As a matter of practical experience in the treatment of diabetes, the complete deprivation of starch in the breadstuffs is found to be so great a trial, and becomes so irksome, that it is usually necessary and often desirable to allow a small amount of ordinary bread.

Fruit when ripe, as a rule, should be avoided because of the large amount of sugar present, but in a few fruits-strawberries, gooseberries, apricots, melons, and oranges-the sugar is in the form of levulose, and this, as has been mentioned before, is more easily utilised by the tissues. Unripe fruits, gooseberries and raspberries, cranberries and rhubarb, sweetened with saccharin or neutralised with an alkali, have to take largely the place of ripe fruit. The "Forbidden Fruit," resembling a pale orange, contains very little sugar, and is suitable for diabetic patients. Diabetic marmalade, made with gelatine, glycerine, and orange juice and rind, is an attractive-looking compound, and a great boon to the diabetic's breakfast-table. Callard \& Co. also make a diabetic jam which is almost sugarless.

Vegetables. - Potatoes should not be taken by most diabetic patients; if taken, they are best in the form of wellfried potato chips. A small amount of potato in this form makes a large dish, as the potato expands with cooking.

Boiled walnuts are recommended as a substitute for potatoes. Place the shelled walnuts in an enamelled pan in 
boiling water and boil for thirty minutes; rrain away the water carcfully, place on a plate and sprinkle well with Aleuront flour or Glidine. Add salt, pepper, and butter.

In cooking green vegetables, butter and fat should be freely used; and oil, eggs, and cream may be uscd with the salad dressings.

Beverages.-Beverages containing carbolnydrates to any degree should be excluded from the dictary. These include beer, porter, ale and stout, rum, sweetened gin, liqueurs, sw'et lemonade, cocoa and chocolate, fruit wines and syrups, port, champagne, sweet wines, and Tokay. The beverages allowable are water, soda-water, and mineral-water, tea, coffee, brandy, whisky, dry sherry, claret, Burgundy, hock, Moselle, most Rhine wines, and Hungarian wines. Citric acid lemonade, 10 grs. to the pint, sweetened with 4 drams of glycerine or a little saccharin, is an admirable thirst-quencher, and the following are also suitable.

Home-made lemonade (lemon juice and water) sweetened with saccharin or Saxin.

Soda and lemon : squeeze a lemon, and add a glass of soda or seltzer water.

A specially prepared diabetic cocoa is prepared, and also chocolate, flavoured with vanilla and sweetened with saccharin.

Hints in tile Preparation of Foom for the Diabetic ON a Rigin DItTakY, witi Menus.

(The bread and biscuits recommended are always to be some of the diabetic bread substitutes.)

Porridge and Puddings.

Porridge or Gruel, made from almonits or cocoa-mut, can be prepared in the following manner:-

A small piece of German yeast (the size of two peas) is dissolved in a little lukewarm water, and added to, and well mixed with 2 tablespoonfuls of ground almonds. The mixture is allowed to stand in a warm place (by the fire) for half an hour or longer. The small quantity of sugar in the almonds is mostly or entirely destroyed by the action of the yeast, and the mixture becrmes spongy. It may be sweetened with a trace of saccharin if desired. The consistence will vary according to the quantity of water which has been added. If the consistence is that of custard or rice pudding, the almonds may be eaten with stewed cran- 
berries or other fruit as a pudding. Or a little more warm water, or warm water and cream, may be added and the mixture will have the consistence of porridye and milk, and may be taken in place of oatmeal porridge. By adding still a larger quantity of water a mixture like gruel may be made. Hesiccated cocoa-nut powder may be used in place of ground almonds, and cocoa-nut pudding, porridge, or gruel may be thus prepared. The almond and cocoa-nut porridge and gruel are of great nutrititive value, on account of the large amount of fat they contain.

Porridge can also be made from protein flours supplied by Messrs Lonthron \& Co. and by Messrs Callard \& Co., London.

Puidings, th-The following are some of the simpler puddings, which are very suitable:-

\section{Cocoa-nut Pulding.}

Half-ounce of German yeast is mixed in a little lukewarm water with $\frac{1}{41}$ b. of desiccated cocoa-nut powder. The mixture is kept in a warm place for fifteen mixtures Then $\frac{1}{2}$ ounce of butter, a pinch of salt, and a little milk are added. All must be well mixed. The mixture is placed in a pudding-dish, and baked in a moderate oven for twenty or thirty minutes until the surface is brown. This pudding can be eaten warm or cold. It may be taken with custard, and sweetened, if desired, with Saxin.

\section{Almond Pudding.}

Take 4 ounces of ground almonds. Nix $\frac{1}{4}$ of an ounce of German yeast with a little lukewarm water. Add the ground almonds to the yeast and water, and mix well. Allow the mixture to stand in a warm place for fifteen minutes until spongy. lieat up one egrg in a little milk, and add a little solution of saccharin. Then mix the egg with the ground almonds, place in a pudding-dish, and bake for about fifteen minutes.

Suet puddings or suet and almond pudding, and especially custard (made in the old-fashioned way from exgs and milk, and not from custard powder), are very suitable. To sweeten the custard or puddings, saccharin may be used.

Suct pudding may be prepared from a milk albumin (pastry flour) obtained from . Vessrs Callard \& Co. Directions are supplied along with the powder.

Swects for dinner, jelly, ices, creams, etc., almost free from carbohydrates, may be prepared by an intelligent cook from cream, eggs, butter, almonds, nuts, leinon, gelatine, vanilla, wine and brandy, and sweetened with Kristallose, saccharin, or Saxin.

Menus for six days are here given :-

Breakfast-

$$
\text { First Day. }
$$

Tea and cream.

Whiting fricd in butter. Squeeze lemon juice when served. Savoury onclet.

Diabetic bread or diabetic toast. Butter. 


\section{Lunch-}

Home-made lemonade sweetened with saccharin.

Vegetable marrow stuffed. Cold ham.

Cream cheese. Almond and bran biscuits. Gluten rolls.

\section{Dinner-}

Clear soup with mixed vegetables.

Steamed halibut. Slices of lemon.

Fillet of beef and cauliflower.

Green apples stewed, sweetened with saccharin. Cream.

Whipped jelly.

Cheese. Biscuits (made with gluten flour).

Pancakes (made with gluten flour, milk, eggs, sweetened with glycerine).

\section{Stuffed Vegetable Marrow.}

Small marrows make an excellent dish, boiled and stuffed with the stuffing of mushroom forcemeat. The marrow should be first peeled very slightly, then cut long-way into three slices; remove the pips, and fill the interior with the forcemeat. The forcemeat should be made hot before it is placed in the marrow ; if not, the marrow will be cooked before the stuffing is heated through. The nuarrow should be placed in boiling water and boiled until tender; this takes about twenty minutes to half an hour.

\section{Mushroom Forcemeat.}

I lb. mushrooms.

Half-teaspoonful lemon juice.
2 hard-boiled eggs.

I ounce butter.

The mushrooms after being cleaned should be chopped and fried in the butter; lemon juice should be added before they are chopped in order to preserve the colour. Add two hard-boiled eggs to the mixture, and rub the whole through a wire sieve while hot.

When hot this mixture is moist, but on standing gets hard.

\section{Savoury Omelet.}

I teaspoonful chopped parsley. Herbs, savoury

3 eggrs.

2 ounces butter.

$\left.\begin{array}{l}\text { Pepper } \\ \text { Salt }\end{array}\right\}$ for flavouring.

Melt the butter in a frying-pan, beat up the eggs thoroughly, add a little pepper and salt, parsley and herb, pour the beaten-up eggs into the frying-pan as soon as the butter begins to frizzle, and with a tablespoon keep scraping the bottom of the frying-pan in every part. Go on scraping until two-thirds of the mixture have become lumpy.

Now lift the pan a little off the fire, and push the omelet into halt the frying-pan. When nearly set, hold the pan in a slanting direction in front of the fire, and as soon as set, slide the omelet from the pan on to a hot dish and serve at once.

This may be varied by addition of a little cooked fish grated cheese, tomato, ham, crab. 


\author{
Sciond Day. \\ Breakfiast- \\ Teil or coffee with cream. \\ Toasted sardines on fricd gluten bread. Boiled egg. \\ Bran bread. liutter. Marmalade.
}

\title{
Lunilb-
}

Fried bacon served on a puréc of spinach.

Cauliflower au gratin with black butter sauce.

Gorgonzolit cheese. Gluten dinner rolls.

Slice of almond pound cake (Mlessrs Calland's).

\section{Dinner-}

Tomato puréc.

Steamed sole. Sauce Hollandaise.

boiled fowl.

Carrageen jelly.

Stufted tomatoes.

\section{Caulifoucer au gratin.}

This makes a nice course by itself. The cauliflower should be boiled untif guite tender. While boiling, remove any scum that rises to the top.

When ready, lifi it out, drain for a minute or two on a colander, and serve with black butter sauce poured over it. Sprinkle the sauce with Yarmesan cheese.

\section{Sauce Hollandaise.}

\section{Yolks of 4 eggs. \\ 妾 grill of cream. \\ 2 ounces tresh butter. Pinch of pepper, salt, nutmeg. \\ I teaspoonful tarragon vinegar.}

Place ingredients into small bowl. Stand it into large pan on the fire containing boiling water. Briskly whisk the sauce over the fire until it begins to thicken and presents a rich, smooth, creamy appearance. Great care is reguired to prevent it from curdling; if, however, this should happen, add yolks of two more eggs.

\section{Stuffed Tomatocs.}

$\begin{array}{lc}3 \text { ripe tomatnes. } & \text { I pinch mixed herbs. } \\ \text { 1 ounce of butter } & 2 \text { mushrooms, or a teaspoonful } \\ 1 \text { spring onion. } & \text { l'armesan cheese. } \\ \text { t teaspounful chopped parsley. Crumbs of I almond biscuit. } \\ \text { l'epper and salt. }\end{array}$

Cut off the stalks, leaving a hole the size of a threepenny bit. Squeeze out the juice and pips. To the juice and pips add the onion chopped, the chopped parsley, mixed herbs, and the mushrooms or chcese. Welt the lutter and fry the mixture. 'Then add sufficient almond biscuit crumbs to make the whole into a moist paste.

Fill the tomatres with the mixture until they resemble their original shape.

l'ut a few crumbs and a little piece of butter on the top of each. 
Place the filled tomatoes in a baking dish and bake until tender, and moisten with a little oil or butter. Serve in a dish with fried parsley round.

\section{Carmecen Jelly, or Irish Moss.}

Irish moss is a seaweed, and is collected on the northern shores of Ireland. Its nutritive value is slight; it contains mainly mucilage, and also some iodine and sulphur. It should be well washed and soaked for some hours previous to cooking. The flavour is somewhat peculiar, but delicate, and to some very palatable.
I ounce Irish moss.
I quart cold water.
Lemon juice.
Saccharin to taste.

Wash the Irish moss well, and soak it for several hours in cold water. Then put into a saucepan with one quart of cold water, and simmer slowly for from four to five hours. Strain, add the lemon juice, and sweeten to taste. Pour into a wetted mould and set aside until cold.

\section{Breakfast-}

\section{Third Day.}

Tea and coffee, with cream.

Scrambled eggs on toasted brown bread. Broiled kippered salmon.

Gluten flour bread. Butter.

\section{Lunch-}

Cocoa nibs and cream.

Chicken panada and green peas. Potted head.

Imperial cheese. Gluten cracknels. Gluten flour scones.

\section{Dinner-}

Chicken broth. Thicken with almond flour.

Fish soufflé.

Curry and French beans. (The basis of this is cocoa-nut, green apples, or green rhubarb.)

Gluten and almond baked pudding. (Make as semolina pudding, using gluten and almond flour.)

Savoury egress.

Sardines. - There are various forms in the market. The smallest fish are the best. They can be procured smoked or preserved with tomatnes. If rolled in slices of streaky bacon and fried, they form a very appetising dish.

\section{Girdle Scones.}

$\begin{array}{ll}\frac{1}{2} \text { lb. of gluten flour. } & \frac{1}{2} \text { teaspoonful of cream of tartar. } \\ \frac{1}{2} \text { ounce of butter. } & \text { Salt or saccharin to taste. } \\ \frac{1}{2} \text { teaspoonful of soda. } & \frac{1}{2} \text { teacupful of buttermilk. }\end{array}$

Rub butter into the flour and other dry ingredients; make into a soft dough with milk. Form into a scone, or little breakfast rolls, or twists, and bake in oven for fifteen minutes. 


\section{Sutroury Figers.}

3 hard bniled egrs.

t gill of cream.

$\frac{1}{2}$ ounce of hutter.

i tablesponnful of l'armesan cheese
I small piece of onion, chopped.

lepper. Salt to taste. Mustard.

I tomato.

Divide the egirs in half; take out the yolks.

Mix togrether the yolks, cream, cheese, butter, onion finely chopped; pepper, salt, and mustard to taste. Fill the white parts of eggs with the mixture.

Cut six rounds of brown bread; butter them; on each piece lay a slice of tomato, and on this half of a tilled egg. Garnish the dish with cress.

\section{Almond Pudling.}

2 eggrs. $\frac{1}{4} \mathrm{lb}$. of almond flour. $\frac{1}{4} \mathrm{lb}$. of butter.

2 tabloids of saccharin dissolved in a tablespoonful of brandy.

Warm the butter, beat in the almond flour and the yolks of the eggs, adding the dissolved saccharm. Whisk the whites to a stiff froth; beat all tosether. I'ut into small cake moulds, bake in a quick oven, and serve with a little hot sance made with dry sherry and saccharin.

Cocoa-nut pudeling can be made in the same way.

Breakfast-

\section{Fourth Day.}

Tea, coffee, or cocoa from nibs.

Grilled kidney and bacon. Crab omelet.

liran bread and cocoa-nut biscuits.

Lunch-

Lime juice and aerated water. (Unsweetened Montserrat lime juice.)

Anchovies on fried gluten bread slices; if cold, a spoonful of cream on the top.

Cold meat and tomato salad.

Pâte de foie gras, with bran biscuits.

Dinner-

Soup Julienne.

Salmon. Mayonnaise sauce and cucumber.

Sweetbreads and tomato.

Junket.

Mushrooms au gratin.

\section{Tomato Salad.}

Slice up two perfectly firm and ripe tomatoes. Sometimes it is neressary to remove the core and pips. Add a teaspoonful of oil and two teaspoonfuls of vinegar, and sprinkle on a little pepper and salt.

\section{Mayonnaise Sauce.}

Yolks of 3 egrgs.

$\frac{1}{2}$ pint best salad oil. $\frac{1}{2}$ gill tarragon vinegar.

Pepper and salt. 
In a round basin begin stirring, with a wooden spoon, the yolk of the egrgs, pepper, and salt, uncil they are quite moxed. "Hhen arld, dopl by drop, the salad oil and the vincyar, stirring all the time in the sime direction; if added quickly, the egy curdles. When finished, the satrce must have a creamy appearance.

Sweitbreads and l'egetables.

For the preparation of sweetbreads, see p. jo\&. The prepared sweetbreads are first stewed in milk, then rolled in slices of fat bacon, and placed in the oven for a quarter of an hour.

The bacon is then removed; the sweetbreads are cut in slices, and grated Parmesan cheese is shaken over them. They are again placed in the oven and braised in a rich brown gravy.

Served on croutons of gluten bread, in the centre of which can be placed stewed tomatoes, green peas, fresh French beans, stewed mushrooms.

Mushrooms au gratin.

Io mushrooms.

Piece of onion.

I teaspoonful chopped parsley.

I saltspoonful of thyme, fresh.

, , dried.

Pepper
Salt
Lemon juice
Almond biscuit crumbs

I ounce butter.

Select ro cup mushrooms about the same size. Peel the mushrcoms very carefully without breaking them; cut out the stalks close down with a spoon, and scoop out the inside. Peel the stalks, and chop them up with the scooped-out portion; add the onion, parsley, and thyme. Fry alt this in the pan with a little butter. Add sufficient biscuit crumbs to make the whole into a moist paste, and season to taste. Bake in the oven until the mushrooms are quite tender. Serve wht some nicely fried parsley round it.

\section{Fifth Day.}

Breakfist-

Tea, chocolate, coffec, and cream.

Findon haddocks, stewed in milk or broited.

Poached eggs on spinach.

Almond loaves. Gluten cracknels. Butter.

\section{Lunch-}

Cocoa nibs.

Potted herrings. Stewed cucumber and cheese sauce.

Stilton cheese. P'ine biscuits. 'loasted gluten flour bread.

\section{Dinner-}

I'urce of lettuce or spinach.

Turbot and tartar sauce (see p. 488).

Roast clicken and watercress.

Blancmange.

(See p. 3or, using sacclarin instead of sugar.)

Tarragon creams. 


\section{Sterued Cucumber and Cheese Sauce.}

Cut a fresh cucumber in pieces about 4 inches long. Boil until tender. I'our over the cucumber when cooked the following cheese sauce :-

Make the sauce in the same way as sauce Hollandaise (p. 484), omitting the tarragon vinegar, and add 3 tablespoonfuls of grated Parmesan cheese before serving.

\section{Tartar Sauce.}

2 tablespoonfuls of mayonnaise sauce.

I teaspoonful chopped parsley.

A small picce of very finely chopped shallot.

I teaspoonful of mustard.

Mix these ingredients well together and gently heat.

$$
\begin{array}{ll} 
& \text { Tarragon Creams. } \\
2 \text { eggs. } & \text { a pint cream. } \\
\text { bepper and salt. } & 2 \text { teaspoonfuls chopped tarragon. }
\end{array}
$$

Put into a basin I white and yolks of 2 eggs, the cream, and a little white pepper and salt. Beat up with a fork until smooth, add a little chopped tarragon.

Butter some little moulds, sprinkle the top with chopped tarragon and truffles.

Pour in the mixture and stand the moulds in a stewpan of boiling water reaching to three-(quarters height of the moulds.

When the water boils, draw the pan to the side of the stove and poach for about wenty minutes till the creams are set.

'Turn out on a warm dish and serve with sauce Hollandaise round them.

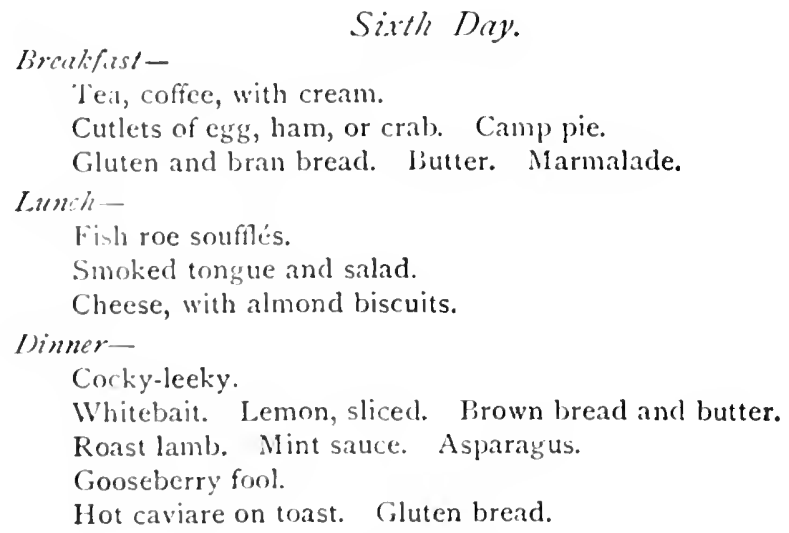

\section{Fish lioe Souffés.}

Take six roes of fresh herrings, blincl and pound them; then flavour with salt, pepper, pounded mace, and nutmeg. Add $\frac{1}{2}$ ounce butter and 
yolks of 2 eggs beaten well together. Whisk the whites of 6 egys into a stiff froth. Mix the same with the roes, and bake in ramekin cups for about five minutes.

Serve immediately the soufflés are removed from the oven.

\section{Oatmeal Diet in the Treatment of Diabetes Mellitus.}

Reference must be made to the use of a largely oatmeal diet recommended by Von Noorden. Von Noorden claims that in some cases of severe diabetes, especially those in which the ordinary diabetic diet fails to rid the urine of sugar, that an oatmeal regime will remarkably diminish the glycosuria, and will cause the acetone bodies to disappear from the urine. The milder cases of diabetes are not benefited by this regime, rather the reverse, but it has proved of value in the treatment of some severe cases. The diet consists in the daily administration of-

250 grammes $^{1}$ of oatmeal $=8 \frac{1}{2}$ to 9 ounces (contains about 150 grammes of starch).

250 and 300 grammes of butter.

Ioo grammes of pure vegetable albumin-or the equivalent taken from the whites of 6 or 8 egrgs.

The oatmeal is cooked thoroughly in water for about 2 hours, and the butter and eggs are well stirred in when the oatineal is nearly cooked. Salt is added to suit the taste. This regime is continued for eight to fourteen days, when the ordinary diabetic regime is gradually resumed. The oatmeal may be taken as a thin soup or gruel, or it may be made into fried meat balls. The explanation of the successful results recorded by this method is not easy. It has been suggested that one kind of starch, such as oatmeal starch, is better tolerated than another. In the writer's opinion, the favourable results which undoubtedly follow this diet in some cases are due to the stimulating effect of oatmeal on the thyroid gland, as proved by experimental observations (p. 602). There is in his view an important relationship between the pancreas and thyroid gland, of a nature of which at present little or nothing is known.

Alimentary Glycosuria. - In cases where sugar only appears in the urine after food, and more especially after a diet rich in carbohydrates, the indication is to recluce the amount of sugar and starches in the food. An incuiry into the dietetic history of these patients frequently show's that they have been taking excess of sugar or starch usually in the form of one or more of the following-sugar, jams, confections, dried fruits, sweet wines, bcer, or potatoes. These must be greatly restricted, or withheld for a time. In other instances it will be found that the patient has long

1 s ounce avoirdupois $=28.35$ grammes. 
been living on a diet which is too cxclusively carbohydrate in character, examples of this condition being especially seen in stout women of forty or fifty years of age. Here the indication is to reluce the amount of bread, bread foods, and puddings rich in starch, and to prescribe a more largely protein dict.

Diabetes in its Milder Forms. - In the milder forms of the discase a moderate restriction in the amount of carbohydrates of the food may lead to a disappearance of the sugar from the urinc. Thus it may be found that a diet, from which the sugar and farinaccous foods are restricted to less than a half of the amount which the paticnt had previously taken, effects the disappearance of the sugar in the urine, and a corresponding improvement in the patient's general condition. In such cases the diet which is sufficient to arrest the glycosuria should be continued for weeks, or months, or, it may be, permanently.

In other cases of a more marked character the sugar excretion may only cease where carbohydrates are practically excluded from the diet, and it may be necessary to maintain a carbohydrate-free diet for several weeks, to enable the tissues to regain their power of assimilating at least a moderate amount of sugar and starchy foods. Our aim here is to kecp the carbohydrates lown to that amount which the paticnt can tolerate without the appearance of sugar in the urinc. This satisfactory result is frequently attained, and the patient before long is able to take a little carbohydrate without the development of glycosuria. Not infrequently, however, it is not practicable, nor desirable, to keep the patient on a carbohydratc-frce dictary for any length of time. It is found that a carefully restricted dietary, such as is given below, suffices to effect a notable improvement in the condition of the urine, and a satisfactory state of the patient's gencral health. In these circumstances the diet is of the nature of a compromise, and although sugar may continue to be excreted in small amounts, the progress of these patients is, for all practical purposes, satisfactory. In these cases it is a wise plan for the patient, once or twice a year, to undergo a course, for threc to four weeks, of a carbohydrate-free diet. 
Breakfint-

Tea, without sugar, with milk or cream.

Good helping of fried bacon, fish, or egzs in any form, cold ham, tongue, or grilled kidney.

Slice of thin-cut bread and butter.

Lunch-

Soup.

Fish, or chicken, game, chop, steak, or roast mutton.

Pudding. Curds. Stewed apples. Soufflé, sweetened with saccharin.

One dry biscuit with cheese.

Tea-

Cup of tea, with half slice of bread, or toast, or rusk.

Dinner-As Lunch.

Severe Diabetes.-In severe cases of diabetes, in which sugar continues to be excreted in the urine even after removal of carbohydrates, the diet should, so far as possible, be along the lines of a carbohydrate-free diet, already outlined. This plan of treatment is, however, frequently impracticable on the grounds of expense, and not infrequently it is inexpedient, on account of the patient's general condition. In these circumstances the diet is of the nature of a compromise, carbohydrates are given in carefully restricted amount, and those given should be of the least harmful character. Milk is specially useful in these cases, more especially in those threatened with diabetic coma, in which cases 2 to 3 pints of milk may be given in the twentyfour hours. 


\title{
CHAPTER XXVIII
}

\author{
OBESITY
}

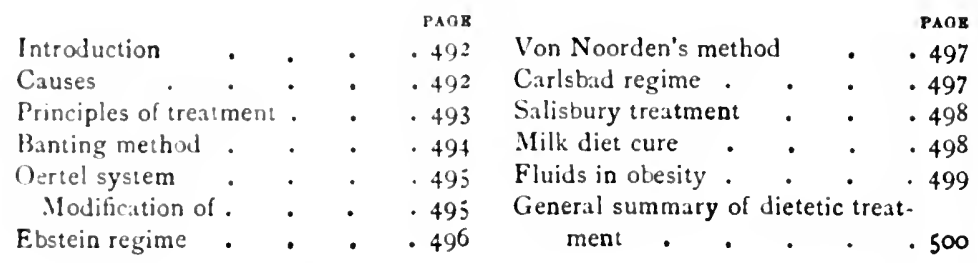

Introduction.-While obesity is not a disease in the common acceptation of the term, it is a condition which seriously disturbs the patient's comfort, curtails his ability to enjoy many of the pleasures of life, and indirectly leacls to disease and premature death. In later life the obese subject is heavily handicapped, every ounce of superfluous fat may tell against him in his combat with disease. In the prophylactic treatment of obesity, attention is being directed to preventing the fatty heart, the sluggish liver, the restricted lung surface, the development of renal disease, and the inevitable cardio-vascular failure, that all too surely await the majority of obese subjects while they are yet young in years.

Causes.-Obesity is hereditary in some instances, and in these cases it is much more difficult to cure. It is, however, cssential to note that the obesity seen in subjects who have a hereditary tendency to it cioes not essentially differ from the acquired form, the difference is entirely one of degree. Such a patient has through his forbears acquired a tendency to lay on fat, but there is good reason to believe that he can by means of diet modify this tendency materially, and hand on to his progeny a diminished susceptibility to the condition. 
To what, then, is obesity due. It results from the excessive consumption of certain foods, and more especially of foods which are fat-forming. Of these the most important clinically are the carbohydrates. The chief function of carbohydrates and fats is that of energy producers, and all the excess of these foods above the bodily requirements is stored up in the tissues of obese subjects as fat. Contributory factors are lack of exercise, and excessive indulgence in wines and malt liquors. A vicious circle is often set up; lack of exercise tends to promote obesity; obesity still further restricts the active bodily movements which are so essential for good health.

The following table is a useful one, indicating what should be the relative weight and height of a pcrson at adult age in good health. On the higher scale a certain percentage is allowed for differences in build, size of bones, etc. A weight beyond the extreme, means diminished respiration and impeded action of the heart, conditions incompatible with robust health and condition :-

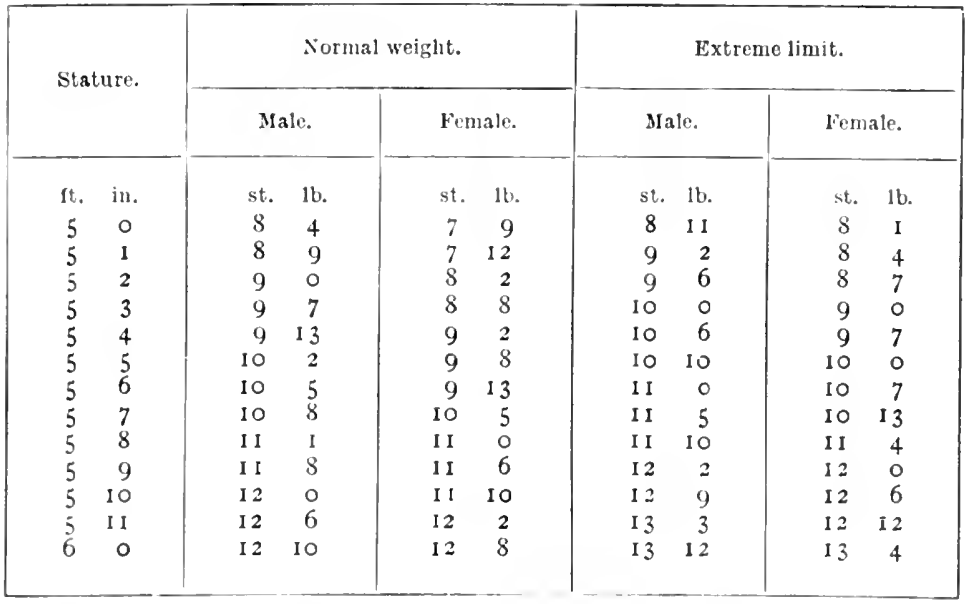

Principles of Treatment.-The first essential in treatment is to greatly reduce the amount of fat-forming foods. These are not required. When these are cut off, nature draws on the reserve fat in the tissues, until that which is superfluous is gone. By this means we reduce the tutal 
amount of energy taken in the form of food. At the same time combustion in the tissues must be promoted by increased physical exercises, which should take the form of walking, riding, golfing, or the like; and if for any reason these are not obtainable, by physical excrcises carried out at home daily under direction. By this means the output of energy in the form of work is increased. A third important factor in treatment is to promote the activity of the skin by a carefully planned course of baths, which must be prescribed with special caution in the case of very obese subjects. The last sencral point to which attention must be directed is the amount of fluid taken, and its relationship to food. On this point a good deal of difference of opinion prevails.

There are many systems of dietetic treatment, some of which only differ in detail. It is unnecessary to describe all the different "systems" that have been advocated at one time or another. Attention will only be directed to the main ones. Before doing so, it is perhaps necessary just to mention the differcnt degrees of obesity clinically met with. For example, there are slighter forms, in which the organs of circulation are unaffected, and rigorous bodily exercise is possible; and more serious forms, in which the heart muscle is invaded, the liver and other viscera are congested, and the tissues generally are embarrassed. The treatment, both as to diet and exercise, varies considerably in the two classes of case.

Banting's method.-In this system the amount of food is reduced, and fats and carbohydrates are largely excluded. The diet consists of animal food, I 3 to 16 ounces; bread, 2 ounces; fruit and vergetables, 6 to 12 ounces; total fluid restricted to 35 ounces, made up as follows :-

Breakfast-; to 6 ounces of animal food; meat (excep: pork and veal), boiled fish, or kidneys; 1 ounce of toast or biscuits ; 9 ounces of tea without milk or sugar.

Dinne, -5 to 6 ounces of lean meat, poultry, game, or fish ; eels, salmon, and herrings are excluded; any vegretable except potato, parsnips, beetroot, turnips, or carrot ; cooked fruit, unsweetened; 1 ounce dry toast; 10 ounces grood claret, sherry, or Madeira.

Tc $\_-9$ nunces plain tea without sugar or milk; 2 to 3 ounces of cooked fruit ; a rusk or two. 
Supper-Meat or fish as at Dinner, 3 to 4 ounces; claret. or sherry and water, 7 ounces.

On this diet Banting reduced himself in one year from 14 stones 6 lbs. to I I stones 2 lbs. The diet, it will be nbscrved, contains very little carbohydrates. This system of diet is a simple one, and it can be casily regulated, hence its popularity. The large amount of meat in this regime is very distasteful to some people, and in cases where there is some renal disease, this diet is unsuitable. Apart from the existence of renal disease, a prolonged course of this regime in some patients sets up dyspepsia and intestinal derangement, with general nervous depression, and these must be guarded against. Another objection to this diet is the alcohol. This is unnecessary, and unless there are special indications for its use, it should be avoided.

In the Oertel sy'stem the dict is combined with exercises, active or passive, to strengthen the heart. Stcady walking exercise to strengthen the muscles of the heart is insisted upon, and walking slowly uphill and going upstairs are especially advocated. Oertel insists on the exercise being taken in the open air, and on its careful resulation by the physician, the amount being regulated by the state of the patient's heart, and by the presence or absence of anæmia. The amount of fluid is reduced, and the excretory function of the skin is promoted by baths. Wasting of the muscles is prevented by an albuminous diet. In Oertel's diet the protein is given in the form of roast or boiled beef, veal, mutton, game, eggs. Fresh vegetables are given, as spinach and cabbage; stale bread, toast, rusk, and biscuits are given in 4 to 6 ounces almost daily. The fluids are restricted to 40 ounces in the twenty-four hours, which may be taken as tea, coffee, stimmed milk, water, claret, and hock. The daily dictary is as follows:-

\section{Morning-}

1 cup of tea or coffee, with a little milk; altogrether about 6 ounces.

Bread, about 3 ounces.

\section{Noon-}

3 to 4 ounces of soup (clear, not thick soup).

7 to 8 ounces of roast or boiled beef, veal, or game, avoiding pork and the fat poultry.

Salad, or a light vegetable, avoiding potatoes, beans, peas, parsnips, 
carrot, or beetroot; a little fish (conked without fat) if desired ; 1 ounce of bread or farinaceous pudding (never more than 3 ounces).

3 to 6 ounces of fruit (freshly prepared) for dessert; avoiding puddings, suet, rice, tapiocat, bread, sago, and macaroni.

It is desirable at this meal to aroid taking fluids; but in hot weather, or in the absence of fruis, 6 to 8 ounces of table water or light wine mily be taken.

Afternon-The same amount of coffec or tea as in the morning, with at most 6 ounces of water; 1 ounce of bread occasionally.

Eacming-

1 or 2 soft-hoiled ergs, or fish, avoiding mackerel, herrings, eels, salmon, and sardines.

1 ounce of bread; a small bit of cheese at times.

Salad fruit.

6 to $S$ ounces of wine with 4 or 5 ounces of water.

In the slighter forms of obesity it is found, if this diet is adhered to and ample exercise is taken, that the reduction of fat is usually satisfactory.

In the severer forms, the cxercise has to be modified and the fluid consumed restricted, vapour and other baths being taken under the strictest medical supervision. Massage has here to replace exercise to a great extent.

The Ebstcin regime is a modification of the Banting method, containing more fat and less protein. Ebstcin contends that the ingestion of fat is useful in curing obesity, if combined with a greatly reduced administration of proteins and carbohydrates, as fat abates appetite and lessens thirst. The Ebstein dict is meagre. About one-half the usual amount of meat is allowed.

Breakfast-White bread well toasted, rather less than 2 ounces, well covered with butter; tca, 9 ounces, without milk or sugar.

Dinner-Snup made with beef marrow; fat meat with gravy, 4 to 5 ounces; a morlerate amount of one of the vegetables allowed, viz., asparagus, spinach, peas, and beans. Two or three glasses of light white wine. After this meal a large cup of tea without milk or sugar.

Supper-An egg; a little roast meat with fat; 1 ounce bread well covered wh butter; a large cup of tea without milk or sugar.

In Schiecinger's modification of this method there is an entire suppression of fuids at meals. Whatever fluid is taken must be taken an hour or two after food. 
Von Woorden's mithod differs from Oertel's in şiving small meals at frepuent intervals.

8 A.M.-Cold lean meat, 3 ounces; bread, 1 ounce; 6 ounces tea or coffee, very linle milk.

1o A.M.-A lightly boiled ergg.

Noon-6 ounces clear soup, without any fat.

I P.ul. A small plate of clear soup, 8 ounces; lean meat or fisli,

5 ounces; potatoes, $3 \frac{1}{2}$ ounces; green vegetables; fresh fruit,

3 ounces ; (no tluid).

3 1.M.-A cup of black coffee, 4 ounces.

4 P.M.-Fresh fruit, 7 ounces.

6 P.M.-A glass of skimmed milk.

S P.N.-Cold lean meat, 4.2 ounces, with pickles; 1 ounce bread; 2 or 3 spoonfuls of fruit cooked without sugar.

The Carlshad rigime.-An interesting and useful account of the regime in vogue at Carlsbad is given by Mrs Emest Hart in her book on Diet in Sickness and Health. Mrs Hart gives her personal experience as follows:- "It may' be of interest to my readers who suffer from too great an abundance of fat to learn how I put theory into practice and reduced my weight 15 lbs. in three weeks. This result was obtained at Carlsbad, and the regime was as follows:Rose at six, took three tumblers of hot Sprudel water, walking for about twenty minutes between each glass. Breakfast at eight, consisting of one or two small crescents of bread and a boiled egg, On alternate mornings a vapour bath with cold douche, or sencral massage of the body: Dimner at one o'clock, consisting of a small amount of fish and meat or poultry, with green vegetables; no potatoes or sweets. In the afternoon a walk of from six to cight miles up the hills in a flannel dress. Supper at seven, consisting of a poached egg, or a small cut of cold meat. There is no doubt that I suffered from constant hunger on this dict, but under it my weight steadily diminisherl, and a fecling of lightness and well-being took the place of previous heaviness. Continuing the diet after I left Carlsbad, I lost another six pounds, and it was some years before the tendency to increase in weight showed itself again. I am quite certain that no one need fear becoming a ponderous size, a source of discomfort to themselves and of disagrecable impression to others, if they checked the beginning of obesity by 
suffering the small inconvenience of submitting to a restricted diet for a time."

A modifucition of the Salishury dit is recommended by some writers. The essential idea here is to limit the food and drink, and sive the lean of meat, and an abundance of hot water. Two pounds of rump-steak, and I lb. of cod, together with 6 pints of hot water are siven, as the daily diet for the first fortnight; for the next three weeks, 4 pints of hot water with other kinds of lean meat and fish are allowed, as well as a little green vegetables and unsweetened rusk. For the following month the hot water is reduced to about one pint a day, and some crusts of stale bread, unsweetened biscuits, srilled meat or poultry, or game of any kind, and hock and claret with seltzer water, are allowed. Five grains of bicarbonate of potash are also prescribed night and morning. This system should only be tried in cases where there is every reason to regard the kidneys as sound.

A milk dict cure for obesity.-An interesting lesson may be learned from a record published by Professor Debroc of l'aris, who treated a man, fifty-five years of age, who weighed on admission to hospital $234 \mathrm{lbs}$, and after a year's treatment weighed only 1 so lbs., the remedy employed being a severely restricted milk diet. The patient had been growing fat from the arge of twenty-five. He was of sedentary habits, and given to alcoholic indulgence. Active exercise could not be prescribed, as, on account of gravel and gout, the patient could not leave his bed. Debroc therefore adopted the only methorl he thought practicable, viz., by giving the patient an insufficient amount of nourishment, and obliging him to consume his own fat.

He was put on an exclusive milk diet, the amount being restricted. For the first month 2 quarts a day were given, during the second month $1 \frac{1}{2}$ quarts, and during the third month 1 quart only. He lost 27 lbs. the first two months, and 4 lbs. the thircl month. During the four following months the patient tork less than a quart of milk a day, and his weight finally fell to 180 lbs. When reported on, the patient was in perfect health. As Burney Yeo points out in commenting on this case, it is a remarkable and most instructive instance of the small anount of food upon which 
existence can be maintained, and excess of weight thereby reduced witiout injury to health, provided the patient be kept at rest in bed. Weir Witchell has also strongly recominended a restricted milk diet for the treatment of obesity. An admirable illustrative case is as follows:-

A lady, xt. 45, 5 feet $4 !$ ins. in height, weight 190 lbs., anamic, feeble, and breathless. She was kept in bed for five weeks. Massage was used at first once daily, and after a fortnight twice a day, while milk was given, and in a week made the exclusive diet. Her average loss for thirty day's was a pound a day, and the dict was varied by the addition of butter after the third week, so as to keep the reduction within safe limits. On the fourth week the diet was added to, and Swedish movements were added to massage, which was applied but once a day, and during the fifth week she began to sit up and move about. Her weight at the seventh week had fallen to $145 \mathrm{lbs}$, and her appearance had decidedly improved. After two years she was a well and vigorous woman.

Fluids in Obesity.-Considerable difference of opinion exists as to the advisability of restricting markedly the amount of fluid taken in obesity. This much is certain. Where any highly nitrogenous dietary is in use, there should be no restriction whatever in the amount of fluid; on the contrary, at least 3 pints of fluid in the form of hot or cold water, or occasionally weak clear soup, should be taken daily, this being taken on an empty stomach between meals. Apart from this, there is no doubt that the amount of fluid taken with meals should always be restricted, and to this end soups are, as a rule, contra-indicated. When there is a special weakness of the heart and circulation, a dry diet is advisable for the sake of the heart, apart altogether from the obesity.

Plain water and the various mineral and table waters may be taken, but all sweetened beverages should be avoidecl. Weak tea and coffec are permissible, and should be taken without sugar and milk. All sweet wines and malt liepuors should be cxcluded from the dietary. Alcolon in all its forms should, if possible, be avoided; but if specially indicated, should be taken in the form of mature whisky or dry, natural wine. 
General Summary of Dietetic Treatment.-Fvery case of obesity must be treated on its merits, remembering always that there are certain broad principles to be followed. The following may be taken as a practical guide to the dictetic treatment of the average casc.

The total amount of food must be reduced, farinaceous foods in particular being very greatly restricted.

Sugar should be cut off from the dietary, saccharin being employed in its place. Dried fruits should be forbididen because of their richness in sugar, but fresh fruits may be allowed in moderation, and, when desired, may be stewed, and sweetened with saccharin. The meats should, as a rule, be selected from the leaner varietics, such articles as pork, mackerel, eel, and salmon being excluded from the list. Skimmed milk may with advantage take the place of ordinary milk, and no milk puddings should be allowed. Bread and bread foods should be given in the greatest moderation, and are often advantageously cut off altogether for a time. Green vegetables should be freely used, as they have comparatively little nutritive value, and by their bulk grive a fecling of fullness. The amount of fluid taken with meals shoukl be much reduced, and alcohol in all its forms should be avoicled. Suitable exercises, either in the form of open-air exercise, Swedish movements, or massage, according to the condition of the patient, constitute a very important part of the trcatment. 


\title{
CHAPTER XXIX
}

\author{
DIET IN NERVOUS DISEASES
}

\begin{tabular}{|c|c|c|c|c|c|}
\hline & & PAOE & & & PAOK \\
\hline Introduction. & & .501 & Special diseases- & & \\
\hline Organic and functional dise: & & - $50 \mathrm{r}$ & Headache, insomnia & - & - 505 \\
\hline General principles of treatme & $n t-$ & & Chorea, epilepsy & . & .505 \\
\hline In organic disease & . & - 503 & Neuralgia, migraine, & sciatica & . 506 \\
\hline In functional disorders & ${ }^{\circ}$ & - 504 & Apoplexy . . & - & - 507 \\
\hline Diet for nervous children & . & .504 & Neurasthenia & . & .508 \\
\hline
\end{tabular}

Introduction. - Diseases of the nervous system are roughly divisible into two great classes, organic and functional. In the former, there is a definite morbicl change in the affected structures, which is usually the result of inflammation, hemorrhage, or chronic degeneration; in the latter, a careful examination of the nervous system fails to reveal any pathological change, and the condition is therefore spoken of as functional. A good example of a so-called functional disease of the nervous system is neurasthenia. Diet is an important factor in the treatment of both functional and organic discase of the nervous system. It is of special importance in the former (see Neurasthenia), but it is also important in the latter, as it is probable that a chronic defect in dietetics plays a more important rôle in the causation of some chronic nervous affections than is commonly supposed. IVe have conclusive eridence that certain articles of food and drink are, for all practical purposes, the causes of certain well-established "nervous" diseases. Thus pellagra, a chronic disease of the spinal cord, is known to be the result of a poison present in unripe maize; the lesions of the posterior columns of the spinal cord in diabetes may also be cited as a nervous affection intimately associated with diet; and in 
alcoholic peripheral neuritis we have a clear cxample of a disease resulting from dictetic crror. In connection with the last named there is a point of some importance which must be noted. There is reason to believe that the deleterious effects of alcohol on the tissues hate a more complex origin than is at first sight apparent. They are in all probability due, not only to the dirit effects of the alcohol on the tissues, but to its indirect influence in promoting an abnormal bacterial activity in the intestinal canal, with resulting absorption of toxins. This point is one of much practical importance. The etiology of such discases as disseminated sclerosis, combined sclerosis, and the like is unknown; all we know is that they are the result of some toxic condition of the blood. If alcohol can act in the manner indicated above, it is possible that other defects in the diet may be a factor of importance in the production of the toxic condition of the blood, which is undoubtedly the cause of these chronic inflammatory affections of the nervous system.

The possibility of the correctness of this view is suggested by the following clinical facts. In many of these nervous disorders the clinical history shows that marked gastrointestinal disturbance preceded the development of the nervous symptoms. This disturbance usually took the form of troublesome flatulence, constipation, diarrhoea, or bilious attacks. Further, cxamination of the stools of these patients frequently shows them to be ill-formed and very foetid, which indicates an unusually septic condition of the alimentary tract. And lastly, an inquiry into the dietetic history of the patient frequently shows that the dict has been defective, and radically so, having been of a nature which conduces to abnormal bactcrial activity in the intestinal canal. The same remarks apply to some chronic mental diseases, which are regarded as the result of a chronic auto-intoxication.

According to this view a defective diet is a factor of some importance in the causation of some chronic nervous diseases, in virtue of its unfavourable influence on the bacteria in the digestive tract. The rôle of dict is thus an indirect onc. This much is certain. In many of these cases an examination of the stools shows a degrec of foetor and other abnormality which is pathological. This condition is either a 
causal factor or an incidental complication of the nervous disease, and in either case it is arlvisable to crorect it if possible, such correction being largely a question of diet.

General Principles of Treatment.-In organic discase-The general principles of treatment can be clearly defincd. In the first place, the diet must be arranged so as to promote a normal state of intestinal secretion and excretion, as revealed by an examination of the stools; and secondly, the diet must be adapted to improve the general nutrition of the patient, which is frcquently unsatisfactory. In this connection it is important to bear in mind that the administration of a generous diet to patients with foctid stools may be attended by much less satisfactory results from the point of view of general nutrition, than a diet which contains less than onehalf the nutritive value of the "generous" diet.

We seek to give effect to these general principles in the following way. IVe first of all determine from the patient's dietetic history in what direction, if any, the diet has been such as to predispose to abnormal fermentation, with increased bacterial activity in the intestinal canal. Thus we may find that the patient has had five or six meals a day, consisting too largely of tea, bread foods, and starchy foods. If so, the meals must be reduced in number, and altered in quality so as to diminish the foodstuffs prone to fermentation, the protein foods being proportionately increased. In other instances the diet is found to be of too liberal a character in other directions, rich animal protein foods being taken in large amount twice or thrice daily, in addition to excess in other foodstuffs. Here the diet has to be reduced in amount, the animal protein being specially reduced, and the diet has to be simplified so as to throw less strain on the digestive secretions. By these means the production and absorption of toxins in the intestinal canal is reduced, with advantage to the patient. In rarer cases we find that the dict has actually been deficient in amount, the patient being in a state of malnutrition; as a rule, in these patients the quality of the food has been equally defective from the point of view of maintaining a healthy state of the alimentary tract. Reference may be made to the great importance of attention being directed to the state of the teeth, and to thorough 
mastication, as prophylactic and therapeutic measures intimately connected with the subject of diet.

In functional disurtirs. - The most important functional disorder of the nerwous system from the point of view of dietetics is neurasthenia, or nervous exhaustion. In the treatment of this discase, complete rest in bed, isolation of the patient from his or her friends, and a special diet are the essential factors of the treatinent. In neurasthenia the nervous system is in a state of cxhaustion, and practical experience has proved the great value of the administration of a large amount of food of an easily digested nature. This will be further discussed under Neurasthenia. In functional conditions other than neurasthenia, diet does not enter specially into the treatment.

Diet in Nervous Children. - The temperament of children should be carcfully studied. This is of practical importance in the management of children. Clouston has given us an admirable description of the nervous child:- "There is the nervous child when the brain is somewhat over-developed, but especially when it is unstable in its action, when sensitiveness is too great, when reactiveness is also exaggerated, and in whom passion and emotion are too exaggeratedly or too easily expressed. Such children are often difficult to manage, are wayward, disobedient, and subject to gusts of apparently causeless passion and sulkiness; they are subject also to whims and groundless fears; they are fidgety, restless, deficient in the elements of control; they are usually thin, often capricious about food, and they are subject to nervous ailments such as chorea and convulsions." The neurotic tendency is further shown by the readiness with which they become delirious unfler the infuence of a trivial catarrh, by the occurrence of night terrors, and by the liability to asthma.

In discussing the manasement of these children from the dietetic point of view, Clouston sums up the position admirably when he states:- "It may be said generally that the child with a strongly nervous heredity or mental taint in ancestry should be fed on milk, farinaceous dict, and fruits, certainly up to seven, and largely up to twenty-five." Further details of the dietetic management of these cases are given on Pp. 201 and $; 26$. 
Headache.-Headache is a symptom, not a discase. Hence the treatment can only be determined after the cause of the condition has been ascertained. Most commonly it is dependent on constipation, gout, renal disease, or neurasthenia, and the dietetic treatment of these diseases is then applicable. The possibility of the headaches being due to eye strain should be kept in mind.

One of the most severe forms of headache-migraine, or sick headache-is a neurosis characterised by pain in the course of the fifth nerve, often accompanied by nausea, vomiting, physical and mental depression, with local vasomotor disorders. The treatment of this condition is further referred to on p. 506.

Insomnia.-In adult and elderly subjects insomnia and disturbed sleep are sometimes dependent on dietetic habits. The most common error is the taking of solid food late at night. In such cases the chief meal of the day must be the midlay one, the evening meal being taken not later than 6.30, and consisting of, at the most, two light, easily digested courses. A hot drink taken at bedtime is frequently of great value as a hypnotic, the best of these being a cup of good beef-tea, or hot milk, which may be malted if desired, e.g. Horlick's malted milk. In elderly and weak subjects a small glass of whisky, or hot toddy, taken the last thing at night, is of value in promoting slecp.

Chorea.-Rest, seclusion, and careful feeding are the essentials for the successful treatment of chorea. In mild cases the diet should be a light, nourishing one. Red meat and rich foods of all kinds should be avoided, the diet consisting of milk, milk foods, eggs, bread, bread foods, and white meats. In more marked cases it is advisable to restrict the diet to milk and milk foods only; this regime diminishes the likelihood of the development of heart complications. In some cases the diet should be liquid, and it may have to be administered by the nasal tube. In these circumstances the daily dict should be-milk, from 2 to 3 pints; beef-tea, I pint; and two to three eggs given in the milk. In severe cases where the patients are practically starved through the violence of the movements, it may be necessary to give in addition $\frac{1}{2}$ ounce of alcohol with each meal. 
Epilepsy.-With regard to the relationship of diet to cpilepsy, the following points may be laid down as established. Over-cating may bring on an attack; an excessive meat dict is prejulicial; rich foods and pastry should be aroided, largely because they foster excesses; and alcohol in all its forms should be aroided. A light, mixed diet is therefore the ideal one for the epileptic. The meals should be given at regular hours, nothing being taken in the intervals. Great care must be taken to avoid constipation, and this may be attained by the proper use of fruits and the coarser forms of cereals. An appropriate diet sheet is here given.

Breakfast-

Porridge and milk, tea, bread and butter; or

Fish or egs's, tea, bread and butter.

Lumch (Lacto-vegetarian)-Lread and cheese, celery, glass of milk, fruit (sce pp. 520, 526).

Tea-Cup of tea with biscuit.

I)inner-

Soup. (This should occasionally be of vegetable stock-p. 527.)

Meat. (Fish or chicken should replace red meat once or twice a week.) I’udding-preferably fruit or milk pudding.

Neuralgia, Migraine, Sciatica.-These forms of nervous discase may be due to many causes, the most common being andemia, sastro-intestinal derangement, gout, rheumatism, and arterio-sclerosis. The dietetic treatment therefore varies with the cause, and this must be determined before a suitable diet can be ordered. In troublesome cases assistance will be obtained from the examination of the stools, which will indicate whether the state of the bowel is satisfactory or not. The following general rules will be found helpful in framing a dictary for these conditions :-

I. Seek to determine whether the condition is a result of insufficient food (malnutrition), or excess of food (over-eating).

2. If dependent on anxmia, indigestion, gout, or arteriosclerosis, the dietetic treatment must be regulated accordingly.

3. Aim at griving a light, casily digested, non-stimulating diet, free of alcoholic liquors. 
4. Attention to the teeth, careful mastication, and the prevention of constipation, are often important factors in the successful treatment.

Apoplexy. - The dietetic treatment of cases of cerebral hamorrhage, thrombosis, or embolism must be regarded from two points of view:-(a) The immediate-the comatrose stage, and after; $(b)$ the remote-after partial or complete recovery.

The comatose stage, and after.-Apoplexy occurs most commonly in well-nourished, full-blooded individuals, and for the first day or two there is no necessity for giving the patient any food. The intestine must be thoroughly cleared out by enema or otherwise, as this improves the state of the circulation. If consciousness does not return within thirtysix hours or so, the question of the necessity of administering food per rectum will have to be considered (see Rectal Fecding). As soon as consciousness is restored, feeding by the mouth should be commenced. This should for some days be restricted to milk only, or milk thickened with eggs, or cereals. Not more than 2 pints should be given in the twentyfour hours, and it should be given cold or lukewarm. As the patient improves the diet may be increased, but it should be kept as light, as easily digestible, and as non-stimulating as possible. For the same reason, all alcoholic drinks should as a rule be avoided. As these patients have usually a high blood-pressure, it is advisable to control the amount of liquid consumed, and care is neccssary in regard to this.

After recozcry.--The practitioner has now to consider and to direct his treatment to the cause of the apoplexy. Most frequently it is dependent on arterial sclerosis, chronic Bright's disease, often associated with high blood-pressure, and these conditions are in some measure amenable to dietetic treatment. In effect, therefore, the dietetic treatment is that of chronic Bright's disease, the main essentials in treatment being :- -

(a) All meat foods to be taken in very sparing amount, the diet to be largely lacto-regetarian in character (sec p. 520). 
(b) The liquids to be restricted in amount, and more especially the lipuids taken with neals; alcohol to be aroidect.

(6) The diet to be light, and easily digested; all rich foods and stimulating foods to be aroided (sce L ight Diet, p. $5+5)$

(d) The total amount of food to be taken to be proportionate to the age of the patient and to his condition otherwise.

Neurasthenia. - The treatment of neurasthenia or nervous cxhaustion is much the same whether the condition is due to an accident, overstrain, or to a faulty inheritance. A great deal of sleep and much food are essential. The indication for treatment is to overcome the sleeplessness and to stimulate the desire for food. Cases vary widely in severity. The treatment of the most severe cases by the Weir Mitchell method is troublesome, tedious, and expensive. The difficult point to determine in certain cases is whether the Weir Mitchell method is necessary, or whether simpler means will suffice.

Diet for neurasthonics.-In mild cases. - A great deal of improvement can be gained by keeping the patients in bed until midday for a month, with the window wide open and with the addition of four tumblers of milk, and four full slices of thickly buttered bread per diem to an ordinary mixed diet. The extra milk may be taken either with the ordinary meals or preferably in the intervals. In these cases an important adjunct to this dietetic treatment is the use of hot and cold water bathing. Bathing the face, neck, and extremities twice or thrice daily, with hot water at a temperature of $105^{\circ} \mathrm{F}$. is very bencficial, and when done at night helps to promote sleep. As the case improves, the temperature of the morning douche may be reduced until a sitz bath with the water at $60 \mathrm{I}$. can be taken, a hot sitz bath being still taken at night.

In seiere cases the Weir Mitchell method should be adopted. This system, in addition to the special feeding, requires absolute rest for some six weeks; seclusion from friends, callers and family; massage and electricity, to promote digestion and the nutrition of the muscles. A good nurse is 
essential; she must be bright, sensible, kindly, and the patient must take to her. The following outline of treatment is adapted to a severe case.

\section{First Weck.}

The patient is to be confined to bed, and the nurse is to feed the paticnt.

Massage.-Two applications a clay. Beginning with a quarter of an hour cach time, and working up to half an hour or more by the end of the week. After the massage, to rest alone in a darkence room for an hour.

Food.-Three ounces of fresh milk every three hours, increasing the amount daily until the patient by the end of the week is taking ro ounces every three hours; that is, an increase from I $S$ ounces to 60 ounces per day. On the sixth and scventh days a little porridgc, gruel, custard, or egr may be adcled.

Gain in a'eight.-During the first weck or so the gain may be 5 to $6 \mathrm{lbs}$. Unless the patient is gaining at least 2 lbs. weckly, it may be assumed that matters are not progressing satisfactorily.

\section{Second IVeck.}

The patient should now be able to fecl herself.

Massage. - This may now be increased to two applications a day, each application lasting from three-quarters to one hour.

Food.-Solid food may be cautiously begun-fish, cgg, chop, mince. The milk taken ought now to be up to 60 to So ounces per day. If dyspeptic troubles arise from over-fecding, all solid food must be stopped for twenty-four hours and resumed. The probability is that the massage is ineffectual, and the operator should be changed.

Gain in weight.-Probably 3 or 4 lbs.

\section{Third and Fourth Wecks.}

Massage.-The same in amount as at the end of the second weck. Electricity in the form of liaraclism to the principal muscles may be employed as an abljunct in treatment; the applications lasting from twenty minutes to half an hour daily. 
Food-by this time the patient may be on a full diet (see below), and in acldition taking at least 60 to so ounces of milk per diem.

\section{Dail" Diet Sheit.}

$7 \mathrm{AN}-10$ ounces of milk.

Livirkfast: 8. 30 A.M. - l'late of porridge, or grucl, or Ilominy; or bowl of bread and milk with a gill of cream; fish, bacon, egrgs, or kidney; cocoa or coffec ; bread or rolls; butter or marmalade.

9.i.is-10 ounces of milk.

1) A.M. - Cup of beef-tea with 2 teasponfuls of beef peptonoids.

Luncheon: 1.30 1.M.-Fish, tripe, sweetbread, cutlets, game, or poultry, served with one vegretable, with a sweet such as stewed fruit; ro ounces of milk to be sipped slowly during this meal.

4 P.M. - so ounces of milk with sponge cake; bread and butter, or rusk.

6.30 1.M.: A three-course meal.-Soup or fish ; joint or poultry; sweet or savoury, or dessert; taking with meal ro ounces of milk.

8. 30 P.s. - Beef-tea and 2 teaspoonfuls of peptonoids.

10 P.M. - Io ounces of milk.

\section{Fifth and Sixth Wecks.}

In the fifth week the patient begins to sit up in bed, and the afternoon massage is gradually reduced, then stopped; then a gradual reduction of the morning massage and electricity takes place. The excess of food is gradually reduced ; firstly, the amount of milk is lessened, and the patient by the end of the sixth week should be eating an ordinary amount of food daily. During the last week the patient can get up daily for a short time. Patients are better not to return at once to their ordinary course of living. It is advisable that they should if possible travel quietly with a suitable companion for a month or more before returning home. In the case of hospital patients, a few weeks' stay at a convalescent home is advantageous.

A rarer form of neurasthenia is occasionally met with, in which the patient is stont and flabby. In these cases a course of milal starvation is a necessary preliminary to the Weir Mitchell treatment. The system of treatment recommended by I'layfair is specially applicable to these patients, as follows :- 
"Confine patient strictly to bed: diet with skimmed milk, at first 2 quarts per diem given in small quantities every two hours, after a day or two lessen this gradually till not more than a pint per diem is taken. If the patient's strength fail unduly under this, some beef-tea or soup may be temporarily substituted for the milk. Under the minimum diet the weight grarlually loses about ! lb. per diem (the patient should be weighed every second day), and when some it to 20 lbs. have been taken off, pure milk may be substituted for shimmed, and the treatment as detailed abuve pursued." 


\section{CIIAPTER XXX}

DHET IN IMSEASES OF TIIE LUNGS-THYROIDAND SKIN

\section{Diseases of the Lungs.}

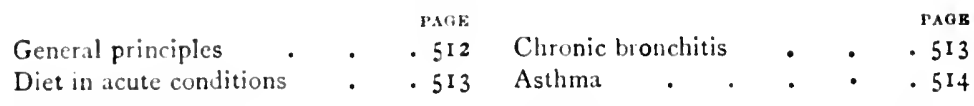

TuE principles underlying the dictetic treatment of discases of the lungs are similar to those laid down for cardiac disorders. Faulty fecding influences lung affections unfavourably in two directions-

(I) By inducing flatulent distension of the abdomen, which mechanically interfercs with the free action of the diaphragm and heart; and

(2) By throwing a strain on the organs of excretion-lungs, kidneys, and bowel-as a result of which free circulation through the lungs is interfered with, and the patient's symptoms are aggravated. The greater the amount of carbohydrate food the greater the demand on the lungs to excrete $\mathrm{CO}_{2}$.

Excess of carbonaceous foods have therefore to be avoided because of their tendency to induce flatulent distension of the stomach and bowel, with resulting mechanical interference with the brcathing; cxcess of proteins has also to be avoided because of the liability for the accumulation of waste products, which injuriously affect the respiratory and cardiac mechanisms; in every instance constipation must be avoided, because its presence aggravates the lung condition, both mechanically and throush the associated auto-intoxication. 
Diet in Acute Lung Affection.-The dict in acute pneumonia, acute pleurisy, and acute bronchitis calls for little comment in the way of detailed description. Pnenmonic is not really a lung discase, but an acute infective fever with a local lung lesion, and it is to be treated with the fever diet elscwhere described, a prolonged course of gencrous fecling being indicated in convalcscence (sce p. 2SS). Similarly, pleurisy is hardly a lung affection, but is usually a tuberculous manifestation, and to be treated along the lines laid down in the section on Tuberculosis. At the outset of an acute plcurisy in a previously healthy subject, the dict for a few days should be the simple fever diet described on p. 267 ; when the initial symptoms have abated, a full convalescent diet (p. 292) may be prescribed, keeping in mind the special value of animal protein foods-meat, eggs, and milk-which should enter largely into the dietary. In acute bronchitis the appropriate diet varies in accordance with the severity of the catarrh, the more serious cases being practically broncho-pneumonia. If moderately severe, the diet should be restricted to such articles as milk, beef-tea, custard, jelly, and wafers of toast. In less serious cases all that is required is to give the patient a simple and nutritious light diet, consisting of milk and milk products, bread or toast, fish or chicken souffé, sweetbread, and light farinaccous or fruit pudding. Greater restrictions may be necessary in those cases where the acute bronchitis is an incident, as it often is, in a case of marked chronic bronchitis and emphysema with a wcak heart (sce Chronic Bronchitis).

Diet in Chronic Bronchitis.-Chronic bronchitis, which is usually accompanied by emphysema, is commonly a late sequel of cardiac or renal discase, and under these circumstances the dietetic treatment is that appropriate to the primary affection. Many cases, howerer, occur in which marked chronic bronchitis exists, for a time at any rate, without any serious disturbance of the cardiac and renal systems. Such cascs hare devcloped as a result of cxposure to unfavourable climatic conditions in susceptible subjects, or as the result of the immoderate use of alcohol. Sooner or later, however, in all cases, cardiac weakness supervencs, and in turn aggravates the bronchial condition.

The essential point underlying the dictetic treatment of 


\section{DISEASES OF THE LUNG, THYROII), AND SKIN}

all cases of chronic bronchitis is to kecp in mind that there is always an associated limitation of the digestive powers, the amount of this being in proportion to the severity of the bronchial affection. The existence of chronic bronchitis always implies a certain degree of chronic disturbance of the circulation in the mucous membrane of the digestive tract, with associated disturbance of the digestive secretions, and limitation in the digestive power. The appreciation of the fact is the keynote to the successful dictetic treatment of chronic bronchitis.

The diet must be light and nutritious, many "extras" must be cut off, the pleasures of the table must, to some extent, be denied. Carbohydrate foods must be specially restricted, on account of their tendency to induce flatulent dyspepsia. The necessity of restricting the carbohydrates is all the greater in obese subjects; such cases indeed may sometimes be advantageously treated for their obesity. The principal meal of the day should be taken in the middle of the day rather than at night, and there should be a restriction in the annount of liquid taken with meals. In the chronic bronchitis of old people the meals should be small and frequently administered, and of such a nature as is little liable to cause flatulence. In these cases a little alcohol (2 ounces daily) is often advantageous. Dictaries appropriate to this condition are given in detail on pp. 404 et seq.

Asthma.-It is easy to overestimatc the importance of dict in relation to asthma. While it is true that in many subjects attacks occur a pparently quitc independently of dictetic conditions, it is equally true that many attacks of asthma are brought on by indigestion. Any food that appears to the patient to cause indigestion must be avoided, and in regard to this the patient is often in the best position to express an opinion as to indigestible foodstuffs. Such patients usually learn by experience what they should and what they should not eat and drink. We meet with peculiar idiosyncrasies as to diet in these cases, some article of food, in itself of a very digestible nature, readily inducing an attack. The dietetic treatment consists in recommending a simple, wholesome, and well-cooked regime, simplicity being attained by cutting off many of those "cxtras" in a mixed diet which 
healthy subjects may take with impunity, but which are injurious to weakly individuals. As a rule a plain, mixed diet is the best, made up of the lighter and more easily digested protein and carbohydrate foods. Such articles of diet as pork, rich sauces, heavy cakes, pastry, dried fruits, nuts, pickles, and in some instances cheese, should be avoided; the lightest vegetables only should be taken, such as spinach, cauliflower tops, asparagus, baked potatocs, and tomatoes; all rich wines should be withheld. A heavy meal in the morning should be avoided, the chief meal of the day being taken in the middle of the day. Alcohol as a rule should be avoided entirely, because of the risk of the alcoholic habit. While a simple, mixed diet, in which there is no excess of protein, carbohydrates, or fat, is usually the best dict for this condition, cases are met with which undoubtedly do better on a largely meat diet or a modified Salisbury regime (p. 534); others again are met with in which greater frecdom from attacks follows on a diet of a more or less strict vegetarian character. Every case has to be carefully studied on its merits in orcter to learn what food is and what is not injurious to the individual. Some cases are undoubtedly of gouty origin, and require the gencral and dietetic treatment appropriate to that condition. In all cases constipation must be avoided. It is well to keep in mind that some asthmatic patients unduly restrict their diet, to the detriment of their general health, without any appreciable gain from the point of view of the asthma.

\section{Diet in the Diseases of the Thyroid.}

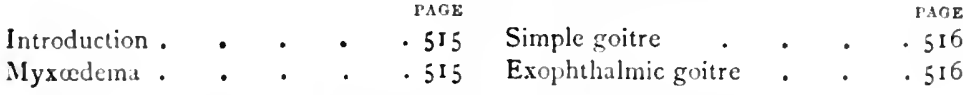

Introduction.-Myxoedema, goitre, and malignant discase of the thyroid are the special diseases of the thyroid gland. Diet is, in general, not an important factor in the treatment of these disorders. At the same time, and more especially in that type of goitre known as exophthalmic goitre, diet is in many cases of considerable importance.

In myxoedema no special dietetic instructions are called for ; plain, simple, nutritive food is indicated. 
In the case of simple goitre, the view has been expressed that the cause of this discase is the use of a drinking-water rich in lime, this theory being based on the prevalence of geitre in certain districts where the water hats this property. More recently, howewer, the view has been expressed that this discase is the result of some infection arising probably from the intestinal tract. The exact causation, however, is as yet unknown. With regard to the dictetic treatment, the diet should be of the nature of plain, simple food, largely lacto-vegetarian in character. Red meats should be used very sparingly; fish, chicken, tripe, and sweetbread supplying the meat foods. Care should at the same time be taken to see that the drinking-water does not contain excess of lime.

Exophthalmic Goitre.-. In exophthalmic goitre or Grave's disease there is very frequently severe gastro-intestinal derangement, such as loss of appetite, flatulence, or diarrhœea, and in these cases dietetic treatment is of the first importance. Careful attention must also be paicl to the hygiene of the mouth, to thorough mastication, and to the prevention of constipation in this clisease. It is in every case essential to make a carcful study of the previous dictetic history of the patient, so as to determine whether the diet has been such as to derange the digestive tract. The most usual defects in the dictary are excess of starchy foods, too much tea, and, less frequently, excess of rich meat foods. It is likewise important to examine carcfully the stools; the presence of illformed, feetid stools points to an abnormally septic state of the intestinal tract, and the passage of scybalous masses would indicate constipation, both of which necessitate treatment.

In acute cases it may be advisable to put the patient on an almost exclusive millk diet for some days or longer, the dict being restricted to 2 or 3 pints of milk (which may, if necessary, be peptonised or administered in the skimmed form), and I pint of strong becf-tea. If diarrhoa be present, lime-water may be given in the milk.

In subacute and chronic cases all that is required is that the diet should be carefully regulated. Excess of starchy foods should be avoided as leading to abnormal fermentative changes: meat foods should be restricted, so as to diminish putrefactive changes in the intestines and also lessen the 
strain on the thyroirl gland. The diet should be light and nourishing, and the drinking of buttermilk shusld be encouraged. The following is an appropriate diet list:-

Breakfast: S A.M.-

Cup of tea. Bread and butter. (Sugar and jam or marmalade should be taken very sparingly.)

Fish or egg.

it A.M.-Glass of milk, or buttermilk.

Luncheon: I P.M.-

Bowl of soup made from grood vegetable stock; or piece of fish or chicken.

Bread and cheese.

Celery, or a little fruit.

(On days when no soup is taken, a glass of milk or buttermilk may be recommended.)

4 P.M.-Cup of tea. Thin slice of bread and butter.

Dinner: 7 P.M. Either-

Soup, meat, pudding ; or

Meat, pudding, savoury.

With regard to this meal the following points should be noted. Soups should occasionally be of vegetable and occasionally of animal stock. The meat course should frequently consist of fish, chicken, rabbit, tripe, or sweetbread in place of the heavier red meats. Care must be taken with the use of root vegetables; occasionally they are better withheld. Suet puddings and pastry are not advisable. Curds, custard, mills puddings, or stewed fruit are the most suitable puddings. Cases of exophthalmic goitre are occasionally met with in which the appetite is keen and the state of the motions satisfactory, where marked benefit accrues from the use of a more liberal dict, such as is employed in cases of neurasthenia.

\section{Diet in Diseases of the Skin.}

The fact that in some individuals the ingestion of certain articles of dict, perhaps notably fruits, is followed by marked skin cruptions-erythema or urticaria (nettle-rash)-shows that there is an important relationship between the processes of digestion and the skin. The cruptions referred to are undoubtedly of a toxic nature, and represent the attempt of the skin to excrete a poison circulating in the blood, this 
poison having been absorbed from the alimentary canal. The subjects of diabetes are specially prone to skin eruptions, notably of the nature of boils; and since diabetes is essentially a disorder of nutrition, we have here further evidence of the close relationship that exists between diet and derangements of the skin functions.

Speaking generally, it can be stated that there is no eviclence that diet enters largely into the treatment of most skin disorders. There are, however, some skin diseases in which the food factor is an important one. These are seen both in childien and in adults, and may be shortly referrect to.

In children.-Children, and more especially the children of gonty parents, by no means infrequently develop skin cruptions that are depcndent on faulty fceding. The most common forms of eruptions are small and large reddish spots of an erythematous nature, and more or less defined areas of nettle-rash (urticaria). These eruptions are usually the result of absorption of some toxin absorbed from the bowel, this toxin being produced under one or other of the following conditions :-

I. The use of too stimulating food, and more especially an excessive supply of meat foorls.

2. Over-indulgence in sweets, usually in the form of confectioncry or fruits.

3. The food being over-abundant, and too rich and varied.

More rarcly the eruptions occur in children who are being too cxclusively fed on a dict rich in carbohydrates and fats which has laid too great a strain on the liver. In every case we must first seck to determine the cause, and an examination of the stools in children is a valuable aid in determining this; and having ascertained in which direction the diet was defective, the fault must be corrected. Frequently a little mild starvation for twenty-four to forty-eight hours is adrantageous. Castor oil, a little magnesia, and a few doses of grey powder are helpful factors in treatment. The subsequent use of a more physiological dietary will prevent the repetition of the skin trouble. 
In adults-Fczema, psoriasis, urticaria, acne, and pruritus are skin diseases seen in adults which can not infrequently be very beneficially treated by dict. Eczema, psoriasis, and urticaria are most frequently secn in gouty individuals; acne is sometimes dependent on excessive indulgence in alcohol; pruritus is met with in diabetic subjects and in cases with pentosuria (p. 377). The dietetic treatment of the skin condition is, therefore, the dietetic treatment of the underlying disease, gout, cliabetes, etc.

Most commonly the error of diet has been in the direction of excess-excess of meat, cxcess of sugar, or excess of alcohol in various forms. These cases are, as a rule, best treated by a lacto-vegetarian diet, in which in addition the amount of sugar is restricted, and all alcoholic liquors forbidden, the aim of dietctic treatment being to diminish the auto-intoxication that is the causal factor in the diseasc. As in children, calomel and salts are important adjuncts in treatment 


\title{
CHAPTER XXXI
}

\author{
SPECIAL DIET CURES
}

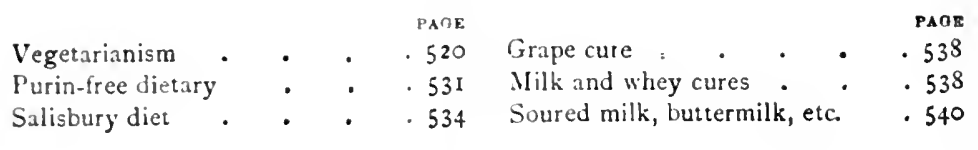

\section{Vegetarianism.}

Definitions-

Strict regetarian, fruitarian, purin-free diet; lacto-regetarian diet., 520

Objections to vegetarianism . $\quad 52 \mathrm{I}$
Source of necessary proteins, fats, and carbohydrates in vegetarianism

Practical points in the formation of dietaries . . . 526 Advantages and disadvantages of vegetarianism

VEGETARIANISM is a term loosely applied to different varietics of restricter dictaries that have one point in common, viz, the exclusion of flesh foods from the diet. The strict vegetarian lives solcly on vegctables grown aboveground, and fruits. The fruitarian or nutarian lives on milk, fruits, nuts, and vegetables. The purin-free dictary allows milk, cheese, cream, butter, white of eggs, vegetables, fruits, and cereal foods, but cxcludes tea, coffee, cocoa, yolk of egg, pulses, and flesh. The lacto-vegetarian diet allows certain animal foods, $\epsilon . g$., milk and its products, eggs, also vegetables, pulses, cercals, fruits, sweets, tea, coffee, and cocoa. A variety of this latter vegetarian dict is one that is restricted to uncooked foodstuffs.

It is possible by restricting ourselves to a vegetarian diet to supply all the food constituents, proteins, fats, and carbo- 
hydrates that are required by the borly. A comparison of flesh and vegetable foorls shows in flesh a very large amount of proteins, a very small amount of glycogen (the animal equivalent of starch and sugar), and a variable amount of fat.

Vegetable foods differ widely, but as a rule they contain a much smaller amount of protein, a larger proportion of starch and sugar, and a small amount of fat. Some vegetable foods, c.g. nuts, contain much fat. Proteins in a vegetarian cliet are derived mainly from vegetables, milk; and eggs. Those derived from vegetables are more difficult to digest, and are on the whole less easily absorbed than those derived from animal food. It is advisable here to refer to the more important objections that are commonly raised to a system of vegetarianism, and to the data on which these are based.

\section{Objections to Vegetarianism.}

In the first place, it is generally urged that in a vegetarian diet the question of the intake of a sufficient proportion of proteins is a practical clifficulty; thus in the text-bools it is stated that, owing to the composition of vegctable foods, in order to get the requisite amount of proteins in the diet, an amount of vegetable foodstuffs far in excess of $b$ xdy requirements has to be taken. The view generally held as to this practical difficulty in vegetarianism was well expressed by the late Sir Henry Thompson as follows:- "The vegetable eater pure and simple can extract from his food all the principles necessary for the growth and support of the body as well as for the production of heat and force, provided that he selects vegetables which contain all the essential elements. But he must for this purpose consume the best cereals, wheat, or oats, or maize, or the legumes, beans, peas, or lentils; or must swallow and digest a large weight of vegetable matter of less nutritive value, and therefore containing at least one elenent in excess, in order to obtain all the elements he needs. This badly balanced type of feeding leads to overloading the digestive system, and sets up dyspepsia in some of its varied forms." In fairness to the advocates of vegetarianism it must be admitted that there is now little or no force in this argument. The advances in the linowledge of the construction of vegetarian dietaries in recent years have 
been very considerable, and it is certainly possible now to frame an cxclusive vegetarian reginc, containing an adequate amount of proteins, fats, carbolyedrates, and salts, in which there is no excess of bulk of vegetarian foodstuff. This point must now be defrnitely conceled. A second objection commonly raised must now be referred to. It is urged that there is evidence that the want of sufficient animal protein in the dietary leads to a lack of resistance to disease, and in support of this vicw the phthisis epjedemics common amongst the Irish peasants, who live mainly on potatoes, may be cited. Chittenden's work (p. 22), however, makes it clear that we must modify markedly our ideas of the necessary amount of protein requisite to maintain the resistant powers of the tissues at a high level. The advantages and disadvantages of a vegetarian regime will be later referred to We will now give some practical details adapted for those who wish to adopt a vegetarian regime.

\section{Source of Food Constituents in Vegetarianism.}

Proteins. - The strict vegctarian and fruitarian has to have recourse to many artificially prepared products in order to get the necessary supply of protein in a fairly concentrated form. Nuts and the pulses supply the proteins, and these furnish the vegetarian meat courses. The manufacture of nut meats has been one of the greatest developments in extending the vegetarian bill of fare. Every year sees a number of new and improved preparations put upon the market.

Mapleton 2 Dolphin Street, Ardwick, Manchester) prepare a varicty of nut and other meat pastes put up in glass moulds, almond nut meat, savour nut meat; and they also make nut meat, walnut, white and brown almond (with or without pea nut), grated and blended with certain cereals. These preparations can be userl to matie cutlets, steamed shapes, etc.

Chapman (Health Food Stores, Eberle Street, I.iverpool) make five or six varictics of tasty and appetising meats put up in air-tight glass moulds. I.cntose (vegctable brawn) and walnut meat are especially to be recommended. They are fully seasoned and may be used hot or cold, and are excellent when sliced and lightly fried, and scrved with tomato sauce 
or gravy. They cost 9 d. or lod. per lb. A book of recipes can be obtained from the makers.

The London Nut Food Company (465 Battersea Park Road, London) also supply several varieties - Meatose, Vegota, and Nut vego; they have distinctive flavours and are suited to different tastes. The Food Reform nut meat is made chiefly from pine kernels: it is said to be hardly distinguishable from galantine of veal.

Protose, Maltose, Nuttolene, made by the International Health Association, Legge Strect, Birmingham, are also of a high standard. Protose has a distinct meaty flavour, and is very good in stews, pies, or fritters, sandwiches, etc.; cost, Is. per pound.

Vegetable Extracts, exactly resembling the meat extracts in appearance, are useful for soups and gravies. They are mainly prepared from grain by special malting processes, and are wonderfully like the best beef extracts in flavour. These are, IVintox and Nutrogen (Winter's), making a soup very like beef-tea; Carnos, made by the Carnos Company; and Marmite, a vegetable food extract which lays claim to possess the same nutrient value as a well-prepared meat extract, and costs about is. Id. for a 4-ounce pot, prepared by Marmite Food Extract Company, Mincing Lane, London. Good vegetable soups in tins and cubes are also available, and are not expensive, e.g., Heinz's tomato soup, Chiver's soups (lentil, tomato, haricot, and pea). Eustace Miles issues two varieties of dried blocks that make excellent soup when dissolved, viz., Savoury protein soup and Protein mulligatawny. These both contain a very large amount of vegetable protein, and quite suffice for an adequate meal.

Pulses. - The pulses may be used fresh or dried, whole and ground into flour; green peas, broad beans, French beans, cooked in the ordinary way, or served with poached or scrambled eggs, are excellent. The large variety of dried pulses are very nutritious: lentils, red or German peas split, dried green and giant green peas, can be used for soup, stews, or cutlets. Brown beans, haricot beans and butter beans, midget butter beans, are used in a similar manner. Vegetable soups made with any of the pulses are 
excellent: German lentils and brown beans produce a very good brown soup.

The Animal Fats are replaced by oil from nuts, and these are largely used by vegetarians for table butter and for cooking purposes. There are now a number of first-rate fats to suit different tastes and purposes, some having very much the appearance and consistency of lard, others closcly resembling prepared suct, while yet others are not unlike dairy butter. These are used for frying, for suet puddings, for pastry, and for table nse. One most like dairy butter is Mapleton's butter, sent out in two qualitics, table and cooking qualitics. Albenc is a hard, white fat, and serves all the purposes for which lard and dripping are used. Cocoa-nut butter, of the London Nut Food Company, can also be used for cooking. Pine kerncls and Vegsu are good substitutes for suct. Most of these fats are put up in I and $2 \mathrm{lb}$. tins, and cost about $\mathrm{Sd}$. or $9 \mathrm{~d}$. per pound.

The nut cream butters retain the nut flavour. Mapleton's walnut cream butter and almond cream butter are generally liked. The nut butter of the International Health Association is made from cooked nuts only, and may be used in soups or stews for thickening, or when diluted forms a nut milk. The same firm also prepares an almond butter for table use which is specially adapted for those with weak digestion.

The Cereals are largely used by vegetarians for porridge, and, in addition to the well-known oatmeal, Quaker oats, and barley meal, one may mention Artox flour, a whole-wheat mcal which makes most excellent porridge, as well as scones and pastry; Banana oats is a recent preparation, and is appetising to some palates. It is easily prepared, and is put up in $3 \mathrm{~d}$. packets with directions. Banana flour is like rice four, and is useful for puddings. Robiuson's patent groats and Nanhu whole-wheat flour, and pure malted barley-meal, also all make excellent porridge, "Kornules" is another good grain food; it is a purc wheat product in granular form, and is ready cooked, and so can be used to prepare a hasty meal. Grape nuts are also much liked.

The so-called breakfast foods consist gencrally of cereals alone, and are predigested, or so heated as to be casy of 
digestion. Shredded wheat biscuits, granose flakes, toasted wheat flakes, Ralston's food and Avenola, are combinations of cooked grains, and make excellent porridge; all are satisfactory foods. Nut cream rolls and nut cream biscuits are made from wheatmeal, or treated with nut butter, and are other forms in which cereals are utilised in the dietary of vegetarians.

Fruitarian Cakes are also useful adjuncts to the vegetarians. There are many varieties, but they are alike in being composed of uncooked fruits and nuts, freed from stones and skins, but otherwise in their natural state. They are compressed into small cakes or slabs. Pitman Company, Birmingham, prepares about one and a half dozen varieties of these cakes, and will supply twelve cakes for Sd. They prepare a cyclist's luncheon for $6 \mathrm{~d}$, consisting of fruitarian cake and banana biscuits. The London Nut Food Company have several dainty fruit and nut cakes covered with chocolate. Mapleton, Manchester, have a large number of calics; pear with walnut, and apricot may be specially recommended.

Gelatine - In the dictary of the vegetarian, gelatine is replaced by Agar-agar, a product derived from a Japanese seaweed. (Chapman, Liverpool, prepares table jellies made from this.)

Beverages.-Tea, coffce, cocoa, and chocolatc are all permissible to the vegetarian; but to avoicl the stimulating effects of the xanthin in tea and coffee, many vegetarians now take some of the ccreal coffees now to be had. These strongly resemble coffee in appearance and flavour, are refreshing, and free from caffeinc. They are prepared by a certain roasting and grinding process from various grains; e.g. Postum, prepared by the Grape Nut Company; Caramel cereal, prepared by the International Health Association; and Lapśe, prepared by Mapleton, Manchester. These, while similar in nature and composition, differ somewhat in flavour, so that various tastes can be suited. They can be prepared as ordinary coffee, but are the better of a few minutes' boiling. Banana coffee is a plcasant beverage, with a flavour not unlike that of ordinary coffec.

A pure vegetable albumin, "Roborat" (Vegctarian Society, Deansgate, Manchester), is now obtainable, and clains to 
contain 9.4 per cent. albumin, and is tasteless. It is the protein of wheat extracted and concentrated, and is especially uscful in invalid dietary, and in helping to curich the food of those who are otherwise unable to take the necessary amount of food. It can be added to any food, in powder form, or better still, by dissolving it by cooking for a few minutes in water. It can also be obtained made up with cocon or chocolates. Emprote (.Miles) is another concentrated vegretable protein, which may be added to all sorts of dishes to increase the otherwise low protein value of the diet. It is practically tasteless, and soluble.

Vegetarian Cheese is made from nut milk, and is practically identical with ordinary soft cream cheese.

The fruturiun finds it more easy to maintain a satisfactory state of health. Milk supplies the animal protein in an casily assimilable form which is not possible in strict vegetarianism.

The purin-free dietery is useful in certain diseased states. A description of it will be found on p. 531 .

The lacto-vesetarian diet is frequently a valuable system of dietetics. It is useful during childhood in the children of gouty parents, in cases of high blood-pressure and chronic renal discase, in many cascs of rheumatism and gout, and in other conditions.

\section{Practical Points in Formation of Dietaries.}

There is often difficulty in planning the meals for a lactovegetarian dietary, and the following may be helpful:-

Breulifist. - This meal may consist of oaten or wheaten porridge, or any other cereal; wholencal bread and white bread, scones, rolls, butter, eggs cooked in any form, jams, marmalade.

Lunch and Dinner.-The soups must be made from vegetable stock, and thickened with various forms of cereal, brown or white roux, tapioca, sago, barley, rice, milk, eggs, and the various forms of vegctables. Farinaceous foods and savoury dishes, pulses and nut meats, eggs in various forms, and preparations with cheese (see below) take the place of meats and cintrées. Vegretables and salads, puddings, fruits, and checse are all permissible. 
Vegctarian Soups.

I. lirown Vegetable sioup.
2 quarts water.
1 ounce butter.
I slice breitl.
I cabbare.
2 carrots.
2 onions.
2 potatoes.
1 turnip).
l'arsley, salt and pepper.

Fry a slice of onion in a large saucepan. When it is brown but not burnt, add water, salt and pepper, and bread toasted, and regetables cut into small pieces. Boil three or four hours, then rul, the vegetables through a colander and boil again for ten minutes, and the soup is ready. If too thick, add a little more water.

\section{Julienne Soup (Vegeturian).}

I quart clarified vegetable stock.

Mushroom ketchup.

Salt and pepper.
Turnip, carrot, celery, onion.

Walnut ketchup.

Sherry, if liked.

Cut the vegetable into fine strips about the size and shape of a small match, and boil them separately until tender but not broken. Have the stock ready boiling; add salt, pepper, a very little ketchup and sherry to taste; put in the prepared vegetables, cook for fifteen minutes, and serve.

2 small onions.

I head celery.

$\frac{1}{2}$ pint milk.

\section{White Soup.}

I turnip.

2 artichokes.

I dessertspoonful flour.
I lb. potatoes.

3 pints water.

I ounce butter.

Cut about 2 lbs. weight of any white regetables, wash and peel and cut pieces, boil them until soft in the water; salt and butter. Rub them through a sieve or colander, put them back in the stewpan with the mill; and let it boil. Put in the flour, mix smoothly with cold water, let the soup boil for ten minutes, and serve with slices of fried bread.

\section{Farinaceons Food.}

There are the porridges made of oatmeal, barley-meal, hominy, and lentil, etc. The following three recipes may be commended :-

I. Hominy Fitters (Ifominy or Maize Meal).

Cold hominy porriclge, fat to fry, and flour.

Cut the cold porridge into slices about I inch thick, flour lightly on both sides, and fry in butter or oil.

\section{Breal Fritters.}

Pieces of stale bread allowed to soak in a little milk flavoured with cinnamon, dipped in batter and fried in boiling fat.

3. Polentiz and Cheese. (This is another form of Maize Meab.)

Cold maize meal porridge.

Salt and cayenne.
Erated chcese.

Butter.

Cut the cold polenta into square or oblong pieces about 3 -inch thick. 
Arronge in a flat dish in layers, with grated cheese between and over the top. l'ut a few pieces of butter over, and bake tall brown in a good oven.

\title{
Jigetarian Sarourics.
}

1. Coulifiacer a Plubicnne.

\author{
I caulifower. 2 tablespoonfuls grated cheese. \\ 1 pint white sauce. 1 tablespoonful cocoa-nut. \\ 1 dessertspoonful curry powder.
}

boil caulifower awenty to thirty minutes until the stalk part is tender. Irain the cauliflower and place on a fireproof clish. Add the curry fowder and the white satuce, pour it over, cooling the cauliflower well. Sprinkle the remainder of the cheese and cocoa-nut on top, and brown quickly in a sood oven. Cauliflower au gratin can be made in the same way; increase the amount of cheese and omit the curry powder and cocoa-nut.

\section{Tomato Suñ'ou'y.}

6 small tomatoes.

I gill tomato sauce.

I teaspoonful curry powder.

i teaspoonful red-currant jelly.
2 tablespoonfuls breadcrumbs.

2 tablespoonfuls gated cheese.

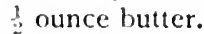

I'epper and salt.

Choose small firm iomatoes. P'ut into bolling water for a minute or two, lift them out, dry and peel them. Then grease a fireproof dish, and place the tomatoes in it. Sprinkle them with half the crumbs and cheese, and a little pepper and salt. Add the curry powder and the redcurrant jelly to the tomato sauce, and pour this over the tomatoes. Put the remainder of crumbs and cheese on the top, then the butter in small pieces, and bake in a moderate oven about twenty minutes. Serve hot.

\section{l'ouched Esgrs with Checse.}

4 or 5 eggs.

$i$ gill white sauce.

A little butter.
3 tablespoonfuls breadcrumbs.

lepper and salt.

3 tablespoonfuls grated cheese.

Butter a flat dish, and sprinkle it with half the breadcrumbs and checse. Poach the exgrs and place them on the top. Then pour over the sauce, and put the rest of the cheese and breadcrumbs on the top.

Iay on a few small pieces of butter, and place in a hot oven to melt the cheese and lightly brown the top.

\section{Parmesan balls.}

2 ounces grated Parmesan cheese.

Cayenne pepper.

2 whites of eggs

Salt.

Beat the whites of ergr to a perfectly stiff froth, with a pinch of salt and cayenne pepper. Then stir in quickly and lightly 2 ounces of freshly grated Parmesan cheese. Shape the mixture into little balls the size of marbles, and drop these grently into a pan of boiling fat. Cook them a pretty brown colour (about five minutes), and drain them well. Serve on 
a doily or dish paper, and sprinkle lightly with Paprika pepper and grated cheese.

\section{Potato and Cheese Mould.}

$\frac{1}{2}$ llb. cooked potatoes.

2 ounces yrated cheese.

2 tablespoonfuls milk.
I ounce butter.

2 eggs.

Browned breadcrumbs.

Pepper and salt.

Sieve the potatoes, and add to them the butter melted, the yolks of eggs, cheese, seasoning, and the milk or cream. Mix well together. Whip the whites to a stiff froth, and stir them in lightly to the other mixture. Grease a plain mould or basin, and line it with brown crumbs. Three-parts fill with the mixture, and bake in a moderate oven about thirty minutes. Turn out on a hot dish, and serve at once.

Lacto-Vegetarian Diet, Uncooked Foods.-Brief mention may here be made of a system of dietary of a largely vegetarian character, of which the distinctive feature is the use of uncooked food. The advocates of this system, first introduced by Christian, believe that the vital principles of food are affected by cooking, and they give effect to this belief in practice. The diet consists largely of fruits, nuts, and especially Christian's protein nuts, pine kernels specially treated; also, milk, raw eggs, uncooked vegetables, and a special unfired bread made from a mixture of grains pressed, and some cereals. The distinctive feature of this dietary is the necessity for thorough mastication ; in this respect the diet will certainly satisfy the most ardent disciples of Fletcher. The writer has had the interesting experience of partaking of an "uncooked dinner," prepared by an expert in this system of feeding, and it is certainly surprising to find that a paiatable and very sustaining menu can readily be prepared. The following is a representative menu, and errs, if anything, in containing an excess of protein foods :-

I. Soup made from milk, raw eggs, ground chestnuts, and finely chopped vegetables, such as raw beetroot, and brusscls sprouts; this soup is taken hot, but is never allowed to come to boiling point.

2. Salad made from brussels sprouts, bectroot, celery, chopped very fine, with a dressing of Protcin nut butter, lemon juice, and a pinch of salt. The mastication that this dish requires is extraordinary, and a tablespoonful contains a large amount of nourishment. An unfired biscuit with butter is taken with this dish. 
3. Savects-(a) Fruit salad made from a variety of fruits, c.s., tinned pincapple, bananas, orange, apple, raisins, dates, with grated nuts added to it, and cream, no sugar; also

(b) Stuffed Talifat dates, stoned and filled with chopped apple, nut cream, and banana.

4. Cheese and biscuits, the latter being the unfired variety before mentioned.

5. Banana coffee, and thin slice of fruit cake. This fruit cake is highly nourishing, consisting of all manner of dried fruits and grated nuts pressed together.

There is no question that a highly nourishing diet in relatively very small bulk can be given along the above lines. A rigid diet of this nature is not a practical one, except for an enthusiast. There are certainly two points in its favour: (1) the absolute necessity of mastication, and (2) possible advantages associated with the presence of vital principles unaltered by cooking; there is no doubt that a little of this system could with advantage be introduced into ordinary dictaries both in health and disease. A word of special commendation may be paid to the unfired bread, which is an excellent preparation.

\section{Advantages and Disadvantages of Vegetarianism.}

Probably the greatest advantages which accrue from the adoption of a vergetarian regime lie in the fast that such a dietary is a most valuable corrective of over-eating. There is no doubt that vergetable foodstuffs are less appetising than animal foods, and accordingly the vegetarian feeder is much less exposed to over-indulgence, with its attendant unfavourable results. The system of diet adopted by the strict vegetarian and fruitarian are not to be commended; the lacto-vegetarian regime, on the other hand, is a most useful form of diet therapy in many diseased states. Its value is none the less pronounced because its beneficial effects may be in many cases to a material extent dependent on its negative property of ensuring moderation in feeding.

Such a dict has special advantages in the upbringing of the children of typically gouty parents; it is also most useful in the treatment of many disorders of the renal, cardiac, and vascular systems. Its use tends to lower blood-pressure and 
diminishes the strain on certain important glandular organs intimatcly concerned in the processes of excretion and general nutrition, notably the kidneys and thyroid gland (sec Appendix). Its long-continued use in certain cases also influences favourably the secretion of mucin from the glands in various mucous membranes, and hence it is of value in chronic catarrh of the mucous membranes, notably the nasal, bronchial, and uterine mucous membranes (dysmenorthoa and menorrhagia). It is also useful in some forms of rheumatism, gout, and chronic nervous disorders, provided due attention is paicl to the quantity and manner of presentation of the vegetarian foods, so as to prevent abnormal fermentation processes. On the other hand, we must recognise that there are not a few cases met with in practice in which patients have either dieted themselves, or taken on medical advice a more or less rigid vegetarian diet, to the serious detriment of their general health, and a corresponding aggravation of their disease. Some more or less strict vegetarian diets occasionally used, including nuts, are difficult of digestion, and therefore of poor nutritive value; and occasionally they profoundly derange primary digestion, inducing diarrhœea or constipation, anæmia, and profound disturbance of general health. Reviewing the subject as a whole, it may be said that in healthy subjects, and more especially young subjects under forty years of age, a lacto-vegetarian diet has no advantages over the more conventional mixed dietary, taken in equal moderation and submitted to the process of thorough mastication ; in later life, however, in health it is a wise rule gradually to more and more restrict the rich animal protein foods, and approximate to a lacto-vegetarian regime; and in the diseased states referred to, the therapeutic advantages of a carefully planned more or less strict lacto-vegetarian diet are very great indeed.

\section{A Purin-free Dietary.}

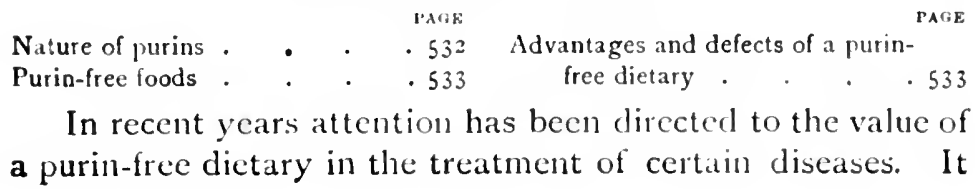


has been recommended for gout, renal disease, neuralgias, headaches, bilious attacks, and chromic discases of all kinds. The system is based on the theory that in these disorders there is a retention of uric acid and other purin bodies in the system, with resulting poisoning of the tissues, due to their defective climination. Certain articles of diet contain more purins than others; it follows that if this theory were correct, much bencfit might be looked for from a dictary in which the purins were absent, or present in very small amount. There is no doubt that great benefit follows the use of this dict in certain cases, but there is good rcason to believe that the benefit is more correctly explained along lines other than the purin-free nature of the food. These will be later referred to.

Nature of Purins.-Purins are substances constructed on the base $\mathrm{C}_{5} \mathrm{~N}_{4}$. Those of chicf clinical importance are uric acid, xantini, hypoxanthin, adenin, and guanin. These purins are present in certain articles of diet, in the tissues, especially muscular tissue, and in the urinary excretion.

Purins in the Food.-Meat and meat extracts contain a large amount of purins; similarly, certain glandular organs, such as the pancreas and liver, are rich in purins. They are also present, though in smaller amount, in many vegetable foods (for example, beans, lentils and oatmeal), and they are relatively abunclint in some accessory articles of diet, notably tea and cuffee. The following table, taken from Walker Hall's work on Purins, indicates what foods are rich in purins. It will be observed that those include the most appetising foodstuffs, such as are readily indulged in to excess.

\section{The Purin Content of Foods in Grains per Pound, Pint, or Tcacup.}

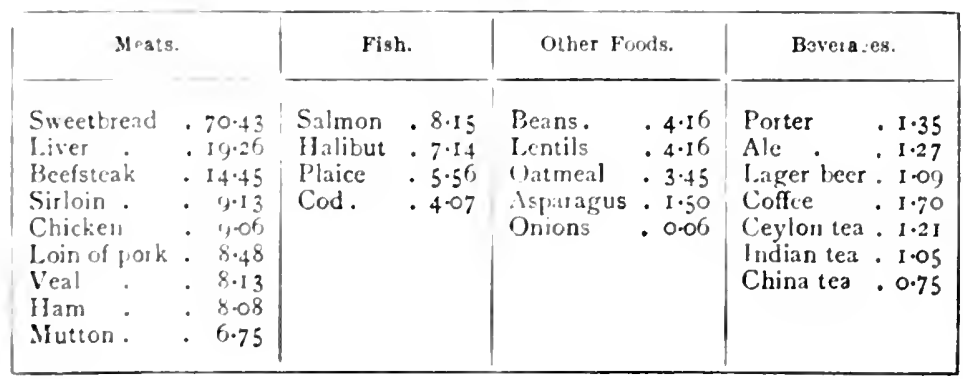


Purin-free Foods. - Milk, white bread, and potatoes contain practically no purius. Similarly, cream, butter, fats, eggs, apples, grapes, figs, dates, and rasius are purin-free. Macaroni, checse, and nuts are in the same categroy. In comparison with foods containing purins, we therefore sec that purin-free foods are on the whole much less appetising, and on that account are less likely to be taken to excess. A typical purin-frec dictary is as follows :-

\section{Breakfast-}

I pint milk.

Bananas.

Apples.

Pears.

Plums, fresh, dried, or cooked.
Any other fresh truit.

Eaten to any extent for which there is appetite.

\section{Lunch-}

Vegetable soup made with milk.

Potatoes (with butter, oil, or milk).

2 ounces cheese, eaten with potatoes and any other vegetables in season.

Stewed fruit, or tart.

Fresh fruit.

I pint of milk drunk during the meal.

Dinner-Much as Lunch.

I pint milk.

I ounce cheese.

Any variety of vegetables and fruits in season; if potatoes and fruit are taken in larger quantity, less milk and cheese will be required.

Points to attend to in the administration.-In order to get the best results from treatment, the transition from an ordinary diet to a purin-free dictary should not be effected too quickly. At the outset there may be slight difficulty in digesting ccrtain foods, and constipation may be a troublesome feature. These difficulties are not as a rule difficult to overcome. It is of the first importance to enjoin thorough mastication of the food.

Advantages and Defects of a Purin-free Dietary.-The advantages may be summarised as follows:-It is a simple diet; its adoption prevents over-eating; it restricts intestinal putrefaction, and so prevents auto-intoxication from the products of imperfectly digested protein foods; it has the 
further advantage of being a "special system," and on that account is followed more rigidly and therefore more successfully than other dietaries framerl along more conventional lines. These advantages give this system of feeding a distinct place in therapent ics. Its undumbted value is probably cxplained along the lines just referred to, rather than by regard to any specific action associated with the absence of purins in the dictary.

The disadvantages of the diet must be referred to. Some patients find the regime very unattractive, and as a result the amount of food taken, and especially the amount of protein food, falls below the necessary standard, and ill-health results from a continuation of the diet. In others its too rigicl adoption may induce diarrhora and other gastro-intestinal disturbance, with resulting deterioration in health.

\section{Meat and Hot-Water or Salisbury Diet.}

A meat diet is specially recommended in tuberculous affections. In I $889 \mathrm{C}$. Richet and Hericourt experimentally proved the value of a raw-meat diet in tuberculosis in degs, and showed that the benefit was derived from the muscle juice and not from the muscle fibre (zomotherapy). The method of preparing meat juice is described on p. 77. A recently introduced muscle juice, Carnine Lefranc, is a valuable meat-juice preparation. It has an agreeable taste; it keeps well, and may be given in doses of from $I$ to 4 ounces daily in any fluid except beef-tea. The special value of meat juice and of other proteins in the treatment of tuberculosis is fully described in Chapter XXV.

Many years ago a meat and hot-water diet, commonly known as the Salisbury treatment, was recommended by Dr Salisbury for the treatment of chronic gout, obesity, chronic gastro-intestinal derangements, and other disorders of nutrition, which were attributed by Salisbury to abnormal carbohydrate fermentation. In its strict form the treatment consists in the daily administration of $\mathrm{I}$ to $3 \mathrm{lbs}$. of meat with 3 to 5 pints of hot water, for a period of four to twelve weeks. The treatment aims at thoroughly cleansing the stomach before eating, by giving a pint of hot water an hour and a half before each meal and at bedtime. If the 
water is drunk slowly, the stomach will not be distended and the patient will not experience any sense of discomfort. The slightly nauseating taste of plain hot water may be overcome by the addition of ginger, lcmon juice, or weak tea, and in cases associated with intense thirst the addition of a little nitrate of potash makes the water a more efficient thirst-quencher. If constipation is present, a teaspoonful of magnesium sulphate can be added to the water. A cardinal point in treatment is to observe the specific gravity of the urine and regulate the amount of water taken accordingly. If the urine gets persistently below sp. gr. IOIO, the patient becomes markedly asthenic, and the amount of water should be considerably reduced. The specific gravity of the water should be kept between IOI2 and IOI5. The chief article of diet is fincly minced steak, which allows the patient to get the maximum of nitrogenous food with the minimum of digestive work. At first the patient begins with lean meat of beef in mince or cakes. If unable to assimilate solid food, other preparations, Carnrick's liquid peptonoids, peptonised home-made becf-teas and essences, Wycth's beef juice, Brand's becf juice, Oxo, and Carnine Lefranc may be used instead. Gradually the patient begins to take lean mutton cakes and the white meat of chicken. The white of an egg, raw, lightly boiled, or poached, is also allowed. The following directions will be found useful in the preparation of the meat cakes.

Lean Meat Cakes. - The beef should be taken from wellgrown animals, and stcaks cut from the centre of the round are the best for this purpose. The beef-pulps can be prepared in the following manner. All the fat, fascia, and connective tissuc and bone are removed, and the meat is placed on a board or in a chipping tray, and is shredded down with a blunt knife; the pulp is then scraped together with a spoon; the result is that all the tough fibrinous parts remain behind. The scraped pulp is lightly moulded by the hand into cakes from $\frac{1}{2}$ to $I$ inch thick, and slowly boiled over a clear fire free from smoke. When cooked, serve on a hot plate with a little butter, and season to taste with pepper and salt. The flavouring may be varied by using Worcestershire or Halford sauce, mlistard and 
horse-radish, or lemon juice. A small quantity of dry celery is also permissible.

from a to 6 ounces of meat is the maximum that can usually be taken at a meal at the outset of treatment; later $S$ to ro ounces ur more may be taken by some patients. Four meals should be taken daily.

Oysters are a welcome addition to the monotony of the diet, and may be prepared as follows:-

$$
\text { Oysters-Panned. }
$$

Take 6 deep-sea oysters, place them in a colander and pour cold water over them. Drain for ten minutes. Place the oysters in a very hot iron pan, add salt, pepper, a small piece of butter, and a teaspoonful of meat stock. Cook for a few minutes, and serve the oysters garnished with a thin slice of lemon.

\section{Oysters-Broiled.}

Take 6 large oysters. Lay them on a board and dry them, season with salt and cayenne pepper. Have a gridiron thoroughly heated, place the oysters on the gridiron and brown them on both sides. Place the oysters on a very warm plate, and pour round them a little heated beef juice and a little melted butter.

Crusts of stale bread, unsweetened rusks, and protein biscuits, $\epsilon . g$. Kalari (p. 476), are the first foods added to this dietary.

Great care and consideration are called for both in the recommendation of this diet and the best means of giving effect to it. Some time ago the writer saw a patient who came to him complaining of intense weakness and loss of flesh, consequent on a course of treatment lasting nine weeks, carried on "by correspondence." The patient had been instructed to take a moderate amount of exercise, including golf, but was greatly surprised to find that not only was exercise impossible, but at times she had hardly strength to stand. Special care has to be taken in the case of stout subjects. The very strict. Salisbury regime is in the author's experience scldom necessary or advisable, but a modified Salisbury dietary (see infra) is of great value in some cases of indigesion and chronic auto-intoxication associated with it. A regime like the following will be found of great value in such cases.

While the nutritive value of this diet is comparatively small, it amply suffices for the short time in which the diet 
is necessary. Its use effects a profound imprivement in the state of the intestinal excretions, and a corresponding improvement in digestion as a whole.

\section{Modifued Salishury Diet.}

7 A.M.

$\frac{1}{2}$ pint or more hot water.

II.3O A.M.

2 pint or more of hot water, flavoured with lemon if desired.

3 P.M.

pint or more of hot water.

6 P.M.

I pint hot water.
8.30 A.M.

4 to $60 \%$ meat rissoles.

2 Kalari biscuits (p. 476) with a little butter.

Small cup of very weak tea.

I P.M.

Breakfastcupful of beef-tea with $\frac{1}{4}$ lb. scraped meat (sec beef purce, p. 77).

Thin slice of baked bread or dinner toast ( $\boldsymbol{y} .93)$.

Half a dozen oysters as above (see also p. 305 ); or

Consommé with custard (p. 272); or consommé with eger (p. 272), with baked bread or toast.

4.30 P.M.

Breakfastcupful of skimmed milk, to which is added a full tablespoonful of Carnine Lefranc or other meat juice; or

Plain egg flip (p. 48) flavoured with cinnamon in place of sugar.

Unsweetened rusk or crisp biscuits.

7.30 P.M.

4 to $6 \mathrm{oz}$. meat rissoles or mince, followed by an egg jelly (p. 302) in which the sugar is reduced in amount; or a blancmange made with milk in place of cream (p. jor).

The above regime should be maintained for ten days to a fortnight, after which additions in the form of steamed fish, chicken, malted breads, green vegetables, jellies, and fruit can be slowly made. The return to ordinary farinaceous foods must be made very gradually, preferably starting with the invalid foods $\left(p .18_{j}\right)$. 


\section{Grape Cure.}

Various forms of iruit cure are occasionally practised Thus we have the lemen cure, in which the juices of two or three lemons are taken in susar water three times a day, milk and fatty fonds being avoided; preserved lemon juice is less efficacious: also the sweet fruit cure (dates, figs, prunes, bananas, and apples). The main action of these "cures" is a laxative one. In California there are people who live on fruit alone, and seem to be able to maintain themselves in health and in fair working condition upon this diet. Fruits as a class are well digested and have a higher nutritive value than is popularly attributed to them; and swect fruit combined with meat and a green vegetable regime is adrocated in some cases of constipation. The grape cure is probably the best-known fruit cure. It is recommended for cases of abdominal plethora, chronic bronchitis and emphysema, chronic constipation, and chronic gastro-intestinal catarrh. It is in vogue in the grape-bearing vineyards in some parts of Southern Lurope, notably Neran and Montreux. It consists in taking from $\frac{1}{2}$ to $\mathrm{I} \mathrm{lb}$. or more of grapes thrice daily about three-quarters of an hour before meals; the meals consisting of light, easily digested foodstuffs, e.g., fish, chicken, milk puddings, stewed fruit, toast or rusks, and green vegetables, avoiding all rich sauces, pickles, potatoes, lentils, pastry, cheese, and sweets. The duration of the course is from four to six weeks. The chief effect of this diet is a laxative one. With regard to the nutritive value of grapes it should be noted that I lb. of grapes contains only about 45 grains of protein; they are, however, rich in carbohydrate (sugar). It is probable that much of the benefit ascribed to this system of cure is due to the change of air, the favourable altiturle, and general surroundings of the patient at the health resort.

\section{Milk and Whey Cures.}

Skimmed Milk Cure.-A diet of skimmed milk has very special value in cases where it is desired to rest the digestive organs to cnable them to recover from an exliausted and irritable condition. It is useful in cases of intestinal indigestion 
and chronic catarh of the small and large bowel (colitis). The diet at first is restricted lo skimmed milk, which should be freshly prepared, and given in conjunction with water or mineral-water. To beurin with, from of to 6 onnecs shoukl be given every two and a half hours, the amount beines gratually increased until io to 12 tumblerfuls are taken daily. If desired the milk may be flavoured with weak tea or coffee, and a pinch of salt may advantageously be added. After ten to fourteen days of this regime, during which the patient is confined to bed, the diet may usually be increased by the addition of stale bread, dry toast, or a malted invalid food (p. I 84). Solid food is best withheld for three to four wecks, when a little lean, raw, scraped beef may usually be addeel to the dietary. To begin with, patients lose weight on this regime, and they may complain of drowsiness and general weakness. The urine is increased in amount, of low specific gravity, and of a pale, slightly greenish tint. Constipation may be a feature, and is best treated by adding to the dict fruit, e.g. prunes or stewed apples, once daily in the forenoon. In some patients diarrhcea and vomiting are set up, this being remedied by reducing the amount of milk, or lengthening the interval between meals, and the addition of sodium citrate or lime-water to the milk. In favourable cases the state of the digestion of the intestinal excretions rapidly improves on this regime, enabling the patient to return in a few weeks to a light convalescent dietary.

Whey Cure.-Whey is practically an aqueous solution of milk sugar. A whey cure is advocated in some cases of chronic indigestion and abdominal plethora; it is used most largely in some health resorts, notably Ems and Reichenhall. It consists in the administration of from 20 to 40 ounces of whey daily, which is taken warm either alone or with a mineral-water. It is given in combination with a vegetarian and fruit regine. In cases of abdominal plethora, as much as $S$ to Io tumblerfuls may be given daily with a diet of fruit and regetables. It is sometimes combined with the Grape cure (p. 53 $)$. When taken in large amounts it sometimes induces diarrhoea and colic. 'The value of whey' is elsewhere referred to (see Infant Feeding, p. 238, also p. 269). 
The Koumiss and Kephir Cures.- The rencral properties of kommise and kephir ane griven an p. at. Koumiss contains from 1 (1) z per cent. of alcolwol. It is more easily digested and more completely ahsorbed than ordinary milk, and can be taken in linge amenunts. It is diuretic, gently laxative, ancl, like other milk cures, lessens intestinal putrefaction in virtue of the lactic acid which it contains. On an average from 2 to 4 quarts are taken daily, but much larger quantities are taken at the special "cure" resorts in Russia where this method is in vogue. The koumiss is given in combination with nourishing food of a protein nature, carbuhydrates, fruits, and saccharine foods being specially restricted. lime-water is added if diarrhoea is present. This koumiss cure is largely employed in Russia in the treatment of pulmonary tuberculosis. In this country the special value of koumiss lies in its being a valuable milk preparation, which can be taken by many patients with whom plain milk and its other modifications disagree. For this reason it is a most useful foodstuff in the treatment of many derangements of the stomach and bowel, either of a primary nature or as occurring in affections of the heart or lungs.

\section{Treatment by Soured Milk-Lactic Acid Therapy.}

In the last year or two a valuable method of treatment by means of soured milk and other methods of administering selected lactic germs has been brought to the notice of the profession by the distinguished French bacteriologist, Eli Mctchnikoff, of the l'asteur Institute, Paris. Treatment by this means has lately become a fashionable craze, and as is usual when a new method of therapy is introduced, exaggerated claims have been made for the treatment. While our knowlerge of this method of treatment and of its limitations is by no means complete, clinical experiences has abundantly shown that this form of treatment is a real and important advance in therapcutics, and very specially in intestinal bacterio-therapy. It is therefore advisable to give a short account of the rationale of this treatment as laid down by Metchnikoff. It is well known that the food exerts an influence on the bacteria normally present in the intestine. 
This dependence of intestinal microbial growths on the nature of food is due to the fact that certain bacilli secrete substances which render the soil unsuitable for others, so that by selecting an organism which is innocuous to human beings we are enabled to destroy active germs productive of injurious effects. In order to attain this we must secure if possible an antiseptic mechanism which, once started, will maintain its effect, and this can only be accomplished by the services of a living organised ferment. It is well known that lactic acid is a powerful anti-putrefactive agrent. When milk turns sour, that is to say, when the milk sugar has undergone lactic fermentation with the formation of lactic acid, it can then resist putrefaction for a long time. This fermentative action is due to the lactic acid, and the knowledge of this formentative property, first shown by Metchnikoff, induced him to employ cultures of the lactic germs in order to produce nascent lactic acid just where its action is required. The product by which this result is achieved is known as "Lacto-bacilline."

Fresh micro-organisms are continually being ingested with uncooked food, and these intensify the effect of pre-existing colonies in inducing putrefaction of the intestinal contents and noxious fermentations, more particularly the butyric formentation. Sour milk, owing to its containing lactic acid, can prevent butyric fermentation and putrefaction, both of which are capable of causing various disorders in the human organism, and it has thus been applied to hinder decomposition changes in the digestive tract. The experiments by Herter of New York and other investigators have clearly established that lactic bacilli marlicdly diminish the putrcfactive process. This has been determined by carcful examination of the amount of decomposition products (in (lisease, etc.) in the urine, when selected species of lactic ferments were administered in the form of curdled milk and other means. In some observations by Cohendy, examination of the faeces demonstrated the presence of lactic germs, which continued to multiply long after the administration of curdled milk had been abandoned.

In endeavouring to combat intestinal putrefaction, instcad of giving lactic acid, which is oxidlised or excreterl by the kidneys, it is better to introduce the living germs into the 
oreanism, either in the form of Lacto-bacilline powder or tablets, or, if preferred, as soured milk. These germs continue to multiply in the intestinc, and as they are amply supplied with the sugar necessary to their maintenance, they set free lactic acid, which permeates the intestinal contents and inhibits putrefaction and all irregular fermentation. It is well known that certain races in Asia and Russia make habitual use of curclled milk, which constitute their staple food, and this itself may be taken as a guarantec of the value of this food. It might be supposed that of the many varieties of curclled milk in daily consumption throughout the world, any one of them would answer the purpose of arresting intestinal putrefaction, but as a matter of fact this is not so. Raw milk may contain in addition fungi, which favour the development of pathogenic bacteria; it may also contain tubcrcle, and other bacteria which are not neutralised by the lactic ferment. In most cases, therefore, it is found more convenient to give the lactic ferments in the form of Lacto-bacilline powder or tablets. Milk in order to undergo thorough lactic fermentation must have the organised ferments-the living microbes-added to it. This is added in the form of pure cultivation of lactic germs, which may be given in the form of Lacto-bacilline powder or tablets, and this may be given without having recourse to milk as the vehicle. The special bacillus used by Metchnikoff, described as the Bulgarian bacillus, is a very active producer of lactic acid, coagulating milk within a few hours, and curdling it without the assistance of any other organism. Since too large a proportion of fats may not be desirable, the curdled mills may sometimes be made with advantage from skimmed milk. Having been boiled and cooled, the milk is inoculated with a sufficient quantity of a pureculture of lactic germs (Lacto-bacilline). When fermentation is complete, it yields a curdled milk which is agreeable to the palate and tends to diminish putrefaction. Taken in duses of from a pint to a pint and a half daily, this product regulates the intestinal functions and also prevents disease. When milk is treated in this way a large proportion of the casein is rendered soluble, and a still greater proportion of the phosphate of lime has its solubility similarly increased. This proves the casily digrestib!c qualities of curdled milk prepared 
with pure cultivation of lactic microbes. Curlled milk is therefore both a food and a medicine. As its preparation requires a little time and trouble it is found more convenient to administer lacto-bacilline in powder or tablet form, mixed with boiled milk, or even in water. Reference is later mate to the unreliability of the commercial forms of lactobacilline in common use.

Diseases benefted by Lactic Bacilli Therapy.-From atl extensive experience of this treatment carried out under conditions specially directed to test its efficiency, the author is satisfied that it is a valuable addition to our therapeutic resources. Certain cases of chronic intestinal catarrh, pernicious anemia, subacute and chronic nephritis, rheumatism, and gout are very strikingly benefited. The treatment is of special value in cases of auto-intoxication, resulting from abnormal putrefaction of proteins; it has litule value in cases due to carbohydrate fermentation.

Methods of Administration.-It may be given as buttermilk, which is the residual milk left after churning and removing the fat; or as soured milk, which differs from buttermilk in that the fat has not been removed; or in the form of one of the many commercial preparations ${ }^{1}$ of lactic bacilli at present in the market, e.g., Lacto-bacilline, Sauerin, Lactigen, Trilactine, which are added to milk for the preparation of an artificial soured milk. Unfortunately these preparations cannot be implicitly relied on, as it has been found that they may contain no active lactic acid bacilli. The writer recently gave a demonstration of the results of the bacteriological analysis of many of the preparations in everyday use, at which it was shown that many of them contained no active lactic bacilli (although other bacteria were numerous), and had not the property of souring milk in twenty-four or forty-eight hours. Other observers have had the same experience. Of the preparations recently examined, Sauerin and Lactigen have given the most satisfactory results. When a freshly made butlermills from a sool source is obtainable, this is probably, on the whole, the safest method of administration. Ilere again, however, we have

1 Alt the makers supply detailed instructions for the special methods of pieparalivin. 
to bear in mind its uncertain composition. The "strain" of germs used in the preparation of commercial buttermilk is, as a rule, renewed every three wecks; as the strain gets attenuated, there is a corresponding increase in the numbers of other bacteria present in the milk, and the presence of these may interfere with the action of the lactic germs present. In the same way, if mill has becn doctored by the addition of preservatives, the curdling may be prevented cven although the lactic bacilli are active. There are also specially prepared buttermilk preparations in the market made from the Bulgarian bacillus, co. "Fermenlactyl," made by the Aylesbury Dairy Company. Bulgarian soured milk chocolates (Rowntrec's), and a cheese containing lactic bacilli in large numbers (Lactic St Ivel checse), are other forms in which the lactic germs may be given. Under the influence of the administration of an active preparation of lactic acid bacilli in favourable cases, a very notable improvement in the state of the stools is brought about; these lose their foetor and become formed, presenting a marked contrast to the extremely foctid, pultaccous stools originally present. It will readily be understood that lactic acid producing germs are more likely to have a beneficial cffect when the diet is simplified along lines such as are laid down in the section on Autu-intoxication, p. 346 . 


\title{
CHAPTER XXXII
}

\author{
HIOSPITAL DIETARIES
}

THE American authors, Friedenwald and Ruhrah, in their text-book on Dictetics, point out that in many hospitals the diet for patients is selected by the nurses, with the exception of a few of the more important diseases such as typhoid fever, cliabetes, and the like.

There is some reason for thinking that the same remark may also be applied to some hospitals in this country. An efficient remedy for this state of affairs will not perhaps be found until instruction in dietetics is made an essential part of the medical student's curriculum.

At the present time it is found that in many institutions where the official dietary leaves little or nothing to be desired, the actual dictary is in a manner faulty. Use and wont has led to the establishment of an increased number of feeding hours with a proportionate increase in the total amount of food, some of which there is good reason to believe is injurious rather than beneficial.

A concrete example of this is given in the table on p. 546, which gives the official dietary of a large infirmary, and, for comparison, the actual dietary in vogue in the same institution.

This official dictary allows for three gond meals a day, which is ample for the majority of patients. Use and wont, however, has led to the following dictary being adopted as the average one for ordinary and convalescent diets in that institution :- 


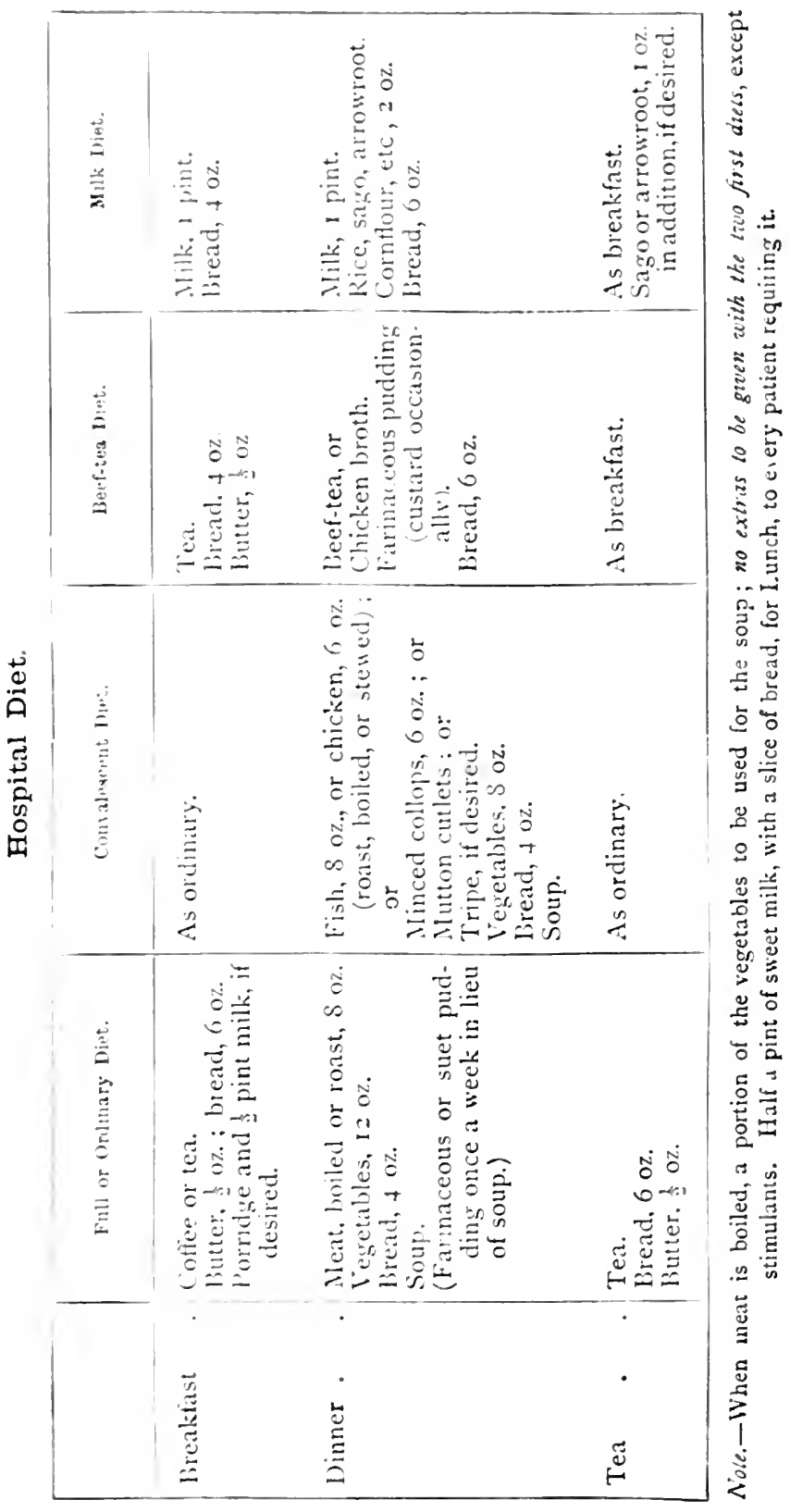


For the purpose of comparison, the official and actual dietaries are here given side by side :-

OFFICIAL DIETARY.

S.A.M. : Trealifnst-

Coffee or tea.

Butter, $\frac{1}{2}$ ounce ; bread, 6 ounces. Porridge and $\frac{1}{2}$ pint of milk, if desired.
Actual Dietary.

5 A.v. : Horning Sumck, consisting of milk, $\&$ ounces; or bcef-tcit, $\$$ ounces. Bread and butter, 2 to 3 ounces.

8 A.M. : Brerlifurst -

As laid down on the chart.

Io to I A.M. : Lunch-

Nilk, 8 to to ounces.

bread and butter, 2 to 3 ounces.

1.30 P.M.: Dinner-

Consisting of soup, meat, and pudding. (Patients on convalescent diet get white meat.)

Soup.

(Farinaceous or suet pudding

once a week in lieu of soup.)

4.30 P.M. : Tea-

Tea.

Bread, 6 ounces.

Butter, 흘 ounce.
4. 3O P.M. : Téz-

Tea.

liread and butter, 3 to 6 ounces. An egrer.

7 I.M. : suffir-

Milk, 6 to 10 ounces.

Bread and butter, I 12 to 2 ounces.

In this actual dictary there is no restriction to the amount of bread, the amomnt being regulated solely by the patient's desires. It will be observed that the nutritive value of this dietary is considerably greater than the official dietary. This regime is one which is for many patients moloubtedly excessive. It is true that there are some patients who thrive on it, and increase in weight in a favourable manner. These are, however, in a minority, and are usually patients who have been mnder-fed prior to admission to hospital. For the majority of patients this dict is excessive. It gives little 
rest to the digestive organs, and such a diet is certainly not one to be adopted as a regular routine.

There is no doubt that too much food is often given to hospital paticnts by over-\%calous nurses who are anxious to hasten convalescence. The desire to feed is a kindly feminine instinct which should be carefully regulated by the practitioner. The medical man should always explicitly inclicate the nature and the amount of food, and the frequency of administration which he considers advisable for each patient.

A uscful way of classifying hospital dietaries is the following :-

1. A Milk Diet, consisting of 4 to 6 pints of milk daily, and nothing else. This may be given in the form of diluted milk, whey, skimmed milk, or koumiss. It is best administered in six meals in the 24 hours.

2. A Fluid Diet, consisting of milk, beef-tea, chicken broth, mutton broth, eggr albumin. The milk or beef-tea may be thickened with one of the predigested invalid foods (P. I 85 ), six meals daily being given.

3. A Light or Convalescent Diet, consisting of the light, nutritive, and more-casily digested foodstuffs-e.g., milk, fish, chicken, tripe, bread, invalid foods, milk puddings, and stewed fruit; green vegetables, red meats, pastry, rich sauces, etc., are withheld. An illustrative dictary is here given :-

Brealifiest-

Milk, flavoured with tea or coffee.

liread and butler, or toast and butter.

Gruel, or Hominy, or Farina ; or lightly-cooked egg or steamed fish.

Dinner-

Soup ; meat- or chicken-tea or broth, thickened with barley or rice (sce p. 302). J)ry bread or toast.

Fish or chicken.

Judding made from invalid food, p. 185 ; or well-made milk pudding, p. 297 ; or stewed fruit-apples, prunes, rhubarb, Teq or gooseberries or plums passed through a sieve.

Milk, flavoured with tea.

Rusk, or sponge biscuit. 
Sufper-

A cupful of gruel, p. 296 ; or malted gruel, p. ISI ; or invalid food, p. 184; or beef-or chicken-tea thukened, p. 176, with a slice of toast.

4. Lacto-Vegetarian or Farinaceous Diet, from which animal food, with the exception of milk and butter, are cxclucled (sec p. 526).

5. Protein or Nitrogenous Diet, from which starchy and saccharine foods are very largely excluded, consisting mainly of meats, fish, esgs, with a specified small amount of starchy foods in the form of dried bread, toast, or rusks, arranged as follows :-

Breakfast-

Tea or coffee.

One slice of toast with butter, and Kalari biscuit (p. 476).

Eggs, bacon, ham, longue, or fish.

Dinner-

Soup from meat stock (pp. 73, 271), crisp toast or rusk.

Fish, fowl, game, meat, with cauliflower, spinach, lettuce, celery, or tomato.

Curds, custard, jeliy, souflé, or stewed fruit.

Supper-

Repetition of dinner, two courses being taken.

6. Ordinary ur House Diet, as in I Iospital Diet, p. 546. 

A P PENDIX 



\section{FOREWORD TO APPENDIX}

TIIE following record is not presented as in any sense a completed piece of work. It is admittedly incomplete. It comprises a series of papers which have been published in the past few years on the influence of diet on the structure of the tissues. They are refublished in the present form in the hope that the record may stimulate further investigation along a line of research which has already yiclded the interesting and suggestive results here recorded.

It is many years since John Hunter demonstrated, in a specimen preserved in the Royal College of Surgeons, that in a gull which had been fed for a year upon grain the muscular coat of the stomach became thickened; and many other examples could be cited from the regetable and animal worlds to illustrate the special effects of food variations upon growth and development. So far as the author is aware, however, there has previously been no systematic attempt to ascertain the nature of the changes induced in the tissues by diet. It will be observer that these changes have been found to be of a striking character, affecting many organs of the body in a somewhat complicated and inconstant manner. The published observations deal especially with the influence of an exclusive meat diet administered in the uncooked form, and it is of interest to note that similar results have been obtained in a more recent series of observations, as yet unpublished, on the influence of an erccssize meat diet, which more closely approximates to the diet in use in the human subject (p. 612). 
It was originally intended to make observations on the bacterial flura in the digestive tract, and also on the resistance of the animals to certain peisons under the different regrimes, but this part of the research was not carried out. The recently published interesting and suggestive results of Herter and Kendall, referred to on page $I 7$, and the still more recent results recorded by Reid Hunt on the effects of a restricted diet and of various foods upon the resistance of animals to certain poisons, indicate the importance of attention being directed to these lines of the investisation.

1 have to express my great indebtedness to the different investigators who have collaborated with me, and whose results are incorporated in this record. I have also gratefully to acknowledge the assistance and encouragement continuously received from Professor Schäfer throughout the whole series of the investigations.

The expenses of these investigations, which were begun in 1898 , have been in great part defrayed by grants from the Moray Fund of Edinburgh University, and from the Carnegie Trust.

II WALKFR STRlet, Noiember tylo. 


\section{TABLE OF CONTENTS}

APPENDIX

PAC:

I. Stimulation of the Thyroid and l'arathyroid Glands by a Protein Dietary (Raw Meat) • • • . 557

II. The Effects of a Protein Dietary (Raw Meat) • • 558

111. The Influence of a Meat Diet on the Thyroid and Parathyroid Glands . . . . . . . 564

IV. The Influence of an Excessive Meat Diet on Growth and Nutrition . $\quad . \quad$. $\quad . \quad$. 565

V. The Influence of a Meat Diet on the Thyroid Gland in the Second Generation of Meat-Fed Rats

VI. The Effect of an Excessive Meat Diet on the Osseous System of Rats . . . . . . . 576

VII. The Inflence of an Excessive Meat Diet on the Development and Structure of the Teeth . . . 577

VIII. The Influence of an Excessive Meat Diet on the Skin of Rats . . . . . . . . . 578

1X. The Influence of a Meat Diet on the Kidneys • . $57 \mathrm{~S}$

$X$. The Effects of I)iet on the Development and Structure of the Uterus . $. \quad . \quad . \quad 587$

XI. The Influence of an Excessive Meat Dict on the Male Reproductive Organs . . . . . . 589

XII. The Influence of an Excessive Neat Diet on the Osseous System . . . . . . . . 590

X11I. The Effects of a Mieat Diet on Animals and on their Irugeny . . • . . . 
AFFSTIT

XIV. The Influence of Jiet on the I.iver

XV. A Note on the Minute Structure of the Thyroid Gland in the kat. . . . . . 600

Xivl. The Effects of an Oatmeal Diet on the Thyroid Gland . 602

XV11. The Changes in the Structure of the Thyroid Gland in

Wild Rats uncler the Influence of Altered Dietetic Conditions

XVIll. A Note on the Adrenal Gland in the Rat . . . 605

XIX. The Effects of Captivity on the Adrenal Gland in Wild Rats . . . . . . . . 607

$X X$. The State of the Ovaries during Lactation, with special reference to the Luteal Tissue . . . . 608

XX1. The Effect of a Meat I) iet on Fertility and Lactation . 608

XXIl. A Rich Protein I)iet in Relation to Gout and the Thyroid Gland . . . . . . 612

\section{LIST OF AUTHORS}

Chitmers Watson, M.D., F.R.C P.E.

A. Dingwall, Fordyce, M.D., F.R.C.P.E.

G. W. Watson, L.I.S., and J. H. GHus, F.R.C.S., L.D.S.

F. Garuiner, M.D., F.R.C.S.E.

ANDREW HUNTER, M.I), and G. LYON, M.I.

Malcolm Camphell, M.I., F.R.C.S.E.

C. H. I'AU1, F.R.C.S.E.

B. I'. Watsox, M.D., F.R.C.S.E. 


\section{APPENDIX}

\section{1.-STIMULATION OF THE THYROID AND PARATHYROID GLANIS BY A PROTEIN DIETARY (RAW MEAT). ${ }^{1}$}

THE research which furnished these results was primarily an experimental research on gout (l'reliminary Note). It consisted in feeding a number of fowls on a diet strictly limited to raw lean meat with a liberal supply of water. Under this regime the animals succumbed at periods varying from three to sixteen months, the terminal symptoms being usually of a paralytic character. All the animals with one exception (No. 4) showed very pronounced disturbance of the cutaneous system, ruffling and loss of feathers, in the course of the experiment. My attention was incidentally directed to an examination of the thyroid and parathyro:d glands in the last four cases of the series.

Parathyroid glands. In two cases, Nos. I (cock) and 2 (hen), after sixteen and fourteen months' meat diet respectively, the parathyroid glands were enormously enlarged, and appeared as large globular masses. The weight of one gland from each case was $.095 \mathrm{gramme}$ and - ro gramme respectively. On microscopic examination these masses showed the normal structure of the parathyroid gland. In No. 3 (cock), after fourteen months' meat dietary, the gland was also much enlarged, but less than in the preceding cases. Its structure was normal. In the remaining animal, No. 4 (hen), after fourteen months' meat dietary, the parathyroid glands were not visible.

Thyroid gland.-In Nos. I and 2 the thyroid glands were much enlarged, being eight times heavier than normal, the weights being $\mathbf{I} \cdot 25$ and $\mathrm{I} \cdot 15 \mathrm{grammes}$ respectively. (The average weight of six glands from healthy fowls was i 4 gramme.) Microscopically these glands presented the appearance of normal thyroid tissue, the size of the spaces being, however, in parts larger than usual. In No. 3 the thyroid gland was enormously increased, one gland weighing 9.5 grammes, the other 3.5 grammes; both lobes showed hremorrhages, more especially the larger gland. In No. 4 the thyroicl was not enlarged; microscopically the gland appeared normal. This animal had been less affected by the diet than any of its companions. It had steadily gained in weight in place of losing as the other animals had done. The terminal symptoms were strikingly different from the other cases, being similar to those produced by strychnine poisoning. The liver was studded with small caseous nodules, varying in size from the head of a pin to a pea. Bacteriological examination proved their tuberculous nature.

\footnotetext{
1 Chalmers Watson, Journal of I'hysiology, vo! xxsi., 1yo4.
} 


\section{II.-THE EFFECTS OF A PROTEIN DIETARY (RAW MEAT).}

\section{(An Faperinental and Clinical Study.)}

The object of this paper is to record the clinical and pathological appearances observed in an experimental research on prolonged feeding of fowls on a diet of raw meat. The main facts to which attention will be directed are :-

1. Negative.-The absence of any indications of gout (uratic deposits).

2. Positive.

(a) The variety in the clinical and pathological features observed in the different subjects.

(b) The lesions in the thyroid and parathyroid glands and bonemarrow.

(c) The very favourable manner in which one fowl affected with well-marked tuberculosis was influenced by the diet.

This research was begun with the object of confirming or otherwise the interesting research of Kionka on avian gout. It may at once be stated that the results obtained did not confirm those described in Kionka's record ; the experiment was unsuccessful so far as the induction of gout was concerned. This negative result is of itself of much interest ; the interest is enhanced by the changes incidentally observed in the thyroid glandular system, the bone-marrow and other tissues in the non-tuberculous fowls, and by the distinctive character of the reactions in the tuberculous subject.

Details of the experiment. - The observations were begun on roth March 1900 , and consisted in feeding eight fowls, six hens and two cocks, on a diet of raw lean meat and water. Four of the fowls were a year old, and four were just under two years of age. The subjects were of a common farmyard stock. For the first six months seven of the fowls were kept in the country, the animals being confined in a hen-run by the side of a wall, the floor being composed of natural soil. This enabled the animals to have a fair amount of exercise, and also to supplement their diet by grit and other material from the soil. The remaining fowl, a cock, No. 6, was kept in an iron cage in the Physiological Department of the University during the whole course of the observations.

The fowls were fed on raw lean ox-meat and a liberal supply of water. About the third month an attempt was made to substitute horse-flesh (which had been cooked for purpose of preservation), but this was abandoned, partly on account of the difficulties in obtaining the meat, and partly because this form of diet was not readily taken by the animals. Some sand and small grit was supplied from time to time. The observations continued until July 1901, a period of sixteen months.

Clinical history.-For the first few months the fowls took the diet greedily, the average amount of meat taken by each fowl being rather

1 Chalmers Watson, Medico-Chirurigical Transactions, London, 1904. 
more than three-quarters of a pound per diem. In the later stages the appetites were not so keen, and at intervals the anmals ate much less heartily, this defect in the appetite being usually associated with other symptoms. The hens appeared to thrive all right for the first few weeks, but about the sixth week slight indications of ill-health set in. This was manifest in a very slight and just perceptible lameness, which later became more pronounced in one of the younger hens (No. 3) and one of the older birds. This tendency to lameness remained more or less throughout the whole course of the observation, but in the case of No. 4 it was not manifest after the fifth month. On several occasions when the lameness was distinct there was a manifest increased heat in the affected limb. A little later the fowls showed a greater tendency to sit, and would rest on the ground for much longer periods than was natural. They roosted each night.

Eggs.-At the outset of the observations the number of eggs markedly increased, this increase persisting for about four wecks, when a gradual diminution set in, terminating in complete cessation. The yolks of the egus became particularly pale; a baked custard and a dish of scrambled egres made with them were perfectly void of colour, and appeared more like thick curds. After four months of the dict the eggs were not edible, on account of decomposition-changes which were revealed in the process of cooking.

Skin.-In about six weeks from the outset the feathers of some of the birds became disarranged. The tails drooped, and the birds appeared out of sorts generally. Several of the fowls lost many of their feathers ; one fowl was almost denucled of its feather covering, the loss being hastened by its companions picking off the feathers. About this time the fowls showed a marked tendency to pick the lime off the walls, and continued doing so for some time. The cutaneous disturbance is shown in the illustration (Fig. I).

Combs. - The combs of all the fowls became pale in colour, indicating anemia. The degree of pallor varied, and was not constant. In some cases it was associated with great duskiness of the comb in its most dependent parts. An examination of blood-films taken just before death from two fowls, Nos. 3 and 6, showed very striking deficiency of white blood-corpuscles.

The later history of the eight fowls may be summarised :-

(a) At the end of six months wo of them were returned to the yard in apparent perfect health.

(b) Two had succumbed to acute nervous derangements at the fourth and seventh months respectively. The animals went off their food, showed symptoms of paralysis and defective co-ordination, rapidly became unconscious, and died. No gross lesions were observed at the post mortem; there was no trace of uratic deposits. The macroscopic and microscopic records are not so complete as in the later group.

(i) Of the four remaining fowls, which were subsepuently observed in the laboratory of the Physiological Department of the University, the 
chart illustrates the records of weights. Attention is specially directed to the following points:-

1. No. 4 steadily satined in weight in place of losing, as in the other cases. This subject had, throughout the course of the observation, shown a much greater tolerance of the diet than its fellows. At the post-mortem examination this fowl wats found to be tuberculous.
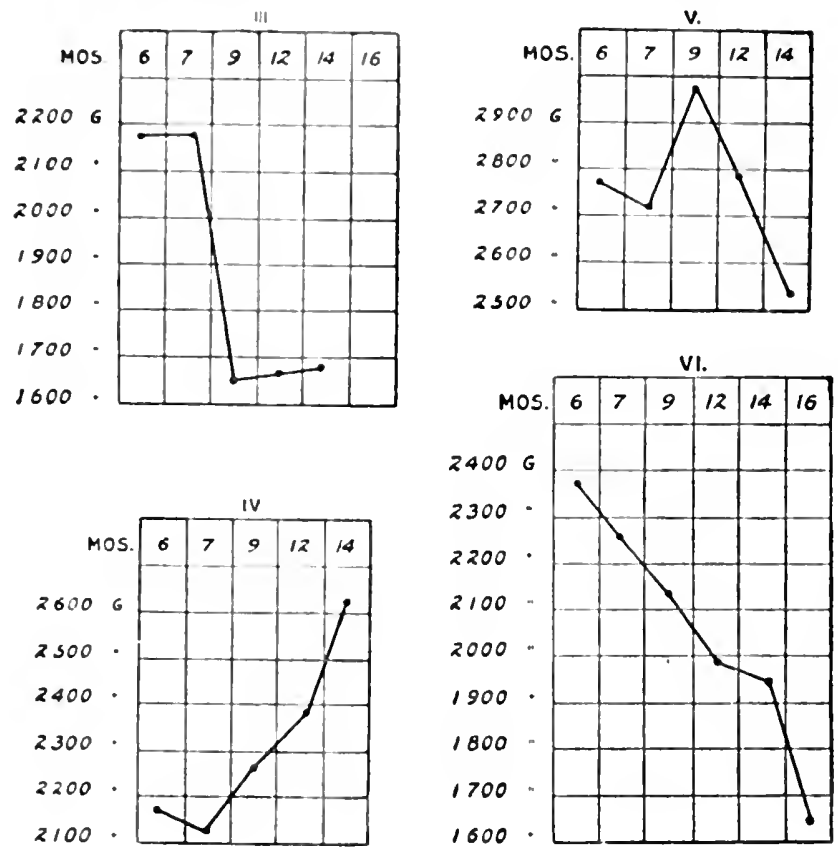

Record of weights of four fowls fed on raw meat for fourteen to sixteen months.

Nos. III., V., and VI, shosed great hypertrophy of thyroid and parathyroid glands. In No. IV. these glands appeared normal; this fowl was affected with intestinal and heparic tuberculosis.

2. While the other animals lost weight, the loss in the case of No. 6 was rematralbly steady and continuous (see chart). This animal was unique in showing profound atrophic changes in the intestinal tract. This animal was fed in the laboratory throughout the whole course of the experiment.

The terminal historics are of interest. No. 3, which all along had been the most injurirusly affected by the diet, was killed on the fourteenth month on account of the supervention of a third attack of paralysis. These attacks were characterised by marked paralysis and loss of appetite, lasting about a week; they were spontaneously recovered from witlout any clange in the regine. Fig. I illustrates the paralysis, and 


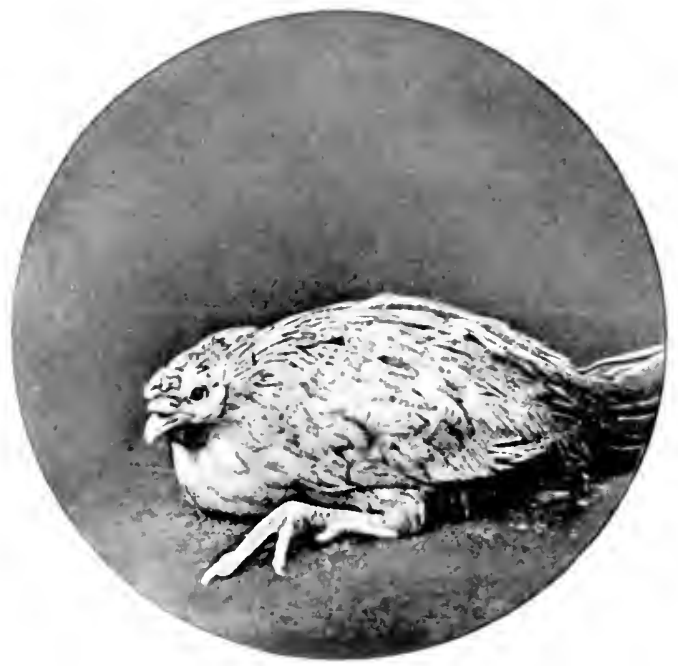

FiG. I illustrates a paralytic attack which developed after six months' ran-meat diet, and also at later intervals (see p.559). Note also the cutaneous disturbance. 

also the cutaneous disturbance present during one of these attacks. It will be observed that the paralysis involved manly the extensors of the limb.

No. 4 remained remarkably well until the end of the thirteenth month, when it appeared ailing. It rested much and ate less. At the end of the fourteenth month it developed symptoms very similar to those of strychnine poisoning (opisthotonos, spasms, etc.), but with this distinction, that the symptons did not appear to be aggravated by handling the animal. The terminal symptoms in this case were unlike those seen in any of the others.

No. 5 (cock). - At the thirteenth month symptoms of distinct paralysis (acute) were manifested, the weakness heing much more pronounced on one side. The animal could not maintain itself in the sitting posture, but fell invariably to one side. The gencral nutrition of the animal had been fairly well maintained, and the loss of weight was not considerable.

No. 6 (cock, black).-The general nutrition of this animal was poor. Many of its feathers had gradually assumed a brown tint; the comb showed a combination of pallor and duskiness. The fowl became paretic, and it was observed that in walking the right leg was raiscd higher and put down more sharply than its fellows, Blood-films taken before death showed very pronounced leucoponia.

Before passing from the consideration of the clinical picture, reference may be made to the striking absence of the clinical features of gout. The occasional lameness and increased heat in the affected limbs were the only symptoms which in any way resembled those of gout. Both the subsequent history and the entirely negative post-mortem evidences show that the attempt to induce gout was entirely unsuccessful. If any doubt exists on this point, that will be dispelled by a reference to the illustrations of Kionka, which show the presence of marked uratic deposits in the limbs of animals in which these local symptoms had been much more severe than in the author's observations. It is worthy of note that Kionka only succeeded in inducing gout in a small proportion of his cases.

\section{Pathological Appearances.}

An examination of the wo fowls that succumbed at the fourth and seventh months respectively revealed no gross lesions. There was no trace of uratic deposits in the articulations or other tissues. The serous membranes, liver, spleen, kidneys, and heart showed no abnormality. Histologically the livers showed a moderate degree of cellular infiltration along the portal tracts and bile ducts, witl considerable deposit of pigment throughout the organ. The renal epithelium contained many fine pigment granules. The spleens werc not enlarged; they showed some pigment deposit. There was no trace of vascular disease in any of these organs, and their parenchyma generally presented a normal appearance. As the examination of these cases was, however, especially directed to the presence or absence of manifestations of gout, the actual records are less complete than in the langer number of cases which survived for longer periods. 
No. 4 fowl, after fourteen months on raw-meat diet. The general nutrition was gool (see chart). All the organs and tissues appeared healthy, with the following exceptions:-

(a) The liver was studded with small caseous-looking nodules, which varied in size from the head of a pin to a small bean. Microscopic cxamination (and the application of suitable staining methods, carried out for me by Mr Kichard Muir, of the Pathological Department of the University) revealed their tuberculous nature.

(b) The lowest part of the ileum, for a distance of 6 inches, showed numerous small circular ulcers. On histological examination characteristic tuberculous nodules were seen in the mucous, submucous, and muscular coats; the ulcers were produced by the extrusion of small cáscous masses.

(c) The bone-marrow was unduly dark in colour, and microscopically was of a leucoblastic type. The microscopic examination of the spleen, kidneys, heart, thyroid, pancrcas, and muscular system revealed no abnormal appearances.

Similarly, the examination of the spinal cord at three different levels, kindly made for me by I)r Ford Robertson, failed to reveal any indication of $(a)$ desease of the vessels, or (b) degeneration of nerve-fibres (Marchi and Weigert-Pal methods). The systemic vessels generally appeared perfectly healthy, with the exception of one artery (sciatic), which showed a well-marked patch of endarteritis. This may have been due to a previous thrombosis.

Fowls 3, 5, and 6.-After fourteen and sixteen months' raw-meat diet. No trace of gout was present. These fowls, unlike the former, showed some pronounced lesions. Of these the only changes common to all of them were found in the thyroid and parathyroid glands. The thyroid gland was much enlarged in the case of Nos. 3 and 6 (see Fig. 3), and enormously so in No. 5. The reights of the two glands in the last mentioned were 9.5 grammes and 3.0 grammes respectively. Histological examination showed :-

i. Increase in size of the vesicles, which were filled with colloid substance which stained perfectly (see Fig. 2, and compare Fig. 3).

ii. Diminution in the intervesicular glandular tissue.

iii. Increase in the number of cells in the wall of vesicles.

The enlarged glands in No. 5 showed well-narked hamorrhages into the vesicles. The parathyroid glands were very markedly enlarged in all three cases, more especially in Nos. 3 and 6 (see Fig. 3). Normally these glands are not visible to the unaided eye; in these three animals the glands stood out as more or less globular masses distinctly larger than a pea (see Fig. 4). Histologically the sections presented the appearance of normal parathyroid tissue.

Bone-marrow. - Very striking changes were found in the bony system in two cases (Nos. 3 and 6). In No. 3 the long bones were increased in thickness, and irregular on their surface; the femora were markedly curved. On section of the long bones it was found that the marrow had almost entirely disappeared (see Fig. 5), being replaced by 


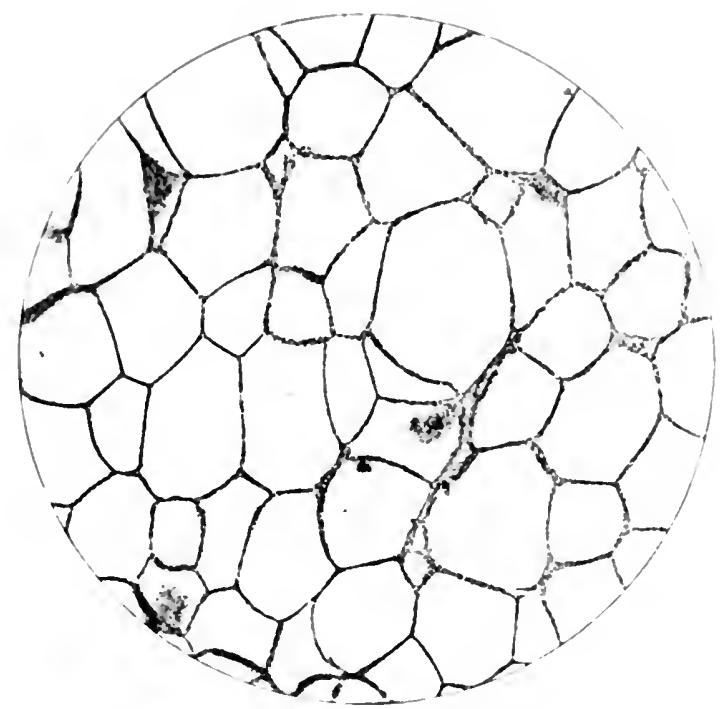

FIG. 2 - Thyroid Gland after It monthe' raw-meat diet. ( 50.) (\% Fig. 3. Ob-erse-i. 'l'he increase in sizm uf the wateln.

ii. The iner'anel thiekness of wall of resielps.

iii. The disalyearance of the intervesicular glandular tione.

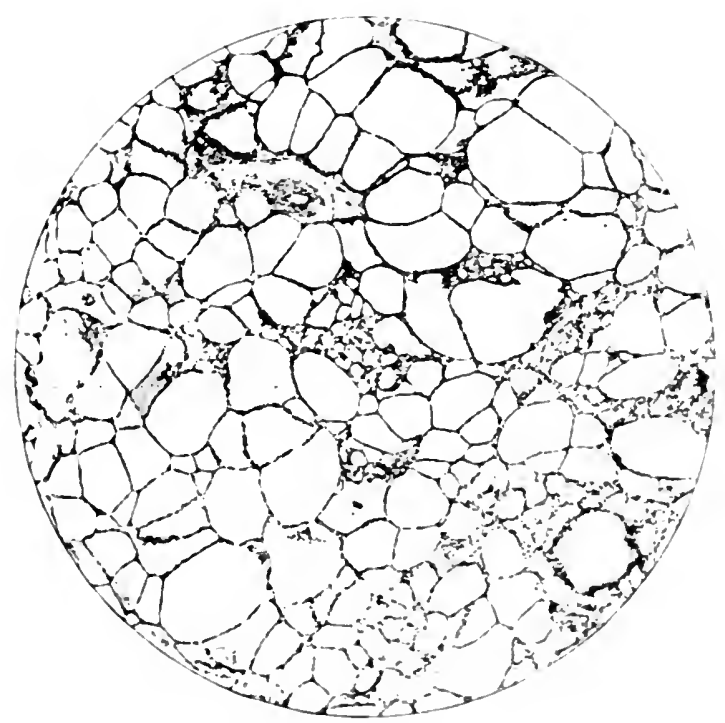

F1G. 3.-Thyroid Gland from normal Fowl. ( $\left(5_{0}\right.$.) ( \%. Fig. 2.

Observe-i. The size of the vesicles.

ii. The thickness of walls of the sugicles

iii. The large anount of intervesicular glandular tissue. 

fairly dense tissue. On microscopic examination the appearance was remarkable (see Fig. $7^{\prime}$ ). The marrow proper was replaced by a non. cellular tissue presenting some of the characters of an osteoid tissue; a similar appearance was seen in the outer part of the bone (see Fig. 7). The large masses apparently represent much altered llaversian spaces, the appearances being due to an infiltration of some substance which stains pink with picro-carmine. Chemical examination showed a great increase in the proportion of organic matter. The appearances in the bone in No. 6 were of a similar character, but less pronounced. The marrow in No. 5 appeared unusually soft in consistence and dark in colour. It was not submitted to microscopic examination.

Other organs and tissues.-No uniform lesions were present; the organs were for the most part normal. The following lesions were, however, noted :-

I. The intestinal tract in No. 5 showed very pronounced atrophic changes.

2. The duodenum in Nos. 5 and 3 was dilated.

3. The liver in No. 6 showed great amount of pigment.

4. The heart in No. 3 appeared to be hypertrophied.

The systemic vessels throughout showed no indications of disease of any of their coats; the vessels in the muscular system showed no abnormal appearance; and the same has to be said of the vessels in the spinal cord. There was no trace of degeneration of the nerve-fibres in the cord ; in one section in No. 6 some minute capillary hamorrhages (recent) were present in the grey matter.

The points to which attention is specially directed are the hypertrophy of the thyroid and parathyroid glands in all the three healthy fowls, and to the freedom for such enlargement in the tuberculous subject. These remarkable changes in the thyroid and parathyroid cannot, it seems to me, be looked upon as an accidental circumstance void of significance on the dietetic regions in rogue. The hypertrophy of these glands is interpreted as the result of the raw-meat dietary. The recent work of Hericourt and Richet, on the special value of raw meat as a curative agent in tuberculosis suggests that in the tuberculous fowl the excessive meat diet was made use of to neutralise the tuberculous toxamia.

The negative features of interest are $(a)$ the entire absence of uratic deposits; $(b)$ the absence of renal disease, and $(c)$ the healthy state of the blood-ressels throughout the system. These last two negative features have significance in relation to the commonly accepted view that a nitrogenous dietary leads to general vascular and renal disease.

' From stained sections kindly made by Dr Carnegie Dickson, of the Pathological Department of the University, it is seen that the large dark areas in the section represent concentric laminx of imperfectly developed bone, the older lamina staining faintly, the younger ones deeply. The Haversian spaces are reduced in size, and as the spaces become narrowed the vessels are obliterated. The spaces are roid of osteoblasts and osteoclasts, and contain simply fat and an artery and vein. 


\section{II.-THE INFIUENCE OF A MEAT DIET ON THE THYROII ANI) HARATHYROII GLANIOS.'}

In view of the results obtained from an investigation on the influence of a raw-meat dict on the thyroid and parathyroid glands in fowls, it was lecmed advisable to repeat the investigation with other animals, $c . g$. rats. Twelve animals were used for this experiment, with eight controls. lileven of these were young subjects, their ages at the outset of the olservations ranging from six to welve weeks; the twelfth was a full-grown rat of unknown age. Except in the case of the adult rat, the control suljects were taken from the same litter as the animals placed on special diet. This diet consisted of raw minced ox-ment and water, as mucl meat being griven as the animals would consume; the diet of the control cases consisted of bread and milk and occasionally porridge, also in unrestricted amount. The investigations lasted in some cases six weeks, in others four months. The results may be summarised.

Clinical.-For the first ten days or so all the rats on meat diet either lost weight or failed to increase in weight like the control subjects. Subsequently six of the meat-fed animals put on weight to an amount almost equal to that of the control subjects ; in the remaining six animals the final record was considerably short of the figures for the bread-andmilk-fed rats. E.g. in one experiment which lasted six weeks, the three animals on the meat dict gained 14 grammes, 15 grammes, and 41 grammes respectively; as against 62 grammes in the case of the control. All the animals appeared in grood health, with the exception of the adult rat, which lost weight markedly and died in three weeks.

Thyroid gland.-Macroscopic changes. In three cases there was a distinct increase in the size and weight of the glands, the glands in two instances weighing just double the weight of the control. In the adult meat-fed rat the grland was distinctly diminished in size. In the remaining eight the general appearance of the glands was normal except in one case, in which the parathyroid glands were double the size of any of the control glands.

Microscopic changes. In ten out of the twelve animals definite histologrical changes were present, these consisting of: ( $I$ ) Active proliferation of the cpithelium of the vesicles. (2) Congestion of bloodvessels. (3) Mucoid degeneration of the colloid material and of the epithelial cells. In some cases there was also distinct enlargement of the vesicles. The colloid material was diminished in amount. In the adult meat-fed rat the colloid sulsstance had practically disappeared, the general appearance of the gland being one of pronounced atrophic catarrh. The histological changes were most pronounced in the animals which had failed to increase in weight like the control subjects.

Parathyroid glands. - In one out of the twelve animals the parathyroid glands were obviously enlarged, and the microscopical appearanres of this gland were abnormal, the epithelial cells being widely separated by large clear spaces, which wcre apparently areas of mucoid

' Chaliners Watson, Journal of Physiology', vol. xxxil., 1 yo4. 


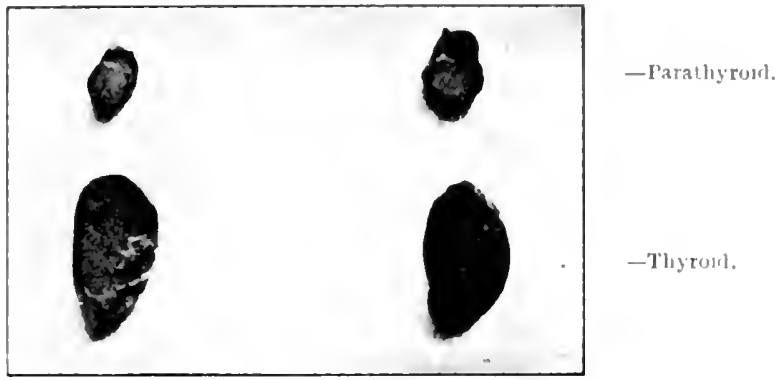

FiG. 4.-Great hypertrophy of thyroid and parathyroid glands after prolonged feeding on raw meat. Weighi of one parathyroid gland (Nos. III. and VI.) was 095 and . 0 gramme. Weight of one thyroid gland (Nos. III. and VI.) was $I \cdot 25$ and $I \cdot I 5$ grammes. The average weight of a normal thyroid is .14 gramme.

Transverse section of normal temur at the same level-

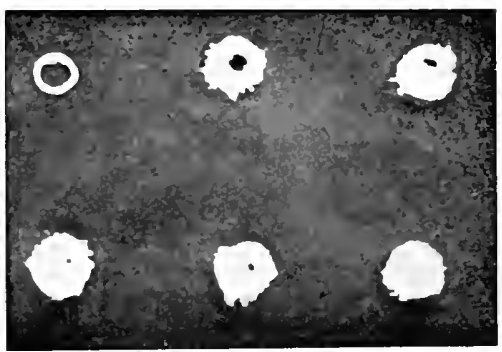

FIG. 5.- To show the changes in the osseous system after fourteen months' raw meat-five sections.

Otservo-i. The increase in thickness of the bone.

ii. The diminution and obliteration of the marrow cavity, due to the formation of an osteoid tissue, see 1. 562. 



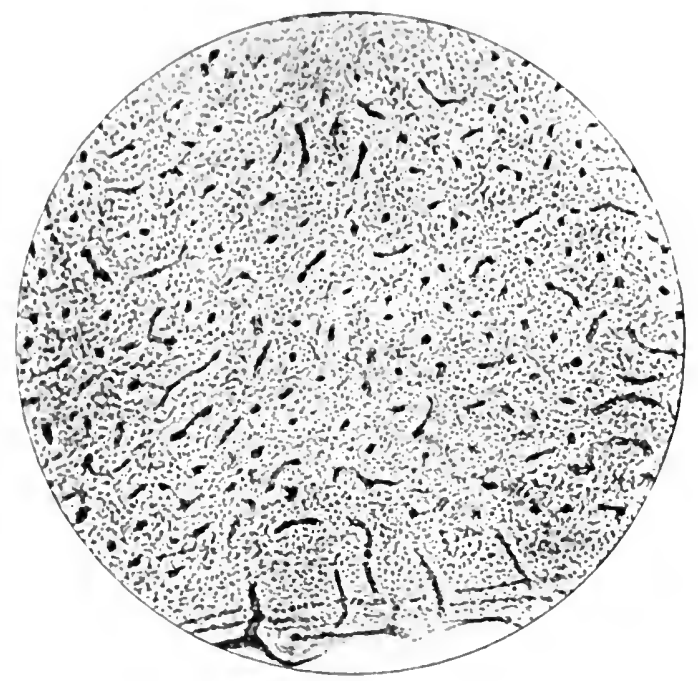

Fli. 6. Trinsverse section of the normal bone seen in Fig. 5, for comparison with Fig. 7.

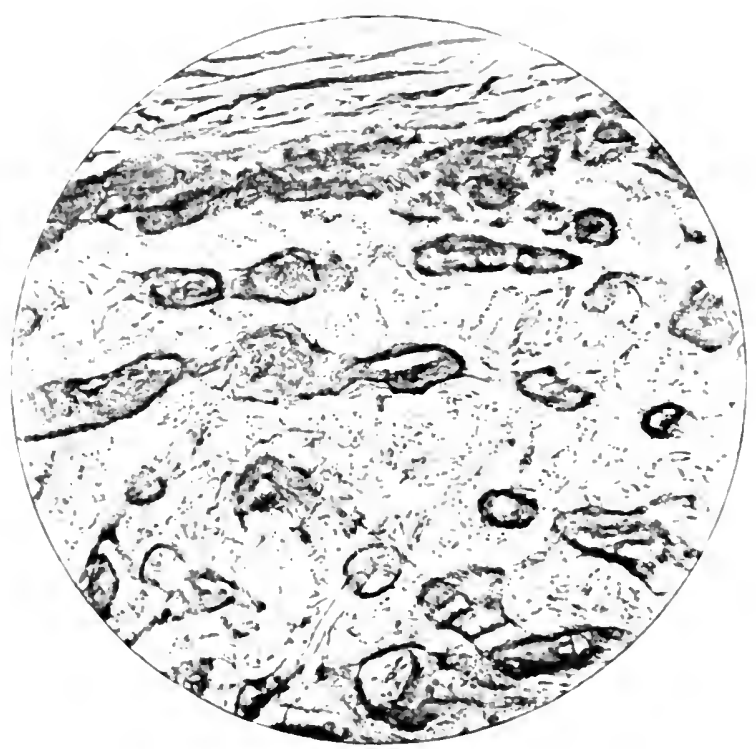

Fig. 7.- Transierse section of the abnormal bonc in Fig. 5 S.ame magnification as in Fig. 6. Unstained. 

degeneration. A much less degree of the same change was observed in one of the control glands. The parathyroid glands of the meat-fed adult rat were lost in the process of preparation. In the remaining ten cases the histological appeitrances were normal.

The general results may be summarised as follow:-

I. The administration of a meat diet to young rats is followed by distinct histological changes in the thyroid gland; this result, although very frequent, is not however a constant one.

2. The changres in the glands are most pronounced in the case of those animals which do not gain in weight at the same rate as the normal animal.

3. The parathyroid glands were in the great majority of cases unaffected by the diet.

4. In the case of an adult meat-fed rat, the animal succumbed after three weeks of the diet, the general appearance of the thyroid gland indicating exhaustion of its functions.

\section{IV.-THE INFLUENCE OF AN EXCESSIVE MEAT DIET ON GROWTH AND NUTRITION.'}

In a paper published in 1905 attention was drawn to the increase that had taken place in the consumption of animal food in this country in the past fifty years. It was there pointed out that the amount of meat imported into this country had increased from 3 lbs. per head per annum in 1853 to 50 lbs. per head per annum in 1903 -a very remarkable increase. A consideration of these figures suggests the question, What amount of animal protein is requisite for the healthy nutrition of normal subjects? The results of Chittenden's recent researches on the amount of protein requirements in health have clearly shown that in some important respects the teaching of the text-books on diet is erroneous and have shown the necessity of, in the words of a leading writer, reconsidering our conclusions on diet from their foundations. The necessity for such a reinvestigation has further been demonstrated by the results of some preliminary observations on diet, investigated from a new standpoint, published by me in 1904-5, which showed that the administration of an excessive meat diet to normal animals was followed by striking histological changes in the thyroid grand. This evidence of structural change in the thyroid gland under a meat diet indicated the advisability of repeating the experiments on a larger scale. I have during the past year made an extensive series of observations on the influence of a meat diet on $(a)$ the growth and general nutrition, and $(b)$ the structure and functions of the organs of a large number of animals. The present paper deals with the former; it gives an account of the clinical results obtained by feeding rats on an exclusive flesh diet and also some comments on the bearing of these resuits on some clinical phenomena in the human subject. The diets employed were ox hesh

I Chalmers IVatson, Lancet, vol, ii., 1906. 
and horse-hesh, with bread and milk as the control diet. The chemical composition of thene dietaries was determined hy Dr Andrew Hunter, assintane in the physiologiont laboratory of the University of Edinburgh, and is elsewhere given in letail.' The essential ficts are summarised in the following table :-

\begin{tabular}{|c|c|c|c|c|c|}
\hline Ox-flest & & $\begin{array}{c}\text { Protelil. } \\
\text {. } 49\end{array}$ & $\begin{array}{c}\text { Fat. } \\
46\end{array}$ & $\begin{array}{c}\text { Isrbolyyirate. } \\
\text { t } 05\end{array}$ & $\begin{array}{c}\text { Salts. } \\
2 \cdot 2\end{array}$ \\
\hline Horse-flesh. & ${ }^{\circ}$ & - 81 & 14 & $1 \cdot 7$ & $2 \cdot 4$ \\
\hline Bread and milk & • & 18 & 4 & $73 \cdot 1$ & 3.9 \\
\hline
\end{tabular}

Bread and milk is the diet in common use for tame rats, and the control det used in this experiment was found to be admirably adapted for the growth and nutrition of rats of all ages. In connection with the experimental diets it may be mentioned that under certain conditions-e.g. in the neighbourhood of abattoirs - the diet of wild rats is mainly one of flesh food of different kinds. Some control observations were made on the influence of the two dietaries (horse-flesh and bread and milk) on wild rats. The eftects of the diet were studied in animals of different ages as follows: ( $t$ ) on very young rats newly weaned (three weeks old), the controls being taken from the same litter-twenty-five rats with nineteen controls; (2) on young rats, approximately two and a half months old-twenty-two rats with twelve controls; and (3) on full-grown adult rats-fourteen rats with ten controls. In the investigations special attention was directed to the following points: (a) the effects of the diet on the growth and nutrition of the meat-fed animals; $(b)$ the health of their offspring ; and $(c)$ the recuperative power of a norma! diet in animals which had deteriorated as a result of the meat-feeding.

Ox-flesh.-1. The effect of an ox-flesh diet on very young rats.Fourteen young rats from five litters, newly weaned, were placed on an exclusively ox-flesh diet, eleven rats from the same litters being used as controls (bread and skimmed milk diet). Five of the meat-fed animals succumbed within four months, their weights and date of death being indicated on Chart 1 . The remaining nine animals lived and appeared to thrive, but they gained in weight less than did the controls. Two representative illustrations are griven. These show the relative sizes of two male rits of the same litter after being fed for three months on bread and skimmed milk (Fig. 8a) and ox-flesh (Fig. $8 b$ ) respectively. The general appearance of these nine ox-flesh-fed subjects was in all respects normal ; it was, however, observed that some of them moved about in a less lively manner than did normal animals. This lessened activity was associated with, and apparently dependent upon, changes in the osseous system of a rachitic-like nature which were revealed at the post-mortem examination. In the meat-fed animals (litters four and five) four were females, and although kept with males none of them became pregnant, whereas of the three control females from the same litters all bore litters. These results admit of the following conclusions:-1. Very young rats, newly weaned, can in the majority of cases live and thrive on an

\footnotetext{
1 Journal of Physiology, vol, xxxiv., No. 12.
} 

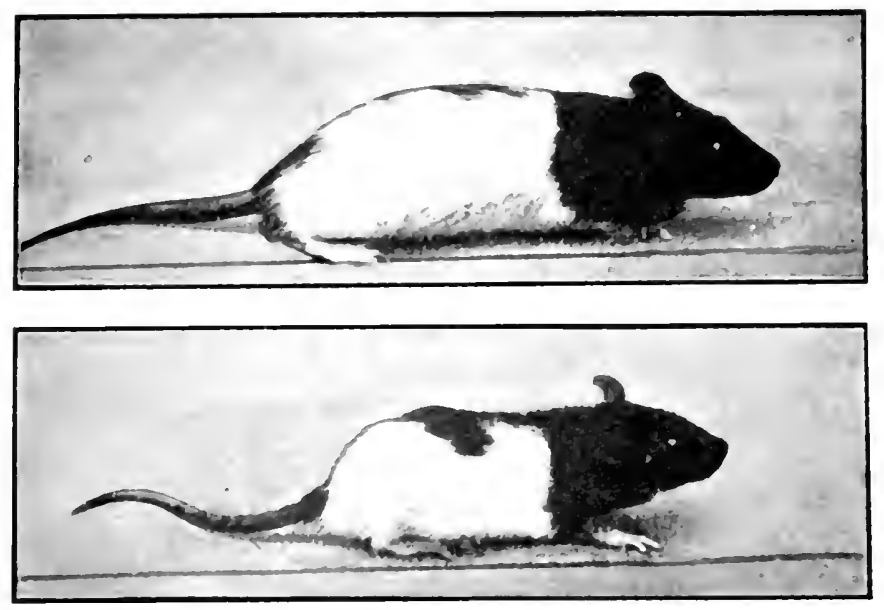

EIG.S. To show the relative -ize of two male ruts if the a ame litter after being fed for three months un lreid and simmed milk (a) and ox-lle-h (i).
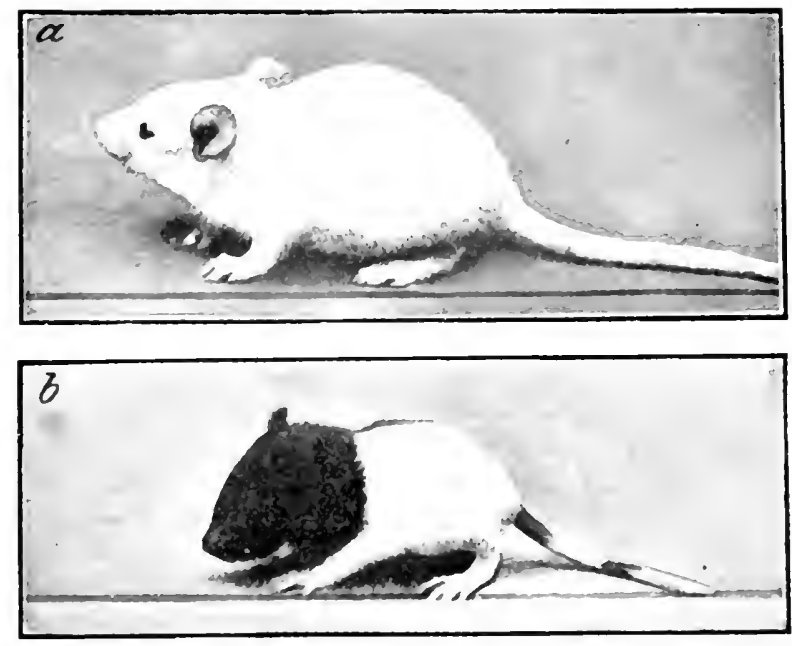

Fic. 9.-To show the stute of development of the prugery of nomally fed (hread an i milk) rat: (1) in comparison with rats of the same age hred on a flesh diet (b). 

exclusive ox-flesh diet; their growth is, however, retarded by this dietary.

2. An ox-flesh diet interferes with the development of pregnancy.

11. The effect of an ox-jle'sh die't on young rats from two and a half to three months old.- Fight rats of an average weight of 65 grammes and approximately two and a half months old were fed on an exclusively ox-

\section{Chart i.}

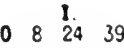
11.
III.
IV.
v. $0 \quad 14294559 \quad 0300192102$
014285283106
03162103

170

160

150

140

130

120

110

100

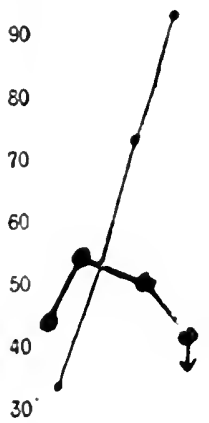

20
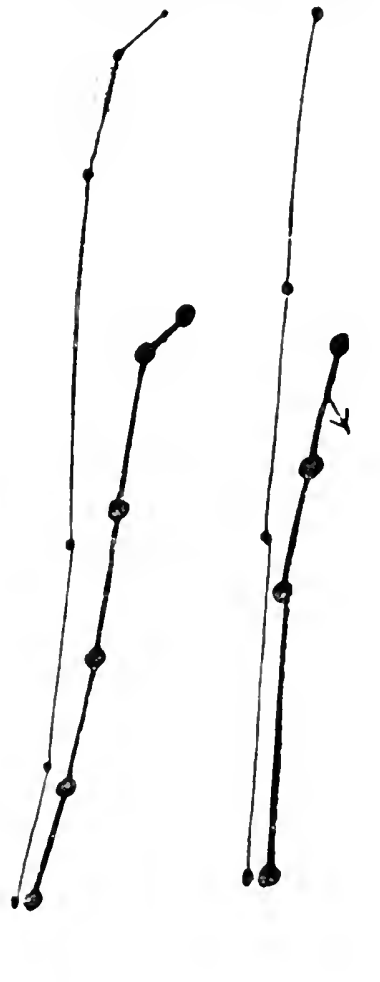

The influence of an ox-Itesh diet on very young rats newly weaned. The dark line equals the average weight of the ox-flesh-fel rats. The arrows indicate deaths. The faint line equals the average weight of the coutrol (breal-and-milk-fod) subjects.

flesh diet, four subjects of similar age and weight being used as controls. The meat-fed animals thrived, and were, with one exception, alive and in apparent health after six months of this feeding. They gained in weight more than the controls (see Chart 2). With the exception of four which became inordinarily fat, all the meat-fed subjects appeared to be in a perfect condition throughout the whole period of observation. 
Horse-fish. - 1. The influence of a diet of horse-Resh on zery young ruts.- Eleven animals from live litters were fed on horse-flesh, eight rats from the same litters being used as controls (bread and skimmed milk diet). Eight of the eleven nreat-fed animals succumbed after a few wecks' diet; the remaining three died within four morths. The control subjects lived and thrived. The weight curve of one meat-fed subject is not included in the chart. These results, which are graphically represented in Chart 3 , show that a diet of horse-flest arrests the growth of, and is speedily fatal to, very young rats.

II. - The influence of horse-flesh on young rats approximately two and a half months old. - Fourteen youmg rits about two and a half months old were placed on a meat diet, eight control aminals of a similar age and weight being fed on bread and skimmed milk. Six of the meat-fed

\section{CHART 2.}

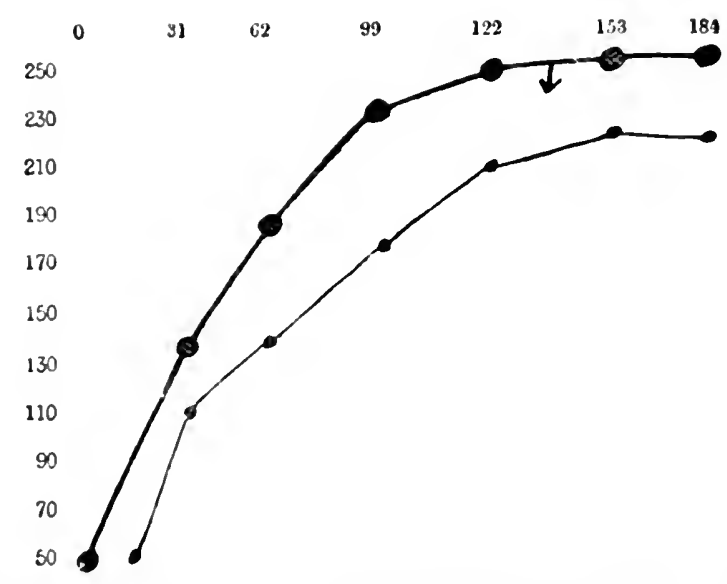

Tho influence of an ox-flesh djet on young rats, the dlet baing commeneed when the animals wore betwent two and three montls oll. The dark line entuals the averago of eight oxHeshleft] rats. Tlue arrow indicatea a death. The faint line equals the average of four

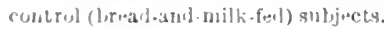

subjects succumbed on the third day. On the morning of this day the rats appeared to be in their usual health. An hour after feeding one of them was fying on its side apparently unconscious. In a few minutes others were affected. They appeared to be paralysed. They felt cold to the touch, exhibited symptoms of tetany, and speedily became unconscious. Six succumbed within half an hour. Of the remainder some slowed similar symptoms, although in a less degree, and they recovered when the diet was changed to bread and skimmed milk. After two days of the normal diet the remaining rats (five males and three females) were again placed on an exclusively horse-flesh dict. Under this regimen they now gamed weight as shown in Chart 4. They exhibited symptoms 
of deranged nutrition such as accelerated and noisy respiration with tendency to "pot-belly," but these symptoms were in the majority of animals recovered from. The females became pregnant and gave birth to four litters. At the end of the eiglath month the animals were alive and in apparent good healtb, their average weight, however, being below the normal (Chart 4). The restults of this observation may be sum. marised as follows:-1. An exclusive horse-tlesh diet was fatal to about

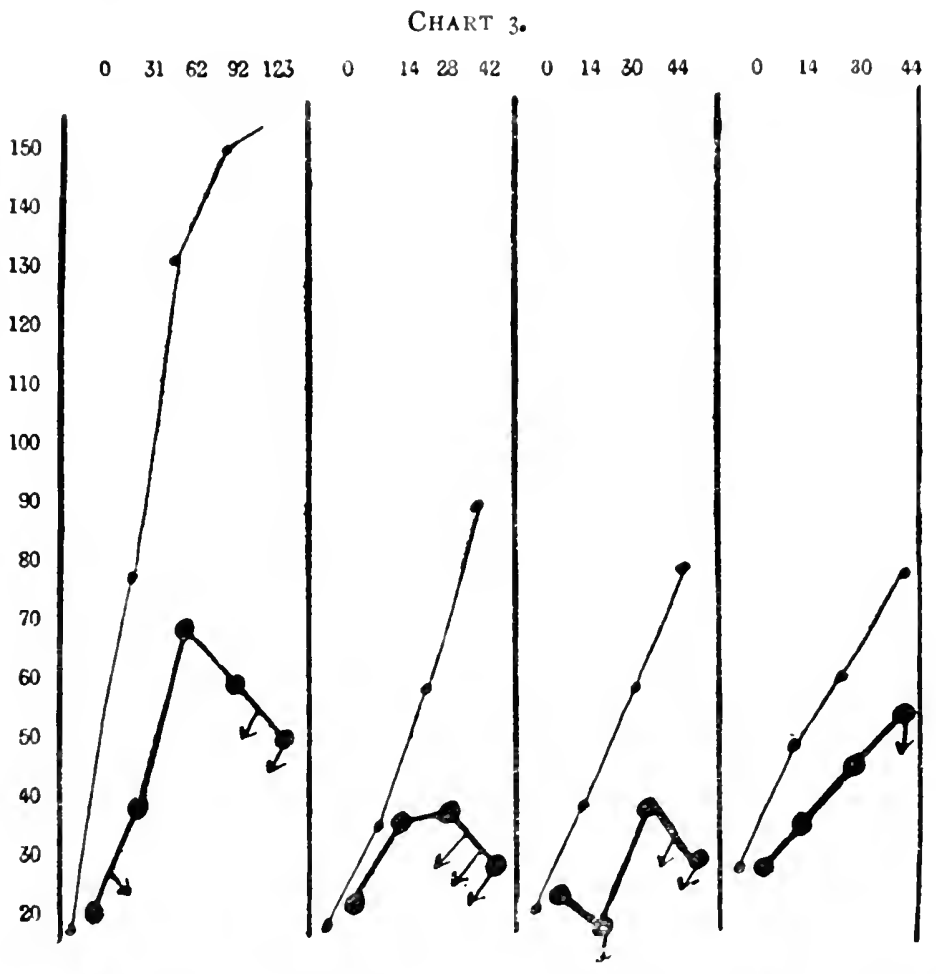

The influppe of a horse-flegh dipt on very young rats newly weaned. The dark lines equal the avarage weight of eleven horse-Hesh-foll rats. The arrows inlicate deaths. The funt lines eifual the average weight of eight control (breal-anul-milh-fell) subjects.

50 per cent. of young rats two and a half months old, death occurring within a few days, with symptoms of acute toxic poisoning. 2. In the remaining 50 per cent. the animals became accustomed to the diet and appeared to thrive on it, but their growth was permanently stunted, the maximum weight of the horse-flesh-fed being distinctly below the control bread and skimmed-milk-fed subjects. 3. The use of this diet in animals of this age appears not to affect the supervention of pregnancy.

111. The effect of horse-flesh diet on adult rats. - Nine adult rats of an 
arevage weight of 210 grammes were put on an exclusively horse-flesh diet on $276 \mathrm{~h}$.1.arth. On this dict their weight wats well maintained (see Chan 5). Two succumbed in five months, the remainder being then in fair but by no means perfect condition, the most striking abnormality being the rough condition of the skin. In some cases the rate of respiration was increased, this symptom varying in severity from time to time. The general result of this observation show's that the exclusive horseDesh diet maintains the body-weight of adult rats in the majority of cases (seven out of nine); and also that the general nutrition of the flesh-fed animals was below that of the control hread and skimmed-milk-fed subjects.

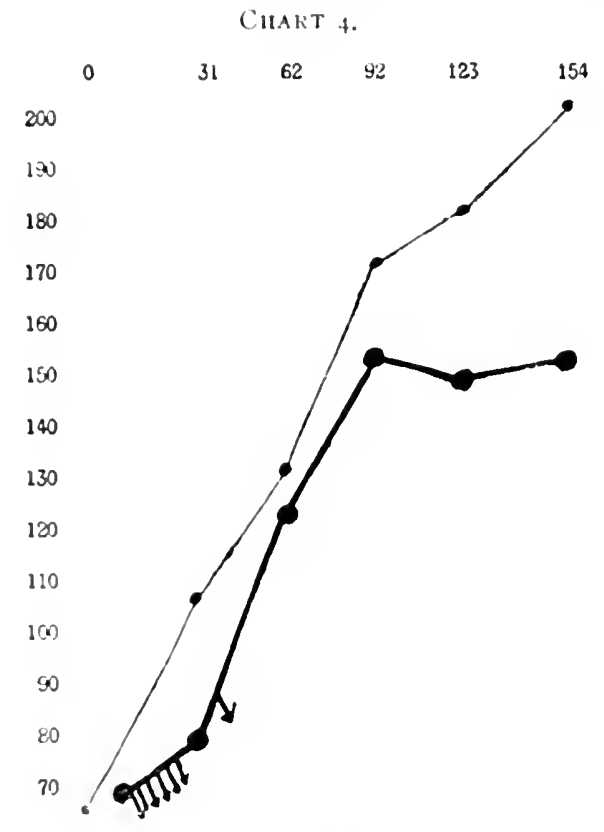

The influegce of a burspeflesh dive on young rats, the diet being commenced when the

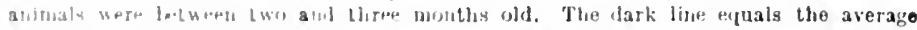

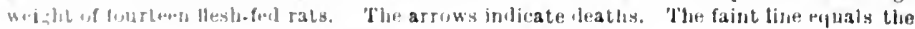
average weinht of eighl coulrul (breal-aid-anilk.feil) subjects.

The effets of a meat diet on pregnancy and lactation.-I have already submitted evidence bearing on this subject. It has been shown that when an ox-flesh diet is commenced at a very carly period of life pregnancy does not supervene, as in animals on a normal diet. Snme further points of interest are supplied in the following record of one animal which had four litters in 1905. This animal, on a bread and skimmed milk diet, had a litter of nime on $22 n d \mathrm{~A}$ pril. This litter lived and thrived. After weaning, the mother was transferred to an exclusively horse-tlesh diet. P'regnancy supervened, and a second litter, also of nine, 
was born on $13^{\text {th }}$ June. None of the second litter survived longer than two months. The horse-flesh die: was continued, and a third litter, six in number, was born on zoth July. These sucrumbed within one unonth. The mother was then transferred to the normal breat and skimmed milk regimen, and while on this diet a fourth litter, eight in number, was born, all of which lived and thrived. In this and other meat-fed subjects it was observed that the mammary glands were less developed than in breadand-milk-fed rats.

The influence of a meat diet on the progeny.-The progeny of meatfed rats are usually poorly developed, and slow a high mortality in early life. Some statistics on this point are given. Of ninety-three rats born of meat-fed parents (ox-flesh and horse-flesh), nineteen (2o per cent.) were alive at the end of two months; while of ninety-seven rats born of breadand-milk-fed rats, eighty-two ( 8.4 per cent.) were then alive and in apparent health. The state of development of the progeny of bread-andmilk-fed rats (Fig. $9 a$ ) in comparison with that of meat-fed subjects

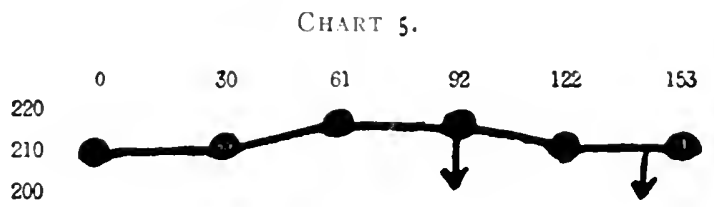

The influence of a borse.flesh diet on adult rats. The lark line represents the average weight of nine alult rats fed for live months on a horse-llesh diet. The arrows indicate death:

(Fig. $9^{b}$ ) is illustrated in Fig. 9, p. 566, for animals six weeks old. The meat-fed animal (Fig. 9b) was puny and ill-developed, with scanty hair and dry skin, a picture of general marasmus. It died two weeks after the photograph was taken. One of the thirteen meat-fed litters (an ox-flesh litter) was a striking exception to the general rule. When two months old this litter, nine in number, appeared to be in perfect health, their average weight and general appearance being quite up to the normal standard. The high mortality in early life of the second generation of meat-fed rats is probably due in yreat part to the defective power of lactation in the mothers.

The recuperative power of a normal diet.-Some observations were made on the recuperative power of a normal diet in animals which hat deteriorated in consequence of having been fed for some time on an abnormal dietary. The results in the case of flesh-fed animals were in this instance controlled by comparison with those obtained from animals fed on $(a)$ an exclusively rice diet, and $(b)$ an exclusively porridge (made with milk) diet. Observations were made on animals of both the first and second generation.

A. In the first generation.-After the primary observation on each diet had been in progress for five weeks and the natural course of events in each group had been determined, an average representative of the rice-fed, flesh-fed, and porridge-fed animals was taken and put on a diet 
of bread and mucet milk, the amount of each loeing unrestricted. This was dome on fith lune. At this tinc the animals showed marked evidence of returled growth and a considerable legree of respiratory embarrass. ment. The change of diet was immediately followed by a marked increase in the rate of growth, this being pronounced in all three cases (see (hart 6). The improvenent in the general condition of the animals was associated with an improvement in the respirations, which became less frecuent, less noisy, and with fewer accompaniments. The subject which was originally fed on rice died after five weeks of the new diet; the other wo were alive and in fair health in the middle of October. It has to be noted, however, that their average weight in October was 136 grammes, considerably less than the awerage of a healthy bread-andmilk-fed subject of the same age. The results of this observation showed

\section{CIIART 6.}

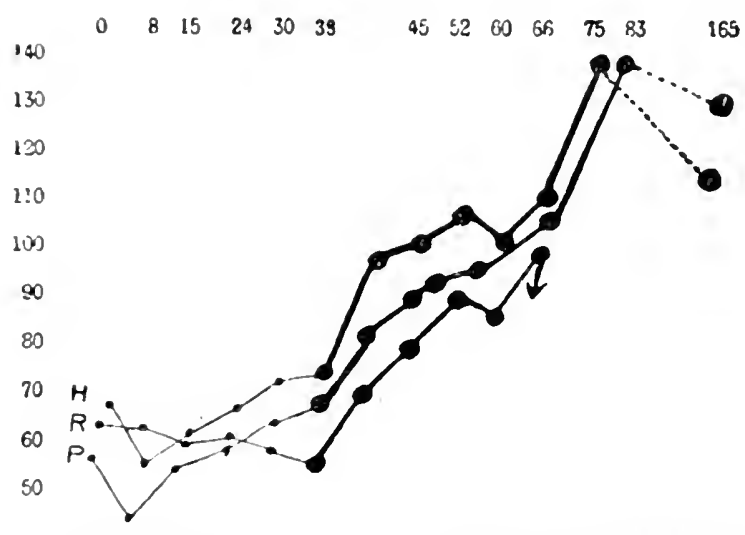

The efpets of a lieal aud areet milk diet on young rats firfionaly fol on an abnormal dietary. The curbes ripresont the weights of threw young rats that were fol on porriclge, rice, and liorse-thesh rapectively for live wewa, and were then transferred on the thirty-eighth day Lis a breal and swetet milk diet.

that the change of diet to bread and sweet milk in all three subjects was followed by a rapid and marked improvement in the general condition and also by a marked improvement in respiration. The recovery from the respiratory embarrassment was, however, not complete. It also showed that the growth of the animals had been permanently stunted by the use of the abnormal dict in early life.

With the object of testing the immediate results observed to follow the change of diet, another animal was taken from each group and was fed on the control diet of bread and skimmed milk. Chart 7 shows the record of weight of these animals for the period of six weeks, during which they were fed on rice, porridge, and horse-flesh diet respectiveiy, and thereafter on the control diet. The condition of the rice-fed subject when removed was such that our experience led us to believe that it 
could not live more than, at the outside, one or two days longer on that diet. After the change of diet there was a rapid and immediate improve. ment in the condition of all three animals. The result was even more striking than in the case of the three animals the diet of which had been changed to bread and sweet milk (see chart). All three animals were alive and in fair condition in the middle of October, their average weight at that time ( $13 \delta$ grammes) being, however, below the normal.

B. In the second generation.-The recuperative power in the second generation of meat-fed rats was tested in four animals taken from two litters, other four animals from the same litters being enployed as controls. After weaning, the eight were kept on a horse-flesh diet for two weeks; in this period their weight was little more than maintained

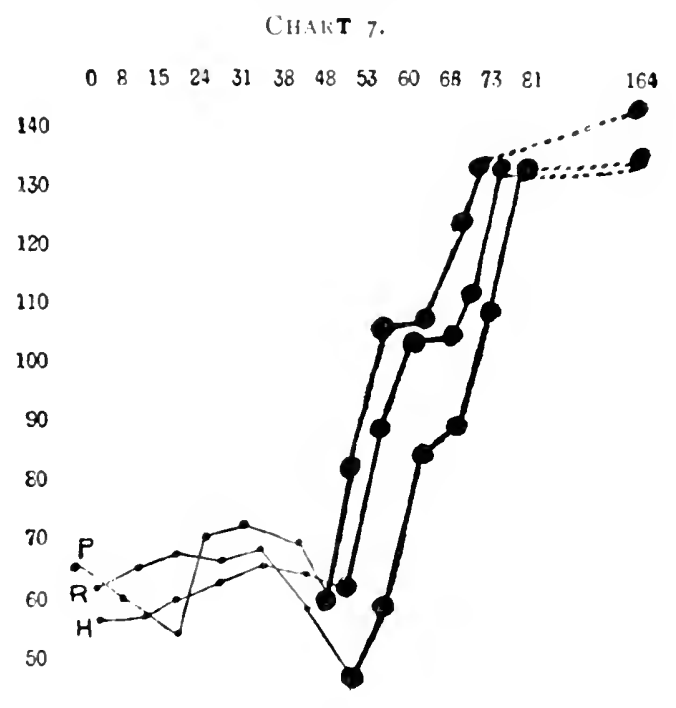

The influence of a bread and skimmed milk diet on young rats previously fed on an abnorma] dietary. The curves represent the weight of three young rats that were fed on norricige, rice, and horie-flesh respectively for sis weeks, and were then (furty -eighth day) transferred to a bread and skimmed milk diet.

(see Chart 8). Two from each litter were then transferred to a bread and skimmed milk dietary, the remaining four being kept on the horse-flesh diet. All four meat-fed subjects succumbed in two to three wecks, the four transferred rats living and gaining in weight in the striking manner shown on the chart. The later history of these four rats is of great interest. The animals were killed when eight months old, their average weight being 150 grammes. Their health during the later months was very defective, the symptoms manifested being, in order of onset and severity, (a) accelerated and noisy respirations, dry râles being audible a considerable distance from the hutch; and $(b)$ a dry condition of the 
skin, with roughness and loss of hair. These clinical features considered alongside of the other facts recorded in this paper point to the general conclusion that the symptoms from which the animals suffered in later life were etiologically related to the use of the defective dietary in very carly life. There can, it appears to me, be no reasonable doubt that the symptoms observed were the result of the premature loss of some vital function or functions, and more especially of those concerned in warding off bacterial infection from the respiratory, and probably also the alimentary, tract.

Summary of results. - These experiments prove that the excessive use of a meat diet in rats is attended with the following results: (1) growth

\section{Chart 8.}

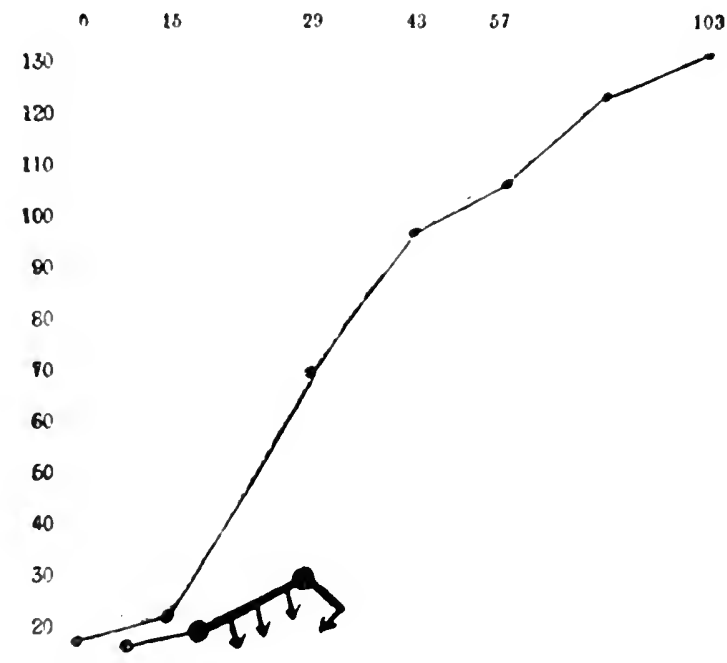

Reciperatue jower in sacond :meration of meat. [u] rats. Thu faint llne oquals the average

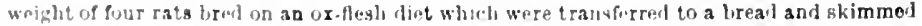
milk diet at the age of six weeks. The dark line equals the average weight of four rats from the same litters which were not trassferred but were kept on the meat dict.

is retarded; (2) sterility is induced if the diet is commenced in very early life; (3) the power of lactation is diminished; (4) a permanent weakening of the resisting power of the animals is induced by the use of an excessive meat diet in early life, the animals succumbing to disease at an unusually early age; and (5) there is a high death-rate in the offspring of animals fed on an excessive meat diet.

Commentary. - The facts recorded have an interesting bearing on the two questions of physical deterioration and high infantile mortality that are engraging medical attention at the present time. With regard to these conditions there is no doubt that not one but several factors are concerned in thoir production. There is equally little doubt that among 
these factors the question of diet occupies a foremost place. The defects in a diet may lie in one of several directions. The food may be of fair nutritive value but insufficient in amount; on the other hand, it may be of high nutritive value, excessive in amount, and of a nature which exercises an injurious effect on the organs and tissues. It is important that some light on this subject should be looked for from experimental medicine, and in view of the increasing prevalence of the consumption of animal food in this country it is of special importance to determine the effects on the organism of an excess of animal protein food. The main interest of my experimental results lies in the clear evidence submitted that an excessive meat diet can itself induce in animals-whose dietetic habits are fairly akin to those of man-some of the most prominent symptoms of physical deterioration-viz., defective general physique, deficient power of lactation, diminished fertility, and a high infantile mortality. I believe that these symptoms are, to an important extent, comparable to those prevailing in the human subject at the present time, the symptoms in man having, however, been established in a more gradual manner, their onset being contributed to by the operation of other etiological factors.

Some points of practical importance are brought out in the record. Of these the most noteworthy is the importance of a proper dietary in very early life. My experiments showed that the use of an excessive meat regime in early life induced a serious and permanent weakness of the animals, which, however, remained for a long time latent after the substitution of a physiological dietary. Clinical experience has led me to think that we have here also a close parallel in diseases in the human subject, and more especially in the class of affections commonly included under the terms gout and goutiness. He that as it may, the experimental results indicate the importance of directing particular attention to the early dietetic history of patients so far as these are obtainable. The necessity for this will be further emphasised by the subsequent records of the structural changes in the organs and tissues observed in the course of these experiments.

\section{V.-THE INFLUENCE OF A MEAT DIET ON THE THYROID GLAND IN THE SECOND GENERATION OF MEAT. FEI) RATS.'}

In the Proceedings of the Physiological Society of 17 th Hecember 1904 (pp. 557, 564), the author gave a communication on the infuence of a meat diet on the thyroid gland of rats which had heen fed on meat for periods varying from six weeks to four months. The present investigation was undertaken to ascertain the effects of the same diet on the thyroid glands in the second generation of meat-fed rats. The thyroid glands of over fifty animals have been examined, with an equal number of controls. The ages of the rats varied from one day to three

1 Cbalmess Watson, journd of Physiology, vol. xxxiv. 
months; thinty of the series were under three weeks old, being unweaned at the time of death.

The histological appearances of the thyy roid glands of the meat-fed rats differed from those of the control glands. These differences were, as a rule, of a striking clanacter ; in a small minority (cight rats) they were mulh less pronounced. The main appearances observed were the following:-

1. Great congestion of the gland, with entire absence of colloid, and little or no attempt at vesicle formation, the gland being in an unusually embryonic state. This appearance was only observed in the case of animals which died in a fortnight after birth. Eight animals.

I1. An increase in the amount of the colloid, with thinning of the walls of the vesicles from pressure. This appearance was most pronounced in the case of animals whose weight and general nutrition at death was above the average of meat-fed subjects. Ten animals.

111. A diminution or entire absence of colloid with degeneration and shedding of the secreting cells. This condition was specially marked in the case of animals whose general nutrition was obviously defective. Fourteen animals.

IV. Types of glands illustrating a transition between II. and III. were found in ten animals.

The results of this investigation confirm the author's earlier observations in showing that an excessive meat diet induces structural changes in the thyroid gland. They further show that these changes may be present to a striking degree in very young animals (unweaned) which had not directly partaken of a meat regime.

\section{VI.-THE EFFECT OF AN EXCESSIVE MEAT DIET ON THE OSSEOUS SYSTEM OF RATS. ${ }^{1}$}

Object of the investigation. - To detcrmine what changes, if any, are induced in the osseous system by an excessive meat diet (ox-flesh).

.Method of observation.-Material cmployed :

(a) Newly-weaned rats.

(b) Young rats of meat-fed mothers.

(a) Diet of ox-flesh commenced on weaning rats, controls being obtained from equal number of same litter fed on bread and milk. Examinations at varying ages from one month to three months.

(b) Young of meat-fed mothers fed when weaned on meat flesh. Examinations at varying ages from one day to three months. Controls of corresponding age fed on bread and milk.

Nature of changes notid. Macrosiofical-

1. General softness of whole osseous system.

2. Increased vascularity.

'A. Dingwall Fordyce, M.D., Journul of l'hysiology, vol, xxxiv. 
3. Bread-like prominences at costo-chondral junctions and less frequently on ribs themselves.

4. Curvatures of the spine and long bones.

\section{Microscofical-}

I. Evidences of defective bone development, both intra cartilaginous and intra-membranous.

2. Markedly increased vascularity.

3. Changes in the bone-marrow.

V1I.-THE INFLUENCE OF AN EXCESSIVE MEAT DIET ON THE DEVELOPMENT AND STRUCTURE OF THE TEETH. ${ }^{1}$

The object of this investigation was to ascertain what effects, if any, were produced in the teeth of rats by an excessive meat diet. The material employed was :-

(a) A series of eiglit animals, which were fed on an exclusive ox-flesh diet for five months, the diet being commenced when the animals were weaned, six controls (bread-and-milk-fed) being examined from the same litters.

(b) Three rats, which were fed on an exclusive horse-flesh diet for five and eight months, the diet being commenced when the animals were about two and a half months old.

(c) A series of the second generation of meat-fed rats, thirty in number, with a like number of control subjects, the ages varying from one day to three months.

The methods of investigation were :-

I. A naked-eye examination of the size and general appearance of the teeth. tion.

II. Grinding down the teeth, and submitting to microscopic examina-

III. Comparison of the histological appearance of the decalcified tissues. This applies to the third series.

The general results may be summarised :-

In series $(a)$ and $(b)$ the enamel and the dentine of the meat-fed subjects are well developed, and, with one exception, show nogross defect Two of the controls show defects similar to the exception noted. An examination of series $(c)$ shows that the general development of the teeth in the meat-fed subjects is perhaps somewhat behind that of the controls.

It is, however, noteworthy that in the oldest animals examined-a litter of three rats - the histological appearances show no indication of retarded

1 G. W. Waison, L.D.S., and J. H. Giobs, F.R.C.S.E., Journal of Physiology, vol. sxaiv. 
grouth. We are $n o t$ in a position to express an opinion as to the rate of eruption of the teeth. A striking feature in our observations was the extreme softness of the bones of the jaws in the meat-fed animals, and in view of this alteration in the bones it is of interest to note the relatuely normal condition of the teeth.

\section{V11.-THE INHUENCE OF AN EXCESSIVE MEAT DIET ON THE SKIN OF RATS.'}

The skin of the progeny of meat-fed rats differs in the majority of cases from that of anmals bred on a bread-and-milk diet. In the latter the coats are thick and well nourished, while in the former there is evident coarseness and the hair is thin. In a very small percentage (one litter out of thirteen) the skin of meat-fed rats compared very favourably with that of the controls. The following investigation was undertaken to determine the microscopic appearances of the skin in young animals bred on the two diets. My observations have so far been confined to rats varying in age from one day to three weeks, twenty-eight being bred on bread and milk and thirty-seven on ox-flesh. Described briefly, the alteration in the skin is one of prolongation of the embryonic state in the meat-fed subjects.

The stratum corneum is less compact and more evidently in detachable layers.

The stratum granulosum shows no definite changes.

The stratum Malphigii shows in the normal bread-and-milk-fed rats a gradual condensation and consequert thinning as age advances; in the meat-fed rats the layers remain more or less swollen, the cells showing greater vacuolation and lessened staining capacity.

Ihis cutis vera shows a more cellular structure in all the meat-fed rats.

The hair is distinctly less advanced in development in the meat-fed suljects.

\section{IX.-THE INFLUENCE OF A MEAT DIET ON THE KIINEYS.}

\section{With Ilistological Report by G. LyON, and a Report on the Nitrogen Excretion by ANDRkw HUNTER. ${ }^{2}$}

Attention is here directed to the influence of a meat diet on the structure of the kidneys.

The diets employed were five in number-rice boiled in water, oatmeal porridge made with skimmed milk and water, uncooked horse-flesh, uncooked ox-Alesh, and a control diet of bread soaked in skimmed milk. The

I Frederick Gardiner, M.D., Journal of I'hyszology, vol. xxxiv.

"Chalmers Watson, Intemationaten. Monatsschrift für Anatome und Physiologie, bu. xxiv, 1907 . 
chemical composition and heat values of these foods were determined by Dr Andrew Hunter, and are given in a former section, along with the results on weight and growth of the animals. The present communication deals with the influence of a meat diet-horse-flesh and ox-fleshon the kidneys. Four series of observations were made as follows :-

I. On adult rats (seven) fed on a horse-flesh diet for five months. Thirteen controls were employed, seven being porridge-fed and six bread. and-milk-fed subjects.

II. On young a nimals (eight), the diet (horse-flesh or ox-flesh) being begun either when the animals were weaned, or at the age of two to three months.

III. On castrated female rats (five) xt. approximately six months, fed on a horse-flesh diet for four or five months. The controls were eight in number, five being rice-fed and three porridge-fed animals.

IV. On the second generation of meat-fed animals (horse-flesh and ox-flesh). This series comprises thirty-two animals of ages varying from twelve days to three months: it includes thirteen rats which had not been weaned.

The special points to which attention was directed were $(a)$ the weight of the kidneys, and $(b)$ their minute structure.

(a) The weight of the kidneys.

The weights are given in the form of tables. Each table records the number of animals on the meat and on the control diets, the total weight of the animals at death, their maximum weight during life, the total weight of the kidneys, and the percentage weight of the kidneys calculated from the weight of the animals at death. The duration of the special feeding and the mortality are also stated. As there are difficulties in the way of drawing deductions from the records of animals which had lost much weight during the observation, these are excluded, and attention is directed solely to the kidneys of animals which had not materially lost weight on the meat diet. In experiments I. and II., a certain loss of weight recorded in the case of the meat-fed subjects is balanced by a corresponding loss in the case of the controls.

TABle I.-Adult Rats.

\begin{tabular}{|c|c|c|c|c|c|c|c|}
\hline $\begin{array}{c}\text { No. of } \\
\text { Animals. }\end{array}$ & Diet. & Duration. & Nortality. & $\begin{array}{l}\text { Maxml } \\
\text { Weight. }\end{array}$ & $\begin{array}{l}\text { Weight } \\
\text { at } \\
\text { lwath. }\end{array}$ & $\begin{array}{l}\text { Weipht } \\
\text { of } \\
\text { Kiduegs. }\end{array}$ & $\begin{array}{c}\text { Per- } \\
\text { rentage }\end{array}$ \\
\hline $\begin{array}{l}7 \\
7 \\
6\end{array}$ & $\begin{array}{l}\text { Horse-llesh } \\
\text { Porriige. } \\
\text { Breadand molk }\end{array}$ & $\begin{array}{l}4-0 \text { mos. } \\
4-6 \quad " \\
4-6 \quad "\end{array}$ & $\begin{array}{l}2 \\
\mathrm{I} \\
\ldots\end{array}$ & $\begin{array}{l}1535 \\
1812 \\
1212\end{array}$ & $\begin{array}{l}1250 \\
1505 \\
1212\end{array}$ & $\begin{array}{l}16 \cdot+5 \\
16 \cdot 55 \\
12 \cdot 95\end{array}$ & $\begin{array}{l}1 \cdot 32 \\
1.017 \\
1.00\end{array}$ \\
\hline
\end{tabular}


Tant E. II.-Castratiat Fimale Rats.

\begin{tabular}{|c|c|c|c|c|c|c|c|}
\hline $\begin{array}{l}\text { No. of } \\
\text { Animsis }\end{array}$ & Diet. & Duration. & Mortality. & $\begin{array}{l}\text { Maxm. } \\
\text { Weight. }\end{array}$ & $\begin{array}{c}\text { Weight } \\
\text { at } \\
\text { Denth. }\end{array}$ & $\begin{array}{c}\text { Weight } \\
\text { of } \\
\text { kidneys. }\end{array}$ & $\begin{array}{c}\text { Per- } \\
\text { centage }\end{array}$ \\
\hline $\begin{array}{l}5 \\
5 \\
3\end{array}$ & $\begin{array}{l}\text { Ilorse-flesh } \\
\text { Rice } \\
\text { Porridge }\end{array}$ & $\begin{array}{l}4-5 \text { mos. } \\
4-5 " " \\
4-5 " ~\end{array}$ & $\begin{array}{l}4 \\
\mathrm{I} \\
. .\end{array}$ & $\begin{array}{l}825 \\
772 \\
470\end{array}$ & $\begin{array}{l}740 \\
740 \\
465\end{array}$ & $\begin{array}{l}9 \cdot 25 \\
7 \cdot 40 \\
4 \cdot 55\end{array}$ & $\begin{array}{l}1.27 \\
1.00 \\
1.02\end{array}$ \\
\hline
\end{tabular}

TAни: III.- Joung liats.

a. Meat diet commenced when the animals were two to three months old.

\begin{tabular}{|c|c|c|c|c|c|c|c|}
\hline $\begin{array}{c}\text { No. of } \\
\text { Animals. }\end{array}$ & Diet. & Iuration. & Mortality. & $\begin{array}{l}\text { Maxul. } \\
\text { Weight. }\end{array}$ & $\begin{array}{l}\text { Weight } \\
\text { at } \\
\text { Death. }\end{array}$ & $\begin{array}{l}\text { Weight } \\
\text { of } \\
\text { kidueys. }\end{array}$ & $\begin{array}{c}\text { Per- } \\
\text { centage. }\end{array}$ \\
\hline 3 & !lorse-flesh & 8 months & $\ldots$ & 525 & 525 & $7 \cdot 15$ & $1 \cdot 36$ \\
\hline I & Bread and milk & & $\ldots$ & 170 & 170 & 1.60 & 0.94 \\
\hline 3 & ()x-flesh . & $4 \quad 1$ & $\ldots$ & 471 & $47 \mathrm{I}$ & $5 \cdot 79$ & $1 \cdot 23$ \\
\hline 3 & Bread and milk & $4 \quad$, & $\ldots$ & $5+4$ & 514 & $4 \cdot 78$ & 0.88 \\
\hline
\end{tabular}

$b$. Diet commenced when the animals were weaned, the controls being from the same litter.

\begin{tabular}{|c|c|c|c|c|c|c|c|}
\hline $\begin{array}{c}\text { No. of } \\
\text { Animals. }\end{array}$ & Diet. & Daration. & Mortality. & $\begin{array}{l}\text { Maxm. } \\
\text { Weight. }\end{array}$ & $\begin{array}{l}\text { Weight } \\
\text { at } \\
\text { Death. }\end{array}$ & $\begin{array}{l}\text { Weight } \\
\text { of } \\
\text { Kidneys. }\end{array}$ & $\begin{array}{c}\text { Per- } \\
\text { centage. }\end{array}$ \\
\hline 1 & Ox-flesh. & 6 months & $\ldots$ & 135 & 135 & $2 \cdot 20$ & $1 \cdot 63$ \\
\hline I & 13read and milk & & $\ldots$ & 160 & 160 & 2.00 & $1 \cdot 25$ \\
\hline 1 & Ox-flesh & $6 \quad$, & $\ldots$ & 120 & 120 & 1.80 & $1 \cdot 50$ \\
\hline 1 & Bread and milk & $6 \quad$, & $\ldots$ & 175 & 175 & $2 \cdot 40$ & $1 \cdot 37$ \\
\hline
\end{tabular}

TAHLE IV.-Sccond Gcneration of Mcat-fed liats.

$a$. One litter of ox-flesh-fed rats at. three months, with an average weight of 68 grammes, the control series being rice-fed subjects whose srowth had been arrested by the use of the rice diet, their average weight being 68 grammes.

\begin{tabular}{|c|c|c|c|c|c|c|c|}
\hline $\begin{array}{l}\text { No. of } \\
\text { Animals. }\end{array}$ & Jift. & buration. & Mortality. & $\begin{array}{l}\text { Maxm. } \\
\text { Weight. }\end{array}$ & $\begin{array}{l}\text { Wright } \\
\text { at } \\
\text { Death. }\end{array}$ & $\begin{array}{l}\text { Weight } \\
\text { of } \\
\text { Kidpeys. }\end{array}$ & $\begin{array}{c}\text { P'er- } \\
\text { contage. }\end{array}$ \\
\hline 6 & $\begin{array}{l}\text { Horse-flesh } \\
\text { Mixed diet }\end{array}$ & 3 nonths & 3 & 412 & $4 I 2$ & $6 \cdot 67$ & $I \cdot 6 y$ \\
\hline 4 & $\left\{\begin{array}{l}\text { mainly rice } \\
\text { (nomeat) }\end{array}\right\}$ & $5 \quad 11$ & $\cdots$ & 275 & 275 & 3.15 & $I \cdot 14$ \\
\hline
\end{tabular}

' In all cases under this table the young were put on meat diet at weaning. The age given denotes age at death. 
b. One litter of three horse-flesh-fed rats art. three months, with one control of exactly the same age.

\begin{tabular}{|c|c|c|c|c|c|c|c|}
\hline $\begin{array}{l}\text { No. of } \\
\text { Animals. }\end{array}$ & Wiet. & Duration. & Mulatily. & $\begin{array}{l}\text { Maxm. } \\
\text { Weiglit. }\end{array}$ & $\begin{array}{c}\text { Weglat } \\
\text { at } \\
\text { llathl }\end{array}$ & $\begin{array}{l}\text { Wripht } \\
\text { of } \\
\text { libitiegs }\end{array}$ & 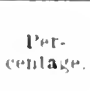 \\
\hline 3 & Horse-flesh. & 3 months & $\ldots$ & 270 & 270 & $4 \cdot 64$ & $I \cdot 7 I$ \\
\hline I & Bread and milk & $3 \quad 11$ & $\ldots$ & 150 & 150 & $I \cdot 50$ & $1 \cdot 00$ \\
\hline
\end{tabular}

$\therefore$ One litter of five ox-flesh-fed subjects xt. two months; the controls in this series were either fed on a bread and whole milk, or on a mixed diet containing a large amount of rice (no meat diet).

\begin{tabular}{|c|c|c|c|c|c|c|c|}
\hline $\begin{array}{l}\text { No. of } \\
\text { Animals. }\end{array}$ & Diet. & Duration. & Mortality. & $\begin{array}{l}\text { Maxm. } \\
\text { Weigllit. }\end{array}$ & $\begin{array}{l}\text { Weight } \\
\text { at } \\
\text { Death. }\end{array}$ & $\begin{array}{c}\text { Weight } \\
\text { of } \\
\text { Kilneys. }\end{array}$ & $\begin{array}{c}\text { Per- } \\
\text { centige. }\end{array}$ \\
\hline $\begin{array}{l}5 \\
6 \\
5 \\
4\end{array}$ & $\begin{array}{l}\text { Ox-flesh } \\
\text { Mixed dict } \\
\text { Do. } \\
\text { Bread and milk }\end{array}$ & $\begin{array}{l}2 \text { months } \\
3 \frac{1}{2} \quad " \\
33 \quad 1 \\
2 \frac{3}{2} " 1\end{array}$ & $\begin{array}{l}\cdots \\
\cdots \\
\cdots\end{array}$ & $\begin{array}{l}462 \\
700 \\
388 \\
291\end{array}$ & $\begin{array}{l}462 \\
700 \\
388 \\
291\end{array}$ & $\begin{array}{l}6.16 \\
5.60 \\
4.65 \\
3.00\end{array}$ & $\begin{array}{l}1 \cdot 33 \\
0.80 \\
1 \cdot 19 \\
1.03\end{array}$ \\
\hline
\end{tabular}

d. A series of five horse-flesh-fed rats from three litters, their ages varying from five to eight weeks.

\begin{tabular}{|c|c|c|c|c|c|c|c|}
\hline $\begin{array}{c}\text { No. of } \\
\text { Animals. }\end{array}$ & Diet & Duration. & Mortality. & $\begin{array}{l}\text { II } a \times m . \\
\text { Weight. }\end{array}$ & $\begin{array}{l}\text { Weight } \\
\text { at } \\
\text { Death. }\end{array}$ & $\begin{array}{c}\text { Weight } \\
\text { of } \\
\text { kidneys. }\end{array}$ & $\begin{array}{c}\text { Per- } \\
\text { centage. }\end{array}$ \\
\hline 5 & Horse-flesh. & $5-8$ wks. & 5 & $17 \mathrm{I}$ & 144 & $3 \cdot 24$ & $2 \cdot 25$ \\
\hline
\end{tabular}

e. A series of thirteen rats from three meat-fed mothers), that died before they were weaned; with eight controls (one litter).

\begin{tabular}{|c|c|c|c|c|c|c|c|}
\hline $\begin{array}{l}\text { No. of } \\
\text { Anlmals. }\end{array}$ & Diet. & Duration. & Mortality. & $\begin{array}{l}\text { Maxin. } \\
\text { Weightit. }\end{array}$ & $\begin{array}{l}\text { Wejght } \\
\text { at } \\
\text { Death. }\end{array}$ & $\begin{array}{l}\text { Weight } \\
\text { of } \\
\text { Kidneys. }\end{array}$ & $\begin{array}{c}\text { Per- } \\
\text { centage. }\end{array}$ \\
\hline 7 & Iorse-flesh . & 3 weeks & 7 & 75 & 75 & I. OI & $I \cdot 34$ \\
\hline 5 & Ox-llesh & & 5 & 52 & 52 & 0.86 & $1 \cdot 72$ \\
\hline 1 & Do. $\cdot$. & 3 & I & 10 & 10 & 0.17 & $1 \cdot 70$ \\
\hline 8 & Bread and milk & I 2 & $\ldots$ & I 20 & 120 & $1 \cdot 54$ & $I \cdot 2 S$ \\
\hline
\end{tabular}

A perusal of the above tables shows that the percentage weight of the kidneys is decidedly higher in meat-fed animals than in animals on a meat-free diet. A general summary of the results of the four series of observations is presented in Table $V$. Of fifty-two animals fed on a meat 
diet, the total weight was 4666 grammes, the total weight of the kidneys being 63.39 grammes, or 1.70 per cent.; whereas of tify-five rats on the meat-frce dies, with a tutal weight of erigs grimmes, the total weight of kilneys was 71.67 , or 1.03 per cent.

Tantr. L-General Summary of Results.

\begin{tabular}{|c|c|c|c|c|c|c|}
\hline & \multicolumn{3}{|c|}{ Flend liet. } & \multicolumn{3}{|c|}{ Control I hiets. } \\
\hline & $\begin{array}{c}\text { No. of } \\
\text { Ammals. }\end{array}$ & $\begin{array}{l}\text { Weight at } \\
\text { Death. }\end{array}$ & $\begin{array}{l}\text { Total } \\
\text { Wild of of } \\
\text { kidulys. }\end{array}$ & $\begin{array}{l}\text { No. of } \\
\text { Atimals. }\end{array}$ & $\begin{array}{l}\text { Weight at } \\
\text { Death. }\end{array}$ & $\begin{array}{l}\text { Weight of } \\
\text { kidneys. }\end{array}$ \\
\hline \multirow{5}{*}{$\begin{array}{c}\text { First } \\
\text { generation }\end{array}$} & 7 & 1250 & $16 \cdot 45$ & 13 & 2717 & $29 \cdot 5^{\circ}$ \\
\hline & 5 & 740 & $9 \cdot 25$ & 8 & 1205 & $11 \cdot 95$ \\
\hline & 3 & 525 & $7 \cdot 15$ & 1 & 170 & 1.60 \\
\hline & 3 & 471 & $5 \cdot 79$ & 3 & 544 & $4 \cdot 78$ \\
\hline & 2 & 255 & 4.00 & 2 & 335 & $4 \cdot 4^{\circ}$ \\
\hline \multirow{6}{*}{$\begin{array}{l}\text { Second } \\
\text { generation }\end{array}$} & 6 & +12 & 6.67 & 4 & 275 & $3 \cdot 15$ \\
\hline & 3 & 270 & $4 \cdot 64$ & I & 150 & 1.50 \\
\hline & 5 & $t^{62}$ & $6 \cdot 16$ & 15 & I 379 & 13.25 \\
\hline & 5 & 137 & 3.27 & $\dddot{8}$ & \%20 & $\cdots$ \\
\hline & & & & & & \\
\hline & 52 & +666 & $64 \cdot 39$ & 55 & 6895 & 71.67 \\
\hline
\end{tabular}

() 1.10 per cent., as compured with 1.03 per cent.

If we further compare the figures for the first and second generation of animals as given in Table VI., we find that the percentage weight of the kirlneys in the second generation of meat-fed rats is decidedly higher than in the first generation-the figures being $\mathbf{1} .59$ grammes against $\mathbf{1} \cdot \mathbf{2} 3$ grammes per cent. So that the percentage weight of the kidneys in thirty-two animals of the second generation of meat-fed rats was more than 50 per cent. greater than that of twenty-eight controls.

TABLE VI.-Comparison of Weights in First and Second Generation of Meat-fed Animals.

\begin{tabular}{|c|c|c|c|c|c|}
\hline & & $\begin{array}{c}\text { No. of } \\
\text { Antimals. }\end{array}$ & $\begin{array}{l}\text { Weight at } \\
\text { D'ath. }\end{array}$ & $\begin{array}{l}\text { Total } \\
\text { Weight of } \\
\text { Kidneys. }\end{array}$ & $\begin{array}{l}\text { Percentage } \\
\text { of Weiglit. }\end{array}$ \\
\hline $\begin{array}{l}\text { Ist generation } \\
\text { 2nd " } \\
\text { " " }\end{array}$ & $\begin{array}{l}\text { Meat } \\
\text { Meat } \\
\left\{\begin{array}{c}\text { Conurols (Bread } \\
\text { and milk) }\end{array}\right\}\end{array}$ & $\begin{array}{l}20 \\
32 \\
28\end{array}$ & $\begin{array}{l}3241 \\
1425\end{array}$ & $\begin{array}{l}42 \cdot 64 \\
2 \cdot 275 \\
I \cdot 944\end{array}$ & $\begin{array}{l}1 \cdot 31 \\
1 \cdot 59\end{array}$ \\
\hline
\end{tabular}

In four animals which were fed on an exclusive ox-flesh diet for nine months, the diet being commenced when the animals were about three months old, the result was different from those of the preceding observa- 
tions All four animals in this series thrived on the diet. and gained in weight more than the controls. Their general appearance was that of good health, except that they were inordinately fat. Ore ded suddenly after four and a half months of the liet, the rematning thee were billed after nine and a half months of special feeding. The kidneys of all four were large, and varted in weight from 2.8 to 3.7 grammes: the average percentage weight being 1.06 grammes, which may be regarded as normal. It has to be noticed, therefore, that in this group the results of the examination of the kidneys are not in conformity with those yielded by the large majority of the experiments here recorded. But it is to be remembered that these animals had put on an unusual amount of fat.

\section{Histological Report by Dr G. Lyon.}

I. In the first series of observations on seven adult rats fed on a horse-fl'sh diet for five months, the kidneys show very striking histological changes, when compared with the kidneys of the control animals fed on porridge and on bread and milk. These pathological changes conform in type to what is seen in the kidney in general toxic conditions, e.g., septicamia, diphtheria, acute lobar pneumonia, etc., the chief incidence of the affection being on the cells of the secreting tubules. While the kidneys of this series show uniformity as regards the type of lesion (catarrhal nephritis), they show variations in degree. The majority of the kidneys of this series are examples of a severe type with bacteria present in large numbers.

In the less affected cases, the earliest changes are always found in the ascending limb of Henle's loop, which appears to be the most vulnerable of the secreting tubules. It is noteworthy that in sections where the cells of the convoluted tubules in the cortex may show little change beyond swelling and increased granularity of their cytoplasm accompanied by karyolytic changes, the cells of the ascending limb of Henle may have already undergone an advanced degree of disintegration; a pyknotic condition of the nuclei and subsequent karyorhexis being very striking and constant associated phenomena.

In the kidneys which are more gravely affected, the convoluted tubules in the cortex are affected equally with the ascending limb of Henle, and while some of the convoluted tubules show disintegration of their cells (especially the tubules immediately subjacent to the capsule), in others the change is more of the nature of a coagulation necrosis. The collecting tubules are for the most part normal, but in the more severe cases many of the smaller collecting tubules in the cortex and medulla contain colloid casts, which have been formed by the fusion of necrosed secreting cells.

The other structures of the kidney are affected to a much less extent than the secreting tubules. The glomerular capillaries show a varying degree of congestion: in the severer cases the capillary walls are the seat of an acute hyaline swelling. The interstitial tissue shows some degree of cedema and congestion of the intertubular capillaries, but no sclerosis. 
11. In the second cerics of ohservations on five castrated femate rats fed on a horie-tlesh diet for four or tive montis, the kidneys of two of the five animals show no differences in structure from those of the control subjects. In the remainn three the kidneys slow an eatly catarrhal nephritis, the lesion being most marked in the ascending limb of Hente's loop. The ressels appear aromal, and there is no indication of interstitial change.

111. In the third series of olvservations on young animals fed on ox-flesh or horse-flesh, the kidneys of the ox-flesh-fed animals are practically normal. In the three rats which were fed on horse-flesh for cight months the appearances are abnomal, the changes being of the same nature as those described in the first series, but much less in degree. In two of this series there are isolated accumulations of cells of the lymphocyte type along the lines of the interlobular vessels.

IV. In the series of observations on the second generation of meatfed animals, the kidneys of the majority show no pathological change. A small minority in this series show changes corresponding to an early catarhal nephritis. In one litter of three animals (b, lable IV.) which were killed when three months old, the kidneys present a perfectly normal appearance.

$V$. In the series of four animals which were fed on ox-flesh for nine months, the diet being commenced when the animals were about three months old, the kidneys appear normal.

The application of Muir's hematoxylin-eosin stain to the kidneys of the meat-fed subjects which appeared normal by ordinary staining methods, shows a striking alteration in the granules of the secreting cells. The changes may be briefly described as-

1. An irregular distribution of granules throughout the secreting cells, the granules not being confined to the base of the cell as in normal kidney's. Many granules may also be present in the lumen (sec Plate).

2. An alteration in the size and staining affinity of the granules, the granules being much larger in size and taking a deeper stain. The nuclei of the secreting cells are also more deeply stained (sce Plate).

In the kidneys which show catarrhal changes the granules are very few in number, or may be absent.

\section{Obserations on Nitrogen Excretion by ANIDEW HUNTER.}

To gain an idea of the conditions of some of the animals as regards nitrogen metabolism, the following experiments were made :-

The adult rats, which for some time had been maintaining nearly the same weiglit, were isolated in specially constructed cages. These cages allowerl of the collection of urine and fieces from day to day. (To prevent the loss of urinary nitrogen as ammonia, a few cubic centimetres of dilute sulphuric acid were placed in each receptacle.) The output of $N$ in each case was then determined by submiting all the fieces and an aliquot part of the urine to the process of Kjeldah!. The intake was calculated from the total amount of food consumed (from a specially conducted analy'sis of each diet). 
Two of the rats were on ox-flech (with water ad lititum), which had been their exclusive diet for four months previously; one was on the standard diet (bread soaked with skimmed milk). The figures represent the intake and output for a period of four diy's. The weight of the animal and the total weight of food which it consumed, are also given.

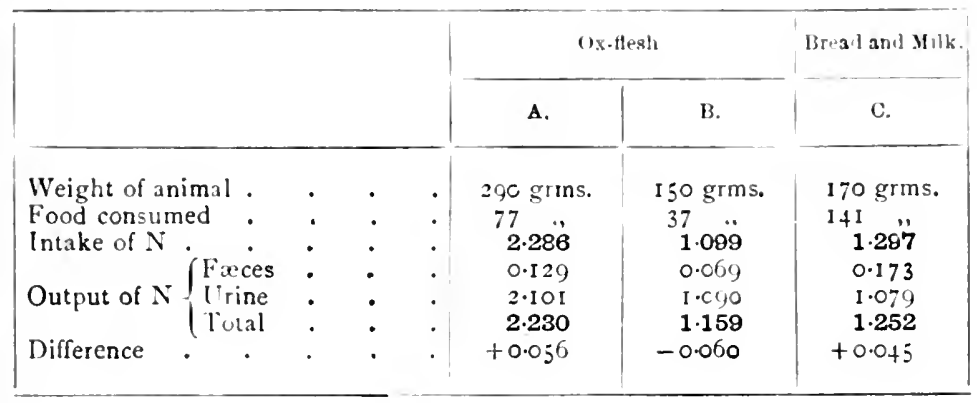

It appears from this table-

I. That all the animals were practically in nitrogenous equilibrium.

2. That the quantity of food taken was such as to render the amount of nitrogen metabolism per unit of body-weight the same, quite irrespective of the nature of the diet provided. Thus, taking the average of intake and output to represent the nitrogen metabolised, we get for each kilogram of body-weight the following figures (for four days) :-

$\begin{array}{lll}\text { A } & 7 \cdot 786 & \text { grammes. } \\ \text { B } & 7 \cdot 527 \quad " \\ \text { C } & 7 \cdot 500 \quad "\end{array}$

The result of this behaviour is that in the case (C) of bread and milk, which contains much less protein, $\mathrm{I}_{4} \mathrm{I}$ grammes of food had to be consumed, as against 37 grammes by a flesh-fed animal (B) of nearly the same weight.

3. The distribution of excreted $\mathrm{N}$ between urine and fieces is, however, materially affected by difference in the diet. On a diet of bread and milk much more of the $N$ appears in the faces than with flesh-feeding. The urinary $\mathrm{N}$ bears to the fiecal $\mathrm{N}$ the following proportion in the three cases :-

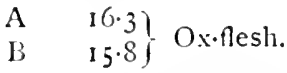

$$
\begin{aligned}
& \text { C } 6.2 \text { Iiread and milk. }
\end{aligned}
$$

The bulk of the feces in the animal $C$ was very much greater than in the other wo. The same is true of the volume of urine passed. This is seen from the following figures.

$\begin{array}{llll} & \text { A } & \text { B } & \text { C } \\ \text { Cubic centimetres of urine } & 15 & 11 & 23 \\ \text { Facal pellets (number of) } & 24 & 12 & 52\end{array}$


With a flech diet, therefore, the t:rine is more concentrated. This was olwous fiom its heh holoured appearance, as much as from the relatwely small quantity passed. On hread and milk there was much more duresis, and the urine was notably paler in hue. In no case were any alnormal constituents piesent. It was noticeable, however, that in the meat fed anmals the urine had a much stronger odour $A$ s regards the froces, Hey wele ill-formed, scanty, and very dark with the meat-fed anımals, but pale, bulky, and weil formed on bread and mulk.

\section{General Conclusions.}

I The prolonged admınistration of a flesh diet (horse-flesh and oxflesh) to rats is followed by hypertrophy of the kidneys.

11. This hypertrophy is more pronounced in the second generation of meat-fecl subjects.

111. The horse-fiesh diet induces in the great majority of animals definite histological changes which affect mainly the epithelial structures of the kidney. These changes are similar to those seen in recognised toxic conclitions.

IV. Similar changes of a less pronounced type are present in a small proportion of the ox-flesh-fed subjects.

$V$. In the kidneys of ox-flesh-fed animals which appear histologically normal by ordinary staining methods, the application of Muir's stain reveals a striking alteration in the secretory granules of the renal epithelium.

11. There is a noteworthy absence of cirrhotic change in the fleshfed animals, both in the first and second generations.

V'Il. The observations on nitrogen metabolism show that the flesh diet throws a special strain on the functional activity of the kidneys, so far as regarels nitrogen excretion.

\section{Description OF PLATE.}

FIG. I. - Kidney of rat fed on a bread and milk diet. Muir's stain. Magnified 400 diameters. Note the size and distribution of the secretory granules in the epithelium of the convoluted tubules. The granules are of uniform size and limited to the deeper part of the cell (compare Fig. 2).

FIG. 2.-Kidney of rat fed on an ox-flesh diet. Muir's stain. Magnified 400 diameters. The granules are not confined to the deeper part of the secrecting cells as in the bread-and-milk-fed animal (Fig. I), but are irregularly distributed throughout the cell and are also present in the lumen. The granules are considerably larger than in the control subject. Note also the deeper staining of the nuclei. 


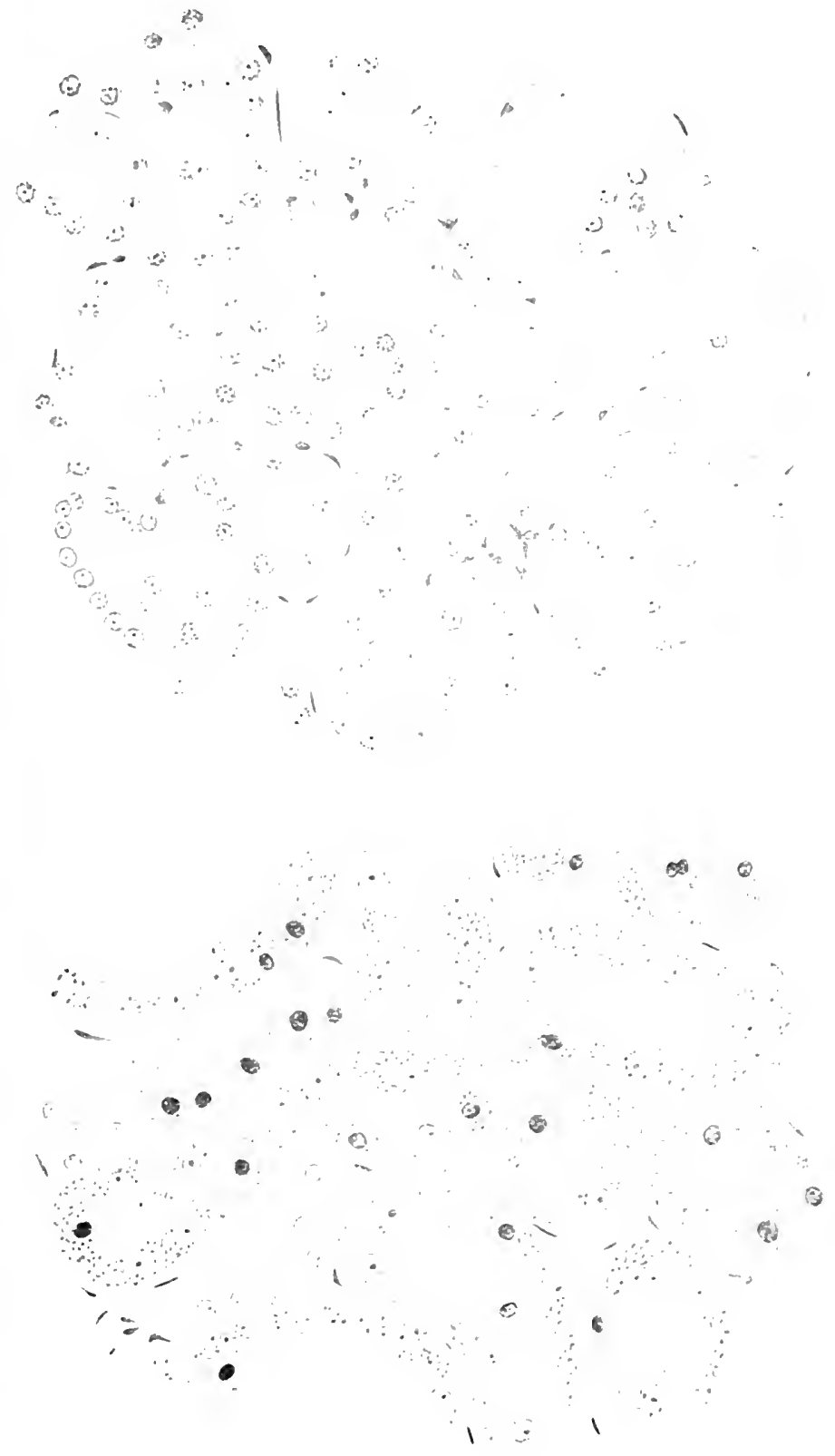





\section{$X$ - EFFECTS OF DIET ON TIE DELEIOPMENT ANI) STRUCTURE OF 'TIIE UTERUS.'}

The alarming and persistent decline in the lirtl rate is a matter of national interest the importance of which can hardly be overestimated. The purely medical aspect of this question is, however, exceedlingly difficult of approach, since social factors and social selfishness have undoubtedly a material influence. During the last generation, however, there has undoubtedly been a marked change in the relative proportions of the constituents of the average man's diet. Can such a change of diet have any influence on the birth-rate?

The following investigation was undertaken to discover what changes, if any, were produced in the development and structure of the uterus by various diets.

The animals employed in the research were rats. The uteri of eighty. six animals were examined, both macroscopically and microscopically. The tissue for microscopic examination was removed in all cases from, as nearly as possible, the same area-the junction of the distal and mid thirds of the uterus.

Eight wild rats, in various stages of development, from the immature to the adult animal, were examined in order to form an opinion as to the structure of the uterus in animals living, presumably, under natural conditions.

The remaining animals were divided into five series, namely :-

(a) A series of thirteen animals fed, from weaning, for periods of from nine to fourteen weeks on an exclusively milk diet. In one section of this series plain milk was used; in another, pasteurised milk; in the third, sterilised milk.

(b) A series of twenty-seven animals fed for periods of from twentyone days to nine months on bread soaked in milk.

(c) A series of eleven animals fed for periods of from four to fourteen weeks on a rice diet.

(d) A series of five animals fed for varying periods on a diet of porridge or oats.

(e) A series of twenty-two animals fed for periods of from twenty days to eight months on a raw-meat diet.

In the cases of the raw-meat and rice diets, some animals were put on the diet as soon as weaned, others after they had reached various stages of development.

The uterus of the adult wild rat is lined by columnar epithelium. There are glands lined by epithelium which varies from low cubical to columnar in type. The mucous coat is bounded externally by a muscular coat. In the mucous layer three varieties of cells are found:-

I. A cell with a large round or oval, relatively faintly-staining nucleus. This appears to be a young connective tissue type of cell.

2. A cell with a small, round, darkly-staining nucleus, comparable to a lymphoid cell.

1 Malcolm Campbell, F.R.C.S., British Wedical Journal, vol, i., 1907. 
3. A cell with an elongated, very darkly-staining nucleus, similar to celle gon in filmons tissue.

In the wild rat the lange cells are most numerous. In the wild rat the cells of the other yyjes are few in number, and are chiefly found in the part of the mucosa near the musular coat.

From the examination of this series of eighty-six animals it is evident that in animals of the same age and approximately of the same weight, living under similar conditions, the uteri may vary within a limited range in size and development. The musculitr coat is relatively uniform. The mucosa shows the greatest variations. While in most cases the epithelium lining the cavity is columnar, in some it is cubical ; there are also found marked variations as to the position of the nucleus and its staining reactions.

The animals fed on milk and bread soaked in milk approximate most nearly to the type of structure got in the wild rat. In the other groups, fed on what we may term "abnormal diets"-namely, rice, porridge, oats or raw meat-there is found a relatively constant departure from the normal. The type of change is common to all abnormal diets; its severity varies.

The severity of the changes induced are found to be in proportion to the ages of the animals at the time when the abnormal diet was begun. The changes are most marked in the animals put on the diet at weaning; they are less marked the more mature the animal at the time of the cominencement of the abnormal diet. In a fully-developed animal, any abnormal diet may fail to materially change either the size or structure of the uterus.

In regard to the development of the uterus, an abnormal diet appears to arrest the growth of the uterus. This arrest of development is most marked in animals fed from weaning on ox-flesh, but is also very well seen in animals fed on rice or on porridge or oats.

In regard to structure, all the abnormal diets led to a diminution of the number of the large connective-tissue type of cells, and a relative increase in the small cells. This change, which may be described as a fibrosis, was most marked in animals fed from weaning on an ox-flesh diet for periods of from four to five months; in this group of animals none became pregnant, while controls from the same litters, fed on bread and milk, all had young.

From these observations it seems justifiable to state :-

1. The use of a non-physiological diet-for example, exclusive flesh, rice, or porridge-induces in the great majority of cases a modification in the structure of the uterine mucous membrane. This modification consists in a diminution in the number of the large connective tissue type of cells, which appear to be important constituents in a physiologically active mucosa.

2. The structural change is most profound in animals fed from weaning on an exclusively ox-flesly diet. In such animals the development of the uterus is also most interfered with. 


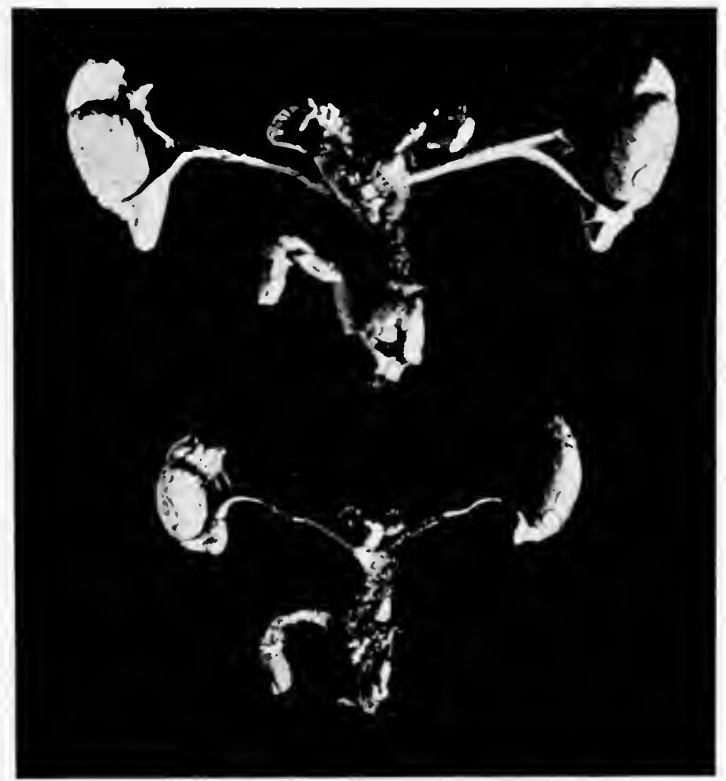

FIG. 10.-Male Reproductive Organs of full-grown Rats from the same litter.

A. After $5 \frac{1}{2}$ months, bread-and-milk diet. Weight of animal $210 \mathrm{grms}$. B. After $5 \frac{1}{3}$ months, ox.flesli. Weight of animal 170 grms. 

3. The structural change in two is associated with sterility. Chalmers Watson, to whom $1 \mathrm{am}$ indebted for much of the material user in this investigation, pointed out that a meat diet, if begun at weaning, almost invariably led to sterility. The present investigation shows that the sterility is probably due to the structural and developmental abnormalities in the uterus induced by the abnormal diet. It has lecen shown that the consumption of meat per head in this country is to-day almost seventeen times as great as it was in 1850 . Iuring the same peried the fall in the birth-rate has been most marked.

While it would be unwarrantable to attempt to found any theories in regard to the falling birth-rate on the results of this limited experiment, yet, when we add to the above facts the further consideration that the diminished birth-rate is most marked in the better-off classes of societythat is, among the very classes whose means permit of an unrestricted use of the more expensive meat diet-it is evident that the food factor is one which is at least worthy of consideration in dealing with the great question of the falling birth-rate.

\section{XI.-THE INFLUENCE OF AN EXCESSIVE MFAT DIET ON THE MALE REIROIUCTIVE ORGANS. ${ }^{1}$}

The object of this investigation was to determine the effects of an exclusive ox-flesh diet on the development of the male reproductive organs of rats. Three series of observations were made as follows :-

(a) A series of eight rats which were first on an exclusive ox-flesh diet for periods ranging from two to six months, the diet being commenced when the animals were weaned; eight rats from the same litters were employed as control-bread-and-milk-fed-suljjects. (The female rats, which were kept in the same hutches as the meat-fed males, were sterile, whereas all the controls bore young.)

(b) Four rats fed on an exclusive ox-flesh diet for periode ranging from five to nine months, the diet beins commenced when the animals were about two and a half months old, with eight controls.

(c) Five adult rats fed on an exclusive horse-flesh diet for five months.

In series $(a)$ the reproductive organs were much less developed in the meat-fed subjects than in the controls. The defective development is most pronounced in the seminal resicles and prostate gland (see Fig. 10).

In series $(b)$ and $(c)$ the testicles, prostate gland, and seminal vesicles are slightly less than in the control animals.

These results show that an excessive meat diet interferes with the development of the male reproductive organs, and that this arrest of development is most pronounced in the case of animals fed on a meat diet since weaning.

1 C. B. Paul, F.R.C.S., Journal of I'hiszology, vol. xxxiv. 


\section{XI1. THE INFLUENCE OF AN E.JCESSIVE MEAT IIET ON THF OSSEOUS SYSTEM.}

The clinical results obtained in an experimental investigation on the influence of an excessive meat diet on the growth and nutrition of rats are described on $\mathrm{T} .565$. It was there shown that the progeny of meat-fed rats are usually poorly developed, and show a high mortality in early life. The present chapter comprises an account of the naked-eye and microscopic appearances observed in the osscous system of these meat-fed sulpjects. The material cmployed consisted in the young of mothers fed for some weeks or months prior to pregnancy, and during pregnancy and lactation, on a diet of ox-Hesh, the animals, after weaning, being continued on the meat regine, an equal number of controls being taken from the young of rats fed on an exclusively bread and skim milk diet. Both diets were given in unrestricted amount, and with the meat diet water was given al libitum. Over a bundred meat-fed rats were utilised for the investigrations, their ages ranging from one day to three months, the majority being under three weeks old at the time of death. A record wis made of the naked-eye appearances of the skeleton, special attention being directed to the consistence as well as to the general appearance of the long bones, ribs, and flat bones. The tissues were fixed in formalin (s per cent.), decalcified in weak nitric acid solution, and stained in the ordinary manner with hamatoxylin and eosin. Sections were made through the anterior part of the cranium so as to demonstrate the conditions present in the frontal, malar, and maxillary bones, while, in the case of rats iet. one day, three weeks, and two months respectively, sections were also made of the tibia, humerus, and ribs. Similarly prepared sections from control animals were, for comparison, mounted on the same slide.

\section{Macroscopic Appearances.}

The macroscopic conditions noted in the bones of the meat-fed rats viry arcording to the asce of the animals, but show throughout, in a more or less marked degree, the same general characteristics. The most striking feature is the marked general softness of the whole osseous system, this condition being present in every meat-fed subject. The long bones of the flesh-ferl rats are distinctly softer and more pliable than those of the bread-and-milk-fed animals; a similar condition is observed in the ribs, short bones, and cranial bones of the meat-fed rats. This soft condition is present in the bones at birth, and becomes accentuated as age advances. A second striking appearance in the meat-fed animals is the darker colour of the long bones, more especially of the ribs, this being due to increased vascularity. This condition is present, in a sreater or less degree, in all the meat-fed suljects which died or were hilled iffer the second week of life. In some cases nothing further was olecried in the bunes of the flesh-fed rats killed even as late as three months after birth, but in the majority of cases a third feature shows

\footnotetext{
' Chalmers Watson, Lancet, vol, ii., I yob.
} 


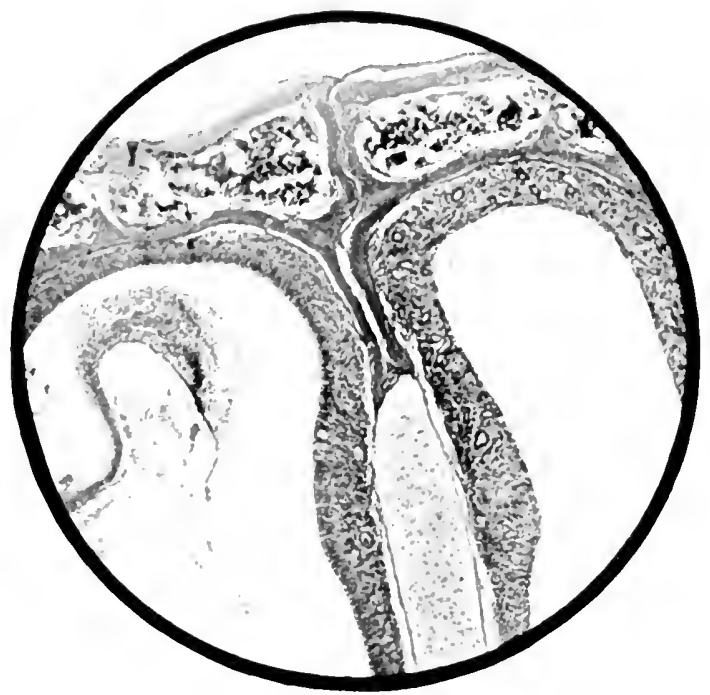

Fig. I2 - From a vertical section of the rinium of a Rat in th three months, fed on cx-flein.

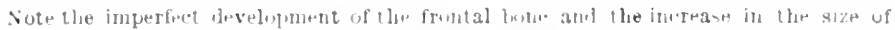

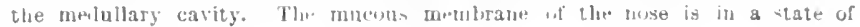
catarrh. Tf. Fig. 13 .

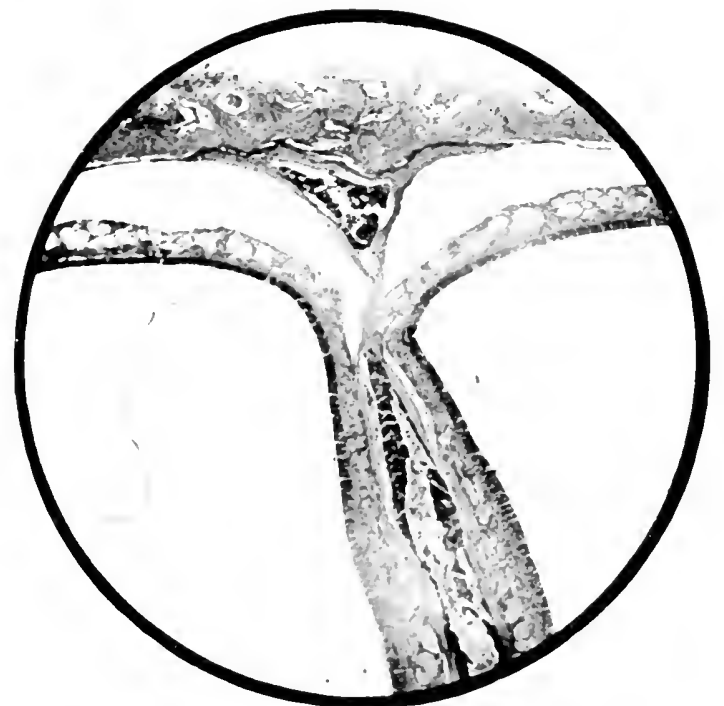

FIG, 13.-From a vertical section of the Cranium of a Rat irt. three months, fed on bread ancl milk.

Ninte the wellaleveloper frontal ins,r. 



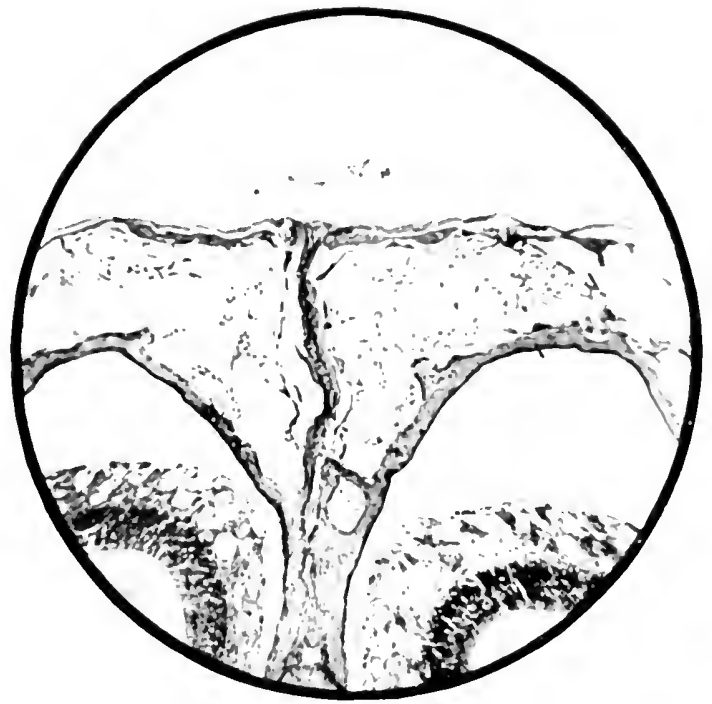

FIG. I4.-From a vertical ection of the Cranium of a Rist at. three weeks, unweaned. Mother fed on an ox-llesh diet. For comprarion with Fig. 15. ( $\quad \times 75$.

Note the inperfect elerelopment of the froutal bus and increas in the size of the ruelullary cavity.

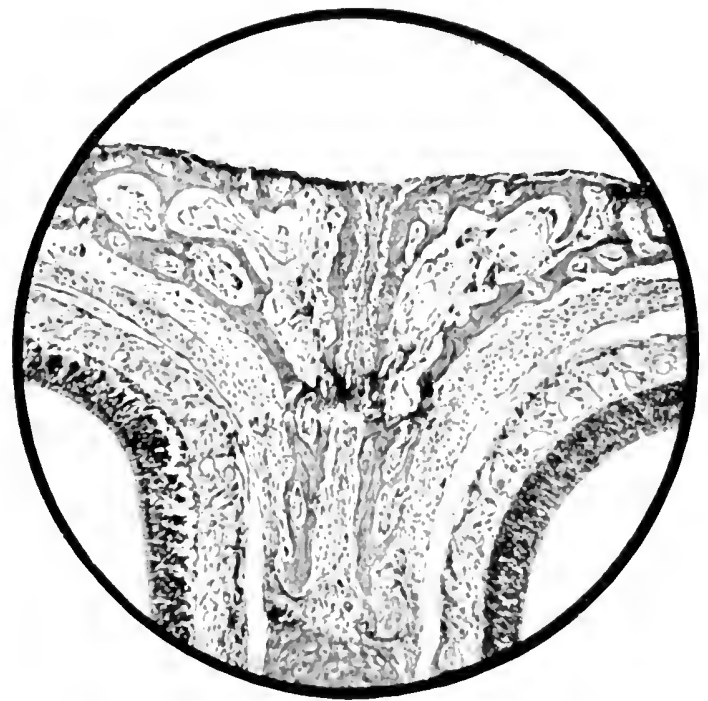

FIG. 15.-From a vertical section of the Cranium of a Rat ixt. three weeks, unweaned. Mother fed on a hread-and-milk diet. The photograph shows the frontal bone, and the upper par of the nasal septum and nasal cavities. ( $\times 75$.

Note the normal state of development of the frontal bune, I'f Fig. 14. 

itself. During the second month various curvatures of the spine and long bones occur. These consist in marked scoliosis and lordosis, with bending of the ribs at their angles, while curving of the bones of the limbs is present in a less degree. This condition of the bones is usually associated with an enlargement of the costo-chondral junction. In a small percentage of cases (about 15 per cent.) an additional feature is the presence of small white nodules in the bony ribs, these nodules standing out as pale bead-like prominences in the substance of the dark bone of the rib. On section these nodules are composed chicfly of cartilage (see Fig. 18). In the more pronounced cases the skelctal changes generally are similar to those seen in advanced cases of rickets in the human subject. Microscopically, however, this simularity is not borne out.

\section{Microscopic Appearances.}

Owing to the uniformity of the bony changes throughout the whole series of meat-fed animals, it was unnecessary to make a histological examination of each subject. Sections were accordingly made from forty out of the hundred meat-fed rats and from an equal number of control bread-and-milk-fed animals. In this examination special attention was directed to the following points :-

(a) Long bones. - The state of their development, by intra-membranous and intra-cartilaginous ossification.

(b) The histological appearances of the cranial bones.

(c) Ribs.-The minute structure of the nodules present in the bony ribs.

(a) Long Bones.-The ossification of the long bones of meat-fed rats is delayed and imperfect, the defect involving both the endochondral and periosteal bone formation. The epiphyses are for the most part normal ; in some instances there is a slight irregularity in the size and arrangement of the cartilage cells at the bone-forming margin. The minute structure of the epiphyses of the long bones may be normal, even in animals in which pronounced rachitic-like changes are present in the skeleton. The bone-marrow of the meat-fed rats axt. six weeks and on. wards shows, in some subjects, a grcat excess of fat.

(b) Cranial bones.-In the meat-fed rats, ossification, both intramembranous and intra-cartilaginous, is less advanced than in the control animals, the bony trabeculac in the former being less numerous and enclosing a marrow excessively rich in red blood-corpuscles (see Fig. I2, and compare Fig. I3). While intra-membranous and intra-cartilaginous ossification are both affected, the defect is in some cases more pronounced in the periosteal bone-formation.

There is a striking difference in the degree of development of the frontal, malar, and maxillary bones in the bones of the meat-fed animals at birth, the contrast becoming accentcated as age advances. The bones of the jaws in the meat.fed subjects are of a different shape from the controls, the former being wider and more square-shaped. This con- 
dition is associated with an extreme himmess of the bones and a great increase in the number of cells-red blood-corpuscles and leucocytes-in the medullary cavity in the meat-fed rats (sce ligs. 12 and 13). In a very few anmals at. three weeks, the difference between the development of the bones in meat-fed and bread-and-milk-fed animals is very slight. The averige state of bone development in the two series is further illustrated in Figs. 14 and 15 for animils at. three weeks. The bony trabecule in the meat-fed rats are extremely thin, and the medullary spaces show a great increase in the number of thin-walled ressels, which are distended with red blood-corpuscles. This increase in the number of red blood-corpuscles in the medulla of meat-fed rats is, in the great majority of subjects, a very striking feature (see ligigs. 16 and 17).

(i) The struture of the alhite nodules in the bony ribs.-These nodules present a striking histological picture. They are composed mainly of cartilage cells, which are derived from the periostem; at the periphery of these nodules the nodules are undergoing transformation into bones (sec Fig. 1S). It is of interest to note that I have recently observed a similar histological appeatrance in the bones of an infant aet. fifteen months, whose mother-a tuberculous subject-was fed during gestation, and for some time prior to it, on a diet containing a great excess of meat (sce kig. 19).

The results show that the bones of animals fed on an excessive meat diet present an appearance of delayed and imperfect ossification, with increased vascularity and an increase in the number of red bloodcorpuscles. Associated with this there is in a number of cases the presence in the bony ribs of nodules of cartilage, developed from the periostem, with direct transformation of these cartilage cells into bone. It is noteworthy that, while the naked-eye appearances of the skeleton may closely simulate those present in advanced cases of rickets in the human subject, the microscopic appearances in the epiphyseal ines of the long bones are quiet distinct from those present in that disease. The (hief object of this paper has been to describe the naked-eye and microscopic appearances of the osseous system in young animals-omnivorous feeders- 1 hich are fed on a diet containing an excessive anount of meat. The full consideration of how far the facts observed admit any deductions applicable to disease in the human subject is beyond the scope of the present work. I may here, howerer, refer in some detail to what, so far as I am aware, is a unique record of disease in an infarit, in which the facts prove that the results of the present investigation have a real and practical value for the practitioner. The essential facts of this case are as follows:-

The mother of the patient had pulmonary tuberculosis, and made a satistactory recovery under prolonged treatment along modern lines, one feature of the treatment being the daily administration of a large amount of ncarly raw meat. The patient married and continued to take an excessive meat dict. A child was born after eighteen months, and, in view of the family history, was artificially reared under the best 


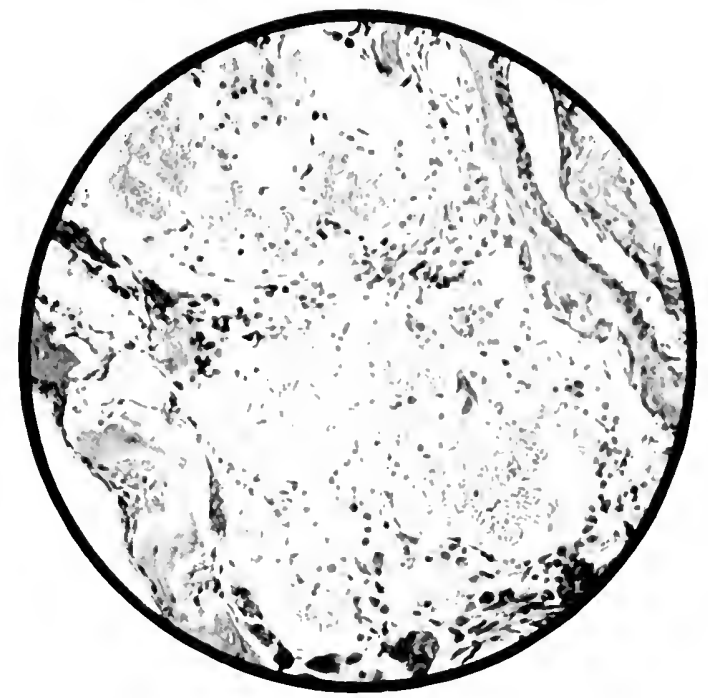

FIG. I6. - The Narrow of a Rat int. three weeks, unweaned. Hother led on an ox-flesh diet. ( 200 .)

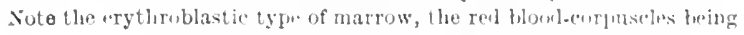
moro numerous than tho leueoeytes. $1 \%$. Fig. 17.

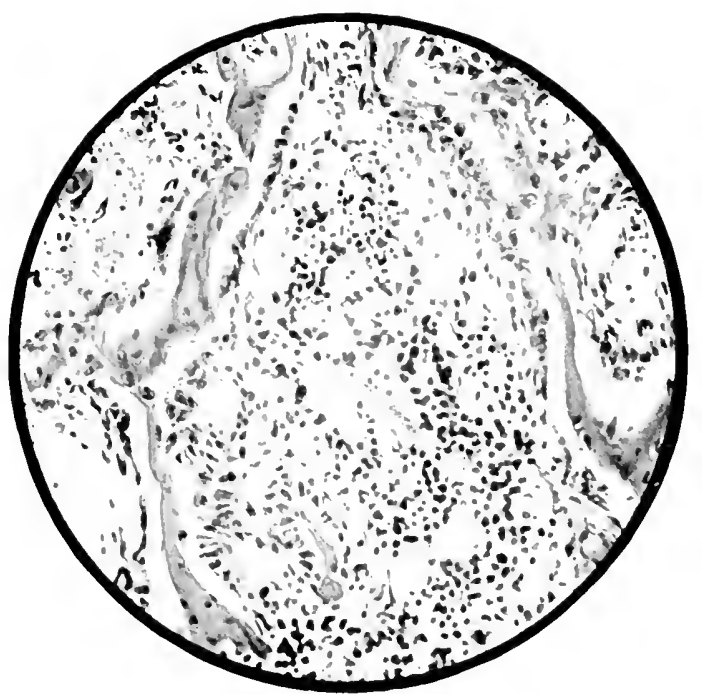

FIG. 17. - The Marrow of a Rat xt. three weeks, unweaned. Mother led on a bread-and-milk diet. $(x 200$.

Nute the lencoblastic type of marrow, the white hum-corpuscles buing in excess of the red blood.curpuscles. Cf. Fig. 16. 



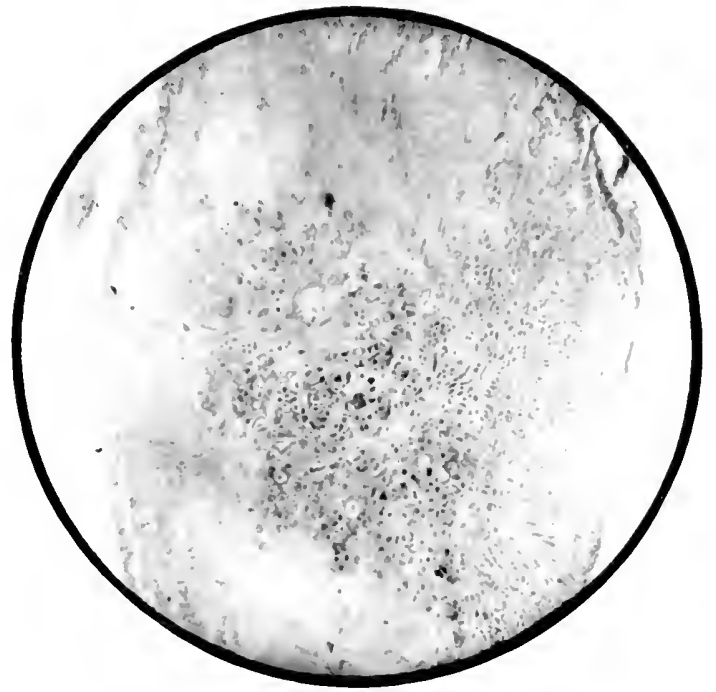

FIG. I8. Longitudinal section of the Bony Rib of a Meat-fed Rat (second generation), a.t. two months, the section taken through one of the nodules described in the text. ( $x 50$.)

Nute the ar"a of cartilage colls in the bun". C). Fig. 1:.

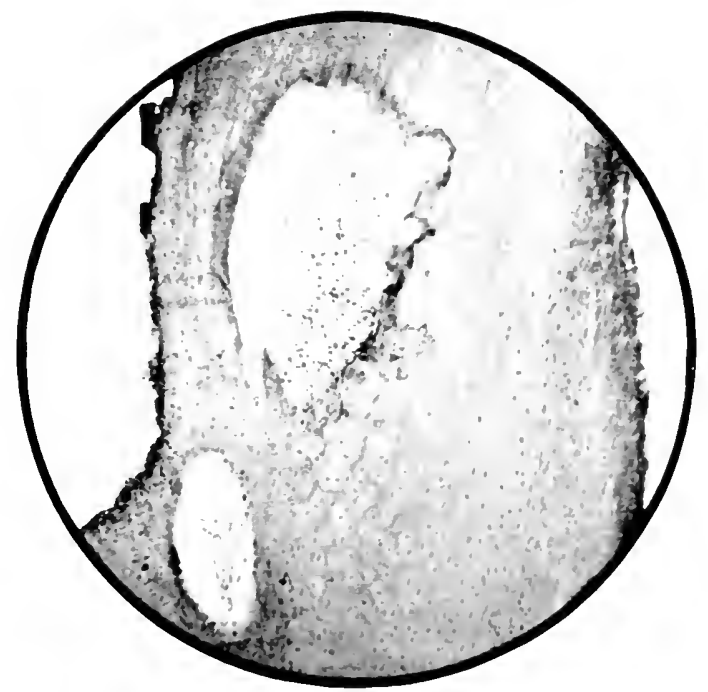

FIG. 19.-Longitudinal section of the Shaft of the Raulius of an Infant a.t. sixteen months, whose mother was fed on an excessive meirt diet. ( : 9o. Note the area of eartilagn culls in the beste. Cf. ris. 1 s. 

hygienic and general conditions. The infant thrived fairly well until a year old, when there was some trouble with delayed dentition, for which the advice of the family practitioner was sought. As the application of simple remedies proved unavailing, and the cliild became anamic and further out of condition, a second opinion wis obtained. The chief alteration in the treatment was the administration of raw-meat juice, which was continued for six weeks. Under this regime the condition of the child steadily deteriorated, the anamia becoming more pronounced and being associated with marked physical and mental lethargy, fretfulness on movement, and a few purpuric and petechial spots; there were no other symptoms or physical signs of note. 'The child was then seen by a distinguished pxdiatric physician. After repeated examination of the case, which was admittedly puzzling, and examination of the blood, etc., the opinion was arrived at that the case was probably one of latent tuberculosis, probably located in the mediastinum. At this juncture I had the opportunity of seeing the patient in a non-professional capacity, and as the clinical appearances vividly recalled a clinical picture which I had frequently observed in very young rats, I formed the opinion that the state of profound anremia and physical and mental lethargy was dependent on an exhaustion of the functions of the bone-marrow, thyroid gland, and other structures, consequent on the excessive meat consumption by the mother. The child died in a few days. At the postmortem examination no trace of tuberculosis was found, nor other recognised cause of marked anemia in children. A partial post-mortem examination only was allowed, and was conducted by the consultant who had charge of the case, and who kindly gave me pieces of tissue for histological examination. The long bones were unduly soft in consist. ence, and it is of special interest to note that the histological appearances of the radius of this child (see Fig. I9) are identical in their essential features with those which were present in the ribs of the rats.

These facts seem to indicate that the results obtained in my experimental investigation here recorded are capable of application to disease in the human subject. The importance of recognising this, both from the point of view of diagnosis and treatment, will be obvious. I desire to draw special attention to the view which is suggested by the record of facts described-viz, that in diseased conditions in early infancy attention should be directed to the dietetic conditions of the parents prior to and during gestation; and, further, that the symptoms should be critically analysed in the light of facts obtained from experimental observations on diet carried out in lower animals. I have pleasure in expressing my indebtedness to Dr A. Dingwall Fordyce for much assistance in this investigation. 


\section{CII.-THE EFFECTS OF A MLAT IIET ON ANIMALS ANH ON 'THEIR PROGENY.'}

In introducing lis subject the atuthor pointed out that the following facts sugsested the research :-First, that in the course of an experimental investigation on grout in fowls the use of an excessive meat diet had induced a striking hypertroplyy of the thyroid and parathyroid glands; and, further, that these changes were not present in the glands of one fowl, simblarly fecl, which was proved to be tuberculous at the postmoricm examination. Secondly, the correlation of these facts in the mind of the author with a well-recognised clinical fact in the dietetic treatment of two diseases-gout and tuberculosis-an excessive meat diet being injurious in the former and beneficial in the latter disease. This indicated that the tissues of a gouty subject reacted to a meat diet in a manner different from the tissues of a tuberculous sulject, and sugrested that an experimental investigation might yield facts which would elucidate the nature of both of these reactions. Thirdly, the present unsatisfactory state of our knowledge of the dietetic treatment of chronic diseases was cited as an additional reason for experimental observations carried out on lower animals. It was probably not too much to sity that in the treatment of many diseases in which meat was restricted in amount, no more scientific explanation could be advanced than was involved in the vague and general statement that meat was a "stimulating" food. One object of this research was to ascertain so far as possible, from observations on lower animals, which, if any, organs were "stimulated" by an excessive meat diet. An additional reason for an investigation of this kind was to be found in the view, held by not a few medical men, that there was an important etiological relationship between the increased consumption of animal food-from 3 lbs. per head per annum to over 50 lbs. per head per annum in the past fifty yearsand the increasing incidence of certain diseases. The investigation, which was still in progress, was being carried out in the Physiological Laboratory of the University of Edinburgh, and in its conduct the author lad secured the co-operation of a number of investi. gators to whose work reference was made. Some results had already been fublished, either in the form of preliminary communications or of crimpleted papers; after a reference to the work already published, he recorded in detail the influence of an excessive meat diet on the thyroid rland. Rats were employed as the subjects of experiment, and the observations were extended to more than one generztion. Bread and milk was given as a control diet, this being the food in routine use in the laboratory prior to the special diet investigation. A bread-and-milk dict was regarded as a plyysirlogical one for tame rats, since, under its use, the foung srew rapidly, the young and adults alike appeared to be in perfect health, and the rate of production was very great. The influence of an cxcessive meat clict on the growth and nutrition of rats of different ages having been fully described in a former paper, little attention was

1 Paper read by Chalmers Watson before the Pathological Society of London, Lancet, vol. ii., 1 go6. 
directed to this point beyond describing and illustrating so far as possible the following three points:-(a) The retardation of growth inducer by the use of a meat diet when begun in very early life; $(b)$ the prejuclicial effects of a meat regime on the reproductive powers; and (c) the high mortality in early life in the second generation of meat-fed subjects. In considering the histological appearances olsserved in the tissues of meatfed animals, it was important to bear in mind that in many of the animals there was no external indication of disturbed nutrition. Dealing first with the reproductive system, it was demonstrated from the results obtained by Dr C. 13. Paul that a meat diet markedly arrested the growth of the male reproductive organs when the faulty feeding was begun when the animals were weaned (p. 589). Attention was then directed to the observations of Dr B. P. Watson, who had extended and amplified the author's original observations on the effect of the diet on fertility and lactation. I)r H. P. Watson's observations proved-(i) that a meat diet was decidedly prejudicial to the occurrence of pregnancy when the diet was begun when the animals were from two to four months old ; and (2) that, when they had young, they were less able to suckle them, owing to the smaller development of mammary tissue (p. 608$)$. The results of Dr Malcolm Campbell's observations on the minute structure of the uterus were then alluded to and demoristrated. That author had shown that the use of an excessive meat diet in very young animals induced alterations in the minute structure of the uterine mucous membrane of the nature of a fibrosis. This change was, however, not peculiar to a meat diet, but was also observed in animals fed on other unphysiological diets, such as rice or porridge (p. 587). The effects of a meat diet on the osseous system of the progeny of meat-fed rats were then considered. The bones were unduly soft and very vascular; many subjects showed marked curving of the bones with curvature of the spine; in about 15 per cent. of the series there were small whitish nodules in the bony parts of the ribs. Microscopically there was imperfect bone formation with great increase in the size of the medullary carity, especially in the cranial bones, with proliferation of the marrow cells (p. 590). The occurrence of similar changes in the bones of an infant, aged sixteen months, suffering from an obscure disease, whose mother was tuberculous and had been treated for a prolonged period prior to and during gestation with a diet containing a great excess of meat, was then referred to. Mention was made of the results of the investigations of $\mathrm{Mr}$ G. W. Watson, L.D.S., and Mr J. H. Gibbs, who found that, notwithstanding the very imperfect state of development of the cranial bones, the teeth showed no noteworthy histological change (1). 577). Reference was then made to the observations of the author in conjunction with Dr G. Lyon, which were not yet published, and which showed that there was a hypertropliy of the kidneys in meat-fed animals, and also that a meat diet threw a marked strain on the secreting cells of the kidney, this leing indicated by the alteration in the size and arrangement of the granules of the cells, as revealed by special staining methods (p. 578). With regard to the thyod gland, reference was made to a preliminary com- 
munication publiched by him in the Procecdings of the Physiological Society in 1904, in which it was shown that the use of a meat diet in young rats induced, as a rule, distinct histological changes in the thyroid gland (ten out of twelve subjects). In the past two years these observations had been extended, and particular attention had been devoted to the histological appearances of the gland in the progeny of rats that had been fed on a meat diet. Attention had also been directed to the appearances of the gland during lactation and to its normal structure as seen in wild rats. The glands of sixty-five animals-second generation of meat-fed rats-were examined, with fifty control bread-and-milk-fed subjects. The ages varied from one day to three months, thirty-five of the series being under three weeks old and unweaned at the time of death. The majority of the meat-fed rats died; the others were killed. As an additional control for the animals which succumbed, a series of sixteen young animals of similar age, which died as a result of feeding on other unphysiologrical diets (rice and porridge), where employed. The histological appearances of the thyroid gland of the meat-fed rats differed from those of the controls. In ten out of the sixty-five the histological changes were slight and did not exceed those occasionally present in bread-and-milk-fed animals. The remainder showed marked changes, which could be classified in the following three groups:-1. Great congestion of the gland with absence of colloid and little or no attempt at vesicle formation, the gland being in an embryonic state. This appearance was only observed in animals which died in the first few neeks; it was observed in twelle of the scrics. 2. An increase in the amount of the colloid, far in excess of that obtaining in bread-and-milk-fed subjects, with thinning of the walls of the vesicles from pressure. This appearance was most pronounced in animals which had apparently adapted themselves to the diet, and whose weight and general nutrition were above the average of meat-fed subjects. This appearance was present in eighteen of the series. 3. A diminution or entire absence of colloid with the degeneration and shedding of the secreting cells. This condition was specially marked in animals the general nutrition of which was obviously defective. The majority of these animals died. This series included twenty-six animals. The result of this investigation confirmed the author's carlier observations in showing that an excessive meat diet induces structural changes in the thyroid gland. The appearances proved, to his satisfaction, that a meat diet at first stimulated and later exhausted the functional activity of the gland. Special attention was directed to the modification in structure acquired by the young of the animals fed on an excessive meat diet. The opinion was expressed that conditions comparable to those described would be found if looked for in thyroid glands of children, and that many symptoms of disease in young children were associated with, and dependent on, an impaired functional activity of the thyroid gland which the child had "inherited" from his parents. Some evidence in support of this view was advanced in the form of a section of the thyroid gland of the infant, aged sixteen months, previously referred to, whose mother 
had heen fed on an excessive meat diet. In this gland the intervesicular glandular tissue was much less in amount than in the glands of infants of the same age which were apparently nomal, the general microscopic appearances of the gland vividly recalling the picture in some of the meat-fed animals. In conclusion, the author drew attention to the importance of the main facts which the investigation had elicited -viz., (1) that an excessive meat diet modifies the structure and function of some important organs, notably the reproductive glands, thyroid gland, and kidney; and (2) that some of these modifications were acquired by the offspring, in which they were present in an accentuated degree, and were in them associated with an increased susceptibility to disease. His clinical experience led him to the view that there was at the present time in this country an increased susceptibility to disease, which was the result in great part of changes in the tissues comparable in their nature and origin to those described in this communication.

\section{XIV.-THE INFLUENCE OF DIET ON THE LIVER.'}

Two series of observations have been made. One experiment consisted in feeding a large number of rats on an exclusive ox-flesh diet, this being essentially a mixed diet of protein and fats. In this cxperiment it was observed that the percentage weight of the liver in meat-fed rats was, as a rule, considerably greater than in the control bread-and-milk-fed subjects, the difference being such as could not readily be explained by mere variation in the blood-supply of the organ. An objection may be raised that the use of an exclusive flesh diet is too unnatural a regime to allow any deductions to be drawn which can be applied to conditions obtaining in man. To meet this objection attention is therefore more particularly directed to the detailed results of a second series of observations, which consisted in comparing the percentage weight of liver tissue in wild rats living, it is assumed, on a highly nitrogenous dietary with those of an equal series of animals obtained chiefly from the same source which were fed on a diet of bread and milk in fixed proportions-a diet which contained a much smaller proportion of nitrogenous food. This diet of bread and milk is one which has been proved to be well adapted for the growth, general health, and fertility of the ordinary tame rat.

\section{Details of the Experimest.}

Young rats. $-A$ series of nineteen young wild rats were caught in the basement of a large hotel. It may, I think, safely be assumed that the diet of these animals was a mixed one, containing a considerable amount of nitrogenous foodstuffs. The coats of many of the animals were unusually rough and dry, but otherwise the animals appeared to be in good nealth. Nine of the rats, of weight ranging from 72 to 150 grammes, were at once killed, ordinary coal-gas being employed as the lethal agent ;

1 Chalmers IVatson, Lancet, vol. ii., 1907. 
the remaining ten were fed in the laboratory for ten weeks on the ordinary laboratory diet of bread and milk, and were then killed in the same manner. Tle livers were weighed out of a 5 per cent. formalin solution, the evcess of muid having previnusly been removed. Table 1 . gives the recout of the weights of the animats am the percentage weight of the liver in the 1 wo series.

\section{TIBI.E I.}

\begin{tabular}{|c|c|c|c|}
\hline \multicolumn{2}{|c|}{ 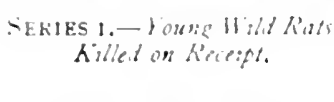 } & \multicolumn{2}{|c|}{ 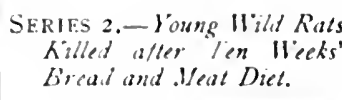 } \\
\hline 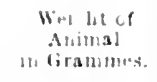 & 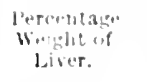 & $\begin{array}{l}\text { Wriplut of } \\
\text { Antusal } \\
\text { in (iramules. }\end{array}$ & $\begin{array}{l}\text { Percentage } \\
\text { Winglit of } \\
\text { Liver. }\end{array}$ \\
\hline 72 & $5 \cdot 6$ & 110 & $3 \cdot 6$ \\
\hline 72 & $6 \cdot 9$ & 120 & 3.5 \\
\hline 75 & $5 \cdot 5$ & 120 & $5 \cdot 0$ \\
\hline 95 & 6.5 & 125 & $4 \cdot 7$ \\
\hline Qi) & 6.7 & 130 & $2 \cdot 9$ \\
\hline 106 & 6.6 & 132 & 60 \\
\hline 130 & $6 \cdot 0$ & 142 & 3.9 \\
\hline If 2 & $5 \cdot 3$ & 150 & $3 \cdot 2$ \\
\hline \multirow[t]{2}{*}{150} & $5 \cdot 2$ & $I=0$ & $4 \cdot 0$ \\
\hline & & 170 & $3 \cdot 7$ \\
\hline Averige. & $6 \cdot 0$ & Average. & $4 \cdot 0$ \\
\hline
\end{tabular}

The figures show that the average percentage weight of the livers of the nine rats which were killed on receipt and which are assumed to have lived on a mixed diet containing much nitrogenous food was $6 \cdot 0$, whereas that of ten rits obtained from the same source and at the same time, which were subsequently fed for ten weeks on a bread-and-milk diet, was $4 \cdot 0$ grammes.

Fully grou'n animals. - Thirty fully grown rats were obtained from a number of sources, the source in each instance being given in Table II. As in the case of the younger rats, it was noted that the coats of many of the animals were rough and dry, but otherwi'se the animals appeared in grond health. Fourteen of these were at once killed, the remaining sixteen were fed in the laboratory for periods ranging from nine to eleven weeks. The weights of the animals and the percentage weight of the liver in the two series are given in Table II.

The figures in Table 11. show that the average percentage weight of the livers of fourteen adult rats which vere killed on receipt was 5.27 grammes, whereas that of sixteen rats obtained from similar sources and at the same time, which were subsequently fed on a diet of bread and milk for periods ranging from nine to eleven weeks, was 3.87 grammes, which represents a striking difference. There are two points in Table II., Series 4, which call for comment. The weights of the laboratory-fed rats show a striking uniformity in the series, the range of variation being 
a small one. On the other hand, the figures in Table II., Seties 3, show that two animals form a striking exception to the general rule in this series, the average percentage weight of the liver in these two rats being actually less than 11 any of the bread-and-molk-fed subjeds. It is note worthy that these two animals cance from a birl shop, which renders it

TABI.E, II.

\begin{tabular}{|c|c|c|c|c|c|}
\hline \multicolumn{3}{|c|}{$\begin{array}{c}\text { SERIES 3. Full-grewn Wild Rats } \\
\text { Killed on Receipt. }\end{array}$} & \multicolumn{3}{|c|}{$\begin{array}{l}\text { SERIES 4.-Full-grown Wild Rats aftes } \\
\text { Feedmg on Bread and Wilk from Aire } \\
\text { to Eleven Wheeks. }\end{array}$} \\
\hline $\begin{array}{l}\text { Weight of } \\
\text { Animal in } \\
\text { Grammes. }\end{array}$ & $\begin{array}{l}\text { Percentage } \\
\text { Woight } \\
\text { of Liver. }\end{array}$ & Source. & $\begin{array}{l}\text { Woight of } \\
\text { Animal in } \\
\text { Grammes. }\end{array}$ & $\begin{array}{l}\text { Percentage } \\
\text { Weinht } \\
\text { of Laver. }\end{array}$ & Source. \\
\hline 190 & $6 \cdot 15$ & Sewer. & 162 & 3.93 & \\
\hline I 90 & 6.94 & " & 170 & $3 \cdot 76$ & \\
\hline 200 & 6.15 & $"$ & I 80 & 3.83 & All from \\
\hline 207 & 6.13 & & Igo & 3.57 & \\
\hline 220 & $5 \cdot 23$ & Canal bank. & 200 & $3 \cdot 0$ & ho:el \\
\hline 237 & 5.57 & Sewcr. & 205 & $3 \cdot S 0$ & \\
\hline 240 & +97 & " & 225 & 4.04 & hasement \\
\hline $2+2$ & & & 237 & +33 & \\
\hline 260 & 5.89 & IIotel basement. & 260 & +30 & or \\
\hline 260 & 4.05 & & 270 & 3.55 & \\
\hline 270 & 3.25 & Bird shop. & 275 & 3.75 & canal bank. \\
\hline 305 & $5 \cdot 17$ & Hotel basement. & 290 & 3.75 & \\
\hline 3.12 & 5.11 & Cinnal bank. & 300 & 4.06 & \\
\hline 370 & $2 \cdot 7.9$ & Bird shop. & 320 & +31 & \\
\hline lverage. & $5 \cdot 27$ & $\ldots$ & Arerage. & $3 \cdot 57$ & $\cdots$ \\
\hline
\end{tabular}

probable that their diet consisted mainly of grain foods. (It was also observed that in these two animals the histological appearances of the thyroid gland were markedly different from the others in this series.) This result, then, confirms that obtained in the case of young rats given in Table I., and, assuming the correctness of the statement that the diet of the animals in their natural state contained a considerable amount of nitrogenous food, the facts indicate that the livers of adult rats which are fed on a diet containing much nitrogenous food have a considerably higher percentage weight than those of animals fed on a diet containing a smaller amount of nitrogen.

In arriving at this conclusion I am aware of the importance of having regard to the possible operation of factors other than the highly nitrogenous diet in inducing the greater amount of liver tissue present in wild rats which were killed on receipt. Of these the two chief are, 1 believe, (1) Inuscular excrcise, and (2) the admixture of foodstuffs. That the first is a factor of importance is rendered improbable by the fact of the low percentacre weight of the liver in the two rats in Table II., Series 3 , which were caunht in the bircl shop and killed on receipt. With regard to the second, I think it probable that the anount of fat and carbohydrates 
Ingested in the mived diet is a factor of very considerable importance, but in the circumstances it is not possible, nor is it necessary, to dissociate these from the more important nitrogenous foodstuffs. While kecping in view, therefore, the possibility that other factors, both in the diet and in the animal's emvironment, may require to be considered, I believe that the difference in the amount of liver tissue present in the two series of animals is chiefly dependent on the relative proportions of nitrogenous foodstuffs in the dietary, and we have in these results a confirmation of those referred to in an earlier part of my paper as to the influence of an excessive meat diet on the liver.

It must not be supposed that I am assuming that the larger percent. age weight of the liver tissue in the wild rats killed on receipt is to be regarded as pathological. No such assumption is made. The alternative view, that the smaller percentage weight of liver tissue in the breadand-milk-fed animals is pathological, may appear to some as the more probable one. But this assumption would be equally unwarranted. Indeed, since it was a noteworthy feature in the experiment that within a week or two of the onset of bread-and-milk feeding, the coats of the rats invariably lost the rough, dry aspect referred to in the text and became smooth and sleek, the balance of clinical evidence is in favour of the bread-and-milk regime. But it is not essential to elaborate a comparison. The one important fact to which attention is directed is the evidence that the liver is modified by diet, and, in particular, that a mixed diet which contains a large amount of nitrogenous food throws a greater strain on the liver than a diet, given in unrestricted amount, in which the nitrogenous elements are in smaller proportion.

\section{XV.A NOTE ON THE MINUTE STRUCTURE OF THE THYROID GLAND IN THE RAT.'}

In the course of an investigation into the effects of varying diets on the structure of the tissues and organs in tame rats, my attention has incidentally been directed to the varying histological appearances of the thyroid gland in wild rats. The examination of the thyroid gland in a scries of forty wild rats, all apparently healthy, has shown wide variations in the histological appearances of this gland. The source from which the animals were obtained was noted in all instances, the rats being caught in such diverse places as a sewer, a hotel basement, nuthouses of an asylum, railway station, a canal bank, and a bird shop. The weight of the rats ranged from 60 to 370 grammes, twenty of the number weighing $200 \mathrm{grammes}$ and upwards. As it was observed that the histological appearances of the gland in quite young animals were not strikingly different from those of the fully grown subjects in the sane series, it is assumed that the differences in the histological appearances to be described are not directly associated with the age of the animal, and accordingly no further differentiation will be made between the condition of the gland in young and adult subjects.

'Chalmers Watson, Quarterly Journal of Experimental Physiology, vol. ii,, 1909. 


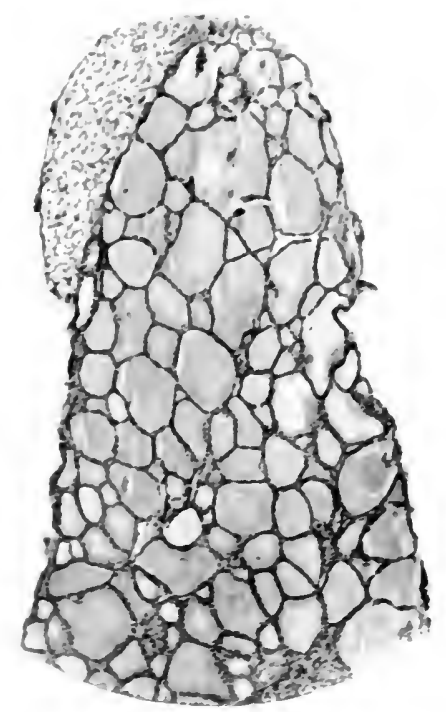

FIG. Ig.A.-Thyroid Gland of Wild R.t. ( jo.)

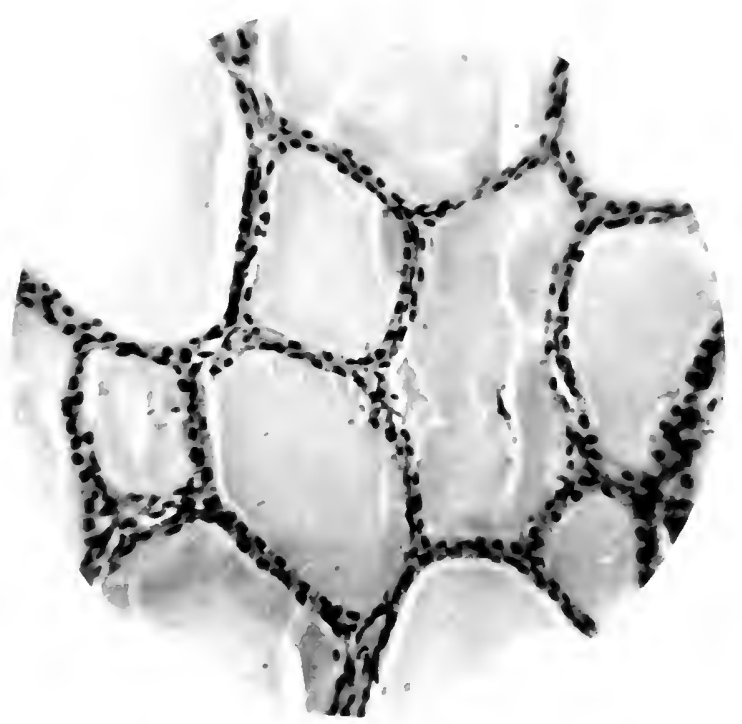

FiG. 20.-Thyroid Gland of Wild Rat. ( 250.)

From same specimen as that shown in Fig. 19.A. 



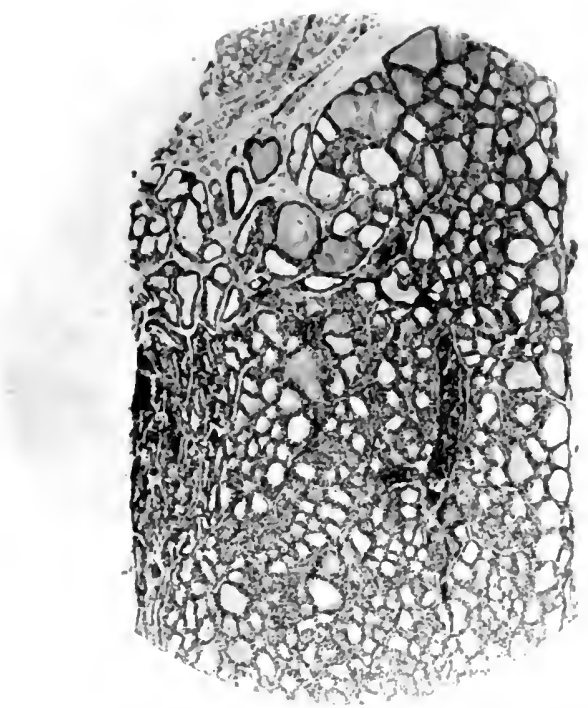

FIG. 21.-Thyruid Gland or Wild Rat. ( 50.)

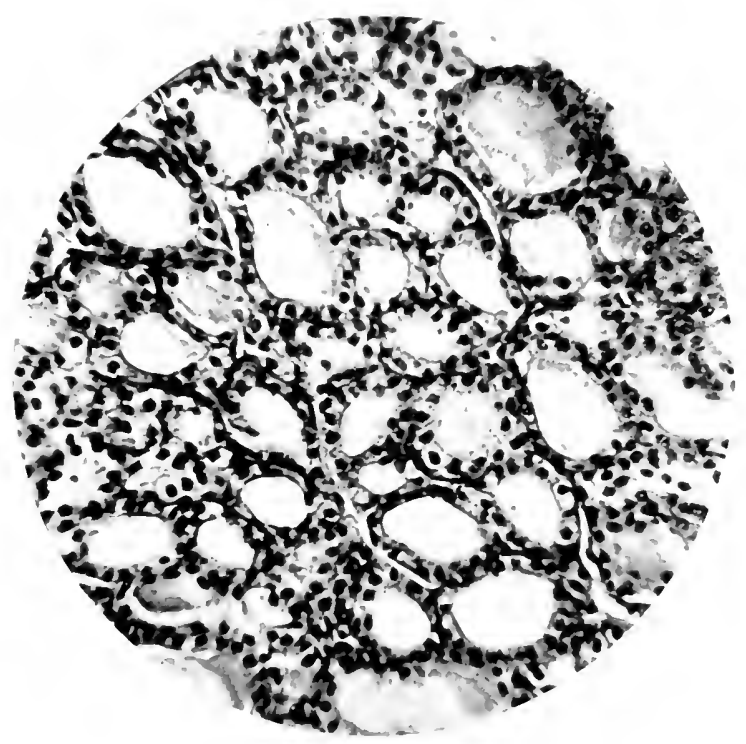

Fig. 22.-Thyroid Gland of Wild Rit. (*250.) From same specimen as that shown in Fig. 21 . 



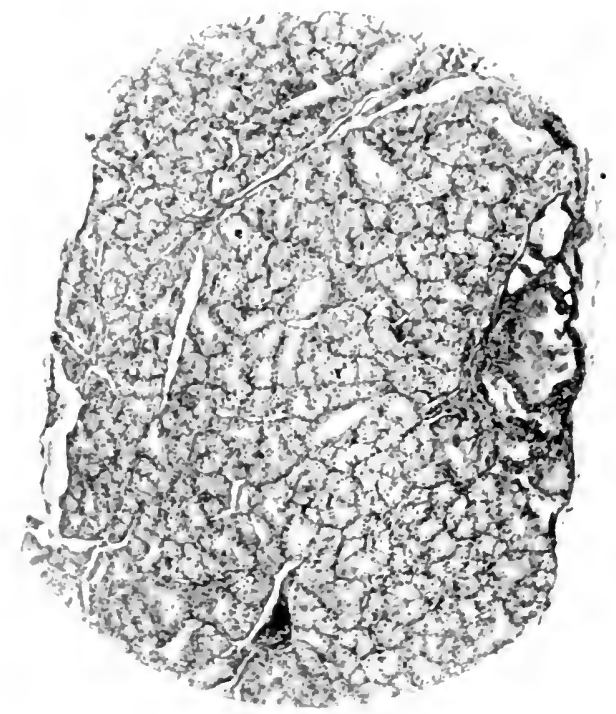

Fl1. 23.-Thyroin Glate! f Wild Rate ( 50.)

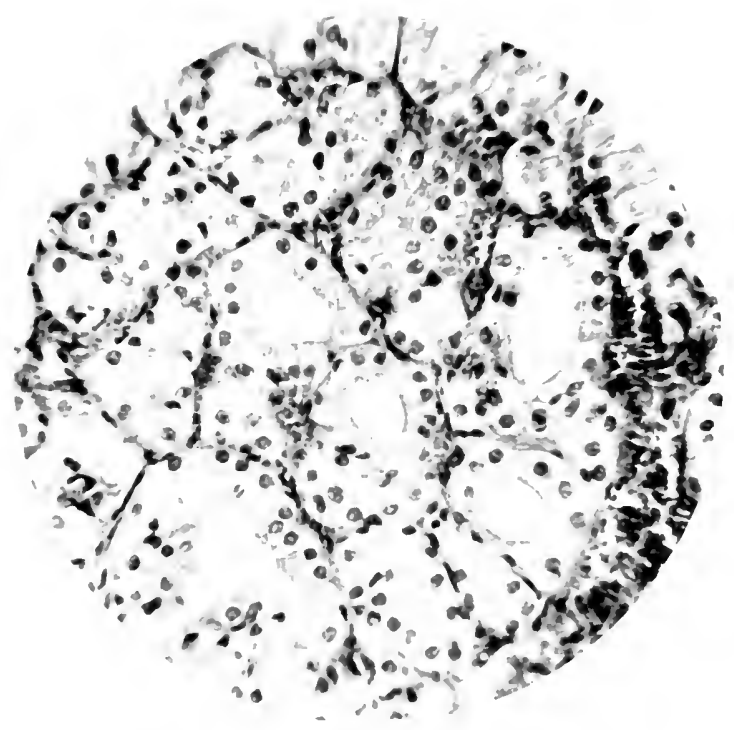

FIG. 24.-Thyroid Glind of Wild Rat, ( 250 .)

From same - precimen at that shown in Fis. 23 . 



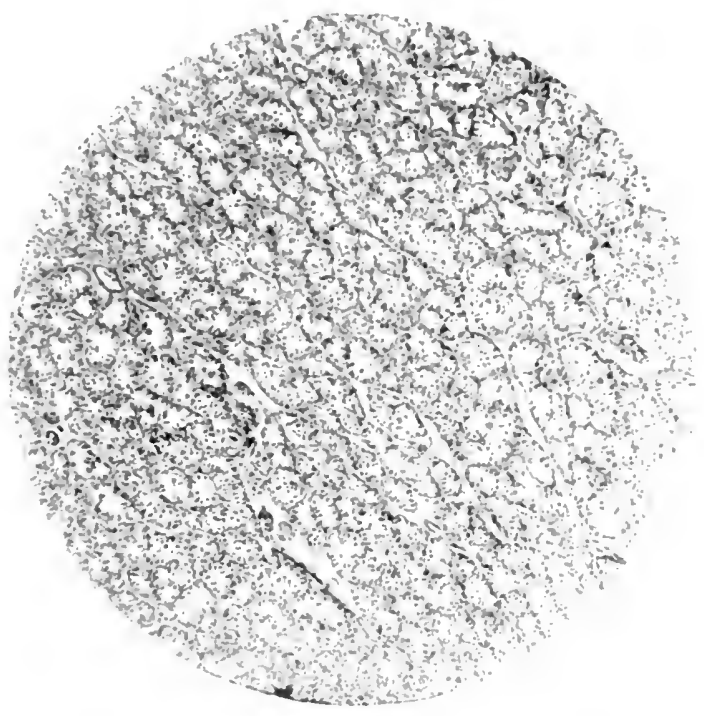

FIG. 25.-Thyroid (iland of Wild Rat. (50.)

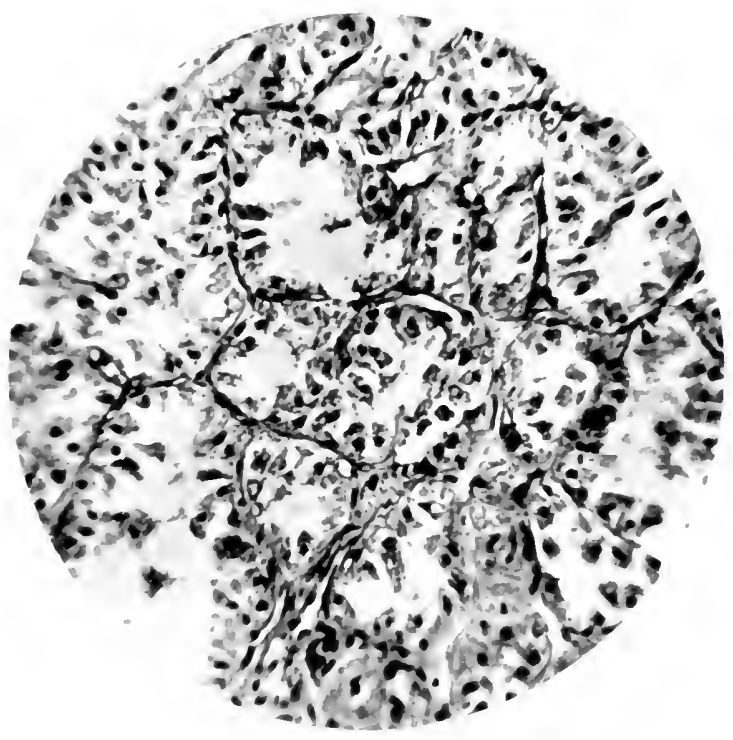

HIG. 26.-Thyroid (iland of Wild Rat. ( 250.)

From same specimen as that shown in Fir. 25. 



\section{Histological Apperarances.}

The microscopic appearances of the gland vary consilerably. In many glands the vesicles are litue (Fig. 19a) and full of colloid, which takes a very delicate pink stain with the hematoxylin and eosin stain ; a few of the vesicles may be empty or may contain a clear watery secretion. The secreting cells lining the vesicles are flat in character, and consist of a darkly stained nucleus with a very small amount of protoplasm in the body of the cell, the nucleus occupying the entire breadth of the cell. There is a relatively small amount of intervesicular glandular tissue (Fig. 20). Blood-vessels are inconspicuous. Fig. 2 I illustrates another type of gland which differs from the first chiefly in presenting a more cellular appearance and containing less colloid; as in the former instance, the colloid may be stained a delicate pink, or may have no affinity for the hamatoxylin and eosin stain. Blood-vessels are more prominent. On high-power examination the secreting cells are of a low columnar or cubical shape, the nucleus being of moderate size and circular shape, and occupying the entire breadth of the cell (Fig. 22). There is a moderate amount of intervesicular glandular tissue, the nuclei in these cells being considerably larger than those of the cells lining the vesicles. There are also glands intermediate in structure between those represented in Figs. $19 a$ and 20, and in Figs. 2 I and 22, respectively. The appearances represented in these figures were present in thirty-one of the series of forty animals; in twenty-six out of the thirty-one the type of gland was similar to that shown in Fig. I $a$.

A third type of gland is depicted in Figs. $19 a$ and $\mathbf{2} \mathbf{r}$, and is entirely different from 23 and 24 . The vesicles are small, and contain little or no secretion. Their contents take the form of a perfectly clear unstained or of a faintly stained granular material. The secreting cells are very large and prominent; the nucleus is large and situated at the basal part of the cell, there being a wide free margin of faintly granular protoplasm. In some vesicles the lumen is not sharply defined, the granular secretion in the vesicles being apparently continuous with the similarly stained protoplasm of the outer part of the secreting cell. The nuclei of the secreting cells are unequally stained, some of these presenting a pale, granular appearance. The gland appears more vascular than either of the foregoing, capillaries and large vessels being alike prominent. This type of gland was present in five of the series.

Yet another type of gland is illustrated in Figs. 25 and 26. The appearance here is different from all the foregoing, and at first sight is not readily recognisable as thyroid tissue. The normal arrangement of lumen and secreting cells is disturbed. The secreting cells are swollen and distorted, and many are detached and lie free in the lumen. There is no colloid. On high-power examination it is also seen that the majority of the secreting cells are swollen, distorted, and detached; others are smaller in size and are represented by a very small deeply stained nucleus with a small amount of granular protoplasm around. There are few blood-vessels. This type of gland was present in four 
of the ceries. These recults therefore show that the minute structure of the thyrnid sland in apparently henluly wild rats differs widely in different animals. The differences must, it seems to me, be explained in one or uther of the following ways. Fither the appearances represent differen stages of activity of the gland comparalule to those observed in other secreting slands, these variations being dependent on the stage of secretion; or they represent modifications in structure and function of the gland which have been induced by dietetic or other factors in the animal's enviromment. The former explanation seems not to hold good, since a careful investigation into the nature of the stomach contents in the different animals, along with a consideration of the microscopic appearances of the thyroid in each case, has yielded evidence against it. For instance, the appearances of the gland shown in Fig. 19a were observed both in animals in which the stomach was full and also when it was empty. And again, the different appearances represented in Figs. 23 and 25 were alike observed in animals in which the stomach was about one-third full, while in other animals with an equal amount of stomach contents the condition of the thyroid gland was entirely different from both. The second explanation seems, therefore, to be the more probable, the facts observed indicating that modifications in structure and function of the thyroid gland occur in association with different envirommental conditions. In view of the fact recently demonstrated by the writer. that certain diets modify the structural appearances of the thyroid gland in tame rats, it is reasomable to conclude that dict has been the chief factor in inducing the modifications of structure described in the present paper. In this connection it is of interest to note that it was observed that the thyroid gland of all the animals from any one source invariably presented the same general characters.

\section{XVI.-THE EFFECTS OF AN OATMEAL DIET ON THE THYROID GLAND.'}

There is ample clinical evidence that a dietary into which oatmeal larsely enters is one which is specially valuable for the growth and nutrition of children. In former days the diet of the people in many districts of Scotland included oatmeal as one of the staple ingredients, and, as is well known, this regime produced a big-boned and welldeveloped race. This being so, it is reasonable to think that there may be some ingredients in an oatmeal diet that have a favourable infuence on one or more glands whose functional activity is of special importance durin: the growing period-for example, the thyroid gland. Some facts in favour of the correctness of this hypothesis have recently been ascertianed. as follows:-

Six yourg rats about six weeks old were fed for four to eight weeks on a diet of uncooked oatmeal and water, an equal number of controls being fed on a bread-and-milk diet. At the post-mortem examination

1 Ch.liners Watson. British Medzcal Journal, vol. i., 1907. 


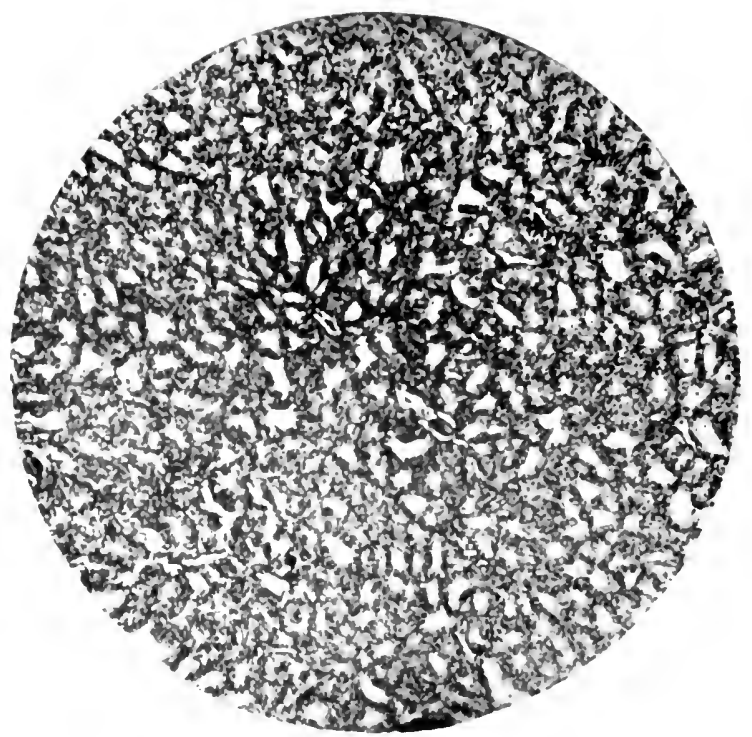

EIG. 2\%. - The normal appearnece of the Thyroid Gland of a Rat fed on tlee ordinary laboratory diet-lread and milk in known propottions. ( $\therefore$ 50.)

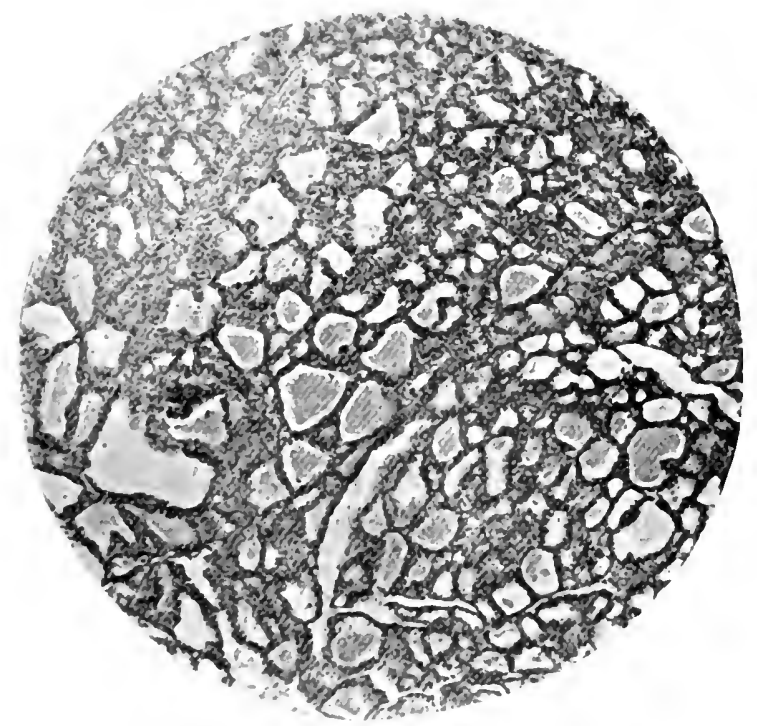

FIG. 28.--Thyrud (iland of : Rat of same age as Fig. 27, after being fed for six weeks on an catmeal diet. The grand is enlarged, the colloid being increased in amount and staining more deeply. ( 50.) 

the most striking feature was the thyroid gland in the oatmeal-fed animals. This gland was markedly cnlarged in the oatmeal-fed rats, the average perentago weight being 0.078 gramme, as against 0.029 gramme in the controls. Hintologically the slands of the oatmeal fed rats showed evidence of sreatly increased functional ativity (cce l.ig. 28 , and compare 27), with in two instances a swollen and detached condition of the secreting cells.

In a second series of six young rats which were fed on an exclusive porridge diet, the porridge being made with skimmed milk, a similar result was obtained.

These results appear to indicate that an excessive oatmeal diet has a markedly stimulating effect on the thyroid gland of young animals, and there seems no reason to doubt that a more moderate and more physiological use of the same food would be followed by a stimulation in a degree which would be wholly beneficial. It appears to me that we ma find in these facts the explanation of the vilue of oatmeal in the dietary of young children, the results furnishing the scientific explanation, in whole or in part, of the well-established clinical fact that porridge is an excellent food for children. In accordance with the teaching of these results, we should no longer regard oatmeal water as a mere diluent or as a convenient form in which starch may first be administered to an infant (Holt), but as a foodstuff of very special value for the growing child.

This brings me to a brief consideration of the practical aspects of the subject, my remarks being restricted to the use of oatmeal in children from the third year onwards. Ireakfast is the meal into which oatmeal should most largely enter, the best form of administration being porridge and milk, which should be followed by a glass of milk and some bread and butter. It is not, in my opinion, advisable to supplement the meal by meat in any form, for two reasons: First, because it is not necessary and may be harmful; and, secondly, because the use of the meat tends to create a distaste for the more wholesome but less appetising meal of porridge. If a child be given for its breakfast a little porridge, followed by bacon, it is certain that in nine out of ten cases, or an even greater proportion, the chief element in the repast, from the child's point of view, is the bacon. In this respect children are just iike young animals. In an extensive experience of feeding rodents on different dicts, I have never seen a young rat which would look at porridge or bread and milk if meat was available. We must, however, recognise two important reservations to this general recommendation of a porridge breakfast for children. In the first plare, a porridge diet, fier se, is not good for children on account of mastication not being essential for this diet. This fault may be counteracted by including in the diet crusted bread, rusks, Vienna rolls, and the like, which should be taken "dry;" and not mercly washed down with fluid, as is often the case. The inclusion of such articles of cliet in the breakfast will ensure that due attention is paid to the development of the muscles of mastication, salivary glands, and jawsa point of very great importance in the dietary of children. Secondly, 
clinical experience teaches us that certain children cannot properly digest and assimilate oatmeal. This feature is, in my experience, most frequently olserved in the oftspring of typically gouty parents. The parents of such children tell us that they cannot take porridge because of its "heating " properties, the objective indications of disturbed nutrition being found chiefly in it concentrated urine and in various skin eruptions These symptoms are, however, much less frequently observed if the porridge forms the main article of the meal and is not followed by other highly nitrogenous food, such as bacon and eggs, as is frequently the case. There are, however, some children who cannot properly digest and assimilate porridge, and these are better without it, but, if careful attention be paid to the details of the dietary as a whole, it will, $I$ believe, be found that these cases are much rarer than is commonly supposed.

\section{XVII.-THE CIIANGES IN THE STRUCTURE OF THE THYROID GLANI) IN WILD RATS UNDER THE INFLU- ENCE OF ALTEREI DIETETIC CONDITIONS.'}

In former papers the author has shown that diet modifies the minute structure of the thyroid gland in tame rats. The following investigation was undertaken to ascertain to what extent, if any, the thyroid of wild rats is influenced by a diet which is unusual for these animals. A series of twenty young wild rats, apparently healthy, was obtained from a hotel basement. (For reasons given later it is essential in such an experiment that all the rats be obtained from the same source and preferably at the same time.) Ten of the scries, of weights ranging from 60 to 130 grammes, were killed on receipt; the remaining ten were fed in the laboratory for ten weeks on a diet of bread soaked in skimmed milk. ${ }^{2}$ Under this regime the animals seemed to maintain perfect health, although it was observed that for a time their growth was retarded; their weight, when killed, ranged from 110 to 170 grammes. The thyroid glands were fixed in 5 per cent. formalin; the glands were weighed on the second day, the excess of fluid having previously been removed; one gland from eacl rat was carried through in the usual manner and stained with hiematoxylin and eosin, a section of each series being stained on the same slide. The average percentage weight of the gland of the rats in Series I -those killed on receipt-was 0202 gramme, that of Series 2-after ten weeks' feeding in the laboratory-.0265 gramme, which represents an appreciable increase in weight. There is a striking contrast in the histological appearances of the gland in the two series. In Series $\mathbf{I}$, where the appearances are uniform throughout, the vesicles are large and full of colloid which takes on a delicate pink stain with the hæmatoxylin and eosin stain; the secreting cells lining the vesicles are flat in character, and consist of a small darkly stained nucleus with a small amount of proto-

'Chalmers Watson, Journal of I'hystology, vol. $x \times x \mathrm{v}$., I907.

2 It is essential that the milk be not given in excess. 


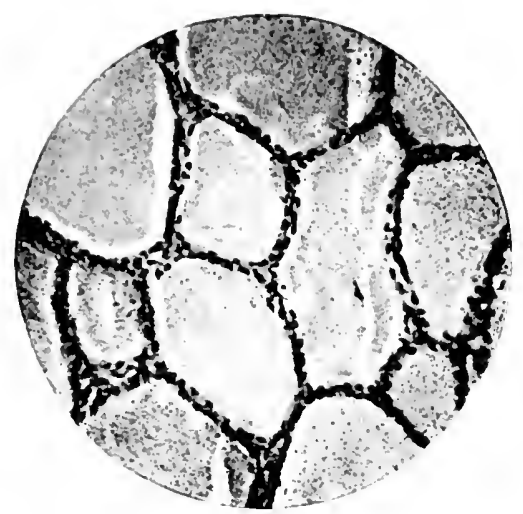

Fic, 29. - Thyroid Gland of Wild Rat (caught in a hotel basement) which was killed on receipt.

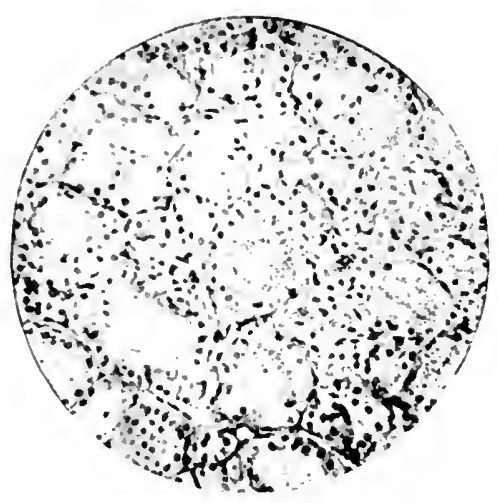

Fig. 30. - Thyroid Gland of Wild Rit from sume source as Fig. 29 after feeding for ten weeks on a trciul-and-milk diet. 

plasm in the body of the cell (Fig. 29). In Series 2 , where the picture is also uniform, the histological appearances are different from the above. The vesicles are for the most part small and contain little or no secretion. If colloid is present it appears as a thin unstained secretion, or as a faintly stained granular colloid. The cells lining the vesicles are large and situated at the basal part of the cell, there being a free margin of faintly granular protoplasm. The blood-ressels are more prominent throughout (Fig. 30). It should be added that in two of this series the histological appearances are intermediate in character between those represented in Figs. $\mathbf{I}$ and 2 . The striking difterences in the histological appearances of the glands in the two series might be due to either $(a)$ altered environment or (b) the changed diet. The former explanation seems not to hold good, since I have observed that in some wild rats obtained from a different source, and which were killed on receipt, the histological appearances of the thyroid gland were identical with those described in Series 2. The second explanation is therefore the more probable, and we have, I believe, in these results evidence of a modification in structure and function of the thyroid gland induced by diet.

\section{XVIII.-A NOTE ON THE ADRENAL GLAND IN THE RAT.}

In the course of an experimental investigation into the effects of varying diets on the structure and function of the tissues in tame rats, my attention has incidentally been directed to the various glands in wild rats. On post-mortem examination of wild rats it was found that the adrenal glands in these animals were considerably larger than in tame rats of similar weights. The explanation which suggests itself as the most likely one has reference to the greater muscular activity in wild rats, the changed diet of the animals may also be a factor. As the data so far obtained are of interest, and suggest a somewhat new line of inquiry as to the influence of different environmental conditions on the structure and functions of organs, I think it well to record the facts given in the following tables. The adrenal glands were in every instance weighed out of a 5 per cent. solution of formalin, the excess of tluid being previously removed.

Table I. gives the percentage weight of the adrenal tissue in twentyseven young tame rats, none of the animals being fully grown. Of these, eighteen were under 100 grammes, and nine weighed from 100 to $\mathbf{5} 50$ grammes. Table II. gives the percentage weight in nineteen fully grown tame rats. The average percentage weight is as follows:-

For the young animals under 100 grammes in weight

For the young animals not fully grown . . .

0.35 gramme.

$.023 \quad 1$

$.019 \quad$,

To turn to the wild rats, we find the ficts recorded in Tables IIl. and IV.

1 Chalmers IVatson, Journal of I'hysiology, 1907. 
TAl一t. I - Showing lenentage II itiph of aldinal cilands in lowoln: libss (tame).

\begin{tabular}{|c|c|c|c|c|c|}
\hline \multicolumn{2}{|c|}{$\begin{array}{l}\text { Wiviglat of } \\
\text { Animal. }\end{array}$} & \multicolumn{2}{|c|}{$\begin{array}{l}\text { Writhe of } \\
\text { Glauls. }\end{array}$} & \multicolumn{2}{|c|}{$\begin{array}{l}\text { F'rrentage } \\
\text { Woight. }\end{array}$} \\
\hline 52 & gums. & .022 & grm. & 0,2 & grill. \\
\hline 57 & . & .020 & , & .034 & $"$ \\
\hline io & $"$ & .020 & $"$ & .033 & $"$ \\
\hline 10 & ", & .024 & " & .040 & $"$ \\
\hline to & , & .020 & $"$ & .043 & $"$ \\
\hline "5 & ." & .024 & ", & .043 & $"$ \\
\hline 19 & " & .030 & . & .043 & $"$ \\
\hline 72 & ", & .023 & ., & .031 & , \\
\hline 73 & $"$ & .02 & " & .031 & " \\
\hline 77 & $"$ & .021 & " & .033 & " \\
\hline 77 & , & $.02 i$ & , & .032 & ". \\
\hline 77 & " & .024 & , & $.0: 2$ & ", \\
\hline Eo & $" 1$ & .023 & , & .035 & " \\
\hline$\therefore t$ & $" 1$ & .030 & $"$ & .035 &, \\
\hline$x-7$ & $"$ & .021 & " & .027 & $"$ \\
\hline$i z$ & 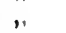 & .021 & 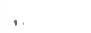 & .029 & $"$ \\
\hline 95 & ", & .021 & ., & .030 & $"$ \\
\hline \multirow[t]{2}{*}{93} & $"$ & .034 & " & .034 & $"$ \\
\hline & & \multicolumn{2}{|c|}{ Average } & .035 & $" 1$ \\
\hline \multicolumn{2}{|c|}{ I 10 gims. } & \multicolumn{2}{|c|}{$.032 \mathrm{grm}}$. & \multicolumn{2}{|c|}{.029 grm. } \\
\hline 115 & " & .023 & $"$ & .020 & $"$ \\
\hline 120 & " & .024 & " & .020 & $"$ \\
\hline 120 & $\because$ & .035 & " & .015 & 1 \\
\hline 140 & . & .041 & ." & .031 & ." \\
\hline 150 & $"$ & $.0+2$ & $"$ & .028 & ," \\
\hline 150 & $"$ & .040 & $"$ & .026 & ," \\
\hline 150 & $"$ & .030 & " & .020 & " \\
\hline \multirow[t]{2}{*}{150} & $"$ & $.02 S$ & " & .018 & ". \\
\hline & & & Average & .023 & $"$ \\
\hline
\end{tabular}

TALIF II.-Shorving Weight of Alivinal Glands in Fully. growen Talme liats.

\begin{tabular}{|c|c|c|c|c|c|}
\hline \multicolumn{2}{|c|}{$\begin{array}{l}\text { Weiplit of } \\
\text { Ambal. }\end{array}$} & \multicolumn{2}{|c|}{$\begin{array}{l}\text { Weithlit of } \\
\text { Twe lilands. }\end{array}$} & \multicolumn{2}{|c|}{$\begin{array}{c}\text { Percentate } \\
\text { Wuinlit. }\end{array}$} \\
\hline 110 & rims. & .028 & rim. & .026 & yin. \\
\hline 115 & " & .035 & " & .030 & $"$ \\
\hline 120 & " & .035 & $"$ & .029 & $"$ \\
\hline 145 & ", & .026 & " & .018 & $"$ \\
\hline 360 & ", & .040 & ,. & .025 & $"$ \\
\hline 16,5 & $"$ & .032 & $"$ & .019 & $"$ \\
\hline 170 & " & .024 & $"$ & .014 & " \\
\hline 182 & " & .034 & $"$ & .018 & " \\
\hline 185 & ", & .040 & ", & .021 & $"$ \\
\hline 195 & $"$ & .040 & $"$ & .020 & $"$ \\
\hline $2 \mathrm{I}$ & .. & .035 & ", & .014 & " \\
\hline $2: 5$ & ". & .031 & $"$ & .016 & " \\
\hline $2: 0$ & .. & .033 & $"$ & .013 & " \\
\hline 255 & 1 & (11i) & $"$ & .027 & ", \\
\hline $24: 5$ & , & 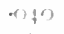 & " & .015 & .. \\
\hline $2 \times 5$ & . & $.01,5$ & ". & .022 & , \\
\hline 300 & " & .054 & " & .018 & , \\
\hline 310 & ", & $.0: 0$ & , & .016 &, \\
\hline 310 & $n$ & .058 & ", & .018 & "1 \\
\hline & & & verage & .019 & $" 1$ \\
\hline
\end{tabular}

TABLE III.-Showing Weight of Adrind Glands in Y'ourig liats (uillt).

\begin{tabular}{|c|c|c|c|c|c|}
\hline \multicolumn{2}{|c|}{$\begin{array}{l}\text { Wight of } \\
\text { Anumal. } \\
60 \text { grms. }\end{array}$} & \multicolumn{2}{|c|}{$\begin{array}{c}\text { Weight of } \\
\text { Two Glamls. }\end{array}$} & \multicolumn{2}{|c|}{$\begin{array}{l}\text { Percentage } \\
\text { Weight. }\end{array}$} \\
\hline & & .040 & " & $.05 x$ & \\
\hline 72 & ") & $.64 t$ & $"$ & .06 I & $"$ \\
\hline 72 & $"$ & .0 .14 & $"$ & .061 & $"$ \\
\hline 75 & $"$ & .050 & " & .066 & $"$ \\
\hline 76 & " & 011 & " & .053 & $"$ \\
\hline so & $"$ & $.07 t$ & $"$ & .092 & " \\
\hline $8_{3}$ & " & .055 & " & $\cdot 102$ & $"$ \\
\hline$\$ 5$ & " & $\left..0 r^{\prime}\right)$ & " & . $0 \$ 2$ & " \\
\hline 86 & " & .0513 & " & .067 & " \\
\hline 92 & ", & .058 & $"$ & .063 & $"$ \\
\hline 95 & ", & .052 & " & .054 & , \\
\hline$\left.y^{(}\right)$ & ", & .048 & " & .050 & " \\
\hline 93 & $"$ & $.05 S$ & , & .059 & $"$ \\
\hline 100 & $"$ & $.06 \mathrm{~J}$ & ". & .ofo & .. \\
\hline & & & terag & .066 & $"$ \\
\hline
\end{tabular}

\begin{tabular}{|c|c|c|c|c|c|}
\hline $\begin{array}{l}102 \\
106\end{array}$ & grms. & $\begin{array}{l}.068 \\
.065\end{array}$ & $\frac{1}{1 .}$ & $\begin{array}{l}.066 \\
.061\end{array}$ & $\begin{array}{l}\text { grm. } \\
\text { " }\end{array}$ \\
\hline 110 & ". & .054 & . & .019 & .. \\
\hline 130 & " & .116 & ", & .089 & .. \\
\hline 130 & $"$ & .160 & ", & .122 & " \\
\hline 140 & $"$ & .130 & ". & .092 & " \\
\hline \multirow[t]{2}{*}{142} & $"$ & 095 & $"$ & .066 & ." \\
\hline & & & Iverage & .077 & $"$ \\
\hline
\end{tabular}

TABIE IV.-Showving Weight of Adrenal Glands in Fully. grown Wild Rats.

\begin{tabular}{|c|c|c|c|c|c|}
\hline $\begin{array}{l}\text { Weig } \\
\text { An }\end{array}$ & $\begin{array}{l}\text { lit of } \\
\text { inal. }\end{array}$ & $\begin{array}{c}\text { Weigl } \\
\text { Glas }\end{array}$ & $\begin{array}{l}\text { tof } \\
\text { ls. }\end{array}$ & $\begin{array}{l}\text { I'erce } \\
\text { Wei }\end{array}$ & $\begin{array}{l}\text { tage } \\
\text { hit. }\end{array}$ \\
\hline 150 & rims. & .085 & $\mathrm{~m}$. & .056 & grm. \\
\hline 190 & " & .125 & " & .065 & $"$ \\
\hline 190 & $"$ & .105 & " & .055 & " \\
\hline 200 & " & .123 &. & $.06 \mathrm{I}$ & $"$ \\
\hline 207 & ", & .0133 & 11 & .044 & $"$ \\
\hline 220 & $"$ & .093 & " & .042 & $"$ \\
\hline 237 & $"$ & $\cdot 108$ & ", & $.0+9$ & " \\
\hline 240 & $"$ & .135 & " & .056 & " \\
\hline 242 & $"$ & .162 & " & .066 & .1 \\
\hline 260 & $"$ & . $16 ;$ & ", & .063 & $"$ \\
\hline 260 & 1. & .220 & "I & .084 & $"$ \\
\hline 26,0 & .. & .114 & , & .043 & " \\
\hline 270 &. & .134 & . & .049 & ." \\
\hline 305 & " & .120 & .. & .039 & " \\
\hline 34 & . & .170 & ,. & .050 & " \\
\hline 342 & , & .129 & ", & .037 & " \\
\hline 370 & $"$ & $.12 S$ & $\because$ & .034 & $"$ \\
\hline & & & verage & .052 & $"$ \\
\hline
\end{tabular}


In fiteen wild rats under 100 grammes in weight the averagc percentage weight of the adrenal tissue was ofo irramme als opposed to .035 gramme in the tame animals; in seven young animals not fully grown, between 100 and 150 grammes in weight, the average was 0.77 gramme as opposed to .023 gramme in the corresponding series of tame rats; in seventeen wild rats that were assuned to be fully grown, the average percentage weight of the glands was .052 gramme as opposed to 019 in the case of the fully-grown tame subjects.

The two noteworthy facts to which attention is directed are:-

(1) The greater amount of adrenal tissue in wild rats in comparison with tame rats of equal weight.

(2) In wild rats there is not the same disproportion in the amount of adrenal tissue in the young and adult subject as obtains in the tame rat.

\section{XIX.-THE EFFECTS OF CAPTIVITY ON THE ADRENAL GLANIOS IN WILD RATS.!}

In a paper published in the fournal of Physiology (vol. xxxv., p. 230), the author pointed out that the percentige weight of the adrenal glands in wild rats was considerably higher than in tame rats of equal weight. This suggested the advisability of ascertaining the effects of captivity on the size of the adrenal glands. Accordingly a series of twenty-five wild rats-nine young and sixteen fully grown-which were obtained at the same time and from the same source as those referred to in the original paper, were kept in confinement for ten weeks, and were fed on a diet of bread soaked in skimmed milk. The animals seemed to thrive well under this regime, but it was observed that for a time the rate of growth of the young rats was retarded. The adrenal glands were, as formerly, weighed out of a 5 per cent. formalin solution. The percentage weight of the wild rats kept in captivity was considerably less than that of the grands of the wild rats which were killed on receipt. The figures are griven in the following tables:-

\begin{tabular}{|c|c|c|c|c|}
\hline \multirow[t]{2}{*}{ Adults } & A. Original series (killed on receipt) & 16 & 190 to 370 & $\begin{array}{l}\text { Weight. } \\
052 \mathrm{glms} \text {. }\end{array}$ \\
\hline & B. After ten weeks' caplivity & 16 & 165,320 & $.038 \quad$ \\
\hline & & No. & Weight. & $\begin{array}{l}\text { Aver. Whight } \\
\text { Iner cemt. } \\
\text { Ailremal. }\end{array}$ \\
\hline & C. Original series (killed on receipt) & 8 & 10010150 & .076 grms. \\
\hline & D. After ten weeks' captivity & 9) & 110,150 & $.05+$ \\
\hline
\end{tabular}

This reduction in weight of the adrenal glands in wild rats in captivity must, it appears to me, be due to one or other of the following causes, either (a) the diminished muscular activity or (b) the changed diet of the animals. Further investigation is necessary to determine which of these factors has led to the reduction in the amount of adrenal tissue observed.

1 Chalmers Watson, Journal of t'hysiology, 1(yo8. 
XX.-THE STATE OF THE OVARIES DURING LACTATION, WITH SIECIA, REFERENCE TO THE LU IEAL TISSUE.!

The present investigation was undertaken to ascertain the histological appearances of the ovarics of animals killed during lactation, special attention being directed to the luteal tissue.

The material employed consisted of the ovaries of a consecutive series of wenty rats which were killed in the puerperium, at periods varying from thirty-six hours to twenty-three days after parturition. The ovaries show very uniform appearances in the entire series. The corpora lutea are large and visible to the naked eye as reddish excrescences on the surface of the ovary. On microscopic examination they present the size and appearance of the corpora lutea of pregnancy, being much larger than the corpora lutea which develop in the absence of pregrancy or lactation. It is obvious that this must be explained in one of the two ways:

(a) These bodies are the corpora lutea of pregnancy which do not degenerate in the later part of gestation in the manner commonly accepted, but persist throughout the lactation period; or

(b) They are developed from follicles which have ruptured at or shortly after parturition, and have attained a larger size than obtains in animals which are not nursing.

It is important to note that the corpora lutea of a rat thirty-six hours after parturition do not differ in size or appearance from those of animals killed when their young are weaned at the age of three weeks. This fact inclines me to the view that they are the corpora lutea of pregnancy. Whichever explanation turns out to be the correct one, the state of the ovaries described appears to indicate that the luteal tissue is functionally active during lactation.

\section{XXI.-THE EFFECT OF A MEAT DIET ON FERTILITY ANi) LACTATION.2}

In a paper on "The Influence of Diet on Growtl and Nutrition," in the Joumal of Physiology (vol. xxxir., p. 3), Dr Chahmers Watson showed that in rats a diet of ox-flesh begun when the animals were weaned interfered with the development of pregnancy, none of the four flesh-fed animals having young, whereas the control animals from the same litter all became pregnant. On the other hand, it is stated of three families fed on horse-flesh from the age of two and a haif months approximately, that all became pregnant, from which he concludes that "the use of this diet in animals of this age appears not to affect the supervention of pregnancy."

It was further found in the case of the meat-fed animals which became pregnant and suckled their young, that the mammary tissue was less dereloped than in the control bread-and-milk-fed rats.

1. I3. Watson, Journal of Phrsiology, wol. xxxiv., I 906.

${ }^{2}$ B. P'. Watson, P'rucedings of the lioyal Soctely of Edinburgh, vol. xxvii., $1906-7$. 
At Dr Chalmers Watson's suggestion I have extended these olscruations, and with a larger amount of material at my disposal am able to amplify his statements, and as regards the question of fertility slightly to modify them.

The method of conclucting the investigation was as follows :- Twelve female rats and several males were put on a head-ind-milk diet, and the females were continued on this throughout pregnancy and lactation. These served as the controls. Seventeen females and five males were pet upon an ox-flesh diet, but were otherwise under exactly the same conditions as the bread-and-milk animals. The animals were begun on the meat diet at various ages, from the second up to the fourth month, and some of them were kept on the diet for as long as five months.

I. Effect of a meat dict on fertility.-Of the seventeen animals fed upon a meat diet only eight became pregnant, and of these four bore young within twenty-one days--the usual gestation period in the rat-of being put on the diet, so that only four actually conceived while on the diet. Of these latter one had been twenty-four, one twenty-five, one twenty-seven, and one thirty day's on an exclusive ox-flesh regimen

The other nine animals, although kept for several months, did not conceive, and this in spite of the fact that they were seen to copulate freely right up to the end of the experiment. This reservation must, however, be made, that one of these nine animals probably had young which were eaten, and it is just possible that this happened in other cases. It is not at all probable, however, as the animals were frequently carefully examined, and if there was any indication of their being pregnant, were at once transferred to separate cages.

Of the twelve animals fed on a bread-and-milk diet, all became pregnant and had young, so that we may conclude that a meat diet is decidedly prejudicial to the occurrence of pregnancy in rats when the diet is begun when the animals are from two to four months old.

In order to determine whether the fault resided in both sexes or in only one, a fresh male which had been fed on bread and milk was put beside the sterile females which had been on meat for several months. When the animals were killed, some time after, one of them was found to be in an early stage of pregnancy, and must have been impregnated by the bread-and-milk male.

This would appear to indicate that the cause of the sterility is partly due to the male, but we have not had sufficient material to form any more definite conclusion regarding this.

2. Effect of a meat diet on lactation.--For this part of the investigation the same animals were used, viz., the twelve controls fed on bread and milk, and the eight meat-fed animals which became pregnant. The point specially attended to was the weight of the nammary tissue of the animals killed after suckling their young for varying periods.

In the nursing rat the mammary tisste forms a continuous sheet spread under the skin of the abdomen on each sicle of the middle line. In addition there are extensions of it into the axilla, up along the neck and into the groins, while in some cases it spreads out so much laterally 
as almost to reach the back. The nipples are in a double row extending from thorax to the groins.

The animals were killed at different periods during lactation. The weight of the mother and the number and weight of the young at the time of death were ascertained. The skin and subcutaneous tissuc of the mother's abdomen was immediately removed down to the muscle, care being taken that no mammary tissue was left behind in the axillix or in the groins. Tlye skin was put into 5 per cent. formalin for a few days, when it was quite easy to separate the mammary tissue from the skin on one hand and from the areolar tissue on the other. If an attempt were made to strip the mamme before first fixing in formalin, it was found that a great deal of milk was squeezed out. The immersion in formalin prevented this, although it extracted a small quantity of milk, as shown by its cloudy appearance at the end of twelve hours. It is to be understood, then, that the mammie were weighed out of formalin.

The basis of comparison between the meat- and the bread-and-milkfed rats is the percentage weight of the mammary tissue to that of the mother.

liy a reference to the tables below it will be seen that there are wide individual variations in this percentage among the bread-and-milk animals.

\section{Table giving the Lactation History of Eight Rats fed on an Exclusize Ox-Flesh Dietary.}

\begin{tabular}{|c|c|c|c|c|c|c|}
\hline $\begin{array}{c}\text { No, of llays } \\
\text { on Moal } \\
\text { before } \\
\text { Parluriturn. }\end{array}$ & $\begin{array}{l}\text { Weigldt of } \\
\text { Animal } \\
\text { at Deall. }\end{array}$ & $\begin{array}{l}\text { Weight of } \\
\text { Maumme. }\end{array}$ & rer cent. & $\begin{array}{c}\text { Time in } \\
\text { lactation } \\
\text { when Killed. }\end{array}$ & $\begin{array}{l}\text { Number of } \\
\text { Young. }\end{array}$ & $\begin{array}{l}\text { Wright of } \\
\text { Young. }\end{array}$ \\
\hline & Grms. & Girms. & & & & Grms. \\
\hline 30 & I 80 & 13 & $7 \cdot 2$ & Ist day & 10 & 50 \\
\hline () & 140 & $8 \cdot 5$ & 6 & Ist dity & 10 & 49 \\
\hline 27 & 230 & 19.5 & $8 \cdot 4$ & Ist day & $\ldots$ & $\ldots$ \\
\hline 25 & 150 & 13 & 8.6, & 7th day & 5 & 48 \\
\hline 12 & $1 I_{5}$ & 10.5 & $9 \cdot 1$ & 20 h day & 6 & 120 \\
\hline 15 & 130 & 12 & 0.2 & 21 st day & 7 & 185 \\
\hline $2 i$ & 110 & 10.1 & $9 \cdot 1$ & 21 st dity & 6 & 110 \\
\hline $2+t$ & $1+0$ & $11 \cdot 5$ & $8 \cdot 2$ & $22 n d$ duy & 4 & 82 \\
\hline
\end{tabular}

Average percentige $=8 \cdot 2$.

This is explained by the different times during the course of lactation at which the animals were killed, and also by the varying numbers of young which they suckled. Thus there is a fairly uniform rise in the percentage from the first up to the twenty-first day, after which there is again a fall; and taking animals killed at the same lactation period, the percentage is higher in those which nursed the larger number of young.

We may therefore take it that the mammary grland in the rat is most actively functioning about the twenty-first day of hactation, and after this, as the young begin to feed themselves, it undergoes atrophy. 
It will be seen that the average percentage weight of the manmax of all the bread-and-milk animals is $9 \cdot 6$, while that of the meat-fed ones is only $S \cdot 2$. This difference would in all prohability have been greater but for the fact that the average number of young suckled by the bread-andmilk animals was only 4.6 , while that of the meat fed animals was $6 \cdot 3$.

As before stated, the longest period before the bith of the young during which the mother had been on a meat diet was thirty days. Taking this into consideration, the difference is sufficiently marked to point to the conclusion that the result of a meat diet is to diminish the amount of mammary tissue in nursing mothers.

\section{Table giving the Lactation History of Turlve Rats fed on an Exclusive Bread-and-Milk Dietary.}

\begin{tabular}{|c|c|c|c|c|c|}
\hline $\begin{array}{l}\text { Weight of } \\
\text { Animal } \\
\text { at Death. }\end{array}$ & $\begin{array}{l}\text { Weight of } \\
\text { Manme. }\end{array}$ & Per cent. & $\begin{array}{l}\text { Time during } \\
\text { Lactation } \\
\text { when Killesl. }\end{array}$ & $\begin{array}{l}\text { Sumber of } \\
\text { Young. }\end{array}$ & $\begin{array}{l}\text { Weight of } \\
\text { Young. }\end{array}$ \\
\hline Grms. & $\begin{array}{l}\text { Grms. } \\
12 . ;\end{array}$ & 8 & & 7 & $\begin{array}{c}\text { Grms. } \\
\hat{3} 2\end{array}$ \\
\hline $\begin{array}{l}147 \\
140\end{array}$ & $\begin{array}{l}12 \cdot 5 \\
10\end{array}$ & $7 \cdot 1$ & 3rd day. & 7 & 45 \\
\hline I So & I8 & 10 & 6 th day & 7 & 70 \\
\hline 225 & $18 \cdot 5$ & $8 \cdot 2$ & Ioth day & 7 & 115 \\
\hline 120 & 17 & $14 \cdot 1$ & 21st day & 5 & 150 \\
\hline I 40 & 19 & $13 \cdot 5$ & 2Ist day & 7 & 220 \\
\hline II 5 & $7 \cdot 5$ & 6.5 & 2 Ist day & 3 & 120 \\
\hline I 30 & II $\cdot 5$ & $x \cdot n$ & $22 \mathrm{nd}$ day & 4 & 100 \\
\hline 160 & 19 & $11 \cdot 2$ & 25 th day & 7 & $I+5$ \\
\hline 160 & 15 & $0 \cdot 3$ & 3oth day & 6 & 175 \\
\hline I 30 & 13 & 10 & & 6 & $\ldots$ \\
\hline 150 & $13 \cdot 5$ & 9 & 27 th day & $\cdots$ & $\cdots$ \\
\hline
\end{tabular}

Average percentage $=9 \cdot 6$.

The effect of this relatively poor mammary development on the young of the meat-fed rats is shown by a comparison of their weinhts with those of the young of the control animals towards the end of the lactation period. Thus the average weight of each of the young of the meat rats at the twentieth to the twenty-first day is $2 \mathbf{r} \cdot 6 \mathrm{grms}$., in contrast to 29.4 grms., the average weight of each of the bread-and-milk young. It is thus evident that the young of the animals fed on meat suffer in general nutrition and growth, as compared with those whose mothers are on a bread-and-milk diet.

Whether this is due to a mere deficiency in the amount of milk available for their use, or to some alteration in its constituents, has not been determined, but the probability is that the former plays a large part.

(In microsiopic cxamination there are no mated differences in the histological chararters of the mammary tissues. The charater of the glandular tissue varies according as the acini are full of serretion or empty, and while the mamme of the meat-fed animals show a pre. ponderance of closely-packed empty lobules, this may only be due to the 
fact that the mothers had been killed shortly after the gland had been emptied by suckling

\section{Conclusions.}

1. That a meat diet is prejudicial to the occurrence of pregnancy in rats.

2. That in rats fed on a meat diet the mammary development of nursing mothers is less than in rats fed on bread and milk.

\section{IXII.-A RICH PROTEIN DIET IN RELATION TO GOUT ANI) THE 'IIYROII) GLAND.'}

At the present time, in existing text-books and otherwise, the subject of diet in its scientific and clinical aspects is studied from two standpoints and two standpoints only. These are: (1) from the point of view of the chemical composition of the food-that is to say, the amount of protein, fats, and carbohydrates and salts in the dietary; and (2) from the point of view of the caloric or heat value of the food.

In the course of the past few years the observations of the writer liave shown the necessity of regarding the subject from a new standpoint, viz.-

(3) The influence of particular foods on the structure and functions of the tissues.

This subject is a very large one, and our knowledge of it is yet in its infancy; and what I propose this evening is to ask your attention to certain points in the effects of a rich protein or rich purin diet in relation to one disease (gout) and one organ (the thyroid gland).

My earlier investigations dealt with the influence of an exclusive meat diet, administered, uncooked, on the structure of the tissues, and notably the thyroid gland, kidneys, and mucous membranes.

These showed that the structure and functions of these tissues were as a rule modified, and some of these modifications were acquired by the offspring, and were associated in them with an increased susceptibility (1) discase, notably catarh of the different mucous membranes. The results therefore showed (what, after all, might well be expected) that dict modified the "soil" in animals, and suggested that similar modifications in structure and function would hold good for man.

II results, and the conclusions drawn from them, have received a fair share of adverse criticism, firstly, from the cxperimental standpoint, and secondly, from the clinical.

Let us deal in the first place with the criticism of my fellow-clinicians. It was urged by clinicians in this and other societies, that it was not permissible to draw any deductions from the results of my experimental investigations applic able to conditions oftaining in the human subject. It was urged that the farts of my dealing with (1) an exclusive meat dict, and (2) arlministering that dict in an uncooted form, were conditions so dissimilar to those in the human subject as to preclude any deductions

' Chalmers Watson, Transactions of the Edmburgh Wedico-Chururgical Society, 1910. 
being drawn from my results applicable to man. There is undouldedly something in this criticism, but I think much less than is at first sight suggested. The matter, however, was essentially one for further investigation, from the experimental standpoint, aloms lines whirh would remove these oljections, and this has been cirrited out, with the results to be immediately referred to.

A more serious criticism has been directed from the experimental standpoint. Thus Forsyth writes :-

"Accepting for the moment the conclusions of Chalmers Watson, it would be expected that the thyroid glands of birds of prey would show to a marked degree the features he has ascribed to excessive protein feeding. It should be found that ( 1 ) the thyroids of these birds consist of large vesicles filled with colloid, so that the intervesicular glandular tissue is diminished; and ( 2 ) that the thyroids of non-raptorial birds, when contrasted with them, show vesicles of comparatively small size, a not over abundant secretion of colloid, and an average amount of intervesicular glandular tissue. In the specimens l have examined I find that this relation does not exist, and that not only were the structural characters which we were assuming to be associated with meat feeding not specially marked in carnivorous birds, but in some cases the exact contrary was prominent." He then proceeds to demolish to his own satisfaction my position by concluding from these data that there are no peculiarities of microscopic structure referable to difference in their natural foods.

Forsyth, I think, fell into error in two directions. In the first place, he has drawn in the above statement a deduction from the facts and statements made by me which is entirely unwarranted. Further, he failed to recognise in dealing with birds dying in captivity in the Zoological Gardens, that many of the animals in virtue of their malnutrition and emaciation at death had been living on their own protein tissue. In such cases it does not matter whether the natural diet of the bird in question be exclusively vegetarian: the practical point is that at the time of its death it had been living on its own protein tissue. In the same way, I have no doubt that the thyroid gland of certain men and women whom we occasionally see in a miserable state of health and malnutrition from living on an exclusively vegetarian dietary of a very unfavourable kind will present a character similar to those associated in others with the ingestion of excess of animal protein food.

Forsytli's paper was published in 1907. Since that time I have carried out a further series of investigations into the effects of a rich protein diet on the structure of the thyroid gland and other tissues. The diet employed was a mixed one, a nsisting of minced ox-tlesh, lentils, and bread and milk, the two former ingredients largely predominating. The diet is one rich in protein and also rich in purins. These observations have been carried out on a large scale, and the effects of the diet on the thyroid gland noted in animals in the first, second, and third generation. A full account of these observations will shortly be published. The results amply confirm my earlier observations, in showing 
that a rich protein liet modifies the structure of the thyroid gland. This may be shown by a marked increase in size of the gland as at whole, and by alterations in the number and arrangement of the sccreting cells or vesictes of the gland. The rich protein diet at forst stimulates, and later exhausts the glime. The diet can be shown to have modified the soil in a manner which increases the susceptihilty to disease. Now there is no reason to loubt that under the conditions described, what is true of animals is also true of man. And I submit that conditions, for practical purposes identical to those lescribed, are seen by us every day, that these are inducing similar maybe less in degrce-modifications of structure and function of the tissues, with corresponding modifications in susceptibility to disease. My experience of the clinical features of gout in its varied forms in the light of the results of these researches led me in 1907 to conclude that "the subjects of inherited or acquired gout have acquired from their environment, which includes diet, a type of thyroid gland which is abnormally active, and which works, so to speak, at high pressure." Further clinical experience, and the results of later investigations have in my mind confirmed and at the same time amplified this view. The amplification is of great practical importance. I have shown how the structure of the gland can be modified in animals, and more especially in young animals, by sustained feeding on a lacto-vegetarian diet (see p. 604). And 1 have little doubt that the beneficial effects of an exclusive milk diet, or a lacto-vegetarian diet, which we are all obtaining in certain cases every day, are largely the result of the special influence of this regimen on the thyroid gland.

Dealing with our special subject, gout, this disease is essentially a disorder of protein metabolism. In its etiology there are probably two main factors :-

(1) A particular diathesis in soil, in which, as I have already indicated, one of the distinctive features is a special type of thyroid activity.

(2) A superadded infective element. It is now some eight or nine years since I first submitted, and I think to this Society, the view that there was an infecive element in gout. That view, although based on some definite new facts in the pathology of the disease, did not then commend itself to my critics. It is of considerable interest to mention that after the short period of eight or nine years, probably more than 50 per cent. of writers on this subject in this and other countries now accept this view-which, however, is not yet fully proved. Gcuty subjects are, in virtue of their diathetic tendency, specially prone to a particular type of auto-intoxication or infection, which is responsible for various gouty symptoms.

In expressing these views 1 am well aware of the existence of certain facts which appear at first sight to disprove it: I refer to the cases, by no means very infrequent, of gouty disorder in patients living on an almost meat-free diet, in which relief from the gouty manifestations is obtained by putting the patient on a diet which contains much animal protein and very little farinaceous foods. I have treated many such, and 
have made a special study of them. These are in my experience cases in which, in addition to a probate thyroid defect, there is a certuin pancreatic disturbance, as can be proved by finding a fronounced pancreatic reaction in the urine. This reaction in these cuse, shows that there is a defect 1 ralwhydrate metibolism, and that the pancreas is working under difficulties. If that is recosuised and the patient treated accordingly, relief from symptoms will very quickly be obtained. We know, from the writings of Dr liyrom Hramwell, that there is such a condition as pancreatic infantilism; thyroid infantilism is even better known. If time had allowed I might have referred to other interesting points touching on the relationship which exists between the pancreas and thyroid.

I must, however, content myself with pointing out that the fact of the benefits undoubtedly obtained in certain cases by a relatively rich protein diet cannot be regarded as in any way antagonistic to the general view set forth in my paper.

Many interesting clinical facts ran be cited bearing on the above views-some of them deal with the antagonism long recognised between tuberculosis and gout. Time will not, I fear, allow me to elaborate these. I would have liked to consider in detail the clinical effects of a judiciously selected rich protein diet in favourable cases of tuberculosis in children and young adults. The small, thin, flabby, anxmic, tuberculouslooking subject gives place to the large, muscular, high-coloured, goutylooking individual. This is $n 0$ fanciful picture. I have had under my own care weakly children with the most prominent tuberculous family history, which were treated with a rich protein diet for two years or more, and I have seen these children in later years present many of the clinical features which we associate with the gouty diathesis. A similar condition is seen in favourable cases of tuberculosis in young adults. Then as to the converse sicle of the picture. Consider the great muscular development, the great bodily activity, the active circulation, and the susceptible liver and skin of the gouty child. The active growth and the great muscular development are here clear indications of a more than usually active thyroid system. We know that these cases are beneficially infuenced by a restriction in the amomst of animal protein foods, and in later life we often see these people, of their own accord, cutting down the animal food-often consideralbly, and we also see them sufiering from so called gouty ailments which are beneficially influenced by the administration of small doses of thyroid glind. 



\section{N D E X}

A BDominal, operations, diet after, $3+5$ tuberculosis, +t I

Absorbability of toods, 5

Absorption of calbohydrates, 12 of fats, II

of proteins, II

of salts, I 2

of water, I2

Acetonuria inchildren, 262

Acid intoxication, 349

Acidity, excessive, 326

Acidosis, 349

Acidosis in children, 262

Acids in fruits, 105

in wine, 147,149

Acne, 519

Acorns, II 3

Acute fevers, diet in, 267 alcohol in, 276

Adenoids, 193

Adulteration of food, 190

Adults, food requirements of, 20

Aerated bread, 92 distilled water, I3t

water, 134

Agar-agar in vegetarianism. 525

Aged, food requirements of the, 20, 203

Albany food, 169

Albumin, vegetable, 79, 470, 522

water to mike, 47

Albuminuria. 417

of pregnancy, diet for. 214

Albumoses, 8

\section{Alcohol, 140}

Alcohol in heer, $I_{4} 6$

effect on cardio-vasculor system, I 42 on digestive system, 143

on energy production, $14=$

on heat production, 142

on muscular system, I 43

on nervous system, $1+3$

effects of, on metabolism, I +1

of, on tissue waste, I 42

in acute disease, 152

in children's diseases, 203

in chronic disease, 152

in fevers, 152
Alcolıol in gout, 153

in heart disease, I 52, fo2

in influenza, 1 53, 290

in obesity, $\mathrm{I}_{42}$

in pneumonia, I52, 288

in theumatism, 153

in typhoid fever, 285

in wines, I 47

nature of, $1+4$

source of, $14 t$

use in surgety, I $\$ 0$

uses of, $15 \mathrm{I}$

Alcoholism, 502, 503

Alderney cow's milk, 30

Ale, $I+7$

Aleuron, 168

Aleuronat, 168

Aleuront cakes, 478

Algx, I I 4

Alimentary glycosuria, +86

Alkaline waters, I 34

Alkaloids in intestine. 17

Allenbury food for infants, 240

No. I food, 158

No. 2 food, 177,241

No. 3 food, 182,184

Allspice, 130

Almond lisead in diabetes, 479

cakes in diabetes, $476,+77,479$

flour in diabetes, $475,+77$

oil, so

porridge, 48 I

pudding, 486

Almonds, I 12

salted, 112

Alum in t real, 9 I

American chece. e. +3

American Swiss fod, 170

Amicles, 80

Amino acids, 9 :absorption of, II

Amyl alcohol. It

Amylopsin in infincy, 228

Anremia, 381

Ansemia in children, 266. 381 lactic bacilli treatment of. $5+3$ pernicious, $3 S 8$ 
Ansmia, primary, $392 \quad 39 \$$

Aneurism, fos

Angina pertoris, diet in, 407

Angh-siri.s ondensed milk, 156 fond, 170

Anmol fats, puritied, fl

Animal foods. 50

Animal sised t.1. 57

Ani citce, $1 f^{\prime \prime}$

Anorex a in tulerculosis. 128

Antiscorbutic property of fruits, 105 of milk, 32

of vegetithes, I I 5

Anticeptics and food, 189

A tweiler's peptones, 179

Aprental witer, 135

Apullinaris, 133

Apoplexy, diet in. 507

Appendicitis, 365

Apperite, loss of, 18

Apple toust water, 275

Apple witer, 275

Auples, 106, 108

Apricols, 106,109

Arturath smokies.62

Arctic regions, fool for, 26

Armour's hicef juice, compesion of, I' 5

extrit i, compusition of, 163

s. lut le beef, I's

wine f peptone, 179

Arrowroor, 116, 297

Artervo-sclerosís. 394

Arthritis, rheumatoid, 465

Artichole, green, 19 Jerucalem, 116

Artificial feeding of infunts, 235, 24I

Aspiarigin 80

in potate, 115

Asparagus, I19. I 22

Ass. mik of $29,33,235$

Asthen at pancreatic origin, 378

Asthrn:s, $:$ It

Athle:es, effects of alcohol on, I +3

food required, 25

Atwater on food requircments, 20

Austrilian wines, I 50

Auto-intoxication, $\mathbf{3 4 6}$

Autr-intoxiration, I7

effects of, on digestion. I 8

fermentution ciless, $3+7$

putrefiction cases, 348

As nine, 88

iyle:tury diary food, 16,7

BAsi, weakly, diet for, $2+8$

Pacillus acidi lactici, $31,5 \div 0$

bifidus in fices, 229

botulinuc. Int

butyricus, IgI

coli in facces, 229
Bacillus enteritilis, I9I

lactis arogenes in ferces, 229

Batkhaus milk, 176

Bacon, 58

lakej, 197

fried, 196

method of cooking, 196

rashers, $19^{6}$,

rolls, 197

to:sted, 197

Bacteria, action of, in digestion, is action of, on proteins, 16

on carbohydrates, 16

in feces of infants, 229

in milk, 236

wutrefactive, 16

B.in-Marie cooking-pot, 69

Butird bread, 93

pudding, 298

custard, 299

fish in convalescence, 305 flour, 274

Baking, 66,68

B.king-powder, adulteration of, I 90 powders in breadmaking, 9 I

Binana, I I

coffee, III, 525

Bananas, composition of, 106 dried, III

flour, 524

outs, 524

Banting system, 494

Barberries, I 10

Barcelona nuts. II 3

Bardswell and Chapman, diet in tuber. culosis, +2 I

Burley, 100

malted, I 4

meal, 100

gruel in convalescence, 296

sugar, $8_{3}$

water, IoI

as diluent for milk, 238

method for making, 34

Batter pudding with invalid food, $15^{8}$

Beans, 103

butter, IO4

composition of, 103

kidney, I03

soya, 104

Beech nuts, II 3

Bee?, 50

Beef, boiled, 6,8

tr th, 73

canned, 188

composition of, 50

diugram for cutting, $\$ 2$

essence, 77

essence in acute fever, 272

extracts, 75

fat, 5 t 
Beef jelly, 77

juices, composition of, 165

as a liet in fever, 270

meal, 166

peptones, 176

peptonoids, 179

powdered, ito

purce, 77

quenelles for convalescence, 312

refrigerated, 188

roast, 67

smoked, 187

stewed, 70

Beef-tea, 75, 162

Beef-tea grticl, method of making, 77

in fever, $27 \mathrm{I}$

jars, 76

methol of m.1king, 76, 77

nutritive value, I6I

tabloids, I 67

uses of, 163

\section{Beer, 148}

Beer, alcohol in, Ift

light varieties, $I+6$

Beet sugar, 82

tops, 119

Benedictine. 146

Benger's foud, I 83

for infants, $2+1$

pancreatised lentil flour, I 83

peptonised beef jelly, 179

jellies, I 78

Bermaline bread, 94, 293

\section{Beverages, 132}

Beverages, alcohol percentage. I. 44 classification of, I 36

for the gouty, 453

\section{Blliousness, 370}

Biogene powder. source of milk, $474,47^{6}$

Bipsine bread, 293

Biscuits, 95

Akoll, 476

casein, in diabetes, 476

for children, I 97

Kalari, 476

Plasmon, in diabetes, +79

Rislacto, 476

Black berries, I06, I 10

Black-currant drink, 276

Blackwheat, 99

Bladder, tuterculosis of, 439

Blancmange, $30 \mathrm{I}$

Blancmanges, peptonised, 175

Blatchley, London, breid lools from, 475

Bloaters, 63

Blood, diseases of, 380

Blood as a food, 57

salts in, I 25

Blood-pressure, increase of, diet for, $394,39^{8}$
Boiling, 65, 6,8

Bomb calorimeter, 3

Bone-matrow, $57,[1,7$

Bones, 57

Boratge, I [ [

Borax in milk, 37

Boric acil in food, Is9 in milk, 37

Bottles, feceling, 245

Botulism, 1yt

Bovillon Ficet, composition of, $\mathbf{I} \mathbf{6}_{3}$

louquet of wiries, $1+7$

Bowinine, I 65

Bovril, becf juice, 163,165 custard, 49

Braising, 70

Bran, 88

bread in diabetes, 177

flour, +75

Brand's beel bouillon, 103 peptone, 179

tea, 162

essence, I 63

fever food, 167,270

meat juice, 165

mutrient powder, 167

Brimdering, 68

Brandy, I $+4,1+5$

Brizil nuts, II 3

Bread, 90

Bread. atisolption of, 92

aerated, 92

taked, 93

bran, 93

brown, 93

Casoid, in diabetes, +76

composition of, go

crumbs and milk, 439

diabelic, 476

digestion of, 92

easily digested, 320

from millet, 99

from rye, 99

malted, $9 .+$

nutritive value of, 92

l'rotene, 478

pudling, 298

sauce, 306

substilutes in diabetes, 475

Tritumen, $\$ 76$

unfermented, 92

varielies of. 93

Breadmaking, 90

fermentation process, co

Bireadstuffs for cliblaren, 197

Breast-feeding, 231

Brewing, $I+6$

Bijll, 62

liriskel of beef, 52

lisirish beer, $1+6$

British gum, 8I 
Broud herm, 103

Broceoli, $1 \mathrm{~s}$

Broiled intuhen in oumbilescence, 308

Broiling, w

Bromchits, acute, 513

chunic 513

Broncherpromonia, 513

brose, itit

Broth, shiken, 300

for children, I ys

mution, 300

veil, 200

Brown bie.de, 93

Brussels sprouls, IIS

Buckwheal, 9u

Buddised milk, 16 I

13ulgarian bacillus, $5+1$

Bullace, ron

Burgoyne 's meat juice, 165

Burgundy, 150

Bustuyer method of diet in syphoicl, $23_{5}$

Bubler, 4

adulueration, 100

beans, 104

vegetilile, 80

Buttered toast, 93

Butterine, \&1

liunernilk, $35+3,5+3$

changes with age, $5+3$

digestibility of, $5+2$

for infants, 23\%, 253

Butyric acid backeria, 16

By?tn, I 8 I

CAMHAGFS, II7, I18

Ciadaverine, 16

Citlé zylak, 17 h

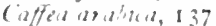

Citfeime in colfce, I 38

in 1 eit, 137

Cakes, 95

Calrium, 23, 126

Calculu, bilialy, 373 ren:il, 418

Cislf's-fu i jelly, 273

Californian wines, 150

Callard's diatetic fools, 475

Cilories, food terjuired, 3, 21

Calorimeter, 3

Calves' trains, phophorus in, 2 4

Cincer of liver, $\left.3 F^{+}\right)$ of stomach, $3+3$

Cane sugat, 82

Canned corti, 93 foods, 188

Cipon, 58

Cispsicum, 129

Ciramel, 83

Carbohydrates. 79

Carbolydrates atsorption of, 12
Carbolyylrates, action of bacteria on, (1)

as photein-sparers, 13

cxcess of, callece of lichets, 260

lus children, loge

in cere:ils, siz

in wilk, 3I, sit

ill toleess, 115

met:tbulism of,

over-indulgence in, 217

predigrested, I75

proprietity foods, 168

tissue-builders, 2

Cilloon required, 2 I

Cabonited waters, 134

('isbonic acid in intestiue, 16

Cardiac valvular disease. 402

('arlsbid regime in obesity, 497

Carnine Lefranc, 534

('unrick's liquid peptonoids, I7y peptonoids, 179 soluble food, 184

Citritgeen jully, $4 S_{5}$ Int)-., 114

Cils alwily sceds, I 30

C.urruls, 1 I 6

Cirr's liread, 94

Ciscin, 3 I

liscuits in diabetes, 476

breal in di.tletes, 476

dried, 158

vegetiable, 79

C:tseinoryen, $31,231,236$

Cisoid hread in diabetes, 476

Casumen, I60

Cimulle, 48, 297

Caulillower, 118

all gritin, 484

in convilesconce, 312

method of cooking, 123

Caviare, 65

Cayenne pepper, 129

Celery, I17, I19

method of cooking, 123

Cellulose, structure of, 81

Cereal coffec, 525

Cereiline, 99

Cereals, 86

Cereals for childsen, 198

Cerebral hamorrhage, 607

Ciylon coffee, I35

Chiblis, 150

Champagne, 144, I5t

Chapman and Bardswell diet in tuber culo is, 421

Chapman's whole flour, 169

Chartreuse, 146

Cheap foods, 215

Cheese, 42

Cheese added to soups, 72

digestibility of, 43 
Cheese, in dysphagia, 438

Lactic St Ivel, $5+4$

ripening of, 43

varieties of, 42

vegetarian, 526

with rice, 313

Cherries, I 06, 109

Cherry brandy, I on

Cheshire cheese, 43

Chestnuts, II 2

Chevril, IIs

Chicken, 58

Chicken broth, 302

broiled, in convalescence, 309

essence, 77

jelly in acute fever, 272

panada, 308

purée, 209

souffé, 308

tea, 75

Chicory, 138

Chilblains, is

Children, anzemia in. 381

Chiluren, appetite of, I9t digestive powers in, 227

food requirement of, 20,24

height and weiglit, 195

indigestion in, 320

nervous, 50 ;

of gouty diathesis, 194

school, zor

tuberculosis of, $19+4,440$

Children, diet for, 193

Chilies, 129

Chiltine's infant food, 182 maltose food, 183

China tea, 136

Chittenden standird, 22, -6

Chives, I 19,120

Chioride-free diet for nephritis 416

Chlorine, source of, 126

Chlorosis, 384

Chocolate, 139 , I 85

Chocolates containing lactic bacilli, $5+4$

Choline, 16

Chorea, 505

diet during pregnancy, 2 If $_{4}$

Christian's dietary, 529

Churning, 4 I

Chyme, 8

Cider, I 51

Cibot, 120

Cimmamon, 130

Ciubosis of liver, 375

Citrate of sodiun added to milk, 239

Citrated milk, cause of constipation, 252 value of, $2=3$

Citric acil in milk. 32

Claret, I44, I 50

clatuceps furpura, Iyz
Climute, effect on fool, 26

Cl ited creitm, 39

Cloves, 130 of garlic, 120

Cobs, 113

Cocat wine, 151

Cockle, 64

Cocoin, 133,139

and milk permonised, 175

butter, So, I I 3

diatetic, $48 \mathrm{I}$

nibs, 139

Cocoatnut cakes in diabetes, 475,477 , 478

oil, 80 , I I 3

porridge, 48 I

Cocon-nuts, I 13

Cod, 62

Coffee, 137

Coffee, adulteration of, Igo

banana, 525

composition of, 138

peptonised, 176

varieties of, i 39

Colic in infants, 253

intestinal, 363

Colitis, 357

Colitis, acute, 357

Bland diet for, 362

cellulose dict Jor, 362

chronic, 358

in children, 265

milk diet for, 363

milcous, 360

skimmed milk in, 539

Colostrum, 246

Combination foods, I 70

Condensed cream, 30

Condensed milk, 155, 157, 240

Condensed milk, peptonised, 175 varieties of, 156

Condiments, 127

Confectionery, 83

Congenital pyloric stenosis, 260 syphilis, 26 I

Consommé, 73, 7t, 27 I

Constipation, 352

Constipation, diet, 6 effects of, on dicestion, 18

fruit cure for, 538

in infancy, $25 \mathrm{I}$ prunes in, Io?

Contamination of milk, 245

Contrcxeville, 135

Convalescence, diet in, 292

Cooking, 65

Conking, of flumr, yo

Cooking, of tish, 65

of fruits, Io7

of meats, 63

of onions, I 20 
Cinking, of potato, 115 of siatch, sit of regetables, 118

i oombis malial ford, 1S1, 1S2

( i)tiduder seed, 130

forn. 98

Cinnthour, 99

puddur, 217

w.1te:, 297

('ornme.1), os

(iornstarch. 4\%, 19n

Co-ta Rica inffec, 138

('oturn-sced vil, 80

(im s nilk. 21). 30

propriestry foods from, 155

(i) $1,63,64$

apples, ins

Cranterries, 106, 110

Cratylish, 64

Cream. 38

Cream, added to sollps, 72

composition nt. 35

dilution of. 40

for dysphanis. 439

for the goury, 450

jelly, 301

liroportion of, 32

varictics of, 39

Cremalto, 170

Cicme de volajlle, 209

Cresol, i6

(iscs, Is),

crucifcrar, 118

Crusiacea, 63

Cucumber 117,121

stewed, 488

Curaran, rog

( urd., 33

Cure, chloride-frec diet, $4: 6$

diet, huttermilk, 540

fruit. 538

सrifie, 538

koumiss and Kephir 540

meat and bot-watc? 534

purin-free dict. $\$ 31$

Salisb.ry dict, 534

skimmed milk. 53.5

wgetsrian dict, 520

whey. $53 \%$

Currants, 106,110

Cinry powder, 150

Curtis desiccated malt, 181

Custard, butied, 20,t

for displatgi.t, 438

pus wer, $\$ 7$

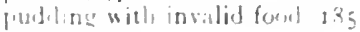

sallie, 2aty

4rolly. 43

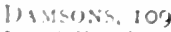

Uardelion leaves, 119
D.uthy's fluid teef, 179

I).ties, 110

Talifat, 530

D).uglisli's process of breadmaking, 92

Denueyer's peptone, 179

besicated vegutalies, 187

I) evonshire crcilm food, 39, 170

Dextrin, 8 s

Dextrose, 82,84

in rectal-feeding, 223,224

1)hoora, 99

Diabetes. 470

Dualetes, beverages in, 473,481 bread substitules in, 475,476 foods to lie al oided, 473

forms of fat aduinistration, 474

fruit in, 480

menus in, 48 !

milder forms of, 490

milk in, 472

oatmeal diet, 489

puldings ill, 482

sacchat in in, 475

severe forms of, 490

vegetables in, 480

Dualetic foods, 475 home-made, 476 scones, 485

Di.l hetin, 84

Diarrhcea, 354

Diarrhoea in infants, 253,259

due to lactic acid, 31

from unilk, 37

nervous, 355

salt-free diet in, 416

summer, 261

Diastase, 178

Diastased farina, 183

Diathesis diet in diathetic tendencies, 191

Diet, convalescent, 292

Diet cures, 520

Diet during childhood, 193

Dlet in old age, 203

Diet, during preguan, y, 21 I

during puerperium. 213

during school life, 201

effect on urine, 410

for gouly child, 200

for nervous child, 201

for tul crculous cirild, 200, 203

fruit, 538

improperly balanced, 217

infuevce of intestinal bacteria on, 17

leglat, huspitil, 548

rneat aud hot-water, 534

milk, 538

in otsesity, 498

preccriling of, 6,219

prescribing of, for infants, $24^{8}$

protein, hospital, 549 
Diet, purin-free, 531 sudden change of, 18 to modify size of chuld. 212 vegetitian, 520

Dietaries, economical. 216 hospitial, 545 ill-ballnced, 2 I 7

Dietary fur disease, general rules, 2 9 standards, 6

Digestilility of foods. 4

Digestion, 7

Digestion, artifleial, 171

Digestion, bacteriat 111,15

tactors modifying, is

Dilated stomach, 339

Dill, 130

Dinner toast, 93

Diphtheria, 290

Diphth.ria, alcohol in, 152

Dipsomaniacs, c ryenne pepper for, 129

Vi-sac harids, $\$ 2$

Double creann, 39

Dough, 90

1)ried foods, 187

Drin'ing-waters, I 33

Dropsy, diet for, 403 salt-free diet in, +16

I)ucks, 58

Dulcin, 85

Duodenum, digestion in, 9 ulcer of, 337

Dutch cheese, 43

Dysentery, 359

Dyspepsia, 314

Dysphagia, 436

Dysphagia, blancmanges for, 439 breadcrumbs for, 439

cheese for, 438

cre.ıms for, 439

custards for, 438

gelaline for, 439

iced foods in, 437

EAsT Indian coffce, 138

Ebstein regime in obesity, 496

Echinococeus in food, I y2

Eczema, 5 I9

Edam cheese, $\$ 2$

Eel, 63

Egg altumin, 45

in puro, 165

baked, 49

boiled, $4^{8}$

compusition of, 45

digestibulity of, 451

Jrink, 47

fats of. $t^{6}$

flip, $4^{8}$

jelly, 302

platit, I 2 I

poiched, $4^{8}$
Egg powder, 47

rumbled, 49

with brandy, +3

yolk, +5

Eggs, 45

Eggs, alded to soups, 72

is a fever diet, 270

cooked, 48

digestibility of, 46

for chiluren, 197

idiosyncrasy to, 45

in convalescence, 2,39

in omelet form, $30 \mathrm{c}-3$ ) I

in proprietary fonds, 167

nutritive value of, 45

raw, 47

raw, manner of using, 47

savoury, $4^{86}$

scrambled savoury, 164

snowball, 301

substitutes for, 47

with meat extract, 164

Egyptian lentil, 104

Emetic from mustard, 129

Endive, I I9

Endocarditis, for

Energy, evolution of. I 3

Enteric fever, 277

Enteritis, acute, in infants, 254, 26r, 265

cattirrhal, 355

in children, 265

lactic bacilli treatment of, $5+3$

Enterokinase, 9

Enteroptosis, 344

Enterospasm, 363

Epilepsy, 506

Ergot, 100

F.rgotism, 192

Eschalot, 120

Esco beef juicc, :65

Essence of rinilla, 1 30

Essences, meat, 75

Ethers in wines, 150

Eucasin, $15 \mathrm{~s}$

Evaporated cream, 39

fruits, 107

Extractives of meat, 53

F.ECES, composition of, ro effects of lactic bacilli on, $5+4$

in infants, 229, 258-259

Fairchild's panopeptone, 179

Falona, 169

Fuina, 96 in milk, 36

lianinaceouls foode, 527

Farol.r, 96

$P$ at, in cuw's mitk, character of, 236 deficiency of, callse of lickets, 206 in eggs, 46

in infuncy, 230, 231, 262 
Fat, in stools of infants, 259 neutral, 11

of meat, 53

of milk, 31

of vegetables, so

Fats, 1, 2

alisorption of, $t 1$

as protein-spartess, 13

casily dipested, $319,47+$

for children, 196

met. bolism of, 15

Faugue, effect of alcobol on, 143

Feeding, artificial, of inf.unts, 235

practice of, $2+1$

totiles, 245

cups, 220

lorced, 224

general rules for, 2 i 9

improper, in infants, 254

nasal, $2: 5$

Feeding, rectal, 221

Fennel. $1: 0$

Fenugreek 131

Fermenlactyl, 544

Fermentation in breadmaking, 90 ol grape juice, $1+7$

in bowel. 346

Ferments, digestive, 171

drred powders, advantages of, 171

in therapeutics, 171

preparation of, 171

Fever. alcohol in, 276

food (Brand"s), 2>0

importance of fluid in, 268

meat infusions in, 270

Fevers, dletary in, 287

Fig $=$, I06, IIo

Filters, II 3

Findon haddock, 61

lirst Swiss condensed milk, 155

Fish, 58

Fish, hakel in batler, 207

in convalescence, 305

cheap varlety, 216

chemical composition of, 61

classification of, 59

cod roe, 207

curried, 208

decomposition of, 60

Jishes for aged, 207

for the gouly, 449

haddock roes, 207

and tomatoes, 207

in convalescence, 305

kedgeree, 208

jhosphorus in, 24

powser, I 67

quenelle in convalescence, 307

roe, grilled and fried, 207

soufflè, 488

scalloped, 208
Fish, seasons for, 60 selection of 60 smoked, 187

sole, steamed, 2c9

soup. 303

soufflé, 208

sieamcil, in convalcseence, 306

stewed, in convalescence, 306

variclies, 60

whiting, steamed, 209

Flank of beef, 52

Flatulence, 318,365

Flavouring agents, I 28

Flesh composition, 50 characteristics of good, 54

Fletcherism, 529

Florador, 96

Flounders, 62

Flour, 89

baked, 274

banana, 524

gluten, 85

malt, 180

mouldy, 192

preparations, S9, 95

varieties of, 89

wheaten, 89

Food, absorption of, 10

Food accessories, 127

Fuod, adulteration of, 190

chemical composition of, 3

chlorine in, 126

condiments, I 27

deficiency in lime, 126

discases caused by, I9I

dried, 187

fever, $35^{\circ}$

flavourings, 28

freezing of, 138

fruts. 105

general serving of, 220

heat vilue of, 3

idiosyncrasies, 26

iron in, 127

malted, $18 \mathrm{I}$

mineral salts in, 125

parasites in, 192

phosphorus in, 127

physiological properties of, 4

poisoning from flesla, I9I

potassiurn in, 126

preservatives, 187

ptomaines in, $19 \mathrm{I}$

rate of digestion, 4

required for children, 24, 193

for lactation, 25

for old age, 203

for pregnancy, 211

for women, 25

requir ements, 20

sedsonal variations in, 26 
Food, smoked, 187 sodium chloride in, I 26 temperature of, i 9 urine and, 410 use of alcohol, I 4 I

Foods, animal, 50

Foods, proprietary, 155

Foods, vegetable, 79

Foods, acidity of, 127 alkalinity of, 127 antiseptic substances used in, I 99 canned, 188

carbohydrate, 79

for infants, 24I, 244

refrigeration, I $S S$

salted, ISS

salts in, 126

Forced feeding, 224

Formaldehyde in milk, 31, 37

Formic acid in wine, 149

Fortified cocon, 139

wines, 148

Fowl, 58 ragoit of, 309

Frame food, 89,168

Franco-Swiss food, 170

Franz Josef, I 35

Freezing of lood, 188

Friederichshall, I 35

Fruit, cooking of, 107

cures, 538

digestibility of, 107

eating, 106

juice, 275

preserving of, 107

ripening of, 105

soups, I08, 275

sugar, 82

syrups, 108

uses of, 107

with whey cure, 539

Fruitirian cakes, 525 diet, 538

\section{Fruits, 105}

Fruits, evaporated, 107

for children, IgS

for the aged, 210

over-ripe, effects of, 108

Frying, 67

Full-weight condensed milk, I56

Fungi, II 3

edible, characters of, II 4

poisonous, II 3

Fusel oil, I+t

Gall-stones, diet in, 373

Game, 58

soup, 303

Garlic, 120

Gases in indigestion, 17, $314,34^{6}$

Gastric catarrh, 322
Gastric catarrh, acute, 323

in , hildren, 325

chronic, 324

juice, 8

Gastric ulcer, 330

Gastriti: 322

from fruit-eatlong. 108

Gastro-enteritis, acute, in infants, 261

from milk, 37

in children, 265

Gistroptosis, $3+4$

Gistrorhexis, 337

Gavage, 224

Geese, 58

Gelatine jelly, to make, 35 as diluent of milk, 35

in fever, $27 \mathrm{I}$

metabulism of, it

source of sweet jelly, 273

Germ I read, 93 of wheat, phosphorus in, 24

German lentil, IOf

Gigot, 55

Gin, 145

Gin, alcohol in, 144

Ginger, 129

ale, I 35

beer, I 29,135

wine, 129

Glaxo dried milk, $15^{8}$

Gliadin, 88

Glidine, I68, 479 cakes in diabetes, 479

Gloucester cheese, 43

Glucose, 83

in honey. 85

in rectal-feeding, 223

Gluten, 88 and almond hread, 479

bread, 94,477

flour in diabetes, 476,477

macaroni, 480

vermicelli, 480

Glutenin, 88

Glycerine as flawouring agent in diabetes, $+75$

in meat juices, 165

Glycosuria, 470

Glycosuria, alimentary, 489

beverages $i n, 473$

cause of, $4: 0$

Goat, milk of, 29. 32, 235

Goitre, 515

Goitre, exophthalmic, 5 I6

Goose, 58

Gooseberries, 106, IIo

Gorgonzola cheese, 42

Gout, 444

Gout, alcohol in, 153

leverages in, 453

causes of, $4+4$ 
Gout, illustrative dietaries, 456 lactir tacilli treament of. $5+3$ meat foods in, $44^{6}$

and hot-uner cure, $+\$ 9$

milk fouds in, 449

muneral waters in, 455

pancreatic seaction in, 451

s. ups in, 447

stimulant in, 433

strawberries in, in t

use of drinking-water, +5 t

use of sweet in, 451

veachutiall regime 111,452

Gury chuld, diet for, b9t

Ni.lihesis, diet for, 194

Grain. source of alcohol It4

poisoning, 192

whisky, I 44

Gramalt, $18:$

Grand bouillon, 73

Giranola, 95

Grumose, of

Girnular contracted kidney: $\$ 12$

Grape cure, 538

Grape fruit. $1=9$

juice for wine, 147

suge.17, 82, 144

Grajes, 10t, 110

sutrce of alcoho', I44

Gravel. 418

Greengages, 109

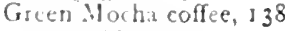

vegeta! les, 117

walnu:, 112

(ireens, its

Grilling, 6,5

Grinding, effert of, 186 of wheat, sis

Groats, yz

Grouse, is

proserning from, 142

Growh, infinence of cxcessive meat dict in, $\quad \vdots \sigma_{j} ;$

Gruel, harley-meal, in convalescence, 295

dictetic, $48 \mathrm{~s}$

maled, in convilescence, 2,36

milk, in c nvalesence, 2g6

oatmeal, in convalescence, 20,5

peptonised, 173,174

port "ine, in convalescence, 2,6

Guavas, 108

HAT IOCK, 6I

Halit ut, 6, I, 6, 2

If s:matemesis, 331

Hirmopiysic, 435

Hirmorthage, cereliral, 507

tyl hoord fever, 284

IJ ximorrhoids, 36,6

llard tack, 93
Ilate, 56

poisoning from, 192

Hiricot be.1119, 10;

"llaricots rus," 104

IJarrogate mineral-waters, 135

l]azel nuts, 113,475

He.tdaclee, 505

Jeart as article of diet, 57

Heart, diseases of, 399

Ileart, acute tisease of, $40 \mathrm{r}$

chronic disease of, 402 salt-free diet in, 4 i 6

dilated, diet in, 404

functional discase of, 400

the senile, 407

Heat, effect on fat, 66 on proteins, 66

evolution of, 13

Height and weight tabie for adults, 493 for children, 195

llemp oil, 80

IJerring, $6_{3}$

llickory nuts, I 3

1 lipi, composition of 163

llock, 149,150

lloff's malt extract, 180

Ilolland gin, it5

Joll india condensed milk, 156

IJomax, 180

Hominy, 99

Joney, 82,85

Horlick's invalid food, 183

malted milk, 177, 241, 250

Horse-radish, I19, 131

Horsley on alcohol, 1.10

Hospital dietaries, 545

IIospital dietaries, classification of, $5+8$

llot water, meat and, cure in gout, 449

Hot-water, meat and, diet, 534, $4 \div 9$

lloush, 52

IIovis bread, $89.94,293$

babies' ford, No.1, I83

No. 2, 182

กิ.บั, 89

No. 1 food for infants, 241

Uum:in milk, 29 composition of, $23 \mathrm{I}$

Jumanised condensed milk, 157

IJungatrian wines, 150

IJunjadi Janos, I 35

IJusk of wheat, 88

Hyperacidity, 328

IJyper:cidity, value of milk in, 36

Hy perehlorhydria, 328

Hyperchlorhydria, casein preparation in 158,160

milk and carbohydrate diet in, 36, 329

protein diet in, 329

II perpeiesis, 398 
ICR cream, 40

Iceland moss, It

Ideal condensed milk, 156

Idiopathic anxemia, 388

Idiosyncrasy, effect on diet, 26

Imperial drink, 276

Imperial Granum food, Iog

Indian corn, $9 \mathrm{~S}$

meal, 99

melon, I 21

pale ale, $I_{4} 6$

Indigestion, $\mathbf{3 1 4}$

Indigestion in childien, 320

intestinal, 349, 352

of pancreatic origin, 377

skimmed milk in, 538

whey cure for, 538

Indol, 10, 16

Infant, feeding of, in disease, 251

Infant, feeding of, in health, 226

Infant, constipation in, 251

diarrhoca in, 253

of, by wet nurse, 232

loods, I 55

mixed feeding of, 234

premature, diet for, 249

Infants, weight of, 233

Infective diseases, diet in, 267

Influenza, 290

alcolol in, 153

lrsane, diet for, 502

Insomuia, 505

Intestinal indigestion, 349

Intestines, diseases of, 340

Intestine, bacterial Aloria of, 15,17

colic of, 253,363

enteroptosis, 344

fermentation, 346

flora, 15, I 7

inflammation of, 355

lactic bacilli treatment of, $5+3$

obstluction of, 364

putrefaction in, 348

tuberculosis of, 433

ulccration of, 363

Invalid Bovril, co:t of, Í́2

Invalid foods, 183

Invalid foods in convalescence, 293 fruits, 107

Invert sugar, 82,85

Irish moss, 114,485 malt whisky, I +5

Iron, 23,127 in meat, 53

Isinglass, 59

Italian wines, 150

Italienne sauce, $3 \mathrm{I} 1$

Jimalca coffee, 138 pepper, 130
Jams, 107, 108 sugar 111,85

Jaundice, malignant, 372 simple, 371

Jellies, 108, 299 adulieration, 190 for dysphagia, 439

lelly, carrageen, $4^{85}$ chicken, in acute lever, 272 cream, 301

egg, 302

from invalid food, i 85

from Irish moss, 485

lemon, 274

orange, 274

peptonised, 175

port wine, 274

sweet, 273

veal, in fever, 272

whipped, 274

Jerusalem articioke, 116

Johannis, I 35

John Bull No. I food, 177 No. 2 foul, 182

John Dory, 62

Juice, fruit, 275

Junket, 33

KALAR! hiscuits in diabetes, 476

Kiale, I 8

Kaukoor, I2 I

Kephir, 44

cure, 540

in fever, 270

Kepler's malt extract, I 80

Kernel of wheat, 88

Ketchup, II 4

Kidney bean, 103

Kidney, diseases of, 410

Kidney, tuherculosis of, $417,+39$

Kidneys as an article of diet, 57

Kippers, 63

$\mathrm{K}$ issingen, $\mathrm{I} 35$

kinife-blade test for good meat, 54

Kuch's meat peptone, 179

Kornules, 524

Koumiss, 33, 44 cure, $5+0$

in fever, 270

Kronthal, 135

Kufeke's infant food, I 82

$\mathrm{K}$ :immel, $1+6$

Kenmerich's meat peptone, 179

1.ACTALBUNIN, 31,236

Lat tation, food required, 25

Laetic aeid therapy, 540

Lactic acid lacilli, 16, 230

effect on stoole, $;+4$ cause of diarrlıcea, 3 I in cheese, +3 
l. actic acid bacilli cases henefited by, $5+3$ mode of adminiztering, $5+3$

Siliel cheese, $5+3$

Lactigen, $5+3$

l.acto-bacilline, $5+1$

Lacto-regetarian fiet, $: 20$ uncooked foods, 529

Laciose, $s_{4}$

Lacumen dicel milk, 158

lacritam died milk, 159

l.ager beer, alcohol in, $1+6$

l.amb. $5^{6}$

L.aparosumy, diet after, 33 S. 315

Lard alulteration. 190

L.ange intestines, calarrl of, 357,360

Laryngeal tuberculosis, 430

Lathyrism, 192

leck, 120

Leeks, to cook, 123

in convalescence, 3 II

Leg of mutton, 55

Legumes, 101

l.egumin, or vegetable cascin, 79

Lemco, 162

l.emonade, 135,276

peptonised, 174

Lemon jelly, 274

L.emons, 106. 109

Lenhartz diet for gastric ulcer, 335

L.entils, rot

composition, 104

varities, 104

Leltuce, 117,119

in convalescence, $3 \mathbf{I} \mathbf{I}$

to prepare, 122

Leucine, 16

Leuk $x$ mia, $37 \mathbf{I}$

L.evulose, $82,8+$

Lichenin, IIt

Lichens, 114

Liebig's haking-powder, 9 I extract, composition of, 163 peptone, 179

Lienteric diarrhoca, 355

Lime, deficiency in food, 126 in food, 126 juice, 109 water as diluent for milk, 34, 238

Ling. 62

linceed oil, 80

Lipton's fluid beef, $16 ;$

Liqueurs, 148

liquids for the aged, 210

Liquor carnis, 165 pepticus, 172 pancreaticus, 172

Litharia, 418

lithia water, 134

Liver, diseases of, 370

Liver as a food, 57
Liver, cancer of, 376

cirrhosis of, 375

salt-free diet in, 416

influence of diet on, 597

l.obster, 63,64

L.ocomotor ataxia, 503

Loeflund's cream emulsion, 177 milk, 176

1.oin of mutton, 55

"l.ongings," 212

Lungs, diseases of, diet in, 612

MACARONI. 96, 313

gluten, 4 so

method of boiling, 313

Nacaroons, it2

Nace, 130

Mackercl, 63

Madeira, 151

Magnesium carhonate in milk, 37

Maize, 98

in beermaking, 1,6

Maizina, 99

Malabar coffec, I 38

Malatia, 291

Malnutrition in infants, 254-255

Malt extracts, 178

Malt extract in indigestion, 318,350 intusions, 180, 181 substitules for, in brewing, 146 sugar, $82,8+$

whisky, I 44

Nialted foods, uses of, 180 gruel in convalescence, 296 to make, 181

milk for infants, 250

Maltico, 177

Maltine, is 1

Malting, $8+$

Maltose, 84,178

Man, food requirements of, 20

Manhu infant food, 177

Manihot utilissima, II 7

Mannite, $8+$

Maple sugar, 82,83

Maranta aruntinacea, 116

Maraschino, 109

Marasmus, 255

Mare, milk of, $29,32,235$

Margarine, 4 I

Marjoram, 130

Marmalade, 109

Marr's food, 169

Marrow-bonse, method of cooking, 197 as a diatetic food, 474

toast, 197

Marsala, I5I

Marvis, 167

Mason's beef-tca, I62 essence, composition of, 163

Mastication by children, 193 
Mastication, defetive, effects of, 8,317

M'Dongall's haking-powiler, ot

Meals, cheap, 216

Meals, during schuol life, 201

for children, 193

hurried, 18 cituse of indigestion, 317

in old age, 203

in typhoid, 2so

irregular, is

cause of indigestion, 317

Measles, 290

Meat, 50

Meat, acids in, 53

and malt wine, 15

boilings, 73

brotl peptonised, I 74

cakes in Salisbury diet, 535

carving of, 53

charitcters of good, $5 f$

chemical composition, 51

consumption of, 565

diet in tuberculosis, 43 I

dishes for aged, 209

excessive, dict, 565

influence on kidneys, 578

on liver, 597

on reproductive glands, 587,589 , 608

on thyroid gland, 557,553,564, 575,612

extracts, 162

extract custard, 164

with eggs, 164

milk, 164

with rice, 313

soup, I 64

factors affecung composition, 50

foods for children, 195

for convalescence, 305.307

for gouty, +49

hanging of, 53

infusions, 75,270

juices. $77,165,312$

juice, propriet:ary, 165

with milk, 16 t

lozenges, 167

peptonised, $17+1,56$

potled, $47+$

powders, dried, If,

ptomaine poisoning hy, I91

riw, in tuberculusis, 534

smoked, 187

tea, pejtonised, 174

teas, 75,162

varieties of, $5+$

Me:llose, 523

Meatox, 167

Meats, clienp, 215

digestibility of, 65

Medicated wines $15 \mathrm{I}$
Melicin.t waters, I35

Ifellin's finl, $183,2+1$

Melon, 12]

Men untlim in I.t.t.tim, 232

Mental work, inbluence on digeition, 19

Metabolism, 13

Metinholism, eflects of alcohol on, If I

Metchnikuff, lactic bucilli therapy, 5 to

Mileil, 100

Meteorism, 365

Meceorism in lyphoid, 284

Migraine, 506

Miles, Eustice, foods, 523, 526

Milk, 28

Milk and cereal foods, 168

Milk cures, $538,+93$

Milk adaptation fur the sick, 33, 237

alulter.tion, 31, 37, 190

alkilis with, 34

and cinnamon, 37

antiscorbutic action of, 32

application of heat 10,237

arrowroot, 297

artilicial, in glycosuria, $\mathbf{4 7 2}$

ass's, 235

bacleria in, 236

blancmange', 301

boiling of, 35

Bovril, 36, 164

carbohydrate, 84

chocolate peptonised, 176

cirrated, 253

clinical uses of. 36

clotting, 33

cocon-nut, 113

colfee, 36

cold, 173

composition of, 29,235

condensed, 155,240

contaminations, 37,245

connflour, 297

curdling, 33

digestibility of, 33

diluents for, 33

diuretic effects of, 36

dried, I58

effect of food on, 30

elfects of, on intestinal bacteria. 17

effervescent, I 73

fit, 3 I

goat's. 235

gruel in convalescence, 296

peptonised, I $7+$

"guaranteed," 37

human, composition of, 231, 235

humanised condenscd, 15 ?

impurities, 37

inlluence of, on putrefaction, $22 c$,

in hyperacidily, 36

keeping of, 38

laboratoies, 160 
Milk lemonade, peptoniced 174 malied, for infunts, 250 minerals ill, 32

mixture, pretigestion of, for infunts, 253

mojitications of, I $60,238,269$

natural souring of, 3 I

nutritive value, 35

oxygenated, I6 I

pancreatised, 173

pasteuriced, 237

peptonised, I73

powders, 158,175

pretigested, 175

preservatives, 37

products pre inested, 175

protcins, 30

pud !ings, 297

punch pepionised, 174

reaction of, 29

regime in typhoid, 273

scalded, 237

separated, 32

skimmed, 32

shimmed, cure by, 538

Sumatose, 178

soured, treatment by, $: 10$

souring of, 3 I

specific gravity of, 3 I

sterilised, 237

sugar, 3 I, 84

tea, to make. 36

wilh starch, 36

Milkmilid condensed milk, is6

$$
\text { for infants, } 240
$$

Milled barley, IoI

Millet, 97

Milo food, 177

Minced beef for convalescence. 3 II

Mincemeat, adulteration of, Igo

$$
\text { juire, } 3 \text { I } 2
$$

Mineral constituents of food, 125

Mineral cunstituents of meat, 53

foods required. 23

salts in vegetables, 24,80

walers, I 3.1

Minerals in milk, 32

Mint, II 9

Mitchell Weir treatment, 508

Mixed leeding of infant:, $23 t$

Mrelified milk prescriptions, I60

Molasses, 83

malied, It4

sources of vinegar, 128

Mollusca, 64

Mcno-saccharids, 82

Moseley's food, I 82

Mosquera beef meal. I I I If meat, I 75

Mostelle grape juice, I 70

Mouth, digestion in, 8
Mnuth, toilet of, in fever. 268

Mucous colltis, 860

Mucone colitis, bland dit lor, j $\boldsymbol{\epsilon}$ cellulose dict for, 362

in ctrildien, 265

Muffler's food, 167,170

Mulberries, I 10

Nush, 99

Mushroom, II 4

ketcliup, IIt

Mushrooms in diabetes, $4 \mathrm{~S}_{3}$

au sratio, 487

Mussel, 6.4

Mussels, poiconing by, I9I

Mustird, I 28

Mutton, 54

Mution broth, 302

เea, 75

Myceloma aceti in intestine, I 6

Myosin in meat, 53

Myxoedema, 5 I 5

NASAL feeding, 225

"Natives," 64

Natural wines, 148

Neck of beef, 52

Nectarines, 109 composition of, 106

Nephritis, acute, 411

Nephritis, chronir, 412

lactic bacilli treatment of, 543

salt-free diet in, 416

subacule, +12

Nervous children, 504

diurrhrea, 355

Nervous diseases 501

Vestle condensed inilk, 156, 24c, 249

Neuralgix, 506

Neurasthenia, 508

Veurine, if

Seurotic child, diet for, 20 I

Neville process of breadmaking, 9 I

New bread, characteristics of, 92

Nicholl's food of health, I 82

Nitrogen, daily requirements of, 2 I

Foorden, l'on, diet in obesily, 497

Nursing mother, drugs ' 0,232 food for, 232

Nut preparations, 522 for diabetics, $47 j$ vego, 523

Nularian diet, 520

Nutmegs, I 30

Nutrien! enemata, 224

suppositories. 224

Nutrose, 31, 102, I58 food, If,9

Niuts I1I

Nuttolere, 523 
OATCAKFS, 98

Oatmeal, 98, 215

cooking of, $4 \mathrm{~s}^{\circ}$

diet in diabetes, 48 ?

effects of, on thy'toid gl.md, 602

gruel in convale cence, ay

water, to make, 35

Oats, 97

grinding of, 97

rolling of, 97

Obesity, 492

Obesity, Banting's diet, 494

Carlsbad regime, 497

causes of, $t^{4} / 2$

due to alcohol, $I_{4} 2$

Ebstein regime In, 496

fluids in, 493

in elderly subject. 407

milk diet cure of, 498

Oertel system, +95

pregnancy will, 212

principles of treatment, 493

Salisbury diet in, 493

summary of treatment, 500

Von Noorden diet, +97

Obstruction, intestinal, 364

Oertel system in obesily, +95

Offal of wheat, 89

Oil of carraway, 130

from ginger, I 29

from pepper, 129

of juniper, it

of mustard, 128

Oils, 80

essential, 80

volatile, in te:1, 137

Old Tom gin, 1,6

Oleo-m.ırg:rine, adulteration, 190

Olive oil, 80, I Io adulteration, 190

Olives, IIo

Omelet with brew?, 30 r

savoury, $301,4^{8} 3$

soufflé, 300

swee!, 300

with tomatoes, $30 \mathrm{I}$

Omelets, how to make, 300

Onions, I 16,120

composition of, I 17

in convalescence, 312

to cook, $12+$

Operations, dietetic after-treatment, 345

Opmus food, I6y

Orange jelly, $27+$ juice, 109

Orangeade. 276

Oranges, 109

bilter, 109

composition of, ICf

Oswego, 99

Over-drinking, 217
Over-feeding, 217

() $v_{0,4}+7$

Ox, mode of cutsung up an, 52

Oxilite of lune, 23

() $x$ uluriti, 4 is

() $x$ ince exeract, c)mposition of, 163

() $x$, composition of, IU2, If 3

Oyster solup, 304

U, stera. 64

aun nuturel. 305

in Sulistury diet, 536

peptonised soup, 175

porsoning from, 192

scallopied, 305

PADDP: 100

P.tict's malsed furina, 133

Pulm oil, so

Patmuda, chicken, 303

veal. 303

Pancreas, disease op, 377

Pancrealuc juce. 9. It reaction, value of, $377,45 \mathrm{I}$

Pancrealicum, extractum 172

Pancreatine, saline essence ol. 172

Pancre.tised foods, 173 milk: in rectal feeding, $22+$

Pancre.titis, 377

Panopeplone, 178

Parmes.n cheese, 43

Parsley, 119, 130

Parsnips, 1 I 6

Partridges, 58. 309

Pasteurised milk, 237

Pustry, 95

P'utent breats, 94 Hour, 89

Patent foods, 154

Pavy on carliohydudues, 12

Peat nut, I02

Peaches, 106, 109

Peacock's conden-ed milk, is6

Pears, 106, 10.8

Peas, compo-ition of, 101

dived, 102

fresh, 102

green, 102

Vurieties, 102

Pease brose, 102 pudding, 103

Pecan nuts, 113

Peclin, 105

Pecrose, 80, 105

Pellagra, 9\$, 192.501

Pemmican, 167, 750

Peperine, I 29

Pepper, 129

bluck, 129

ciyenlle, 129

white, 129

Pepsencia, 172 
Pepsin, 171

medium for, ip

powilers, 172

suline, essence of, 172

uses of, 172

Peptogenic milk powder, 175

Peptones, 9. 172

Peptonised foods, 171

Peptonised blanem.nges, 175

cuco.r, is 5

and milk, 175

coffee, 176

condensed milk, 175

food, uses of, 172

grtuel, I73

jelly, I75

meat, 174

broti, 174

1e.t, 174

milk, 173

chocolite, 175

cold process, 173

gruel, $17 t$

lemonade, 174

punch, 174

oyster soup, 175

soup, 175

Peptonising agents, I 7 I

pellets, 173

tubes, 172

Percentage method of milk-fecding, 160 , 239

of alcohol in bever.ages, $14+$

Pericarditis, for

Periwinkle, 64

Pernicious anirmis, 388 vomiting, diet in, 214

Perry, I 51

Pheasants, 58

Phenol, 16

Phosphate of line. 32 of potassium. 32

Phospluturia, fig

Phosphoru . 2.4. I 27

Pickles, 128

Pigeons, 58

Pilchirds, 63

Piles, $3 f, f$,

Pineapple, Iof. III

Pine kerrels II 3475

Pictachic, 113

Plaice, 62

Plasmon, 31 159

Plasmon arrouroot, if o

biscuits in diatuetes, $47 \%$

b]ancrnange, 160

butter, I 59

chocolate, 160

cocoa. I6o

in diatetes, 476

milk, I 59
Plismon porridge, 159

powiter, 159

preparced, I 59

quantity to use, 159

snow creatn, 159

Iea, 160

Pleurisy, 513

P'lums, rog

Pneumonia, 288, 513

Pneumonia, broncho-, 513

stimulants in, 288

Poisoning from grains, 192

ptomane, I9 I

Puiconous fungi, II 3

Pulenta, 99

Poluboskos, 94

Popcorn, 99

Poppy oil, 80

Pork. 58

Porridge, value of, 98, 2 Is

from almonds, 4 SI

from cocoa-nuts, 48 I

Port, I $4+$, I 50

l'ort-wine gruel in convalescence, 295 jelly, 274

Porter, $1+6$

Post-operative dietetic treatment, 345

Put-au-feu, 73

Pol barley, $10 \mathrm{I}$

Potash water, 134

Potassium, 24, 126

Potatoes, 115,452

alcohol from. 144

in beermaking, 145

sweet variety, is

value in scurvy, I15

Poultry, 5s

I'rairie oyster, 47

Prawns, 64

Predigested preparations, 171

I'rodigested meats, I 76 milks, 175

Predigestion of milk for infants, 239 , 253

\section{Pregnancy, 211}

Pregnalucy, abnormal diet in, 214 diet to modify size of child, 212 lood requirements of, 25

Premature infant, diet for, 249

Prescribing of dlet, rules for, 219

Prescribing of diel for infants, 248

Preservatives, food, I 87

Preserving of fruits, 107

Primary anæemia, 382

Prolacto breand, 476

Proprietary foods, 154

Proprietary food, artohydrate, 169 combination, 170

for inlants, $241,24 t$

made from rneat. I 61

types of, 155 
Proprietary food, vegetables, I 68 with egg, I67

Pro-secretin, 9

Protein, Ito

absorption of, 11

bread in diabetes, 479

digestion of, 8

excess of, $\mathrm{I}_{4}, 2 \mathrm{I} 7$

influence on kidney's, 578

on liver, 597

on reproductive glands, 587,589 . $59+, 608$

on thyroid gland, $557,558,564$. $575,604,612$

of barley, 100

sparers of, 23

regetable, $79,476,522$

Proteins suitable for children, I 66

gluten, 88

in diabetes, +76

in growth, if

in maize, 98

in meat, 53

in pulses, 101

metabolism of, 13

of milk, 3 i

Protene, $31,+79$

flour, 158

Proteolytic ferment, 9

Protose, 523

Provost oats, 98

Prune, 109 composition of, Io6

Pruritus, 5 I9

Psoriasis, 519

Ptomaine poisoning, I9 $\mathbf{I}$

Ptyalin, 8

Pudding, al mond, 4 86

arrowroot, 297

bread and butier, 298

cornflour, 297

ground rice, 298

milk, 428

rice, 293

sago, 298

semolina, 29.9

Puddings, 95

Puddings for children, 193

for the gouty, 453

made with invalid $\mathrm{f}$ rod, I 86

Puerperium, diet in, 213

Pulled bread, 96

Pulses, 101

Pulses in vegetarianism, $\vdots 23$

P'umpkin, 121

Purée, 73

Purin-free diet, 531

Purin-free dier, advantages and disadvintages of, 533

Purins in food, $53 \mathbf{I}$

nature of, 532
Puro, ito5

Purafactive hacteria, if actuon of, 10

decomposition in faces of infants, 229

I'yelitis, 417

P'yloric stenosis in infuncy, 260

Qualls, $5^{9}$

Ouaker oats. $9^{8}$

Quenelle of fish in convalescence, 307

tJuenelles, beef, for convalescence, 312

()uinces, 108

Quinsy, 291

RAB!IT, 56

lagoût of. 309

soup. 303

Ragout of $f, w l, 309$

of rabbit, 309

Raisins, IIO

Raisin tea, $3+5$

Raspterries, I 10 composition of, 106

Raw eggs, 47 and invalid food, 186

meat in tuberculosis, +30

Rectal feeding, 221

Rectal feeding, foodstuffs in, 222 management, 221

Red herring, $6_{3}$ wines, $\mathrm{I}+7$

Renal disease, diet in, 410

Rennet, 40

Respiratory diseases, diet in. 5 I 2

Rest and exercise in relation ro diet, 25

Rest cure, 508

Reialenta arabica, I04

Rheumatic fever, 288

Rheumatism, alcohol in, 153

buttermilk in, 465

Rheumatism, chronic 463

Rheumatism, lactic bacilli ueatment of, 543

Rheumatoid arthritis, 465

Rheumatoid al thritis, buttermilk in ${ }_{4} 68$

Rhubarb, 12 I composition $\cap f$, I 17

Rilis of beef, 52

Rice, 100

Rice, boiled, in convalescence 3 I 2 digestibility of, 100

flour in bre:tdmaking, 92 uses of, 100

in beermaking, $1+6$

I talian, 3 I 3

meat extract with, 3 I 3

method of boiling.

Milan. 313

pudding. 298

soup, 302

water. 275

to make, 35 
Rire witl cheese. 313

Rithet? 20 's

11,11 txiled milh $=15$

kinter's ford, Ifu

Rigur motic, 5:

Rionffere, 135

Rislacu biscuits in diabetes, 470

Rowting, 60,07

Robimon's glo.sts, y7, toy

puteme butey, ilug

kutiorat, 168, 525

Roe, 24, 05

liolled oats, 97

livots, it 4

kompefort, +3

Rose's comdensed milk, is6

liosch's system, Ifo

Round, 52

Roundworm in food, 192

liubluer, fuod requicments, 20

Rum, alcolus in, 1.4

Rump, 52

Run luney, 85

Runner of leef, 52

liusks, 9.4

kussian tea, 109

wheat, 87

Rye, 97

SACIIARIN, 85, 475

Sigo, 117

pulding, 20,8

water, 297

Salid iegetilles, 119

Silicylic acid as a preservative 189 in milk. 31. 37

Salisbury dlet, 534

Sali-bury diet, in olesity, 498 oyster-in, $53^{\text {t) }}$ urine in cases uf, 535

Siliviry ecretion, 8

Salivation, diet for, 21.4

Silmon, ",3

Salt, daily amount, 326 , detwicucy of, in pellagra, 192 free dee in nephritis, 4 (6) in other diceases, 416 in rectil feeting, 223

Salted forrts. I88

Salts in cow's milk, 236 atsorption of, 12 in medicinal water, 135

Salutari= water, 134

Samp, gry

Sanatogen, $1: 8$

Sanose. 158,167

Sarcina: 16)

Sardines, 63. +85

Sisure, lrearl, 308

cheese, 488

custard. 29 ?
Siluce, II ollumbiase, tist

lablienne, 31

M tyuntraise, f 80

Timare, 4 sis

white, 305

Sutuces, with vinegir, 128

S.tuerin, $5+3$

Sillerkriut, 113

S.l11s.uges, gs

S.utuing, 6r)

Savore, $18 t$

S.lvory \& Moore's fluid beef, I79

food for unfants, $2+1$

invalid food, 184

meat peptone, 178

Sivoury omclet, $301,4^{8} 3$

Saroy, 118

Sixin in diabetes, 475

scalled milk, 237,245

Scalloped oysicrs, 305

Scarlet fever, 289

Scarlet fever, infection from milk, 37 rutuner, 104

Schuol diecaries, 201

Sciatica, 506

Scotch bioth, 73 whisky, 145

Scott's Midluthian oatflour, 97, 169

Scraped becf, 535

Scurvy, 392

Scurvy, cituse of, 126

from boiled milk, 245

from buddised milk, i 6 I

in infants, 256

Seakile, 118,123

Se.rson, effect on food, 26

Secretin, 9

Selentary life, food requirement of, 20

Seeds, 86

Seltzer, 134,135

Semolina, y6, 156.298

Senile heart, 407

Separator cream, 39

Serving of food, 220

Shaddock, 109

Shilllots, i 20

Sheep, mode of cutting up a, 55

Shellfish, 64

Sherry, 144. 150

Shin of beef, 52

Ship biscuits, 95

Shoulder of inutton, 55

Shedded wheal, 96

Shrimps, 64

Sick headiche, 506

Sirloin, 52

Skate, 62

Shatol, 16

Skimmel milk, 32

cure, 538

Skin, diseases of, 517 
Skin affections in children, 518 Sleep, 19

Sloes, 10y

small intestine, digestion in, y

Simallpox, 290

Smelts, 62

Smith's patent, 89

Smoked foods, 157

Snipe, 58

So:tps, intestin:al, I I

Sodit-water, 134

Sodium, 24, 126

bicarbonate in milk, 34

chloride, 126

free diet, 416

citrate alded to milk, 239

Sole, 62

Som:t tose, $167,17 \mathrm{~S}$

Sorghum, 99

Sonfflé, chicken, 308

fish roe. 488

Soup, 67, 71

Soup, brunoise, 206

clear, $74,27 \mathrm{I}$

fish, 303

for gouly subjects, 447

from vegetarian stoch, $4 \uparrow^{8}$

fruit, 108, 275

game, 303

lentil, 206

making of, 72

nutritional value of, 71

oyster, $30+$

peptonised, 175

peptonised, 175

potato, 206

rabbit, 303

rice, 302

and iomato, 206

varieties of, 72

real, 302

Soups, 71

for the aged, 205

for children, lys

Sour milk treatment, 540

Sour milk chucolates, $5+4$

from decomposition, 236

in rheumatism, 465

in rheumatoid atthritis, +68

Soya beans, jot

Spaghet ii, 96

Spanich onion, 120

Spare rib of me.tt, 52

Spearmint, I 30

Spices, $12 y$

Spinach, 117,119,122

"1ith prached egg, 122

Spirits, 144

Spoiled breid, 92

spores of fungi, 16

Sprats, 63

\section{Sprue, 386}

Siprue, strmberies in, in

Sifut h, 117,121

Stareh, 81

St.uch dige: tion in infuuts, 227, 228

in malted lond, 180

in potitoes, 115

predigested, ISI

substitutes for, 475

Starchy foous, excess of, cause of indigrestion, 317

Steimed lish in cunvalescence, 306

Ste:uming, 66, 68

Sterilised milk, 237

Stewed fish in comralescence, 306

lartridge, 309

Stewing, 67, 70

Stewing of meat, 70

Still wine, 149

Stilton cheese, +2

Stimulants for the iged, 2 I I

effects of, $1+1$

in fever, 276

\section{Stoek, 72}

Stock to make brown soup, if vegetarian soup, 448,527

white soup, 74

Stock pot, 73

Stomach, diseases of, 314

Stomatch, cancer of, $3+3$

catarrb of, 322

chronic ulcer of, 337

digestion in, 8

dilited, 339

gistropio: is, 344

in infuncy, 228, 232

tube, feeding $1 y, 224.225$

ulcer of, 330

of prost-operative treatment, 338

Stools, 10, 229, 258

Stools, effects of lacto-bacilli on, 5 tt

in infuncy, characler of, 22y, 259

\section{Stout, 146}

Strawlerries, 106, : 10

in sprue, 369

St Galmier mineral w ther, 135

St liel cheese, 43, 5.44

Succinic acid in wine, 149

Stcons enterii us, 9

suchling, $2: 1$ contro-indi : tions to, 232

Suctol, 85

Suctoses, 82

Sulfulk cheese, 43

Sugar, 82

Sugit biet, 82

randy, 83

calle, 82

commercial. 83

corn, 95

co.rrse brown 83 
Silgar, cffect of he:at on, $s_{3}$

for chalom, lox

free milk, $4 ; 2$

indigestron in infunts, 258

invert, s2, $\delta_{5}$

in milk, $236^{\circ}$

in urine, 15.470

in wines, $1+9$

sutstitules, 85,475

Sugits, uses of, 82

virieties of 82

Sulphuretted hydrogen, 16

Simmer diarrhe: 201

Sweetbreads, 56, 310, 457

Sweet jelly; 273

potato, 115

wines, it7

Sweets, 83

excess of, cause of indigestion, 317

Sylioes, 120

Symborin, s

Syphilis, congenital, 26I

S) iup, 83

TABES mesenterica, 440

Titnial solium, 192

Tillifat dates, 530

T. \& T. food, 182

Tannic acid in coffee, 133

$$
\text { in lea, } 137
$$

Tapeworm in food, 1 y 2

T:apioca, I I6, 297

Tarragin, IIg

creams, 488

Tartaric acid in wines, 149

Tea, 136

Teit composition, I 37

cream, 39

drinking, excessive, calse of indiges. tion, 317

infusion, composition of, 137

poisoning from, 137

raisin, 345

varietics of, 136

Theinhat l's hygiama, 177

infantina, 177

Theotrom: 138, 139

Thirst-quencher, milk as, 26

Thirst-quenchers, 275

Thyme, 130

Thy roid, diseases of $\mathbf{5 1 5}$

Thyroid, effects of oatmeal on, 602 of protein diet un, $557,558,564$,

Tilia, 160

$$
575,600,612
$$

Tissue-builders, I

Toası, 93

dinner, 93

water, wo make, 35

Tobacco as cause of arterio-sclerosis. 395 lioilet of mouth in fever, 268

Tiumato, 121

composition of, 117

stuffed, $4^{3} 4$

to cook, 122

Tongue, 56, 209

Tonsillitis, 291

Tragacanth in milk 37

Treacle, 83

Triclina in food, I92

Trilactin, 543

Tripe, 56, 309

Trisket, 96

Triticumina, 182

Tritumen bread, 476

'Trommer's malt extract, I 8 I

Tropical regions, food for, 26

Tropon, 168

Trout, 62

Trypsin, 172

Tuberculosis, 420

Tuberculosis, abdominal, 44I

anorexia in, 428

bladder, 439

cheap nutritious foods in, 4267

eggs in, 422,424

fat in, 422

fluid dietary in, 430

glandular, 439

impaired digestion in, 428

in children, 194, 266, 440

intermediate dicts for, 432

intestinal, $364,+33$

kidney, 439

$\operatorname{laryn} x,+36$

lungs, 420

meal dietary, 422, 43t

milk in, 422

milk, infection from, 236

principles of feeding, 421

raw meat in, 430

surgical, 439

Tubers, IIt

Tufnell's diet for aneurism, 408

Turbot, 63

Turkey, 58 poisoning from, I9I

Turmeric powder, 131

Tunip), I 6

$$
\text { lops, II } 9
$$

\section{Typhoid fever, 277}

Ty'phoid fever, complications of, 284 convalescence of, $28 \mathrm{I}$ empty bowel theory, 286 homorrbage in, 284 milk infection, 37 milk regime in, 278 other systems of feeding, 285 starvation treatment of, 287

Typhoid fever, water-drinking in, 
Typhus, 2nt

Tyrosine, If

ULCER of duorlenum, 337 of intestine, 363

of stomach, 330

Under-feeding, 215, 263

Unfermented bread, 92

Unleavened breas, 92

Uric acid diathesis 418

Urinary diseases, diet in, 410

Urine, acidity of, $\$ 10,+1$;

after asparagus, 119

diet and, 4 IO

pancreatic reaction in, 377,463 , $4^{65}$

pentose in, 377

sugar in, 470

Urticaria, 519

from strawberries, II I

VALENTINE'S beef juice, 165,179

Vanillil, 130 beans, I 30

Veal, $51, \vdots 6$ broth, 302

jelly, 165,272

panada, 308

soup, 304

tea, 75

Veda bread, 94, 293

Vegetable abbumin, 79

acids in tubers, 115

butters, 80

digestibility of, 118

fats, 80

Vegetable Foods. 79

Vegetable gums, Iof

jelly, 80, 105

in Irish moss, IIt

marrow, 121,124

propriecary food, is 58

proteins, $79,80,4 ; 6,522$

salts, 80

Vegetables, economical, 216

for the aged, 210

for children, 198

for convalescence, 312

green, composition, I 77

varieties of, I I 8

Vegetarian cheese, 526

diet, uncooked foods, $\$ 29$

regitne in gout, 452

solips, 448,527

Vegetarianism, 520

Vegetaianism, advantages and dis. advantages of, 530

cereals in, $52+$

fats in, 524

objections to, 521

practical dietiries in, 526
Vegetarianism, proteins in, $\mathbf{5 2 2}$ julses in, 523

vegetable extracis 111,523

Vegota, 523

Vegox, 168

Velvet soup, 4:9

Vermicelli, yt, gluten, tyo

Vichy waler, I 35

Vienna bread, 89,94

Viking beef essence, ${ }^{6} 63$ condensed milk, I 56

Vinegar, 128

from malt, 128

from wood, $1 \geq 8$

Vinsep, I66

Virol, 1607,170

Virvis, 167

Vitalia meat juice, 165

Volt food requirements, 20

Volatile acid in wine, $1+9$

Vomiting in infants, 252,256 of acidosis in children, 262

Von Noorden's diet in obesity, 497 in diabetes, $4^{89}$

WAINUT ketchup, 112 oil, so

Walnuts, I I 2 briled, 480

IV.urren cooking-pot, 69

Water, 132

Water, alsorption of, 12 aerated, I34 alkaline, I 35 amount requircd daily, 132 as a therapeutic agent, 134 boiling, effect of, 134

chalyheate, I 35

daily requirements, 132

drinking, effect on tissues, 133

errors in, 133

rules for, 134

value of, in typhoid fever, 28.4

hard, I 33

hot, and meat in gortt, $4+9$

melons, 121

mineral, 134

of egg-white, to make, 47

sago, 247

soft, I 33

statiation, 133

sweetened, i 35

table, 135

with carbunic acid gas, 134

Weaning, process of, 234,263

Weight of adults, 493

of children, 195

of infants, 233

Weir Mitchell treatment, 508

Welsh uniun, I 20 
Wet nursing, 2:2

IVheat grain. 95 mill products. S? parts of, 88 preparations of 95 varietics, 87

Wheaten groats, 96

Wheatena, 96

Whelk, 64

Whey, 40

Whey cure, 538

Whey, prepatration of, $4 \mathrm{I}$ value of, in fever, 270 in infant feeding, $23 \mathrm{~S}$

I'hipped jelly, 27t

Whisky, 144

Whicky, alcohol in, 144 blends of, $1+5$

White sauce. 123 wines, if 8

Whitehait, 62

Whiting, 6I in milk, 3

Whole wheaten meal, 89

Whooping-cough, 283

lViesbaden, waters of, 135

11 indsor hean, 103

Winc jelly, 274

"line, "turned," I +9

\section{Wines, 147}

Wines, adulteration of. i 51 houquet of, I 47 composition of, 148 fortified, 147 manufactured, $15 \mathrm{I}$ medicated, 151 natural, 148 red, $I+8$ sparkling variety, 148 still variety, 148 white, 148

Woolcock, 58

Worcester sauce, 128

Work, effect on digestion, 19

Worth's perfect food, 182

IIyeth's meat juice, It 5

YAM, II

Yeasts, I6 effect on bread, 90 in intestine, 16

Yolk of egg. 45

Yorkshire relish, 128

ZOMOTHERAPY, 534

Zwieback, 94

Zynine powders, 172 

(1)

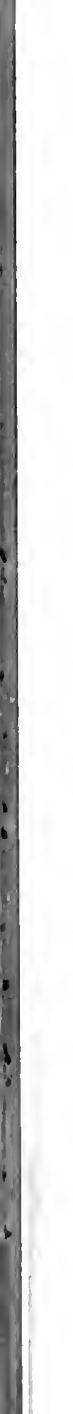







\section{PLEASE DO NOT REMOVE CARDS OR SLIPS FROM THIS POCKET}

\section{UNIVERSITY OF TORONTO LIBRARY}

RM

216

W3

1915
Watson, Chalmers

Food and feeding in health and disease

2d ed., rev.

ironcal

Virical 
